\title{
‡USGS
}

Exmons

\section{Bighorn Sheep Habitat Studies, Population Dynamics, and Population Modeling in Bighorn Canyon National Recreation Area, 2000-2003}

By Kathryn A. Schoenecker, compiler, U.S. Geological Survey

Any use of trade, firm, or product names is for descriptive purposes only and does not imply endorsement by the U.S. Government

Open-File Report 2004-1337

U.S. Department of the Interior

U.S. Geological Survey 


\section{Bighorn Sheep Habitat Studies, Population Dynamics, and Population Modeling in Bighorn Canyon National Recreation Area, 2000-2003}

By Kathryn A. Schoenecker, compiler, U.S. Geological Survey

Open-File Report 2004-1337 


\title{
U.S. Department of the Interior
}

\author{
Gale A. Norton, Secretary
}

\section{U.S. Geological Survey \\ Charles G. Groat, Director}

U.S. Geological Survey, Reston, Virginia 2004

For product and ordering information:

World Wide Web: http://www.usgs.gov/pubprod

Telephone: 1-888-ASK-USGS

For more information on the USGS - the Federal source for science about the Earth, its natural and living resources, natural hazards, and the environment:

World Wide Web: http://www.usgs.gov

Telephone: 1-888-ASK-USGS

\section{Suggested citation:}

Schoenecker, K.A., compiler, 2004, Bighorn sheep habitat studies, population dynamics, and population modeling in Bighorn Canyon National Recreation Area, 2000-2003: U.S.

Geological Survey, Biological Resources Discipline, Open File Report 2004-1337, 202 p.

Although this report is in the public domain, permission must be secured from the individual copyright owners to reproduce any copyrighted material contained within this report. 


\section{Contents}

I. Executive Summary (Francis J. Singer and Kathryn A. Schoenecker).............................. vii

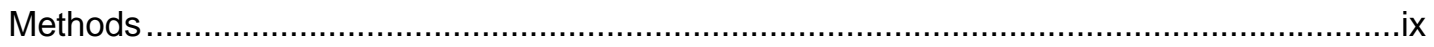

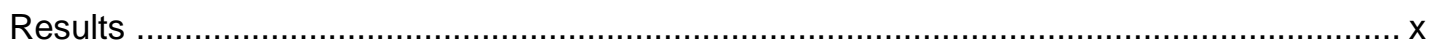

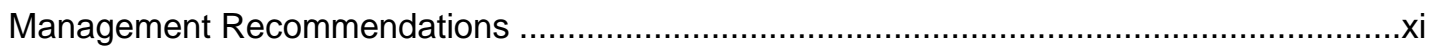

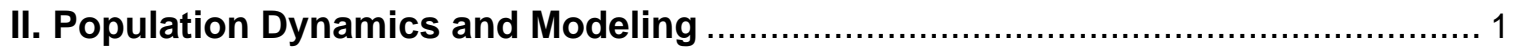

Bighorn Sheep (Ovis canadensis) Survivorship and Habitat Studies in Bighorn Canyon National Recreation Area and Surrounding Lands, Wyoming and Montana, 2000-2003

(Kathryn A. Schoenecker, Francis J. Singer, Kayla A. Grams, and James E. Roelle) ................... 3

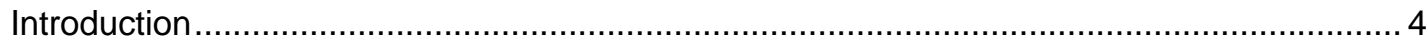

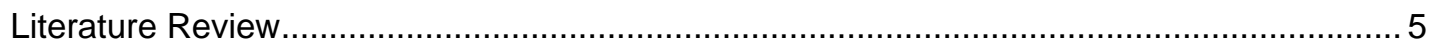

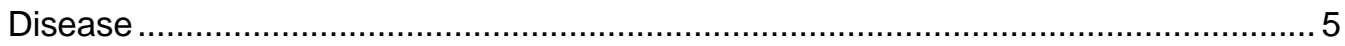

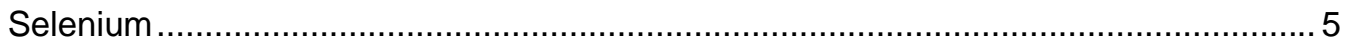

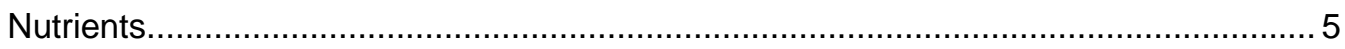

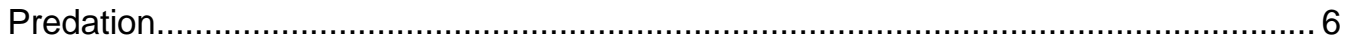

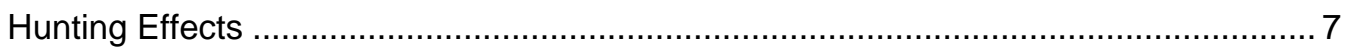

Guidelines to Avoid Depressed Survival of Young Rams ....................................... 7

Study Area

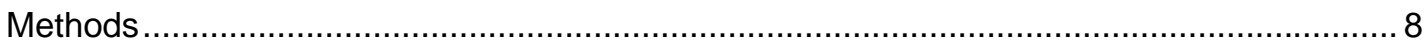

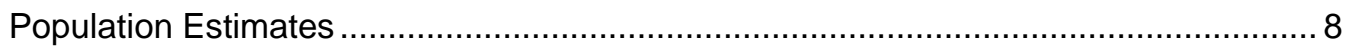

Bighorn Sheep Monitoring and Survivorship .................................................... 10

Population Range of Bighorn Sheep and Wild Horses............................................ 10

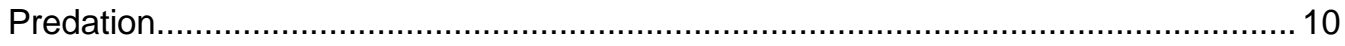

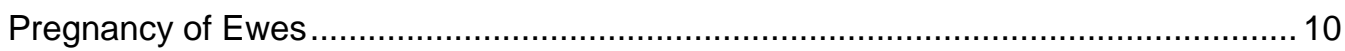

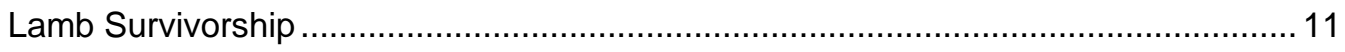

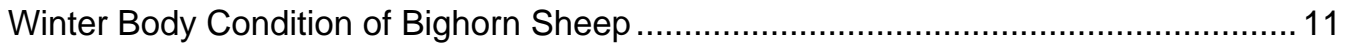

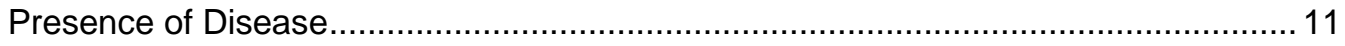

Competition Between Bighorn Sheep and Wild Horses ......................................... 11

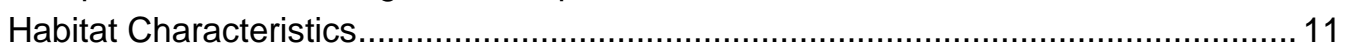

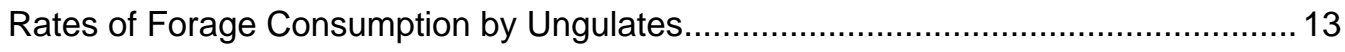

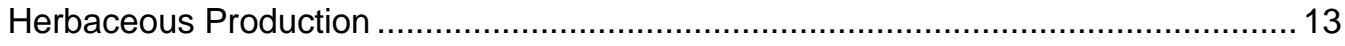

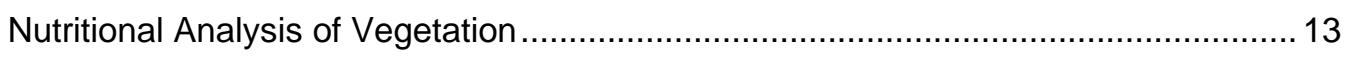

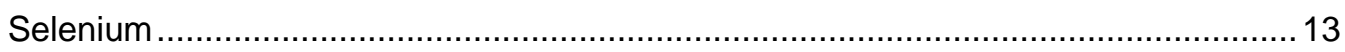

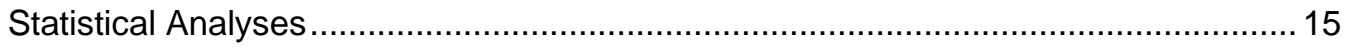

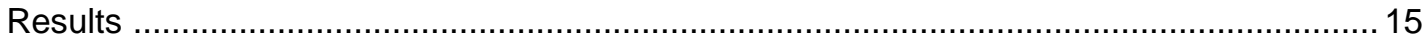

Population Estimates and Population Range of Bighorn Sheep ................................ 15

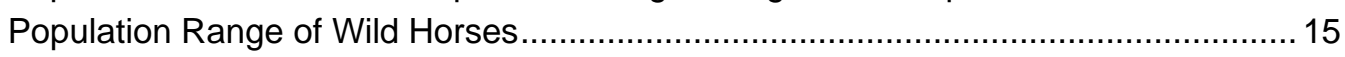

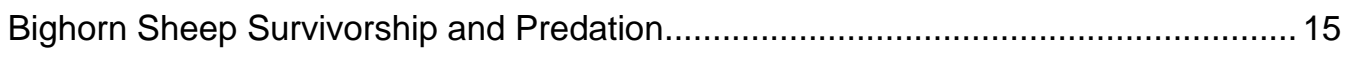

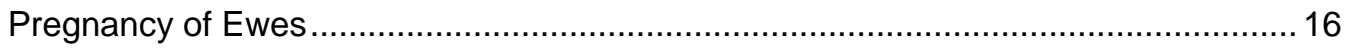

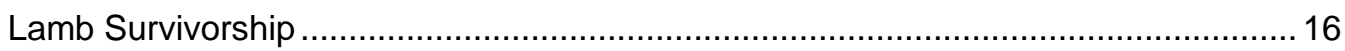

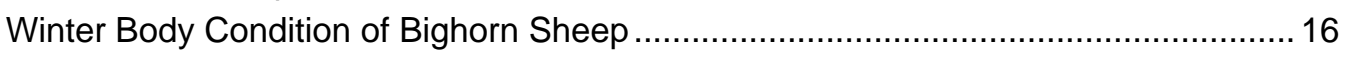




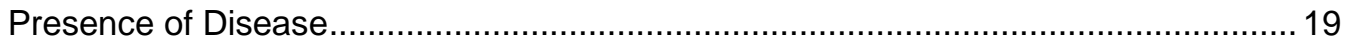

Competition Between Wild Horses and Bighorn Sheep ............................................ 19

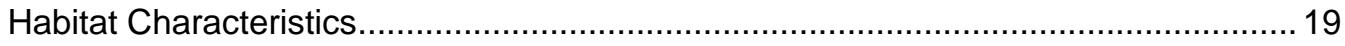

Rates of Forage Consumption by Ungulates........................................................... 22

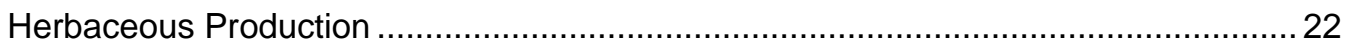

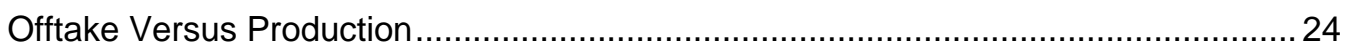

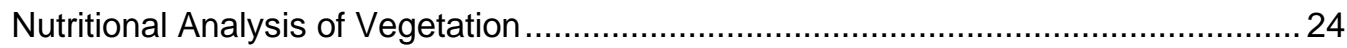

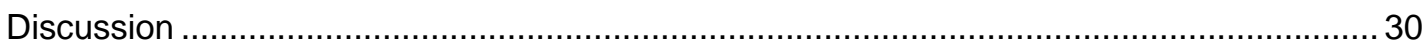

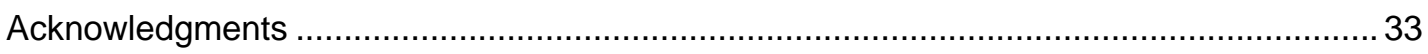

Literature Cited

Bighorn Sheep Demography and Population Modeling, Bighorn Canyon National Recreation Area, Wyoming and Montana, 2000-2002 (James E. Roelle) ............................. 37

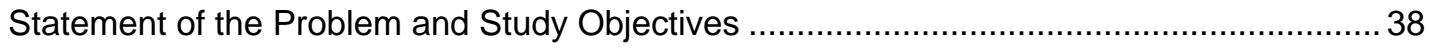

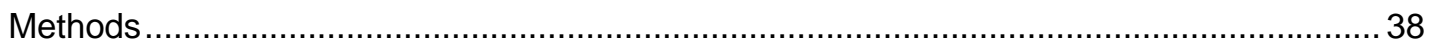

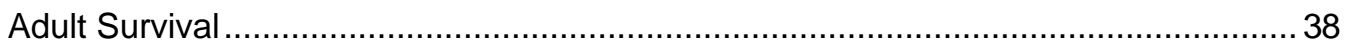

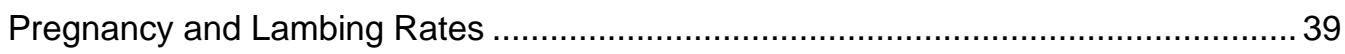

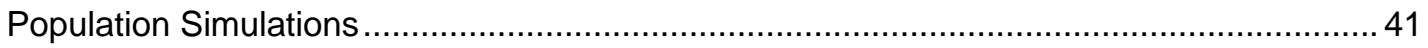

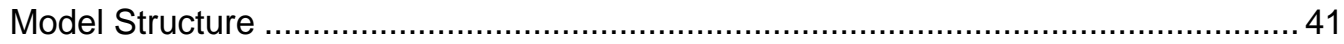

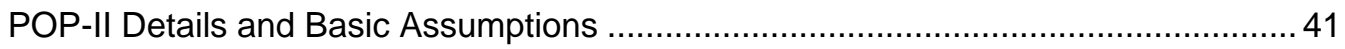

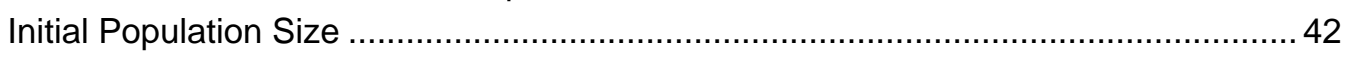

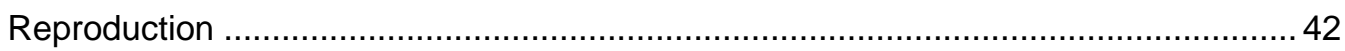

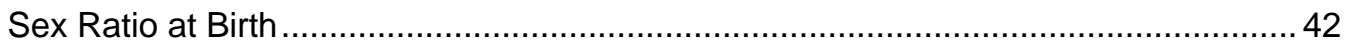

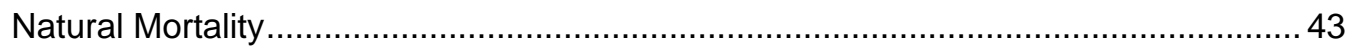

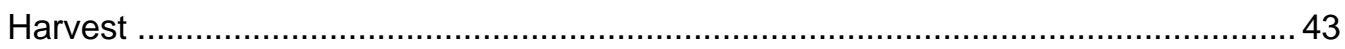

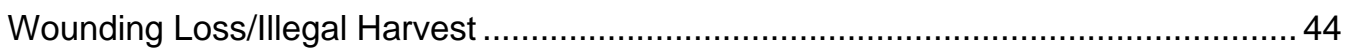

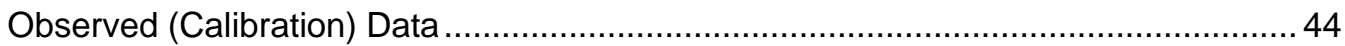

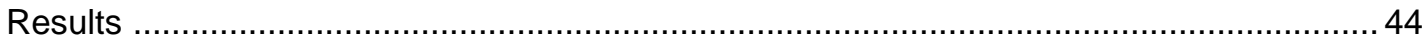

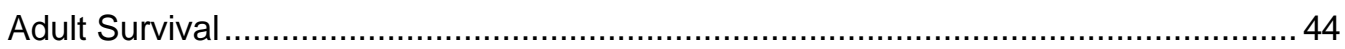

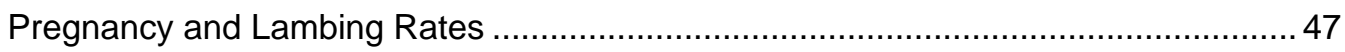

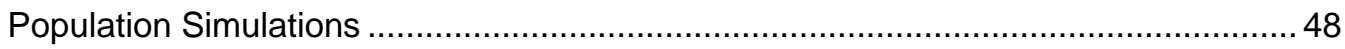

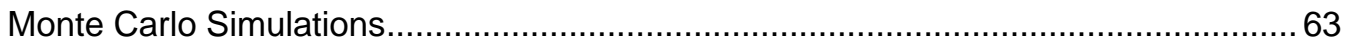

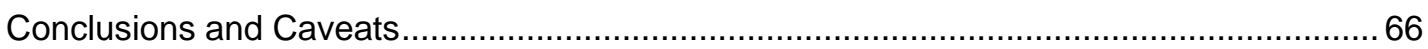

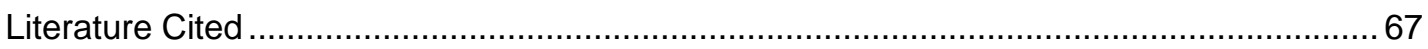

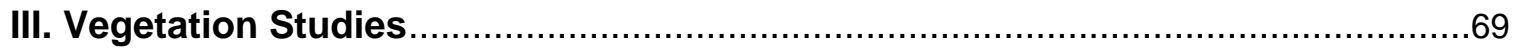

Vegetation Monitoring of the Pryor Mountain Wild Horse Range and Bighorn Canyon National Recreation Area, Montana and Wyoming, 2002 (Troy Gerhardt) ............................ 71

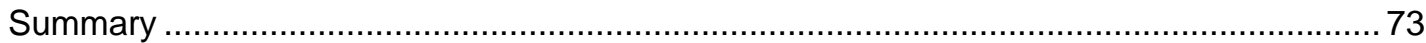

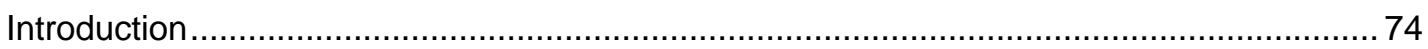

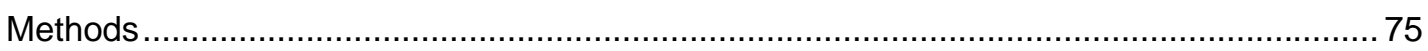

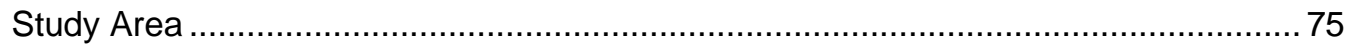

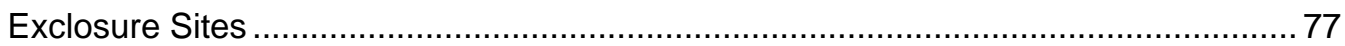

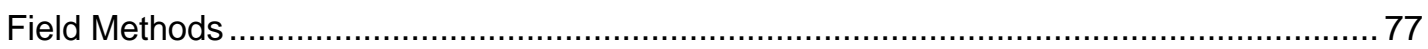

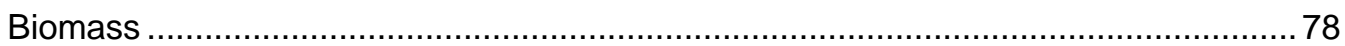




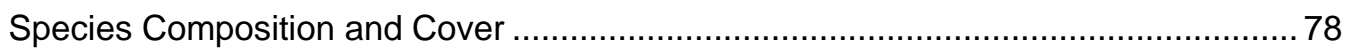

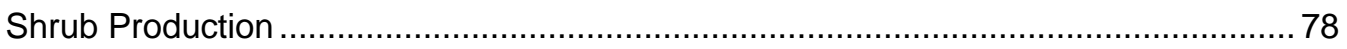

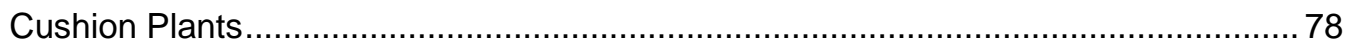

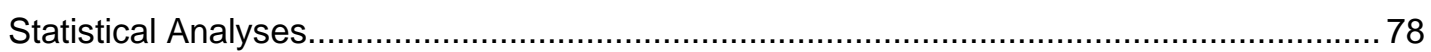

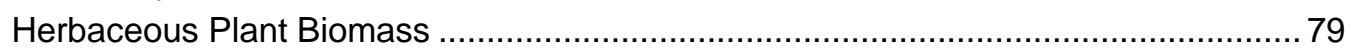

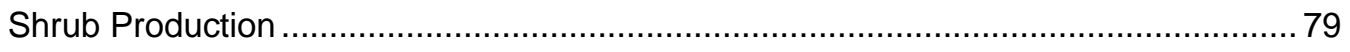

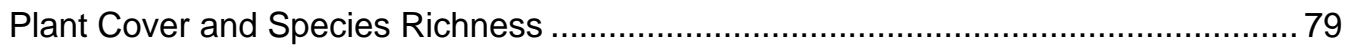

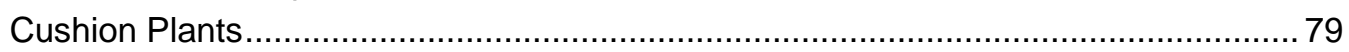

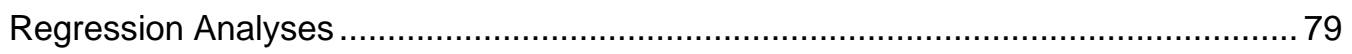

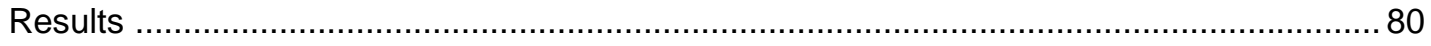

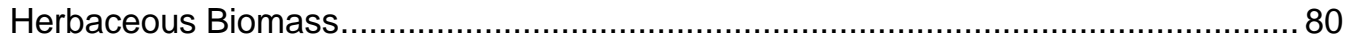

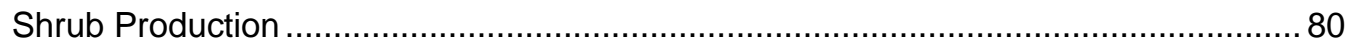

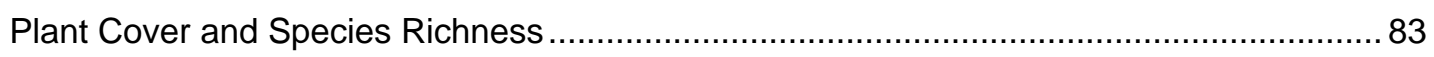

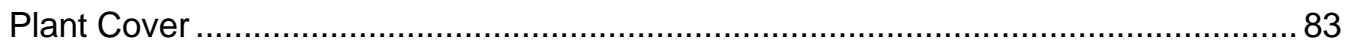

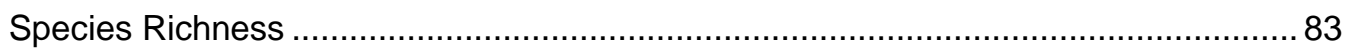

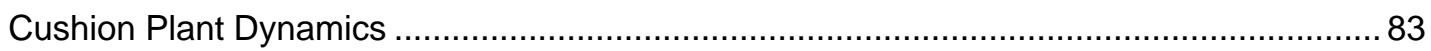

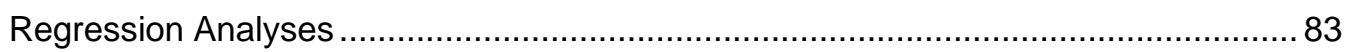

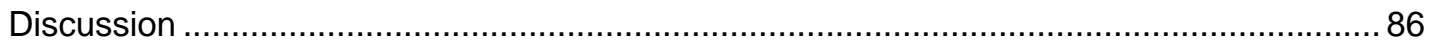

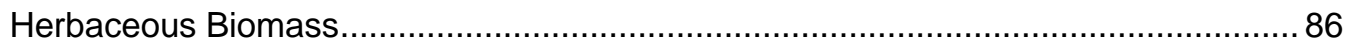

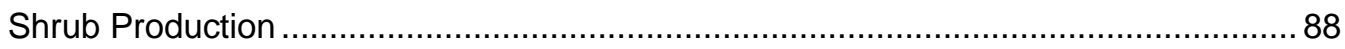

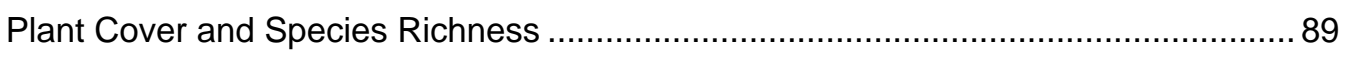

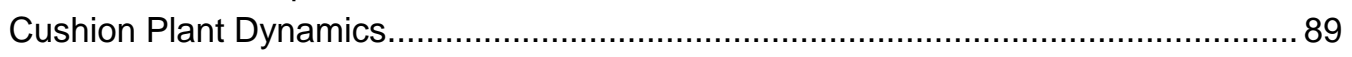

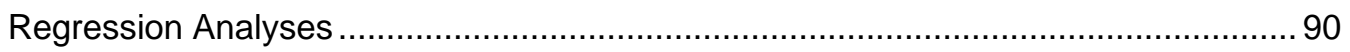

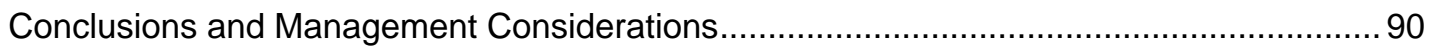

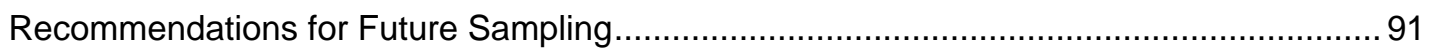

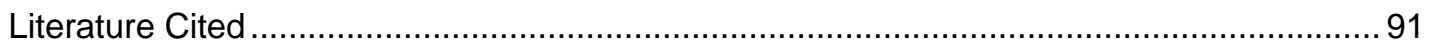

Appendix A. Plots of total herbaceous plant biomass at 10 sites for the period

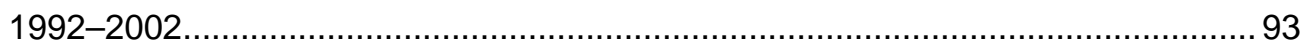

Appendix B. Mean herbaceous biomass of live grass, current years' dead grass, previous years' dead grass, forbs and dwarf shrubs, and total for each site in 2002 (mean and standard error shown) ................................................................95

Appendix C. Cover and species richness in grazed and permanently exclosed plots.......... 99

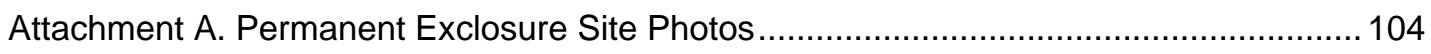

Attachment B. Cushion Plant Site Photos ........................................................................ 129

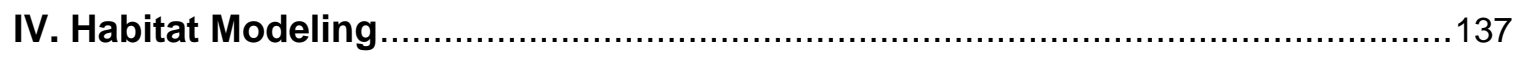

Bighorn Sheep Habitat Suitability Assessment of the Greater Bighorn Canyon National Recreation Area: A Higher Resolution Analysis (Michelle A. Gudorf) .................................. 139

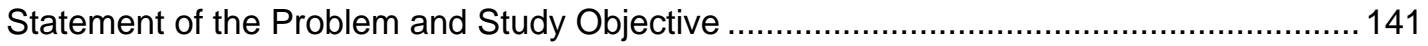

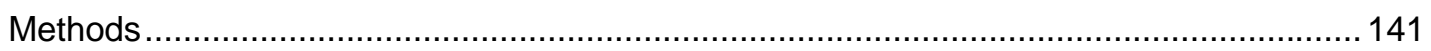

The Habitat Evaluation Procedure ................................................................. 141

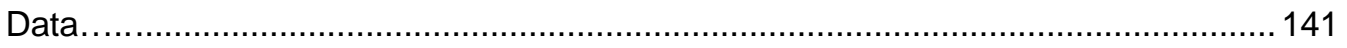

Study Area

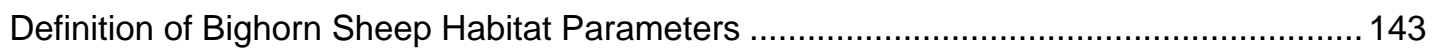

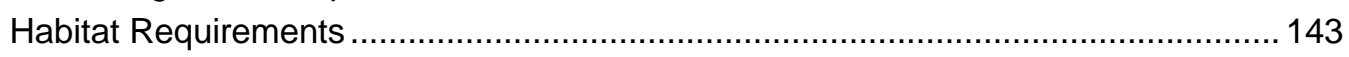




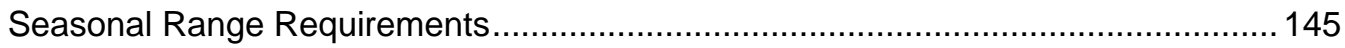

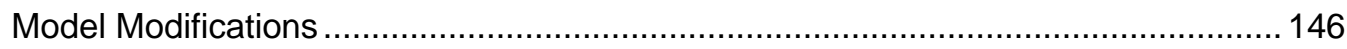

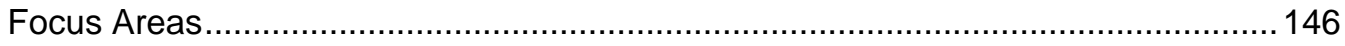

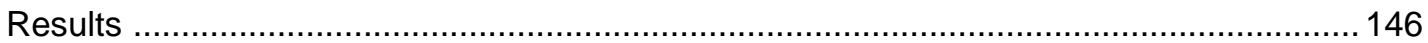

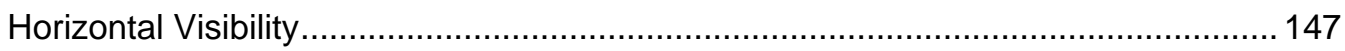

Wyoming Gap Analysis, 1996, Landcover for Wyoming ................................... 147

NPS: Vegetation Ecology in the BICA (Knight and others, 1987) .......................... 147

USGS Gap Analysis Program: Montana Landcover, 1997 ....................................... 148

Landcover Classifications for the Sheridan Region Wyoming Game and Fish

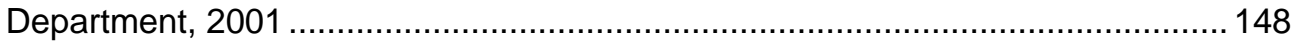

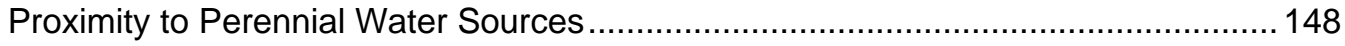

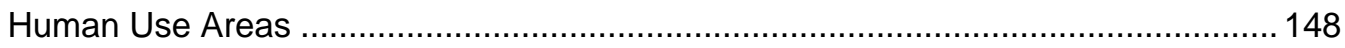

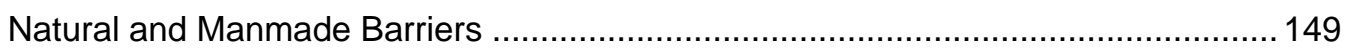

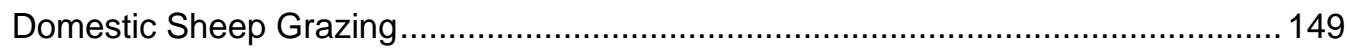

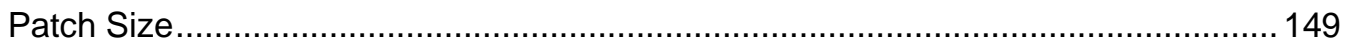

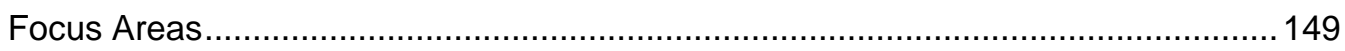

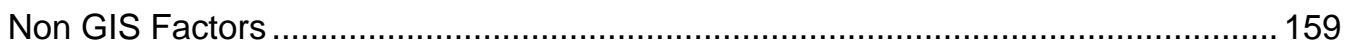

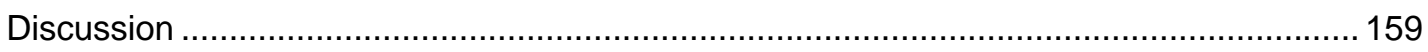

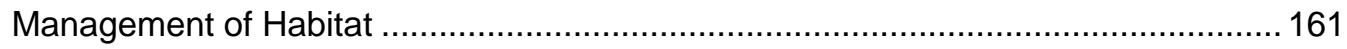

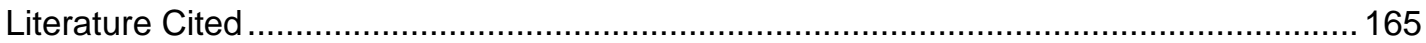

Model for Bighorn Sheep and Wild Horses in Bighorn Canyon National Recreation Area and the Pryor Mountain Wild Horse Range, Montana, and Wyoming (Gary Wockner,

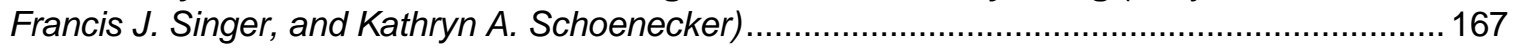

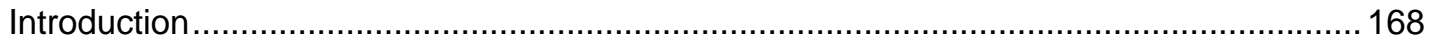

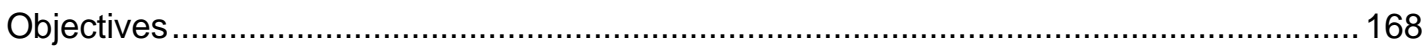

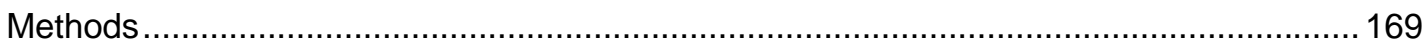

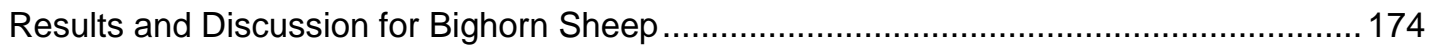

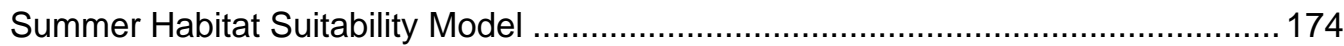

Winter Habitat Suitability Model......................................................................... 175

Comparison of the Animal Location-Based Model with the Intermountain West

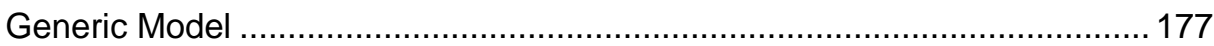

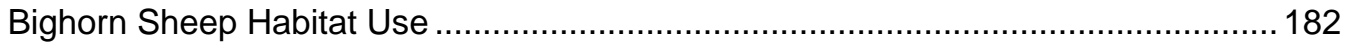

Bighorn Sheep Habitat Improvement Scenarios ................................................ 182

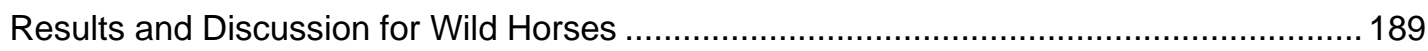

Current Summer Habitat Selections and Distributions of Wild Horses ...................... 189

Current Winter Habitat Selections and Distributions of Wild Horses.......................... 191

Potential Habitats that are Unused or Little-Used by Wild Horses-Habitat Improvement Scenarios.................................................................... 191

Potential Additions of New Areas to the Wild Horse Range ...................................... 193

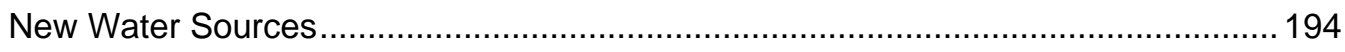

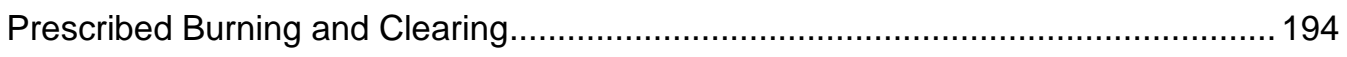

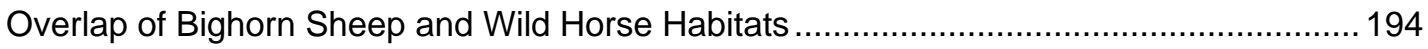

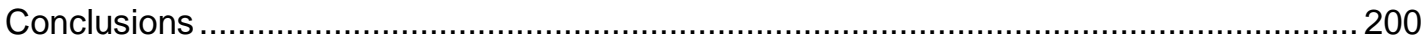

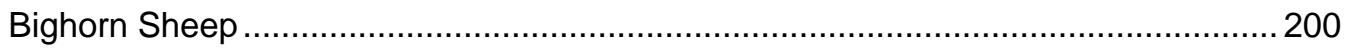

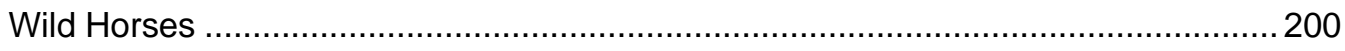

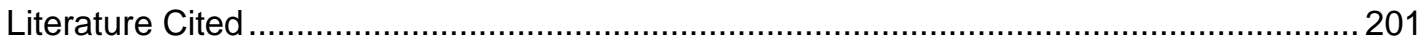




\section{Executive Summary}

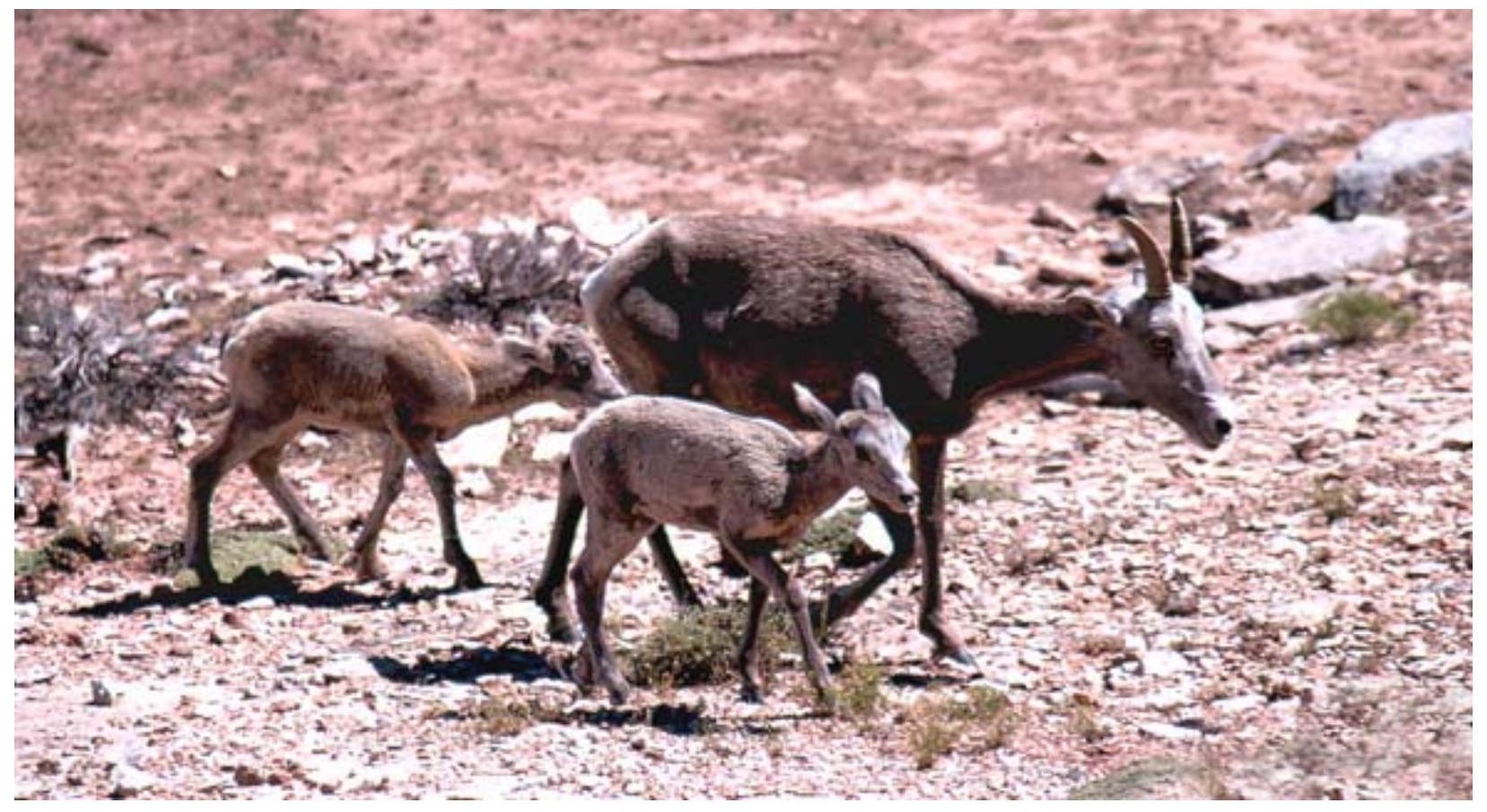





\title{
Bighorn Sheep Habitat Studies, Population Dynamics, and Population Modeling in Bighorn Canyon National Recreation Area, 2000-2003
}

\author{
By Francis J. Singer and Kathryn A. Schoenecker, U.S. Geological Survey
}

\section{Executive Summary}

At the request of National Park Service resource managers, we began a study in 2000 to evaluate causes for the decline of the bighorn sheep (Ovis canadensis) population inhabiting Bighorn Canyon National Recreation Area (BICA), the Pryor Mountain Wild Horse Range, and surrounding state and U.S. Forest Service lands in Montana and Wyoming. Our study consisted of radio-collaring adult rams and ewes with mortality sensors to monitor adult mortalities, tracking ewes to determine pregnancy and lambing rates, habitat assessments to determine why the population was not expanding into what had been modeled using GIS methodology as suitable bighorn sheep habitat, measuring ungulate herbaceous consumption rates and herbaceous production to determine plant responses, and aerial and boat surveys to determine bighorn sheep population range and population dynamics (Schoenecker and others, this report). Two habitat suitability models were created and conducted (Gudorf, this report; Wockner and others, this report) using different methodologies, and comparisons made between the two. Herd population dynamics were modeled using the POP-II and POP-III programs (Roelle, this report), and a reassessment of ungulate exclosures that were established 8-10 years ago was conducted (Gerhardt, this report).

The bighorn sheep population of the greater Bighorn Canyon National Recreation Area (BICA) was extirpated in the 1800s, and then reintroduced in 1973. The herd increased to a peak population of about 211 animals (Kissell and others, 1996), but then declined sharply in 1995 and 1996. Causes for the decline were unknown. Numbers have remained around $100 \pm 20$ animals since 1998. Previous modeling efforts determined what areas were suitable bighorn sheep habitat (Gudorf and others, 1996). We tried to determine why sheep were not using areas that were modeled as suitable or acceptable habitat, and to evaluate population dynamics of the herd.

\section{Methods}

We conducted our 3-year study from 2000-2002. We used radio-telemetry on 30 collared bighorn sheep ( $\sim 1 / 3$ of herd) and collected daily VHF signals to monitor adult mortality and population range, and tracked ewes to determine lambing rates during the lambing season. We gathered data on habitat parameters for bighorn sheep to evaluate areas they were using and compared them to areas they did not use. We evaluated nutrient concentrations in key forage species for bighorn sheep and compared habitat areas for differences. To estimate population size, we flew annual aerial helicopter surveys, conducted boat surveys along Bighorn Lake, and monitored radio-collar locations with fixed-wing surveys. Plant production and structural responses to ungulate herbivory were evaluated by measuring plants and clipping plants inside and outside of ungulate grazing exclosures that were established 8-10 years ago. We measured ungulate consumption rates across the range.

After gathering several years of empirical data, we used the data to develop a habitat suitability model using bighorn sheep locations, and conducted a reanalysis of a previous habitat suitability model for the greater BICA area. Population estimates and sex ratios were used to run the POP-II and POP-III models in order to evaluate population dynamics of the herd and make management predictions. 


\section{Results}

Results of our research indicate that disease played a primary role in the decline of the herd in 1995. We found evidence of Mannheimia haemolytica in $42 \%$ of the bighorns sampled, and $82 \%$ had high concentrations of antibodies in their blood for para influenza, suggesting they had been at least exposed to it. We have no historic baseline for predation rates on this herd, but current predation does not appear to be taking a large percent of adult sheep ( 6 of 13 mortalities). We were not able to determine predation on lambs, but we did radio-track ewes every 2 weeks during lambing season and determined that $21 \%$ of lambs survived to $\geq 1$ year old in 2001 and $44 \%$ in 2002 . We suspect closure of Bighorn Lake to human recreation and boating in 2002 due to lack of water in the lake helped increase survivorship of lambs that year. Bighorn sheep nursery groups were observed all summer foraging on the lakebed sandbars on the lake bottom and there was no human activity from boats or jet skis. Also, bighorn sheep were more secure from predation by bears and mountain lions because larger predators could not readily access the lake bottom due to steep slopes on both sides of the lake.

Consumption rates of vegetation were higher on the shared wild horse-bighorn sheep range (winter consumption \pm s.e. $=37.0 \pm 6.0$ in shared range, $23.4 \pm 5.7$ in bighorn-only range, $P=0.1280$; and summer consumption $=15.6 \pm 5.1$ on shared range, $14.9 \pm 7.5$ on bighorn-only range, $P=0.8336$ ), as might have been expected where two grazing ungulates share a range. However, the area where they shared the range (the Dry Head) was better bighorn sheep habitat for a number of reasons. First, the Dry Head had more mountain mahogany habitat, which bighorn sheep appear to rely on in BICA, especially in winter. Second, our nutrient analyses suggested the Dry Head had higher concentrations of palatable nutrients in summer especially. Thirdly, the horizontal visibility for bighorn sheep was statistically higher on the Dry Head -- even within the same vegetation types -- than other areas, due to smaller shrub sizes. The quality of habitat for bighorn sheep appears to be better on the Dry Head than other areas, although selenium levels in soil were lower on the Dry Head than areas to the west. Lower herbaceous production on the Dry Head compared to areas further north did not appear to deter sheep from concentrating there in both summer and winter. Lastly, habitat modeling indicated that there is more overall suitable habitat for bighorn sheep on the Dry Head where they share the range with wild horses than other areas.

Although competition in the past is difficult to decipher, our data suggested no obvious negative effect of horse grazing or the presence of wild horses on bighorn sheep. Bighorn sheep demographic patterns did not differ between the wild horse-bighorn sheep and bighorn-only areas. We found no differences in pregnancy rates, lambing rates, or lamb survivorship in bighorn sheep inhabiting areas on versus off the wild horse range (pregnancy rate of ewes ( \pm s.e.) was $77 \pm 4 \%$, and lambing rate was $68 \pm 5 \%$, overall), although our sample sizes were small. This finding is in general agreement with those of Kissell and others (1996) and Coughenour (2000), who found little overlap in use of resources. Kissell and others (1996) and Coughenour (2000) found considerable spatial and habitat separation. Even where habitats were shared, diets tended to be largely different between the two species.

Our body condition analysis indicated that body measurements and body weights of bighorn sheep were smaller in BICA than a herd in Alberta, Canada, but this may be due to climate and elevation differences. Body mass is correlated with survival in both adults and lambs (Festa-Bianchet and others, 1997), but since we could not compare BICA sheep to any other herds in Wyoming or Montana due to lack of published data, we do not know if smaller body mass could be associated with poorer body condition and thus the decline of the herd.

The population dynamics modeling (POP-II and POP-III) showed that in order for this herd to increase so rapidly for $\sim 20$ years after reintroduction $(\mathrm{r}=0.23)$, there must have been very little mortality coupled with very high reproductive success. This rapid increase following a translocation has been reported in other herds (McCarty and Miller, 1998). Annual adult survival rates for this herd from February 2000 to January 2003 were about $90 \%$. Based on 15-year modeling projections, a harvest of $<2$ rams/year is appropriate and consistent with NPS goals of increasing the size of the herd.

The vegetation analysis of ungulate grazing exclosures indicated that total biomass and grass biomass was significantly higher inside than outside all exclosures, while forb biomass was lower inside exclosures. Grazing effects were detected for total plant cover, litter cover, and absolute and relative grass cover which were all lower in grazed plots than exclosed plots. Bare ground was higher in grazed plots. Species richness was lower in grazed plots. 
Frequency of cushion plant species ${ }^{1}$ was the same in grazed and exclosed plots on the Dry Head, suggesting ungulate grazing on the Dry Head is not affecting cushion plants. Plots in areas of historic cattle trailing, however, showed significantly different cover and frequencies for some species of cushion plants than nearby native plots that had not been trailed in $>20$ years. Correlations of biomass, precipitation, and horse population indicated that negative grazing effects from higher horse populations are mitigated by precipitation.

Habitat modeling for bighorn sheep and wild horses showed that there is considerable unused bighorn sheep habitat (both winter and summer) north of currently occupied areas, along the Bighorn Lake canyon and in Devil's Canyon. Suitable habitat for bighorn sheep in Crooked Creek, Big Coulee, and West Pryor was more limited. Horizontal visibility for bighorn sheep differed within the same vegetation type (e.g., juniper type) on different parts of the range, and the Dry Head area had the highest visibility for bighorn sheep of the 4 study areas sampled (Big Coulee, Crooked Creek, Dry Head, and Barry's Landing).

\section{Management Recommendations}

We recommend the following management actions:

1. Conduct habitat treatments (burning and thinning) to improve habitat for bighorn sheep, particularly in areas of decreased visibility $(<55 \%)$ such as the Barry's Landing area and north of Barry's Island where all other habitat characteristics for bighorn sheep are present.

2. Continue radio-tracking and monitoring bighorn sheep. Population modeling indicated that more data is needed to better predict population characteristics of this herd. Sample sizes need to be increased. Also, sex ratios of new lambs, and better age and sex ratios of adults would be useful.

3. Encourage dispersal or translocate bighorn sheep to the northern end of Bighorn Lake, and consider improving habitat in southern end of the canyon to increase dispersal. Consider burning or thinning treatments in areas that add useable clusters of suitable habitat that can support new nursery bands, as opposed to small isolated patches of habitat. Consider connecting habitats. Big Coulee, West Pryor, and the northwest periphery of the study area were not as favorable for bighorn sheep, and we encourage focusing on improving other habitat areas first.

4. Supplement selenium to the herd using selenium blocks. Selenium levels in plants and feces were consistently on the low end of the acceptable range. Higher selenium levels in the diets may bolster the immune systems of adult bighorn sheep and help lamb survivorship.

\section{References Cited}

Coughenour, M.B. , 2000, Ecosystem modeling of the Pryor Mountain wild horse range: Final report to U.S. Geological Survey, Biological Resources Discipline, U.S. National Park Service, and U.S. Bureau of Land Management, $63 \mathrm{p}$.

Festa-Bianchet, M., Jorgenson, J.T., Berube, C.H., Portier, C., and Wishart, W.D., 1997, Body mass and survival of bighorn sheep: Canadian Journal of Zoology, v. 75, p. 1372-1379.

Gudorf, M., Sweanor, P.Y., Singer, F.J., Blankenship, A., Bleich, V., Easterly, T., Emmerich, J., Eustace, C., Irby, L., Jaynes, D., Jellison, B., Kissell, R., Lindsay, J., Parks, J., Peters, T., Reid, K., Stewart, S., and Voss, T., 1996, Bighorn sheep habitat assessment of the Greater Bighorn Canyon National Recreation Area: National Park Service and National Biological Service cooperative report, Bighorn Canyon National Recreation Area, Lovell, Wyoming, 43 p.

Kissell, R.E., Jr., Irby, L.R., and Mackie, R.J., 1996, Competitive interactions among bighorn sheep, feral horses, and mule deer in Bighorn Canyon National Recreation Area and Pryor Mountain wild horse range: Final report on Cooperative Agreement CA-1268-9017, Montana State University, Bozeman, $146 \mathrm{p}$.

McCarty, C.W., and Miller, M.W., 1998, Modeling the population dynamics of bighorn sheep: a synthesis of literature: Colorado Division of Wildlife Special Report No. 73, 35 p.

${ }^{1}$ Cushion plants are generally higher elevation vascular plants displaying tiny flowers and have a carpet-like appearance, or look like flattened cushions hugging the ground. Often they indicate humid and acid soil conditions. Their root system is numerous and penetrates deep into the soil. Often different species intermingle to form a mosaic. Because the leaves are so densely packed, the branches inside are protected from wind, snow, and ice, and the core of the plant retains a fairly constant temperature. 



\section{Population Dynamics and Modeling}

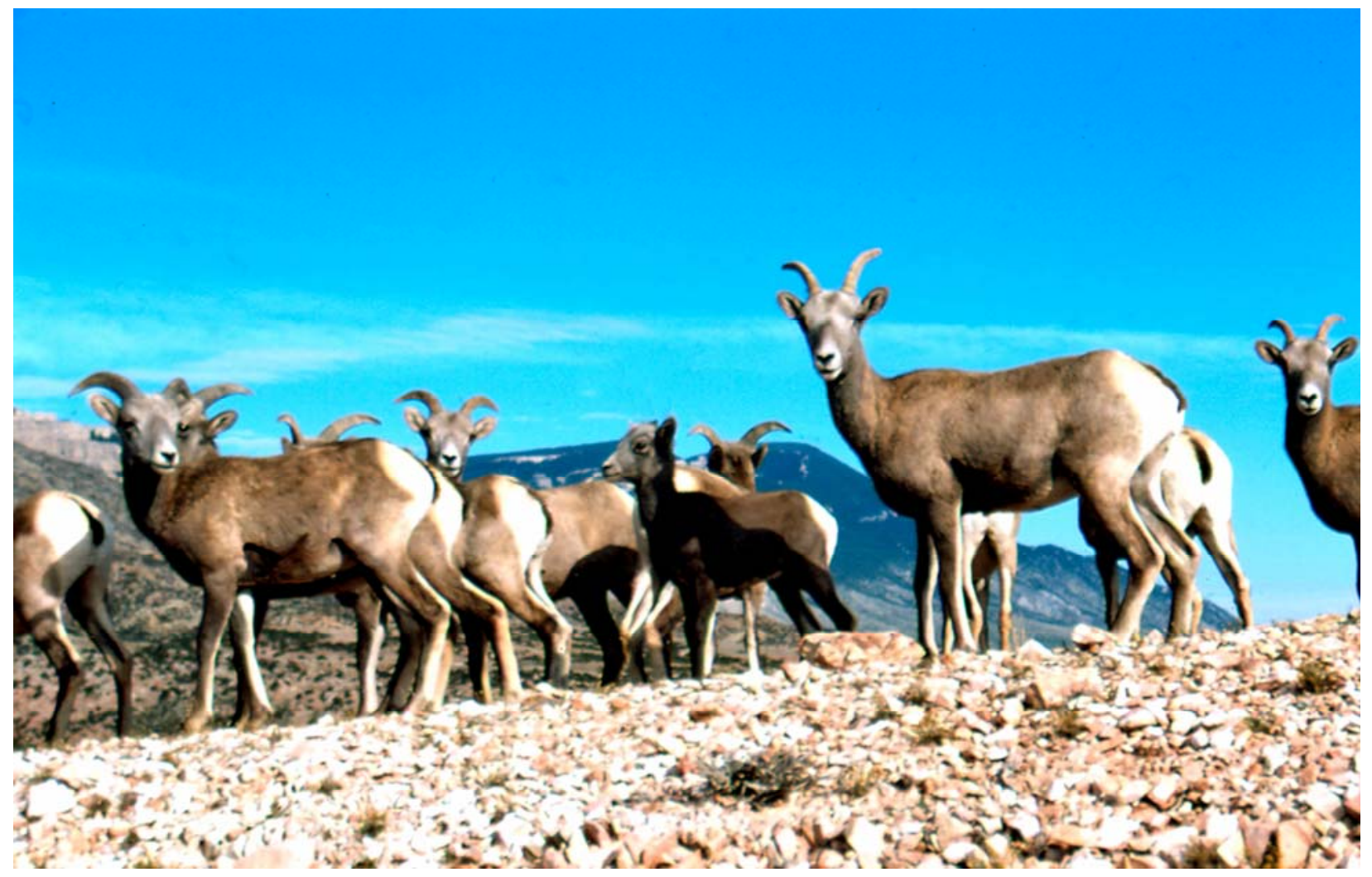





\section{Bighorn Sheep (Ovis canadensis) Survivorship and Habitat Studies in Bighorn Canyon National Recreation Area and Surrounding Lands, Wyoming and Montana, 2000-2003}

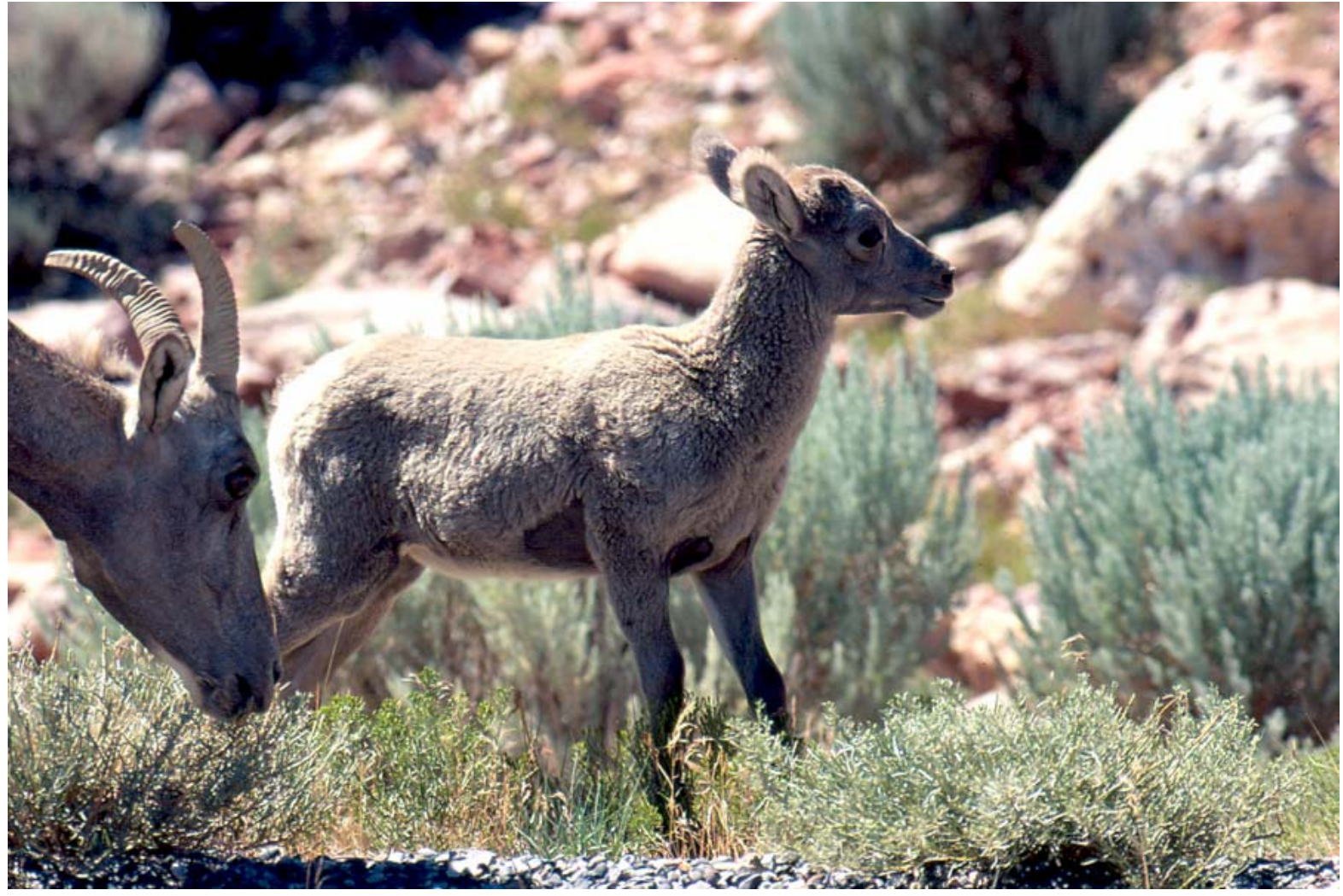




\section{Introduction}

In the 1850s, bighorn sheep (Ovis canadensis) were numerous and distributed throughout the Bighorn and Pryor Mountains of Montana and Wyoming. After European settlement, bighorn sheep populations declined, and local extinctions occurred in much of their historic range in the western United States. The current bighorn sheep population of Bighorn Canyon National Recreation Area (BICA) is the product of several reintroductions into BICA and surrounding lands. Following a release in 1973 and growth rates near maximum potential of $19.8 \%$ per year, the population grew to an estimated peak population of about 211 animals in 1993 and 1994 (Kissell and others, 1996). Recent counts indicate the bighorn sheep population has declined. Kissell and others (1996) reported that the population began to decline rapidly in 1995 and 1996. He noted low ewe:lamb ratios during the decline phase. Bighorn sheep numbers declined to the lowest minimum viable population size of 100 animals recommended by several bighorn sheep experts (Bailey, 1990; Berger, 1990; Smith and others, 1991). National Park Service (NPS) and Bureau of Land Management (BLM) managers were concerned about the decline and requested a study of its causes. In 2000, the U.S. Geological Survey- Biological Resources Division (USGS-BRD) received funding to start a 3-year study of survivorship, condition, and population growth rate of the BICA bighorn sheep population.

Several possibilities exist for the bighorn sheep decline. The herd may have experienced a rapid population expansion, followed by a decline to stability at a lower long-term carrying capacity. This pattern of apparently overshooting carrying capacity following an initial release has been reported for a number of ungulates (Caughley, 1976). Disease may have caused the decline; predation and/or competition with wild horses (Equus caballus) may also have been factors.

A spatial model of wild horse carrying capacity (Coughenour, 1999) was developed to assist managers in evaluating wild horse population numbers. Studies of summer consumption rates by wild horses and other ungulates were conducted by James Detling and students from Colorado State University (Peterson and others, 1997; Gerhardt and Detling, 1998; Fahnestock, 1998). Diets and habitat use of wild horses, bighorn sheep and mule deer were studied by Coates and Schemnitz (1989) and Kissell and others (1996). Both Coates and Schemnitz (1989) and Kissell and others (1996) reported a high degree of dietary overlap between wild horses and bighorn sheep. However, Kissell and others (1996) concluded that a high degree of spatial separation between wild horses and bighorn sheep, at least under the study conditions, precluded any significant negative competitive influences. The most important overlap of bighorn sheep and wild horses seems to be on winter range. Competition can be difficult to determine, since current conditions may not reveal competition that has already occurred. Managers remained concerned about the declining bighorn population for the following reasons:

1. Lamb:ewe ratios and population estimates plummeted in 1995 and 1996. There had been a large wild horse gather and removal from the range in fall 1994, so wild horse numbers were not high at this time.

2. Kissell and others (1996) raised concerns about predation and disease, as bighorn sheep populations are highly susceptible to rapid die-offs from disease epizootics (Onderka and Wishart, 1984), and bighorns with lowered body condition due to disease would be at greater risk of predation.

3. The Big Coulee area, especially the low elevation, exposed knife-like ridges and steep slopes to the east of Big Coulee, is a relatively snow-free area and has been mapped by a GIS-based habitat model as suitable bighorn sheep winter range (Gudorf, 2002), but bighorn sheep were rarely observed there. But similar steep canyon habitat to the west and just outside of the wild horse range in Crooked Creek canyon was also mapped as suitable and was colonized by a small group of bighorn sheep lambs and ewes (Kissell and others, 1996). However, this area was not used after 1996 with the exception of occasional sightings, and bighorns were not using what seemed to be suitable habitat elsewhere in the area. Bighorn sheep occupied $<15 \%$ of the area rated as suitable by Singer and others (2000a).

Our objectives for the study were to:

1. Evaluate current disease problems and mortality rates, including predation rates, in bighorn sheep through captures and monitoring of bighorn sheep.

2. Determine winter spatial relations of wild horses and bighorn sheep through aerial surveys of winter range. 
3. Conduct habitat measurements to determine why bighorn sheep were not using what had been mapped with a GIS-based habitat model as suitable bighorn sheep habitat, and sample winter and summer consumption rates of key forage species to see if there were other factors precluding use of these areas by bighorn sheep.

4. Compare winter lamb recruitment rates and total vegetation consumption rates on bighorn sheep winter use areas, with and without wild horses present.

5. Complete year-round GIS-based distribution maps for wild horses and bighorn sheep in order to identify key areas of species overlap and key areas of species separation for potential habitat improvements.

NPS park staff asked USGS to answer the following questions: (a) how large is the population?; (b) how many rams are in the population?; (c) in addition to low lamb recruitment, is mortality or dispersal of adults likely contributing to the decline?; and (d) is trophy hunting of rams contributing to the decline?

\section{Literature Review}

\section{Disease}

Research has shown that diseases, especially bronchopneumonia due to pasteurellosis, can kill bighorns of all ages. Pasteurellosis is a contagious disease of domestic and wild ruminants, and epizootic outbreaks have caused widespread mortality and major die-offs in bighorn sheep (Potts, 1937; Onderka and Wishart, 1984). Signs of pneumonic pasteurellosis in bighorn sheep include serous nasal discharge and infrequent coughing (Gilmour and Gilmour, 1989; Miller and others, 1991). During an initial outbreak bighorn sheep of all ages die, followed by very low lamb survival for several years (Foreyt, 1990). After the initial outbreak, most adults are apparently immune and are no longer susceptible, but lambs carry no such immunity. Once passive immunity from colostrum in ewes wanes, lambs succumb and continue to die for two years after onset of the disease (Foreyt, 1990). If a population has a chronic pasteurellosis problem, lambs most typically succumb at 4-8 weeks of age (28-56 days). Initial high lamb:ewe ratios may be observed, but they are typically followed by low ratios by late summer. There is evidence that stressed bighorn sheep are more susceptible to pneumonic pasteurellosis than bighorn sheep that are not stressed (Kraabel and Miller, 1997). No vaccine for pasteurellosis (Manhiemia haemolytica) currently exists (Foreyt, 1992). Some experimental vaccines have been attempted with little success (Cassirer and others, 2001); but nothing is available in a useable format at this time (Miller and others, 1997; Kraabel and others, 1998).

\section{Selenium}

Selenium is an essential nutrient (trace element) that prevents oxidation of unsaturated fats in cell membranes (Robbins, 1993). When selenium is deficient in the diets of animals and this oxidation occurs, muscle membranes rupture and the muscle tissue becomes nonfunctional and turns white. This is called "white muscle disease" (Robbins, 1993). Selenium deficiency in bighorn sheep probably occurs when whole blood concentrations or plant dry matter selenium levels fall below $0.05 \mathrm{ppm}$ (Hebert and McTaggart-Cowan, 1971). In one study, mountain goats with blood selenium concentrations as low as $0.014 \mathrm{ppm}$ were highly susceptible to capture myopathy (Robbins and others, 1995). Selenium deficiency has been implicated in low lamb survivorship and population decline of the Whiskey Basin, Wyoming, bighorn sheep herd (Hnilicka and others, 2001).

\section{Nutrients}

Proteins are major constituents of animals' bodies, and a continuous supply of dietary protein must be available to animals for a host of functions. Deficiencies in the essential amino acids that make up proteins will reduce growth and reproduction (Robbins, 1993). Wildlife nutritionists have typically determined the nitrogen content of food in order to provide an index of its protein content. Nitrogen $(\mathrm{N})$ is an essential nutrient for plants and animals. Plants obtain the majority of their nitrogen from the soil by absorption through the roots, while herbivores 
get it primarily from plants. Carbon is another organic constituent, like N, and is an essential nutrient. Measures of dry matter digestibility (Dmd) and acid detergent fiber (Adf) provide an index to the digestibility of plant material by ungulates and other wildlife (Robbins, 1993). Digestibility is important because not all plant parts are useable by vertebrates. While energy is expended consuming plants, not all of the plant material provides energy (gained) in digestion. Cellulose and lignin are structural carbohydrates of plant cell walls that provide rigidity and are largely indigestible by vertebrates (Robbins, 1993).

Other trace elements that are important or relevant to bighorn sheep include iron, zinc, manganese, molybdenum, and copper. Iron is important for hemoglobin and is a component of many enzymes. Iron deficiency causes weight loss, impaired brain and immune function, and anemia (Robbins, 1993). Zinc is essential for the synthesis of DNA, RNA, and proteins, and zinc-deficient diets cause retarded growth, hair loss and rough hair coat, weight loss, impaired reproduction, impaired wound healing, and increased susceptibility to infections (Robbins, 1993). Manganese is necessary for bone formation and energy metabolism, and deficiencies cause reduced growth or weight loss, impaired reproduction, nervous disorders, slipped tendons, and bone malformations (Robbins, 1993). Molybdenum is an important component of enzymes, and deficiencies cause reduced growth. Copper is necessary for hemoglobin and melanin formation and is a component of blood proteins and enzyme systems. Copper deficiencies in wild ruminants have occurred world-wide. Symptoms include pale, faded, brittle pelage, osteoporosis and fractures, abnormal hoof and antler growth, impaired movement, weight loss, reduced reproduction, and sudden death (Robbins, 1993). Thus, copper-deficient animals in the wild would be highly susceptible to predation. Copper deficiencies have also been reported to alter immune response in humans and animals (Minatel and Carfagnini, 2000). Innate immune response is impaired in ruminants with copper deficiencies, but not acquired immune function (Minatel and Carfagnini, 2000).

\section{Predation}

Some theories about predator-prey relationships suggest that predation may increase due to variables like overpopulation or chance. Predation may weed out the debilitated, the too numerous, and the unfortunate (Cain and others, 1972). Caughley (1976) suggested that predators were not capable of stopping ungulate population irruptions. McCullough (1979) believed that wolves (Canis lupus) could not drive white tailed deer (Odocoileus virginianus) to low population densities because density-dependent factors of deer condition would decrease their vulnerability to predation. Other research on ungulates and predation contends that the group behavior of bighorn sheep greatly reduces their vulnerability to predation and that predation is unlikely to cause a population decline in bighorn sheep herds (Hornocker, 1970; Buechner, 1960). However, in an 8-year study of bighorn sheep herds in the Sierra Nevada and Granite Mountains of California, Wehausen (1996) found that mountain lions were the primary cause of decline of two herds of bighorn sheep. Predation by mountain lions caused bighorns to abandon seasonal winter range, giving up nutritional advantages of migration and eventually delaying timing of lambing by one month. Lambs born later had lower survivorship to yearling age, and the population dropped further (Wehausen, 1996). Annual survivorship of adult ewes in Wehausen's (1996) study averaged 62.5\% in the first 3 years.

Wehausen (1996) concluded that group behavior of bighorn sheep was not sufficient to prevent population declines from mountain lion predation.

Mountain lions are the most important feline predator on bighorn sheep (Kelly, 1980). Mountain lions that had home ranges overlapping bighorn sheep habitat rarely killed sheep, while other individual lions preyed heavily on sheep, suggesting that mountain lion predation on bighorn sheep is an individual, learned behavior (Ross and others, 1997). Thus, for bighorn sheep that occur in small, isolated groups, the presence of a few such predators may strongly influence their survival rates and behavior (Ross and others, 1997). Ross and others (1997) reported that bighorn sheep incurred 34\% over-winter mortality due to cougars in Alberta, Canada. Some reports indicate that predator control efforts have contributed to increased lamb survival (Halloran, 1949), while others believe that controlling predators has had little effect (Russo, 1956). 


\section{Hunting Effects}

Since the 1970's there has been concern about possible negative effects of trophy hunting on mountain sheep. Biologists have observed a strict dominance hierarchy in rams. Class IV rams, the largest-horned rams typically 8-years or older, obtained most copulations. These large-horned and older rams courted ewes in a more deliberate, controlled fashion (Geist, 1971; Nichols, 1972). Younger rams were usually restricted from breeding, and when they did get an opportunity they courted ewes aggressively, with few displays and much chasing. The suspected negative effects of trophy hunting fell into two major concerns. The first involved possible negative effects on ewe energetics and reproduction from harassment by the young rams. This first hypothesis has never been demonstrated. Trophy hunted herds, even the most heavily hunted herds, produce and recruit equivalent numbers of lambs, and ewe survival rates are also equivalent (Nichols, 1972; Jorgenson and others, 1997; Singer and Zeigenfuss, 2002). Apparently, even though young rams in hunted herds may harass ewes more, this is canceled out by the fact there are fewer rams in hunted herds to court ewes (Singer and Zeigenfuss, 2002). Breedings may be a few days later in trophy hunted herds (Nichols, 1972; Singer and Zeigenfuss, 2002), but apparently births still fall within the optimum period for survival of lambs. Birth dates would have to be several weeks later, not several days later, to reduce lamb survival (Bunnell, 1980, 1982). There is considerable evidence to support the second hypothesis, however -- that of depressed survival of young rams in hunted herds (Heimer and others, 1984; Jorgenson and others, 1997; Singer and Zeigenfuss, 2002). Young rams participate more in rut activities in hunted herds. As a result of increased energy expenditures just before winter, these young rams have higher rates of mortality than is typical of prime breeding (> 8 year-old) rams (Jorgenson and others, 1997; Singer and Zeigenfuss, 2002).

\section{Guidelines to Avoid Depressed Survival of Young Rams}

No magic guidelines exist that will apply in all situations. The typical healthy mountain sheep population of 100 animals (census N) recruits 5-6 rams into legal size ( $\geq 4$ yr old, or $1 / 2$ curl) category each year (Geist, 1971; Wishart, 1986). Conservative harvests of about $1.5 \%$ of census $\mathrm{N}$ (population size) of Dall sheep across broad areas of Alaska (Heimer, 1985) resulted in no detectable depressed survival of sublegal ( $\leq 1 / 2$ curl) rams (Murphy and others, 1991). Two herds harvested at $3 \%$ of census N showed no statistically significant effects (Singer and others, 2000b), although in one of the herds there were nonsignificant tendencies to lower survival. Heimer and Watson (1986) also predicted that a harvest of 3\% of census N could be sustained for Dall sheep. The province of Alberta aims to harvest about two-thirds of the recruitment of rams to legal size, or about $4 \%$ of census $\mathrm{N}$ per year -- but this may be too high, since depressed survival of young rams was documented in two Alberta herds (Ram Mountain and Sheep River; Jorgenson and others, 1997). Intense harvest of all or nearly all of the recruitment of rams to legal size (i.e. 5-6\% of census N) resulted in depressed survival of young rams in two highly accessible Dall sheep populations in Alaska, Dry Creek (Heimer and others, 1984) and Usibelli (Singer and others, 2000b). Therefore, $\leq$ $3 \%$ harvest of census $\mathrm{N}$ (i.e., less than one-half of the ram recruitment to legal size each year) seems to be a safe harvest for healthy herds. Harvests should be more conservative in declining or diseased herds.

\section{Study Area}

Our study area includes BICA, portions of Custer National Forest, and BLM lands (with some interspersed private lands) in the East and West Pryor Mountains. The Pryor Mountains contain a maze of canyons, limestone caves, and steep ridges. Mountain slopes are forested, but alpine-like meadows, dryland flats, and less vegetated canyons intersperse with forested areas (Gudorf and others, 1996). Elevation ranges from 900-2500 m (Gudorf and others, 1996).

BICA was established in 1966, following construction of the Yellowtail Dam by the Bureau of Reclamation. The dam channeled the flow of the Bighorn River into a 100-km long lake. The park spans the Montana-Wyoming stateline and encompasses $>28,000$ ha of land. There is a strong precipitation gradient in the park, varying from approximately $15 \mathrm{~cm}$ annually at the south (upstream) end of the park and $45 \mathrm{~cm}$ at the north end 
(Knight and others, 1987). Vertical canyon walls are up to $1,700 \mathrm{~m}$ high, containing limestone caves and talus slopes.

Vegetation communities in the park have been categorized by Knight and others (1987), and include desert shrubland, juniper woodland, mountain mahogany woodland, sagebrush steppe, basin grassland, juniper/mountain mahogany woodland, riparian, and coniferous woodland.

The climate is characterized by long cold winters and hot dry summers, but diversity in geography creates locally variable weather conditions (Gudorf and others, 1996). Semi-arid conditions along the Dry Head area of the park are contrasted with sub-alpine zones at higher elevations in the Pryor Mountains.

\section{Methods}

Our 3-year study in BICA was conducted from 2000-2002. We also conducted research on the wild horses of the Pryor Mountain Wild Horse Range (PMWHR) from 1992 through 2000. To focus our sampling on several opportunistic features of the wild horse range grazing system and to answer questions concerning possible competition between the two species, we divided the study area into 4 zones based on densities of ungulates (Figure 1). The Dry Head (DH) area of the park is habitat with high densities of both bighorn sheep and wild horses in summer, and high density of sheep in winter. North of the DH and north of the wild horse range boundary is the Barry's Landing (BL) area with bighorn sheep but no wild horses. The Big Coulee (BC) area contains high winter densities of wild horses but no known established groups of bighorn sheep (although they have access to the area), and the Crooked Creek (CC) area contains low densities of both bighorn sheep and wild horses. All of these areas are inhabited by mule deer (Odocoileus hemionus) also.

\section{Population Estimates}

To estimate bighorn sheep population size, we conducted 1-2 aerial helicopter surveys/year in the fall and sometimes spring. Methodology for the bighorn sheep survey followed that of Unsworth and others (1994) for the Idaho sightability model. This involved stratifying the area into no sheep, low, and moderate-high density strata. All of the high and a random sample of the low-density count units were flown in tight contours. Known sheep and mule deer ranges were surveyed in grid patterns about 1/4-1/3 mile apart. The sheep range was divided into 14 count units. Sighting conditions during the flight for each group were recorded (activity of sheep, percent vegetation cover, percent snow cover, group size, sun/shade, position of helicopter), and a population estimate and confidence intervals were generated following the Idaho Sightability model for bighorn sheep (Unsworth and others, 1994). Animals were classified by sex and age and lamb:ewe ratios recorded.

To estimate wild horse populations, we used a photo ID system, as recognizable markings permit identification of all individual horses. All harem stallions and nearly all mares and young can be recognized from a helicopter. All locations were recorded with a GPS unit in the aircraft and later plotted in a GIS along with habitat features (slope, elevation, cover vegetation type, exposure) generated from UTM locations.

To determine distribution of sheep, we flew 4 aerial fixed-wing surveys/year and conducted 4-5 boat surveys/summer to monitor canyon cliffs for ewes and lambs. All sheep locations were recorded. Also, bighorn sheep locations were recorded by ground crews when animals were seen near the road or from vantage points along the road.

Additional efforts were made to search for rams. Separate survey flights were flown in July 1998, with little success, and in early rut 1999. Both of these flights were funded by NPS due to concerns over fewer observations of rams by park staff. USGS-BRD scientist F. Singer spent 3 days in November and 5 days in December 1999 classifying and searching for rams. All the rams observed from the air and from the ground were classified into 6 curl classes $(1 / 4,3 / 8,1 / 2,5 / 8,3 / 4,7 / 8$, and $8 / 8)$. F. Singer also counted growth rings on rams during ground rut observations.

Previous population estimates for the area (Kissell and others, 1996), from 1993-96, were based on the joint hypergeometric estimator of the Lincoln-Peterson index using marked animals (NOREMARK, White and 


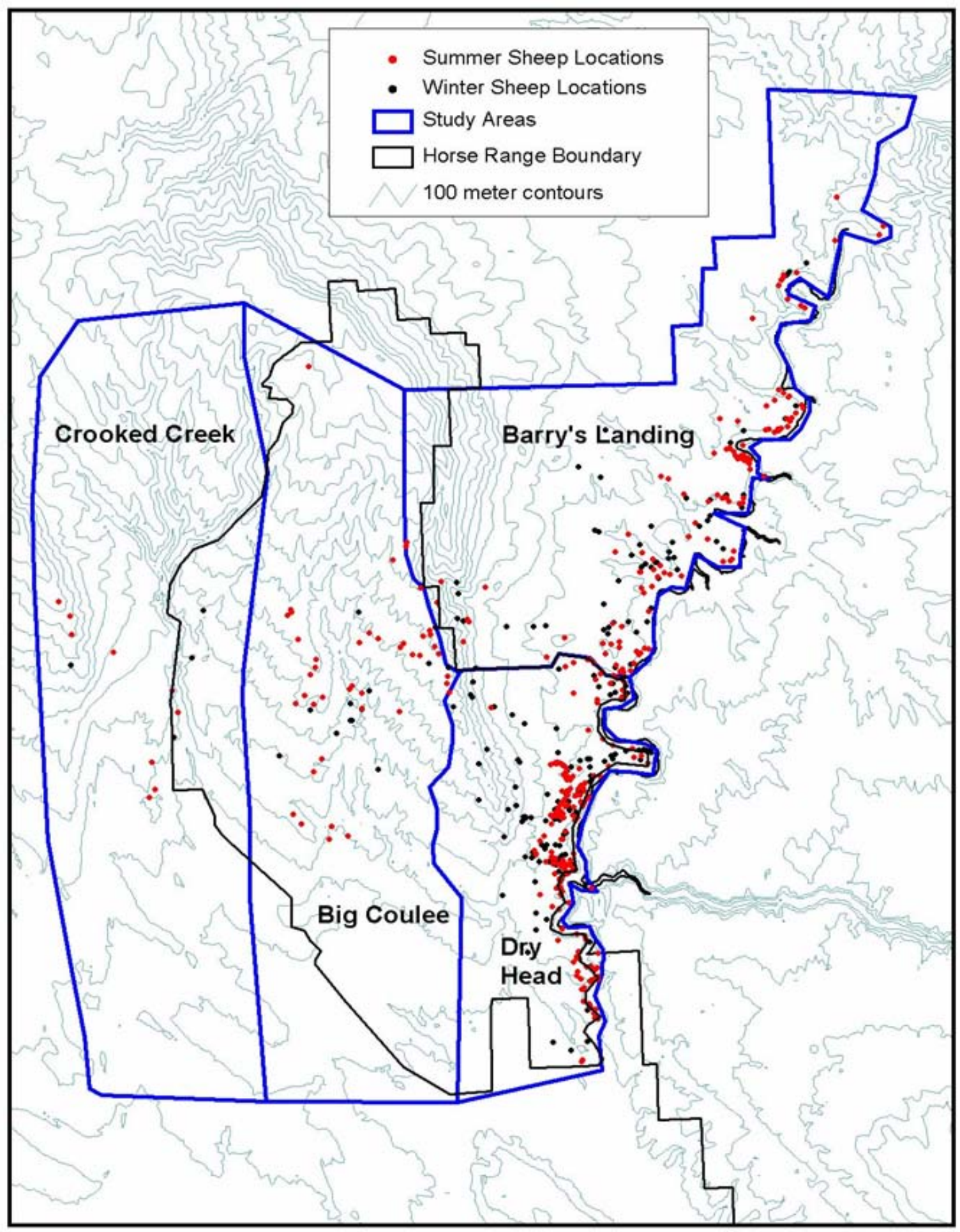

Figure 1. The four study areas in Bighorn Canyon National Recreation Area, the Pryor Mountain Wild Horse Range, and surrounding lands, delineated based on density of wild horses and bighorn sheep. 
Burnham, 1999). Kissell and others (1996) also sampled ram and ewe ratios during extensive ground and aerial searches for bighorn sheep groups containing radio-collared animals. We compared our population estimates from the Idaho Sightability model (Unsworth and others, 1994) to NOREMARK (White and Burnham, 1999) estimates reported by previous researchers (Kissell and others, 1996).

\section{Bighorn Sheep Monitoring and Survivorship}

We radio-collared 23 bighorn sheep in 2000 ( 8 rams, 15 ewes), and 20 additional bighorn sheep in 2001 ( 8 rams, 12 ewes). No neonates were collared. We collected blood samples from bighorns to evaluate concentrations of copper, zinc, iron, and molybdenum. In 2000, radio collars were equipped with mortality sensors (Advanced Telemetry Systems, model 9c) that activated after 8 hours. In 2001, we set the collars to activate mortality signals after only 4 hours to decrease the time between mortality and notification. Also, we found that collars could be reactivated to a normal signal if scavengers moved or shook the carcass/collar. Six radio collars failed or shorted-out during the study. Bighorn sheep were monitored daily (every-other-day on weekends) for mortality signals from January 2000-May 2003. Mortality signals were investigated within 1-3 days, depending on how fast the collar could be located, and cause of death determined at the site of the carcass or remains. Any remains were sent to the Wyoming State Vet Lab, Laramie, for analysis or necropsy. Photographs were taken at each mortality site and date, time, location, field estimated cause of death, estimated time/date of death, age, and sex of bighorn sheep were also recorded.

\section{Population Range of Bighorn Sheep and Wild Horses}

We conducted fixed-wing surveys 5-7x/year in summer and winter to locate radio-collared animals and determine the population range of bighorn sheep. We also tracked bighorn sheep on the ground, locating collared ewes every 2 weeks and collared rams every month from April-September in 2001 and 2002. Wild horse locations were monitored daily throughout summer months in all study years, and 1-2 aerial surveys/year were conducted to determine wild horse population range.

\section{Predation}

We evaluated predation on bighorn sheep by monitoring mortalities of adults. Each mortality was investigated to determine cause of death of the animal. In addition, we collected 11 skulls and carcass remains in the field to conduct observational analyses following the methods of Kunkel (K. Kunkel, Montana State UniversityBozeman, unpubl. data) to determine cause of death when possible. Remains were categorized as either "depredated" or "unknown."

\section{Pregnancy of Ewes}

We collected blood samples at the time of capture in 2000 and 2001 to test for pregnancy. Pregnancy tests (progesterone analysis) on blood were conducted by BioTracking, Moscow, Idaho in 2000 and the University of California, Davis in 2001. In addition, we collected fresh fecal samples from collared ewes for pregnancy analysis by fecal steroid metabolites. With both blood and fecal sampling, we tested 15 ewes in 2000, 18 ewes in 2001, 16 ewes in 2002, and 21 ewes in 2003. Most of the same ewes were sampled each year (those with collars), so samples were not independent of each other. Analysis of fecal samples was conducted by the Science and Conservation Center at Zoo Montana in Billings, Montana. Fecal samples were collected from March-May each year, frozen in plastic bags, and stored until analysis. 


\section{Lamb Survivorship}

We tracked and located collared ewes every 2 weeks from lambing season until late fall (May-September) in 2001 and 2002 to determine lambing success and survivorship of lambs. Ewes were followed and observers recorded whether the ewe had a lamb or the lamb was missing, sex of lamb when possible, location of the bighorn sheep group, and group composition.

\section{Winter Body Condition of Bighorn Sheep}

We collected chest girth measurements on 16 bighorn sheep at the time of capture in 2001 for analysis. We compared chest girth measurements of bighorn sheep from BICA to a herd in Alberta, Canada (Blood and others, 1970). We were not able to use chest girth size as an indicator of winter body condition because we did not find any studies in Wyoming or Montana to which we could compare our chest girth measurements. We compared body weights of 6 bighorn sheep collected at the time of capture in 2001 to weights from a wild herd in Alberta, Canada (Jorgenson and Wishart, 1984) and from captive bighorn sheep (Woolf, 1971). Published information on body weights of bighorn sheep is rare, presumably because capturing and recapturing wild bighorn sheep is too difficult and costly (Festa-Bianchet and others, 1997).

\section{Presence of Disease}

We used blood samples collected at the time of capture in 2000 and 2001 to determine presence or absence of disease isolates and disease titers. We collected blood, pharyngeal, nasal, fecal, and ear swab samples from captured animals. Samples were tested for the presence of mites, lungworm, Pasteurella, and bluetongue. All analyses for disease were conducted at the Wyoming State Veterinary Lab, Laramie. We collected fecal samples at the time of capture to evaluate for parasites. We also collected 5 fecal samples in 2002 for parasitology analysis at the Wyoming State Veterinary Lab.

\section{Competition Between Bighorn Sheep and Wild Horses}

To determine if bighorn sheep were compromised in habitats where they shared the range with wild horses, we evaluated bighorn sheep mortality rates, pregnancy rates, lambing rates, and lamb survivorship in areas shared with wild horses versus areas not shared with wild horses. Because wild horses were only found in areas that were also inhabited by bighorn sheep, we were not able to test the opposite hypothesis, i.e., that wild horses might have been compromised in areas where they shared the range with bighorn sheep.

\section{Habitat Characteristics}

To identify key habitat characteristics for bighorn sheep in BICA and surrounding lands, we measured habitat parameters from May-July, 2000 and 2001 in known bighorn sheep use areas (determined by either direct observation of bighorn sheep or fresh fecal sign; Figure 2). Measurements taken included slope, aspect, herbaceous groundcover, shrub density by species, horizontal visibility (Johnson and Swift, 1995), distance to escape terrain, primary vegetation type using categories of Knight and others (1987), and average \% ground cover of grass, forbs, rock, moss, cactus, lichen, wood, shrub, and bare ground. We compared these habitat parameters between our 4 study areas. We also compared areas used by wild horses and bighorn sheep versus areas used only by bighorn sheep. We compared the 4 study areas to determine if there were differences in habitat that may have prevented bighorn sheep from using areas that have been modeled as suitable bighorn sheep habitat by Gudorf and others (1996) and Gudorf (2002). 


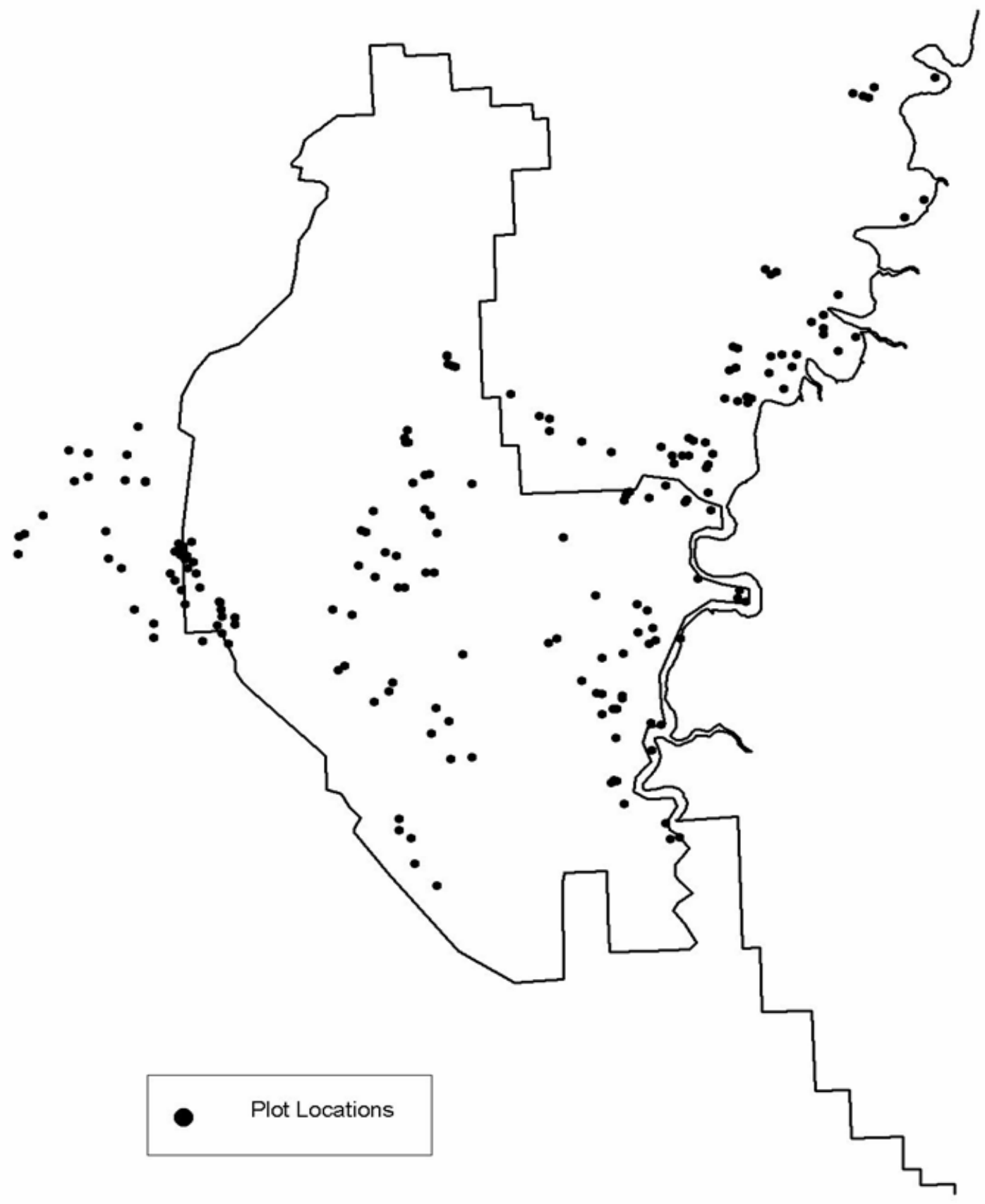

Figure 2. Locations of bighorn sheep habitat parameter measurements taken in Bighorn Canyon National Recreation Area and surrounding lands, 2000-2001. 


\section{Rates of Forage Consumption by Ungulates}

We used $1-\mathrm{m}^{2}$ grazing utilization cages and permanent exclosures to measure seasonal offtake by ungulates for three years in summer 2000, 2001 and 2002, and in winters 2000-2001, 2001-2002, and 2002-2003. We selected areas of similar slope, aspect, elevation, and vegetation type to establish paired sites to compare areas on versus off the wild horse range (Figure 3). Sites were set up in grazed versus ungrazed plots with 3 cages per site. Plant material was clipped in July and in September for summer offtake, and in early April before spring greenup for winter offtake using a $1 / 4-\mathrm{m}^{2}$ metal ring to clip equal amounts in grazed and ungrazed plots. Plant material was then placed in paper bags, oven dried at $41^{\circ} \mathrm{C}$ for $12-24$ hours, weighed, and analyzed by the difference method:

$$
\% \text { Consumption }=100 \times\left(\mathrm{B}_{i}-\mathrm{B}_{o}\right) / \mathrm{B}_{i}
$$

where $\mathrm{B}_{i}=$ dry weight of biomass inside grazing cage, and $\mathrm{B}_{o}=$ dry weight of biomass outside cage. Researchers also estimated the amount of ground cover in each metal ring before clipping, and recorded \% cover of grass, forbs, rock, lichen, moss, wood, cactus, and bare ground. Grazing utilization cages were removed from all field locations in April and May 2003. We analyzed data using paired t-tests.

We conducted linear regression analysis to test the following hypotheses: did winter offtake affect summer production, did summer offtake affect the next summer's production, did June offtake affect September production, and did both summer and winter offtake affect the next summer's production?

\section{Herbaceous Production}

We measured herbaceous production using the offtake plots described above. Peak standing crop was calculated as the amount of biomass clipped in the ungrazed plot in June. For total summer production, plots were clipped and weighed in June at peak greenup, cages moved, and clipped again in September to measure initial peak growth, and any compensatory growth from grazing. We calculated production following Bonham (1989) where June ungrazed biomass is added to September ungrazed biomass minus September offtake to get total production for the season. We analyzed data using paired t-tests from our paired plots on and off the wild horse range.

\section{Nutritional Analysis of Vegetation}

To measure nutrient concentrations in bighorn sheep forage, we collected samples of the 3 most preferred species of grass for bighorn sheep in the area (Kissell and others, 1996), including Stipa comata (needle and thread grass), Bouteloua gracilis (blue grama), Pseudosuega spicata (bluebunch wheatgrass), and the preferred shrub Cercocarpus ledifolius (mountain mahogany) to determine if there were differences in nutritional content between the 4 study areas. Three composite samples consisting of $\geq 5$ individual plants each ( $\geq 15$ plants/site/season) were collected in late winter and also at peak growing season in 2001 and 2002. Samples were collected in the four study areas (Dry Head, Barry's Landing, Crooked Creek, and Big Coulee) in specific areas of known bighorn sheep use. Plant samples were oven dried at $41{ }^{\circ} \mathrm{C}$ for $12-24$ hours. Samples were analyzed for $\%$ content of N, C, acid detergent fiber (Adf), cellulose, lignin, and protein by LECO (Laboratory Equipment Corporation, St. Joseph, MI) $\mathrm{CNH}$ analyzer, and for dry matter digestibility (Dmd) by in vitro digestibility. N, C, Dmd, Adf, cellulose, and lignin analyses were conducted at the Range Nutrition Lab, Colorado State University, Fort Collins, Colorado. We analyzed selenium levels in plants at the Olsen Biochemistry Lab at South Dakota State University.

\section{Selenium}

We measured soil selenium content in 5 vegetation types in each of the 4 habitat areas: Big Coulee, Crooked Creek, Barry's Landing, and Dry Head. Soil cores were taken to $10 \mathrm{~cm}$ in depth in September 2003 and analyzed using extraction methodology by the Olsen Biochemistry Laboratory at South Dakota State University for 


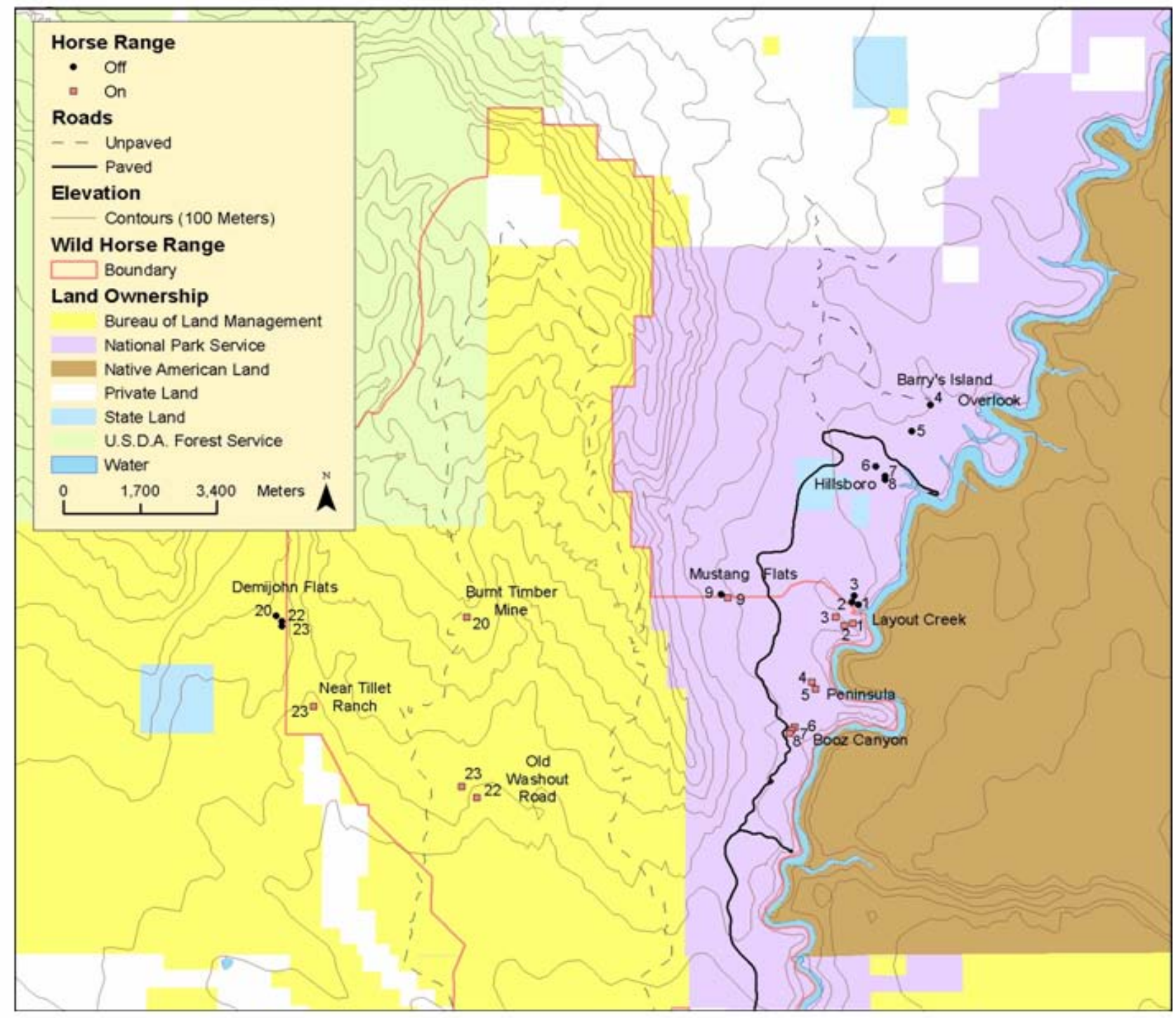

Figure 3. Paired sites used to compare \% ungulate offtake and herbaceous production on versus off the wild horse range in known bighorn sheep use areas, Bighorn Canyon National Recreation Area, the Pryor Mountain Wild Horse Range, and surrounding lands, 2000-2003. 
percent selenium, soluble selenium, exchangeable selenium, and total available selenium. We also collected fecal samples from ewes, rams, and lambs on the $22^{\text {nd }}$ of each month in 2002 for a complete year. Fecal samples were collected by using radio-collared animals to find bighorn sheep groups, visually observing them until they defecated, and then collecting 10-12 pellets from each animal in the group. Age and sex of each animal was recorded. We collected feces from as many bighorn sheep as we could find in one day. Sample sizes for each month ranged from 5 to 14. Samples were oven-dried and stored in paper bags until analysis. Fecal samples were analyzed for fecal nitrogen (fecal-N) content and percent selenium by the Olsen Biochemistry Laboratory at South Dakota State University.

\section{Statistical Analyses}

We used SAS statistical software version 8 for all analyses (SAS Institute, 1988). We present differences at the $P \leq 0.10$ level. We used ANOVA procedures for comparisons between the 4 study areas, and corrected for lack of homogeneity of variances where necessary with Welch's test. Paired t-tests were used for analysis of offtake and production at paired sites.

\section{Results}

\section{Population Estimates and Population Range of Bighorn Sheep}

Our aerial helicopter surveys suggested a possible increase in the bighorn sheep population over the 3-year study period, shown in Table 1, although confidence intervals were very wide. Bighorn sheep ranged from locations just north of Horseshoe Bend in the south, to West Pryor in the west, to just south of Dry Head Creek at the north end of the park, to the Lake on the east end of the park (Figure 1). In 3 years of monitoring, we did not observe any collared sheep east of Bighorn Lake (Figure 1). Bighorns were observed in summer 2002 in the lakebed, when Bighorn Lake was closed to boating and human activities due to lack of water, and forage-filled sandbars lined the Lake bottom. We calculated 39 rams:100 ewes in 2000, 58 rams:100 ewes in 2001, and 69 rams:100 ewes in 2002 from ground and fixed-wing aerial surveys.

\section{Population Range of Wild Horses}

The wild horse population is contained with a combination of natural geographic boundaries and fences. At the northern end the range extended to a BLM fenceline along Layout Creek, to Bighorn Lake in the east, to the mouth of Crooked Creek and a fenceline at the south end of the range, and along Crooked Creek Canyon at the west end of the range. The wild horses inhabited areas on BLM, NPS and USFS lands.

\section{Bighorn Sheep Survivorship and Predation}

We had 13 radio-collared bighorn sheep die during our 3-year study. Of those, 4 died as mountain lion kills, 1 died from black bear kill, 1 died of coyote kill (although this ewe had a broken leg for 5 months prior to being depredated), 1 died from illness or disease, 3 died from unknown causes or presumed old age, and 3 died from capture myopathy. None of the bighorn sheep mortalities were found in Big Coulee or Crooked Creek (Figure 4). Forty-six percent were located on the Dry Head (including Layout Creek and behind Sorenson Ranch) and 54\% were north of the horse range. The majority (77\%) of mortalities occurred in winter months (Oct, Nov, Dec, Jan, Feb, Mar), with only $33 \%$ occurring in summer months. Of the 11 sheep remains and skulls found in the field, 5 were determined as "depredated" and 6 were "unknown." 
Table 1. Idaho sightability model and NOREMARK model estimates for population size of bighorn sheep in Bighorn Canyon National Recreation Area and the Pryor Mountain Wild Horse Range, Montana and Wyoming, from 1993-2002. USGS surveys were conducted 1-2 times/year. Kissell and others (1996) methods include 4-5 surveys/population estimate.

\begin{tabular}{|c|c|c|c|}
\hline Year (survey date) & Source & $\begin{array}{l}\text { Idaho sightability model' } \\
\text { population estimate } \\
( \pm 90 \% \mathrm{Cl})\end{array}$ & $\begin{array}{l}\text { NOREMARK }^{2} \\
\text { population estimate } \\
(95 \% \mathrm{Cl})\end{array}$ \\
\hline 1993 & Kissell and others (1996) & -- & $217(140-360)$ \\
\hline 1994 & Kissell and others (1996) & -- & $215(152-325)$ \\
\hline 1995 & Kissell and others (1996) & -- & $149(125-180)$ \\
\hline 1996 & Kissell and others (1996) & -- & $125(109-169)$ \\
\hline 1997 & No data & & -- \\
\hline \multicolumn{4}{|l|}{1998} \\
\hline Spring (3-20-98) & USGS data & $95 \pm 25$ & -- \\
\hline Winter (1-21-99) & & $94 \pm 64$ & -- \\
\hline \multicolumn{4}{|l|}{1999} \\
\hline Spring (3-31-99) & USGS data & $47 \pm 20$ & -- \\
\hline Winter (11-16-99) & & $72 \pm 26$ & -- \\
\hline 2000 & USGS aerial capture & No survey & -- \\
\hline 2001 & & & $(90 \% \mathrm{CI})$ \\
\hline Spring (3-7-01) & USGS data & $115 \pm 65$ & $187(133-297)$ \\
\hline Winter (11-12-01) & & $64 \pm 19$ & $86(67-126)$ \\
\hline \multicolumn{4}{|l|}{2002} \\
\hline Spring & USGS data & No survey & -- \\
\hline Winter (11-18-02) & & $113 \pm 37$ & $134(106-188)$ \\
\hline
\end{tabular}

${ }^{1}$ Unsworth and others (1994).

${ }^{2}$ White and Burnham (1999).

\section{Pregnancy of Ewes}

Average pregnancy rate $( \pm$ s.e.) for ewes was $77 \pm 4 \%$ ( $n=4$ years). Average lambing rate was $68 \pm 5 \%$ over 3 years. We defined neonatal loss as ewes that were observed pregnant (with extended teats) and tested pregnant in pregnancy tests, but were not seen $\leq 3-4$ weeks after presumed lambing to have a lamb at their side. We calculated neonatal and/or in-utero loss ( \pm s.e.) to be $16 \pm 6 \%$ ( $n=3$ years). Lambing locations of radio-collared bighorn ewes in BICA are shown in Figure 5. Sex ratios of lambs were 1 male to 1.3 females in 2001 and also in 2002 (Table 2), although this is based on a small sample size ( $n=7$ lambs/year).

\section{Lamb Survivorship}

Twenty-one percent of lambs of collared ewes born in 2001 ( 3 of 14) survived to $\geq 1$ year old and $44 \%$ born in 2002 survived to $\geq 1$ year old ( 7 of 16). Lambs that did not survive lived an average of $108 \pm 22$ days (123 \pm 34 days from June 2001- June 2002 and 89 24 days from June 2002- June 2003).

\section{Winter Body Condition of Bighorn Sheep}

Necropsies conducted at the Wyoming State Veterinary Lab in Laramie, Wyoming on bighorn sheep mortalities indicated that none of the sheep that died were in poor body condition, but several had healed fractured tibias or other fractures that likely predisposed them to predation. Chest girth measurements indicated that BICA 


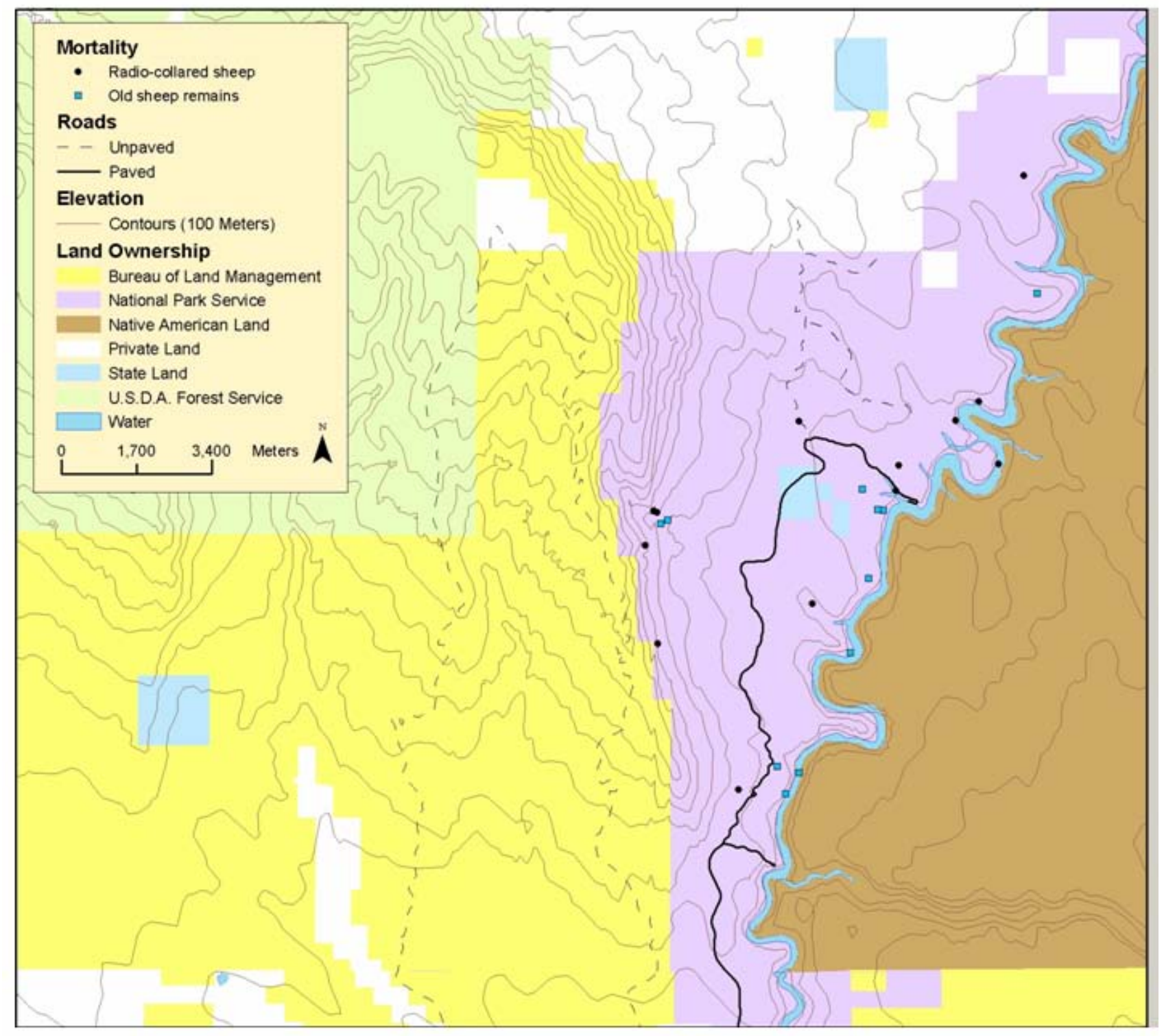

Figure 4. Locations of mortalities for radio-collared bighorn sheep and sheep remains found in the field by ground crews from 2000-2003, Bighorn Canyon National Recreation Area, Montana and Wyoming. 


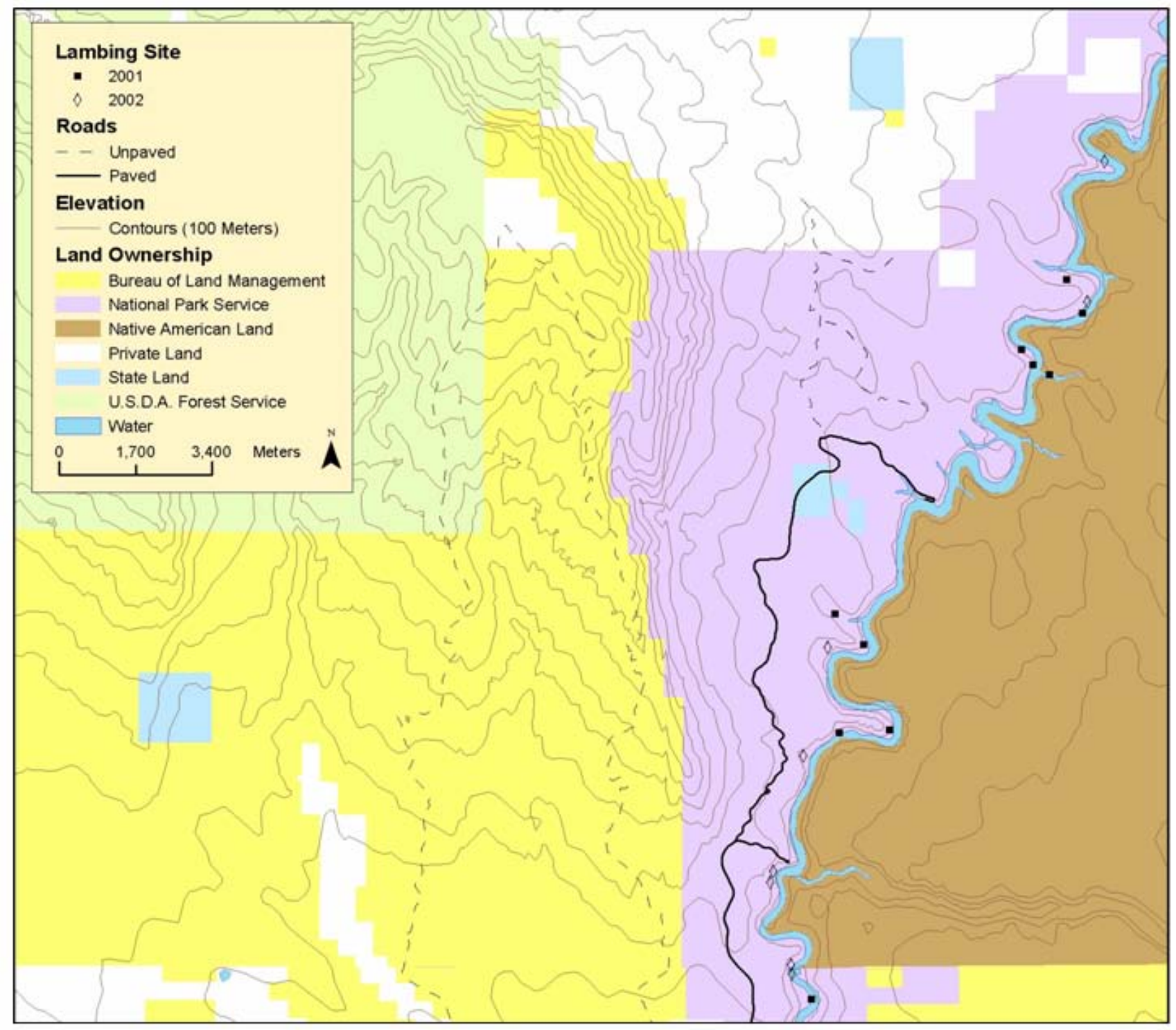

Figure 5. Lambing locations of radio-collared bighorn ewes in 2001 and 2002 in Bighorn Canyon National Recreation Area, Montana and Wyoming. 
Table 2. Sex ratios of bighorn sheep lambs born in Bighorn Canyon National Recreation Area, Wyoming and Montana, in 2001 and 2002. Lambs monitored were of collared ewes. Sexing of lambs was conducted by ground observers. Not all lambs could be sexed.

\begin{tabular}{lcccc}
\hline Year & Number of males & Number of females & Number of unknowns & Sex ratio M:F \\
\hline 2001 & 3 & 4 & 7 & $1: 1.3$ \\
2002 & 3 & 4 & 10 & $1: 1.3$ \\
\hline
\end{tabular}

bighorn sheep were smaller by an average of $3.7 \pm 1.2 \mathrm{~cm}(P=0.0102)$ than bighorn sheep in Alberta, Canada (Blood and others, 1970). When we compared winter body weights of Bighorn Canyon sheep to the wild herd in Canada (Jorgenson and Wishart, 1984), we found that body weights of Bighorn Canyon sheep were significantly lower (by an average of $10.2 \mathrm{~kg} \pm 2.0 ; P=0.0042)$. Bighorn Canyon sheep also had lower body weights than captive Rocky Mountain bighorn sheep (Woolf, 1971) by an average of $18 \pm 4 \mathrm{~kg}(P=0.0050)$.

\section{Presence of Disease}

In 2000, samples revealed the presence of Pasteurella in tonsil swabs taken from captured animals. However, at that time the Wyoming State Veterinary Lab was not able to discern between the toxic Pasteurella bacteria and the non-toxic Pasteurella bacteria, thus we do not know if toxic or passive Pasteurella bacteria infected the herd (Walt Cook, Wyoming State Vet Lab, oral commun., 2001). Once the lab had the capabilities (Pasteurella was renamed Mannheimia) in 2001, we were able to discern more meaningful results. In 2001 we found evidence of a toxic Pasteurella bacteria, Mannheimia haemolytica in $42 \%$ of the sheep sampled. Thirty-two percent of the sheep had evidence of $P$. trehalosi (non-toxic Pasteurella bacteria), and $26 \%$ had no significant bacteria isolated. In addition, a domestic ewe was found roaming the park in summer 2002 on the bighorn sheep range on the Dry Head. Contact with wild bighorn sheep was not witnessed, but the domestic ewe was in the park for $\geq 10$ days during which time contact could have occurred. USGS researchers subsequently observed coughing lambs, monitored them, and two of these lambs died.

No evidence of ear mites or bluetongue was found either year. Parasites found in feces included Nematodirus (ranging from 2-18 eggs/gram feces), Eimeria (2-44 ova/gram feces), and Marshallagia (2-12 eggs/gram feces). No ectoparasites were found. Lungworm larvae (Protostrongylus) were found in fecal samples in both 2000 and 2001, ranging from 2-489 larvae/gram feces in 2000. In 2001, one animal had 120 larva/gram feces, while the majority $(90 \%)$ had $\leq 15$ larva/gram feces. Eighty-two percent $(82 \%)$ of the bighorn sheep sampled had been exposed to para influenza and had high concentrations of antibodies in their blood.

\section{Competition Between Wild Horses and Bighorn Sheep}

Our analysis of lambing rates, lamb survivorship, and pregnancy rates on versus off the wild horse range showed little evidence of competition (see analysis in Population Demography and Modeling section of this report). We found no differences between bighorn sheep inhabiting areas on versus off the wild horse range for any of these population variables.

\section{Habitat Characteristics}

When we compared bighorn sheep habitat characteristics on versus off the wild horse range, we found differences in shrub density, total live plant cover, live grass cover, cactus cover, and dead cover. Density of mountain mahogany was higher on versus off the horse range $(P=0.0146)$. There were no differences in density of other shrubs on versus off the horse range. Live plant ground cover was significantly lower on the horse range $(P=$ $0.0024 ; 13.25 \pm 0.98 \%)$ compared to off horse range sites $(18.09 \pm 1.25 \%)$. The horse range sites also had $77 \%$ less cactus cover $(P=0.0070), 32 \%$ less dead plant cover $(P=0.0341)$, and $38 \%$ less live grass cover $(P=0.0041)$ than sites off the horse range. 
We found differences in habitat features between the 4 study areas (Table 3). Barry's Landing sites had $18 \%$ lower visibility than Dry Head and Crooked Creek sites $(P=0.0223)$, but also higher dead plant cover, live grass cover, cactus cover, and total groundcover than all other sites (Table 3). Big Coulee had the lowest live cover of all the sites $(P=0.0004$; Table 3$)$. Because visibility is such an important habitat feature for bighorn sheep, we specifically compared visibility in key vegetation types at Barry's Landing versus the Dry Head to see if the same vegetation type had the same horizontal visibility in both places. We found that visibility was consistently higher on the Dry Head than at Barry's Landing in all vegetation types $(P=0.0625$; Figure 6$)$.

We calculated amount of bighorn sheep habitat in the 4 study areas by vegetation type using "suitable," plus "acceptable," plus "marginal" habitat from the Animal Location-based model (see Habitat Modeling section of this report; Figures 7 and 8). The Dry Head and Barry's Landing had higher amounts of mountain mahogany/juniper and juniper woodland habitat than Crooked Creek and Big Coulee. The Dry Head had less sage and less grassland habitat than all the other areas (Figures 7 and 8).

Table 3. Bighorn sheep habitat characteristics of the four study areas, Dry Head, Big Coulee, Crooked Creek, and Barry's Landing measured in 2000 and 2001 in Bighorn Canyon National Recreation Area and surrounding lands, Montana and Wyoming. Different letters indic ate significant differences at the $P<0.10$ level.

\begin{tabular}{|c|c|c|c|c|c|}
\hline \multirow[b]{2}{*}{ Habitat parameter } & \multicolumn{5}{|c|}{ Location } \\
\hline & Dry Head & Big Coulee & Crooked Creek & $\begin{array}{l}\text { Barry's } \\
\text { Landing }\end{array}$ & $P$-value \\
\hline Visibility (\%) & $73.0 \pm 3.1^{\mathrm{a}}$ & $67.3 \pm 3.2^{\mathrm{ab}}$ & $72.8 \pm 4.0^{\mathrm{a}}$ & $60.0 \pm 3.7^{\mathrm{b}}$ & 0.0361 \\
\hline Slope (\%) & $15.4 \pm 1.9$ & $10.6 \pm 1.4$ & $13.0 \pm 2.8$ & $16.2 \pm 2.5$ & 0.1154 \\
\hline Distance to escape terrain (m) & $63.0 \pm 15.2$ & $60.2 \pm 11.8$ & $90.7 \pm 38.9$ & $52.0 \pm 10.3$ & 0.7616 \\
\hline Shrub density $\left(\# / \mathrm{m}^{2}\right)$ & $0.49 \pm 0.07$ & $0.34 \pm 0.05$ & $0.37 \pm 0.13$ & $0.51 \pm 0.12$ & 0.3192 \\
\hline$\%$ live cover & $15.7 \pm 1.5^{\mathrm{a}}$ & $10.4 \pm 1.3^{\mathrm{b}}$ & $15.0 \pm 1.8^{\mathrm{a}}$ & $19.7 \pm 1.6^{\mathrm{a}}$ & 0.0003 \\
\hline$\%$ dead cover & $2.9 \pm 0.5^{b}$ & $3.9 \pm 0.6^{b}$ & $4.2 \pm 0.6^{\mathrm{b}}$ & $7.4 \pm 1.2^{\mathrm{a}}$ & 0.0087 \\
\hline$\%$ total cover & $18.6 \pm 1.8^{a}$ & $14.2 \pm 1.5^{\mathrm{a}}$ & $19.3 \pm 2.0^{\mathrm{a}}$ & $27.1 \pm 2.3^{\mathrm{b}}$ & 0.0002 \\
\hline$\%$ grass & $6.2 \pm 1.1^{\mathrm{b}}$ & $4.5 \pm 0.6^{\mathrm{b}}$ & $5.6 \pm 0.9^{b}$ & $11.0 \pm 1.5^{\mathrm{a}}$ & 0.0021 \\
\hline$\%$ forbs & $6.1 \pm 1.0$ & $4.4 \pm 0.8$ & $6.0 \pm 0.9$ & $5.3 \pm 0.9$ & 0.5368 \\
\hline$\%$ cactus & $0.14 \pm 0.1^{\mathrm{b}}$ & $0.07 \pm 0.05^{\mathrm{b}}$ & $0.4 \pm 0.2^{\mathrm{ab}}$ & $0.9 \pm 0.3^{\mathrm{a}}$ & 0.0169 \\
\hline $\begin{array}{l}\text { Amount of summer bighorn } \\
\text { habitat/area }\left(\mathrm{km}^{2}\right)^{1}\end{array}$ & 32.0 & 0.6 & 5.7 & 34.6 & -- \\
\hline $\begin{array}{l}\text { Amount of winter bighorn } \\
\text { habitat/area }\left(\mathrm{km}^{2}\right)^{1}\end{array}$ & 35.7 & 0.4 & 2.7 & 43.2 & -- \\
\hline
\end{tabular}

${ }^{1}$ From Animal location-based model (see Habitat Modeling section of this report); includes both "acceptable" and "suitable" habitat. Does not include "marginal" or "unsuitable" habitat. 


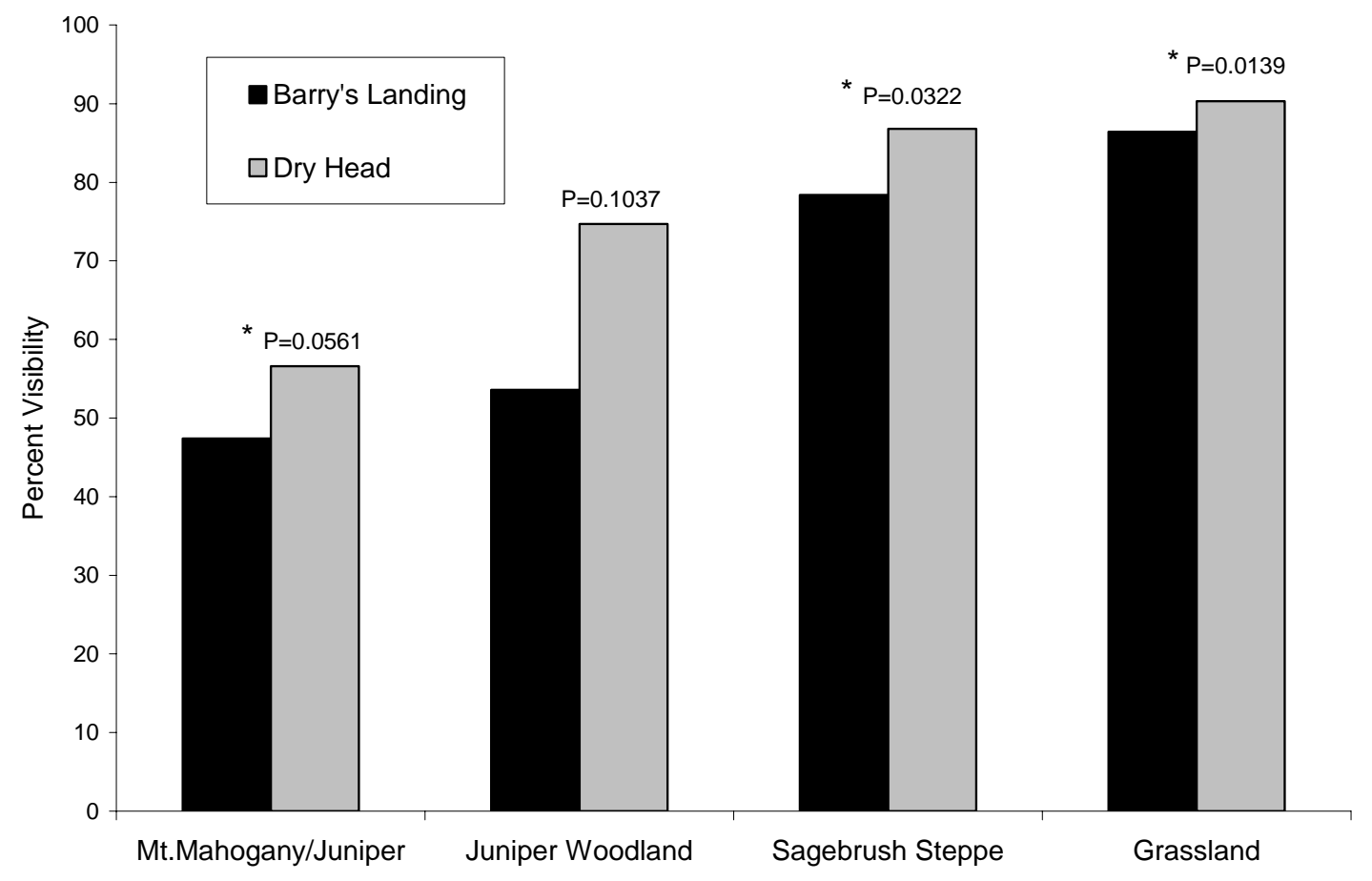

Figure 6. A comparison of percent horizontal visibility between the Dry Head and Barry's Landing study areas in the same vegetation types, Bighorn Canyon National Recreation Area, Montana and Wyoming, 2000-2001. * indicates a significant difference.

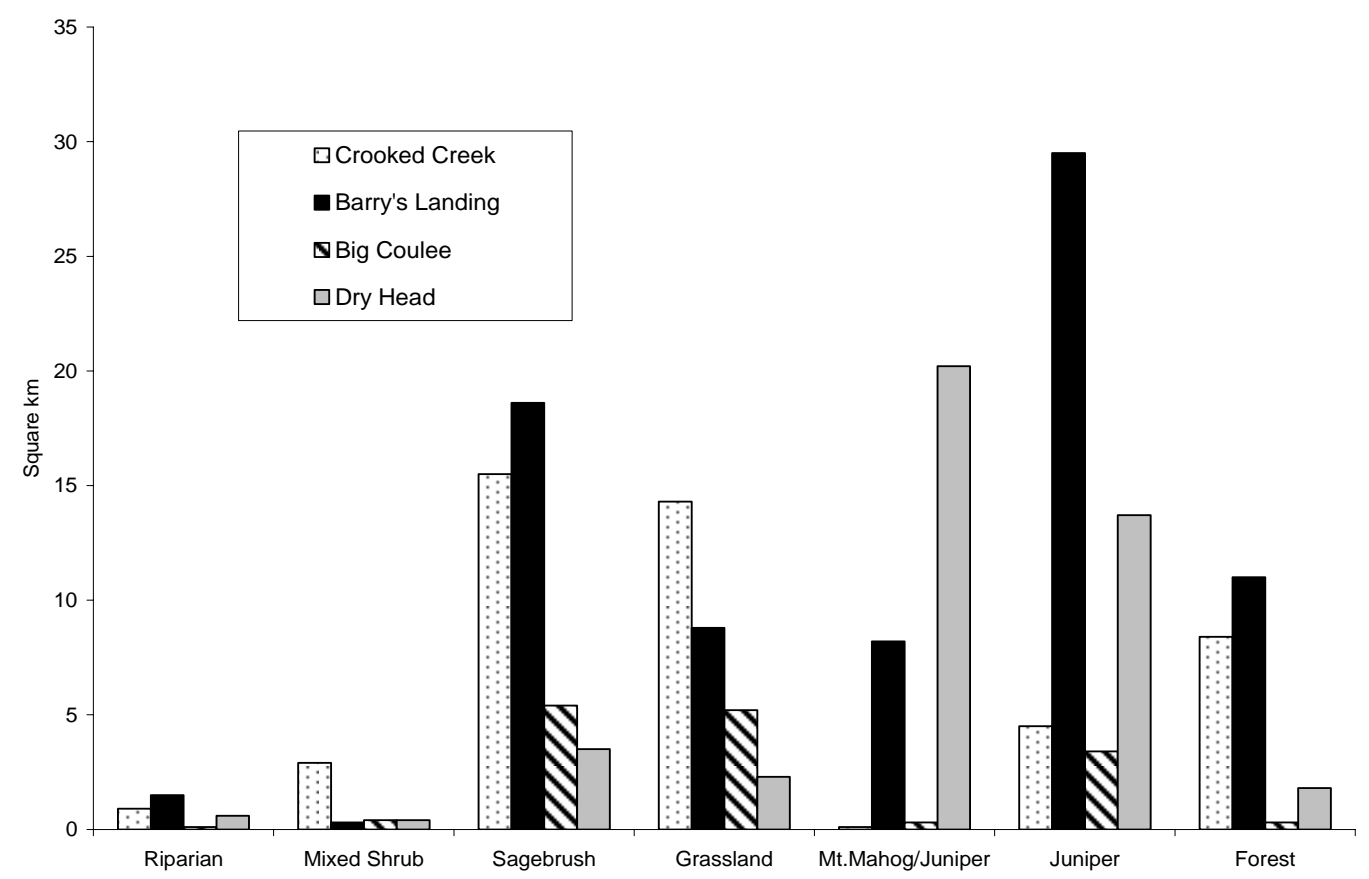

Figure 7. Amount of suitable + acceptable + marginal summer bighorn sheep habitat generated by the Animal location-based model in each of the four study areas by vegetation type in Bighorn Canyon National Recreation Area and surrounding lands, Wyoming and Montana, 2000-2002. 


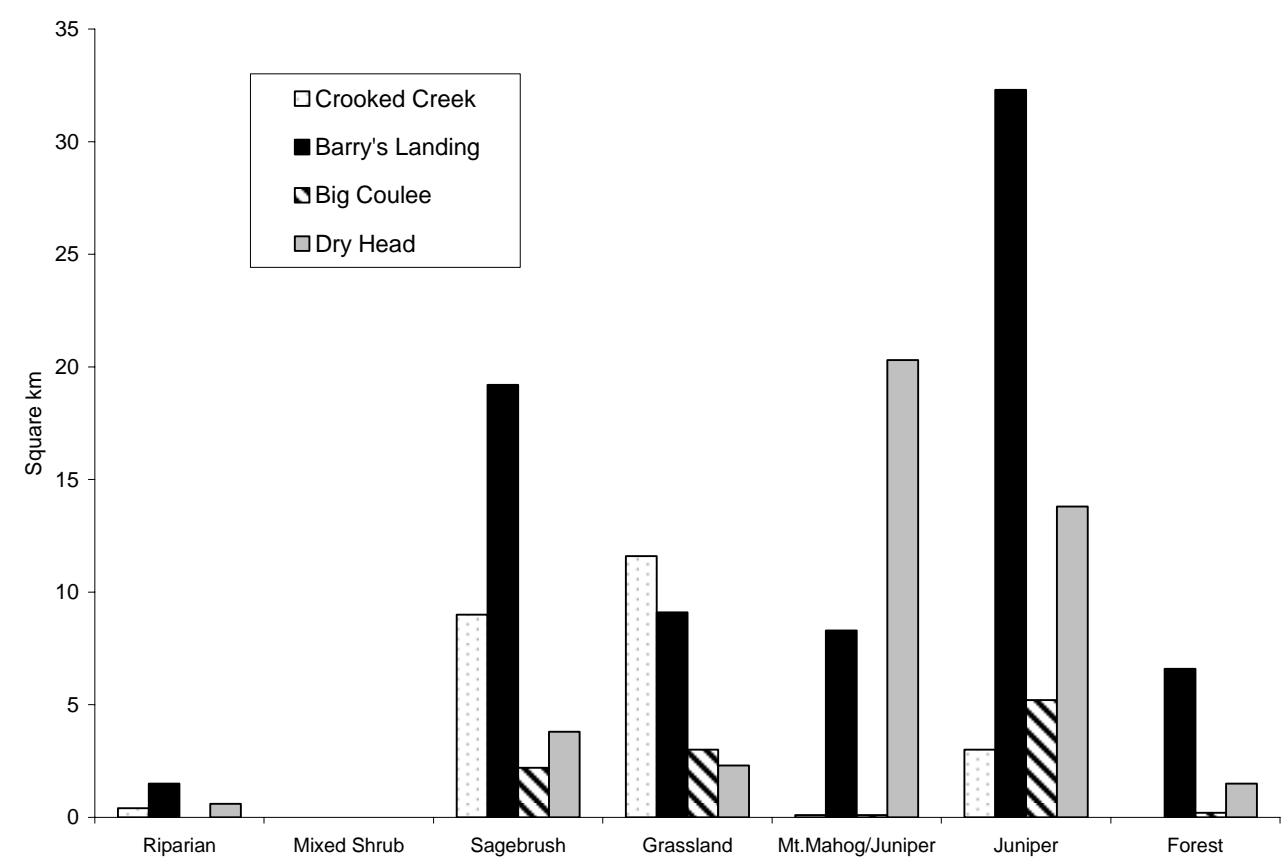

Figure 8. Amount of suitable + acceptable + marginal winter bighorn sheep habitat generated by the Animal location-based model in each of the four study areas by vegetation type in Bighorn Canyon National Recreation Area and surrounding lands, Wyoming and Montana, 2000-2002.

\section{Rates of Forage Consumption by Ungulates}

We found differences in percent offtake between paired sites in summer (Table 4), but not in winter (Table 5). Offtake at sites within the horse range boundary at Booz Canyon (Dry Head) were 3x higher than Hillsboro (Barry's Landing) over 3 years. Slopes in Big Coulee near the old Washout Road had higher offtake than similar slopes in Crooked Creek (Table 4). The Barry's Island area had higher offtake in summer than the Peninsula area (Dry Head). However, overall we found no difference in offtake on versus off the wild horse range (Tables 4 and 5) in either summer or winter. Ungulate consumption across the entire study area averaged $15.0 \pm 6.3 \%$ in summer, and $30.2 \pm 5.9 \%$ in winter.

\section{Herbaceous Production}

Overall plant production was significantly lower on the horse range, compared to off the wild horse range $(P=0.0184$; Table 6). Barry's Island Area sites (off horse range) had higher herbaceous production than sites on the Peninsula (on horse range), and Hillsboro (off horse range) had higher production than Booz Canyon sites (off horse range; Table 6). 
Table 4. Comparison between site pairs in \% summer offtake ( \pm s.e.), averaging data from summer 2000, 2001, and 2002, in Bighorn Canyon National Recreation Area and surrounding lands. Site pairs (Figure 3) were established in known bighorn sheep habitat, in areas selected for similar aspect, slope, elevation, and vegetation type to the extent feasible, in order to compare areas on versus off the wild horse range. Significant differences $(P<0.10)$ are indicated by*

\begin{tabular}{|c|c|c|c|c|c|}
\hline $\begin{array}{c}\text { Site } \\
\text { no. }\end{array}$ & Site/pair locations & $\begin{array}{c}\% \text { offtake on horse } \\
\text { range }\end{array}$ & $\begin{array}{c}\% \text { offtake off horse } \\
\text { range }\end{array}$ & $\begin{array}{c}\text { Difference in } \\
\text { offtake }\end{array}$ & $P$-value \\
\hline 1 & Layout Creek/Layout Creek & $44.8 \pm 3.8$ & $26.5 \pm 23.6$ & 18 & 0.5193 \\
\hline 2 & Layout Creek/Layout Creek & $31.7 \pm 26.5$ & $18.6 \pm 6.0$ & 13 & 0.6727 \\
\hline 3 & Layout Creek/Layout Creek & $-19.1 \pm 14.1 *$ & $16.6 \pm 3.2$ & -36 & 0.0691 \\
\hline 4 & Peninsula/Barry's Island Area & $12.3 \pm 14.2 *$ & $47.5 \pm 3.3$ & -35 & 0.0731 \\
\hline 5 & Peninsula/Barry's Island Area & $5.2 \pm 20.5$ & $38.3 \pm 10.4$ & -33 & 0.2229 \\
\hline 6 & Booz Canyon/Hillsboro & $31.2 \pm 7.0$ & $16.3 \pm 6.4$ & 15 & 0.1911 \\
\hline 7 & Booz Canyon/Hillsboro & $41.0 \pm 24.5$ & $55.9 \pm 15.4$ & -15 & 0.7179 \\
\hline 8 & Booz Canyon/Hillsboro & $24.4 \pm 19.3^{*}$ & $-44.5 \pm 20.9$ & 69 & 0.0724 \\
\hline 9 & Mustang Flats/Mustang Flats & $-5.0 \pm 14.0$ & $24.4 \pm 9.8$ & -29 & 0.2583 \\
\hline 20 & Burnt Timber Mine/Demijohn Flats & $10.7 \pm 14.6$ & $39.4 \pm 11.8$ & -28 & 0.2888 \\
\hline 22 & Big Coulee slope/Crooked Creek slope & $28.0 \pm 11.1^{*}$ & $-22.8 \pm 16.7$ & 51 & 0.0646 \\
\hline 23 & Big Coulee slope/Crooked Creek slope & $33.0 \pm 15.3$ & $-10.3 \pm 14.3$ & 36 & 0.1997 \\
\hline \multicolumn{2}{|c|}{ Average of all sites $(\%)$} & $15.6 \pm 5.1$ & $14.9 \pm 7.5$ & 1 & 0.8336 \\
\hline
\end{tabular}

Table 5. Comparison between site pairs in \% winter offtake ( \pm s.e.), winters 2000-2001, 2001-2002, and 2002-2003, in Bighorn Canyon National Recreation Area, the Pryor Mountain Wild Horse Range, and surrounding lands. Site pairs (Figure 3) were established in known bighorn sheep habitat, in areas selected for similar aspect, slope, elevation, and vegetation type to the extent feasible, in order to compare areas on versus off the wild horse range.

\begin{tabular}{|c|c|c|c|c|c|}
\hline $\begin{array}{l}\text { Site } \\
\text { no. }\end{array}$ & Site/pair locations & $\begin{array}{l}\% \text { offtake on } \\
\text { horse range }\end{array}$ & $\begin{array}{c}\% \text { offtake } \\
\text { off horse range }\end{array}$ & $\begin{array}{c}\text { Difference in } \\
\text { offtake }\end{array}$ & $P$-value \\
\hline 1 & Layout Creek/Layout Creek & $19.9 \pm 15.3$ & $17.1 \pm 33.8$ & 3 & 0.9535 \\
\hline 2 & Layout Creek/Layout Creek & $28.2 \pm 8.1$ & $30.6 \pm 12.9$ & -2 & 0.8791 \\
\hline 3 & Layout Creek/Layout Creek & $51.9 \pm 21.4$ & $43.9 \pm 13.1$ & 8 & 0.7646 \\
\hline 4 & Peninsula/Barry's Island Area & $39.9 \pm 28.5$ & $-19.2 \pm 20.4$ & 59 & 0.1669 \\
\hline 5 & Peninsula/Barry's Island Area & $47.2 \pm 17.5$ & $29.1 \pm 20.9$ & 16 & 0.5562 \\
\hline 6 & Booz Canyon/Hillsboro & $-16.0 \pm 31.7$ & $37.4 \pm 13.6$ & -53 & 0.1972 \\
\hline 7 & Booz Canyon/Hillsboro & $50.5 \pm 12.9$ & $32.9 \pm 34.6$ & 18 & 0.6591 \\
\hline 8 & Booz Canyon/Hillsboro & $66.2 \pm 1.0$ & $3.2 \pm 34.3$ & 63 & 0.2505 \\
\hline 9 & Mustang Flats/Mustang Flats & $51.0 \pm 17.6$ & $14.1 \pm 23.0$ & 37 & 0.2727 \\
\hline 20 & Burnt Timber Mine/Demijohn Flats & $35.6 \pm 4.1$ & $6.3 \pm 34.2$ & 29 & 0.4840 \\
\hline 22 & Big Coulee slope/Crooked Creek slope & $26.8 \pm 46.4$ & $37.3 \pm 22.9$ & -11 & 0.8488 \\
\hline 23 & Big Coulee slope/Crooked Creek slope & $58.4 \pm 9.7$ & $48.0 \pm 7.4$ & 10 & 0.5153 \\
\hline \multicolumn{2}{|c|}{ Average of all sites $(\%)$} & $37.0 \pm 6.0$ & $23.4 \pm 5.7$ & 14 & 0.1280 \\
\hline
\end{tabular}


Table 6. Comparison between site pairs in herbaceous production ( \pm s.e.), summer 2000, 2001, and 2002, in Bighorn Canyon National Recreation Area and surrounding lands. Site pairs (Figure 3) were established in known bighorn sheep habitat, in areas selected for similar aspect, slope, elevation, and vegetation type to the extent feasible, in order to compare areas on versus off the wild horse range. Significant differences $(P<0.10)$ are indicated by *.

\begin{tabular}{|c|c|c|c|c|c|}
\hline $\begin{array}{l}\text { Site } \\
\text { no. }\end{array}$ & Site/pair location & $\begin{array}{c}\text { Herbaceous } \\
\text { production }{ }^{1} \text { on } \\
\text { horse range }\left(\mathrm{g} / \mathrm{m}^{2}\right)\end{array}$ & $\begin{array}{c}\text { Herbaceous } \\
\text { production }{ }^{1} \text { off } \\
\text { horse range }\left(\mathrm{g} / \mathrm{m}^{2}\right)\end{array}$ & $\begin{array}{c}\text { Percent } \\
\text { difference }(\%)\end{array}$ & $P$-value \\
\hline 1 & Layout Creek/Layout Creek & $11.3 \pm 2.3$ & $8.4 \pm 0.5$ & 3 & 0.3279 \\
\hline 2 & Layout Creek/Layout Creek & $8.3 \pm 1.9$ & $8.0 \pm 0.6$ & 0.3 & 0.8849 \\
\hline 3 & Layout Creek/Layout Creek & $16.4 \pm 4.5$ & $8.5 \pm 0.9$ & 8 & 0.2137 \\
\hline 4 & Peninsula/Barry's Island Area & $4.0 \pm 2.8$ & $21.9 \pm 8.8$ & -18 & 0.1237 \\
\hline 5 & Peninsula/Barry's Island Area & $12.1 \pm 2.0^{*}$ & $44.9 \pm 0.2$ & -33 & 0.0033 \\
\hline 6 & Booz Canyon/Hillsboro & $15.0 \pm 0.4^{*}$ & $42.9 \pm 10.1$ & -28 & 0.1089 \\
\hline 7 & Booz Canyon/Hillsboro & $11.3 \pm 1.9$ & $10.5 \pm 3.8$ & 1 & 0.8490 \\
\hline 8 & Booz Canyon/Hillsboro & $30.9 \pm 18.9$ & $48.0 \pm 2.8$ & -17 & 0.4614 \\
\hline 9 & Mustang Flats/Mustang Flats ${ }^{2}$ & 7.8 & 30.6 & -23 & -- \\
\hline 20 & Burnt Timber Mine/Demijohn Flats & $20.4 \pm 6.8$ & $39.5 \pm 2.1$ & -19 & 0.1157 \\
\hline 22 & Big Coulee slope/Crooked Creek slope & $3.8 \pm 1.8$ & $8.5 \pm 8.5$ & -5 & 0.6440 \\
\hline 23 & Big Coulee slope/Crooked Creek slope & $10.3 \pm 5.7$ & $7.2 \pm 7.1$ & 3 & 0.7772 \\
\hline \multicolumn{2}{|c|}{ Average of all sites $\left(\mathrm{g} / \mathrm{m}^{2}\right)$} & $13.2 \pm 1.9$ & $22.0 \pm 3.2$ & -9 & 0.0184 \\
\hline
\end{tabular}

${ }^{1}$ Herbaceous aboveground annual production; grasses and forbs combined.

${ }^{2} \mathrm{SE}$ and $P$-value not available due to only 1 year of sampling $(n=1)$

\section{Offtake Versus Production}

In the regression analysis of offtake versus production, we found a correlation between summer offtake and the next summer's herbaceous production showing that higher offtake in summer decreased production at the same sites the following summer $\left(P=0.0045 ; \mathrm{r}^{2}=0.2142\right.$; Figure 9$)$. We also found a correlation between summer plus winter offtake and the next summer's production $\left(P=0.0795 ; \mathrm{r}^{2}=0.0877\right.$; Figure 9$)$, where higher summer plus winter offtake decreased the next year's herbaceous production. We also found that higher ungulate offtake in June negatively affected production in September $\left(P=0.0227 ; \mathrm{r}^{2}=0.0836\right.$; Figure 9$)$, but winter offtake did not appear to greatly affect the next summer's herbaceous production $(P=0.1321)$.

\section{Nutritional Analysis of Vegetation}

We found the greatest differences in nutrient concentrations in bluebunch wheatgrass and needle and thread grass between the 4 study areas. Where there were differences in forage nutrient concentration, the Dry Head site had higher concentrations of beneficial nutrients and digestibility than some other sites, as well as higher concentrations of indigestible, fibrous material (lignin, Adf, cellulose).

\section{Nitrogen}

Nitrogen concentrations were higher at the Dry Head sites than Barry's Landing and Crooked Creek sites in blue grama and bluebunch wheatgrass in summer. The Dry Head sites also had higher $\mathrm{N}$ concentrations than Crooked Creek in needle and thread grass in both winter and summer (Tables 7 and 8). 

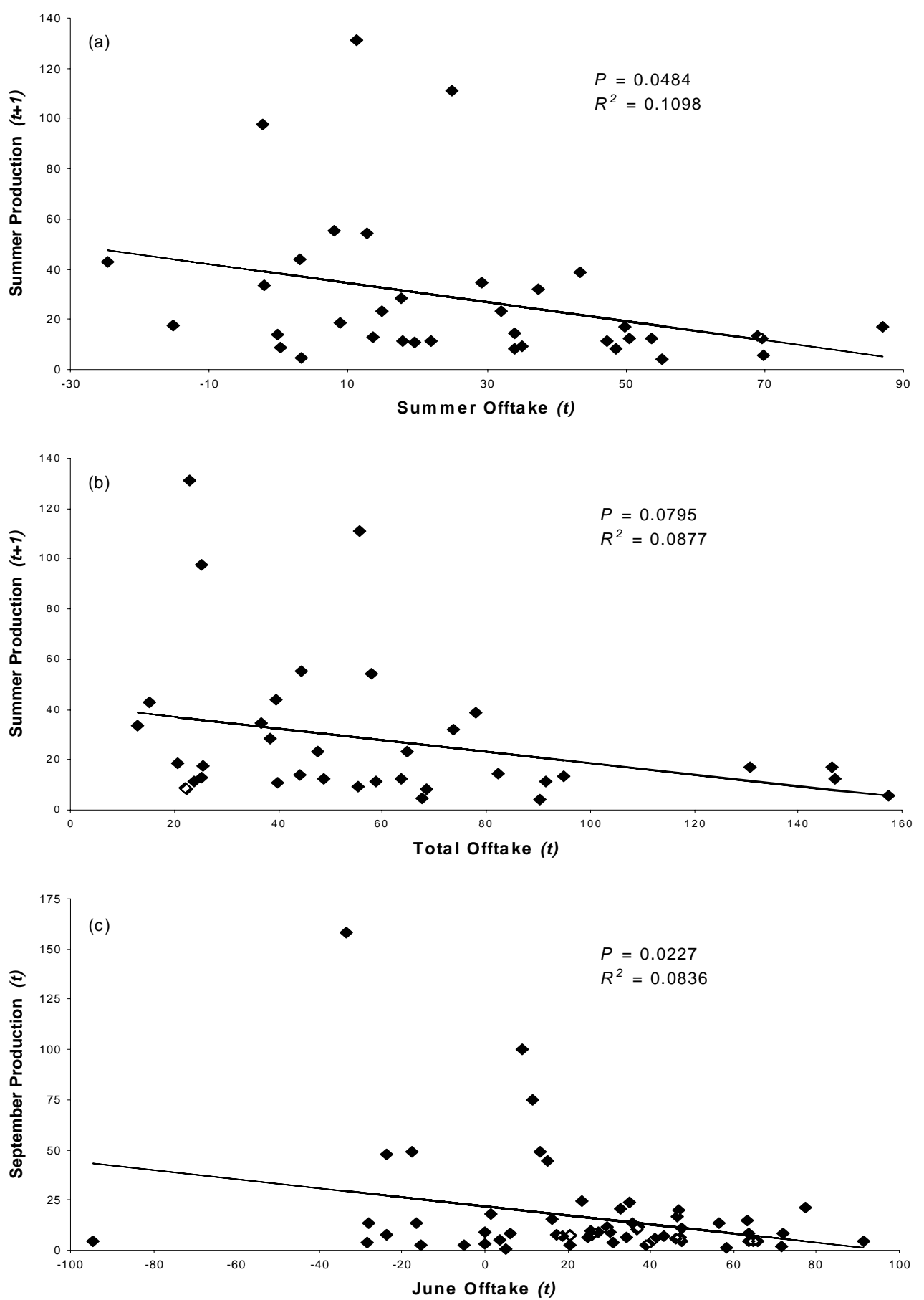

Figure 9. Production as a negative function of increasing offtake in Bighorn Canyon National Recreation Area, the Pryor Mountain Wild Horse Range, and surrounding lands, Montana and Wyoming, 2000-2003. 
Table 7. Summer (peak) nutrient concentration ( \pm s.e.) of specific plant species at the four study areas (Big Coulee, Crooked Creek, Dry Head, and Barry's Landing) on the Pryor Mountain Wild Horse Range and Bighorn Canyon National Recreation Area, Montana and Wyoming, 20002002. Mountain mahogany was not present at the Crooked Creek site. Different letters indicate significant differences at the $P<0.10$ level. $P$ values are presented for significant differences only.

\begin{tabular}{|c|c|c|c|c|c|}
\hline \multirow{2}{*}{$\begin{array}{l}\text { Plant Species } \\
\text { Nutrient } \\
\end{array}$} & \multicolumn{5}{|c|}{ Location } \\
\hline & Big Coulee & Crooked Creek & Dry Head & $\begin{array}{l}\text { Barry's } \\
\text { Landing }\end{array}$ & $\boldsymbol{P}$-value \\
\hline \multicolumn{6}{|c|}{ Mountain mahogany } \\
\hline $\mathrm{Se}$ & $0.07 \pm 0.01^{\mathrm{b}}$ & -- & $0.08 \pm 0.01^{\mathrm{b}}$ & $0.13 \pm 0.01^{\mathrm{a}}$ & 0.0298 \\
\hline $\mathrm{N}$ & $1.71 \pm 0.05$ & -- & 1.770 .04 & $1.78 \pm 0.08$ & \\
\hline $\mathrm{C}$ & $52.02 \pm 0.35$ & -- & $51.92 \pm 0.15$ & $52.21 \pm 0.21$ & \\
\hline Dmd & $30.89 \pm 1.62$ & -- & $28.89 \pm 0.64$ & $28.06 \pm 0.73$ & \\
\hline Adf & $53.91 \pm 1.75$ & -- & $50.39 \pm 1.14$ & $50.94 \pm 1.08$ & \\
\hline Lignin & $33.36 \pm 0.91$ & -- & $32.54 \pm 1.26$ & $33.36 \pm 0.94$ & \\
\hline Protein & $116.4 \pm 44.3$ & -- & $95.49 \pm 37.97$ & $113.33 \pm 41.57$ & \\
\hline Cellulose & $20.07 \pm 1.05^{\mathrm{a}}$ & -- & $17.91 \pm 0.47^{\mathrm{ab}}$ & $17.21 \pm 0.99^{b}$ & 0.0540 \\
\hline \multicolumn{6}{|c|}{ Bluebunch wheatgrass } \\
\hline $\mathrm{Se}$ & $0.16 \pm 0.08$ & $0.14 \pm 0.03$ & $0.14 \pm 0.01$ & $0.08 \pm 0.02$ & \\
\hline $\mathrm{N}$ & $1.59 \pm 0.14^{\mathrm{a}}$ & $1.23 \pm 0.06^{\mathrm{b}}$ & $1.64 \pm 0.11^{\mathrm{a}}$ & $1.14 \pm 0.05^{\mathrm{b}}$ & 0.0066 \\
\hline $\mathrm{C}$ & $44.01 \pm 0.33^{\mathrm{b}}$ & $45.21 \pm 0.09^{\mathrm{a}}$ & $45.27 \pm 0.26^{\mathrm{a}}$ & $44.83 \pm 0.56^{\mathrm{ab}}$ & 0.0771 \\
\hline Dmd & $34.34 \pm 1.18^{\mathrm{ab}}$ & $33.01 \pm 1.11^{\mathrm{b}}$ & $36.34 \pm 1.05^{\mathrm{a}}$ & $32.18 \pm 1.02^{\mathrm{b}}$ & 0.0778 \\
\hline Adf & $49.58 \pm 0.64^{\mathrm{ab}}$ & $48.55 \pm 0.38^{\mathrm{b}}$ & $48.08 \pm 0.41^{\mathrm{b}}$ & $50.69 \pm 0.83^{\mathrm{a}}$ & 0.0351 \\
\hline Lignin & $13.69 \pm 0.53^{\mathrm{a}}$ & $11.22 \pm 0.41^{\mathrm{c}}$ & $13.13 \pm 0.65^{\mathrm{ab}}$ & $11.58 \pm 0.47^{\mathrm{bc}}$ & 0.0100 \\
\hline Protein & $98.88 \pm 42.63$ & $122.04 \pm 46.57$ & $118.52 \pm 48.52$ & $99.63 \pm 41.23$ & \\
\hline Cellulose & $30.98 \pm 0.86^{\mathrm{b}}$ & $34.72 \pm 0.31^{\mathrm{a}}$ & $32.12 \pm 1.10^{\mathrm{b}}$ & $34.84 \pm 0.41^{\mathrm{a}}$ & 0.0040 \\
\hline \multicolumn{6}{|c|}{ Needle and thread } \\
\hline $\mathrm{Se}$ & $0.09 \pm 0.01$ & $0.08 \pm 0.02$ & $0.09 \pm 0.01$ & $0.09 \pm 0.02$ & \\
\hline $\mathrm{N}$ & $1.39 \pm 0.10^{\mathrm{ab}}$ & $1.21 \pm 0.11^{\mathrm{b}}$ & $1.57 \pm 0.07^{\mathrm{a}}$ & $1.31 \pm 0.06^{\mathrm{ab}}$ & 0.0738 \\
\hline $\mathrm{C}$ & $44.88 \pm 0.45$ & $45.49 \pm 0.31$ & $45.18 \pm 0.39$ & $45.23 \pm 0.43$ & \\
\hline Dmd & $33.40 \pm 0.74^{\mathrm{ab}}$ & $31.37 \pm 1.13^{\mathrm{b}}$ & $35.05 \pm 0.70^{\mathrm{a}}$ & $34.79 \pm 1.31^{\mathrm{a}}$ & 0.0759 \\
\hline Adf & $46.04 \pm 0.80$ & $46.21 \pm 0.25$ & $47.55 \pm 0.46$ & $47.31 \pm 0.40$ & \\
\hline Lignin & $10.23 \pm 0.38$ & $9.80 \pm 0.54$ & $11.52 \pm 0.69$ & $10.76 \pm 0.25$ & \\
\hline Protein & $96.74 \pm 41.57$ & $126.77 \pm 49.19$ & $113.45 \pm 46.89$ & $115.24 \pm 48.46$ & \\
\hline Cellulose & $32.94 \pm 0.61$ & $34.02 \pm 0.37$ & $33.49 \pm 0.59$ & $34.37 \pm 0.25$ & \\
\hline \multicolumn{6}{|l|}{ Blue gramma } \\
\hline $\mathrm{Se}$ & $0.06 \pm 0.004$ & $0.08 \pm 0.02$ & $0.11 \pm 0.02$ & $0.07 \pm 0.02$ & \\
\hline $\mathrm{N}$ & $1.91 \pm 0.16^{\mathrm{ab}}$ & $1.51 \pm 0.08^{\mathrm{bc}}$ & $2.14 \pm 0.16^{\mathrm{a}}$ & $1.51 \pm 0.08^{\mathrm{c}}$ & 0.0059 \\
\hline $\mathrm{C}$ & $44.34 \pm 0.45$ & $43.19 \pm 0.30$ & $43.97 \pm 0.23$ & $43.99 \pm 0.78$ & \\
\hline Dmd & $32.26 \pm 0.10^{\mathrm{b}}$ & $35.45 \pm 0.67^{\mathrm{ab}}$ & $40.04 \pm 2.11^{\mathrm{a}}$ & $34.25 \pm 0.87^{\mathrm{b}}$ & 0.0157 \\
\hline Adf & $45.50 \pm 0.41^{\mathrm{a}}$ & $42.67 \pm 0.51^{\mathrm{b}}$ & $45.26 \pm 0.61^{\mathrm{a}}$ & $45.26 \pm 0.75^{\mathrm{a}}$ & 0.0567 \\
\hline Lignin & $13.05 \pm 1.00$ & $10.40 \pm 1.67$ & $11.94 \pm 0.87$ & $11.12 \pm 0.49$ & \\
\hline Protein & $201.64 \pm 0.64$ & $221.59 \pm 4.18$ & $120.01 \pm 47.27$ & $128.92 \pm 49.21$ & \\
\hline Cellulose & $28.67 \pm 1.01$ & $27.33 \pm 2.55$ & $29.98 \pm 0.92$ & $30.36 \pm 0.90$ & \\
\hline
\end{tabular}


Table 8. Winter nutrient concentration ( \pm s.e.) of specific plant species at the 4 study areas (Big Coulee, Crooked Creek, Dry Head and Barry's Landing) on the Pryor Mountain Wild Horse Range and Bighorn Canyon National Recreation Area, Montana and Wyoming, 20002002. Mountain mahogany was not present at the Crooked Creek site. Different letters indicate significant differences at the $P<0.10$ level. $P$-values are presented for significant differences only.

\begin{tabular}{|c|c|c|c|c|c|}
\hline \multirow{2}{*}{$\begin{array}{l}\text { Plant species } \\
\text { Nutrient }\end{array}$} & \multicolumn{5}{|c|}{ Location } \\
\hline & Big Coulee & Crooked Creek & Dry Head & $\begin{array}{l}\text { Barry's } \\
\text { Landing }\end{array}$ & $P$-value \\
\hline \multicolumn{6}{|c|}{ Mountain mahogany } \\
\hline $\mathrm{Se}$ & $0.08 \pm 0.03$ & -- & $0.15 \pm 0.04$ & $0.11 \pm 0.02$ & \\
\hline $\mathrm{N}$ & $1.55 \pm 0.03$ & -- & $1.51 \pm 0.05$ & $1.62 \pm 0.03$ & \\
\hline $\mathrm{C}$ & $52.49 \pm 0.27$ & -- & $51.53 \pm 0.39$ & $52.18 \pm 0.14$ & \\
\hline Dmd & $32.01 \pm 0.42$ & -- & $37.15 \pm 3.50$ & $30.71 \pm 0.58$ & \\
\hline Adf & $47.88 \pm 0.49$ & -- & $39.26 \pm 3.69$ & $45.57 \pm 1.18$ & \\
\hline Lignin & $31.49 \pm 0.49$ & -- & $25.85 \pm 3.65$ & $31.14 \pm 0.71$ & \\
\hline Protein & $9.67 \pm 0.19$ & -- & $9.41 \pm 0.34$ & $10.11 \pm 0.17$ & \\
\hline Cellulose & $15.84 \pm 0.32^{\mathrm{a}}$ & -- & $13.48 \pm 0.44^{\mathrm{b}}$ & $13.55 \pm 0.25^{\mathrm{b}}$ & 0.0093 \\
\hline \multicolumn{6}{|c|}{ Bluebunch wheatgrass } \\
\hline $\mathrm{Se}$ & $0.18 \pm 0.06$ & $0.26 \pm 0.18$ & $0.08 \pm 0.02$ & $0.13 \pm 0.04$ & \\
\hline $\mathrm{N}$ & $0.47 \pm 0.03$ & $0.45 \pm 0.01$ & $0.45 \pm 0.02$ & $0.45 \pm 0.05$ & \\
\hline $\mathrm{C}$ & $42.32 \pm 0.45^{\mathrm{ab}}$ & $41.94 \pm 0.32^{b}$ & $43.15 \pm 0.32^{\mathrm{a}}$ & $43.24 \pm 0.37^{\mathrm{a}}$ & 0.0946 \\
\hline Dmd & $34.21 \pm 1.07^{\mathrm{a}}$ & $28.88 \pm 2.31^{\mathrm{b}}$ & $29.43 \pm 1.06^{\mathrm{b}}$ & $28.41 \pm 0.15^{\mathrm{b}}$ & 0.0592 \\
\hline Adf & $51.60 \pm 0.40$ & $54.18 \pm 1.18$ & $52.68 \pm 0.59$ & $53.14 \pm 1.03$ & \\
\hline Lignin & $10.08 \pm 0.92$ & $9.88 \pm 0.55$ & $9.18 \pm 0.88$ & $9.69 \pm 0.26$ & \\
\hline Protein & $2.97 \pm 0.20$ & $2.84 \pm 0.06$ & $2.85 \pm 0.14$ & $2.82 \pm 0.32$ & \\
\hline Cellulose & $34.68 \pm 1.30^{\mathrm{b}}$ & $38.42 \pm 1.30^{\mathrm{a}}$ & $38.93 \pm 0.41^{\mathrm{a}}$ & $37.07 \pm 0.70^{\mathrm{ab}}$ & 0.0669 \\
\hline \multicolumn{6}{|c|}{ Needle and thread } \\
\hline $\mathrm{Se}$ & $0.05 \pm 0.01$ & $0.07 \pm 0.00$ & $0.16 \pm 0.08$ & $0.08 \pm 0.00$ & \\
\hline $\mathrm{N}$ & $0.48 \pm 0.02^{\mathrm{ab}}$ & $0.44 \pm 0.002^{b}$ & $0.55 \pm 0.01^{\mathrm{a}}$ & $0.52 \pm 0.03^{\mathrm{a}}$ & 0.0375 \\
\hline $\mathrm{C}$ & $44.03 \pm 0.05^{\mathrm{a}}$ & $42.17 \pm 0.27^{\mathrm{b}}$ & $44.21 \pm 0.25^{\mathrm{a}}$ & $43.46 \pm 0.44^{\mathrm{a}}$ & 0.0041 \\
\hline Dmd & $29.07 \pm 0.89^{\mathrm{ab}}$ & $27.64 \pm 1.33^{\mathrm{b}}$ & $31.41 \pm 0.77^{\mathrm{a}}$ & $26.92 \pm 1.00^{\mathrm{b}}$ & 0.0594 \\
\hline Adf & $52.84 \pm 0.38^{\mathrm{a}}$ & $52.43 \pm 0.44^{\mathrm{a}}$ & $51.03 \pm 0.49^{\mathrm{b}}$ & $51.81 \pm 0.19^{\mathrm{ab}}$ & 0.0513 \\
\hline Lignin & $8.51 \pm 0.28$ & $8.45 \pm 0.20$ & $8.10 \pm 0.18$ & $8.64 \pm 0.29$ & \\
\hline Protein & $3.01 \pm 0.11^{\mathrm{ab}}$ & $2.76 \pm 0.10^{\mathrm{b}}$ & $3.41 \pm 0.09^{\mathrm{a}}$ & $3.24 \pm 0.20^{\mathrm{a}}$ & 0.0390 \\
\hline Cellulose & $40.50 \pm 0.82^{\mathrm{a}}$ & $37.14 \pm 0.17^{\mathrm{b}}$ & $38.88 \pm 0.64^{\mathrm{ab}}$ & $37.25 \pm 0.67^{\mathrm{b}}$ & 0.0162 \\
\hline \multicolumn{6}{|l|}{ Blue gramma } \\
\hline $\mathrm{Se}$ & $0.11 \pm 0.02$ & $0.11 \pm 0.01$ & $0.17 \pm 0.07$ & $0.07 \pm 0.01$ & \\
\hline $\mathrm{N}$ & $0.68 \pm 0.01$ & $0.56 \pm 0.03$ & $0.73 \pm 0.12$ & $0.76 \pm 0.11$ & \\
\hline $\mathrm{C}$ & $43.38 \pm 0.31$ & $42.24 \pm 0.80$ & $42.77 \pm 0.37$ & $43.18 \pm 0.39$ & \\
\hline Dmd & $27.44 \pm 0.38$ & $27.77 \pm 0.42$ & $27.53 \pm 1.31$ & $28.53 \pm 1.19$ & \\
\hline Adf & $46.65 \pm 0.57$ & $47.84 \pm 0.64$ & $46.73 \pm 0.33$ & $47.11 \pm 1.31$ & \\
\hline Lignin & $7.54 \pm 0.24^{\mathrm{ab}}$ & $7.57 \pm 0.16^{\mathrm{ab}}$ & $8.61 \pm 0.48^{\mathrm{a}}$ & $6.91 \pm 0.59^{\mathrm{b}}$ & 0.0929 \\
\hline Protein & $4.25 \pm 0.07$ & $3.53 \pm 0.16$ & $4.59 \pm 0.74$ & $4.78 \pm 0.70$ & \\
\hline Cellulose & $35.78 \pm 1.01$ & $34.99 \pm 0.84$ & $34.16 \pm 0.76$ & $36.27 \pm 1.42$ & \\
\hline
\end{tabular}


Carbon

Carbon concentrations were higher at the Dry Head sites than Big Coulee in summer in bluebunch wheatgrass. Dry Head concentrations were also higher than Crooked Creek in winter in both bluebunch wheatgrass and needle and thread grass (Tables 7 and 8).

\section{Dry Matter Digestibility}

Dry Head sites had higher dry matter digestibility concentrations than some of the other sites, in both summer and winter, particularly in bluebunch wheatgrass, needle and thread grass, and blue grama (Tables 7 and 8 ).

\section{Acid Detergent Fiber}

Concentrations of acid detergent fiber (Adf) were not consistent by site or season. In summer, Adf was higher at Barry's Landing than Dry Head and Crooked Creek sites in bluebunch wheatgrass. The three other sites were higher than Crooked Creek in Adf concentration in blue grama in summer. Only needle and thread grass showed differences in Adf concentrations in winter, where Big Coulee and Crooked Creek had higher concentrations than Dry Head sites (Tables 7 and 8).

Lignin

The Dry Head and Big Coulee sites had higher lignin content in summer than Crooked Creek in bluebunch wheatgrass. The Dry Head was also higher than Barry's Landing in lignin content in winter for blue gramma (Tables 7 and 8).

Protein

There were no differences in summer protein concentration of any plants between study areas. Only needle and thread grass showed differences in winter, with the Dry Head and Barry's Landing sites having higher protein concentrations than the Crooked Creek site (Tables 7 and 8).

\section{Cellulose}

We found differences in cellulose in both summer and winter (Tables 7 and 8). In summer, cellulose concentration was higher at Dry Head and Barry's Landing sites in bluebunch wheatgrass than Crooked Creek and Barry's Landing sites, and higher at Big Coulee than the Barry's Landing site in mountain mahogany. In winter, concentrations of cellulose were higher at Big Coulee than other sites in mountain mahogany and needle and thread grass, and lower than other sites in bluebunch wheatgrass (Tables 7 and 8).

\section{Selenium}

We found higher summer selenium levels in mountain mahogany at the Barry's Landing sites than at Dry Head and Crooked Creek sites $(P=0.0298$; Table 7). No other plants had differences in selenium levels in summer or winter, nor on versus off the horse range (Tables 7 and 8 ) with the exception of summer 2002 in which bluebunch wheatgrass had higher selenium concentrations at the Dry Head than Big Coulee and Barry's Landing sites $(P=$ 0.0900). Selenium levels of all plants sampled are presented in Tables 7 and 8.

Selenium levels in soils varied greatly between vegetation types (Table 9) and between habitat areas for bighorn sheep (Table 10). Juniper vegetation type had the highest total available selenium in the soil $(44.55 \mathrm{ppb} ; P=$ 0.0064; Table 9) and mixed shrub vegetation type had the lowest (5.666 ppb). Big Coulee and Crooked Creek consistently had higher levels of selenium in the soil compared to the Dry Head and Barry's Landing areas (Table 10). 
Table 9. Soil selenium (Se) levels $( \pm S E)$ in 5 vegetation types in Bighorn Canyon National Recreation Area and surrounding lands, 2003. Different letters indicate significant differences at the $P<0.05$ level.

\begin{tabular}{lcccccc}
\hline & \multicolumn{5}{c}{ Vegetation Type } \\
\cline { 2 - 6 } Soil Nutrient & Juniper & $\begin{array}{l}\text { Mountain } \\
\text { Mahogany }\end{array}$ & Mixed Shrub & Sagebrush & Grassland \\
\hline Selenium & $0.32 \pm 0.04^{\mathrm{a}}$ & $0.22 \pm 0.02^{\mathrm{b}}$ & $0.14 \pm 0.02^{\mathrm{b}}$ & $0.31 \pm 0.04^{\mathrm{a}}$ & $0.24 \pm 0.18^{\mathrm{b}}$ & $\boldsymbol{P}$-value \\
Soluble Se & $10.22 \pm 2.33^{\mathrm{a}}$ & $4.17 \pm 1.52^{\mathrm{ab}}$ & $0.33 \pm 0.33^{\mathrm{b}}$ & $7.75 \pm 1.95^{\mathrm{ab}}$ & $6.75 \pm 1.45^{\mathrm{ab}}$ & 0.1001 \\
Exchangeable Se & $34.00 \pm 3.07^{\mathrm{a}}$ & $21.83 \pm 3.8^{\mathrm{b}}$ & $5.33 \pm 1.09^{\mathrm{c}}$ & $28.50 \pm 3.67^{\mathrm{ab}}$ & $25.33 \pm 3.43^{\mathrm{ab}}$ & 0.0064 \\
Total Available Se & $44.55 \pm 4.69^{\mathrm{a}}$ & $26.17 \pm 5.39^{\mathrm{bcd}}$ & $5.66 \pm 1.42^{\mathrm{c}}$ & $36.21 \pm 5.05^{\mathrm{ab}}$ & $32.00 \pm 4.45^{\mathrm{ad}}$ & 0.0064 \\
\hline
\end{tabular}

Table 10. Soil selenium (Se) levels ( \pm SE) in the 4 study areas: Big Coulee, Crooked Creek, Barry's Landing and the Dry Head in Bighorn Canyon National Recreation Area and surrounding lands, 2003. Different letters indicate significant differences at the $P<0.05$ level.

\begin{tabular}{|c|c|c|c|c|c|}
\hline \multirow[b]{2}{*}{ Soil Nutrient } & \multicolumn{4}{|c|}{ Study Area } & \multirow[b]{2}{*}{$P$-value } \\
\hline & Big Coulee & Crooked Creek & Barry's Landing & Dry Head & \\
\hline Selenium & $0.348^{\mathrm{a}}$ & $0.329^{\mathrm{a}}$ & $0.218^{\mathrm{b}}$ & $0.194^{\mathrm{b}}$ & 0.0002 \\
\hline Soluble Se & $9.722^{\mathrm{a}}$ & $12.888^{\mathrm{a}}$ & $3.967^{\mathrm{b}}$ & $3.222^{\mathrm{b}}$ & $<0.0001$ \\
\hline Exchangeable Se & $30.333^{\mathrm{ac}}$ & $32.778^{\mathrm{a}}$ & $22.400^{\mathrm{bc}}$ & $21.667^{\mathrm{a}}$ & 0.1096 \\
\hline Total Available Se & $40.056^{\mathrm{a}}$ & $45.667^{\mathrm{a}}$ & $26.600^{\mathrm{b}}$ & $24.778^{\mathrm{b}}$ & 0.0105 \\
\hline
\end{tabular}


Selenium levels in bighorn sheep feces were significantly different during different months of the year (Table 11; $P=<0.0001$ ), with the highest levels in June and September and the lowest levels from November to January. There were no differences in selenium levels between age and sex classes (rams versus ewes versus lambs), but fecal-N in bighorn sheep feces was higher in rams than ewes, and higher in rams than lambs $(P=0.0021$; Table 12). There was no difference in fecal-N concentration between lambs and ewes.

\section{Other Trace Elements}

Blood collected from bighorn sheep at the time of capture revealed no deficiencies in iron. In $35 \%$ of the bighorn sheep we sampled, iron levels were above the normal range reported for domestic sheep and other wild bighorn sheep populations in Wyoming. Zinc was found to be sufficient and even slightly high, ranging from 1.0 to 2.3 parts per million (ppm) over 2 years, as normal range for healthy bighorns is $0.8-2.0 \mathrm{ppm}$. Selenium levels in blood were within the normal range $(0.12-1.00 \mathrm{ppm})$ for healthy sheep, but consistently on the low end of the range (avg. $=0.33 ;$ all $\leq 0.42 ; \mathrm{n}=22$ ). Manganese ranged from $0.003-0.005 \mathrm{ppm}$ (2001 data only), and molybdenum was not detected in either year, indicating it was less than the $0.5 \mathrm{ppm}$ detection limit for the Wyoming State Veterinary Lab. Copper concentrations ranged from $0.58-1.20 \mathrm{ppm}$, mostly within the normal range for healthy sheep which is $0.60-1.20 \mathrm{ppm}$.

\section{Discussion}

The bighorn sheep population of the Pryor Mountains and Bighorn Canyon, as well as the ram segment of the herd, appears to be increasing. The population modeling supported our field observations of a greater number of rams in the herd in recent years. Lamb survivorship was 23\% higher in 2002 than 2001, but we don't know if this trend will continue. It may be a function of the closure of Bighorn Lake in 2002. The lake was closed due to low water level/drought, and bighorn sheep were observed from late June through fall on sandbars on the lake bottom, foraging on green grass and forbs. Animals were protected in 2002 from human disturbance from boats and jet skis, and from larger predators (bears, mountain lions) that cannot scale the cliff walls to reach the lake bottom. Data from 2003 will reveal more information on lamb survivorship, as the lake will be opened again for the 2003 boating season and the sheep will not have the same access to rich forage on the lake bottom, nor protection from predators via the tall, steep canyon walls.

Bighorn sheep do not appear to be under extreme pressure from predation. Of the total number of mortalities of radio-collared animals each year, predation was responsible for only 1 bighorn death in 2000, 2 deaths in 2001, and 2 deaths in 2002, but sample sizes were very small each year ( $n=5,3$, and 4 total deaths, respectively). At the time this report was written, there was 1 radio-collared bighorn sheep death in 2003, a mountain lion kill in February 2003. There may be an individual mountain lion that has learned how to hunt the Sykes Face (normally considered escape terrain) and is selecting bighorn sheep. Several mountain lion kills of radio-collared bighorn sheep were concentrated on the northern 1/3 of the Sykes Face -- behind Sorenson Ranch (Figure 6) in Layout Canyon. Several uncollared ram carcasses were also found in the same area. In a Yellowstone National Park study, bighorn sheep, moose (Alces alces), and pronghorn (Antilocapra americana) combined represented $<5 \%$ of mountain lion kills (Murphy and others, 1997). If mountain lion predation on bighorn sheep is high, it is likely only one or two individual lions have learned how to hunt sheep (Ross and others, 1997).

Disease is evident in the herd and was likely the cause of the decline in 1995-1996, based on Pasteurella titers found in blood samples as well as the high number of sheep of all ages (82\%) that had been exposed to para influenza. In addition, the decline followed a pattern of a disease epizootic, with chronic low lamb survival for several years (Foreyt, 1990). Nutritionally, bighorn sheep were not found to have deficiencies in trace elements, although iron levels were elevated (as high as $6.3 \mathrm{ppm}$ in some cases). No other deficiencies were found in trace elements, although selenium was consistently on the low end of the acceptable/healthy range for bighorn sheep in blood samples, feces, soil samples, and in bighorn sheep forages across the range.

In another bighorn sheep herd in Wyoming where selenium deficiency was linked to low lamb survivorship, total selenium levels in soil were $0.339 \mathrm{ppm}, 0.13 \mathrm{ppm}$ in blood samples of bighorn sheep, and $0.005 \mathrm{ppm}$ in forages where white muscle disease was reported. The selenium levels of these same variables in the BICA range were higher than in the Hnilicka and others (2001) study, but we do not know what effect potentially 
Table 11. Monthly fecal nitrogen and fecal selenium (Se) levels $( \pm S E$ ) from bighorn sheep (all sex and age classes pooled) in Bighorn Canyon National Recreation Area and surrounding lands, 2002.

\begin{tabular}{|c|c|c|c|c|c|c|c|c|c|c|c|c|c|}
\hline \multirow[b]{2}{*}{ Nutritent } & \multicolumn{12}{|c|}{ Month } & \multirow[b]{2}{*}{$P$-value } \\
\hline & Jan & Feb & Mar & Apr & May & Jun & Jul & Aug & Sep & Oct & Nov & Dec & \\
\hline $\begin{array}{l}\text { Fecal-N } \\
(\%)\end{array}$ & $\begin{array}{c}1.21 \pm \\
0.06\end{array}$ & $\begin{array}{l}1.29 \pm \\
0.06\end{array}$ & $\begin{array}{c}1.13 \pm \\
0.03\end{array}$ & $\begin{array}{l}1.41 \pm \\
0.05\end{array}$ & $\begin{array}{c}2.02 \pm \\
0.07\end{array}$ & $\begin{array}{c}2.12 \pm \\
0.11\end{array}$ & $\begin{array}{c}1.50 \pm \\
0.07\end{array}$ & $\begin{array}{c}1.39 \pm \\
0.04\end{array}$ & $\begin{array}{l}1.59 \pm \\
0.05\end{array}$ & $\begin{array}{c}1.66 \pm \\
0.06\end{array}$ & $\begin{array}{l}1.16 \pm \\
0.04\end{array}$ & $\begin{array}{l}1.21 \pm \\
0.03\end{array}$ & $<0.0001$ \\
\hline $\begin{array}{l}\text { Selenium } \\
(\mathrm{ppm})\end{array}$ & $\begin{array}{c}0.23 \pm \\
0.03 \\
\end{array}$ & $\begin{array}{c}0.26 \pm \\
0.01 \\
\end{array}$ & $\begin{array}{c}0.31 \pm \\
0.02 \\
\end{array}$ & $\begin{array}{c}0.34 \pm \\
0.06\end{array}$ & $\begin{array}{c}0.34 \pm \\
0.04\end{array}$ & $\begin{array}{c}1.11 \pm \\
0.44\end{array}$ & $\begin{array}{c}0.64 \pm \\
0.09 \\
\end{array}$ & $\begin{array}{c}0.33 \pm \\
0.06 \\
\end{array}$ & $\begin{array}{c}1.25 \pm \\
0.37\end{array}$ & $\begin{array}{c}0.38 \pm \\
0.01 \\
\end{array}$ & $\begin{array}{c}0.24 \pm \\
0.02\end{array}$ & $\begin{array}{c}0.28 \pm \\
0.02 \\
\end{array}$ & $<0.0001$ \\
\hline
\end{tabular}


Table 12. Fecal nitrogen and fecal selenium (Se) levels ( \pm SE) in rams, ewes, and lambs in Bighorn Canyon National Recreation Area and surrounding lands, 2002. Different letters indicate significant differences at the $P<0.05$ level.

\begin{tabular}{lcccc}
\hline & \multicolumn{4}{c}{ Bighorn Sheep Class } \\
\cline { 2 - 4 } Nutritent & Rams & Ewes & Lambs & $\boldsymbol{P}$-value \\
\hline & $1.709 \pm 0.09^{\mathrm{a}}$ & $1.396 \pm 0.05^{\mathrm{b}}$ & $1.414 \pm 0.06^{\mathrm{b}}$ & 0.0021 \\
Fecal-N (\%) & & & & \\
Selenium $(\mathrm{ppm})$ & $0.434 \pm 0.11$ & $0.478 \pm 0.06$ & $0.331 \pm 0.07$ & 0.5975 \\
\hline
\end{tabular}

chronic low levels (as opposed to "deficient" levels) of selenium may have on lamb or adult survivorship. White muscle disease was not observed in the BICA herd. However, low selenium levels may reduce immunity of individual bighorn sheep, especially if coupled with other population pressures or stressors. Deficiencies in selenium cause decreased immune response in bighorn sheep and may make sheep susceptible to disease. Animals that are stressed (from human disturbance, extreme predation pressure, a combination of these, or other causes) are also more susceptible to disease than bighorn sheep that are not stressed (Kraabel and Miller, 1997).

Both chest girth measurements and body weights of bighorn sheep were smaller in BICA than a herd in Alberta, Canada, but this may be due to climate and elevation differences. Also, we had a small sample size ( $\mathrm{n}=6$ animals) for body weights, and we had 16 chest girth measurements. Since body weight and chest girth size are correlated (Mayaka and others, 1995), it was not surprising that if one body measurement variable was smaller, the other variable was also smaller. In general, necropsies did not indicate that bighorn sheep in BICA were in poor body condition. Body mass is correlated with survival in both adults and lambs (Festa-Bianchet and others, 1997), and since we were not able to compare BICA sheep to any other herds in Wyoming or Montana, we do not know if smaller body mass could be associated with decline of the herd.

Information about competition between wild horses and bighorn sheep was somewhat conflicting. On one hand, we did not find compelling evidence in parameters of fecundity, survival, or forage use to support a theory of resource competition between bighorn sheep and wild horses, comparing $n=12$ ewes on horse range vs. $n=10$ ewes off horse range. Pregnancy, lambing, and lamb survivorship were almost identical on versus off the wild horse range, although sample sizes there were even smaller. There were no more bighorn sheep mortalities on the horse range than off. Ungulate consumption was higher on the horse range at some but not all of our sites compared to off the horse range, which would be expected with the addition of another large herbivore to the area. However, when we pooled all sites on the horse range and compared them to all areas off the horse range in a paired t-test, we found no differences on versus off in ungulate consumption in either winter or summer, suggesting that the areas shared with wild horses were not grazed more than unshared areas. We did, however, find a significantly lower rate of herbaceous plant production on versus off the wild horse range, and regression analyses showed a significant correlation between offtake and production. That is, offtake levels were high enough to have a negative affect on herbaceous plant production, suggesting that ungulate consumption levels across the range were very high. Similar to our findings of lowered production by ungulate consumption, Fahnestock (1998), Peterson and others (1997), and Gerhardt and Detling (1998) all found lower cover in bluebunch wheatgrass in grazed plots than exclosed plots on the Dry Head area, and overall grass biomass was higher inside than outside exclosures there. Fahnestock (1998) reported that precipitation had a greater affect than herbivory on overall vegetation dynamics on the PMWHR, and herbivory had greater effects on grasses in the lowland, arid sites (the Dry Head area) than on other plant groups. Absolute cover of grasses in lowland sites was $62 \%$ lower than in ungrazed sites (Fahnestock, 1998). Plant production was also lower on the low elevation Dry Head compared to higher elevation sites (Fahnestock, 1998). Our results indicated that the current levels of grazing negatively affected herbaceous plant production, at least in the Dry Head areas that bighorn sheep use. This result may be aggravated by low precipitation in the past several years.

Our analysis of nutrients, offtake, production, and habitat characteristics revealed some interesting correlations, which may be driving sheep distribution behavior across the range. We noted at the beginning of the study that there were areas that had been modeled as suitable bighorn sheep habitat by Gudorf and others (1996) that were not being used by bighorns (e.g., Big Coulee). At the same time, surrounding areas were established and 
inhabited by both rams and at least some ewe groups. Big Coulee is an area with high wild horse densities in winter. We suspect bighorn sheep are not using Big Coulee for a number of reasons. First, modeling has shown that Big Coulee has less suitable bighorn sheep habitat than the other 3 areas (Crooked Creek, Dry Head, and Barry's Landing -- areas they currently use). Lower overall suitable habitat may be deterring ewe groups from establishing in Big Coulee. In addition, the Dry Head area has the most mountain mahogany/juniper woodland habitat, and sheep appear to rely on this type in BICA especially in winter. Second, the Dry Head appears to have higher concentrations of palatable nutrients in summer especially, and the visibility for bighorn sheep is statistically higher -- even within the same vegetation types -- than other areas, due to smaller shrub sizes on the Dry Head. The quality of habitat appears to be better on the Dry Head than other areas. Lower herbaceous production on the Dry Head compared to the Barry's Landing area does not appear to deter sheep from concentrating there in both summer and winter. Summer plant nitrogen concentrations in 2 preferred grass species for bighorn sheep were higher on the Dry Head than Barry's Landing area. Summer Adf (fiber) content was lower on the Dry Head, suggesting that plant quality may be higher on the Dry Head than Barry's Landing area. The combination of these factors (more suitable habitat overall, higher concentrations of palatable nutrients, greater horizontal visibility for sheep, and more mountain mahogany habitat) may explain why bighorn sheep appear to concentrate on the Dry Head in both winter and summer, and are not using other accessible areas of the range that have been modeled as suitable sheep habitat.

We recommend further investigations into the spatial dynamics of bighorn sheep across the landscape, and more detailed analysis of habitat for habitat improvements. Specifically, we recommend thinning and burning treatments to improve visibility in habitat that has lower visibility but all other habitat requirements for bighorn sheep are present, such as the Barry's Landing area. We recommend continuing to monitor radio-collared animals, and adding collars to bighorn ewes that have established in Crooked Creek and areas north of Barry's Landing. These are the animals of particular interest, as they appear to be moving into new habitats and expanding the bighorn range. We do not recommend any habitat treatments in Big Coulee at this time, until more is known about the habitat. According to our habitat modeling (see Habitat Modeling section of this report), Wockner and others determined that there is less habitat for bighorns in Big Coulee than in other areas of the range. This area should be studied further to determine possibilities for habitat improvement to increase the size of the useable bighorn sheep range.

We recommend supplementing the herd with selenium blocks because selenium levels in plants and blood samples were on the low end of the acceptable range. Also, selenium levels in soil were lowest in the areas where bighorn sheep concentrate in both summer and winter - the Dry Head area. Supplementing the herd with selenium blocks may help increase the survivorship of lambs by bolstering bighorn sheep immune systems.

\section{Acknowledgments}

We wish to thank Nani Teves, Dana Cole, Jim Jolin, Jarrod Christianson, Mike Rock, Sarah Beck, Susan Hahn, Lissa Deslandes, Kerri Minatre, Linda Mitchell, Pat and Tom Clark, Jason Dungan, Paul Withington, Tom Williams, Walt Cook, and USGS volunteers for field monitoring and tracking help, plant sampling assistance, and help with capture and radio-collaring of sheep. We thank NPS staff Darrell Cook, Rick Lasko, Robert Byrne, Susanne Morstad, Laurie Janzen and NPS Rangers Bonnie Winslow, Wendy Bredow, Patrick Peralez, and Melissa Post for logistical support, housing, and project input. We thank Hip and Loretta Tillet for allowing access to the northern segment of the herd, and Abbey Tillet for her support and land access. Ron Hitchcock was instrumental in providing interns for the project for winter and summer sampling, Shawn Stewart and Tom Easterly provided valuable project input and equipment, and Linda Zeigenfuss provided statistical guidance and help with surveys. The Wyoming Game and Fish Department Fish Hatchery provided the use of their freezer for storing samples. We thank Kevin Hurley, WGFD for reviewing the report. This project was funded by the Natural Resources Preservation Program of the Biological Resources Discipline of the U.S. Geological Survey, Washington, DC.

\section{Literature Cited}

Austin, M.A., Obbard, M.E., and Kolensosky, G.B., 1994, Evidence for a black bear, Ursus americanus, killing an adult moose, Alces alces: Canadian Field Naturalist, vol. 108, no. 2, p. 236-238. 
Bailey, J.A., 1990, Management of Rocky Mountain bighorn sheep herds in Colorado: Colorado Division of Wildlife Special Report 66, Denver, Colo.

Berger, J., 1990, Persistence of different sized populations: an empirical assessment of rapid extinctions in bighorn sheep: Conservation Biology, vol. 4, p. 91-98.

Blood, D.A., Flook, D.R., and Wishart, W.D., 1970, Weights and growth of Rocky Mountain bighorn sheep in western Alberta: Journal of Wildlife Management, vol. 34, p. 451-455.

Bonham, C.D., 1989, Plant communities; measurements for terrestrial vegetation: New York, John Wiley and Sons, 339 p.

Buechner, H.K., 1960, The bighorn sheep in the United States, its past, present, and future: Wildlife Monograph vol. 4, p. 174.

Bunnell, F.L., 1980, Factors controlling the lambing period of Dall's sheep: Canadian Journal of Zoology, vol. 58, p. $1027-1031$.

Bunnell, F.L., 1982, The lambing period of mountain sheep: synthesis, hypothesis and tests: Canadian Journal of Zoology, vol. 60 , p. 1-14.

Cain, S.A., Kadlec, J.A., Allen, D.L., Cooley, R.A., Hornocker, M.G., Leopold, A.S., and Wagner, F.H., 1972, Predator control - 1971 : Report to Council on Environmental Quality and the Department of Interior by the Advisory Committee on Predator Control.

Cassirer, E.F., Rudolph, K.M., Fowler, P., Coggins, V.L., Hunter, D.L., and Miller, M.W., 2001, Evaluation of ewe vaccination as a tool for increasing bighorn lamb survival following pasteurellosis epizootics: Journal of Wildlife Diseases, vol. 37, p. $49-57$.

Caughley, G. , 1976, Wildlife management and the dynamics of ungulate populations: Advanced Applied Biology, vol. 1, p. $183-247$.

Coates, K. P., and Schemnitz, S.D., 1989, The bighorn sheep of Bighorn Canyon National Recreation Area and Pryor Mountain Wild Horse Range: Ecological relationships and management recommendations: Completion report to the National Park Service and Bureau of Land Management, New Mexico State University, Las Cruces, $47 \mathrm{p}$.

Coughenour, M.B., 1999, Ecosystem modeling of the Pryor Mountain wild horse range: Final report to USGS, Biological Resources Division, U.S. National Park Service, and U.S. Bureau of Land Management, $63 \mathrm{p}$.

Fahnestock, J.T., 1998, Vegetation responses to herbivory and resource supplementation in the Pryor Mountain Wild Horse Range: Ph.D. dissertation, Colorado State University, Ft. Collins, $125 \mathrm{p}$.

Festa-Bianchet, M., Jorgenson, J.T., Berube, C.H., Portier, C., and Wishart, W.D., 1997, Body mass and survival of bighorn sheep: Canadian Journal of Zoology, vol. 75, p. 1372-1379.

Foreyt, W.J., 1990, Pneumonia in bighorn sheep: effects of Pasteurella haemolytica from domestic sheep and effects on survival and long-term reproduction: Proceedings of the Biennial Symposium of the Northern Wild Sheep and Goat Council, vol. 7, p. 92-101.

Foreyt, W.J., 1992, Failure of an experimental Pasteurella haemolytica vaccine to prevent respiratory disease and death in bighorn sheep after exposure to domestic sheep: Proceedings of the Biennial Symposium of the Northern Wild Sheep and Goat Council, vol. 8, p. 15-163.

Geist, V., 1971, Mountain sheep: Chicago, University of Chicago Press, 383 p.

Gerhardt, T.D., and Detling, J.K., 1998, Monitoring vegetation in the Pryor Mountain Wild Horse Range: Addendum report, $46 \mathrm{p}$.

Gilmour, N.L., and Gilmour, J.S., 1989, Pasteurellosis of sheep, in Adlam, C., and Rutter, J.M., eds., Pasteurella and pasteurellosis: San Diego, Academic Press, Ltd., p. 223-262.

Gudorf, M., Sweanor, P.Y., Singer, F.J., Blandenship, A., Bleich, V., Easterly, T., Emmerich, J., Eustace, C., Irby, L., Jaynes, D., Jellison, B., Kissel, R., Lindsay, J., Parks, J. Peters, T., Reid, K., Stewart, S., and Voss, T., 1996, Bighorn sheep habitat assessment of the Greater Bighorn Canyon National Recreation Area: National Park Service and National Biological Service cooperative report, Bighorn Canyon National Recreation Area, Lovell, Wyo., 43 p.

Gudorf, M.A., 2002, Bighorn sheep habitat suitability assessment of the greater Bighorn Canyon National Recreation Area; Second analysis: Addendum report to the National Park Service and U.S. Geological Survey, Fort Collins Science Center, Fort Collins, Colorado, $31 \mathrm{p}$.

Halloran, A.F., 1949, Desert bighorn management: North American Wildlife Conference Transactions, vol. 14, p. $527-537$.

Hebert, D.M., and McTaggart-Cowan, I., 1971, White muscle disease in the mountain goat: Journal of Wildlife Management, vol. 35, p. 752-756.

Heimer, W.E., Watson, S.M., and Smith, III, T.C., 1984, Excess ram mortality in a heavily hunted Dall sheep population: Proceedings of the Biennial Symposium of the Northern Wild Sheep and Goat Council, vol. 4, p. 425-432.

Heimer, W.E., 1985, Population status and management of Dall sheep in Alaska, 1984, in Hoefs, M., ed., Wild sheep distribution, abundance, management and conservation of the sheep of the world and closely related mountain ungulates: Special Report, Northern Wild Sheep and Goat Council, Whitehorse, Yukon, p. 1-5.

Heimer, W.E., and Watson, S.M., 1986, Harvest strategy: maximizing ram harvests: Proceedings of the Biennial Symposium of the Northern Wild Sheep and Goat Council, vol. 5, p. 24-36. 
Hnilicka, P.A., Mioncynski, J., Mincher, B.J., States, J., Hinschberger, M., Oberlie, S., Thompson, C., Yates, B., and Siemer, D.D., 2001, Bighorn sheep lamb survival, trace minerals, rainfall and air pollution: are there any connections?: Proceedings of the Biennial Symposium Northern Wild Sheep and Goat Council, vol. 13, p. 69-94.

Hornocker, M.G., 1970, An analysis of mountain lion predation upon mule deer and elk in the Idaho Primitive Area: Wildlife Monograph, vol. 21, p. 1-39.

Johnson, T.J., and Swift, D.M., 1995, A test of a habitat evaluation procedure for Rocky Mountain bighorn sheep: Final report to Rocky Mountain Regional Office, National Park Service, Denver, Colo., 25 p.

Jorgenson, J.T. and Wishart, W.D., 1984, Growth rates of rocky mountain bighorn sheep on Ram Mountain, Alberta: Proceedings of the Biennial Symposium of the Northern Wild Sheep and Goat Council , vol. 4, p. 270-284.

Jorgenson, J.T., Festa-Bianchet, M., Gaillard, J.M., and Wishart, W.D., 1997, Effects of age, sex, disease, and density on survival of bighorn sheep: Ecology, vol. 78, p. 1019-1032.

Kelly, W.E., 1980, Predator relationships, in Monson, G., and Sumner, L., eds., The desert bighorn: Tucson, The University of Arizona Press, p. 186-196.

Kissell, R.E., Jr., Irby, L.R., and Mackie, R.J., 1996, Competitive interactions among bighorn sheep, feral horses, and mule deer in Bighorn Canyon National Recreation Area and Pryor Mountain wild horse range: Final report on Cooperative Agreement CA-1268-9017, Montana State University, Bozeman, 146 p.

Knight, D.H., Jones, G.P., Akashi, Y., and Myers, R.W., 1987, Vegetation ecology in the Bighorn Canyon National Recreation Area: Final report submitted to the U.S. National Park Service and the University of Wyoming, National Park Service Research Center, $113 \mathrm{p}$.

Kraabel, B.J. and Miller, M.S.,1997, Effect of simulated stress on the susceptibility of bighorn sheep neutrophils to Pasteurella haemolytica leukotoxin: Journal of Wildlife Diseases, vol. 33, p. 558-566.

Kraabel B. J., Miller, M.W. , Conlon, J.A., and McNeil, H.J., 1998, Evaluation of a multivalent Pasteurella haemolytica vaccine in bighorn sheep: Protection from experimental challenge: Journal of Wildlife Diseases, vol. 34, p. 325-333.

Mayaka, T.B., Tchoumboue, J., Manjeli, Y., and Teguia, A., 1995, Estimation of live body weight in west African dwarf goats from hearth girth measurement: Tropical Animal Health and Production, vol. 28, p. 126-128.

McCarty, C.W. and Miller, M.W., 1998, Modeling the population dynamics of bighorn sheep: a synthesis of literature: Colorado Division of Wildlife Special Report, no. 73, 35 p.

McCullough, D.R., 1979, The George Reserve deer herd: Ann Arbor, University of Michigan Press, 271 p.

Miller M.W., Hobbs, N.T., and Williams, E.S., 1991, Spontaneous pasteurellosis in captive Rocky Mountain bighorn sheep (Ovis canadensis canadensis): Clinical, laboratory, and epizootiological observations: Journal of Wildlife Diseases, vol. 27p. 534-542.

Miller, M.W., Conlon, J.A., McNeil, H.J., Bulgin, J.M., and Ward, A.C.S., 1997, Evaluation of a multivalent Pasteurella haemolytica vaccine in bighorn sheep: safety and serologic responses: Journal of Wildlife Diseases, vol. 33, p. 738-748.

Minatel, L., and Carfagnini, J.C., 2000, Copper deficiency and immune response in ruminants: Nutrition Research, vol. 20, p. 151915229.

Murphy, E.C., Singer, F.J., and Nichols, L.K., 1991, Effects of hunting on survival and productivity of Dall sheep: Journal of Wildlife Management, vol. 54, p. 284-290.

Nichols, L.K., 1972, Productivity in unhunted and heavily hunted Dall sheep populations: Alaska Department of Fish and Game, Juneau, P-R Report, Projects W-17-3 and W-17-4, 51 p.

Onderka, D.K., and Wishart, W.D., 1984, A major die-off from pneumonia in southern Alberta: Proceedings of the Biennial Symposium Northern Wild Sheep and Goat Council, vol. 4, p. 356-363.

Peterson, J., Fahenstock, J., and Detling, J.K., 1997, Ungulate/vegetation interactions at the Pryor Mountain Wild Horse Range: Completion report on Cooperative Agreement no. 1268-1-9002, Fort Collins, Colo, 154 p.

Potts, M.K., 1937, Hemorrhagic septicemia in the bighorn of Rocky Mountain National Park: Journal of Mammalogy, vol. 18, p. 105106.

Robbins, C.T., 1993, Wildlife feeding and nutrition (2 ${ }^{\text {nd }}$ ed.), in Cunha, T.J. ed.: San Diego, Academic Press, 351 p.

Robbins, C.T., Parish, S.M., and Robbins, B.L., 1995, Selenium and glutathione peroxidase activity in mountain goats: Canadian Journal of Zoology, vol. 63, p. 1544-1547.

Ross, P.I., Jalkotzy, M.G.,and Festa-Bianchet, M., 1997, Cougar predation on bighorn sheep in southwestern Alberta during winter: Canadian Journal of Zoology, vol. 74, p. 771-775.

Russo, J.P., 1956, The desert bighorn sheep in Arizona: Arizona Game and Fish Dept. Wildlife Bulletin No. 1, 153 p.

SAS Institute, 1988, SAS/Systat User's Guide, Release 8.0 edition: Cary, N.C., SAS Institute.

Singer, F. J., Bleich, V.C., and Gudorf. M.A.. 2000a, Restoration of bighorn sheep metapopulations in and near western national parks: Restoration Ecology, vol. 8, p. 14-24. 
Singer, F.J., Williams, E., Miller, M.W., and Zeigenfuss, L.C., 2000b, Population growth, fecundity, and survivorship in recovering populations of bighorn sheep: Restoration Ecology, vol. 8, p. 75-84.

Singer, F.J., and Zeigenfuss, L., 2002, Influence of trophy hunting and horn size on mating behavior and survivorship of mountain sheep: Journal of Mammalogy, vol. 83, p. 682-698.

Smith, T.S., Flinders, J.T., and Winn, D.S., 1991, A habitat evaluation procedure for Rocky Mountain bighorn sheep in the Intermountain West: Great Basin Naturalist, vol. 51, p. 205-225.

Unsworth, J.W., Leban, F.A., Leptich, D.J., Garton, E.O., and Zager, P., 1994, Aerial Survey: User's Manual (2 ${ }^{\text {nd }}$ ed.): Idaho Department of Fish and Game, Boise, $84 \mathrm{p}$.

Wehausen, J.D., 1996, Effects of mountain lion predation on bighorn sheep in the Sierra Nevada and Granite Mountains of California: Wildlife Society Bulletin, vol. 24, p. 471-479.

White G.C., and Burnham, K.P., 1999, Program MARK: Survival estimation from populations of marked animals: Bird Study, 46(Supplement): S120-S139.

Wishart, W.D., 1986, Bighorn harvest strategy in Alberta: Proceedings of the Northern Wild Sheep and Goat Council, vol. 5, p. 1213.

Woolf, A., 1971, Influences of lambing and morbidity on weights of captive Rocky Mountain bighorns: Journal of Mammalogy, vol. 52, p. 242-243. 


\section{Bighorn Sheep Demography and Population Modeling, Bighorn Canyon National Recreation Area, Wyoming and Montana, 2000-2002}

By James E. Roelle, U.S. Geological Survey

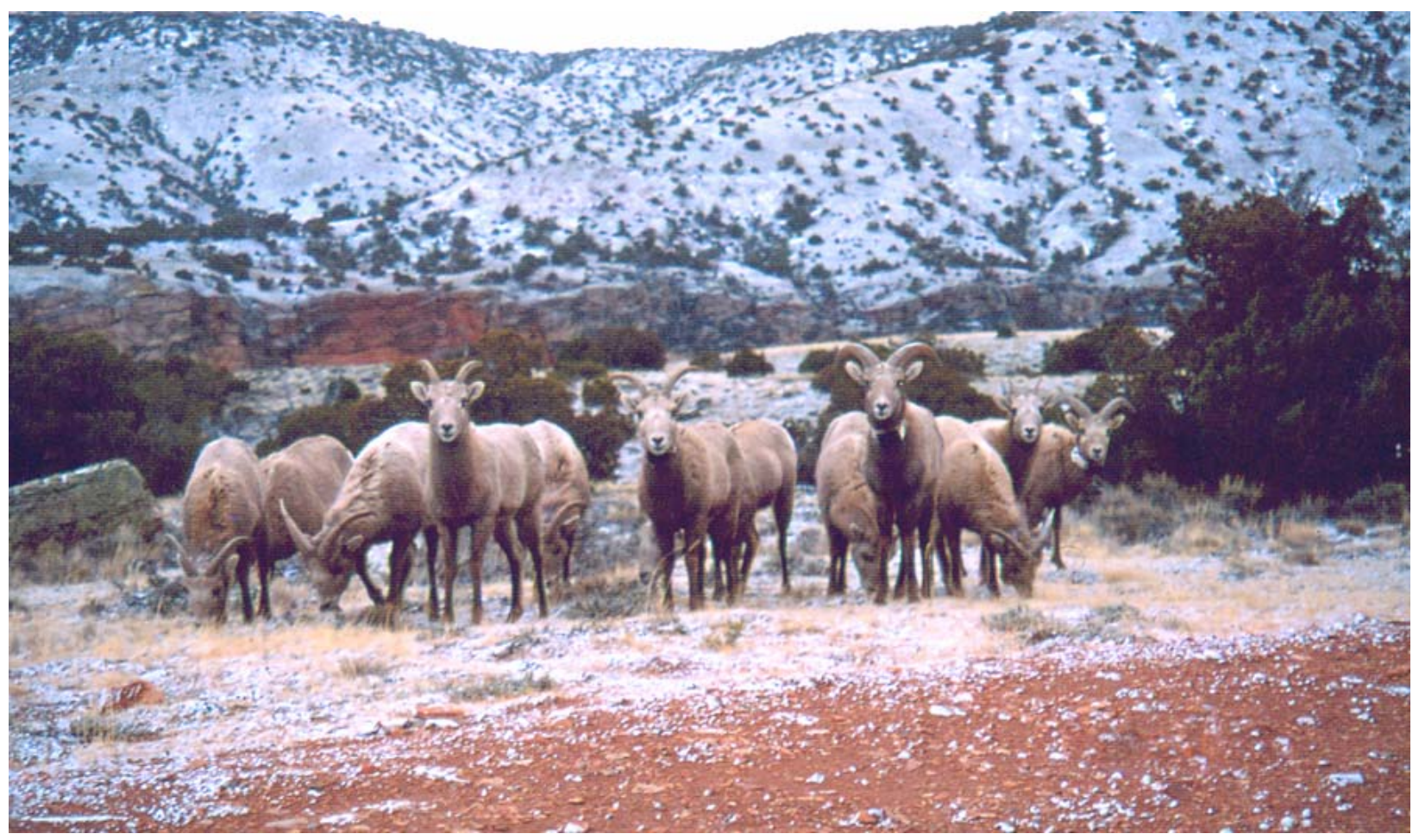




\section{Statement of the Problem and Study Objectives}

In order to evaluate the decline of the bighorn sheep population and herd population dynamics in Bighorn Canyon National Recreation Area (BICA), I conducted a population analysis using the population modeling programs POP-II and POP-III (Fossil Creek Software, Fort Collins, CO). In addition, I analyzed data on bighorn sheep lambing rates and pregnancy rates. The objectives of the analyses were to: (1) summarize available data on survival, reproduction, and harvest; (2) assess possible effects of sharing range with wild horses on ewe survival, lambing, and pregnancy rates; (3) evaluate the internal consistency of the various demographic data by combining them in a population model; and (4) assess the probable effects of various harvest levels on herd size and structure given the best estimates of other population parameters.

\section{Methods}

\section{Adult Survival}

Data for analysis of adult survival are available from the known history of animals radio-collared in February 2000 and January 2001 (Table 1). The three animals that died within about one week of the first capture in 2000 (presumably as a result of handling stress) were eliminated from the analysis. No animals died after the second capture in 2001. Many ewes can be classified as either on or off the horse range, but some use habitat in both areas. Rams tend to travel larger distances and cannot be so classified. Comparisons were made of ewes on versus off the wild horse range to evaluate possible effects of sharing range with wild horses. The years of the study were considered normal-dry years for precipitation, with the exception of 2002, which was a drought year.

Annual survival rates and confidence limits were calculated using the Known Fate module, which is appropriate when the fate of every individual is known, in Program MARK (White and Burnham, 1999). Survival rates were modeled with parameters representing year, group (sex, location of animals on or off the horse range), and a year by group interaction. Years were loosely defined as February 15, 2000 to January 25, 2001 (year 1), January 26, 2001 to January 25, 2002 (year 2), and January 26, 2002 to January 25, 2003 (year 3). Unfortunately, this definition combines parts of two winters in each year; however, it is consistent with the times at which animals were marked. 
Table 1. Fate of animals radio-collared in 2000 and 2001. Dots indicate missing data (e.g., the animal has not yet died or is known to utilize habitat both on and off the horse range).

\begin{tabular}{|c|c|c|c|c|c|c|}
\hline Collar \# & Sex & $\begin{array}{l}\text { Age at } \\
\text { Capture }\end{array}$ & $\begin{array}{l}\text { Date } \\
\text { Collared }\end{array}$ & $\begin{array}{l}\text { Date } \\
\text { Died }\end{array}$ & $\begin{array}{l}\text { Cause of } \\
\text { Death }\end{array}$ & $\begin{array}{l}\text { Horse } \\
\text { Range }\end{array}$ \\
\hline E021 & Female & 4.5 & $02 / 15 / 2000$ & $02 / 21 / 2000$ & Capture & . \\
\hline E100 & Female & 2 & $02 / 15 / 2000$ & $04 / 10 / 2000$ & Predator & Off \\
\hline E110 & Female & 7.5 & $02 / 15 / 2000$ & $02 / 23 / 2000$ & Capture & . \\
\hline E140 & Female & 1.5 & $02 / 15 / 2000$ & . & . & Off \\
\hline E181 & Female & 7 & $02 / 15 / 2000$ & $10 / 14 / 2000$ & Unknown & Off \\
\hline E210 & Female & 7.5 & $02 / 15 / 2000$ & . & . & Off \\
\hline E299 & Female & 3.5 & $02 / 15 / 2000$ & . & . & . \\
\hline E419 & Female & 3.5 & $02 / 15 / 2000$ & . & . & Off \\
\hline E560 & Female & 3.5 & $02 / 15 / 2000$ & . & . & Off \\
\hline E750 & Female & 6.5 & $02 / 15 / 2000$ & 05/12/2001 & Unknown & Off \\
\hline E790 & Female & 1.5 & $02 / 15 / 2000$ & . & . & Off \\
\hline R012 & Male & 2.5 & $02 / 15 / 2000$ & . & . & . \\
\hline R031 & Male & 1.5 & $02 / 15 / 2000$ & $02 / 21 / 2000$ & Capture & . \\
\hline R071 & Male & 4 & $02 / 15 / 2000$ & . & . & . \\
\hline R190 & Male & 1.5 & $02 / 15 / 2000$ & . & . & . \\
\hline E052 & Female & 7 & $02 / 16 / 2000$ & 02/08/2001 & Predator & On \\
\hline E060 & Female & 4 & $02 / 16 / 2000$ & . & . & On \\
\hline E721 & Female & 5.5 & $02 / 16 / 2000$ & . & . & On \\
\hline E910 & Female & 3.5 & $02 / 16 / 2000$ & . & . & On \\
\hline R411 & Male & 6.5 & $02 / 16 / 2000$ & . & . & . \\
\hline $\mathrm{R} 770$ & Male & 6.5 & $02 / 16 / 2000$ & 01/16/2002 & Unknown & . \\
\hline $\mathrm{R} 811$ & Male & 7.5 & $02 / 16 / 2000$ & . & . & . \\
\hline R849 & Male & 6.5 & $02 / 16 / 2000$ & . & . & . \\
\hline E021a & Female & 2.5 & $01 / 26 / 2001$ & . & . & On \\
\hline E100a & Female & 3.5 & $01 / 26 / 2001$ & 09/05/2001 & Predator & . \\
\hline E110a & Female & 2.5 & $01 / 26 / 2001$ & . & . & On \\
\hline E181a & Female & . & $01 / 26 / 2001$ & . & . & On \\
\hline E661 & Female & 4.5 & $01 / 26 / 2001$ & . & . & Off \\
\hline E822 & Female & 4.5 & $01 / 26 / 2001$ & $10 / 22 / 2002$ & Unknown & On \\
\hline E840 & Female & 3.5 & $01 / 26 / 2001$ & . & . & Off \\
\hline E861 & Female & 1.5 & $01 / 26 / 2001$ & . & . & On \\
\hline E882 & Female & 3.5 & $01 / 26 / 2001$ & . & . & On \\
\hline E919 & Female & 3.5 & $01 / 26 / 2001$ & . & . & On \\
\hline E963 & Female & 6.5 & $01 / 26 / 2001$ & . & . & On \\
\hline E992 & Female & 4.5 & $01 / 26 / 2001$ & 02/10/2002 & Predator & . \\
\hline R031a & Male & 2.5 & $01 / 26 / 2001$ & . & . & . \\
\hline R428 & Male & 7.5 & $01 / 26 / 2001$ & . & . & . \\
\hline R578 & Male & 1.5 & 01/26/2001 & . & . & . \\
\hline R601 & Male & 4.5 & $01 / 26 / 2001$ & . & . & . \\
\hline R620 & Male & 2.5 & $01 / 26 / 2001$ & . & . & . \\
\hline R639 & Male & 6.5 & $01 / 26 / 2001$ & . & . & . \\
\hline R679 & Male & 3.5 & $01 / 26 / 2001$ & . & . & . \\
\hline R940 & Male & 4.5 & $01 / 26 / 2001$ & $12 / 28 / 2001$ & Predator & . \\
\hline
\end{tabular}

\section{Pregnancy and Lambing Rates}

Data available for the analysis of pregnancy and lambing rates are mostly from ewes radio-collared in this study, with a few observations of ewes originally marked by Kissell (1996) (Table 2). Pregnancy was determined by tests of either blood or feces. To confirm lambing, ewes were directly observed for both the presence of a lamb and other external signs of maternity. Only ewes age 3 and older were considered, because ewes typically are not bred until the fall after they reach age 2 . 
Table 2. Reproductive history of radio-collared ewes from this study and ewes marked by Kissell (1996). Dots indicate missing data or animals known to use habitat both on and off the horse range.

\begin{tabular}{|c|c|c|c|c|}
\hline Collar & Year & Pregnant & Lamb & Horse range \\
\hline E140 & 2000 & 1 & 0 & off \\
\hline E181 & 2000 & 0 & 1 & off \\
\hline E210 & 2000 & 0 & 0 & off \\
\hline E419 & 2000 & 1 & 1 & off \\
\hline E560 & 2000 & . & 1 & off \\
\hline E750 & 2000 & 0 & 0 & off \\
\hline E052 & 2000 & 1 & 1 & on \\
\hline E060 & 2000 & 1 & 1 & on \\
\hline E721 & 2000 & 1 & 0 & on \\
\hline E910 & 2000 & 1 & 1 & on \\
\hline E299 & 2000 & 1 & 1 & . \\
\hline E140 & 2001 & . & 1 & off \\
\hline E210 & 2001 & . & 0 & off \\
\hline E419 & 2001 & 1 & 1 & off \\
\hline E560 & 2001 & 0 & 1 & off \\
\hline E661 & 2001 & 1 & 1 & off \\
\hline E750 & 2001 & 0 & . & off \\
\hline E790 & 2001 & . & 1 & off \\
\hline E840 & 2001 & 1 & 1 & off \\
\hline E021a & 2001 & 1 & 1 & on \\
\hline E060 & 2001 & . & 1 & on \\
\hline E110a & 2001 & 0 & 0 & on \\
\hline E181a & 2001 & 0 & 0 & on \\
\hline E721 & 2001 & 1 & 1 & on \\
\hline E822 & 2001 & 1 & 1 & on \\
\hline E861 & 2001 & 1 & 1 & on \\
\hline E882 & 2001 & 1 & 1 & on \\
\hline E910 & 2001 & 0 & 0 & on \\
\hline E919 & 2001 & 1 & 1 & on \\
\hline E963 & 2001 & 0 & 0 & on \\
\hline E100a & 2001 & . & 0 & . \\
\hline E992 & 2001 & 1 & 1 & . \\
\hline E140 & 2002 & 1 & 1 & off \\
\hline E210 & 2002 & 0 & 0 & off \\
\hline E419 & 2002 & . & 1 & off \\
\hline E560 & 2002 & 1 & 1 & off \\
\hline E661 & 2002 & . & 0 & off \\
\hline E790 & 2002 & 1 & 1 & off \\
\hline E840 & 2002 & 1 & 1 & off \\
\hline E021a & 2002 & 1 & 1 & on \\
\hline E060 & 2002 & 0 & 0 & on \\
\hline E110a & 2002 & 1 & 1 & on \\
\hline E181a & 2002 & 1 & 0 & on \\
\hline E721 & 2002 & 1 & 1 & on \\
\hline E822 & 2002 & 1 & 1 & on \\
\hline E861 & 2002 & 1 & 1 & on \\
\hline E882 & 2002 & 1 & 1 & on \\
\hline E910 & 2002 & 1 & 1 & on \\
\hline E919 & 2002 & . & 1 & on \\
\hline
\end{tabular}


Table 2. Reproductive history of radio-collared ewes from this study and ewes marked by Kissell (1996)-Continued.

\begin{tabular}{ccccc}
\hline Collar & Year & Pregnant & Lamb & Horse range \\
\hline & & & & \\
E963 & 2002 & 0 & 0 & on \\
KREDOR & 2002 & 1 & 1 & on \\
KYROW & 2002 & 1 & 1 & on \\
KYSTAG & 2002 & 1 & 1 & on \\
KBLUE & 2002 & 1 & 1 & . \\
\hline
\end{tabular}

Pregnancy rates and lambing rates on and off the horse range were compared using Fisher's exact test (Mielke and Berry 2001:259) both for each year individually and for data pooled across all years. While this test is valid even for small sample sizes (such as we have for any single year), it ignores potential problems with multiple comparisons (i.e., individual years) and lack of independence in the samples if the data are pooled (i.e., many of the collared ewes were the same from year to year). In an effort to avoid the problem of lack of independence in the samples, data were also subjected to a permutation analysis for multiple binary responses (Berry and Mielke 2003). This approach examines whether the pattern of responses (e.g., across multiple years) varies within treatment groups. Sample sizes were large enough for this approach only for 2001 and 2002 . The relation between pregnancy rates and lambing rates (all groups pooled within years) was also examined using simple linear regression.

\section{Population Simulations}

\section{Model Structure}

Population simulations were conducted using POP-II and POP-III (both copyrighted by Fossil Creek Software, Fort Collins, CO), which are discrete-time, difference-equation models. POP-II begins simulations with a sex- and age-distributed population, subtracts animals for the current year due to natural mortality and harvest, increments all age classes, calculates a reproductive crop for the next year, and repeats this process for as many years as desired. Model output is in the form of deterministic tables and time-traces (graphs) that can be compared with observed data (e.g., population size, age and sex ratios) to calibrate model parameters. POP-III is similar in structure, but model parameters can be specified as statistical distributions (uniform, normal, or cumulative). Multiple Monte Carlo simulations are run by sampling from these distributions. Output is in the form of frequency distributions of outcomes in terms of population size and sex ratio.

\section{POP-II Details and Basic Assumptions}

In POP-II, the biological year is divided into three periods as shown in Table 3.

Table 3. The biological year as described for POP-II.

\begin{tabular}{ll}
\hline Time Period & Interpretation for Bighorn Canyon Sheep Population \\
\hline Preseason & From immediately post-lambing to start of harvest (approximately June 1 to October 10) \\
Harvest & Approximately October 11 to November 20 \\
Postseason & $\begin{array}{l}\text { From immediately after harvest to immediately before lambing in the following year } \\
\text { (approximately November 21 to May 31) }\end{array}$ \\
\hline
\end{tabular}

The program produces summary population statistics at four times during the biological year: immediately after births, immediately prior to harvest (described as preseason statistics), immediately after harvest (postseason statistics), and immediately prior to births in the next year. Most of the available data on population size, sex ratios, and age ratios for the Bighorn Canyon sheep herd appear to have been gathered in either late fall (November) or late winter (say, March). As a starting point, it was assumed that these data represent the postseason statistics as calculated by POP-II. There are two possible problems with this assumption. First, it is known that some data were 
gathered prior to the completion of harvest, and are thus not exactly comparable to the postseason statistics produced by POP-II. This is not a serious error, however, because the harvest is small relative to the population size. Second, data gathered in mid-winter represent a herd in which some postseason natural mortality has occurred, whereas POP-II calculates its postseason statistics before any postseason natural mortality. This is potentially a more serious problem. However, given the available data, there seems to be no solution other than to use data gathered as close to the harvest as possible whenever there is a choice.

It was assumed that nearly all natural lamb mortality occurs in the preseason (summer and early fall) and that by the end of harvest, lamb natural mortality rates are the same as those for adults. In addition, it was assumed that all natural adult (i.e., non-lamb) mortality occurs in the post season (winter and spring).

\section{Initial Population Size}

The earliest demographic data available for the herd are from Coates and Schemnitz (1989). The population structure for initializing POP-II (Table 4) was taken from their Figure 4, using the midpoint where they reported a range and assuming that lambs and yearlings were evenly distributed between males and females. These data were assumed to represent the population immediately after lambing in 1985. Ewes 2 years of age and older were arbitrarily distributed among age classes 2 through 8.

Table 4. Population structure for initializing POP-II in biological year 1985.

\begin{tabular}{cccccc}
\hline Age Class & Number of Males & Number of Females & Age Class & Number of Males & $\begin{array}{c}\text { Number of } \\
\text { Females }\end{array}$ \\
\hline 0 & 6 & 5 & 9 & 0 & 0 \\
1 & 2 & 2 & 10 & 0 & 0 \\
2 & 2 & 2 & 11 & 0 & 0 \\
3 & 3 & 3 & 12 & 0 & 0 \\
4 & 3 & 2 & 14 & 0 & 0 \\
5 & 1 & 1 & 15 & 21 & 0 \\
6 & 2 & 2 & Total & \\
\hline
\end{tabular}

\section{Reproduction}

While there are some data on natality (number of lambs actually born) for radio-collared ewes in years 2000-2002, most information on reproduction is in the form of age ratios (lambs/100 ewes) obtained in the late fall or winter. These data (Table 5) were used to represent reproduction, and it was assumed that lamb mortality during the preseason period is already accounted for in these ratios. In all cases but one, the value obtained closest to the time of harvest was used if more than one value was available. However, in 1993-94, the value from Kissell's survey flights (18.0 lambs/100 ewes) was used, even though summer and fall values were available, on the grounds that it was likely to be most consistent with data from later years. While this approach effectively obscures one of the most interesting (and probably most variable) aspects of sheep population dynamics (i.e., lambing rates and early lamb survival), it is at least consistent with the available data. Note that because all ewes age 1 and up are included in these ratios, the "reproductive rate" is applied to all ewes when used in the simulation to calculate reproduction.

\section{Sex Ratio at Birth}

It was assumed that the sex ratio of lambs at birth is 1:1 because there are no data to indicate otherwise (McCarty and Miller, 1998). 
Table 5. Available age ratio data (lambs/100 ewes). In all cases, it is assumed that animals age 1 and older are included in the number of ewes. Numbers actually used in POP-II are marked with an asterisk.

\begin{tabular}{|c|c|c|c|c|c|}
\hline \multirow[b]{2}{*}{$\begin{array}{c}\text { Biological } \\
\text { Year }\end{array}$} & \multirow[b]{2}{*}{ Season or Date } & \multicolumn{4}{|c|}{ Source } \\
\hline & & $\begin{array}{c}\text { Kissell and others } \\
\text { (1996) Survey } \\
\text { Flights }\end{array}$ & $\begin{array}{l}\text { Kissell and others } \\
\text { (1996) Data }\end{array}$ & $\begin{array}{c}\text { Idaho Sightability } \\
\text { Model }\end{array}$ & $\begin{array}{c}\text { Coates and } \\
\text { Schemnitz (1989) }\end{array}$ \\
\hline $1986-87$ & Summer? & & & & $60.0 *$ \\
\hline $1987-88$ & Summer? & & & & $51.9 *$ \\
\hline $1988-89$ & Summer? & & & & $54.8 *$ \\
\hline $1989-90$ & \multicolumn{5}{|c|}{ No data available-repeat value $\left(54.8^{*}\right)$ from $1988-89$} \\
\hline 1990-91 & \multicolumn{5}{|c|}{ No data available-repeat value $(54.8 *)$ from $1988-89$} \\
\hline $1991-92$ & \multicolumn{5}{|c|}{ No data available-repeat value $\left(54.8^{*}\right)$ from $1988-89$} \\
\hline \multirow[t]{2}{*}{ 1992-93 } & Winter & \multicolumn{3}{|c|}{$37.1^{*}$} & \\
\hline & Spring & \multicolumn{3}{|c|}{24.8} & \\
\hline \multirow[t]{4}{*}{ 1993-94 } & Summer & \multicolumn{3}{|c|}{50.0} & \\
\hline & Fall & \multicolumn{3}{|c|}{55.6} & \\
\hline & Winter & \multicolumn{3}{|l|}{$18.0 *$} & \\
\hline & Spring & \multicolumn{3}{|c|}{50.5} & \\
\hline \multirow[t]{2}{*}{ 1994-95 } & Summer & & & & \\
\hline & Winter & \multicolumn{3}{|c|}{36.1} & \\
\hline \multirow[t]{2}{*}{ 1995-96 } & Summer & \multirow{2}{*}{\multicolumn{3}{|c|}{56.4}} & \\
\hline & Winter & & & & \\
\hline $1996-97$ & \multicolumn{5}{|c|}{ No data available-repeat value $(21.3 *)$ from $1995-96$} \\
\hline 1997-98 & $3 / 20 / 98$ & & & $24.2 *$ & \\
\hline \multirow[t]{2}{*}{ 1998-99 } & $1 / 21 / 99$ & & & $36.7 *$ & \\
\hline & $3 / 31 / 99$ & & & 15.0 & \\
\hline $1999-00$ & $11 / 16 / 99$ & & & $11.6^{*}$ & \\
\hline $2000-01$ & $3 / 7 / 01$ & & & $16.6^{*}$ & \\
\hline $2001-02$ & $11 / 12 / 01$ & & & $14.0^{*}$ & \\
\hline $2002-03$ & $11 / 18 / 02$ & & & $52.6^{*}$ & \\
\hline
\end{tabular}

\section{Natural Mortality}

POP-II calculates natural mortality using age-specific rates (\%) and annual mortality severity indices, each of which may be specified for both the preseason and postseason periods. The mortality severity indices may be either linear (i.e., a simple multiplier of each age-specific rate) or curvilinear (which affects younger age classes disproportionately). As mentioned above, it was assumed that there is no natural mortality in the preseason period. For the postseason period, the rate (0.90) from the maximum likelihood model estimated by Program MARK (based on data from radio-collared animals in 2000-2002) was used. Lambs were also subjected to this same rate in the postseason. For initial simulations, the postseason mortality severity indices were set to 1.0 (i.e., no effect) for all years.

\section{Harvest}

Data on numbers of animals harvested were provided by S. Stewart, Montana Fish, Wildlife, and Parks Department (Table 6). It was assumed that all animals taken were Class III and above (age 6 and above). The harvest was also limited (using POP-II's effort values, which are multipliers used to proportion the harvest across age classes) to 4 age classes to try insofar as possible to minimize the number of fractional animals removed, though this probably has no real impact on the simulations. 
Table 6. Number of animals (all rams) removed.

\begin{tabular}{cccc}
\hline Biological Year & Number Harvested & Biological Year & Number Harvested \\
\hline $1990-91$ & 2 & $1997-98$ & 4 \\
$1991-92$ & 2 & $1998-99$ & 2 \\
$1992-93$ & 2 & $1999-00$ & 2 \\
$1993-94$ & 2 & $2000-01$ & 1 \\
$1994-95$ & 4 & $2001-02$ & 0 \\
$1995-96$ & 4 & $2002-03$ & 1 \\
$1996-97$ & 4 & & \\
\hline
\end{tabular}

\section{Wounding Loss/llegal Harvest}

POP-II includes a parameter that can be used to incorporate wounding loss and/or illegal harvest as a proportion of the legal harvest. During the course of the current study, investigators have found no evidence that these factors are significant for the Bighorn Canyon herd (e.g., there have been no unexplained disappearances of known rams) (K. Schoenecker, oral commun., 2003). This parameter was therefore set to zero for all simulations.

\section{Observed (Calibration) Data}

These values represent data points for comparison of the simulated results with field results. Only two types of information are available for this purpose: population size (Table 7) and sex ratios (Table 8). In each case, information that corresponded most closely to the time of the postseason calculations in POP-II (i.e., immediately post-harvest) was used.

\section{Results}

\section{Adult Survival}

\section{Grouping by Location}

Estimated survival rates for ewes for all combinations of year and group (on or off the horse range) are shown in Table 9. The maximum likelihood model for describing sheep survival (ewes only) on versus off the wild horse range contained only a single parameter (i.e., no effect of year or location; survival $=0.900 ; 95 \%$ C.L. $=$ $0.7813,0.9578$ ). Based on the corrected Akaike Information Criterion (AIC), the model incorporating an effect of location was nearly as good (change in AIC from the model without location $=1.73$ ). In this model, the survival estimate for ewes inhabiting areas on the horse range $(0.926 ; 95 \%$ C.L. $=0.7475,0.9814)$ was somewhat higher than that for ewes inhabiting areas off the wild horse range $(0.870 ; 95 \%$ C.L. $=0.6645,0.9573)$. Note, however, that confidence intervals for these two models overlap and sample sizes are small.

\section{Grouping by Sex}

Estimated survival rates for adult sheep for all combinations of year and sex are shown in Table 10. The maximum likelihood model for describing sheep survival contained only a single parameter (i.e., no effect of year or sex; survival rate $=0.902 ; 95 \%$ C.L. $=0.8207,0.9477$ ). The next best model (change in AIC from the model excluding sex $=0.90$ ) incorporated an effect of sex. In this model the estimated survival rate for females was lower $(0.875 ; 95 \%$ C.L. $=0.7602,0.9392)$ than that for males $(0.943 ; 95 \%$ C.L. $=0.7984,0.9857)$. Again, however, there is considerable overlap between the confidence limits for these two models and sample sizes are small, especially for males. Note that Singer and others (2000) also found that rams survived somewhat better than ewes (0.94 vs. 0.89) in unhunted sheep herds recently introduced into parks in the western United States. Data reported here for the Bighorn Canyon herd are comparable in the sense that harvest mortality is not included. 
Table 7. Estimated population size. Values actually used in the model are marked by an asterisk.

\begin{tabular}{cccc}
\hline Biological Year & Season or Date & Population Estimate & Source \\
\hline $1985-86$ & Fall & $42^{*}$ & Coates and Schemnitz (1989) \\
$1986-87$ & Fall & $51^{*}$ & Coates and Schemnitz (1989) \\
$1987-88$ & Fall & $62^{*}$ & Coates and Schemnitz (1989) \\
$1988-89$ & Fall & $71^{*}$ & Coates and Schemnitz (1989) \\
$1989-90$ & (Projected) & $99^{*}$ & Coates and Schemnitz (1989) \\
$1990-91$ & & No data available & \\
$1991-92$ & & No data available & \\
$1992-93$ & Winter & $211^{*}$ & Kissell (1996) \\
$1993-94$ & Winter & $211^{*}$ & Kissell (1996) \\
$1994-95$ & Winter & $145^{*}$ & Kissell (1996) \\
$1995-96$ & Winter & $125^{*}$ & Kissell (1996) \\
$1996-97$ & & No data available & \\
$1997-98$ & $3 / 20 / 98$ & $95^{*}$ & Idaho Model \\
$1998-99$ & $1 / 21 / 99$ & $94^{*}$ & Idaho Model \\
& $3 / 31 / 99$ & 47 & Idaho Model \\
$1999-00$ & $11 / 16 / 99$ & $72^{*}$ & Idaho Model \\
$2000-01$ & $3 / 7 / 01$ & $115^{*}$ & Idaho Model \\
$2001-02$ & $11 / 12 / 01$ & $61^{*}$ & Idaho Model \\
$2002-03$ & $11 / 18 / 02$ & $113^{*}$ & Idaho Model \\
\hline
\end{tabular}


Table 8. Observed sex ratios (rams/100 ewes). Rams and ewes include all animals in age class 1 and up. Data actually used are marked by an asterisk.

\begin{tabular}{|c|c|c|c|c|c|}
\hline \multirow[b]{2}{*}{ Biological Year } & \multirow[b]{2}{*}{ Season or Date } & \multicolumn{4}{|c|}{ Source } \\
\hline & & $\begin{array}{l}\text { Kissell (1996) } \\
\text { Survey Flights }\end{array}$ & $\begin{array}{c}\text { Kissell (1996) } \\
\text { Other Data }\end{array}$ & Idaho Model & $\begin{array}{c}\text { Coates and } \\
\text { Schemnitz } \\
\text { (1989) }\end{array}$ \\
\hline $1985-86$ & Fall & & & & $93.8^{*}$ \\
\hline $1986-87$ & Fall & & & & $95.0^{*}$ \\
\hline $1987-88$ & Fall & & & & $77.8^{*}$ \\
\hline $1988-89$ & Fall & & & & $74.2^{*}$ \\
\hline 1989-90 & & & No data available & & \\
\hline 1989-91 & & & No data available & & \\
\hline 1991-92 & & & No data available & & \\
\hline \multirow[t]{2}{*}{ 1992-93 } & Winter & & $44.9^{*}$ & & \\
\hline & Spring & & 74.1 & & \\
\hline 1993-94 & Winter & $45.3^{*}$ & 37.9 & & \\
\hline 1994-95 & Winter & $40.7^{*}$ & & & \\
\hline 1995-96 & Winter & $68.5^{*}$ & & & \\
\hline 1996-97 & & & No data available & & \\
\hline 1997-98 & $3 / 20 / 98$ & & & $16.2 *$ & \\
\hline \multirow[t]{2}{*}{ 1998-99 } & $1 / 21 / 99$ & & & $11.1^{*}$ & \\
\hline & $3 / 31 / 99$ & & & 5.6 & \\
\hline 1999-00 & $11 / 16 / 99$ & & & $43.2^{*}$ & \\
\hline 2000-01 & $3 / 7 / 01$ & & & $20.4^{*}$ & \\
\hline 2001-02 & $11 / 12 / 01$ & & & $62.7 *$ & \\
\hline $2002-03$ & $11 / 18 / 02$ & & & $68.4 *$ & \\
\hline
\end{tabular}

Table 9. Survival of adult ewes by year and habitat group (on versus off wild horse range).

\begin{tabular}{cccccc}
\hline Year & Location & $\begin{array}{c}\text { Number Alive at } \\
\text { Start }\end{array}$ & $\begin{array}{c}\text { Number Alive at } \\
\text { End }\end{array}$ & $\begin{array}{c}\text { Annual } \\
\text { Survival Rate }\end{array}$ & Standard Error \\
\hline 1 & Off & 8 & 6 & 0.75 & 0.153 \\
1 & On & 4 & 4 & 1.00 & 0.000 \\
2 & Off & 8 & 7 & 0.88 & 0.117 \\
2 & On & 12 & 11 & 0.92 & 0.080 \\
3 & Off & 7 & 7 & 1.00 & 0.000 \\
3 & On & 11 & 10 & 0.91 & 0.087 \\
1 & All & 12 & 10 & 0.83 & 0.108 \\
2 & All & 20 & 18 & 0.90 & 0.067 \\
3 & All & 18 & 17 & 0.94 & 0.054 \\
All & Off & 23 & 20 & 0.87 & 0.070 \\
All & On & 27 & 25 & 0.93 & 0.050 \\
All & All & 50 & 45 & 0.90 & 0.042 \\
\hline
\end{tabular}


Table 10. Survival of adult sheep by year and sex.

\begin{tabular}{cccccc}
\hline Year & Sex & $\begin{array}{c}\text { Number Alive at } \\
\text { Start }\end{array}$ & $\begin{array}{c}\text { Number Alive at } \\
\text { End }\end{array}$ & $\begin{array}{c}\text { Annual } \\
\text { Survival Rate }\end{array}$ & Standard Error \\
\hline 1 & F & 13 & 11 & 0.85 & 0.100 \\
1 & M & 7 & 7 & 1.00 & 0.000 \\
2 & F & 23 & 20 & 0.87 & 0.070 \\
2 & M & 15 & 13 & 0.87 & 0.088 \\
3 & F & 20 & 18 & 0.90 & 0.067 \\
3 & M & 13 & 13 & 1.00 & 0.000 \\
1 & All & 20 & 18 & 0.90 & 0.067 \\
2 & All & 38 & 33 & 0.87 & 0.055 \\
All & Fll & 33 & 31 & 0.94 & 0.042 \\
All & F & 56 & 49 & 0.88 & 0.044 \\
All & All & 35 & 33 & 0.94 & 0.039 \\
\end{tabular}

\section{Pregnancy and Lambing Rates}

For all groups and years combined, the pregnancy rate was 0.73 and the lambing rate was 0.72 (Table 11). Fisher's exact test showed no differences in pregnancy rates for ewes inhabiting areas on versus off the wild horse range either for individual years $(P \geq 0.17)$ or with all years pooled $(P=0.29)$. Similarly, as judged by Fisher's exact test, lambing rates were not different on versus off the wild horse range in individual years $(P \geq 0.57)$ or with all years pooled $(P=1.00)$. The permutation analysis of multiple binary responses also showed no difference in pregnancy rates $(P=1.00)$ or lambing rates $(P=0.83)$ of ewes inhabiting areas on versus off the wild horse range. Linear regression analysis also revealed no significant relationship $(P=0.53)$ between pregnancy rates and lambing rates across years with both ewe groups (on and off the wild horse range) combined.

Table 11. Pregnancy and lambing rates of ewes by habitat group (on versus off the wild horse range) and year. Dots in the group column represent animals that utilize habitat both on and off the horse range.

\begin{tabular}{|c|c|c|c|c|c|c|c|}
\hline Year & Group & $\begin{array}{l}\text { Number } \\
\text { Pregnant }\end{array}$ & $\mathbf{N}$ & $\begin{array}{c}\text { Proportion } \\
\text { Pregnant } \\
\end{array}$ & $\begin{array}{l}\text { Number } \\
\text { Lambing }\end{array}$ & $\mathbf{N}$ & $\begin{array}{c}\text { Proportion } \\
\text { Lambing }\end{array}$ \\
\hline 2000 & - & 1 & 1 & 1.00 & 1 & 1 & 1.00 \\
\hline 2000 & Off & 2 & 5 & 0.40 & 3 & 6 & 0.50 \\
\hline 2000 & On & 4 & 4 & 1.00 & 3 & 4 & 0.75 \\
\hline 2001 & & 1 & 1 & 1.00 & 1 & 2 & 0.50 \\
\hline 2001 & Off & 3 & 5 & 0.60 & 6 & 7 & 0.86 \\
\hline 2001 & On & 6 & 10 & 0.60 & 7 & 11 & 0.64 \\
\hline 2002 & . & 1 & 1 & 1.00 & 1 & 1 & 1.00 \\
\hline 2002 & Off & 4 & 5 & 0.80 & 5 & 7 & 0.71 \\
\hline 2002 & On & 11 & 13 & 0.85 & 11 & 14 & 0.79 \\
\hline 2000 & All & 7 & 10 & 0.70 & 7 & 11 & 0.64 \\
\hline 2001 & All & 10 & 16 & 0.63 & 14 & 20 & 0.70 \\
\hline 2002 & All & 16 & 19 & 0.84 & 17 & 22 & 0.77 \\
\hline All & . & 3 & 3 & 1.00 & 3 & 4 & 0.75 \\
\hline All & Off & 9 & 15 & 0.60 & 14 & 20 & 0.70 \\
\hline All & On & 21 & 27 & 0.78 & 21 & 29 & 0.72 \\
\hline All & All & 33 & 45 & 0.73 & 38 & 53 & 0.72 \\
\hline
\end{tabular}




\section{Population Simulations}

\section{Simulation 1}

Figure 1 illustrates the results of an 18-year simulation (1985-2002) using the basic data described above. The population of 42 animals present in 1985 (Coates and Schemnitz, 1989) grew to a maximum simulated population of about 97 animals in 1992, or less than half of the total population (211) reported by Kissell (1996) for that year (Figure 1A). Simulated sex ratios remained higher than those observed in the field for most of the time period (Figure 1B), though the modeled ratios were close to observed values in 2001 and 2002.

Failure of the simulated population to increase to the levels reported by Kissell (1996) in 1992-1993 is somewhat surprising in that reproductive rates used for the period 1985-1992 were relatively high (Table 5) and the calculated survival rates ( 0.90 for both sexes, or $10 \%$ mortality) were essentially the same as those derived by McCarty and Miller (1998) in their review and modeling exercise. In addition, if the Bighorn Canyon population actually grew from 42 animals in 1985 to 211 animals in 1992, the exponential growth rate (r) would have been about 0.23 , which is well within the range reported by McCarty and Miller (1998) for introduced sheep populations in Colorado. Thus, while growth of the actual population from 42 to 211 animals in 7 years seems plausible, the reproductive and survival rates used in Simulation 1 did not allow growth that rapid in the simulated population.

The fact that simulated sex ratios (i.e., more males) were often higher than those reported from the field is

probably not surprising. Rams are often found in rougher topography, making them more difficult to find by ground observers, and tend to be more solitary than females, thus making them more difficult to see from a helicopter. 
A. Population Size - Simulation 1

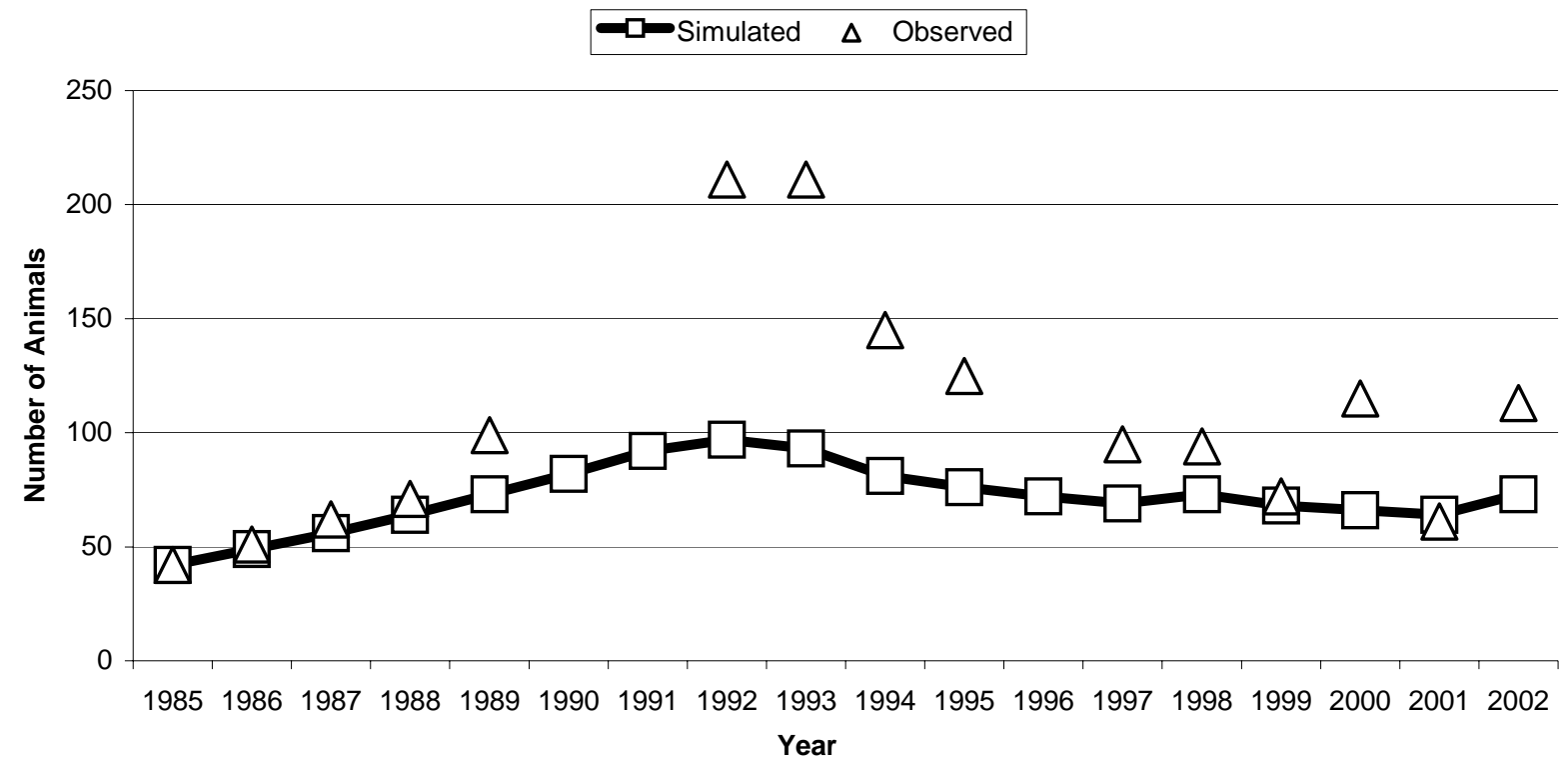

B. Sex Ratio - Simulation 1

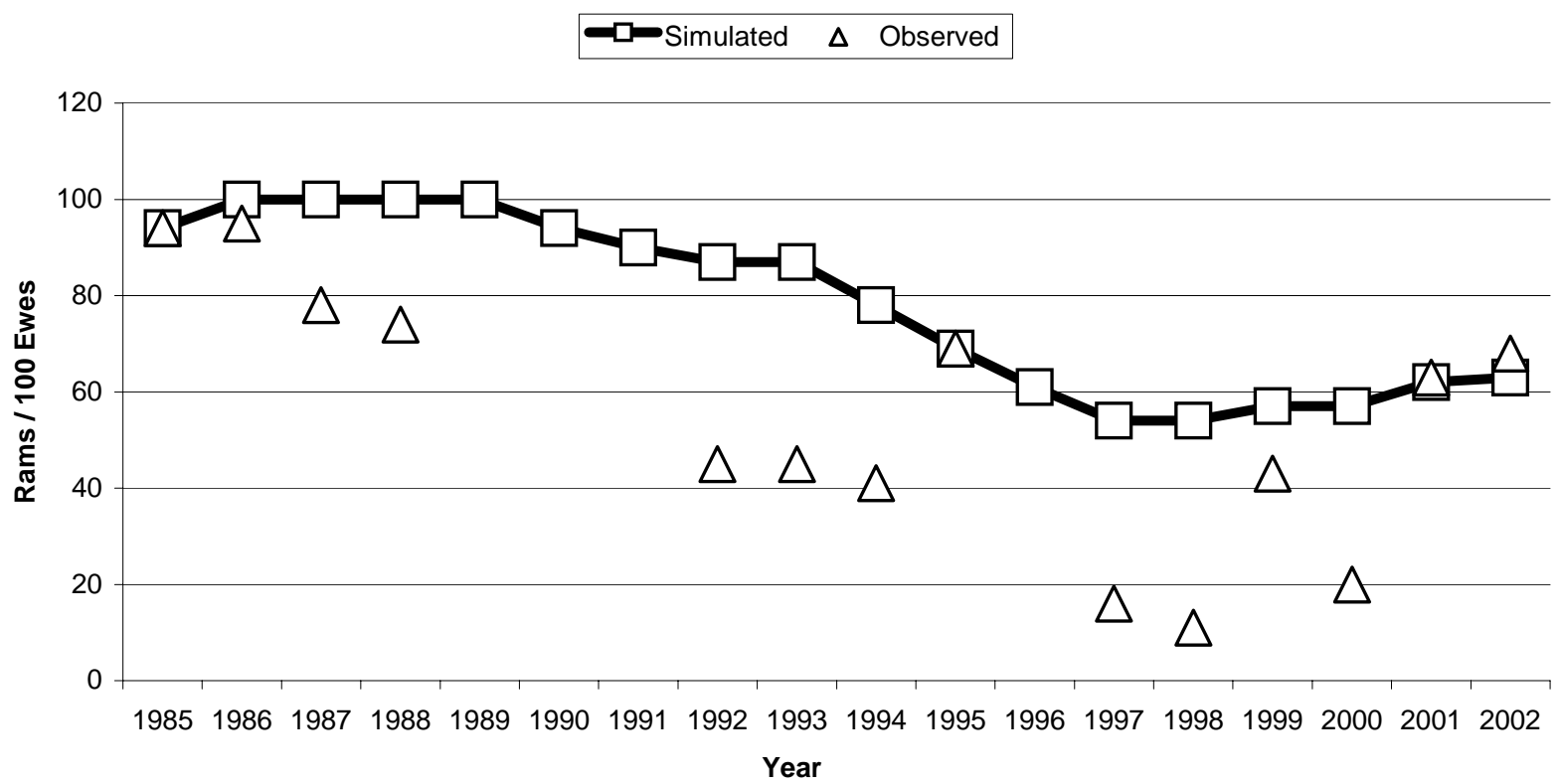

Figure 1. Results of Simulation 1. 


\section{Simulation 2}

The second simulation focused on the period from 1985 to 1992 and asked the question "If reproductive rates were maximum in the period, could the population have grown to 211 animals, and, if so, what natural mortality rates could have been sustained?" Maximum reproduction was defined as follows: 1) all ewes 3 years of age or older give birth, and 2) based on pooled data from McCarty and Miller (1998), 21\% of age 2 ewes give birth. With these reproductive rates, the simulated population grew to about 204 animals in 1992 when the postseason natural mortality rates were set to $5 \%$ on rams and $4 \%$ on ewes (Figure 2A). The slight differential in survival between rams and ewes was introduced in an attempt to move the simulated sex ratios toward the reported, but had little effect (Figure 2B). 


\section{A. Population Size - Simulation 2}

$\square$ Simulated $\Delta$ Observed

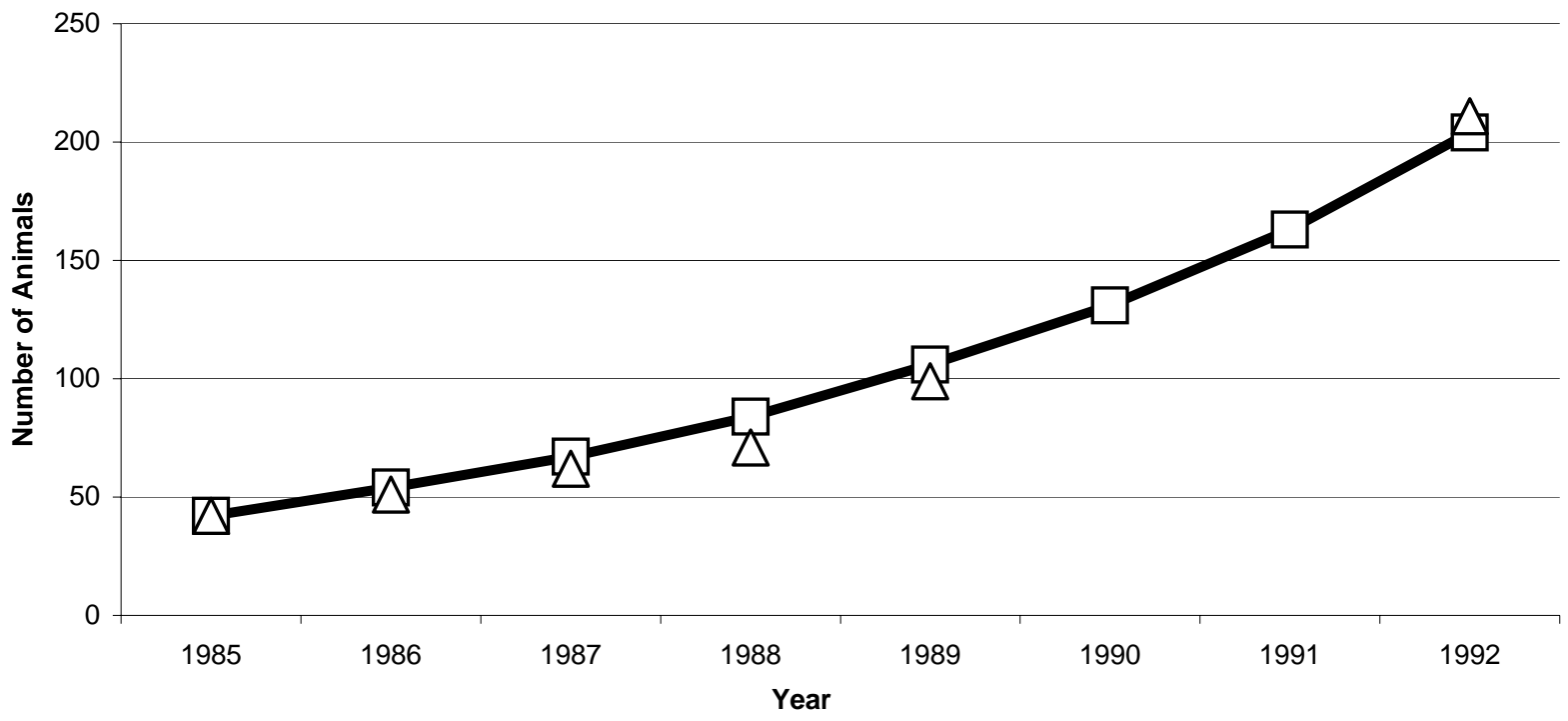

B. Sex Ratio - Simulation 2

$\boldsymbol{\square}-$ Simulated $\Delta$ Observed

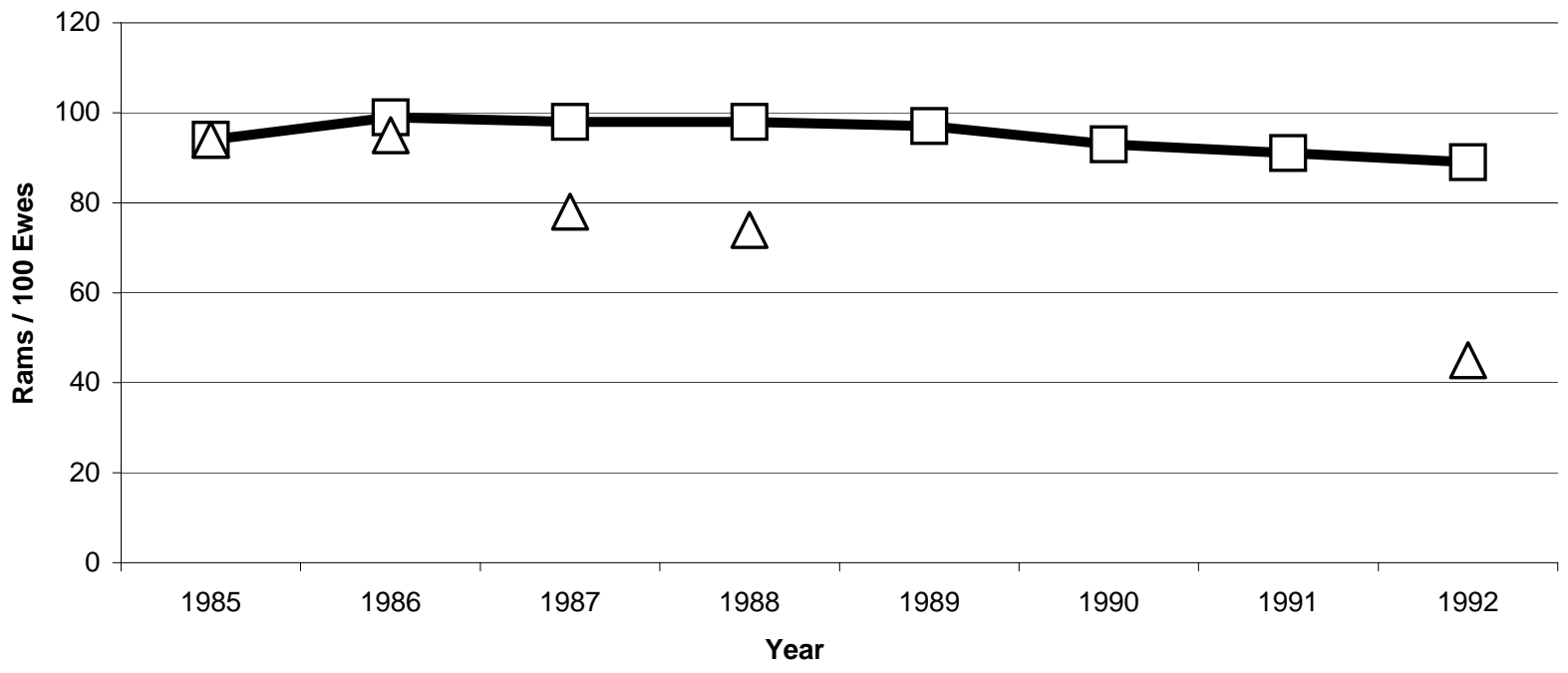

Figure 2. Results of Simulation 2. 


\section{Simulation 3}

The third simulation focused on the same time period and asked a similar question: "If reproductive rates were as recorded, could the population have grown to 211 animals, and, if so, what natural mortality rates could have been sustained?" The simulated results shown in Figure 3 were generated using the reported reproductive rates and postseason natural mortality rates of $1 \%$ on rams and $0.8 \%$ on ewes. Under these conditions the simulated population grew to 196 animals in 1992 (Figure 3A). Sex ratios, however, remained substantially higher than the reported values (Figure 3B) but not markedly different from Simulation 2.

The purpose of Simulations 2 and 3 was simply to demonstrate that the Bighorn Canyon sheep population could have grown as reported under reasonable assumptions about survival and reproduction. Based on these simulations, it appears that such growth could have occurred, but only under very good conditions (i.e., high reproduction and low mortality). It is, of course, impossible to know which set of simulated conditions is closest to what actually occurred. However, given that both produced similar results, it is probably unimportant to make any further distinction. The conditions in Simulation 3 produced results that are plausible and have the advantage of using reported reproductive rates. Simulation 3 was therefore chosen as the basis for continuing the analysis of historical population behavior. 


\section{A. Population Size - Simulation 3}

$\square-$ Simulated $\Delta$ Observed

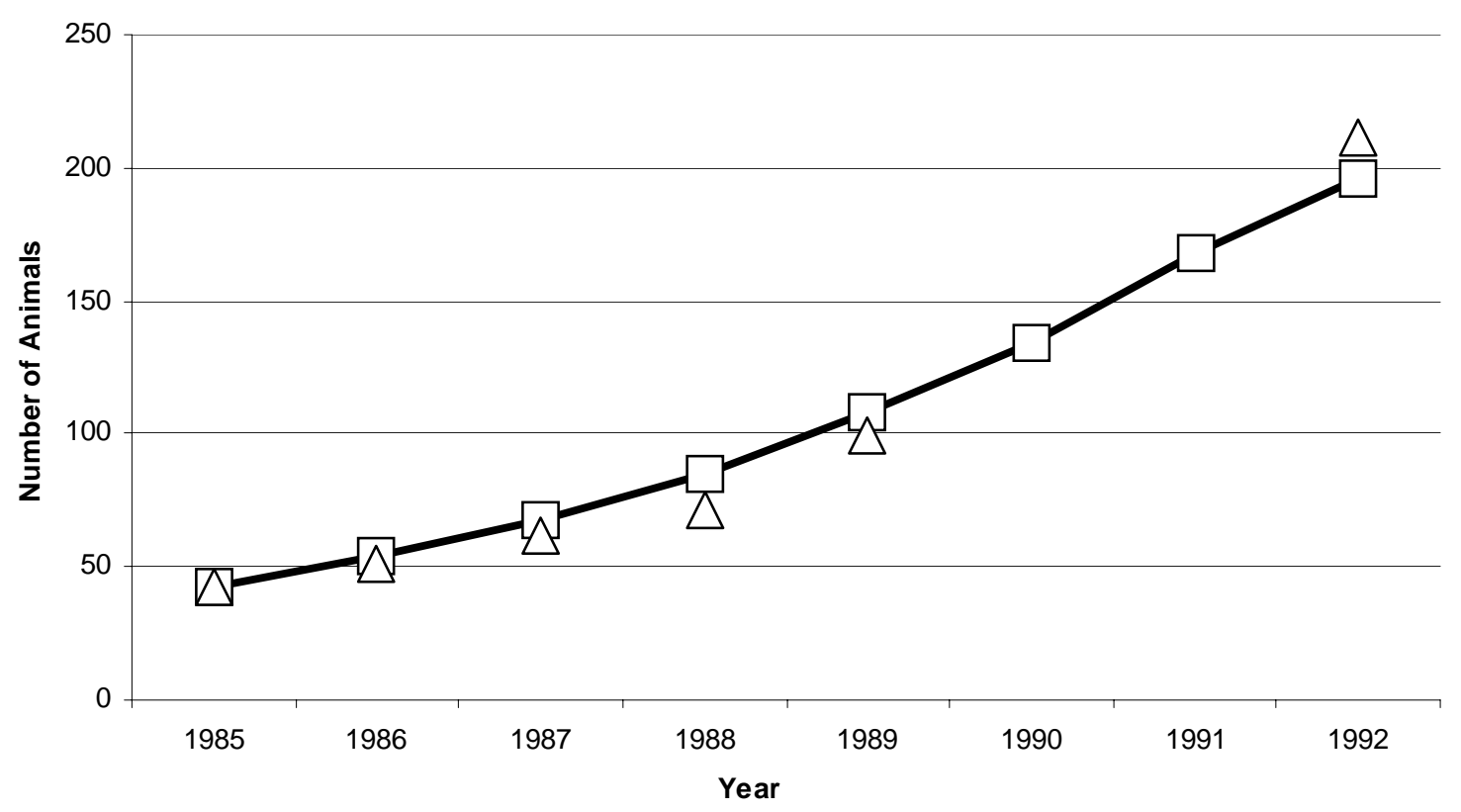

B. Sex Ratio - Simulation 3

$\square-$ Simulated $\Delta$ Observed

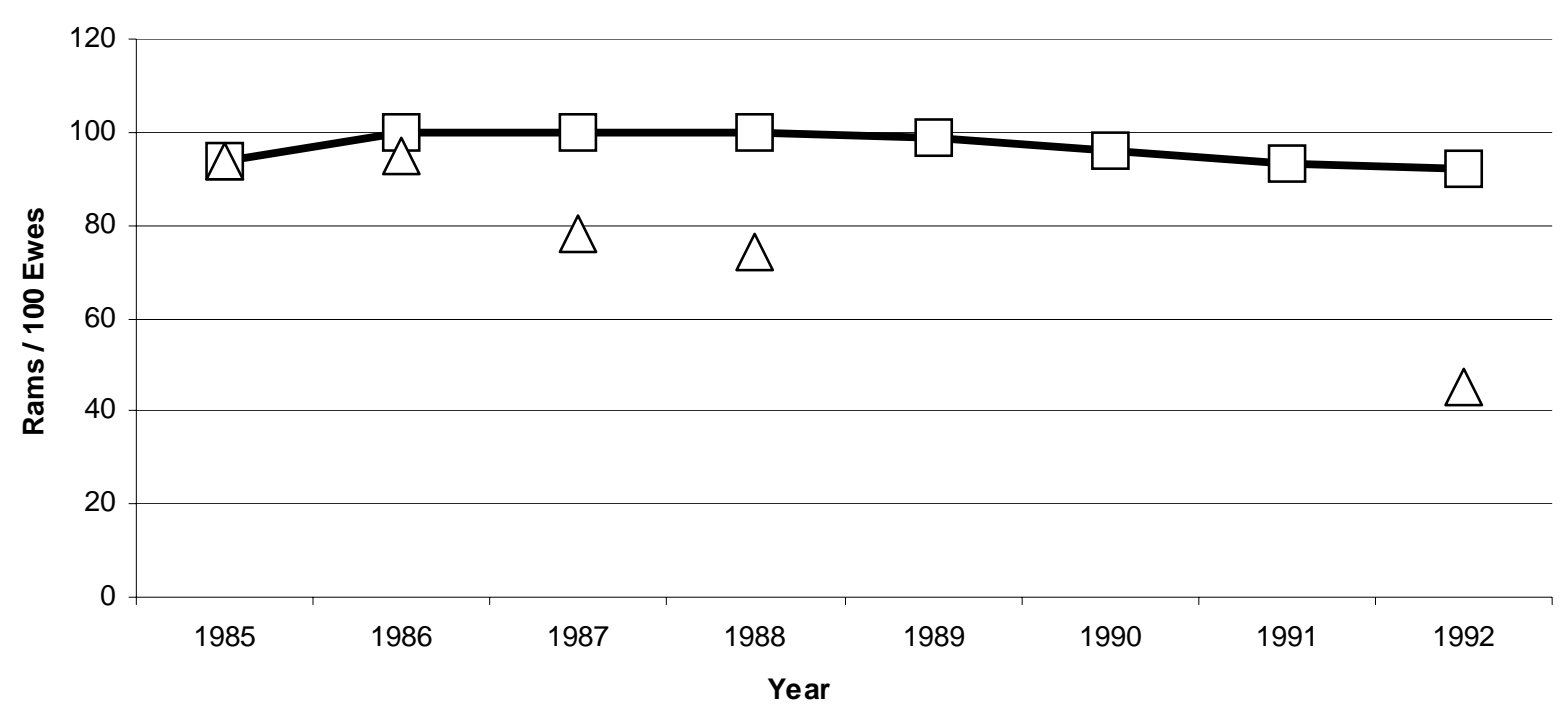

Figure 3. Results of Simulation 3. 


\section{Simulation 4}

Simulation 4 used reported reproductive rates and continued annual mortality rates of $1 \%$ on rams and $0.8 \%$ on ewes through 2002. Under these conditions, the simulated population grew to about 424 animals in 2002 (about 4 times the reported population size in that year; Figure 4A), and sex ratios remained higher than reported throughout the simulation (Figure 4B). Thus, it seems clear that the lower reproductive rates reported for the midand late 1990s (Table 5) could not by themselves have caused the reported population decline that occurred between 1993 and 1997. 


\section{A. Population Size - Simulation 4}

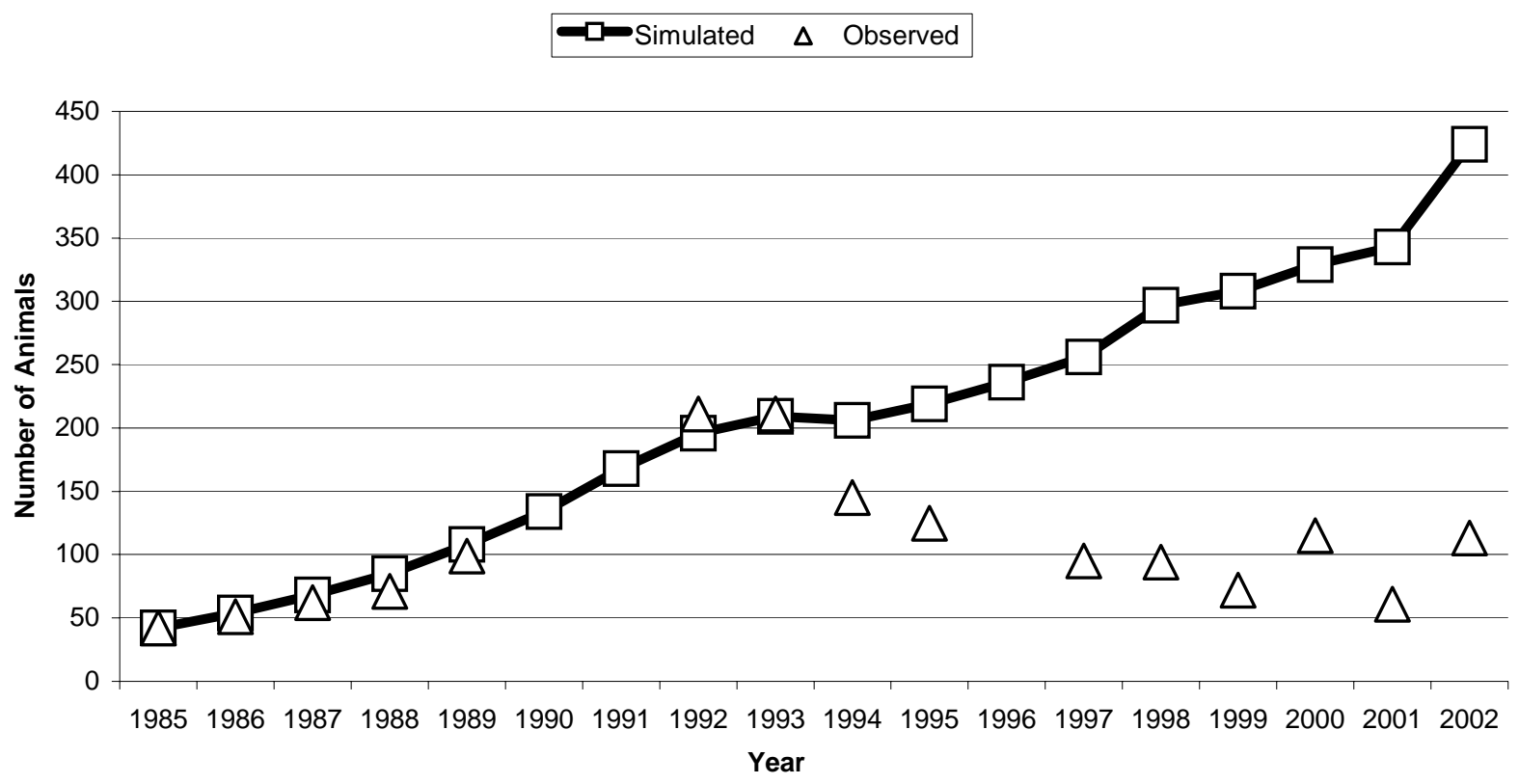

\section{B. Sex Ratio - Simulation 4}

$\square$ Simulated $\Delta$ Observed

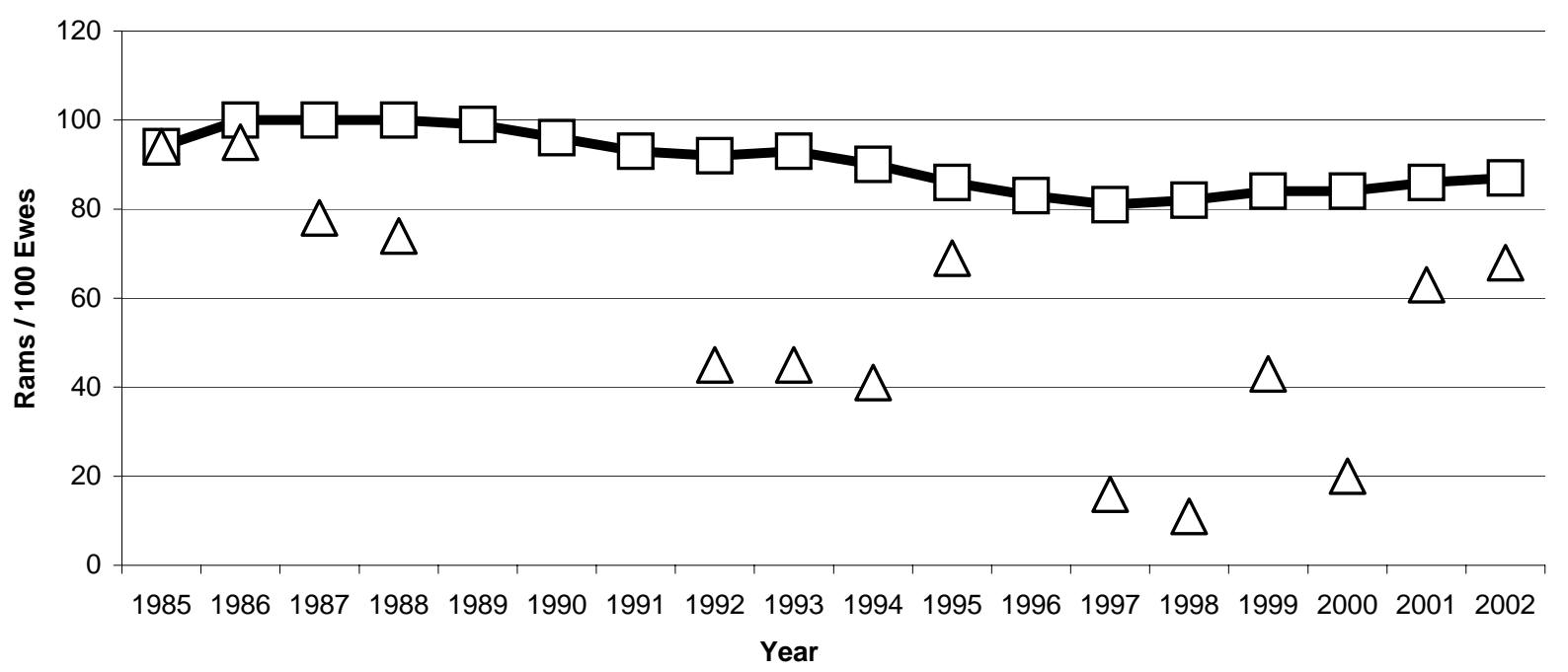

Figure 4. Results of Simulation 4. 


\section{Simulation 5}

Annual mortality rates for 1993-2002 were then adjusted (using the Mortality Severity Index parameter in POP-II) to produce the behavior shown in Figure 5. In order to replicate the reported population decline, mortality rates were set at 30\% for rams and 24\% for ewes from 1993 to 1995 (Figure 5A). Similarly, mortality rates of 10\% on rams and $8 \%$ on ewes from 1996 to 2002 produced a relatively stable population for the remainder of the simulation. Note that these rates for 1996 to 2002 are essentially the same as the survival rate calculated for all years (2000-2002) and both sexes in Table $10(90 \%)$. Note also that the introduced disparity in natural mortality between rams and ewes, in combination with harvest of 4 rams per year from 1994 to 1997 (Table 6), reduced the simulated sex ratio to between 50 and $60 \mathrm{rams} / 100$ ewes toward the end of the simulation (Figure 5B). 


\section{A. Population Size - Simulation 5}

$-\square$ Simulated $\Delta$ Observed

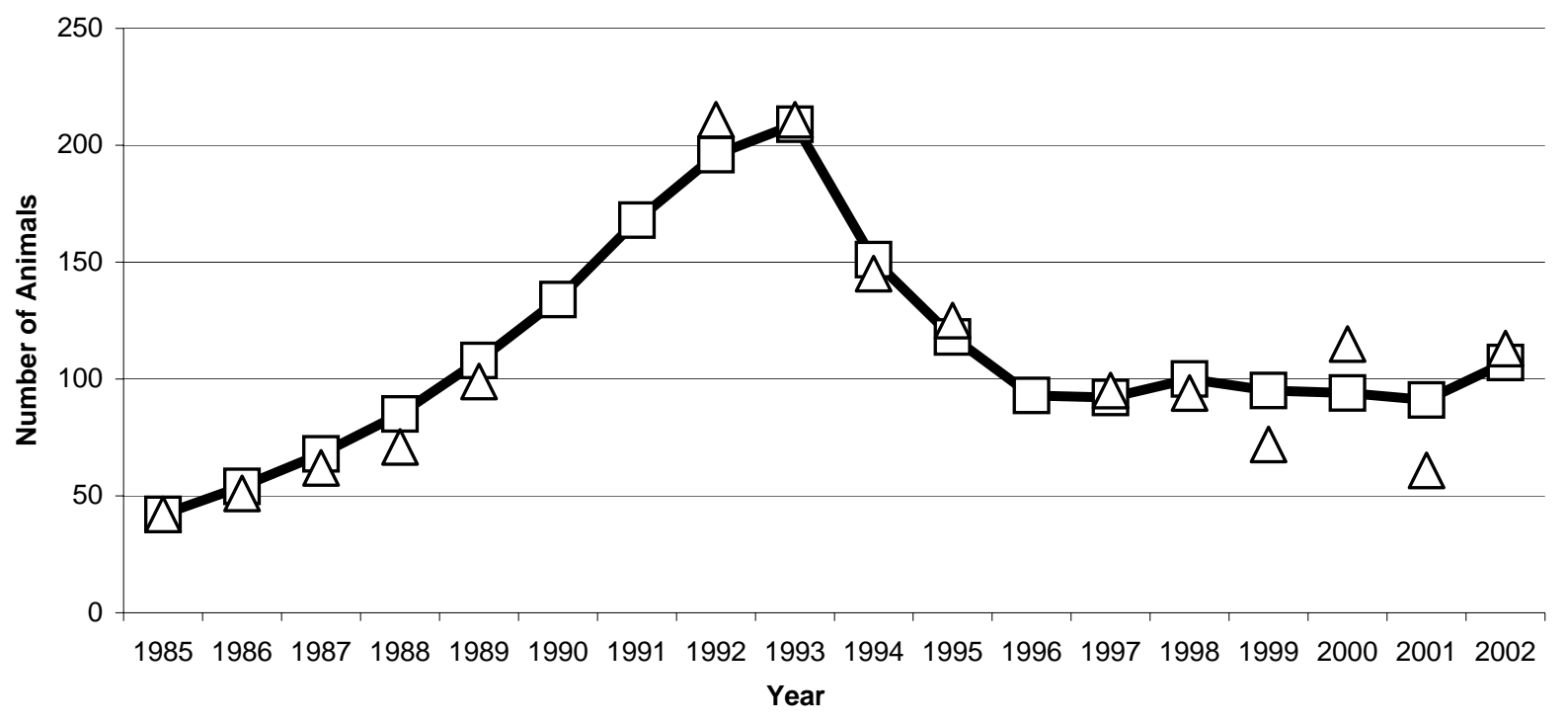

B. Sex Ratio - Simulation 5

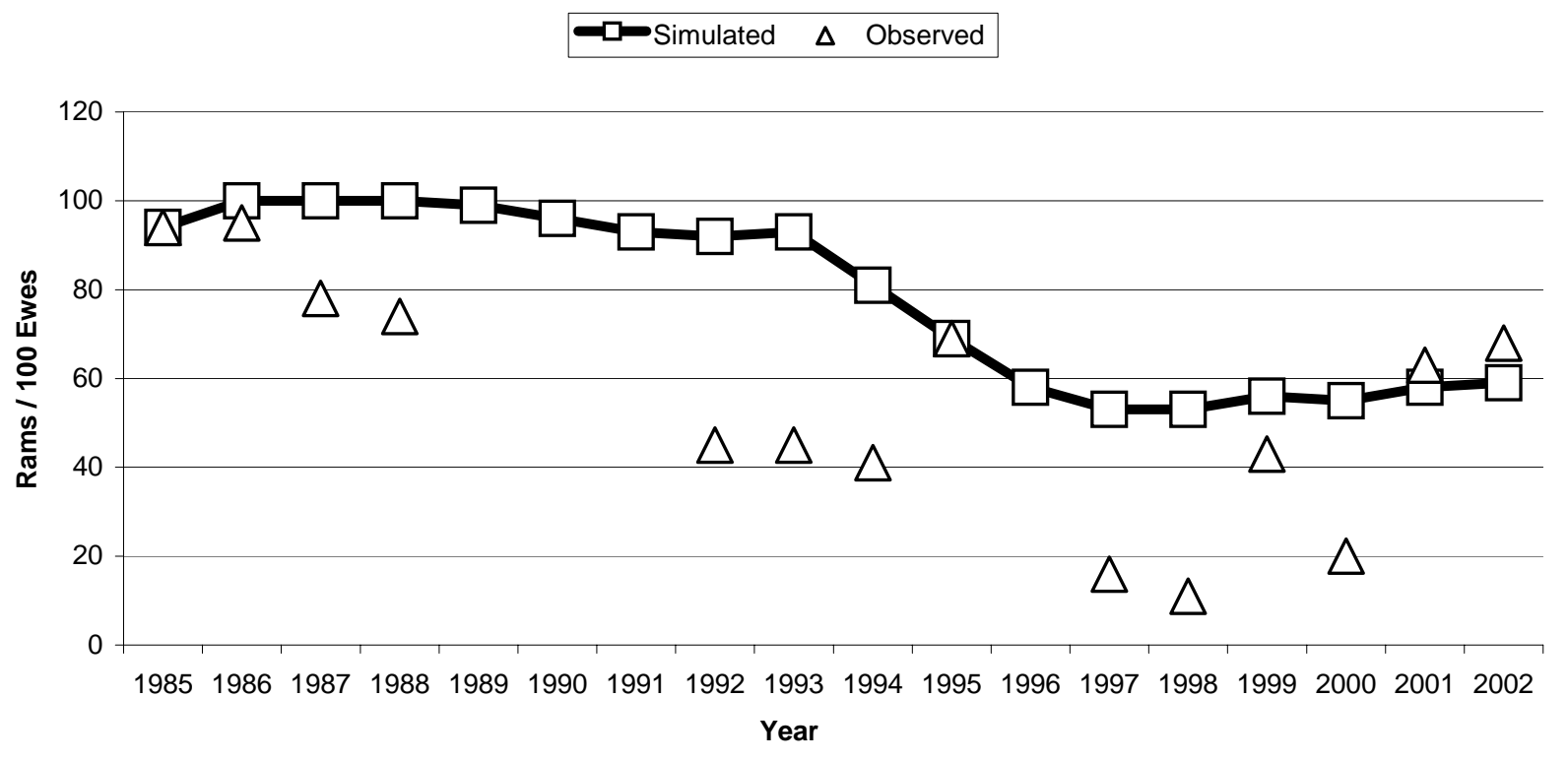

Figure 5. Results of Simulation 5. 


\section{Simulations 6-9}

The population parameters used in Simulation 5 produced plausible behavior as judged by comparisons with reported population sizes and sex ratios and were therefore used as the basis for exploring various future (15year) scenarios (Table 12). Natural mortality rates were maintained at the values used in Simulation 5 because they produce reasonable population behavior, are similar to the rates calculated for radio-collared animals in this study, and are comparable to rates reported elsewhere in the literature. Reproductive rates were chosen to represent the mid-range of those reported for the Bighorn Canyon herd, and harvest levels were selected to be representative of actual harvests in recent years.

Table 12. Population parameter values used in years 2003 through 2017 in Simulations 6-9.

\begin{tabular}{c|c|c|c|c}
\hline $\begin{array}{c}\text { Simulation and } \\
\text { figure number }\end{array}$ & $\begin{array}{c}\text { Ram natural mortality } \\
(\mathbf{\%})\end{array}$ & $\begin{array}{c}\text { Ewe natural mortality } \\
(\mathbf{\%})\end{array}$ & $\begin{array}{c}\text { Number of rams } \\
\text { harvested }\end{array}$ & $\begin{array}{c}\text { Reproduction } \\
\text { (lambs/100 ewes) }\end{array}$ \\
\hline 6 & 10 & 8 & 2 & 25 \\
7 & 10 & 8 & 4 & 25 \\
8 & 10 & 8 & 2 & 30 \\
9 & 10 & 8 & 4 & 30 \\
\hline
\end{tabular}

Under the conditions used in Simulation 6, the population stabilized at about 110 animals (Figure 6A) and the sex ratio was similarly stable at about $66 \mathrm{rams} / 100$ ewes (Figure 6B). In the final year of the simulation, there were about 16 rams in age class 6 or above (data not shown). Note that a reproductive rate of $25 \mathrm{lambs} / 100$ ewes has been achieved or exceeded historically in about $55 \%$ of the years for which there are reported data (see Figure 10). With this same reproductive rate and a harvest of 4 adult rams per year, the population stabilized at about 100 animals (Figure 7A). The sex ratio declined slowly throughout the simulation to about $45 \mathrm{rams} / 100$ ewes in the final year (Figure 7B). In this case, however, the oldest rams (4) in the final year were in age class 6. With an assumed reproductive rate of 30 lambs/100 ewes (historically achieved or exceeded about $50 \%$ of the time; see Figure 10) and a harvest of $2 \mathrm{rams} / \mathrm{year}$, the population grew slowly to about 175 animals in the final year (Figure 8A), and the sex ratio stabilized at about $73 \mathrm{rams} / 100$ ewes (Figure 8B). In the final year of Simulation 8, there were 22 rams in age class 6 or older. Increasing the harvest to 4 rams/year (with a reproductive rate of 30 lambs/100 ewes) resulted in a smaller ending population in Simulation 9 (Figure 9A) and a sex ratio of about 58 rams/100 ewes (Figure 9B). In the final year of Simulation 9, the oldest rams were in age class 9, and there were about 11 rams in age class 6 or older. 


\section{A. Population Size - Simulation 6}

$\boldsymbol{\square}-$ Simulated $\Delta$ Observed

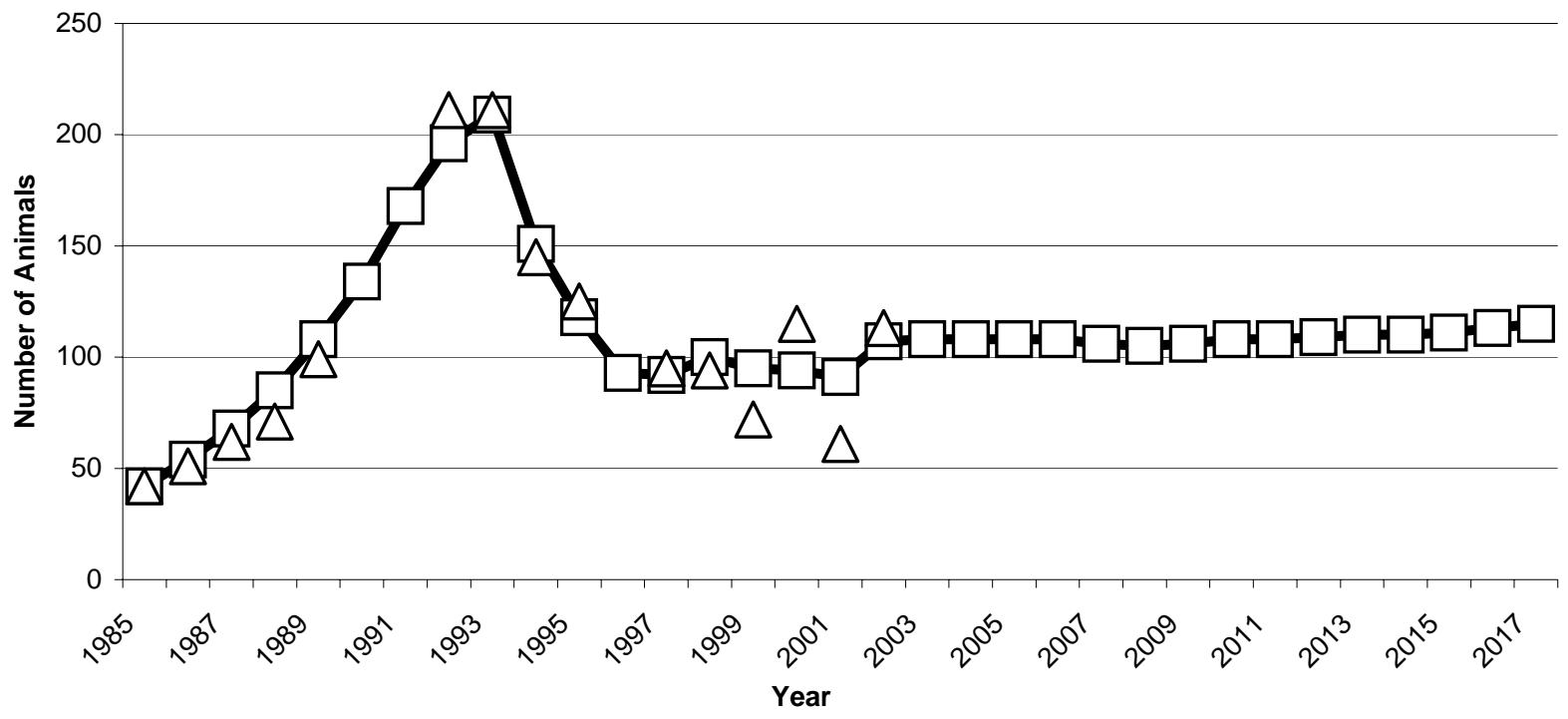

B. Sex Ratio - Simulation 6

$\boldsymbol{\square} \boldsymbol{D}$ Simulated $\Delta$ Observed

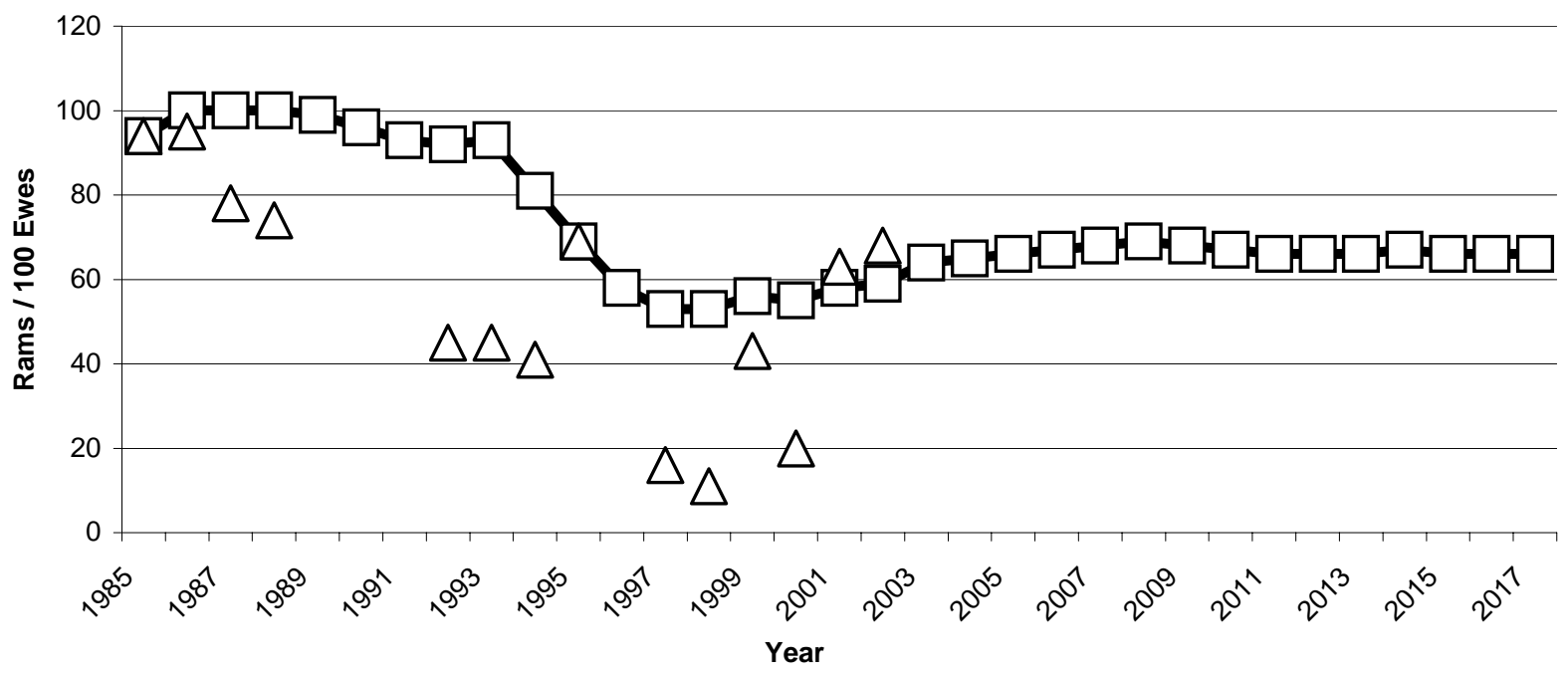

Figure 6. Results of Simulation 6. 


\section{A. Population Size - Simulation 7}

$\boldsymbol{\square} \boldsymbol{-}$ Simulated $\Delta$ Observed

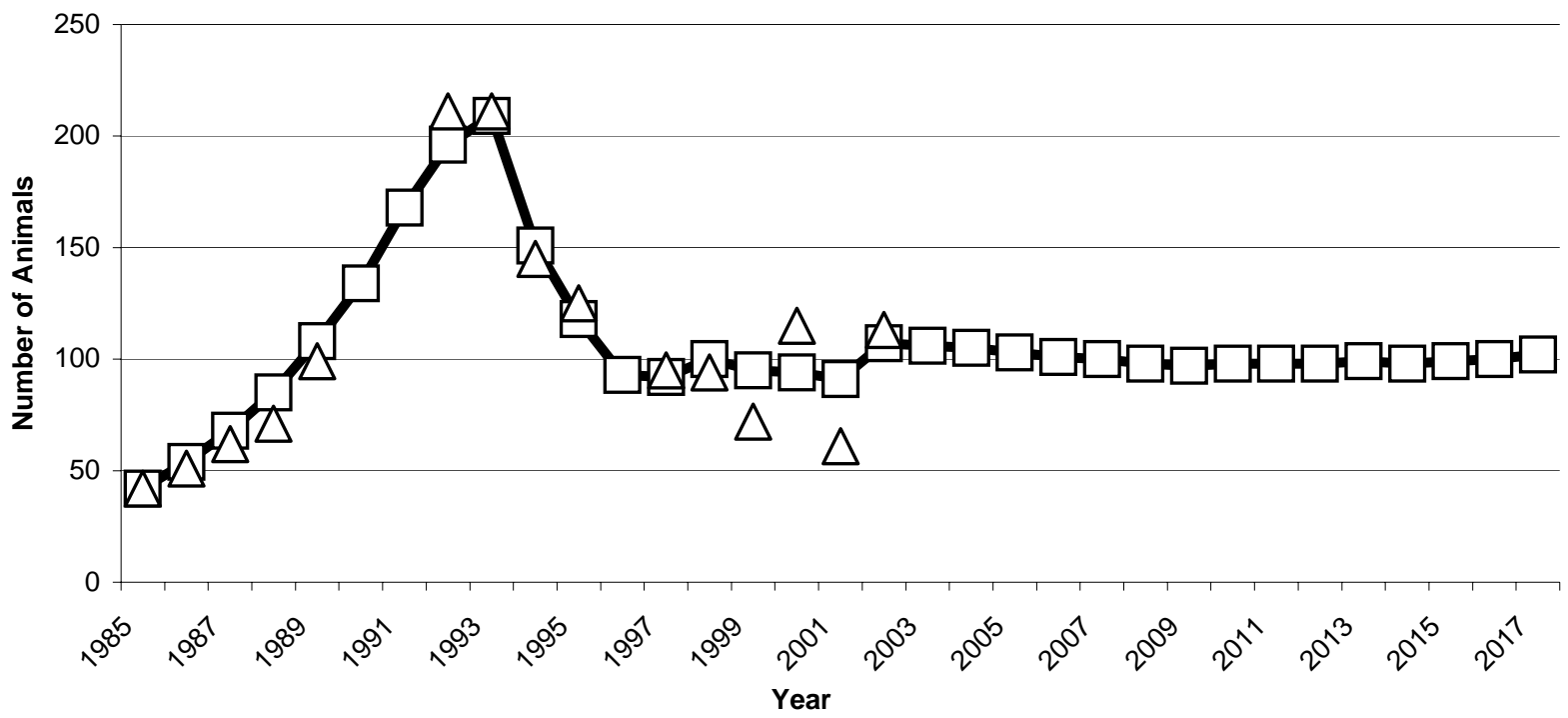

B. Sex Ratio - Simulation 7

$\boldsymbol{\square}$ Simulated $\Delta$ Observed

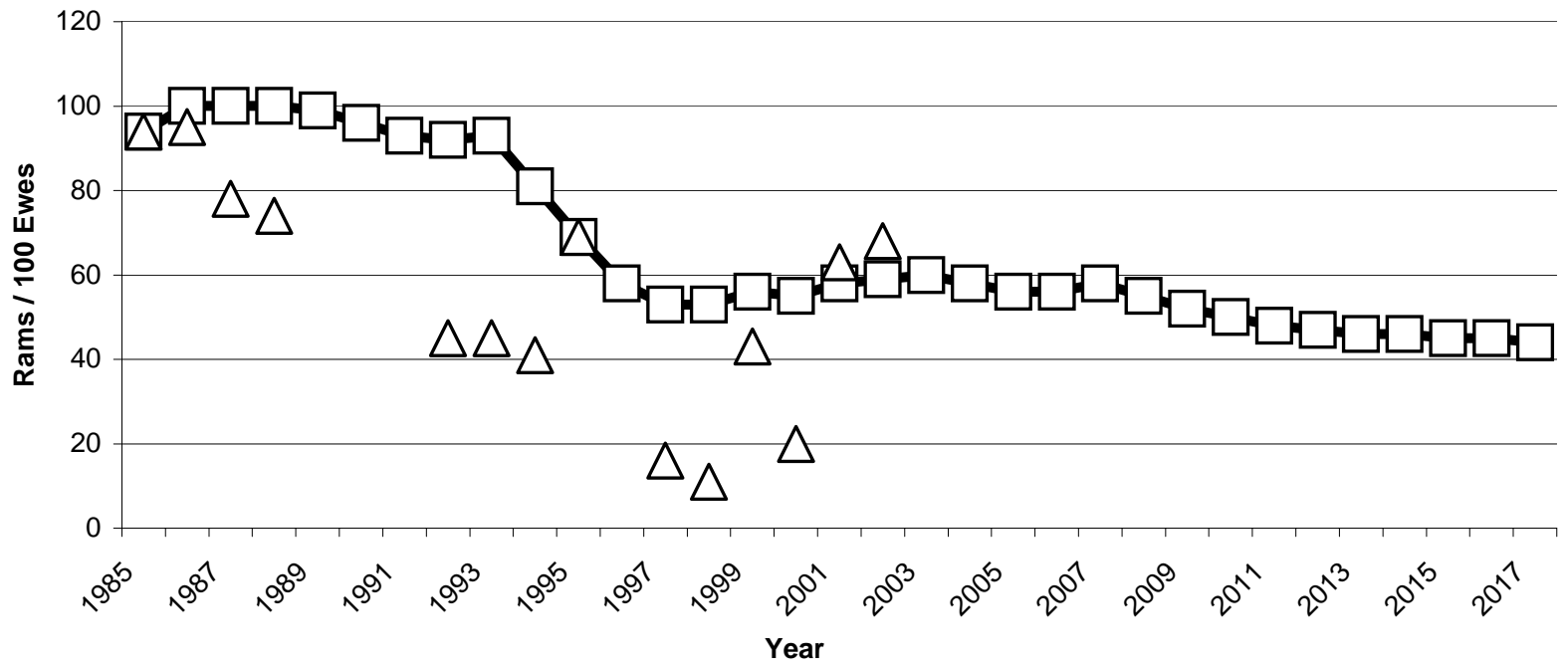

Figure 7. Results of Simulation 7. 


\section{A. Population Size - Simulation 8}

$\sim$ Simulated $\Delta$ Observed

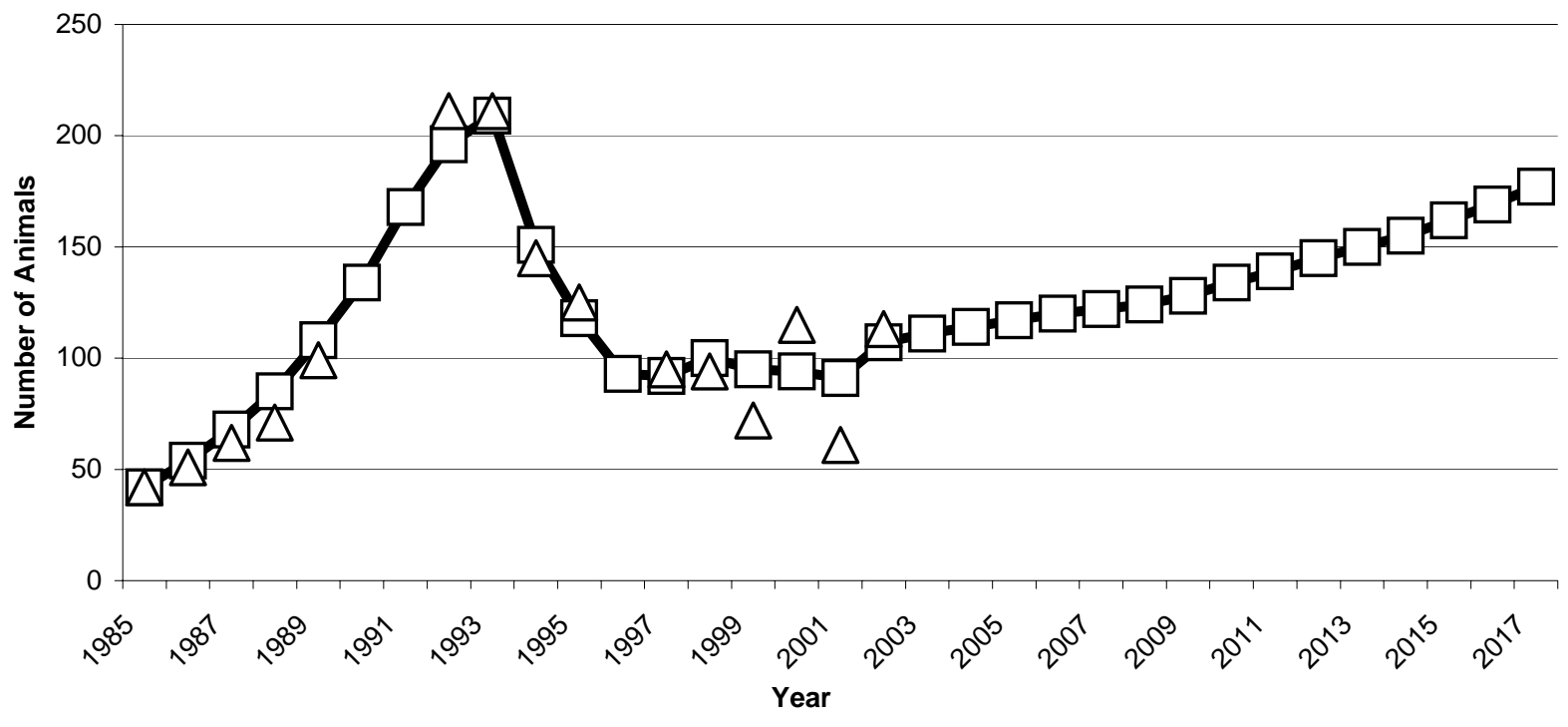

B. Sex Ratio - Simulation 8

$\square$ Simulated $\Delta$ Observed

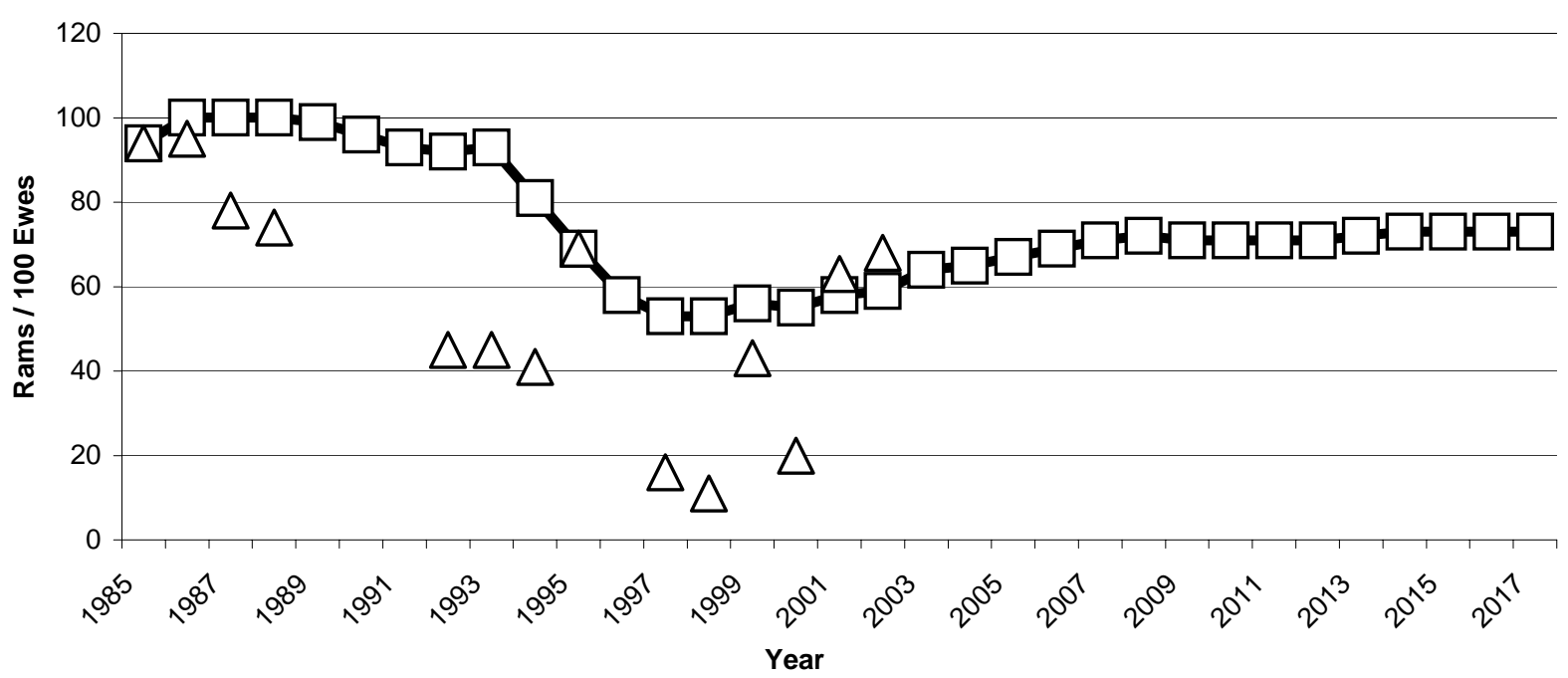

Figure 8. Results of Simulation 8. 


\section{A. Population Size - Simulation 9}

$\sim$ Simulated $\Delta$ Observed

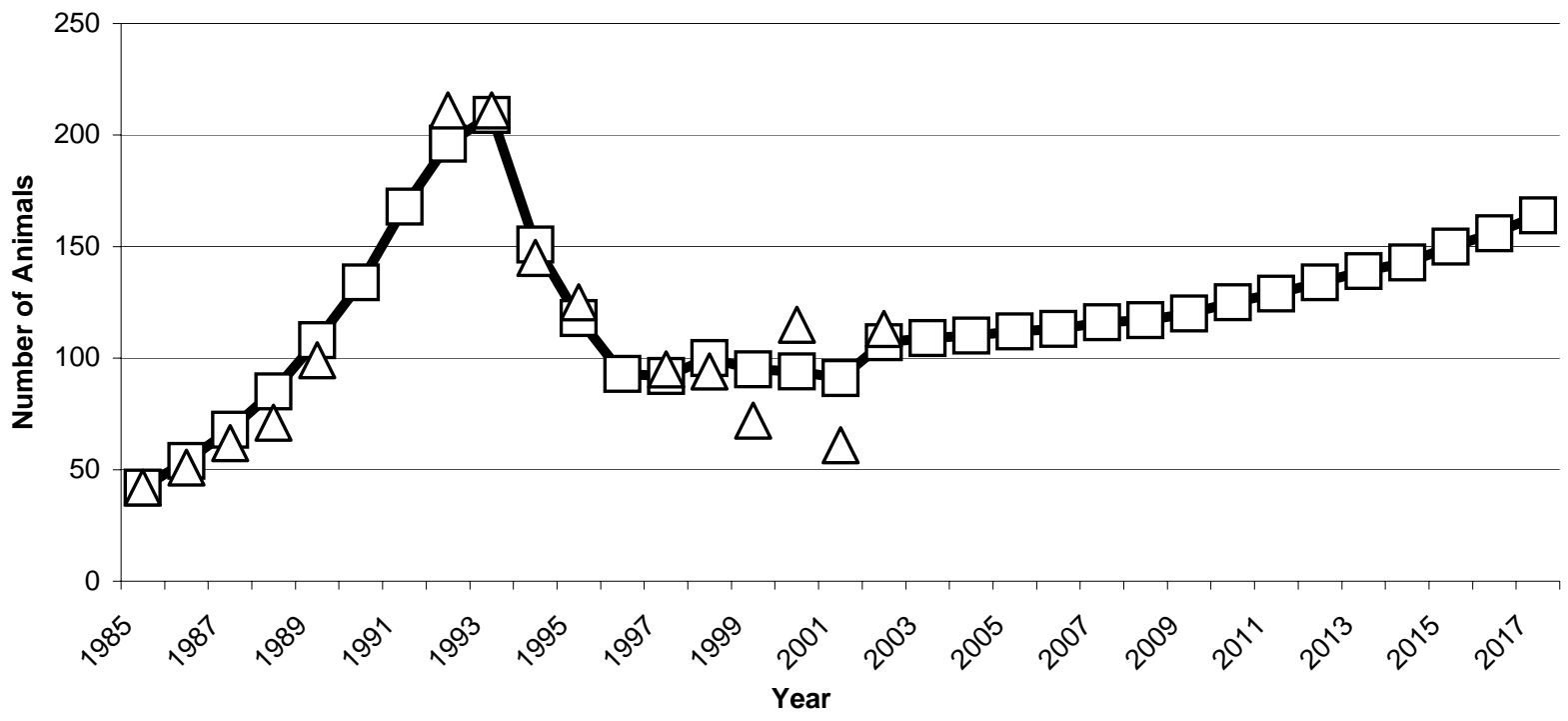

B. Sex Ratio - Simulation 9

$\boldsymbol{\square}$ Simulated $\Delta$ Observed

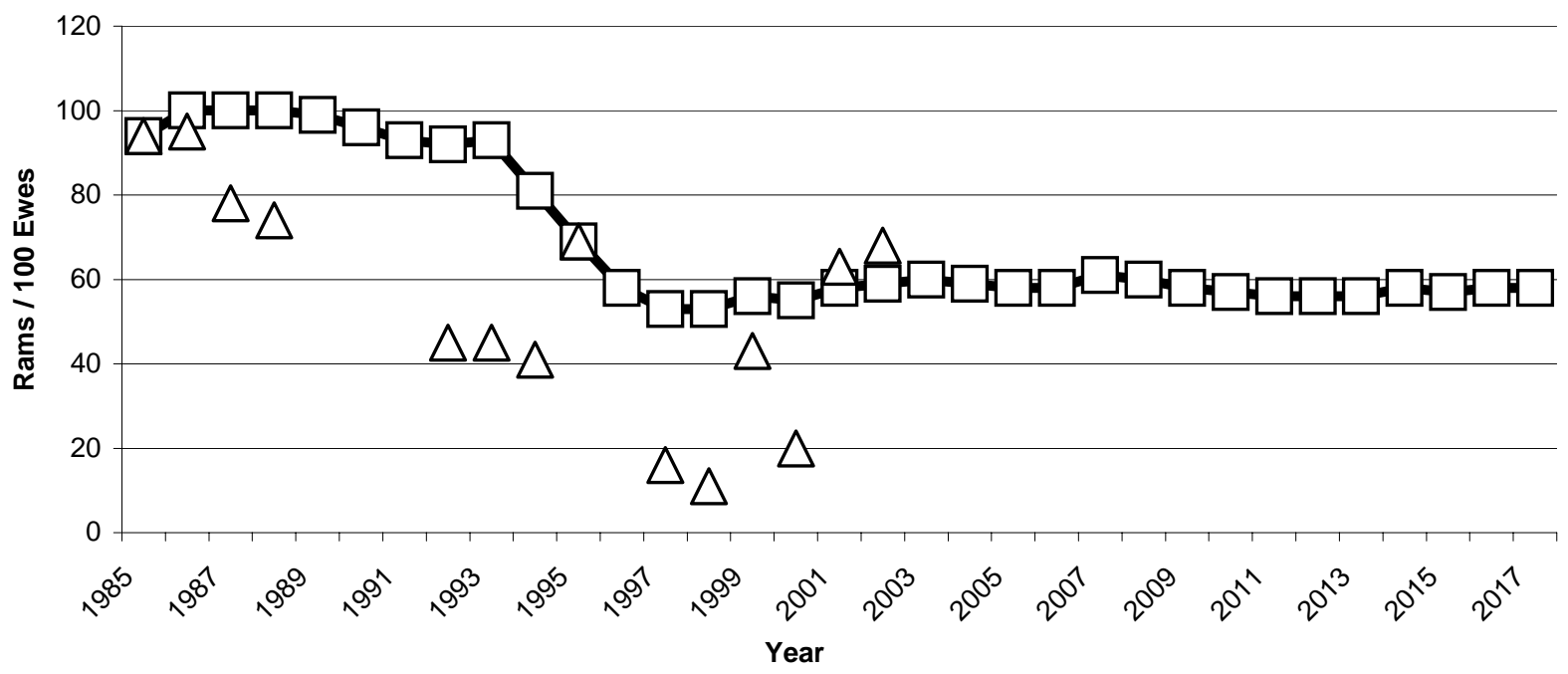

Figure 9. Results of Simulation 9. 


\section{Monte Carlo Simulations}

Deterministic simulations of populations as small as the Bighorn Canyon sheep herd must be interpreted with care. Consider two hypothetical populations, one with 10 animals and one with 1,000, each having an annual survival rate of $90 \%$. In either herd, each animal has a $10 \%$ chance of dying in a particular year. If there are only 10 animals, the probability of the entire herd dying in a given year is $(0.1)^{10}$, whereas the probability of all 1,000 animals dying in the larger herd is $(0.1)^{1000}$. Thus, uncertainty, which is ignored in deterministic simulations, is inherently of greater concern when dealing with small populations. Monte Carlo (stochastic) models such as POP-III are one method for attempting to quantify such uncertainty.

The basic structure of POP-III is similar to that of POP-II. Simulations begin with an initial population, subtract animals due to natural mortality and harvest, add animals due to reproduction, and repeat the process for a specified number of years. However, POP-III differs in several ways. First, it has a simpler representation of the age and sex structure of the population, using only subadults (young of the year, which are assumed to be distributed equally between the sexes), adult males, and adult females. Second, harvest is specified as a rate, rather than a number of animals to be harvested (or conversely, a number to be left in the population). And third, in POP-III model parameters are specified as statistical distributions (normal, uniform, or cumulative) rather than deterministic (fixed) values, although fixed values can also be used by specifying only a single value for the uniform distribution. These distributions are then sampled to provide the exact values used in any iteration. Multiple runs produce output in the form of frequency distributions of resulting population sizes and sex ratios.

POP-III was used to simulate the behavior of the Bighorn Canyon sheep herd using the parameter values and distributions shown in Table 13. As in the POP-II simulations, all natural mortality was assumed to occur in the postharvest period. All preharvest survival rates were therefore set to $100 \%$. Harvest was limited to adult males at a rate of 5\% (or 95\% survival). In a population of about 120 animals, with a sex ratio of 60 rams/100 ewes and an age ratio of 50 lambs/100 ewes, a 5\% harvest removes approximately 2 adult males annually. Postseason mortality rates (assumed to be equal for all age and sex classes) were specified as a normal distribution with mean and standard deviation calculated from the annual rates (only 3 years) estimated in Program MARK. Reproduction was specified as a cumulative frequency distribution (Figure 10) derived from the annual values used in POP-II (Table 5). Finally, a fixed initial age and sex structure was taken from Simulation 5 (above) at the end of 2002. Ten sets of 100 trials were run under these conditions, with each trial lasting 15 years.

Table 13. Population parameters used in Monte Carlo simulations.

\begin{tabular}{ll}
\hline \multicolumn{1}{c}{ Population parameter } & \multicolumn{1}{c}{ Implementation } \\
\hline Preharvest subadult survival & Fixed at $100 \%$ \\
Preharvest adult male survival & Fixed at $100 \%$ \\
Preharvest adult female survival & Fixed at $100 \%$ \\
Subadult harvest survival & Fixed at $100 \%$ \\
Adult male harvest survival & Fixed at $95 \%$ \\
Adult female harvest survival & Fixed at $100 \%$ \\
Postharvest subabult survival & Normal distribution with mean $=90.3$ and standard deviation $=3.56$ \\
Postharvest adult male survival & Normal distribution with mean $=90.3$ and standard deviation $=3.56$ \\
Postharvest adult female survival & Normal distribution with mean $=90.3$ and standard deviation $=3.56$ \\
Reproductive rate & Cumulative distribution as in Figure 10 \\
Initial number of subadults & Fixed at 27 \\
Initial number of adult males & Fixed at 32 \\
Initial number of adult females & Fixed at 54 \\
\hline
\end{tabular}

At the end of 15 years, the average simulated population for the 1000 trials was 179 animals and was 170 animals or larger in 50\% of the trials (Figure 11). Minimum and maximum population sizes achieved were 51 and 569. Sex ratios at the end of the trials ranged from 43 to 93 rams/100 ewes and were $\geq 70$ rams/100 ewes in $50 \%$ of the cases. 
Lambing Rates - Probability of Exceedence

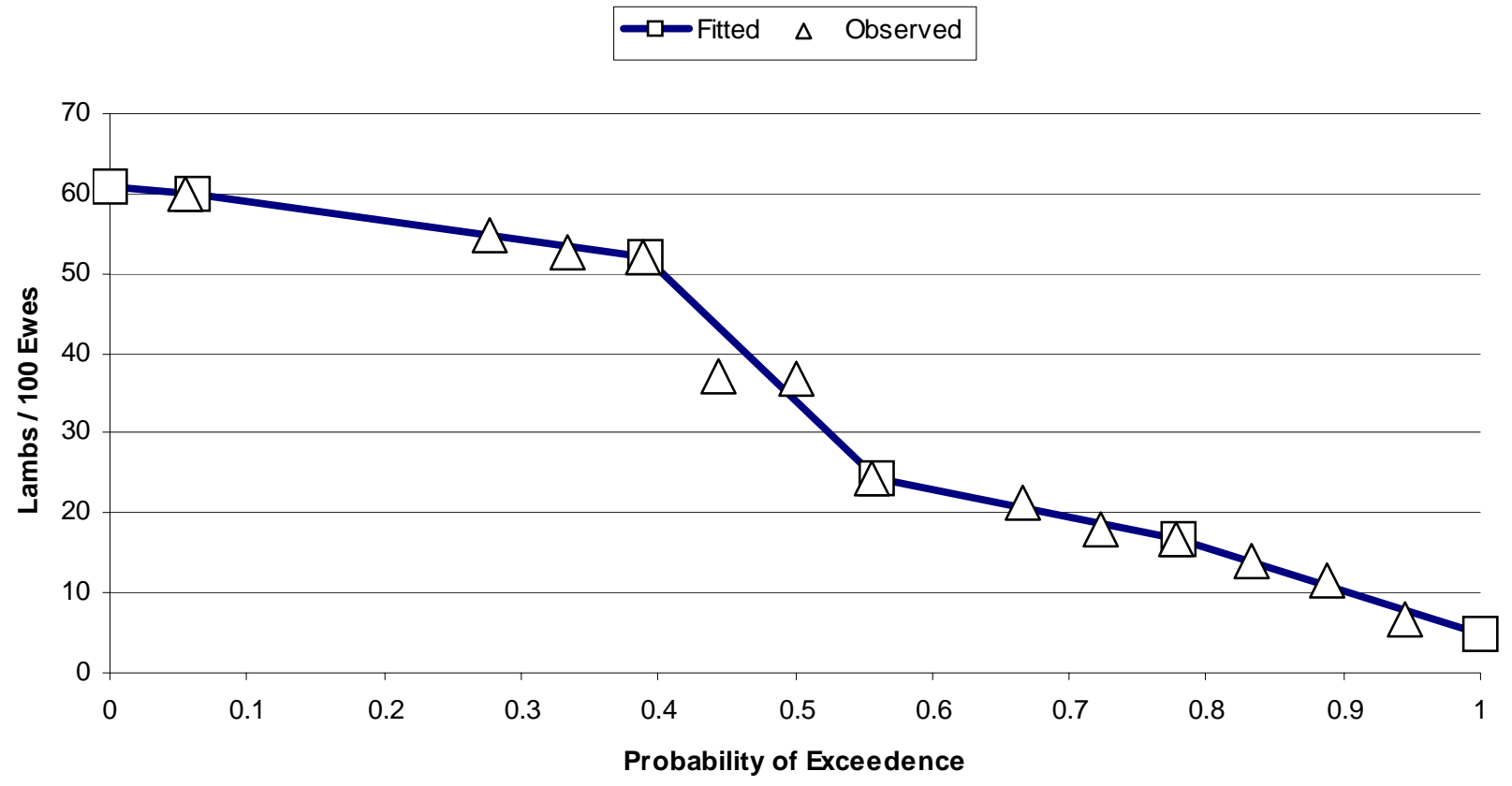

Figure 10. Cumulative frequency distribution for reproductive rates. 


\section{A. Population Size - Monte Carlo Simulations}

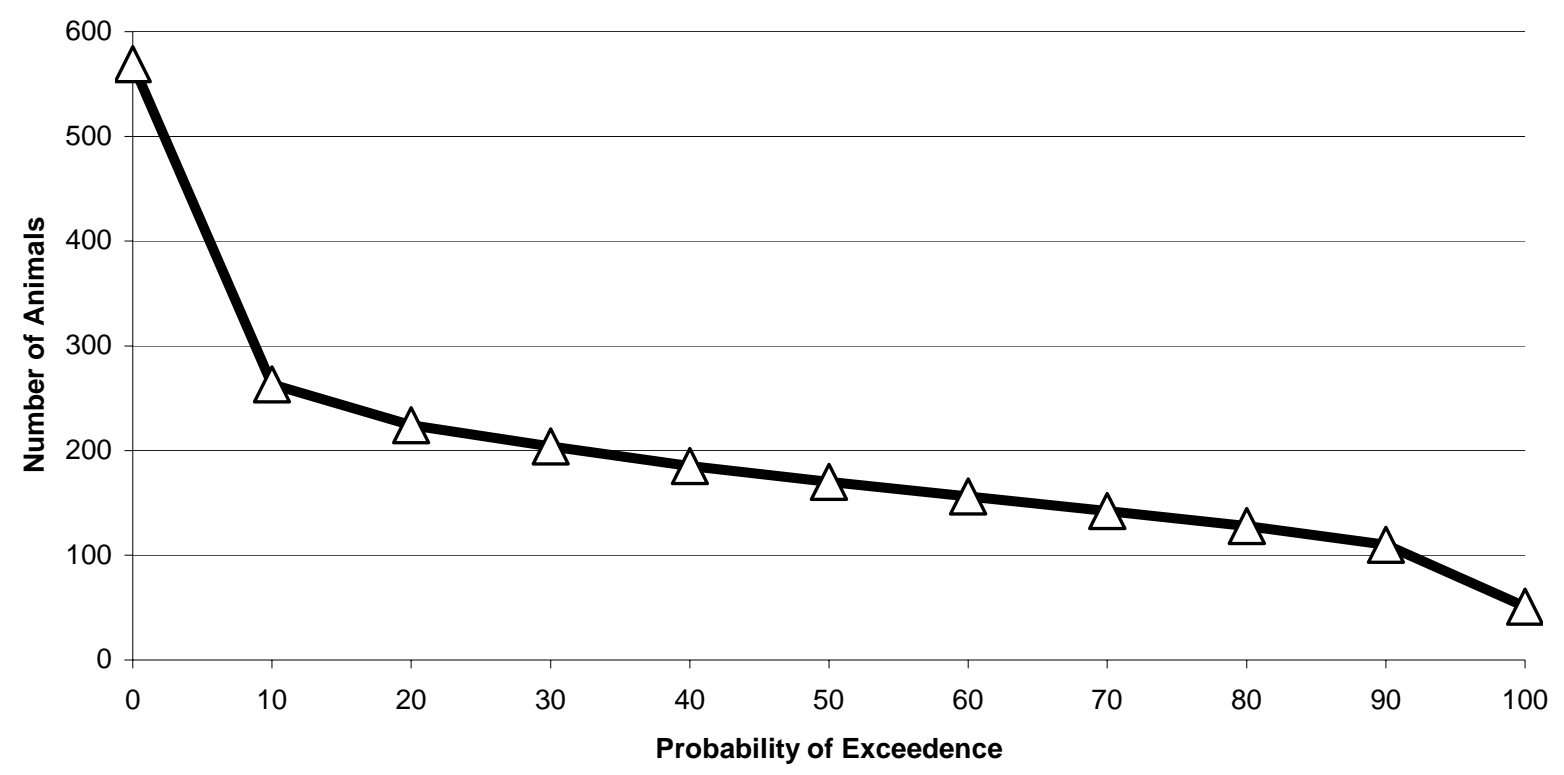

B. Sex Ratio - Monte Carlo Simulations

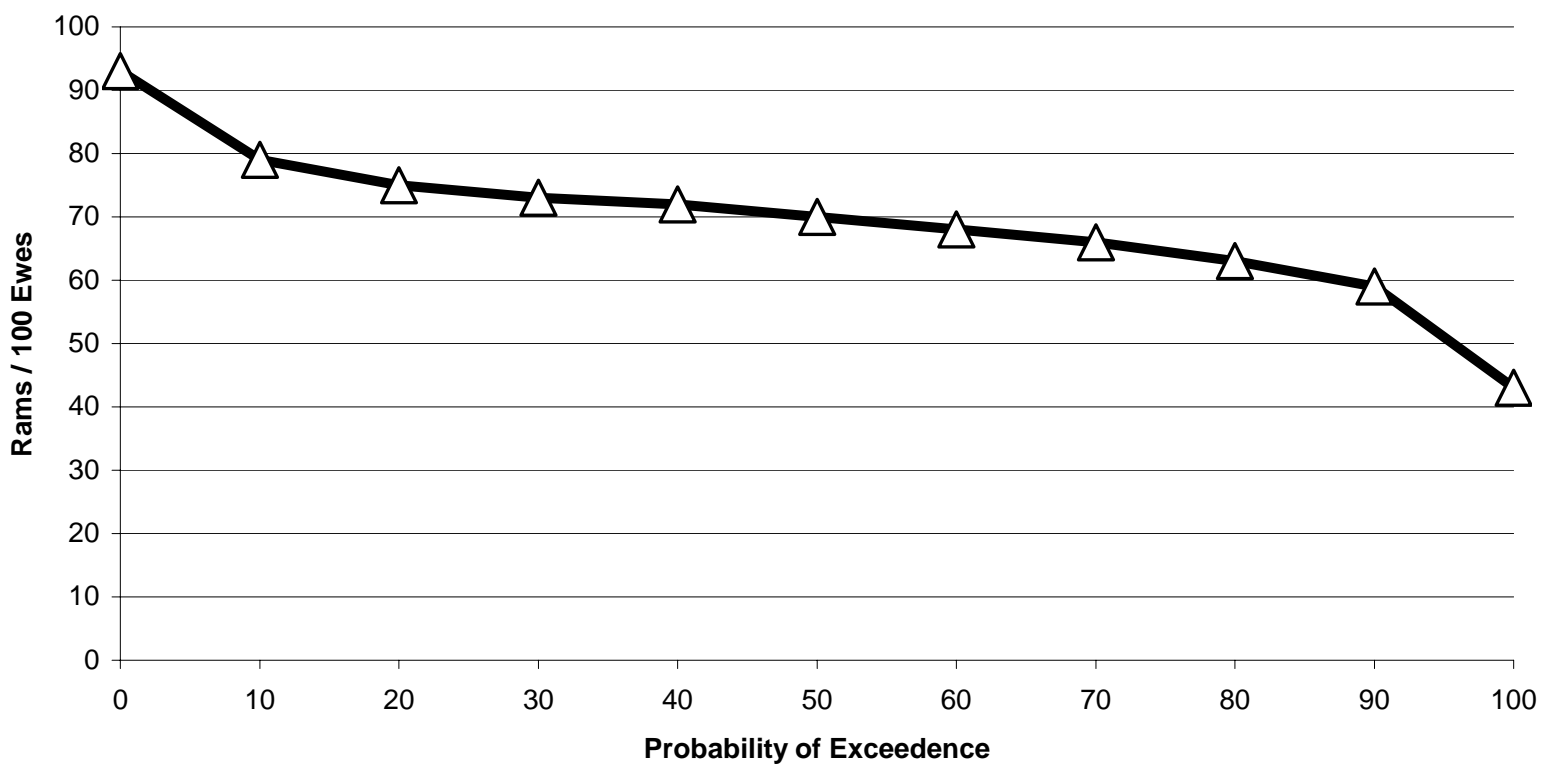

Figure 11. Results of Monte Carlo simulations. 


\section{Conclusions and Caveats}

1. Based on data from radio-collared animals, annual survival of adult animals was about $90 \%$ from February 2000 to January 2003. There is no evidence from these data of differential survival between rams and ewes or between ewes inhabiting on versus off the wild horse range. Sample sizes are small, however.

2. Despite the fact that there is no apparent difference in natural mortality between rams and ewes, sex ratios observed in the field are consistently less than $100 \mathrm{rams} / 100$ ewes, and simulations indicate that the historical ram harvest ( $\leq 4$ animals annually) is probably not sufficient to account for these reduced sex ratios. It therefore appears that either: a) sex ratios observed in the field are inaccurate (i.e., rams are being missed in the counts); b) fewer male lambs are born than females (although there appears to be no evidence for this in the Bighorn Canyon herd or others [McCarty and Miller, 1998]); or c) rams in fact suffer higher natural mortality than ewes, but this is not yet reflected in the small sample of radio-collared animals. Note, however, that sex ratios observed in the field in 2001 and 2002 are close to simulated values.

3. Continued monitoring of existing radio-collared animals would be useful in further examining potential differential mortality in ewes residing on versus off the wild horse range and between rams and ewes. Radiocollaring additional animals to increase sample size would also be highly desirable.

4. From 2000 through 2002, the pregnancy rate of adult ewes was $73 \%$ and the lambing rate was $72 \%$. Based on data from these three years, there is no evidence of differential pregnancy or lambing rates between years or between ewes residing on versus off the wild horse range.

5. Coates and Schemnitz (1989) reported a population of about 42 animals in 1985, and Kissell (1996) reported about 211 animals in 1992. The exponential growth rate implied by these two numbers $(r=0.23)$ is within the range reported by McCarty and Miller (1998) for introduced herds in Colorado; however, to achieve growth at this rate, reproduction must be quite high and mortality quite low.

6. The population decline reported by Kissell (1996) between 1993 and 1995 or 1996 cannot be accounted for by the observed decrease in reproduction or the known harvest. Natural mortality must have increased during this period if the population declined as much as reported.

7. In simulations, the period of relative population stability between 1996 and 2002 is consistent with reported reproductive rates and fitted natural mortality rates of about $10 \%$ on rams and $8 \%$ on ewes. These values are also very similar to mortality rates reported for radio-collared animals from 2000 to 2003.

8. Based on 15 -year modeling projections, assuming annual natural mortality rates of $10 \%$ on rams and $8 \%$ on ewes and reproduction of 25 lambs/100 ewes (as measured in postseason counts --postseason age ratios of $\geq 25$ lambs/100 ewes have been recorded in about $55 \%$ of the years since 1985), the population should be able to support a harvest of 2 rams/year, as long as the population remains stable (i.e., mortality does not increase and reproductive rates do not decrease). With a harvest of 4 rams/year, however, legal rams (age class 6 and above) are eliminated from the population by the end of 15 years. If resource management goals include increasing the size of the herd, then a more conservative harvest $(<2)$ is appropriate.

9. Similar projections show that reproduction must be at a level of at least $30 \mathrm{lambs} / 100$ ewes (again, as measured in postseason counts) to support an annual harvest of 4 rams from age class 6 and above. Postseason age ratios of $\geq 30$ lambs/100 ewes were recorded in about $50 \%$ of the years since 1985 .

10. Deterministic simulation modeling of populations as small as the Bighorn Canyon sheep herd must be interpreted carefully, because deviations from average conditions in the field can have more drastic impacts than on larger populations. However, Monte Carlo simulations, which attempt to incorporate the effects of such deviations by using parameter distributions derived from historical data, resulted in a population $\geq 128$ animals in about $80 \%$ of the trials when the harvest rate was set at $5 \%$.

11. Nothing in the data analyses or simulations described above addresses the question of genetic viability of the herd, whatever its size.

12. The simulations described above all assume that reproductive rates are not limited by the number of breeding males in the population.

13. The simulations also do not directly address the question of whether higher harvest rates on older rams may depress survivorship in younger rams as suggested by Singer and Zeigenfuss (2002). 


\section{Literature Cited}

Berry, K.J., and Mielke, Jr., P.W., Jr., 2003, Permutation analysis of data with multiple binary category choices: Psychological Reports, no. 92, p. 91-98.

Coates, K.P., and Schemnitz, S.D., 1989, The bighorn sheep of Bighorn Canyon National Recreation Area and Pryor Mountain Wild Horse Range: Ecological relationships and management recommendations: Contract report for the National Park Service and Bureau of Land Management, Department of Fishery and Wildlife Sciences, New Mexico State University, Las Cruces, $47 \mathrm{p}$.

Kissell, R.E., Jr., 1996, Population dynamics, food habits, seasonal habitat use, and spatial relationships of bighorn sheep, mule deer, and feral horses in the Pryor Mountains, Montana/Wyoming: Ph.D. dissertation, University of Montana, Bozeman, $153 \mathrm{p}$.

McCarty, C.W., and Miller, M.W., 1998, Modeling the population dynamics of bighorn sheep: a synthesis of the literature: Special Report No. 73, Colorado Division of Wildlife, $35 \mathrm{p}$.

Mielke, P.W., Jr., and Berry, K.J., 2001, Permutation methods: a distance function approach: New York, Springer, 352 p.

Singer, F.J., Williams, E., Miller, M.W., and Zeigenfuss, L.C., 2000, Population growth, fecundity, and survivorship in recovering populations of bighorn sheep: Restoration Ecology, vol. 8, p. 75-84.

Singer, F.J., and Zeigenfuss, L.C., 2002, Influence of trophy hunting and horn size on mating behavior and survivorship of mountain sheep: Journal of Mammalogy, vol. 83, p. 682-698.

White, G.C., and Burnham, K.P., 1999, Program MARK: Survival estimation from populations of marked animals: Bird Study 46 Supplement, p. 20-138. 



\section{Vegetation Studies}

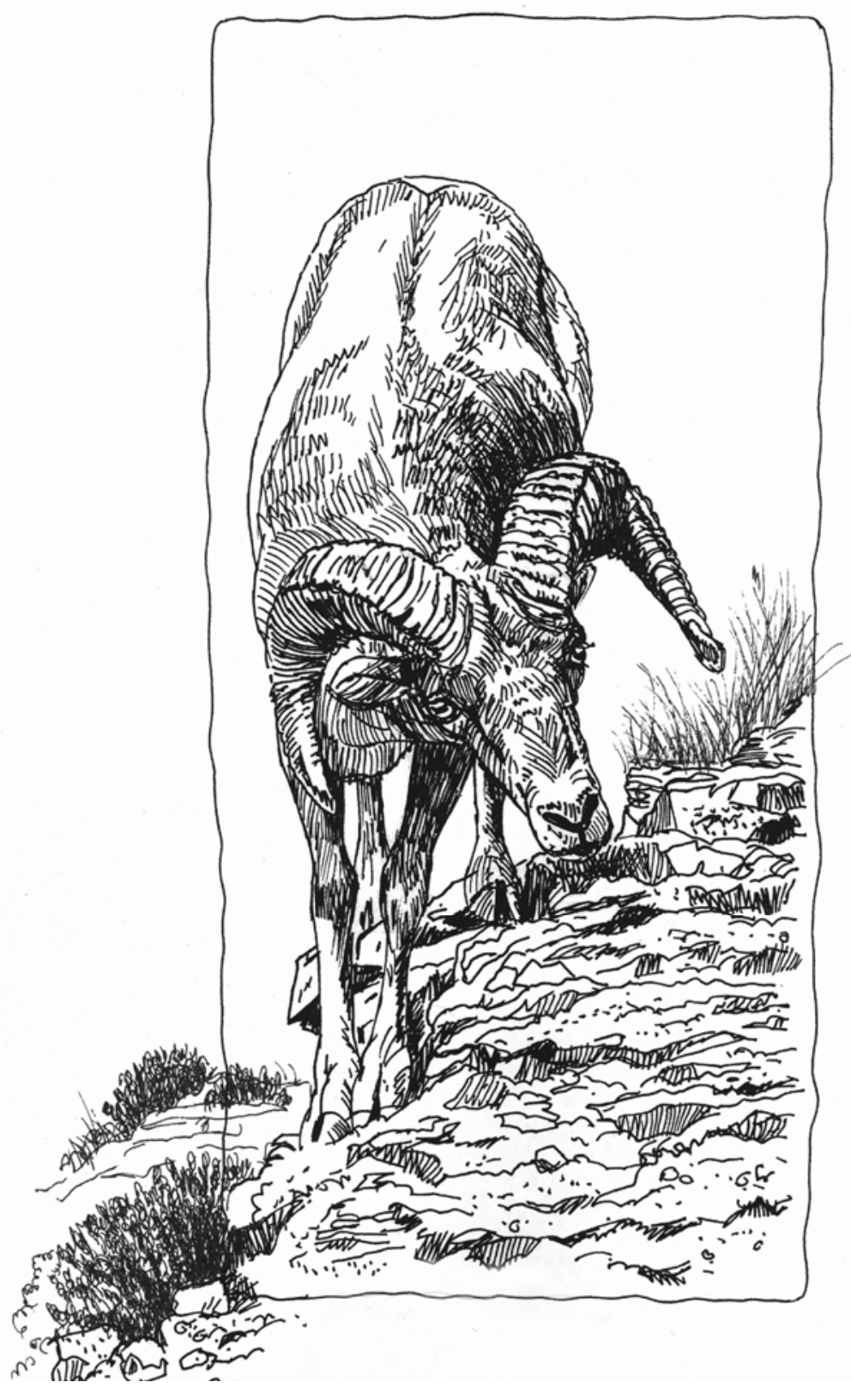





\section{Vegetation Monitoring of the Pryor Mountain Wild Horse Range and Bighorn Canyon National Recreation Area, Montana and Wyoming, 2002}

By Troy Gerhardt, Fort Collins, Colorado

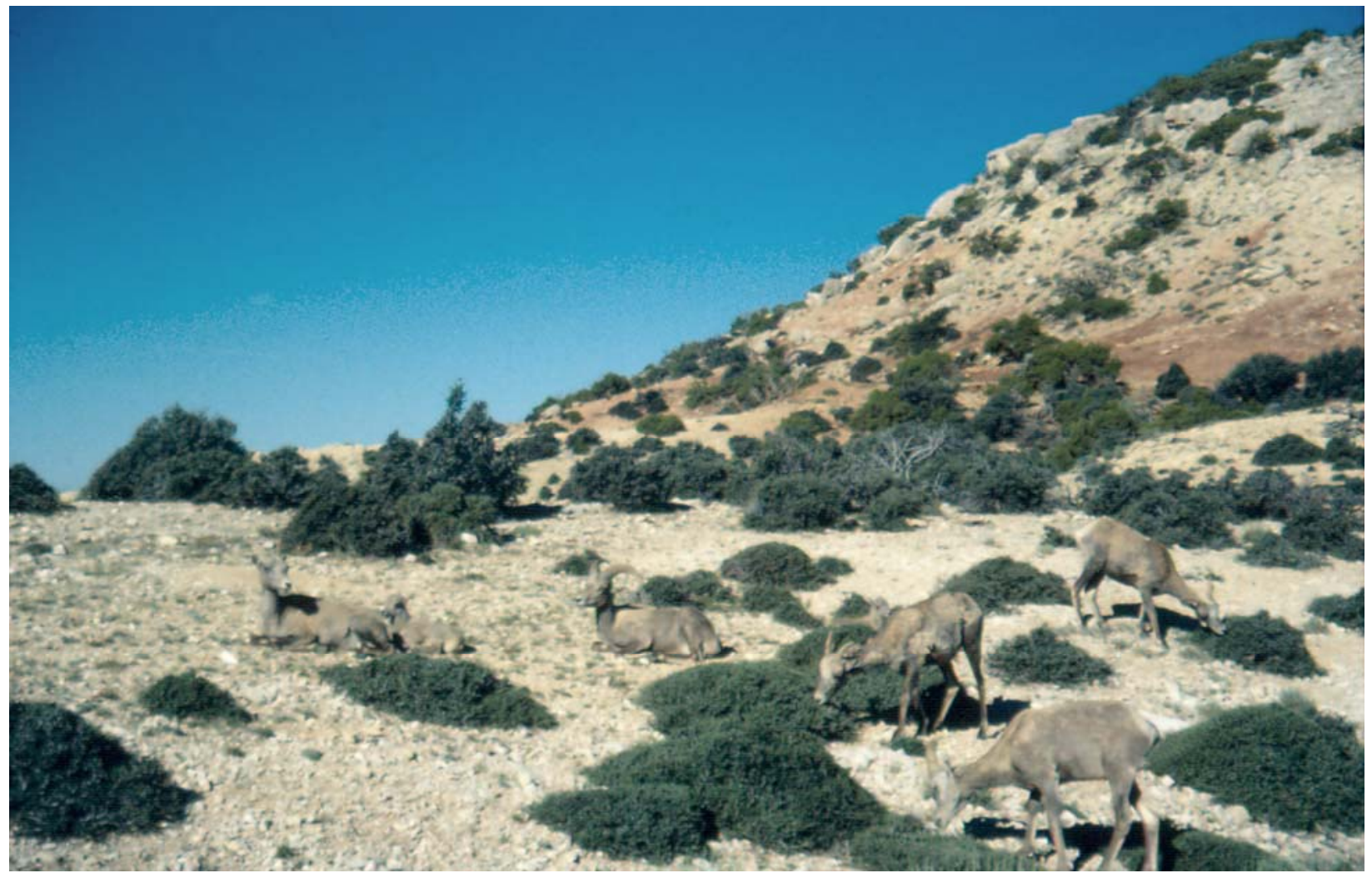





\section{Summary}

A network of large permanent exclosures was established in the Pryor Mountain Wild Horse Range (PMWHR) and Bighorn Canyon National Recreation Area (BICA) from 1992 to 1994 to monitor the effects of large herbivore grazing and management practices on vegetation. Sampling was conducted at exclosure sites from 19921996. The current project was initiated to continue monitoring vegetation at established exclosure sites, providing data for management decisions and input for system models. This report describes results of the 2002 sampling effort and reviews relevant findings from a series of previous studies.

Sampling methods and analyses were based on those used in previous PMWHR studies to provide continuity and were designed to compare vegetation inside and outside permanent exclosures 10 years after the current series of monitoring began. The objectives of this study were to: (1) measure herbaceous biomass; (2) estimate plant cover and determine species richness; (3) measure shrub (Cercocarpus ledifolius) production; (4) map cushion plants; and (5) document vegetation inside and outside of permanent exclosures at all sites with photographs.

Herbaceous biomass, species richness, and species cover were estimated inside and outside exclosures at all 12 sites. Biomass was estimated by clipping aboveground biomass in five plots inside and outside exclosures. Plant cover and species richness were estimated by species in 10 Daubenmire plots inside and outside each exclosure. Shrub production was estimated at the two sites where curlleaf mountain mahogany ( $C$. ledifolius) is a dominant species. Cushion plant mapping was conducted at four sites including two inside the PMWHR and BICA, and two inside BICA but not within the PMWHR boundaries.

Averaged across sites, biomass differences inside and outside of permanent exclosures were significant for all variables tested: total herbaceous biomass, live grass, current year's dead grass, old dead grass, and forbs (all $P$ $<0.001$ ). Total biomass and grass biomass (live and dead) were significantly higher inside exclosures, while forb biomass was lower inside exclosures. Although these results were relatively consistent across sites, the interaction between site and exclosures was also significant, indicating that the effects of grazing were not distributed evenly across the landscape.

Of the 16 cover variables analyzed, five were significantly different inside and outside of permanent exclosures. Grazing effects were detected for total plant cover, litter cover, and absolute and relative grass cover which were all significantly lower in the grazed plots outside of the exclosures. Bare ground showed an opposite trend and was higher in grazed plots. Species richness was slightly but significantly greater in plots protected from grazing.

Production of a broad-leaved evergreen shrub (C. ledifolius) was similar inside and outside exclosures at two sites. Shrub production was lower than during previous years.

Cushion plant frequency/cover was determined by mapping at four sites. At the sites inside the PMWHR (North and South Dryhead) frequency of all four cushion plant species in mapped grids was similar inside and outside permanent exclosures. There is no evidence that horse grazing is affecting cushion plant frequency/cover based on sampling inside and outside permanent exclosures. Historical cattle trailing occurred at the other two sites in BICA (North and South Lockhart Ranch). No differences were found between grazed/trampled and exclosed plots, however nearby "native" plots not subjected to cattle trampling show significantly different cover/frequency for some species. Trails are still clearly visible inside the exclosures, suggesting that these communities recover relatively slowly when trampled to bare ground.

At the time of sampling in July 2003, regional precipitation had been below the long-term average for several years. The 10-year trend in vegetation dynamics at the exclosure sites in the PMWHR and BICA is generally for lower mean biomass both inside and outside the exclosures. To explore the relationships between grazing effects, precipitation, and horse populations, several correlations and regressions were done on previous and current data. Grazing effects were calculated as a percent difference inside and outside permanent exclosures ([biomass insidebiomass outside]/biomass inside). Percent biomass difference tended to increase with both current and past year's horse population and decrease with increasing precipitation although regressions were not significant. Simple correlations between biomass difference and both past horse population and precipitation were nearly significant 
suggesting that average grazing effects increase as the horse population increases and decrease in years with higher precipitation.

\section{Introduction}

The Pryor Mountain Wild Horse Range (PMWHR) was established in 1968 and has a long-term management goal of maintaining a "thriving ecological balance" (BLM, 1984). The PMWHR and Bighorn Canyon National Recreation Area (BICA) support a population of wild horses of Spanish ancestry and a population of bighorn sheep. The United States Geological Survey and other federal and state agencies have funded a series of ecological studies on horse genetics, vegetation dynamics, ungulate diets and habitat use, carrying capacity, and ecosystem modeling in the PMWHR (Kissell, 1996; and summary in Singer and Schoenecker, 2000). A bighorn sheep study in BICA is ongoing.

Understanding how ungulate populations affect the PMWHR and BICA vegetation and alter forage and habitat availability is critical for a sound evaluation of management options. Because of concern about the effects of wild horses, bighorn sheep, and mule deer on the vegetation of the PMWHR and about the ability of the range to support ungulate populations, vegetation monitoring was initiated in 1992 at five permanent exclosure sites (Peterson and others, 1997). Biomass and plant cover were measured inside and outside of permanent exclosures, and grazing cages were established to measure growing season herbivory. Intensive studies on herbaceous and shrub biomass dynamics and shrub digestibility (Peterson, 1999) and on species composition, plant cover, and resource limitation (Fahnestock, 1998) were completed from 1992-1994. In 1994, nine additional permanent exclosures were established, and vegetation monitoring continued at all exclosure sites through 1996 (Gerhardt and Detling, 1998).

Previous studies have reported a variety of vegetation responses to exclosures in the PMWHR and BICA. Analysis of vegetation data collected from 1992-1994 focused on detecting localized effects (Fahnestock, 1998; Fahnestock and Detling, 1999; Fahnestock and Detling, 2000; Peterson and others, 1997; Peterson, 1999). Results from these reports generally indicate detectable herbivory effects at some sites for some vegetation variables, and showed a large inter-annual variation in vegetation with differences in cover and biomass often greater between years than between grazed and ungrazed plots. Later analyses included data from the expanded exclosure network and focused on depicting both localized and range-wide effects of herbivory (Gerhardt and Detling, 1998). Results from these data generally agreed with earlier work, detecting more vegetation differences at some sites than at others.

Select data from these studies were used to: (1) summarize major trends in vegetation dynamics within the PMWHR and BICA (Gerhardt and Detling, 2000); and (2) develop an ecosystem model to assess the impacts of grazing across the landscape and support informed management decisions (Coughenour, 1999, 2000). The summary analyses attempted to detect the spatial and temporal factors (including the exclosure) most related to vegetation dynamics. Across sites and years, significant effects of grazing were detected for some vegetation variables (grass cover and near significant differences for total herbaceous biomass and litter cover). However, factors related to site location and/or the time of measurement explained most of the variability for each vegetation variable (Gerhardt and Detling, 2000). A spatially-explicit ecosystem model incorporating these data was developed by Coughenour (1999, 2000) and used to examine the effects of alternative scenarios of weather, land use, and horse population management. The model realistically represented the PMWHR and BICA grazing system and demonstrated the effects of varying climate and ungulate populations on vegetation and other ecosystem properties. Modeling results suggest that the effects of horse grazing will not be distributed homogeneously across the landscape and that effects will vary depending on the size of the horse population, weather patterns, and site location. In addition, the model predicted that horse grazing has little effect on bighorn sheep populations due to spatial and dietary separation and strong intra-specific density dependence.

The current project was initiated to continue monitoring vegetation at established exclosure sites, providing data for ungulate management decisions and input for system models. Sampling methods and analyses were based on those used in previous PMWHR studies to provide continuity (Fahnestock, 1998; Gerhardt and Detling, 1998; Peterson and others, 1997; Peterson, 1999) and were designed to compare vegetation inside and outside permanent exclosures 11 years after the current series of monitoring began. 
The objectives of this study were to:

1. measure herbaceous biomass inside and outside of permanent exclosures at 12 sites,

2. estimate plant cover and determine species richness inside and outside permanent exclosures at 12 sites,

3. measure shrub (Cercocarpus ledifolius) production inside and outside exclosures at two sites,

4. map cushion plants inside and outside permanent exclosures at five sites, and

5. document vegetation inside and outside of permanent exclosures at all sites with photographs.

\section{Methods}

\section{Study Area}

The PMWHR is located along the border of Montana and Wyoming (Carbon County, MT, Big Horn County, WY), encompassing approximately 18,000 ha of Bureau of Land Management (BLM), Custer National Forest, BICA and state and private lands. Topography and vegetation are variable, ranging from steep cliffs and rocky canyons to rolling meadows and desert shrublands. Elevations range from approximately 1150 to 2500 meters, with lower elevations found towards the south, east, and southwest. Previous studies classified the vegetation into nine main types (Knight and others, 1987): juniper woodlands, mountain mahogany woodlands, juniper/mountain mahogany woodlands, desert shrubland, sagebrush steppe, grasslands, coniferous woodlands, riparian, and agricultural. Annual rainfall across the PMWHR varies from approximately 150 to $500 \mathrm{~mm}$, increasing with elevation.

The exclosure sites monitored as part of this study were scattered across the PMWHR (Figure 1). Sites were located in several vegetation communities on several soil types. Site elevation spanned the range found in the PMWHR, and mean annual site precipitation ranged from 200 to $510 \mathrm{~mm}$ (Table 1).

Populations of three herbivores forage solely or seasonally within the PMWHR and were studied by Kissell and others (1996) from 1993 to 1996. The population of mule deer (Odocoileus hemionus) in the PMWHR varied annually and seasonally, with winter populations varying from 143 to 780 between 1993 and 1996 (Kissell and others, 1996). Mule deer use of vegetation types varied seasonally: deer used juniper and mountain mahogany vegetation types most in winter and used coniferous woodlands, sagebrush, and juniper during the summer. Deer diets varied seasonally, with browse constituting almost the entire diet during the winter (98\%), and forbs forming an important dietary component during the spring and early summer. One shrub species, curlleaf mountain mahogany (Cercocarpus ledifolius) made up over 66\% of the deer diet each year (Kissell, 1996).

Bighorn sheep (Ovis canadensis) were extirpated from the Pryor Mountains around 1860. The current sheep population within PMWHR was founded by sheep from nearby reintroductions during the early 1970's and increased exponentially from a population of six animals (Coates and Schemnitz, 1988, 1989; Kissell and others, 1996). From a peak of 211 animals in 1993/1994, the PMWHR sheep population decreased to 125 in 1996 and has remained low. Sheep mostly use lower elevation $(<1,500 \mathrm{~m})$ mountain mahogany and juniper vegetation types year round (Kissell and others, 1996). Sheep diets were dominated by browse (primarily mountain mahogany) during the fall and winter, by grasses in the spring, and by a fairly even mixture of browse and grass during the summer. Forbs consistently represented a minor portion of sheep diets except during the spring when diets were $16 \%$ forbs (Kissell and others, 1996).

The herd size of horses (Equus caballus) is intensively monitored and managed in the PMWHR with gathers and culling every 1-3 years to maintain the population at an Appropriate Management Level (AML) in accordance with the Wild Free-Roaming Horse and Burro Act of 1971 and BLM plans (BLM 1984, 1997). The horse herd is typically distributed among three distinct but interbreeding subpopulations, particularly during the summer (Singer and others, 2000). Horse diets are dominated by grasses (Kissell, 1996) and grazing is spatially and seasonally variable (Kissell and others, 1996; Coughenour, 2000). 


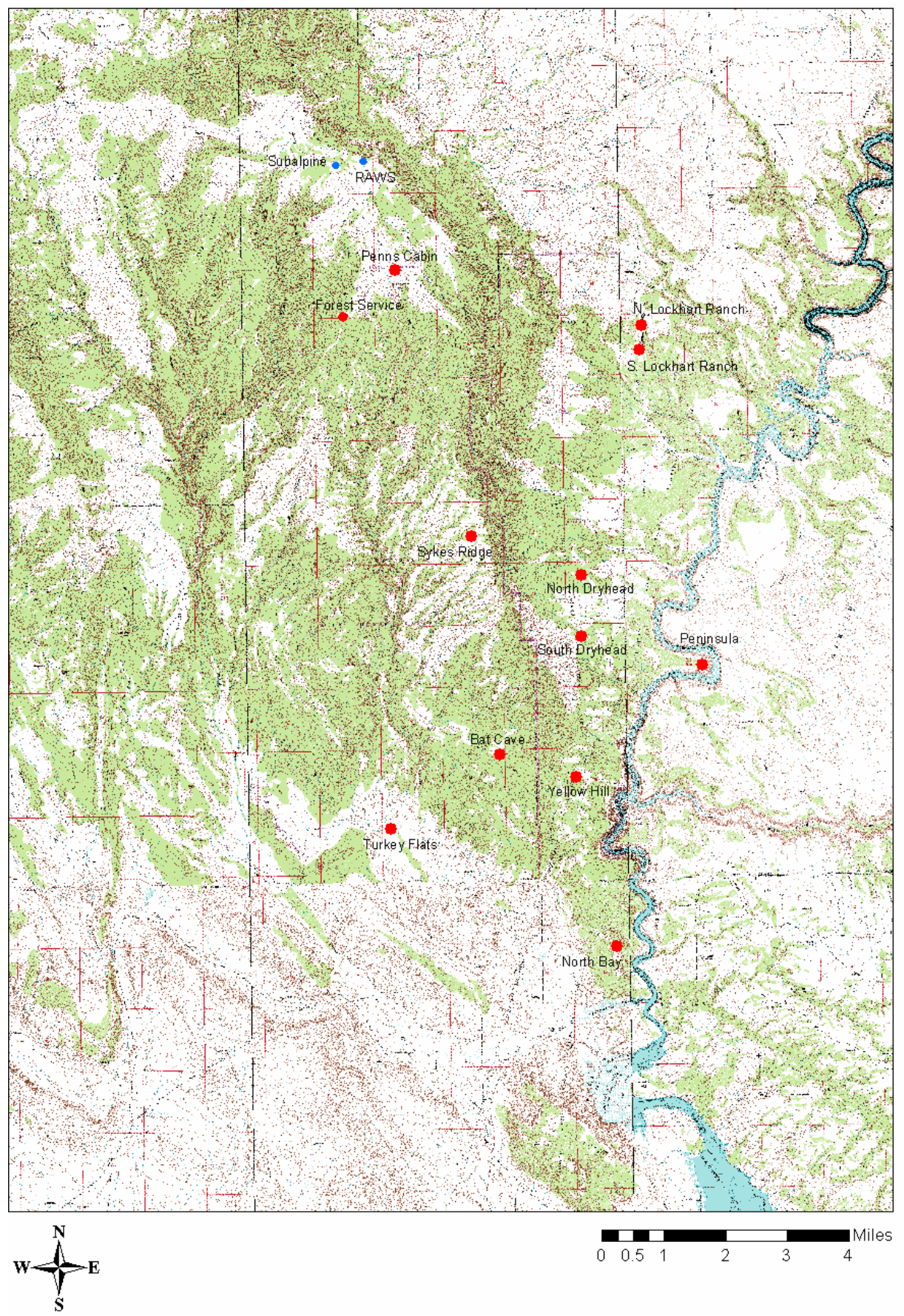

Figure 1. PMWHR area map showing location of permanent exclosure sites. Map was created on 1:24,000-scale USGS quads and is shown at a 1:100,000 scale. Site names are provided. Vegetation sampling was conducted at 12 sites in July 2002 (red markers). Plant cover and herbaceous biomass inside and outside of permanent exclosures were estimated at all sampled sites. Herbaceous biomass inside temporary grazing exclosures was estimated at all sites except Turkey Flats. Production of Cercocarpus ledifolius was estimated inside and outside permanent exclosures at Yellow Hill and Bat Cave. Cushion plant mapping was completed at the North and South Dryhead sites and at the North and South Lockhart Ranch sites. Sites shown in blue were not sampled during 2002. 
Table 1. Location (UTMs), elevation (m), soil, and mean annual precipitation ( $\mathrm{mm}$ ) data for each site provided by Coughenour (1999). Soil unit code, name and series, and range site are listed below the table; more complete soil descriptions can be found in Coughenour 1999. Lockhart Ranch sites were not mapped by Coughenour (1999).

\begin{tabular}{|c|c|c|c|c|c|}
\hline Site & East & North & Elevation & Soil & Mean precipitation \\
\hline Bat Cave & 713239 & 4989779 & 1540 & LH2 & 200 \\
\hline Forest Service & 709042 & 5001156 & 2490 & HD & 495 \\
\hline North Bay & 716437 & 4984732 & 1175 & SA1 & 205 \\
\hline North Dryhead & 715368 & 4994476 & 1320 & Hk2 & 300 \\
\hline \multicolumn{6}{|c|}{ North Lockhart Ranch } \\
\hline Peninsula & 717136 & 4992480 & 1275 & Hk2 & 260 \\
\hline Penns Cabin & 710300 & 5002000 & 2540 & $\mathrm{HE}$ & 510 \\
\hline South Dryhead & 715360 & 4992896 & 1340 & Hk2 & 300 \\
\hline \multicolumn{6}{|c|}{ South Lockhart Ranch } \\
\hline Sykes Ridge & 712499 & 4995456 & 2000 & HD & 414 \\
\hline Turkey Flats & 710597 & 4987887 & 1290 & Hf & 260 \\
\hline Yellowhill & 715257 & 4989259 & 1410 & LH2 & 280 \\
\hline
\end{tabular}

HD Hanson association very steep 45-70\% slope, Clayey

HE Hanson-Duncom association rolling, Stoney/Shallow

Hf Harvey loam 4-8\% slope, Limey

Hk2 Harvey deep highly calcareous at surface, Limey

LH2 Limestone outcrop 15-45\% slope, Rock Outcrop

SA1 Sandstone outcrop 25-45\% slope, Rock Outcrop Sandstone

\section{Exclosure Sites}

Data were collected from a total of 12 exclosure sites. Two exclosures located in montane grasslands were established in the 1960's (Stohlgren and others, 1999). Three exclosures were erected in late June of 1992, and vegetation sampling began at these five sites in the summer of 1992 (Peterson and others, 1997; Fahnestock, 1998; Peterson, 1999). The remaining exclosure sites were selected and established in 1994. See Appendix A for site ages and biomass sampling history.

\section{Field Methods}

To allow comparisons with vegetation data collected in earlier studies, methods were based on those used previously in the PMWHR for vegetation monitoring (Fahnestock, 1998; Gerhardt and Detling, 1998; Peterson and others, 1997; Peterson, 1999). Sampling was completed July 8-12, 2002, the approximate time of peak standing crop for herbaceous species. 


\section{Biomass}

Peak standing crop of herbaceous material was estimated inside and outside of permanent exclosures at 12 sites (Figure 1; Table 1). Inside permanent exclosures, five sample locations were selected using a random number table, and herbaceous vegetation was clipped to ground level inside of a circular quadrat $\left(0.25 \mathrm{~m}^{2}\right)$. Five quadrats outside of the permanent exclosure were placed according to the location of temporary grazing exclosures. Cages were established in April and early May 2002 by USGS personnel. Data from inside temporary cages (used to calculate grazing offtake) is not reported here.

\section{Species Composition and Cover}

Species composition and cover were estimated inside the permanent exclosure and in the control plot of 12 sites (Figure 1). Canopy cover was estimated by species in 10 Daubenmire frames located every $3 \mathrm{~m}$ along the plot diagonal.

\section{Shrub Production}

Production of current annual growth (CAG) was measured on curl-leaf mountain mahogany shrubs at two sites: Bat Cave and Yellow Hill (Figure 1). At each site, production of CAG twigs inside and outside permanent exclosures was estimated for small $(<10 \mathrm{~cm}$ tall), medium $(>10 \mathrm{~cm}$ and $<40 \mathrm{~cm})$, and large $(>40 \mathrm{~cm})$ shrubs. Ten shrubs in each size class were selected inside and outside of each exclosure. On each shrub, the number of CAG twigs was counted. On larger shrubs, the canopy was visually divided into sections. CAG twigs were counted in one randomly selected shrub section and multiplied by the appropriate integer to estimate total CAGs/shrub. Ten CAG twigs were clipped at the bud scale scar and collected to estimate mass/CAG twig.

\section{Cushion Plants}

Cushion plants were mapped at four low elevation sites: North and South Dryhead, and North and South Lockhart Ranch (Figure 1). At each site, cushion plants were mapped inside permanent exclosures and in established control plots. The two northern sites (North and South Lockhart Ranch) were specifically established to monitor dynamics in cushion plant communities subjected to concentrated trampling from trailing cattle during seasonal drives. At these sites an additional "native" plot was established in 1994 at some distance from the road. This plot did not contain visible cattle trails and was selected to represent areas not trampled by cattle. Two sites (North and South Dryhead) were established in 1992 to monitor vegetation dynamics caused primarily horse grazing. "Permanent" $1 \mathrm{~m}$ x $1 \mathrm{~m}$ plots were established at these sites in 1994 and marked with large nails driven to ground level. Most of the sites could not be relocated; those that were located often had corner nails that were no longer square. Cushion plants were mapped using the same method as earlier studies and employing a $1 \mathrm{x} 1 \mathrm{~m}$ grid divided into 10010 x $10 \mathrm{~cm}$ sub-grids. Grids were randomly placed at three locations in each plot. Presence/absence in each sub-grid was recorded for each cushion plant species.

\section{Statistical Analyses}

All analyses were made with S-PLUS 4.5, and results were considered significant if $P<0.05$. Although data from previous years are cited in the results, statistical analyses were made only on data collected in 2002. 


\section{Herbaceous Plant Biomass}

Biomass data were analyzed to test for differences inside and outside of permanent exclosures. Four components of total herbaceous biomass were analyzed separately: live grass, current year's dead grass, previous years' dead grass, and forbs.

Two-way (site x plot type) factorial ANOVAs were used to test for biomass differences in each biomass component and for total biomass. For each biomass component, tests for the effect of the permanent exclosures were performed through separate analyses. Individual clipped plots (5/plot type/site) were used as samples. Biomass varies widely across sites, and the site factor was included to account for this variance without reducing sample size by using site means as samples.

\section{Shrub Production}

Number of CAGs, mean CAG mass, and CAG mass/shrub were analyzed with three-factor analysis of variance (shrub size class $\mathrm{x}$ site $\mathrm{x}$ plot type). Because Cercocarpus shrubs were sampled at only two sites, individual shrubs were used as replicates. Interaction terms were included based on previous results (Gerhardt and Detling, 1998). The square root of number of CAGs was used in analyses.

\section{Plant Cover and Species Richness}

Plant cover and species richness data were analyzed to test for differences inside and outside of permanent exclosures. Cover data were analyzed by functional groups (Grass, Forbs, Cushion plants, Shrubs/dwarf shrubs, Cercocarpus, Cactus) to allow comparisons with previous data and provide input for available vegetation models (Singer and Schoenecker, 2000).

Paired t-tests were used to compare cover and species richness inside and outside of permanent exclosures. Data from inside and outside of permanent exclosures at each site were considered to be pairs. Previous analyses indicate that cover and richness range widely across sites. Paired t-tests were chosen to reduce the variability caused by site differences and provide a more powerful statistical test.

Separate analyses were used for the absolute and relative cover of each plant functional group, and on the absolute cover of bare ground, litter, rock, and total plant cover. Sample size was 12 pairs for all variables except Cercocarpus $(\mathrm{n}=3)$ and cushion plants $(\mathrm{n}=10)$. Cover data $\left(\sin ^{-1} \sqrt{x}\right)$ and richness data $(\sqrt{x})$ were transformed before analysis.

\section{Cushion Plants}

Cushion plant frequency data from the two Dryhead sites were pooled for analysis. Analysis of variance for the effects of permanent exclosures and site were conducted using grids as replicates $(\mathrm{n}=12)$. Separate analyses were run for four cushion plant species: Phlox bryoides, Phlox hoodii, Leptodactylon caespitosum, and Arenaria hookeri. Data from the two Lockhart Ranch sites were pooled and analyzed similarly, however the plot factor had three levels (grazed/trampled, exclosed, native) and sample size was higher $(\mathrm{n}=18)$.

\section{Regression Analyses}

To explore the relationships between grazing effects, precipitation, and wild horse population levels, several correlations and regressions were done on previous and current data. Total peak biomass data for 1992-1996 (summarized in Gerhardt and Detling, 2000), annual horse count data (L. Coates-Markle, oral commun., 2002), and monthly precipitation data from the Lovell weather station (National Climatic Data Center website, 2002) were used. 
Trends in horse population, local annual precipitation, and local water year precipitation (October-June was used because sampling occurred in early July) from 1968 (when the PMWHR was established) to 2002 are informative (Figure 2). Although the long-term trend in wild horse population level is relatively flat, the horse population has been managed at higher numbers since vegetation monitoring began in 1992. Both annual precipitation and water year precipitation have tended to decrease since 1968, but linear trends are not significant (Pearson $\mathrm{r}=-0.25$ and -0.12 respectively; $P>0.15$ ). Since 1992 when vegetation monitoring began, annual precipitation has been above the long-term average five years, but water year precipitation has been above average only twice and has been consistently below average since 1996. A plot of cumulative precipitation from 1992 through the sampling date in 2002 suggests that the area was in a multi-year precipitation deficit during the 2002 sampling period (Figure 3).

The trend in vegetation dynamics at the exclosures in the PMWHR and BICA is generally for lower mean biomass both inside and outside the exclosures (Appendix A). However, an overall average for each year is derived from different numbers of exclosures each year with most newer exclosures established in lower elevation, lower production areas.

To accommodate this limitation, grazing effects were calculated as a percent difference inside and outside permanent exclosures ([biomass inside - biomass outside]/biomass inside). For each year, only data from exclosures at least 1-year old were included. Difference data were regressed against and correlated with three factors: current year's wild horse annual count, previous year's wild horse annual count, and water year precipitation.

\section{Results}

\section{Herbaceous Biomass}

Averaged across sites, biomass differences inside and outside of permanent exclosures were significant for all variables tested: total herbaceous biomass, live grass, current year's dead grass, old dead grass, and forbs (all $P$ $<0.001$ ). Total biomass and grass components were higher inside the exclosure, while biomass of forbs was greater outside the exclosures (Figure 4).

The interaction (plot type $\mathrm{x}$ site) was significant for all biomass components (all $P<0.002$ ) and nearly significant for total herbaceous biomass $(P=0.057)$. The interaction term tests whether exclosure effects were similar across the 12 sites. A significant interaction indicates that biomass differences were not consistent at all sites (Appendix B).

Of the five biomass components, the most consistent differences are in the grass components. It was not possible to statistically compare vegetation inside and outside exclosures separately for each site, however data are plotted separately for each site in Appendix B, showing that grass is higher inside exclosures at all sites except for Penn's Cabin. Although average forb biomass was significantly lower inside exclosures, some sites had greater forb biomass inside exclosures. Photographs inside and outside exclosures are provided in Attachment A.

\section{Shrub Production}

CAG and shrub production was similar at both sites (Figure 5; all $P<0.20$ ), and was not affected by the permanent exclosures (Figure 6; all $P<0.25$ ). Shrub size had significant effects on number of CAG twigs, mean CAG mass, and CAG production/shrub (Figure 7; all $P<0.005$ ). 


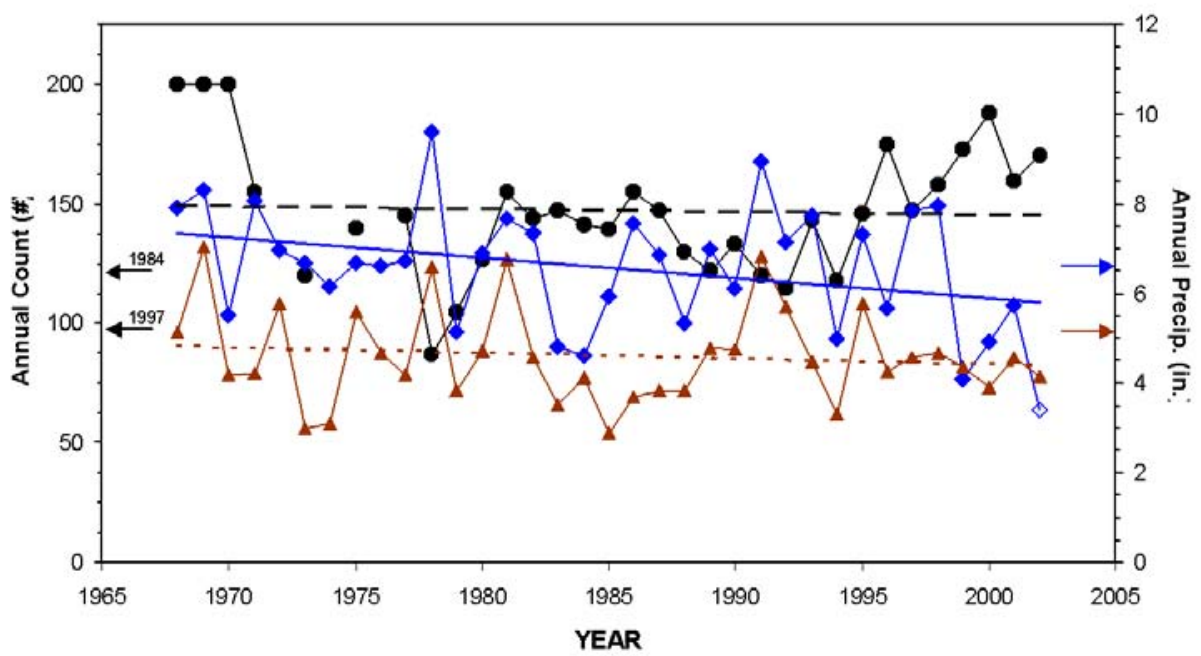

Figure 2. Horse population (๑), annual precipitation ( $\square$ ), and water year precipitation ( $\square$; 0 ct. - June) plotted from 1968, when the PMWHR was established, through 2002. Population estimates are missing for some years. Linear trends are shown, although were not statistically significant. Values (121 and 95) indicated by arrows on the horse population y-axis show estimated carrying capacity (BLM 1984, 1997). The upper value indicated on the precipitation y-axis shows long-term (1949-2001) mean annual precipitation; the lower value shows long-term mean water year (Oct. - June) precipitation. Annual precipitation data for 2002 includes only January through June.

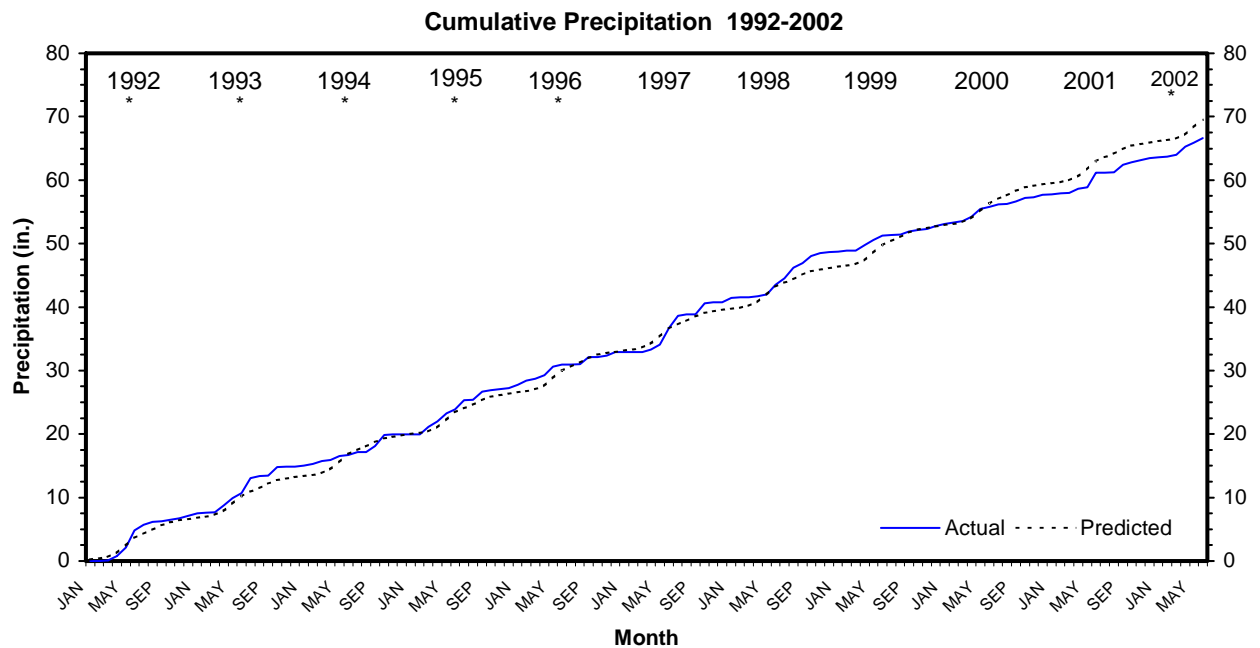

Figure 3. Actual and predicted cumulative precipitation over the recent vegetation monitoring period (1992-2002). Monthly precipitation data were obtained for the Lovell station (National Climatic Data Center website, 2002). The predicted cumulative precipitation was obtained by sequentially adding monthly long-term average precipitation. Years during which permanent exclosures were sampled are indicated $\left({ }^{*}\right)$. 

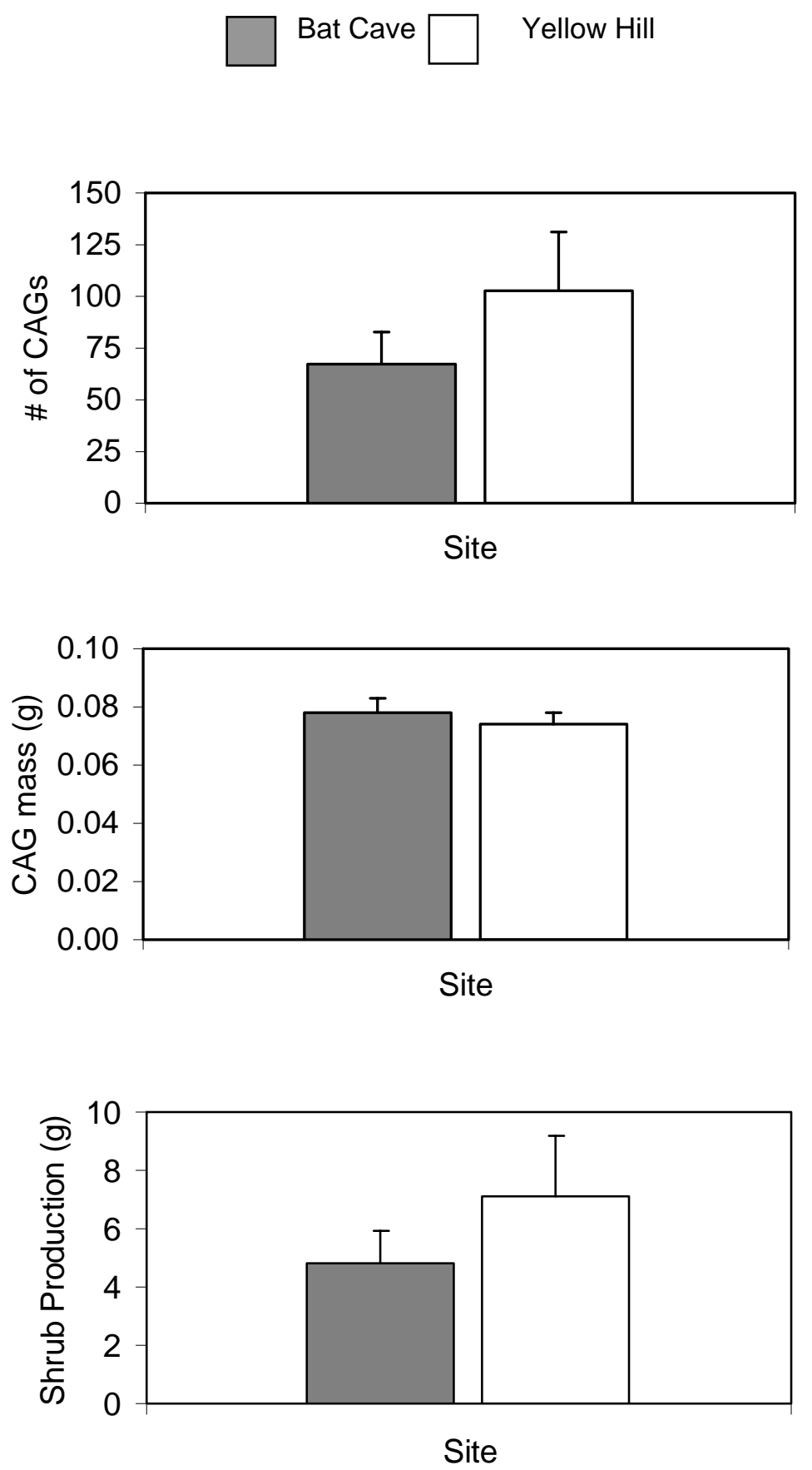

Figure 4. Mean number of CAG twigs per shrub, mean CAG mass, and mean production per shrub at two sites. Means and standard errors based on a sample of 60 shrubs at each site. Differences between sites were not significant $(P>0.05)$. 


\section{Plant Cover and Species Richness}

\section{Plant Cover}

Of the 16 cover variables analyzed, five were significantly different inside and outside of permanent exclosures (Table 2 and Appendix C). Total plant cover, grass cover, and litter cover were significantly higher inside the permanent exclosure. Mean differences for other plant functional groups were close to zero. Bare ground was significantly lower inside the exclosure (grazed $=48.5$, exclosed $=39.0 ; P=0.013$ ). Similar to absolute cover, the relative cover of grasses was higher inside than outside exclosures (grazed $=0.22$, exclosed $=0.34 ; P=0.013$ ).

\section{Species Richness}

Species richness was slightly but significantly higher inside permanent exclosures (Table 2 and Appendix $\mathrm{C} ; P=0.018$, mean difference $=1.4$ species). The largest difference was observed at the North Lockhart Ranch site ( 5 species) followed by Bat Cave (4 species; Figure 1). Richness data were obtained from Daubenmire cover sampling and do not represent a complete list of species at the site.

\section{Cushion Plant Dynamics}

At the sites inside the PMWHR (North and South Dryhead), frequency of all four cushion plant species in mapped grids was similar inside and outside permanent exclosures (Table $3 ; P$. bryoides, $P=0.462 ; P$. hoodii, $P=$ $0.532 ;$. caespitosum, $P=0.546 ;$ A . hookeri, $P=0.263)$. Only $P$. hoodii differed between sites $(P<0.001)$.

At sites established in BICA outside of the current Range, cushion plant frequency was compared among three plot types: grazed/trampled, exclosed, and native. Both Phlox species differed significantly among plot types ( $P$. bryoides, $P=0.003 ; P$. hoodii, $P<0.001)$. Phlox hoodii was much more prevalent in native plots than in either grazed or exclosed plots (Tukey $P<0.001$ ) but did not differ between grazed and exclosed plots (Tukey $P=0.878$ ). Phlox bryoides showed an opposite response and was significantly higher in grazed and exclosed plots than in the native plot (Tukey $P<0.01$ ). Again, differences between grazed and exclosed plots were not significant (Tukey $P=$ 0.895). The other two species did not show significant differences between plots (Table $3, P<0.10$ ). Only A. hookeri frequency differed between sites $(P=0.039)$. Photographs of sampling grids in each plot type at each site are provided in Attachment A for visual comparisons and future reference.

\section{Regression Analyses}

Percent biomass difference tended to increase with both current and past year's wild horse population and decrease with increasing precipitation although regressions were not significant (Figure 8). Simple correlations between biomass difference and both past wild horse population and precipitation were nearly significant (current population: $\mathrm{r}=0.52, P=0.29$; past population: $\mathrm{r}=0.79, P=0.06$; precipitation: $\mathrm{r}=-0.78, P=0.07 ; \mathrm{n}=6$ ). This suggests that average grazing effects increase as the wild horse population increases and decrease in years with higher precipitation.

Although grazing effects were detected, the effect of the exclosure was not significant across sites (significant site $\mathrm{x}$ exclosure interaction), with some areas showing much stronger exclosure effects (Appendix B) than others. The heterogeneous distribution of grazing effects agrees with past sampling data and is consistent with modeling results, indicating that grazing distribution and intensity varies across the PMWHR and BICA (Coughenour, 2000). 

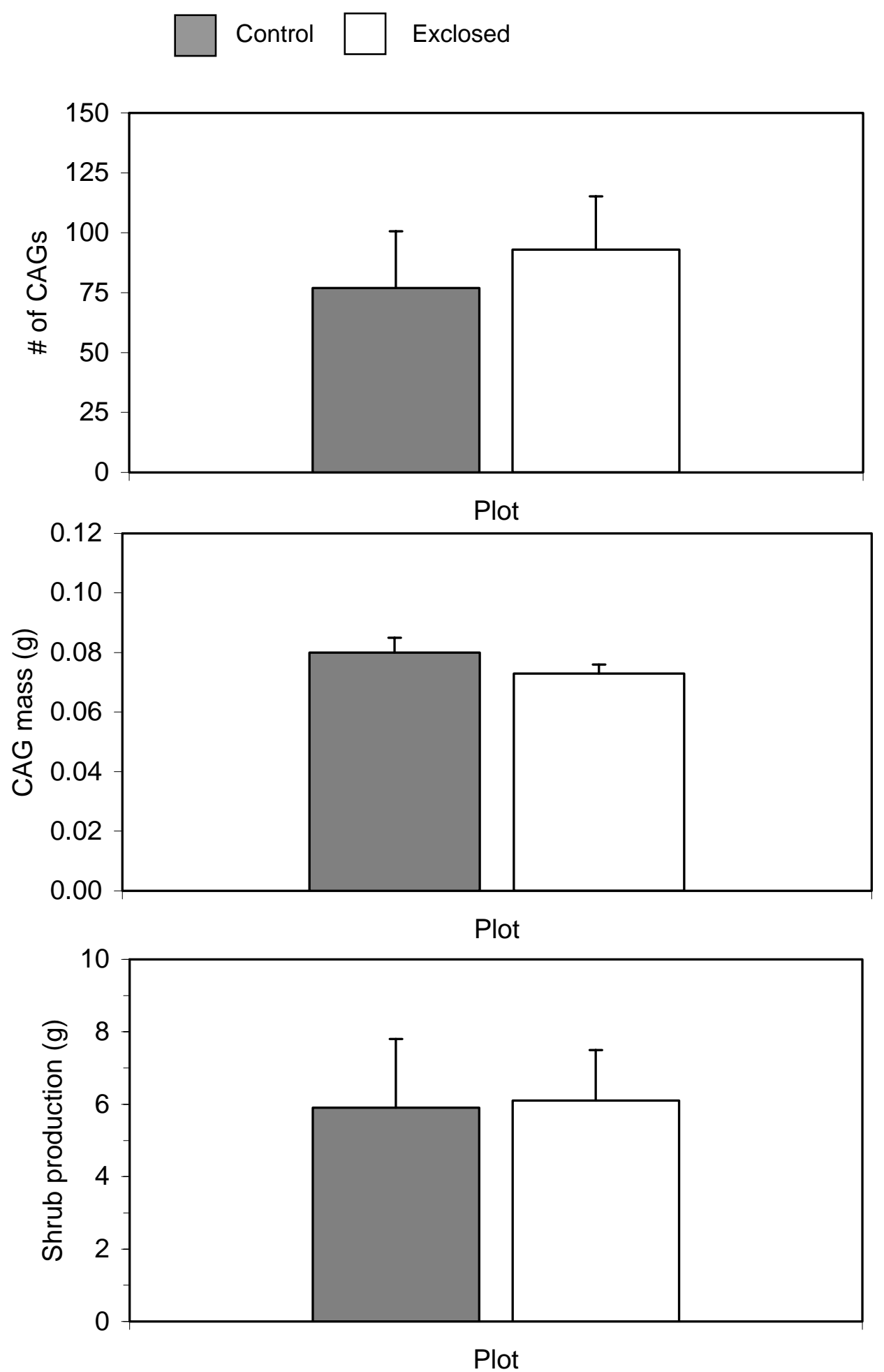

Figure 5. Mean number of CAG twigs per shrub, mean CAG mass, and mean production per shrub in control and exclosed plots. Means and standard errors based on a sample of 60 shrubs per plot type ( 30 each at two sites). Differences between plots were not significant $(P>0.05)$. 

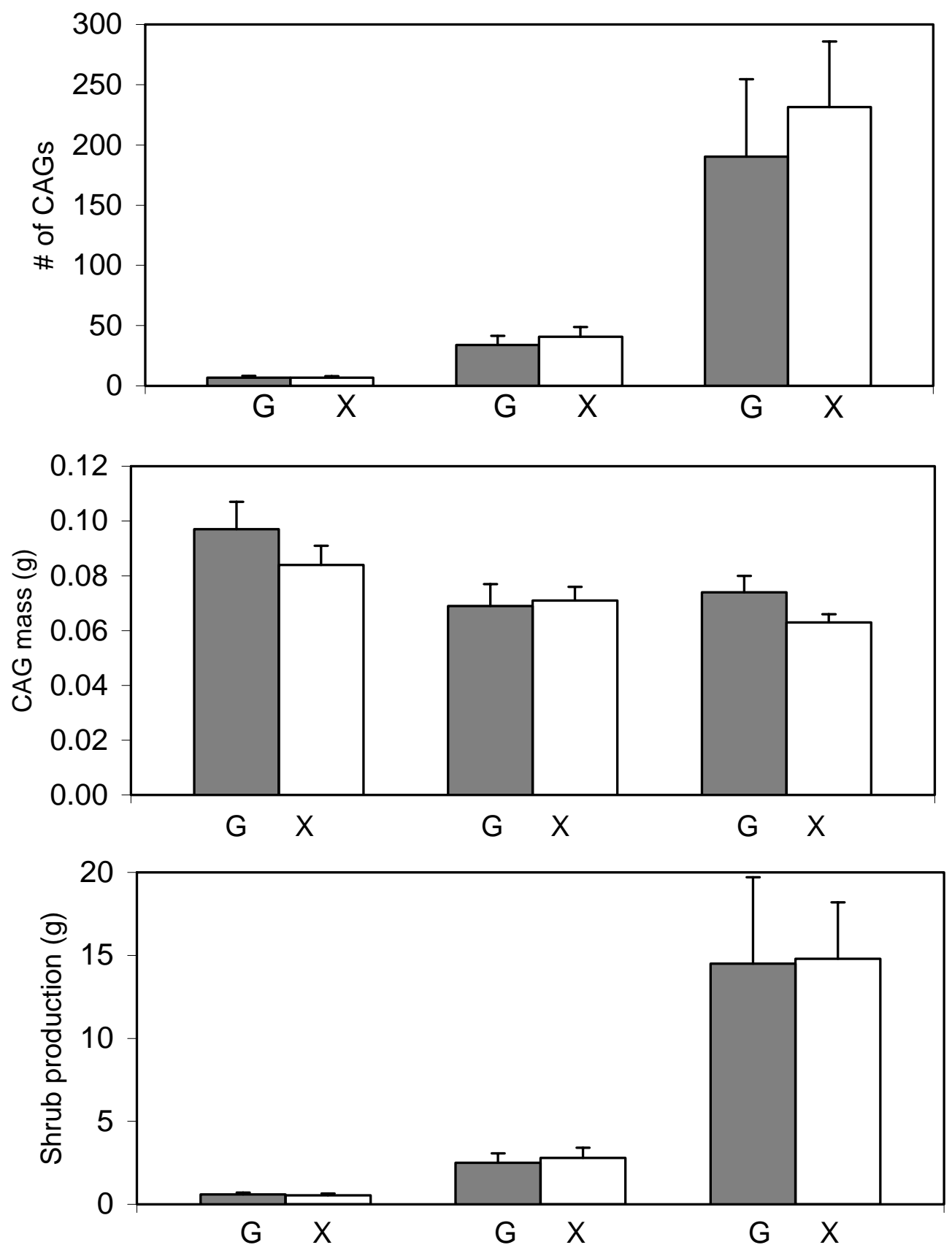

Figure 6. Mean number of CAG twigs per shrub, CAG mass, and production per shrub in grazed $(G)$ and exclosed $(X)$ plots for Cercocarpus shrubs of three size classes. Size classes were based on shrub height $(<10 \mathrm{~cm},>10 \mathrm{~cm}<40 \mathrm{~cm}$, and $>40 \mathrm{~cm})$. Size class effects were significant $(P<0.05)$ for all variables. Differences between shrubs in control plots and permanent exclosures were not significant. 


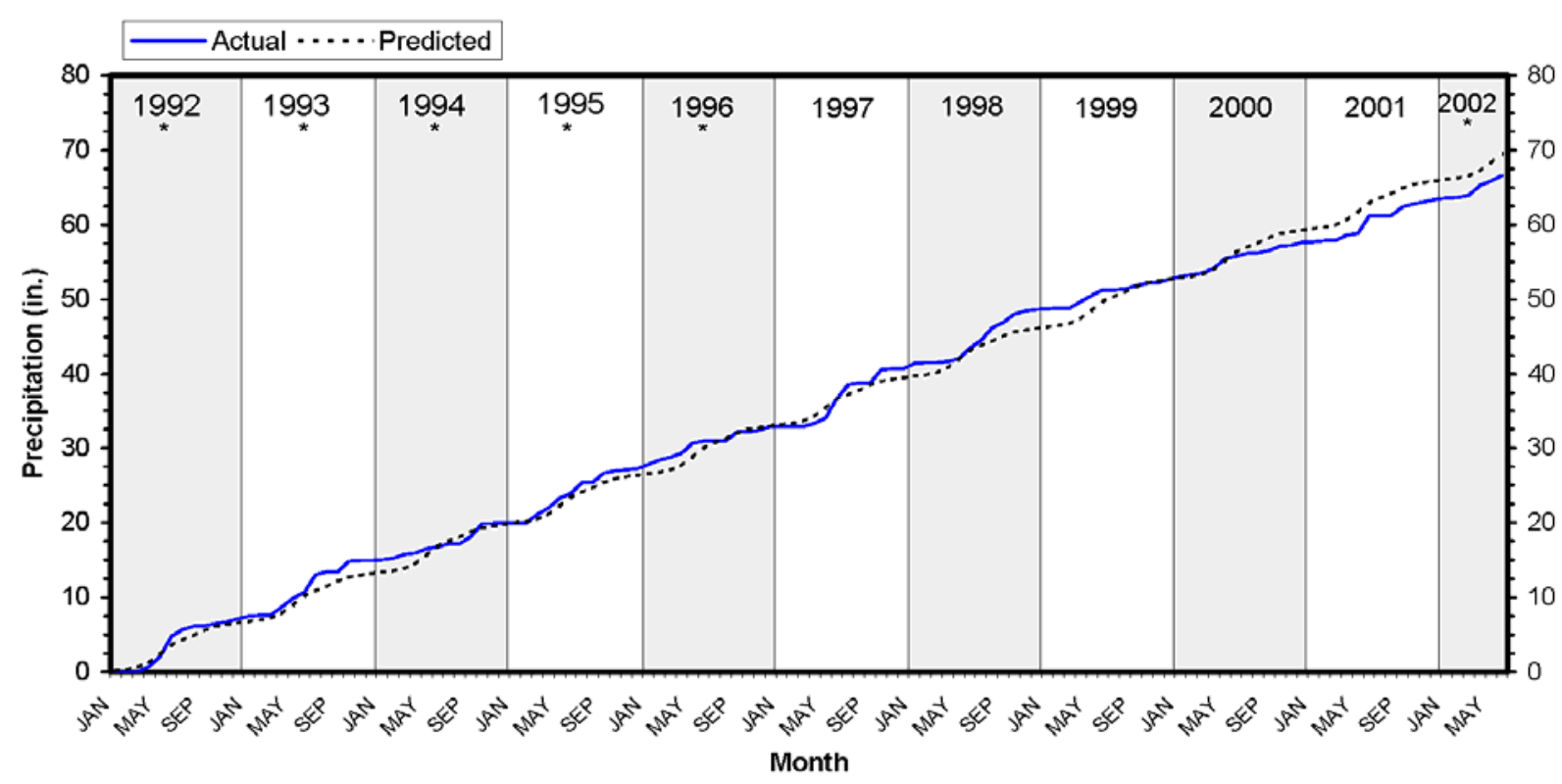

Figure 7. Mean number of CAG twigs per shrub, CAG mass, and production per shrub in grazed and exclosed plots for Cercocarpus shrubs of three size classes. Size classes were based on shrub height $(<10 \mathrm{~cm},>10 \mathrm{~cm}<40 \mathrm{~cm}$, and $>40 \mathrm{~cm})$. Size class effects were significant $(P<0.05)$ for all variables. Differences between shrubs in control plots and permanent exclosures were not significant.

\section{Discussion}

\section{Herbaceous Biomass}

Total herbaceous biomass and biomass of live and dead grass were higher inside permanent exclosures, while forb biomass was significantly higher outside. Previous analyses have found biomass differences inside and outside permanent exclosures (Peterson and others, 1997; Peterson, 1999; Gerhardt and Detling, 1998), and previous analyses comparing across years and sites have found nearly significant differences inside and outside permanent exclosures (Gerhardt and Detling, 2000). In general, significantly higher biomass inside exclosures has only been found previously at certain sites (Forest Service, North and South Dryhead, Sykes Ridge) when sites where analyzed individually, or when analyses included these sites.

Gerhardt and Detling (2000) analyzed multi-year data from 10 of the sites sampled in 2002, and two high elevation sites established in 1994 but not sampled this year (Figure 1). The North and South Lockhart Ranch sites were substituted in 2002 to include lower elevation areas used by bighorn sheep. The two sites not sampled in 2002 are both high-elevation, high-production sites with relatively high forb cover. Horse access to one of these sites (Subalpine, Figure 1) may now be limited due to fencing. The Lockhart Ranch sites are dry, low-elevation, relatively low-production sites inside BICA but outside the PMWHR and therefore not grazed by horses. Bare ground and cushion cover is relatively high. The substitution of these sites invariably had some effect on the results of biomass and other vegetation variables, especially in decreasing the average biomass compared to previous years.

Detection of range-wide grazing effects in 2002 could be the result of several factors. Biomass differences may be the result of aging exclosures, with differences taking several years to develop. The youngest exclosures were constructed in 1994, and biomass differences may have developed gradually over the years. Alternatively, low precipitation and relatively high horse populations may have increased the effect of grazing during the current year only. If this is the case, biomass differences should be expected to decrease if precipitation is high, horse populations are lower, or other management options are pursued which distribute horse and sheep grazing or improve currently used habitat. 
Table 2. Cover and species richness in grazed and permanently exclosed plots. Means (\%) for absolute and relative cover are provided for plant functional groups, and absolute cover only is provided for total plant, bare ground, litter, and rock. $P$-values from paired t-tests are listed, and variables with significant differences are indicated $(*)$.

\begin{tabular}{lccc}
\hline \multicolumn{1}{c}{$\begin{array}{c}\text { Functional group/ } \\
\text { cover group }\end{array}$} & Grazed & Permanent Exclosure & P-value \\
\hline $\begin{array}{l}\text { Absolute cover } \\
\text { Total plant* }\end{array}$ & 29.9 & 35.9 & \\
Grass* & 6.6 & 14.3 & 0.034 \\
Forbs & 7.3 & 7.2 & 0.004 \\
Shrubs/dwarf shrubs & 5.8 & 5.2 & 0.414 \\
Cercocarpus & 3.5 & 3.2 & 0.423 \\
Cactus & 0.4 & 0.3 & 0.809 \\
Cushion plants & 5.5 & 5.8 & 0.589 \\
Bare ground* & 48.5 & 39.0 & 0.859 \\
Rock & 13.5 & 13.5 & 0.013 \\
Litter* & 4.3 & 13.2 & 0.919 \\
Relative cover & & & 0.001 \\
Grass* & & & \\
Forbs & 21.9 & 38.3 & 0.013 \\
Shrubs/Dwarf shrubs & 16.8 & 17.1 & 0.618 \\
Cercocarpus & 24.2 & 16.3 & 0.067 \\
Cactus & 12.4 & 10.0 & 0.373 \\
Cushion plants & 1.3 & 0.7 & 0.824 \\
Species Richness* & 21.5 & 17.6 & 0.227 \\
\hline & 14 & & 0.018 \\
\hline
\end{tabular}

Table 3. Percent presence of cushion plant species in mapping grids. Three grids were mapped in the grazed (G) and permanently exclosed (X) plots at the North and South Dryhead sites. At the North and South Lockhart Ranch sites, three grids were also mapped in a previously established Anative@ plot (N) located west of the road. Data presented are means (1 SE) of presence averaged across sites $(n=6)$. Subscripts indicate significant differences based on Tukey tests $(P<0.05)$.

\begin{tabular}{lccccc}
\hline & & \multicolumn{5}{c}{ Species } \\
\cline { 3 - 6 } \multicolumn{1}{c}{ Sites } & Plot & Phlox bryoides & Phlox hoodii & $\begin{array}{c}\text { Leptodactylon } \\
\text { caespitosum }\end{array}$ & Arenaria hookeri \\
\hline \multirow{2}{*}{ North and South Dryhead } & $\mathrm{G}$ & $20.0(2.1)$ & $11.8(6.0)$ & $20.0(4.5)$ & $12.2(3.7)$ \\
& $\mathrm{N}$ & $17.8(2.1)$ & $13.5(6.1)$ & $22.0(1.2)$ & $16.3(1.3)$ \\
\multirow{2}{*}{ North and South Lockhart Ranch } & $\mathrm{G}$ & $26.5(1.9)_{\mathrm{a}}$ & $0.3(0.3)_{\mathrm{a}}$ & $3.8(1.9)_{\mathrm{a}}$ & $19.0(4.1)_{\mathrm{a}}$ \\
& $\mathrm{X}$ & $28.0(1.8)_{\mathrm{a}}$ & $1.2(1.2)_{\mathrm{a}}$ & $4.8(2.6)_{\mathrm{a}}$ & $22.5(2.4)_{\mathrm{a}}$ \\
& $\mathrm{N}$ & $16.5(2.3)_{\mathrm{b}}$ & $31.0(2.1)_{\mathrm{b}}$ & $5.7(0.8)_{\mathrm{a}}$ & $14.0(3.1)_{\mathrm{a}}$ \\
\hline
\end{tabular}



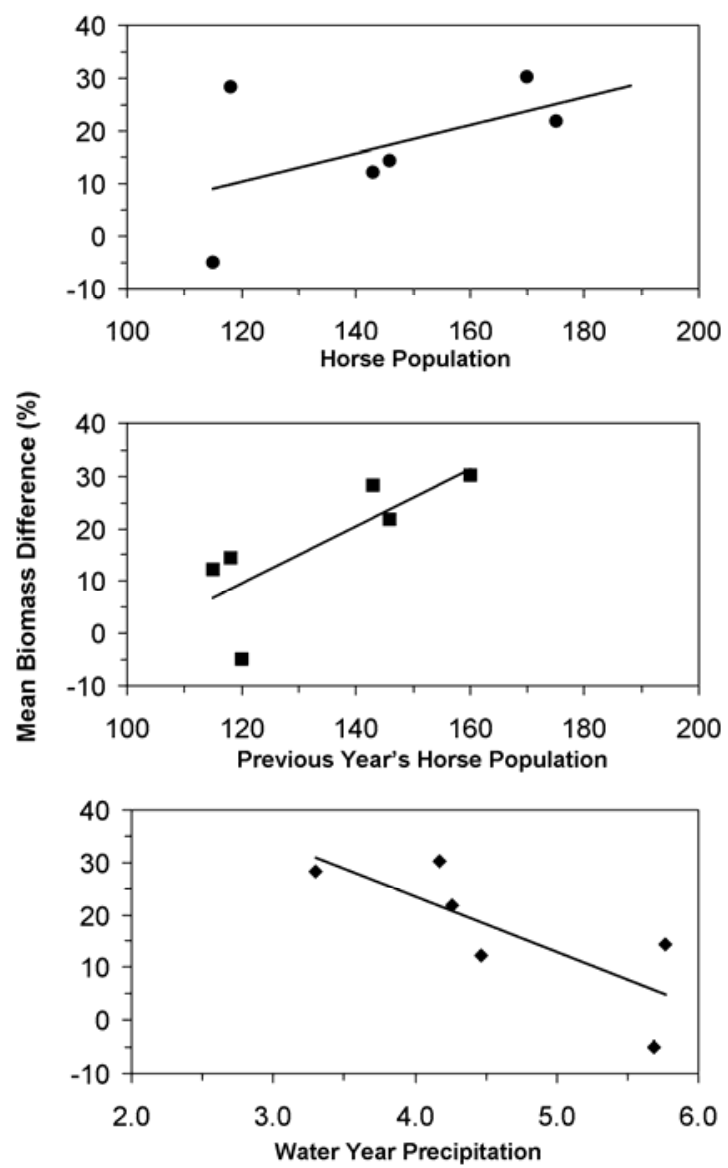

Figure 8. Mean difference in total herbaceous biomass inside and outside permanent exclosures plotted against current year's horse population, previous year's horse population, and water year precipitation (October-June). Data were collected 1992-1996 and 2002. Mean biomass was calculated as the quotient of the difference inside and outside divided by the biomass inside the exclosure. Regression statistics: horse population $P=0.24, \mathrm{R}^{2}=0.33$; previous year's horse population $P=0.20, \mathrm{R}^{2}=0.37$; precipitation $P=0.12, \mathrm{R}^{2}=0.49$.

\section{Shrub Production}

The significant effect of shrub size on number of CAGs and total shrub production was expected. This size classification was originally designed to allow CAG production to be estimated over larger areas by providing an estimate of average shrub production (Gerhardt and Detling, 1998). Larger shrubs had many more CAGs than smaller shrubs and more total production (Figure 5), however individual CAG mass was significantly higher on small shrubs. These results differ from prior analyses which showed more and larger CAGs on the largest shrubs (Gerhardt and Detling, 1998) and significant site differences. Compared to previous years, CAG mass was lower in 2002, especially on large shrubs. In addition, the number of CAGs produced per shrub was lower than in previous years, and again reduced production was particularly evident on the largest shrubs. Lower Cercocarpus production could result in less available shrub forage for bighorn sheep, however shrub offtake and forage availability were not estimated. 


\section{Plant Cover and Species Richness}

The differences in grass cover contributed strongly to the significant difference in total plant cover, with grass cover higher inside than outside exclosures at 10 of 12 sites (Table 2 and Appendix C). Grass cover was only higher outside the exclosure at Penn's Cabin. Lower plant cover and biomass inside the exclosure at this site have been found previously (Fahnestock and Detling, 1999; Fahnestock and Detling, 2000; Gerhardt and Detling, 1998; Peterson, 1999; Peterson and others, 1997). Despite the influence of grass cover on total plant cover differences, site ranks for total plant cover and grass cover were not identical, with the site showing the highest difference in total cover (Sykes Ridge) ranking third in grass cover difference (Appendix C). Results from Sykes Ridge, Forest Service, and South Dryhead should be viewed with some caution when comparing to other years' data. At these sites, the grazed plot was in a slightly different location from previous sampling efforts based on the need to sample adjacent to temporary grazing cages. However, data from these sites are valid for the current analyses, as grazed plots were still near permanent exclosures in visually similar habitat and vegetation.

These results differ from previous results in which data were analyzed across sites. Analyses of cover data from 1992-1996 found a significant exclosure effect only for relative grass cover, although effects were nearly significant for absolute grass and litter cover (Gerhardt and Detling, 2000). In addition, paired t-test analyses of 1998 cover data from six sites found no significant differences inside and outside of permanent exclosures (Gerhardt, 2000). Site-specific analyses by functional group or individual species show differences in cover inside and outside exclosures at some sites and during some years (Fahnestock and Detling, 2000; Fahnestock and Detling, 1999).

\section{Cushion Plant Dynamics}

Cushion plants were mapped at two pairs of sites: North and South Dryhead and North and South Lockhart Ranch (Figure 1). All four are low-elevation, low-gradient sites located in grassland/juniper-grassland habitat within BICA. Cushion plant mapping was initiated at each site in 1994 and continued during 1995 and 1996.

Because of the history of site establishment, the Dryhead sites and the Lockhart Ranch sites measure responses to different system dynamics and management actions. To best interpret results, original site selection and plot placement should be considered. Permanent exclosures were erected at the Dryhead sites in 1992, primarily to monitor vegetation dynamics related to horse grazing. Permanent exclosures were established at the Lockhart Ranch sites in 1994 along the west side of Highway 14 outside the PMWHR boundary. When the exclosures were established, the road (Highway 14) served as a travel corridor for cattle trailing through BICA in spring and fall. Cattle were concentrated in the area by a fenceline to the east and a fenceline and gate immediately north of the North Lockhart Ranch Site. The impact of cattle trailing and grazing near the road was identified as a management concern because this area had previously been identified as supporting a rare cushion plant community. The Lockhart Ranch sites were established specifically to address BICA questions about the possible impact of cattle trailing on cushion plant communities. At each Lockhart Ranch site, three $25 \times 25$ m plots were established: control, exclosed, and native plots. Two plots were paired on opposite sides of the road, both of which were lined with cattle trails running approximately parallel to the road. A permanent exclosure was established around one of these plots to monitor changes in cushion plant communities when protected from additional trailing. A third $25 \mathrm{x} 25 \mathrm{~m}$ plot (native) was established west of the road in areas where cattle trails were not evident.

There is no evidence that horse grazing is affecting cushion plant frequency/cover based on sampling inside and outside permanent exclosures. No species showed significant grazing/exclosure effects at the North and South Dryhead sites (Table 3).

At the Lockhart Ranch sites Phlox hoodii was much more common in native plots than in either grazed/trampled or exclosed plots. In contrast, $P$. bryoides was less common in native plots. Differences between exclosed and nearby grazed/trampled plots were not significant for any species. The relative absence of $P$. hoodii in the grazed/trampled plot and the exclosed (previously grazed/trampled) suggests that cattle trailing reduced cover of this species, and that cover is not rebounding quickly toward more natural conditions. Trails are still clearly visible inside the exclosures (Attachment B), suggesting that these sites recover relatively slowly when trampled to bare ground. If cattle trailing continues through these areas, periodic sampling at these sites could show whether cushion 
plant community composition along the trails converges with the untrampled communities. Differences in species responses are likely due to differences in response to trampling or possibly to some effects of the road, as cushion plant species are not heavily grazed by cattle. In addition, the lower height of these 2 exclosures may not exclude deer, so some non-cattle grazing may still occur inside the exclosures.

\section{Regression Analyses}

Regressions indicate that grazing effects from an increasing wild horse population are mitigated for by increased precipitation. Thus drier years will show greater grazing effects when the wild horse population is higher, or closer to AML, than wetter years. This suggests that low levels of precipitation over the past few years are adding to the current range conditions.

\section{Conclusions and Management Considerations}

Vegetation monitoring in 2002 detected significant differences inside and outside the permanent exclosures for herbaceous biomass and cover. Total herbaceous biomass and grass biomass were lower outside exclosures at most sites; forb biomass and litter were generally higher inside exclosures (Figure 2 and Appendix B). Although not quite significant, correlations between percent biomass difference inside and outside exclosures with horse populations and precipitation suggest that biomass differences increase with increasing horse numbers and decrease with increasing precipitation (Figure 8).

Total cover and grass cover were significantly lower outside exclosures. Mean species richness was slightly higher (1.4 species) inside exclosures. Effects were not distributed equally across the exclosure network, and differences were greater at some sites than at others (Appendix B and Table 2).

Shrub production and cushion plant frequencies did not show effects due to exclosures. Shrub production was similar at both sampling sites and inside and outside exclosures. There is no evidence that horse grazing is affecting cushion plant frequency/cover based on sampling inside and outside permanent exclosures. At two sites inside the BICA and the PMWHR cushion plant frequencies in mapped plots did not differ between grazed and ungrazed plots.

\section{Recommendations for Future Sampling}

If managers plan to use the model developed by Coughenour $(1999,2000)$ to interpret system dynamics or predict the effects of natural events and planned management actions, vegetation monitoring should be prioritized based on the model tool. The model requires spatially-explicit data and generates spatially-explicit results. Planned (e.g., creating or eliminating water sources, fencing, habitat manipulation) and unplanned (e.g., natural fires, droughts, disease, range expansion) events influence grazing patterns, and the effects are likely to be detectable through vegetation monitoring at some sites more than others. The following suggestions are made for future monitoring efforts and use of monitoring data:

1. Sampling efforts should focus on sampling all sites, or as many possible. Because grazing distribution and habitat use and overlap are management concerns, collecting data at the largest number of exclosures possible seems wise. The ability of the model to utilize data distributed across the landscape and make localized predictions of vegetation dynamics is fully used when the full exclosure network is sampled.

2. Biomass measurements inside and outside the exclosures are important. Coughenour (1999) identified the lack of data on plant production in the long-term absence of grazing, and suggested that peak biomass be monitored across the exclosure network. In addition, species composition differences inside and outside exclosures in the PMWHR and BICA are small (Fahnestock, 1998; Stohlgren and others, 1999; Gerhardt and Detling, 2000) and probably respond more slowly to changes in grazing patterns. If only biomass were sampled, some information about grass:forb:litter ratios could be obtained by sorting samples. More 
intensive or full-scale monitoring efforts across the exclosures could be done occasionally, and site-specific concerns could be addressed with specific sampling designs.

3. Collected data should be incorporated into the developed ecosystem model when possible. Coughenour (1999) showed that vegetation dynamics vary across the PMWHR and BICA landscape. Detecting largescale trends in biomass or grazing intensity is complicated by the large differences in vegetation between sites. Averaging across sites and utilizing traditional statistics without including spatial information makes interpretation difficult, especially when different sites are sampled in different years. The ecosystem model is designed to make spatially explicit predictions about grazing patterns and vegetation dynamics, allowing informed decisions to be made at a landscape level. Including additional data also allows the model to be refined and accuracy improved.

4. Site specific questions may require more intensive sampling than is needed for monitoring efforts. The current study sampled 5 plots inside and outside exclosures at each site. This level of sampling proved sufficient to detect differences due to grazing when data was analyzed across the exclosure network. However, statistical tests at each site would have little power with this few samples. One example of where higher sample sizes could be required is in detecting offtake. Some attempts to detect growing season or monthly grazing offtake using temporary cages demonstrate the large sample sizes that can be required, especially when vegetation is patchy and bare ground is high (Peterson and others, 1997; Peterson, 1999). Sampling efforts designed to detect localized or short-term effects should consider the probable need for higher sample sizes, especially at lower elevation sites.

\section{Literature Cited}

Bureau of Land Management, 1984, Herd management area plan, Pryor Mountain Wild Horse Range: U.S. Department of the Interior, Bureau of Land Management, Miles City District Office, Billings Resource Area, Mont.

Bureau of Land Management, 1997, Pryor Mountain Wild Horse Range, Wild Horse Removal Plan: U.S. Department of the Interior, Bureau of Land Management, Miles City District Office, Billings Resource Area, Mont.

Coates, K.P., and Schemnitz, S.D., 1988, Habitat utilization, interspecific interactions and status of a recolonized population of bighorn sheep at a wild horse range: Completion report to the University of Wyoming - National Park Service Research Center and Bighorn Canyon National Recreation Area.

Coates, K.P., and Schemnitz, S.D., 1989, The bighorn sheep of Bighorn Canyon National Recreation Area and Pryor Mountain Wild Horse Range: ecological relationships and management recommendations: Completion report to National Park Service and the Bureau of Land Management.

Coughenour, M.B., 1999, Ecosystem modeling of the Pryor Mountain Wild Horse Range: Final report to the U.S. Geological Survey, National Park Service, and Bureau of Land Management.

Coughenour, M.B., 2000, Ecosystem modeling of the Pryor Mountain Wild Horse Range, in Singer, F.J. and Schoenecker, K.A., compilers, Manager's summary - Ecological studies of the Pryor Mountain Wild Horse Range, 1992-1997: U.S. Geological Survey, Midcontinent Ecological Science Center, Fort Collins, Colo., p. 125-131.

Fahnestock, J.T., 1998, Vegetation responses to herbivory and resource supplementation in the Pryor Mountain Wild Horse Range: Ph.D. dissertation. Colorado State University, Fort Collins.

Fahnestock, J.T., and Detling, J.K., 1999, The influence of herbivory on plant cover and species composition in the Pryor Mountain Wild Horse Range, USA: Plant Ecology, vol. 44, p. 145-157.

Fahnestock, J.T., and Detling, J.K., 2000, The influence of herbivory on plant cover and species composition in the Pryor Mountain Wild Horse Range, USA, in Singer, F.J. and Schoenecker, K.A., compilers: Manager's summary - Ecological studies of the Pryor Mountain Wild Horse Range, 1992-1997: U.S. Geological Survey, Midcontinent Ecological Science Center, Fort Collins, Colo, p. 37-62.

Gerhardt, T.D., 2000, Plant cover species richness in the Pryor Mountain Wild Horse Range-1998, in Singer, F.J. and Schoenecker, K.A., compilers, Manager's summary - Ecological studies of the Pryor Mountain Wild Horse Range, 1992-1997: U.S. Geological Survey, Midcontinent Ecological Science Center, Fort Collins, Colo, p. 63-69.

Gerhardt, T.D., and Detling, J.K., 1998, Monitoring vegetation in the Pryor Mountain Wild Horse Range: Addendum report to the U.S. National Park Service.

Gerhardt, T.D., and Detling, J.K., 2000, Summary of vegetation dynamics at the Pryor Mountain Wild Horse Range, 1992-1996, in Singer, F.J., and Schoenecker, K.A., comp., Manager's summary - Ecological studies of the Pryor Mountain Wild Horse Range, 1992-1997: U.S. Geological Survey, Midcontinent Ecological Science Center, Fort Collins, Colo, p. 3-36. 
Kissell, R.E., Jr., 1996, Competitive interactions among bighorn sheep, feral horses, and mule deer in the Bighorn Canyon National Recreation Area and the Pryor Mountain Wild Horse Range: Ph.D. dissertation, Montana State University, Bozeman.

Kissell, R.E., Jr., Irby, L.R., and Mackie, R.J., 1996, Competitive interactions among bighorn sheep, feral horses, and mule deer in Bighorn Canyon National Recreation Area and Pryor Mountain Wild Horse Range: Completion report.

Knight, D.H., Jones, G.P., Akashi, Y., and Myers, R.W., 1987, Vegetation ecology in the Bighorn Canyon National Recreation Area: Final report submitted to the U.S. National Park Service and the University of Wyoming - National Park Service Research Center.

Peterson, J. 1999, Ungulate/vegetation dynamics in the Pryor Mountain Wild Horse Range: Ph.D. dissertation. Colorado State University, Fort Collins.

Peterson, J., Fahnestock, J., and Detling, J.K., 1997, Ungulate/vegetation interactions at the Pryor Mountain Wild Horse Range: Completion report to the U.S. National Park Service and the Bureau of Land Management.

Singer, F.J., and Schoenecker, K.A., compilers, 2000, Manager's summary - Ecological studies of the Pryor Mountain Wild Horse Range, 1992 -1997: U.S. Geological Survey, Midcontinent Ecological Science Center, Fort Collins, Colo, $131 \mathrm{p.}$

Singer, F.J., Zeigenfuss, L., Coates-Markle, L., and Schwieger, F., 2000, A demographic analysis, group dynamics, and genetic effective number in the Pryor Mountain Wild Horse Range, 1992-1997, in Singer, F.J. and Schoenecker, K.A., compilers, Manager's summary - Ecological studies of the Pryor Mountain Wild Horse Range, 1992-1997: U.S. Geological Survey, Midcontinent Ecological Science Center, Fort Collins, Colo, p. 73-89.

Stohlgren, T.J., Schell, L.D., and Vanden Heuvel, B., 1999, How grazing and soil quality affect native and exotic plant diversity in Rocky Mountain grasslands: Ecological Applications, vol. 9, p. 45-64. 
Appendix A. Plots of total herbaceous plant biomass at 10 sites for the period 1992-2002. All estimates are from early July sampling efforts inside and outside permanent exclosures. Data from 1992-1994 were obtained from Peterson and others (1997) and Peterson (1999). Data from 1994-1996 were obtained from Gerhardt and Detling (1998). Data from 2002 were collected as part of this project. Mean biomass was estimated by clipping inside and outside permanent exclosures. Sample size per plot per site was 5 in 2002 and ranged from 15-10 plot/site/year from 1992-1996. Establishment date for each exclosure is shown below the site name. Estimates include live and dead aboveground material.
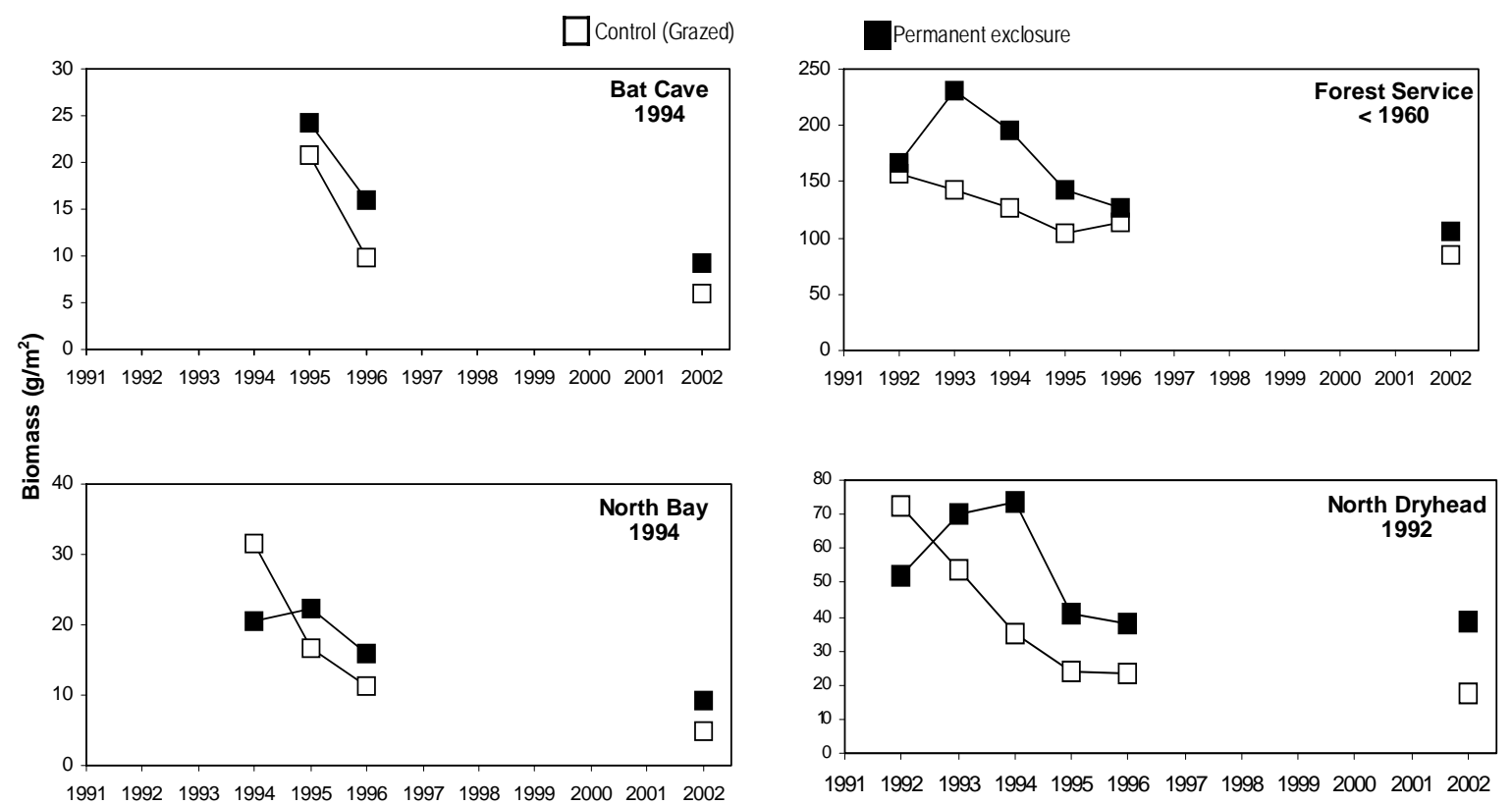

Year
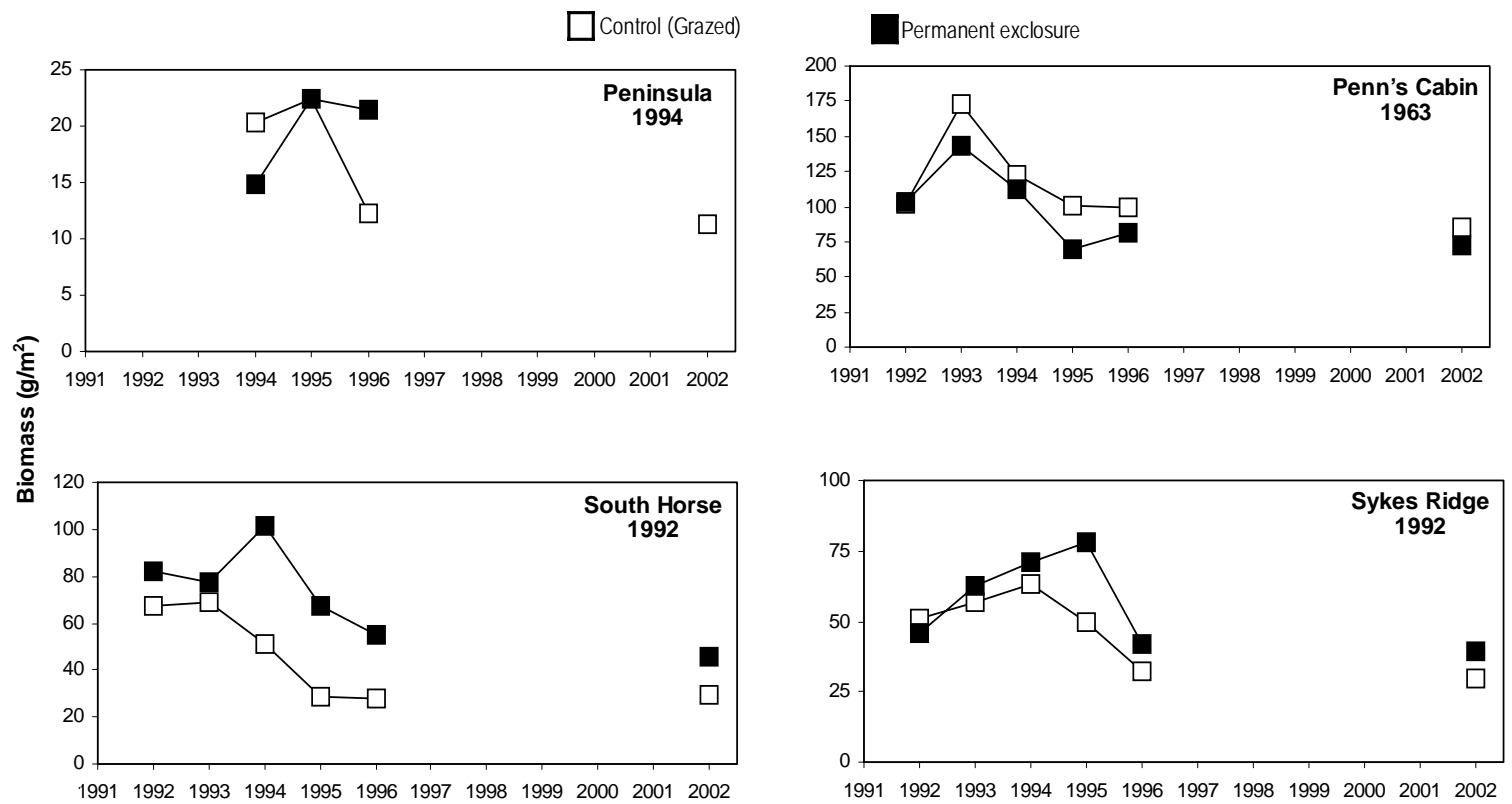

Year 
Appendix A. Plots of total herbaceous plant biomass at 10 sites for the period 1992-2002.—Continued.

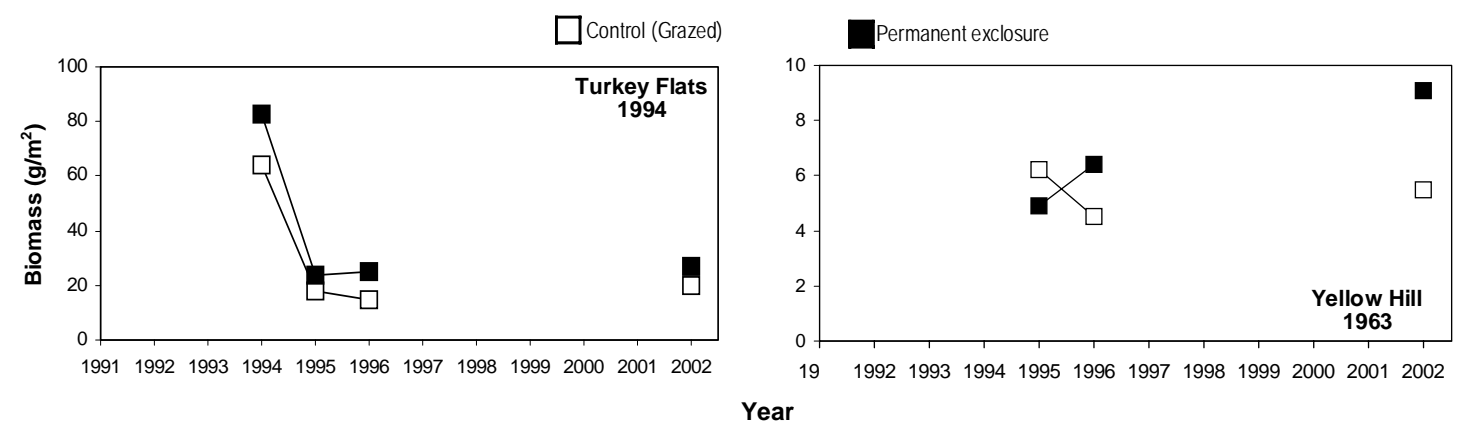


Appendix B. Mean herbaceous biomass of live grass, current years' dead grass, previous years' dead grass, forbs and dwarf shrubs, and total for each site in 2002 (mean and standard error shown). Dead forbs were typically a very small proportion of total biomass and are included with forbs and dwarf shrubs. Biomass in the grazed plot (outside of exclosure) and inside the permanent exclosure is shown in 12 sites. Notice that the y-axis has a different scale for each site.
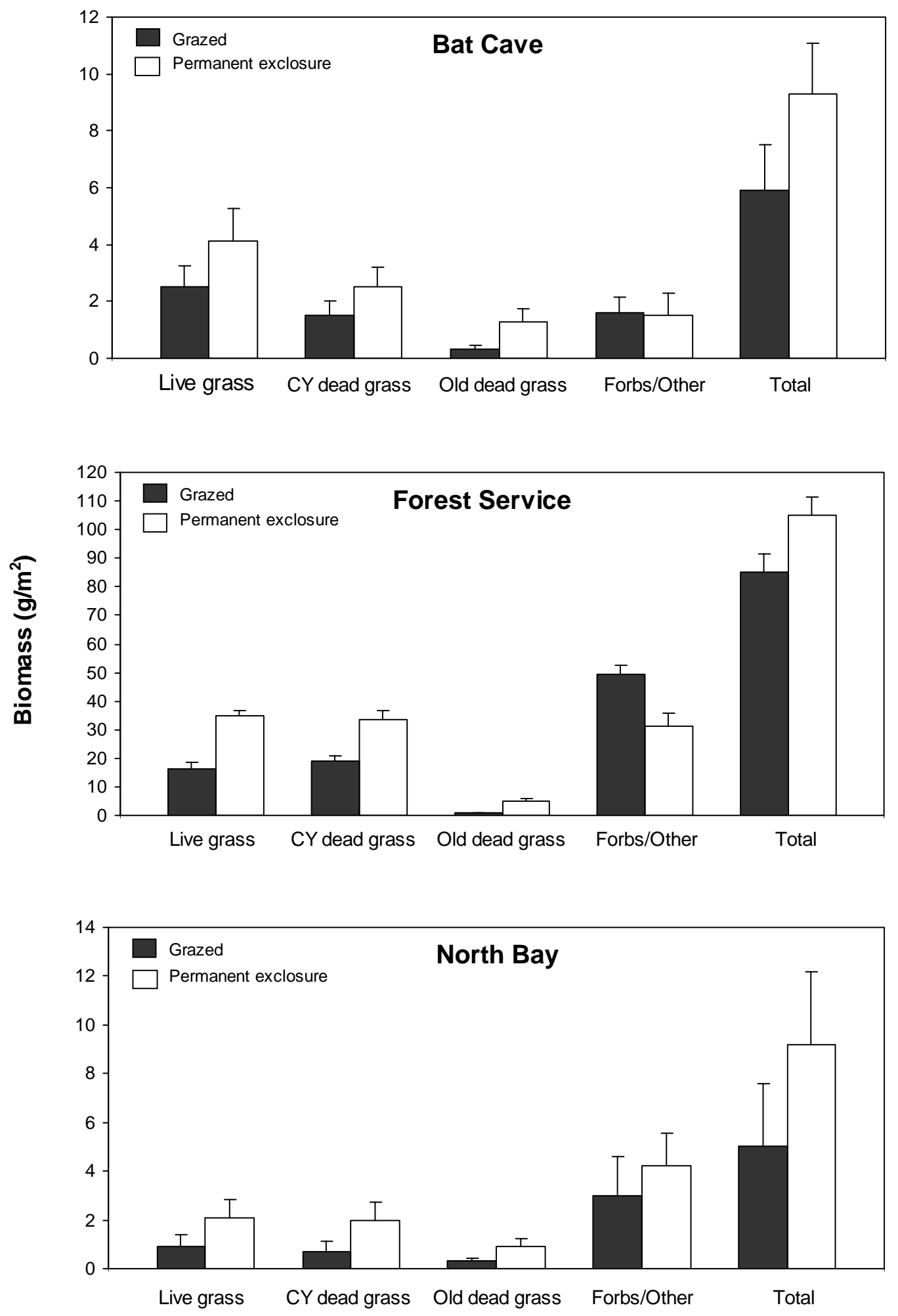
Appendix B. Mean herbaceous biomass of live grass, current years' dead grass, previous years' dead grass, forbs and dwarf shrubs, and total for each site in 2002-Continued.
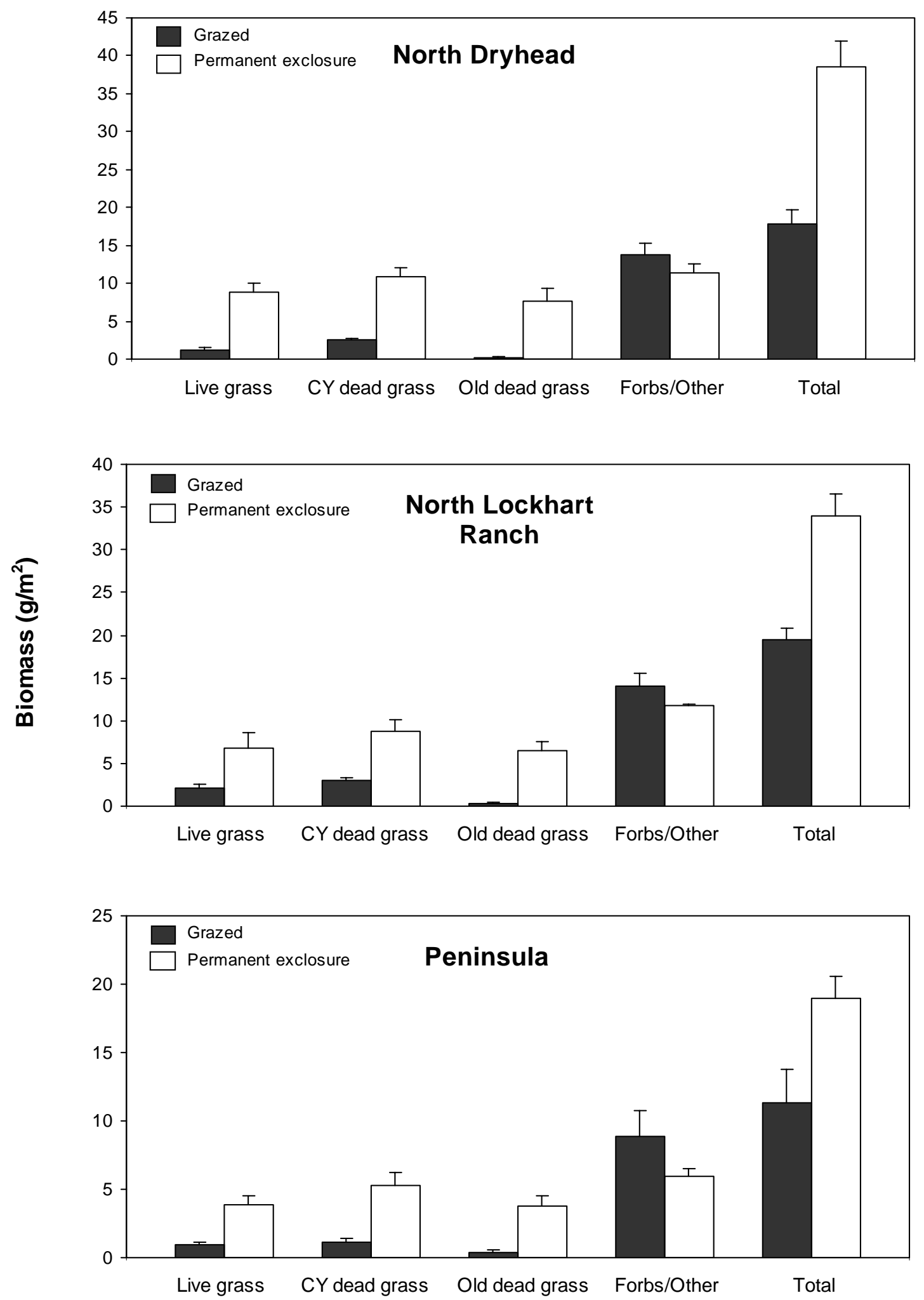
Appendix B. Mean herbaceous biomass of live grass, current years' dead grass, previous years' dead grass, forbs and dwarf shrubs, and total for each site in 2002-Continued.
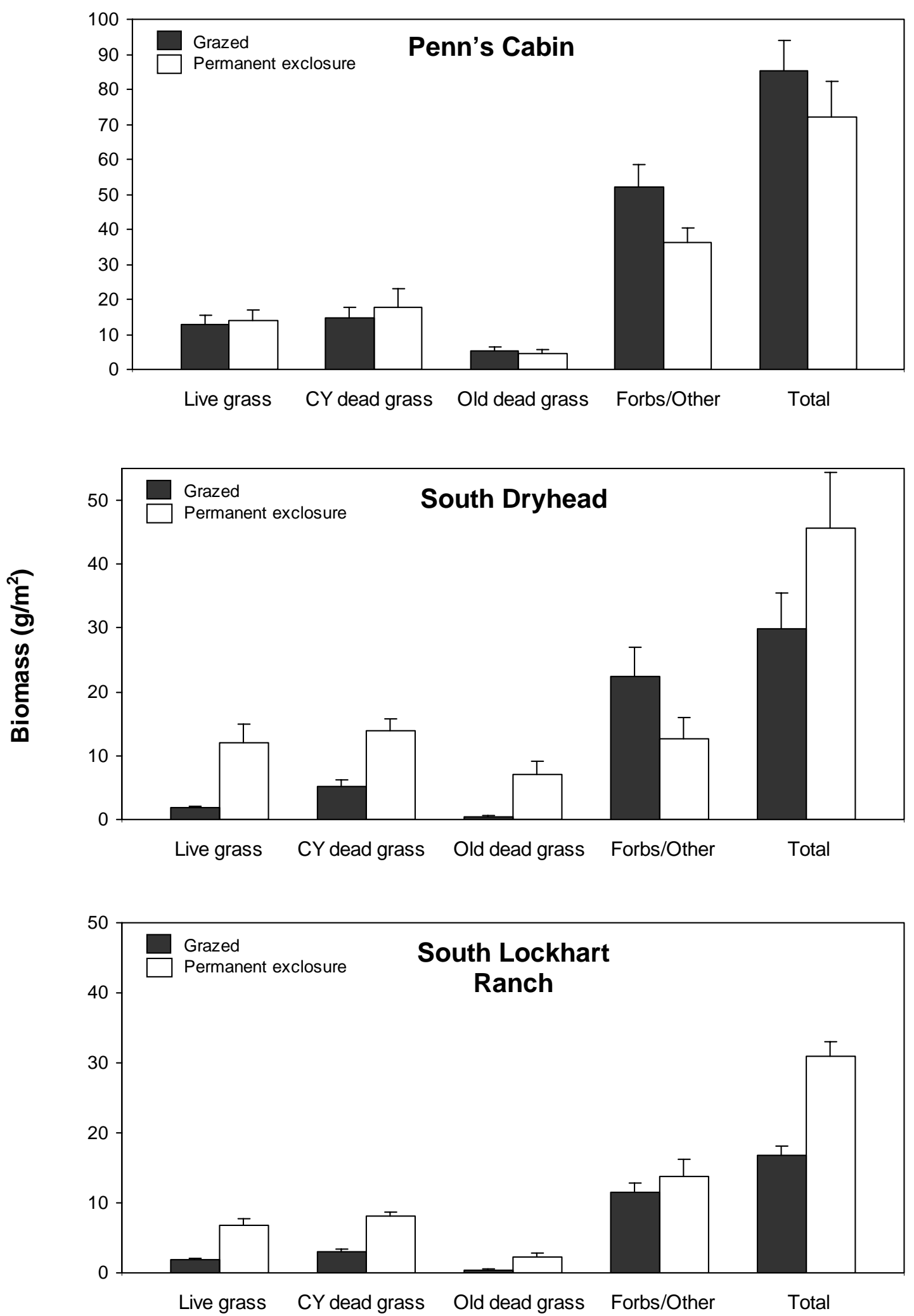
Appendix B. Mean herbaceous biomass of live grass, current years' dead grass, previous years' dead grass, forbs and dwarf shrubs, and total for each site in 2002-Continued.
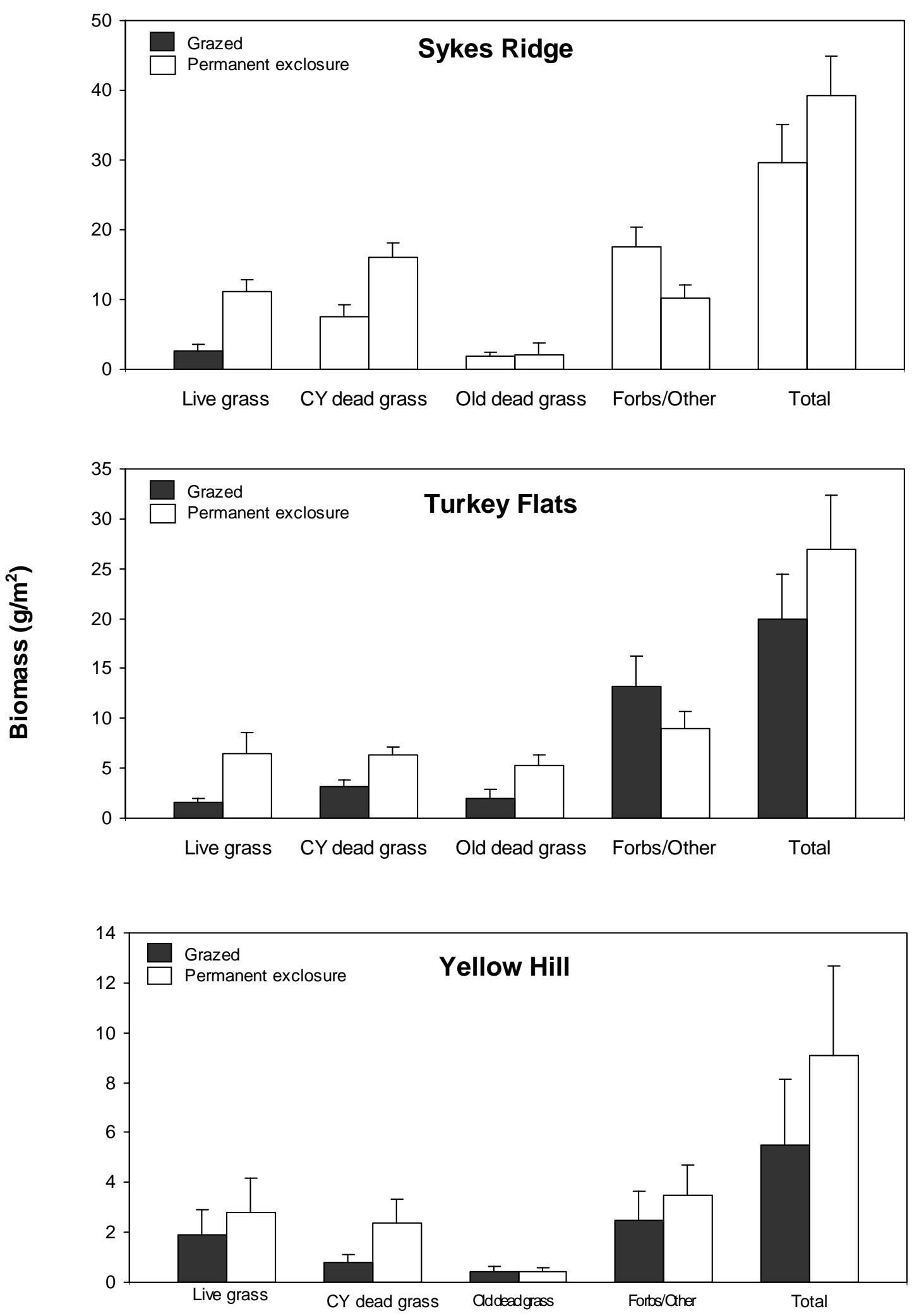
Appendix C. Cover and species richness in grazed and permanently exclosed plots. Data provided indicates the difference between exclosed and grazed plots $\left(\%\right.$ cover $_{\text {exclosed }}-\%$ cover $\left._{\text {grazed }}\right)$. Results are provided by functional group/variable. A positive number indicates that the variable was higher inside the permanent exclosure; a negative number indicates the variable was lower inside the exclosure. Sites are listed from most positive to most negative for each variable. Mean difference and $P$ values are provided (paired t-tests). Cover data is provided separately in digital report.

Total Plant

$$
\text { Mean }=6.0 \quad P=0.034
$$

\begin{tabular}{c|c}
\hline \hline Site & Difference \\
\hline Sykes Ridge & 19.3 \\
South Dryhead & 13.9 \\
North Bay & 10.5 \\
Peninsula & 10.3 \\
Turkey Flats & 8.0 \\
Forest Service & 7.8 \\
Yellow Hill & 7.5 \\
North Dryhead & 6.5 \\
North Lockhart Ranch & 6 \\
South Lockhart Ranch & 1.5 \\
Bat Cave & -2 \\
Penn's Cabin & -17.5
\end{tabular}

Forbs

Mean $=-0.1 \quad P=0.414$

\begin{tabular}{c|c}
\hline \hline Site & Difference \\
\hline Peninsula & 5.0 \\
Forest Service & 3.4 \\
Yellow Hill & 1.0 \\
South Lockhart Ranch & 1.0 \\
North Bay & 0.8 \\
Sykes Ridge & 0.8 \\
Turkey Flats & 0.3 \\
North Lockhart Ranch & 0.0 \\
North Dryhead & 0.0 \\
South Dryhead & -0.4 \\
Bat Cave & -0.8 \\
Penn's Cabin & -12.5
\end{tabular}

\section{Grass}

$$
\text { Mean }=7.7 \quad P=0.004
$$

\begin{tabular}{c|c}
\hline \hline Site & Difference \\
\hline Peninsula & 21.0 \\
North Dryhead & 16.5 \\
Sykes Ridge & 14.0 \\
Forest Service & 13.5 \\
Turkey Flats & 11.3 \\
South Dryhead & 10.9 \\
North Bay & 5.0 \\
Bat Cave & 3.8 \\
North Lockhart Ranch & 0.8 \\
South Lockhart Ranch & 0.3 \\
Yellow Hill & 0 \\
Penn's Cabin & -5.0
\end{tabular}

\section{Shrubs / Dwarf Shrubs}

Mean $=-0.6 \quad P=0.423$

\begin{tabular}{c|c}
\hline \hline Site & Difference \\
\hline Bat Cave & 6.0 \\
Yellow Hill & 1.5 \\
Forest Service & 0.0 \\
South Lockhart Ranch & 0.0 \\
Penn's Cabin & 0.0 \\
North Bay & -0.3 \\
North Lockhart Ranch & -0.3 \\
Turkey Flats & -1.0 \\
North Dryhead & -1.3 \\
South Dryhead & -1.3 \\
Sykes Ridge & -2.0 \\
Peninsula & -8.3
\end{tabular}


Appendix C. Cover and species richness in grazed and permanently exclosed plots.-Continued.

\section{Cercocarpus}

Mean $=-0.4 \quad P=0.809$

\begin{tabular}{c|c}
\hline \hline Site & Difference \\
\hline Yellow Hill & 6.0 \\
North Lockhart Ranch & 0.0 \\
Penns Cabin & 0.0 \\
Forest Service & 0.0 \\
North Dryhead & 0.0 \\
Peninsula & 0.0 \\
South Lockhart Ranch & 0.0 \\
Turkey Flats & 0.0 \\
Sykes Ridge & 0.0 \\
South Dryhead & 0.0 \\
North Bay & -0.3 \\
Bat Cave & -10.1
\end{tabular}

\section{Cushion Plants}

Mean $=0.3 \quad P=0.859$

\begin{tabular}{c|c}
\hline \hline Site & Difference \\
\hline Sykes Ridge & 6.0 \\
North Lockhart Ranch & 4.8 \\
South Lockhart Ranch & 2.3 \\
South Dryhead & 0.5 \\
North Bay & 0.3 \\
Forest Service & 0.0 \\
Penn's Cabin & 0.0 \\
Turkey Flats & 0.0 \\
Yellow Hill & -1.0 \\
Bat Cave & -1.3 \\
Peninsula & -3.0 \\
North Dryhead & -5.5
\end{tabular}

\section{Cactus}

$$
\text { Mean }=-0.1 \quad P=0.589
$$

\begin{tabular}{c|c}
\hline \hline Site & Difference \\
\hline South Dryhead & 1.0 \\
Sykes Ridge & 0.3 \\
North Lockhart Ranch & 0.0 \\
South Lockhart Ranch & 0.0 \\
Forest Service & 0.0 \\
Penn's Cabin & 0.0 \\
Turkey Flats & 0.0 \\
Yellow Hill & 0.0 \\
Bat Cave & 0.0 \\
Peninsula & 0.0 \\
North Bay & -0.3 \\
North Dryhead & -1.8
\end{tabular}

\section{Bare Ground}

$$
\text { Mean }=-9.5 \quad P=0.013
$$

\begin{tabular}{c|c}
\hline \hline Site & Difference \\
\hline Bat Cave & 13.8 \\
Penn's Cabin & 4.5 \\
North Bay & 1.5 \\
South Lockhart Ranch & -7.3 \\
Sykes Ridge & -11.5 \\
Turkey Flats & -11.9 \\
Yellow Hill & -13.5 \\
Peninsula & -14.8 \\
South Dryhead & -16.0 \\
North Dryhead & -16.5 \\
North Lockhart Ranch & -19.5 \\
Forest Service & -23.3
\end{tabular}


Appendix C. Cover and species richness in grazed and permanently exclosed plots.-Continued.

\section{Rock}

Mean $=-9.5 \quad P=0.919$

\begin{tabular}{c|c}
\hline \hline Site & Difference \\
\hline Penn's Cabin & 11.8 \\
North Dryhead & 5.8 \\
South Lockhart Ranch & 3.5 \\
Turkey Flats & 2.5 \\
Peninsula & 0 \\
North Lockhart Ranch & 0 \\
Sykes Ridge & -0.8 \\
South Dryhead & -1.3 \\
Forest Service & -1.5 \\
North Bay & -3.7 \\
Yellow Hill & -4.8 \\
Bat Cave & -11.5
\end{tabular}

\section{Species richness}

Mean $=1.4 \quad P=0.018$

\begin{tabular}{c|c}
\hline \hline Site & Difference \\
\hline North Lockhart Ranch & 5 \\
Bat Cave & 4 \\
Penn's Cabin & 2 \\
Forest Service & 2 \\
Yellow Hill & 2 \\
South Dryhead & 1 \\
South Lockhart Ranch & 1 \\
Turkey Flats & 1 \\
Sykes Ridge & 0 \\
Peninsula & 0 \\
North Bay & 0 \\
North Dryhead & -1
\end{tabular}

\section{Litter}

$$
\text { Mean }=8.9 \quad P<0.001
$$

\begin{tabular}{c|c}
\hline \hline Site & Difference \\
\hline Forest Service & 18.8 \\
South Dryhead & 17.3 \\
Turkey Flats & 16.8 \\
Sykes Ridge & 14.5 \\
North Dryhead & 8.8 \\
North Bay & 7.5 \\
Bat Cave & 7.5 \\
North Lockhart Ranch & 6.8 \\
Peninsula & 3.4 \\
Penn's Cabin & 2.5 \\
Yellow Hill & 1.3 \\
South Lockhart Ranch & 1
\end{tabular}


Appendix C. Cover and species richness in grazed and permanently exclosed plots.-Continued.

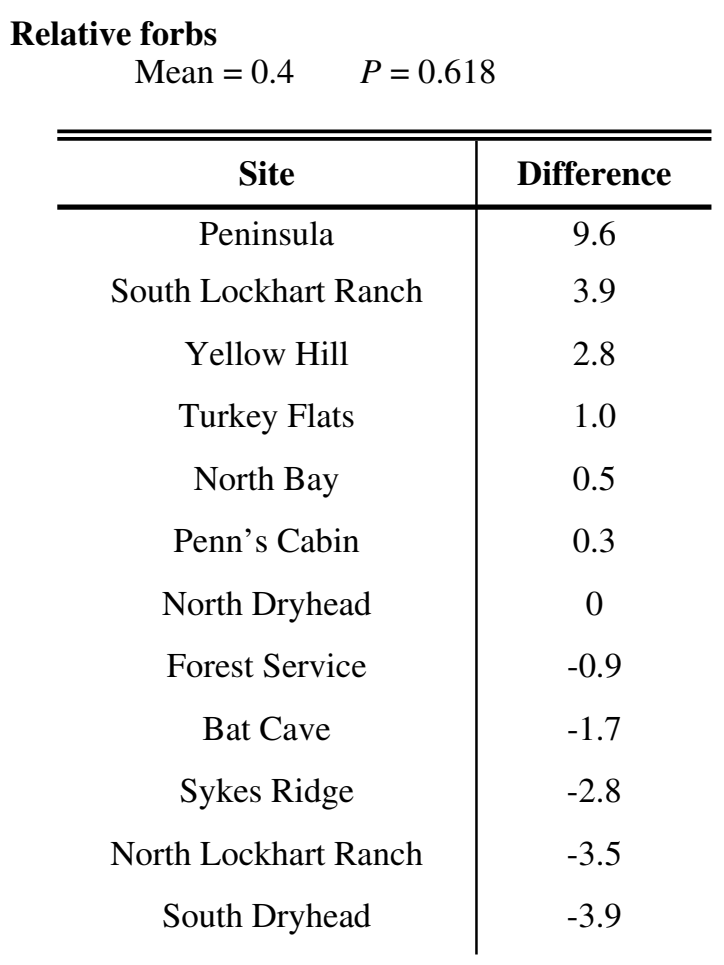

\section{Relative grass}

Mean $=12.5 \quad P=0.013$

\begin{tabular}{c|c}
\hline \hline Site & Difference \\
\hline Turkey Flats & 38.9 \\
Peninsula & 37.9 \\
Sykes Ridge & 24.3 \\
Forest Service & 22.7 \\
North Bay & 12.9 \\
Bat Cave & 10.8 \\
South Dryhead & 5.1 \\
North Dryhead & 0 \\
Penn's Cabin & -0.3 \\
Yellow Hill & -0.6 \\
South Lockhart Ranch & -1.0 \\
North Lockhart Ranch & -1.3
\end{tabular}

\section{Relative shrubs/dwarf shrubs}

Mean $=-7.3 \quad P=0.067$

\begin{tabular}{c|c}
\hline \hline Site & Difference \\
\hline Bat Cave & 17.3 \\
Penn's Cabin & 0 \\
North Dryhead & 0 \\
Forest Service & 0 \\
Yellow Hill & -1.1 \\
South Lockhart Ranch & -1.3 \\
North Lockhart Ranch & -5.1 \\
South Dryhead & -8.4 \\
North Bay & -16.9 \\
Sykes Ridgekes Ridge & -21.9 \\
Peninsula & -24.0 \\
Turkey Flats & -26.6
\end{tabular}

Relative Cercocarpus

Mean $=-0.1 \quad P=0.373$

\begin{tabular}{c|c}
\hline \hline Site & Difference \\
\hline Yellow Hill & 0.1 \\
Sykes Ridge & 0 \\
South Dryhead & 0 \\
Peninsula & 0 \\
Turkey Flats & 0 \\
Forest Service & 0 \\
North Dryhead & 0 \\
North Lockhart Ranch & 0 \\
South Lockhart Ranch & 0 \\
Penn's Cabin & 0 \\
North Bay & -0.1 \\
Bat Cave & -0.3
\end{tabular}


Appendix C. Cover and species richness in grazed and permanently exclosed plots.-Continued.

\section{Relative cushion plant}

Mean $=-1.6 \quad P=0.227$

\begin{tabular}{c|c}
\hline \hline Site & Difference \\
\hline South Lockhart Ranch & 9.1 \\
North Lockhart Ranch & 6.4 \\
Penn's Cabin & 0 \\
North Dryhead & 0 \\
Forest Service & 0 \\
Sykes Ridge & -0.6 \\
North Bay & -0.7 \\
Turkey Flats & -0.9 \\
Bat Cave & -2.9 \\
Yellow Hill & -7.4 \\
South Dryhead & -9.2 \\
Peninsula & -12.8
\end{tabular}

\section{Relative cactus}

Mean $=-0.1 \quad P=0.824$

\begin{tabular}{c|c}
\hline \hline Site & Difference \\
\hline South Dryhead & 1.2 \\
Sykes Ridge & 0.5 \\
South Lockhart Ranch & 0 \\
North Lockhart Ranch & 0 \\
Penn's Cabin & 0 \\
North Dryhead & 0 \\
Forest Service & 0 \\
Turkey Flats & 0 \\
Bat Cave & 0 \\
Yellow Hill & 0 \\
Peninsula & -0.9 \\
North Bay & -1.1
\end{tabular}




\section{Attachment A. Permanent Exclosure Site Photos}

Photographs were taken when vegetation was sampled (early July 2002) and are provided in alphabetical order by site name. For most sites, four views are included: along the permanent exclosure boundary, close-up view of vegetation inside the exclosure, close-up view of vegetation outside the permanent exclosure, temporary grazing cages. Established grazed plots $(50 \times 50 \mathrm{~m})$ are not located directly adjacent to the permanent exclosure at all sites. 


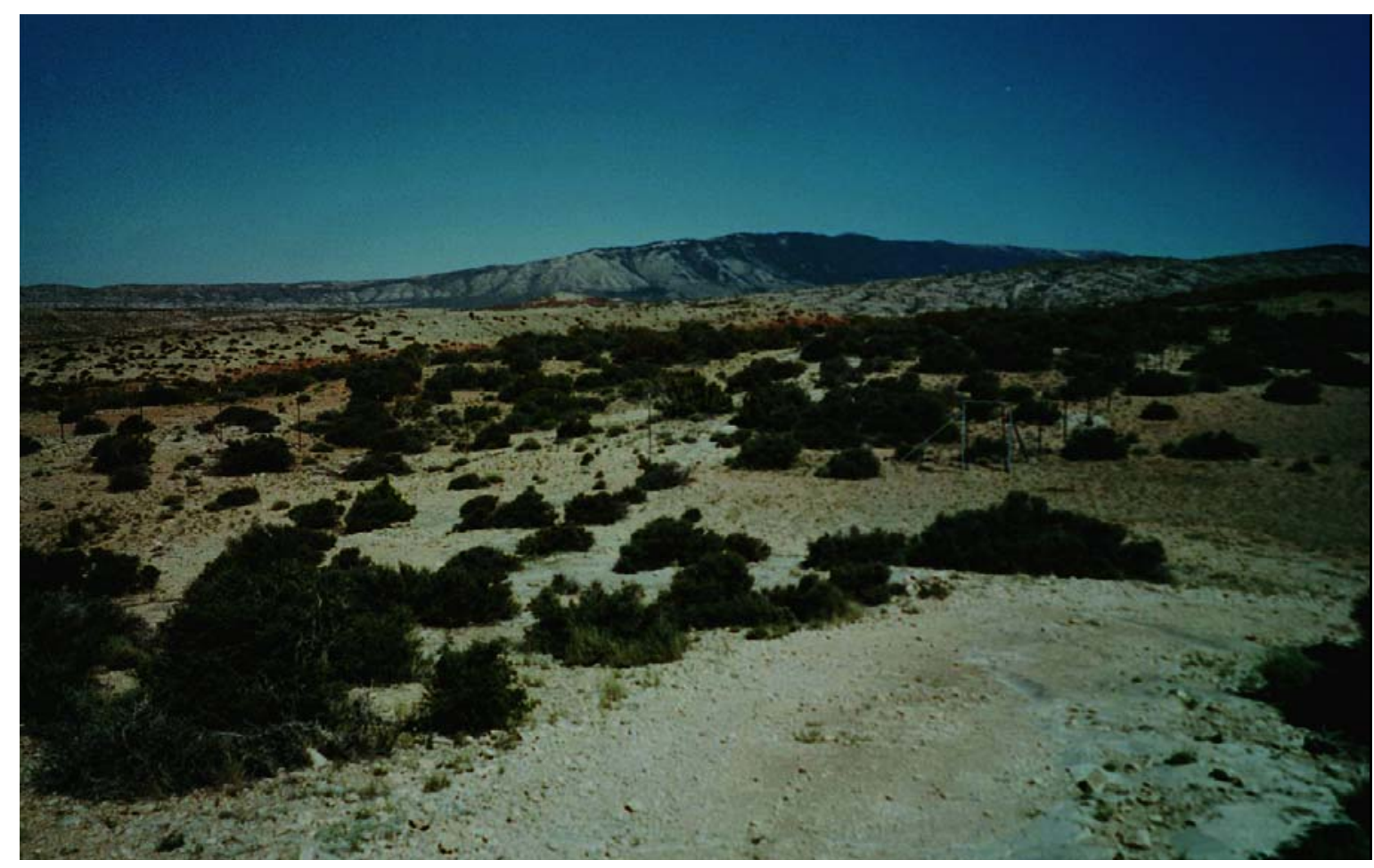

Photo 1. Bat Cave - View of permanent exclosure. Exclosure was established in 1994. Unpaved road is visible bending to the right from the center foreground.

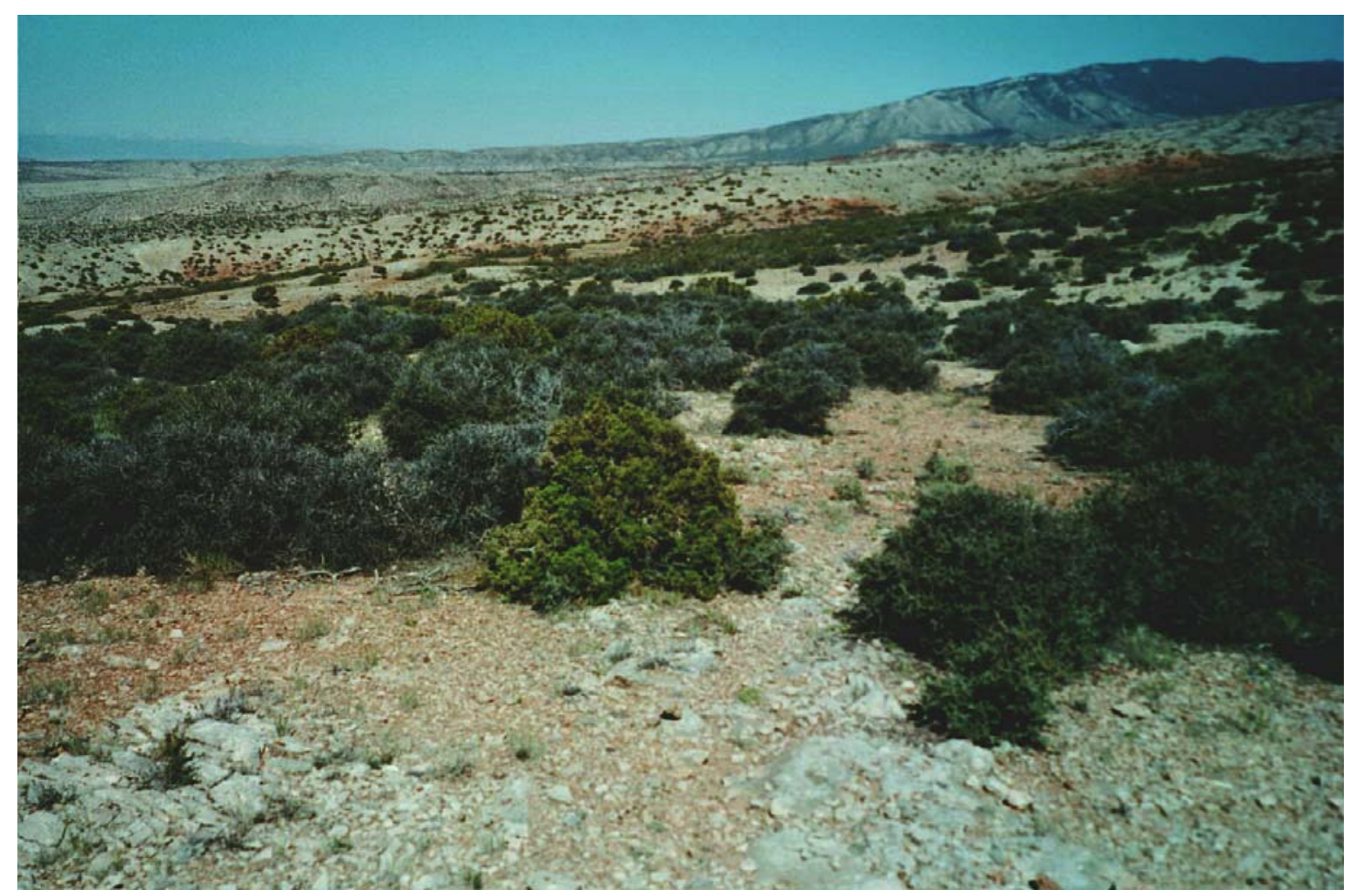

Photo 2. Bat Cave - View of control plot. 


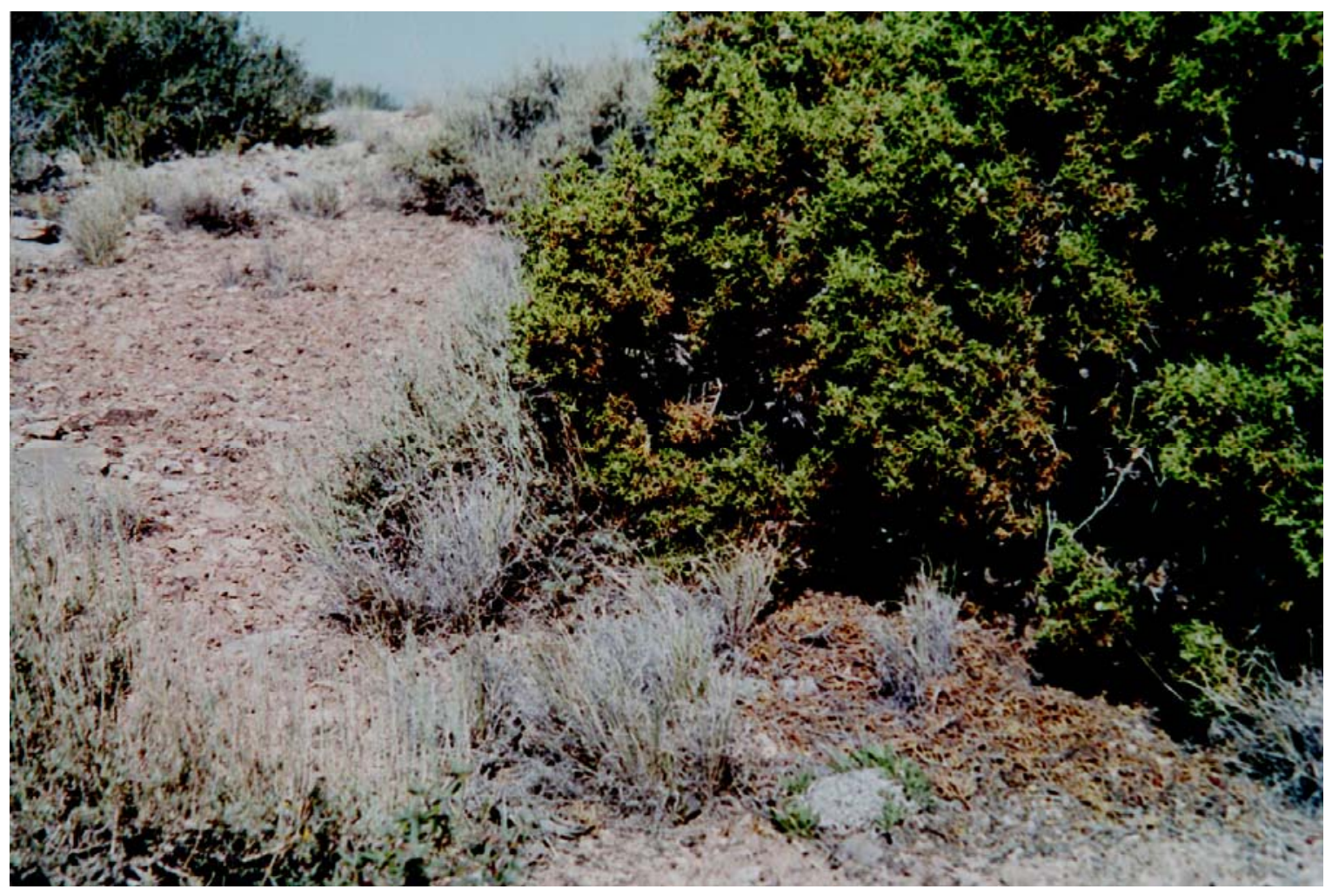

Photo 3. Bat Cave - Close view of vegetation inside exclosure.

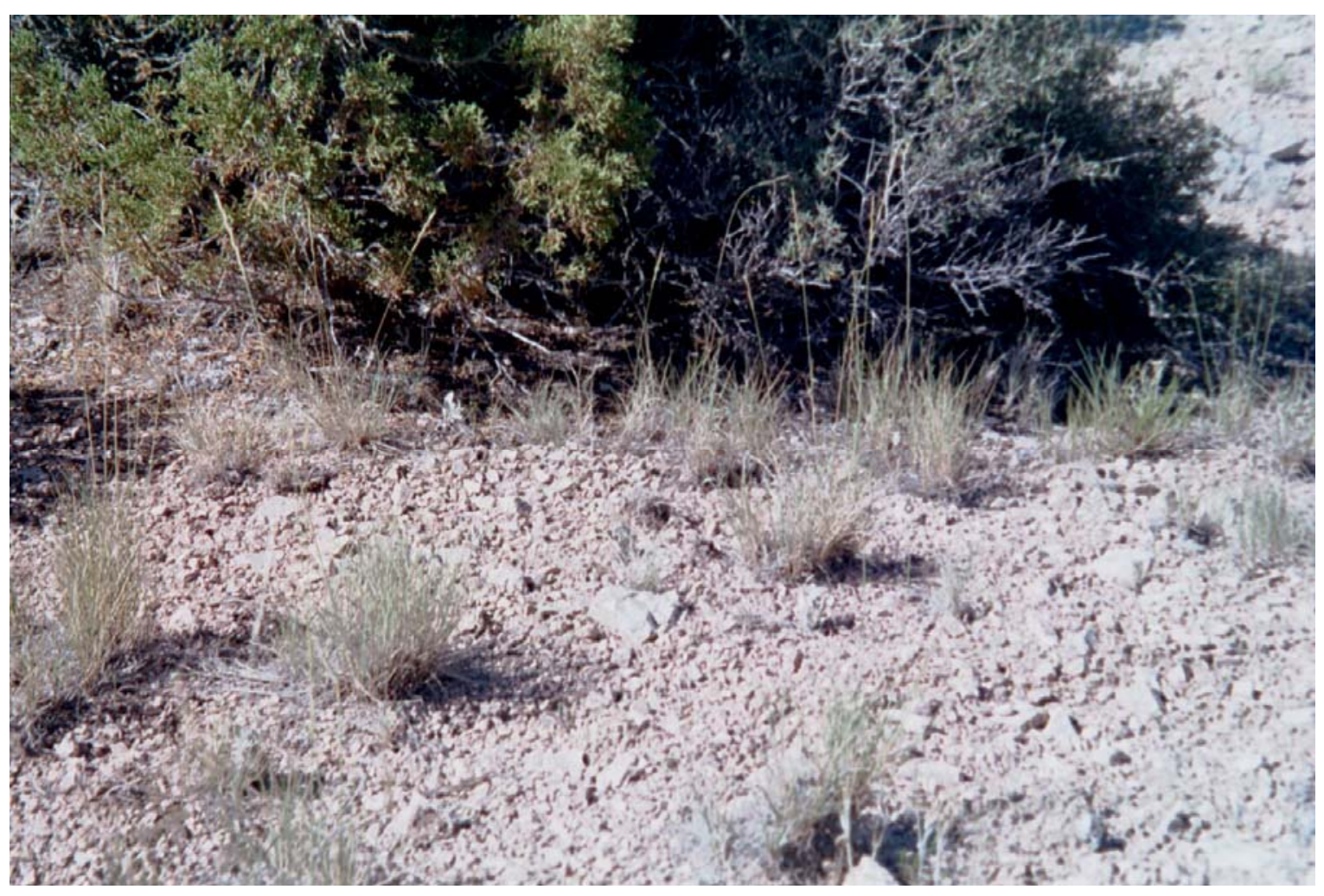

Photo 4. Bat Cave - Close view of vegetation outside of permanent exclosure in control plot. 


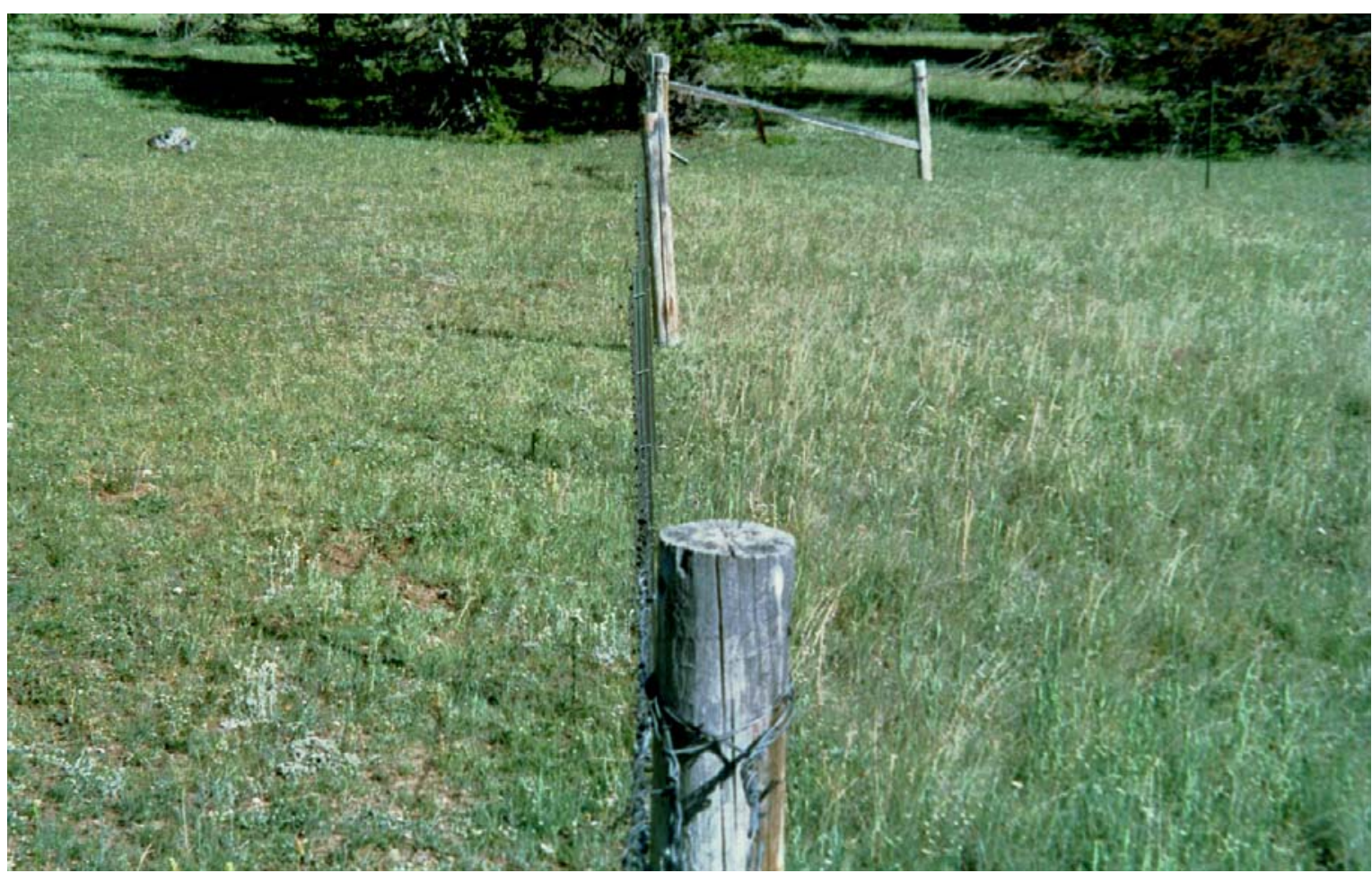

Photo 5. Forest Service - View along permanent exclosure fence. Vegetation inside the exclosure (right) has presumably been protected from grazing since the exclosure was erected over 40 years ago.

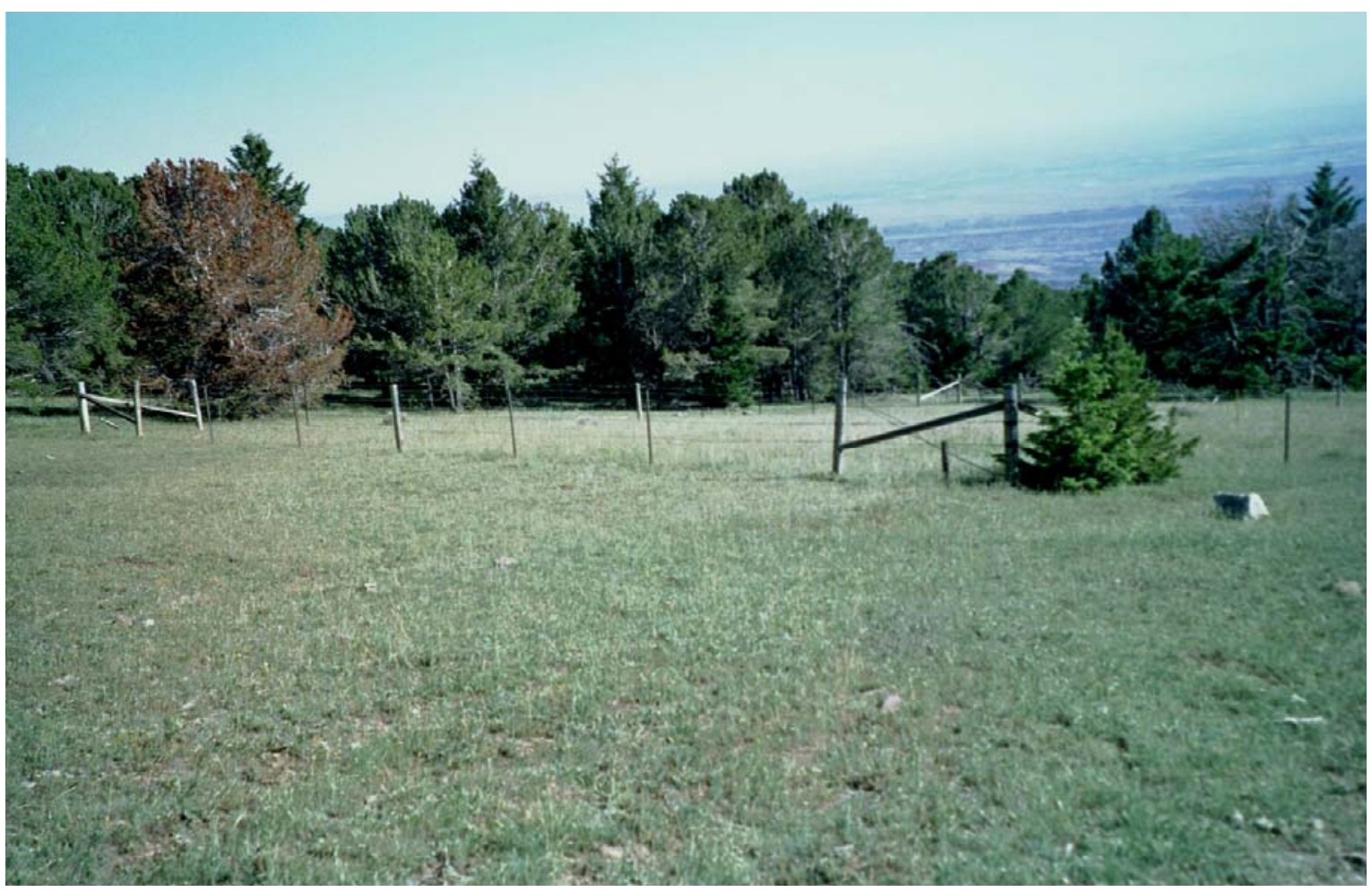

Photo 6. Forest Service - View of permanent exclosure from Burnt Timber Ridge Road. 


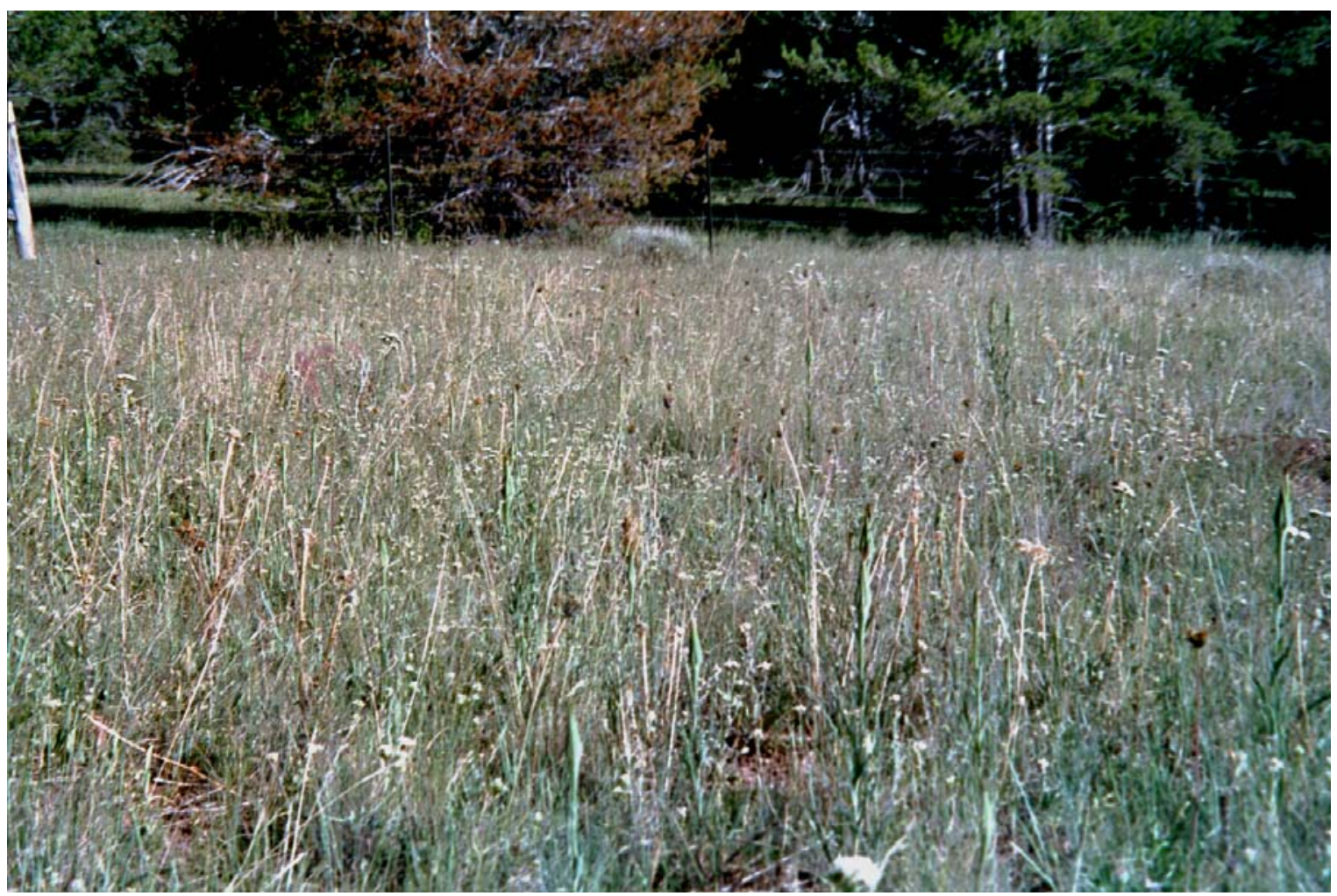

Photo 7. Forest Service - Close view of vegetation inside the permanent exclosure.

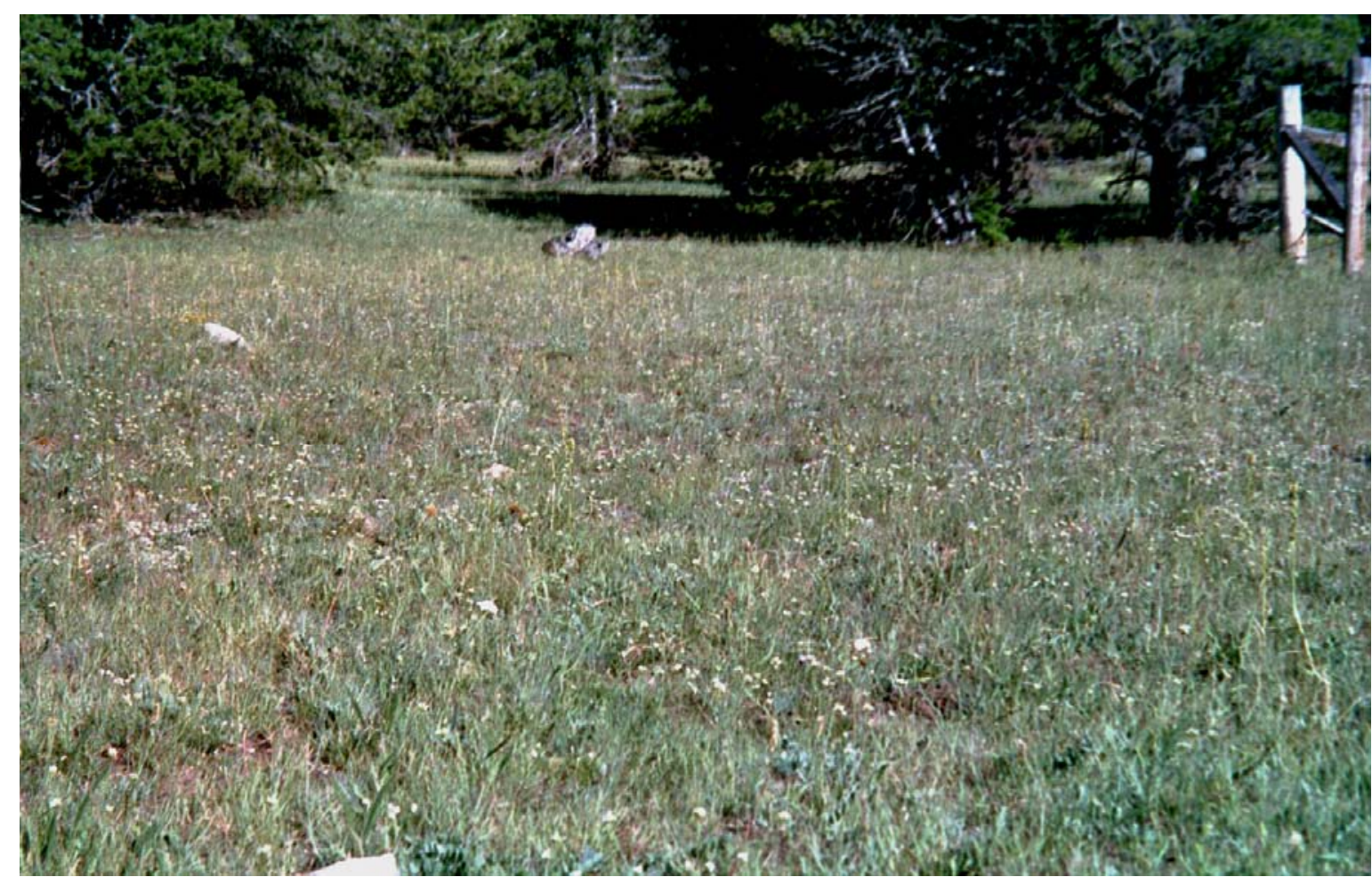

Photo 8. Forest Service - Close view of vegetation outside the permanent exclosure. 


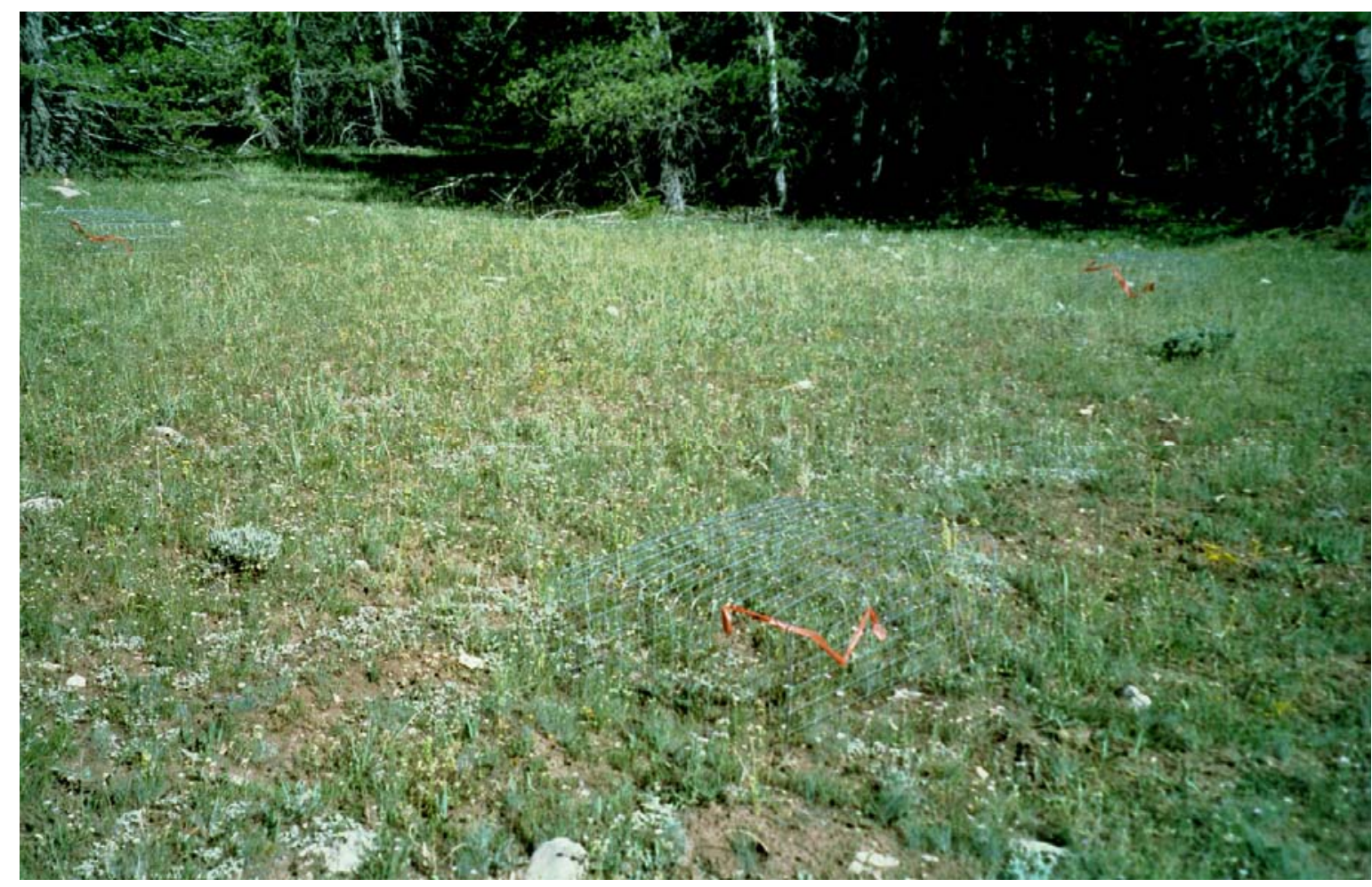

Photo 9. Forest Service - Close view of temporary grazing cages placed outside the permanent exclosure.

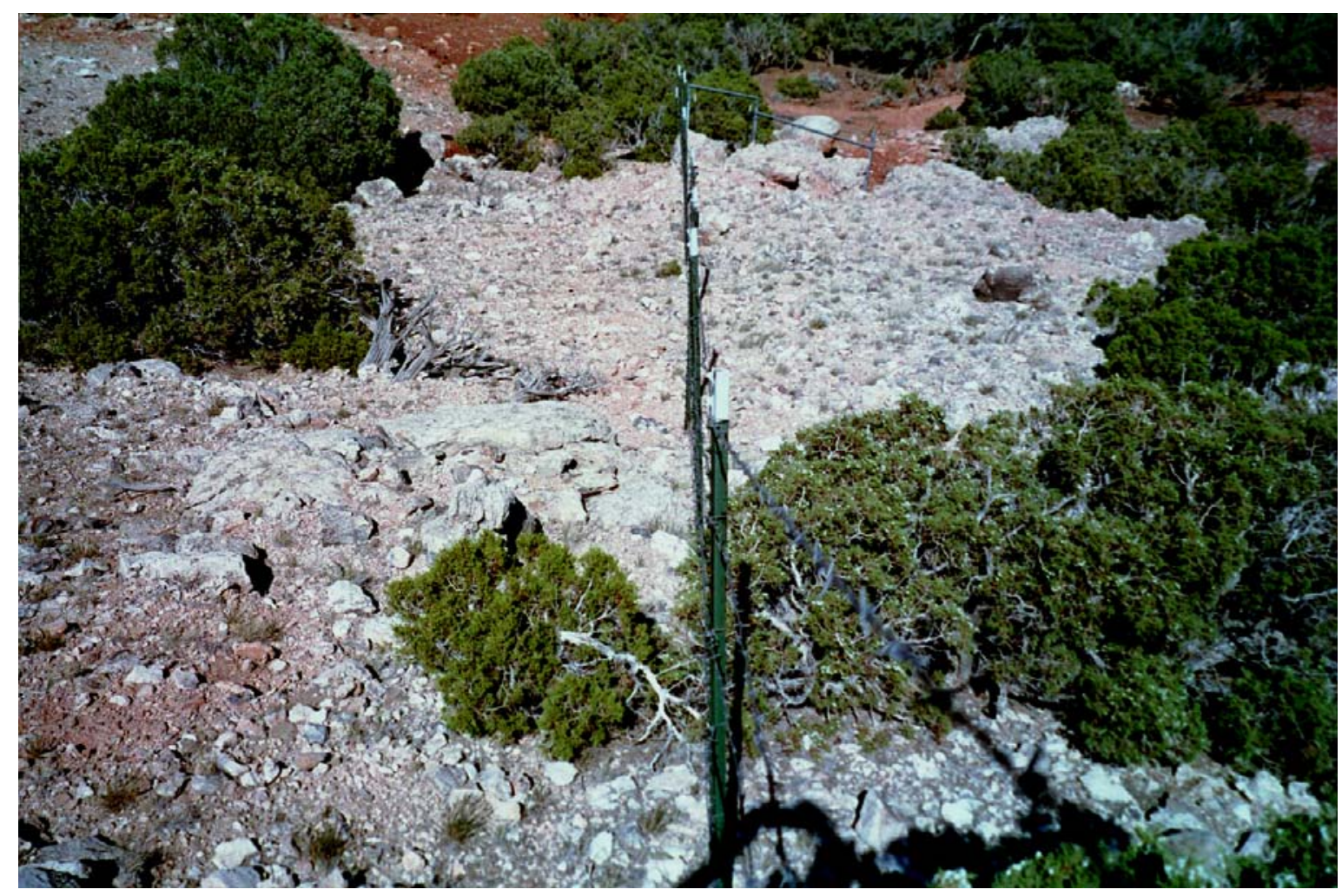

Photo 10. North Bay - View along permanent exclosure fence. Vegetation inside the exclosure (right) has been protected from grazing since 1994. 


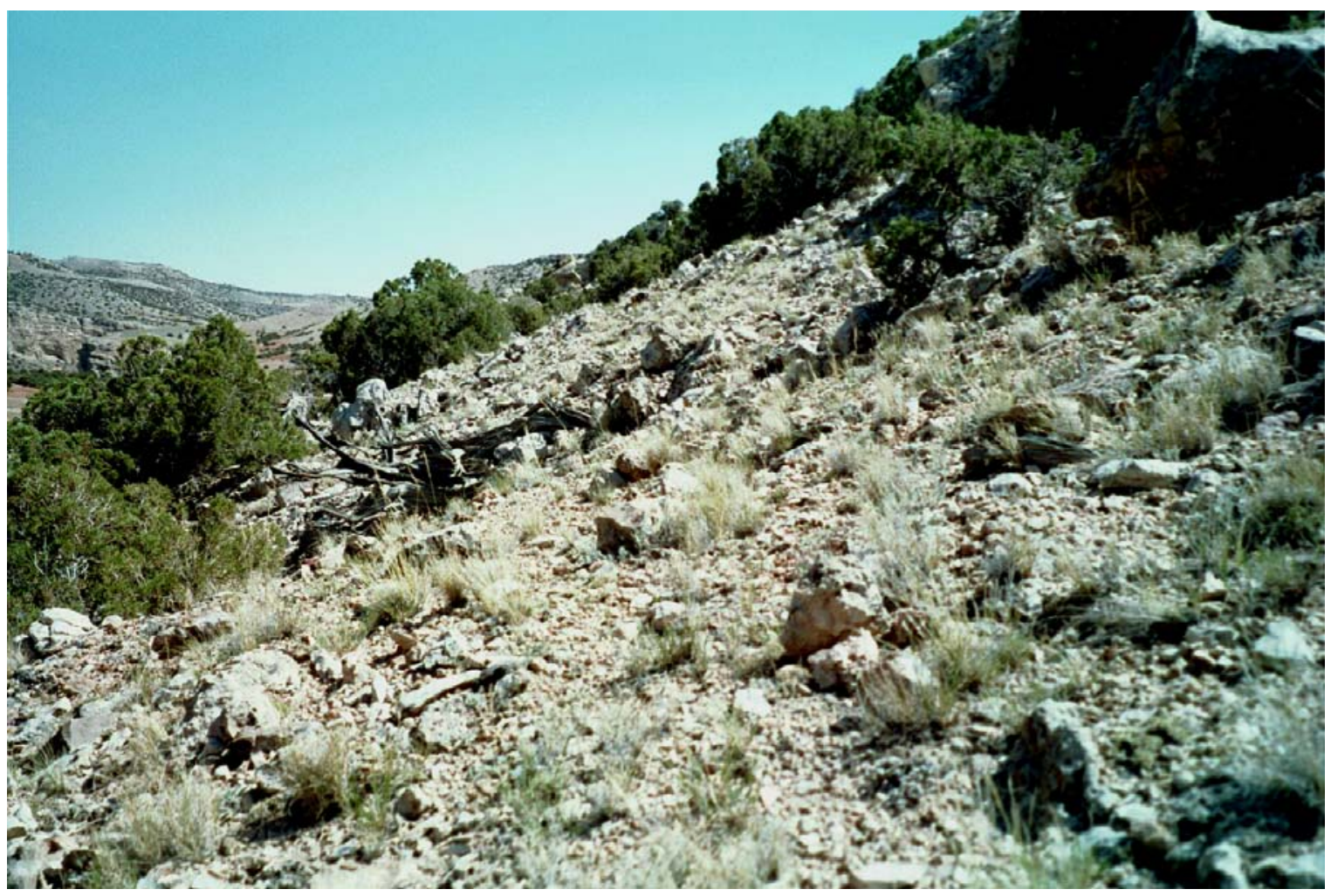

Photo 11. North Bay - Close view of vegetation inside the permanent exclosure.

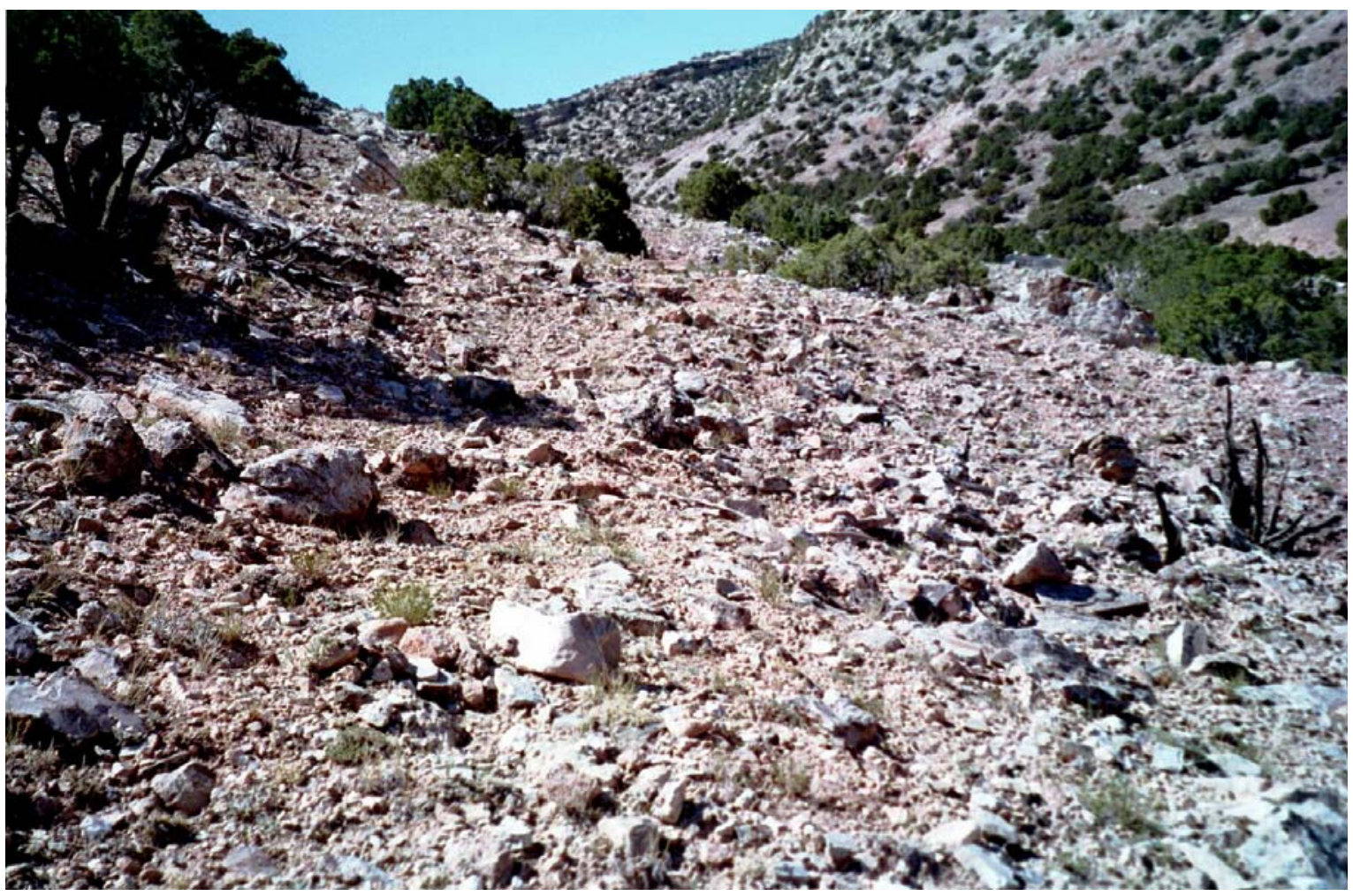

Photo 12. North Bay - Close view of vegetation outside of permanent exclosure in the $50 \times 50 \mathrm{~m}$ control plot. 


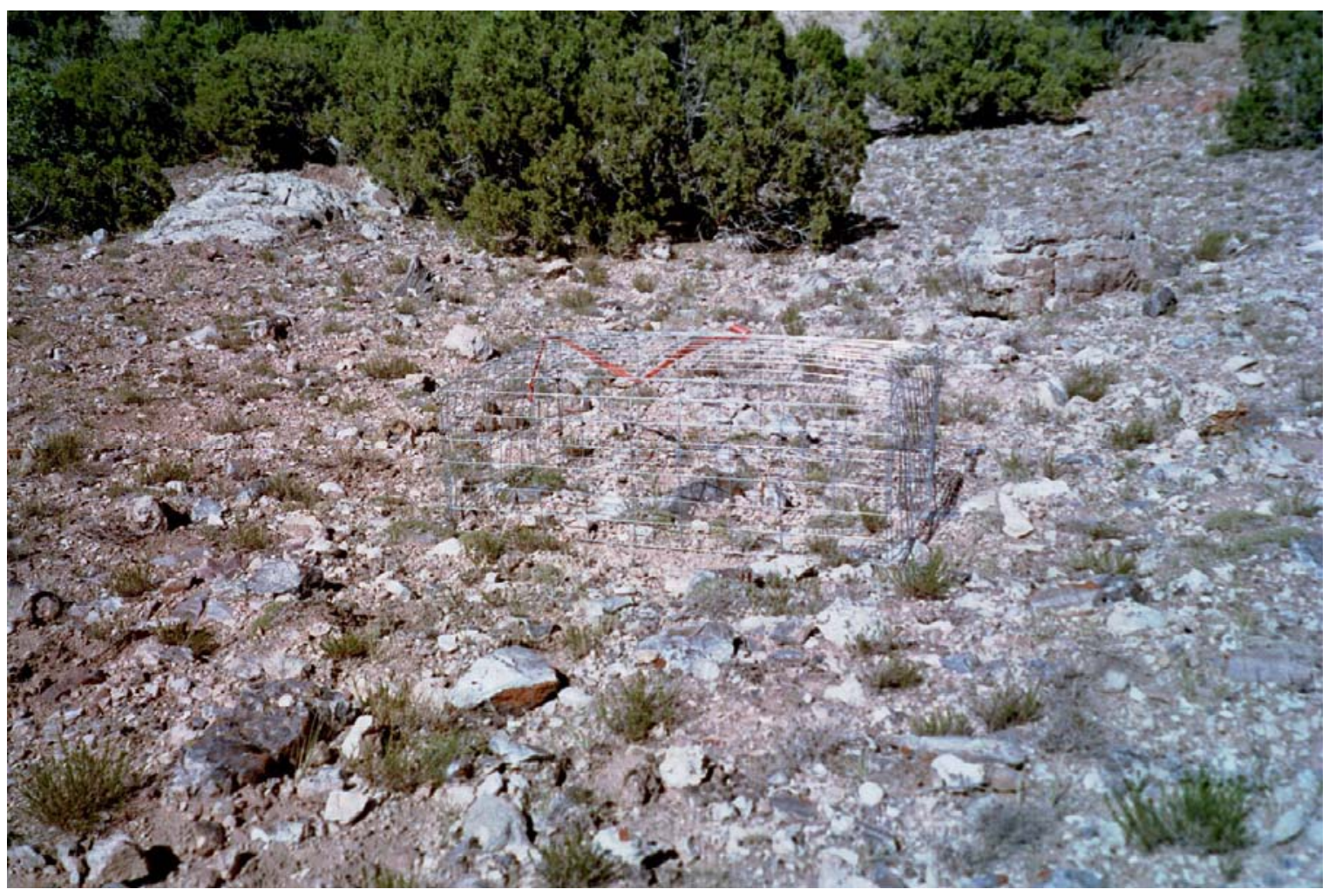

Photo 13. North Bay - View of temporary grazing cage outside of permanent exclosure.

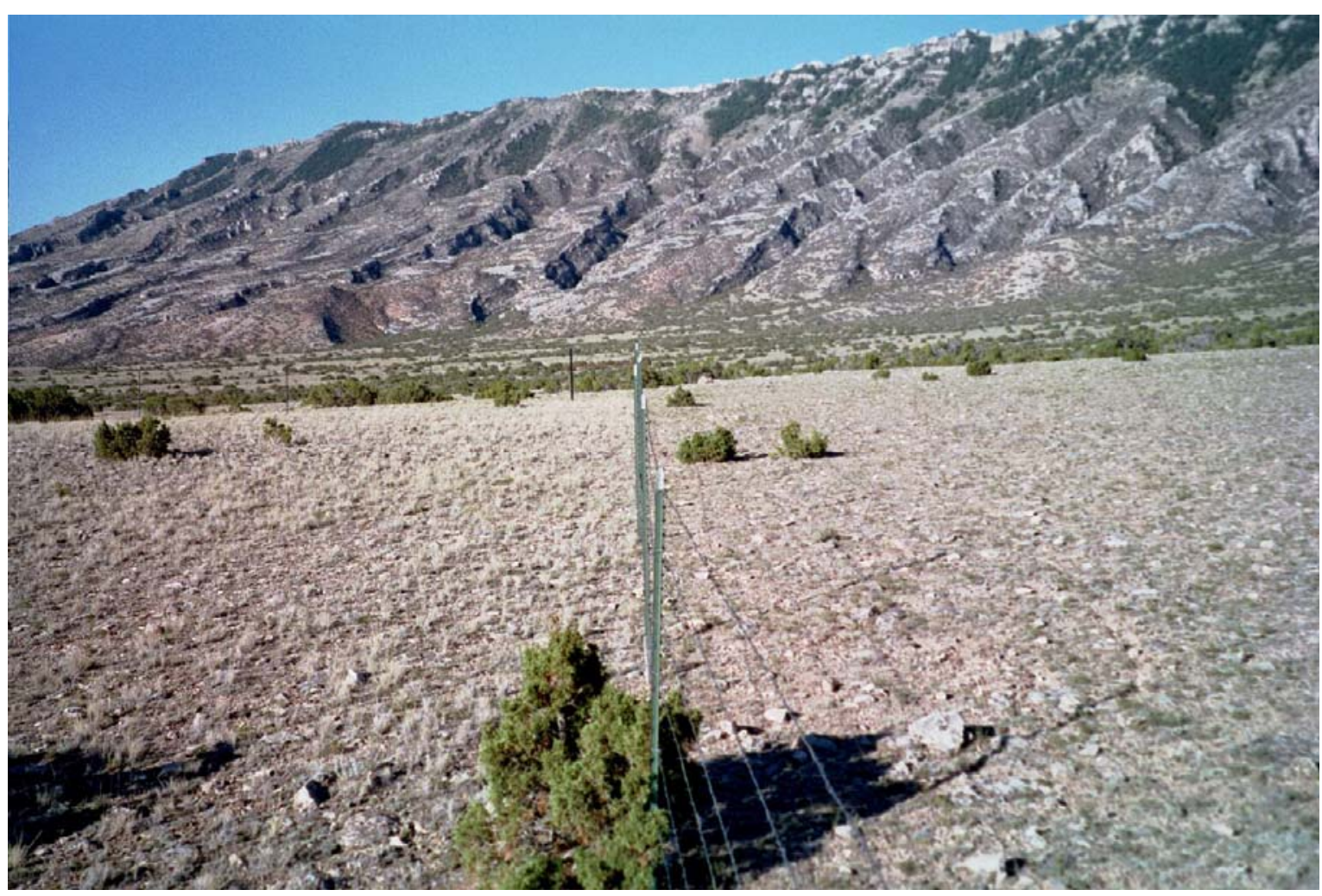

Photo 14. North Dryhead - View along permanent exclosure fence line. Vegetation inside exclosure (left) has been protected from grazing since 1992. 


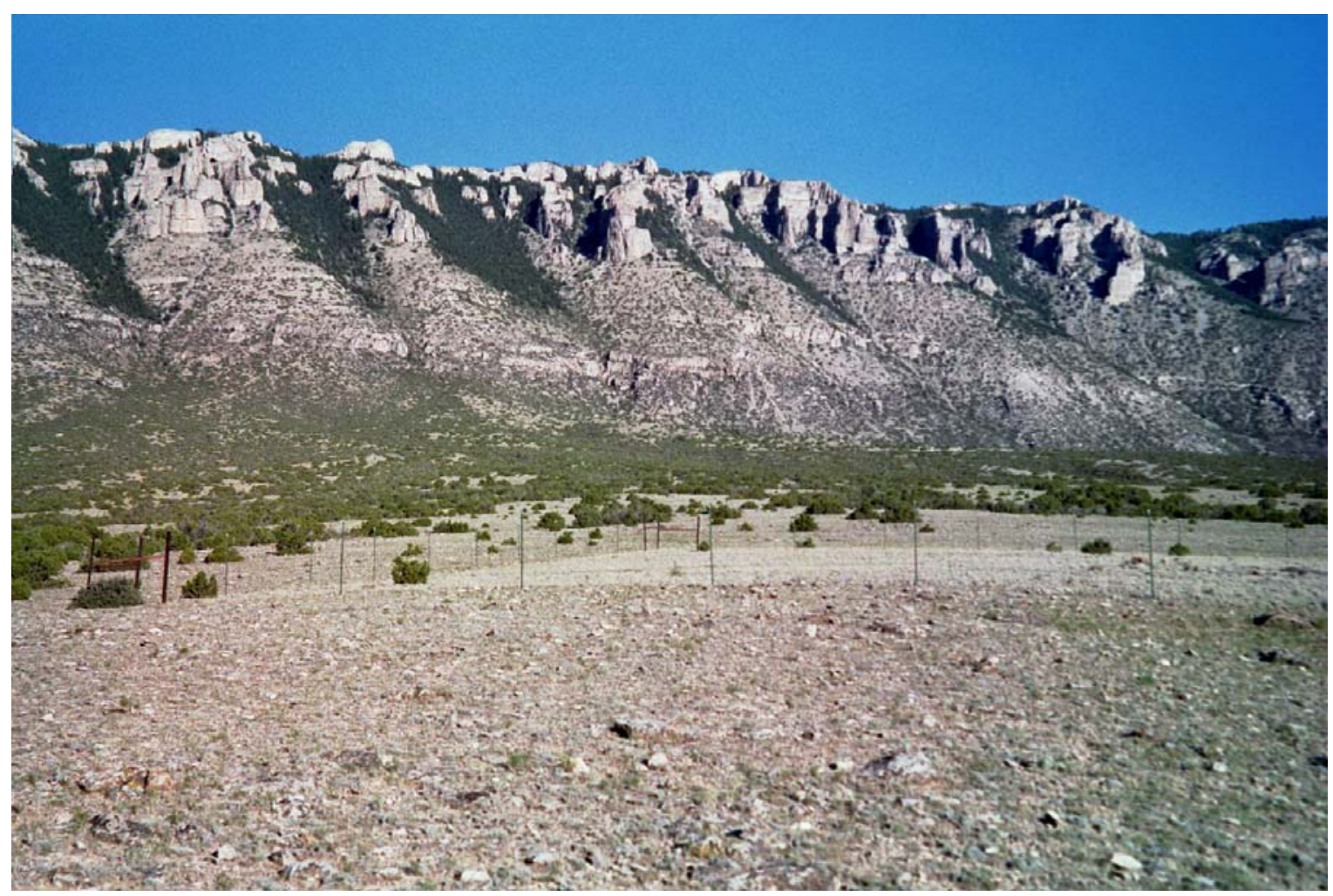

Photo 15. North Dryhead - View of permanent exclosure and surrounding vegetation. Standing dead grass inside the exclosure is visible from a distance.

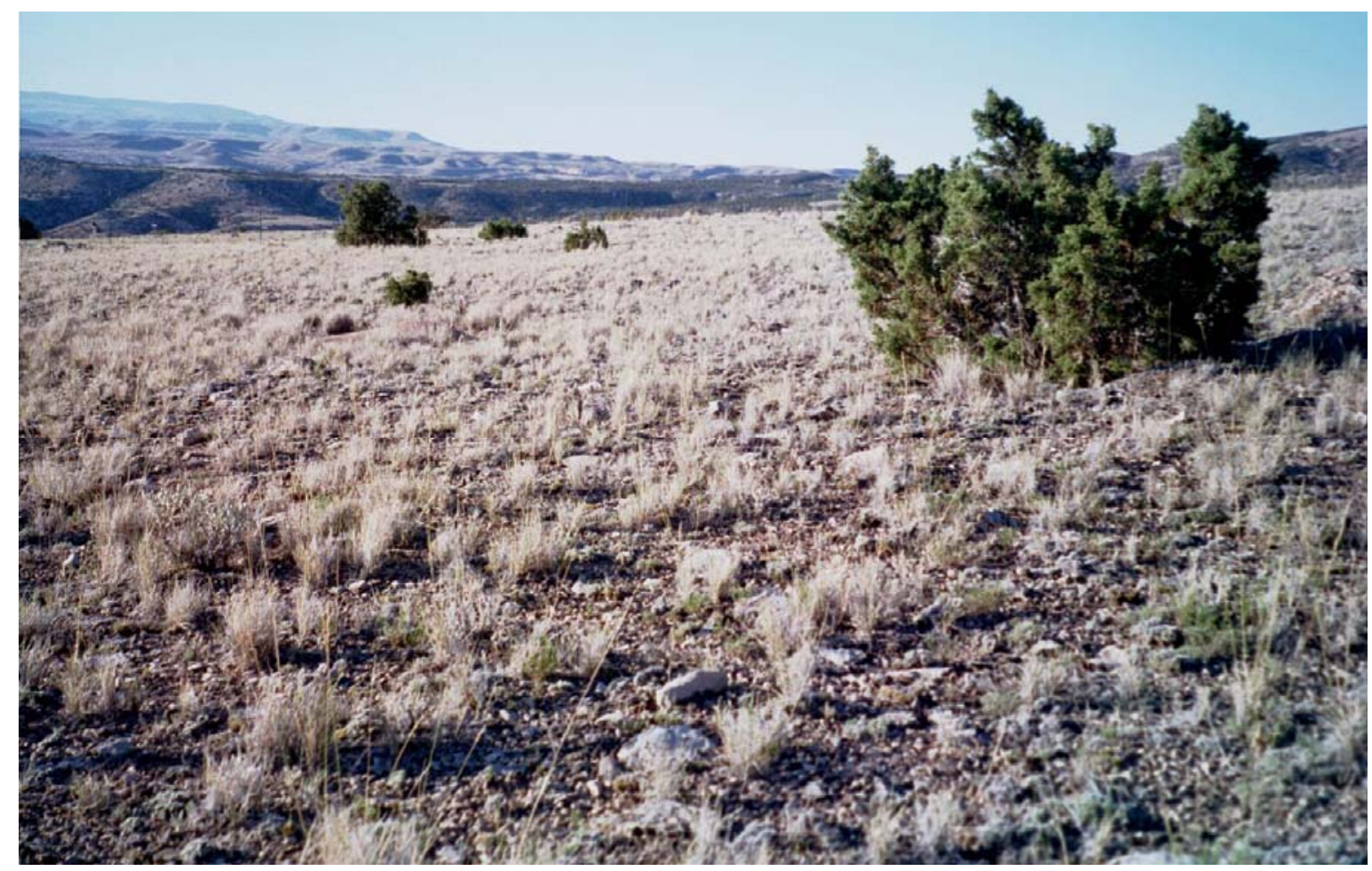

Photo 16. North Dryhead - Close view of vegetation inside the permanent exclosure. Compare with photo 17. 


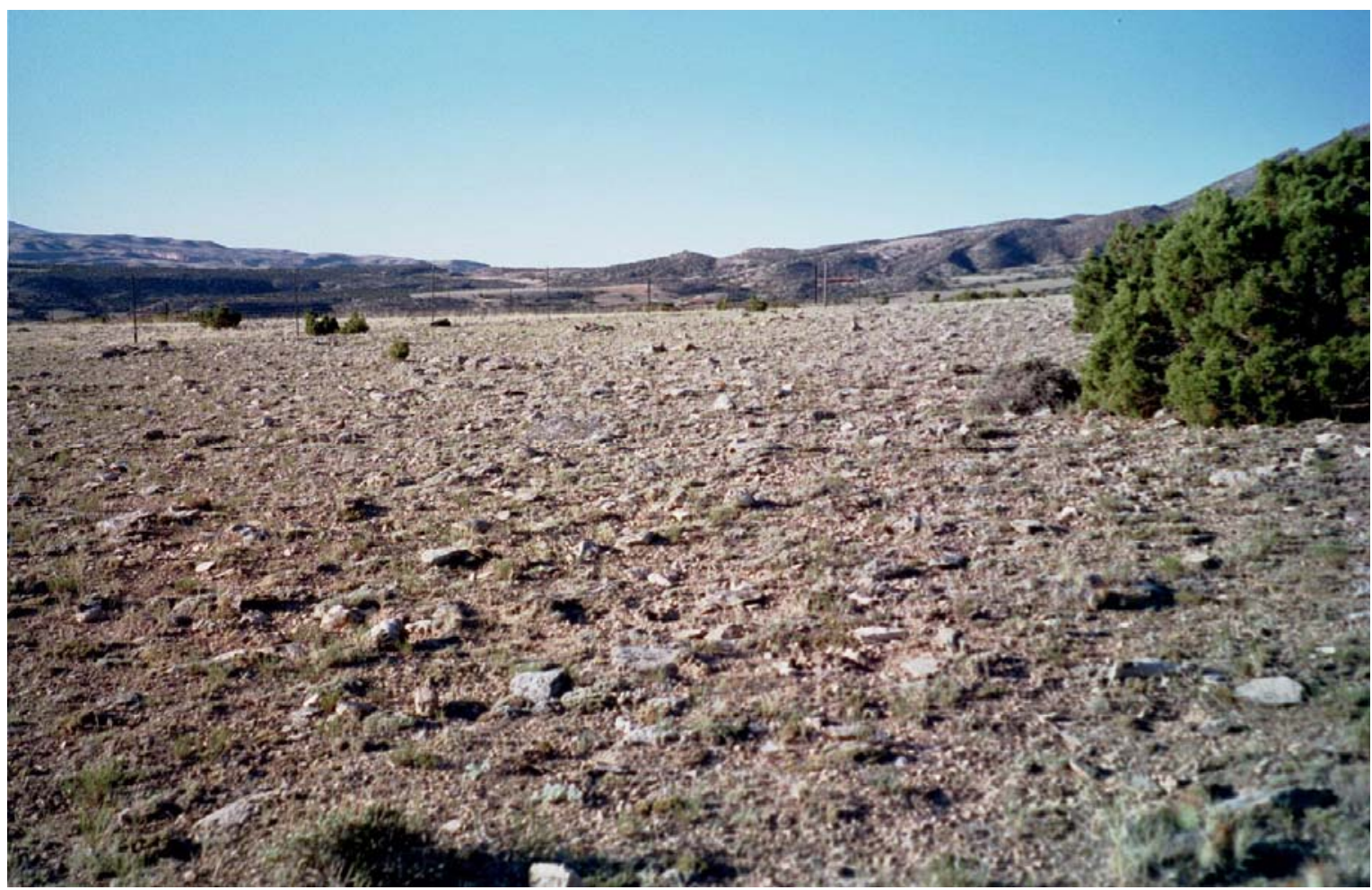

Photo 17. North Dryhead - Close view of vegetation outside the permanent exclosure. Exclosure is visible in the background.

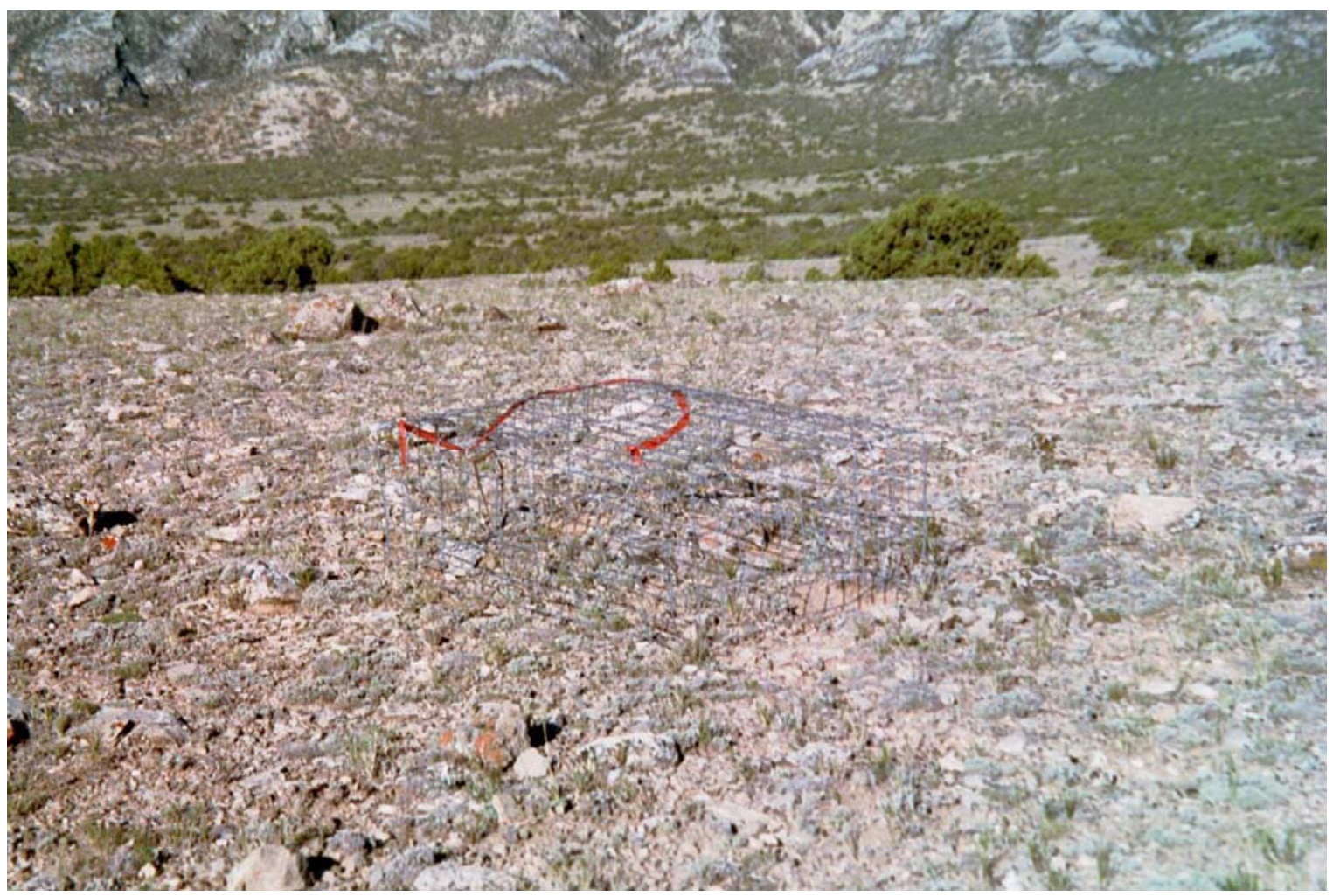

Photo 18. North Dryhead - Temporary grazing cage established outside of permanent exclosure. 


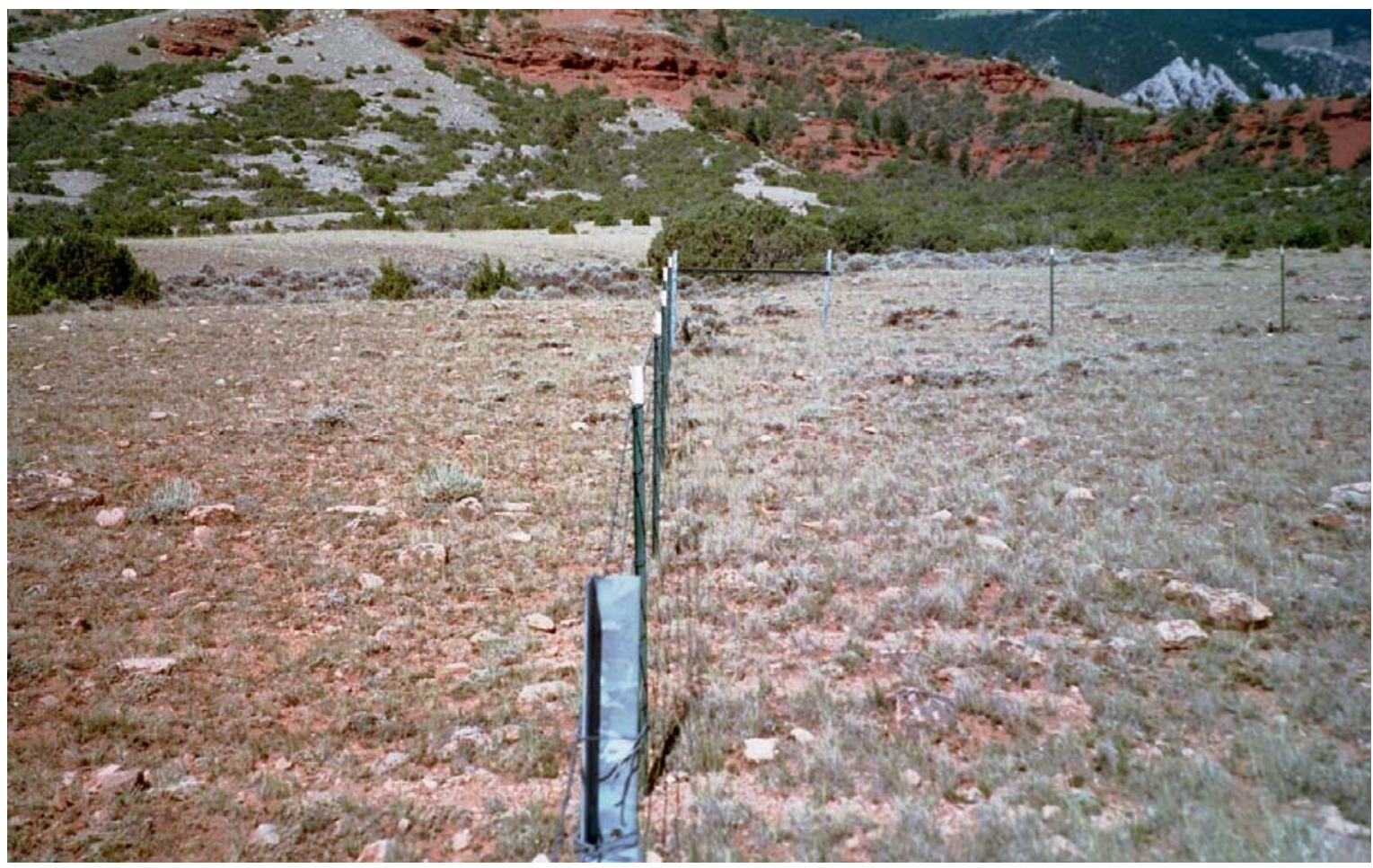

Photo 19. North Lockhart Ranch - View along permanent exclosure fence line. Exclosure $(25 \times 25 \mathrm{~m})$ was established in 1994 to investigate impacts of cattle trailing on cushion plant communities. Vegetation to right is inside exclosure.

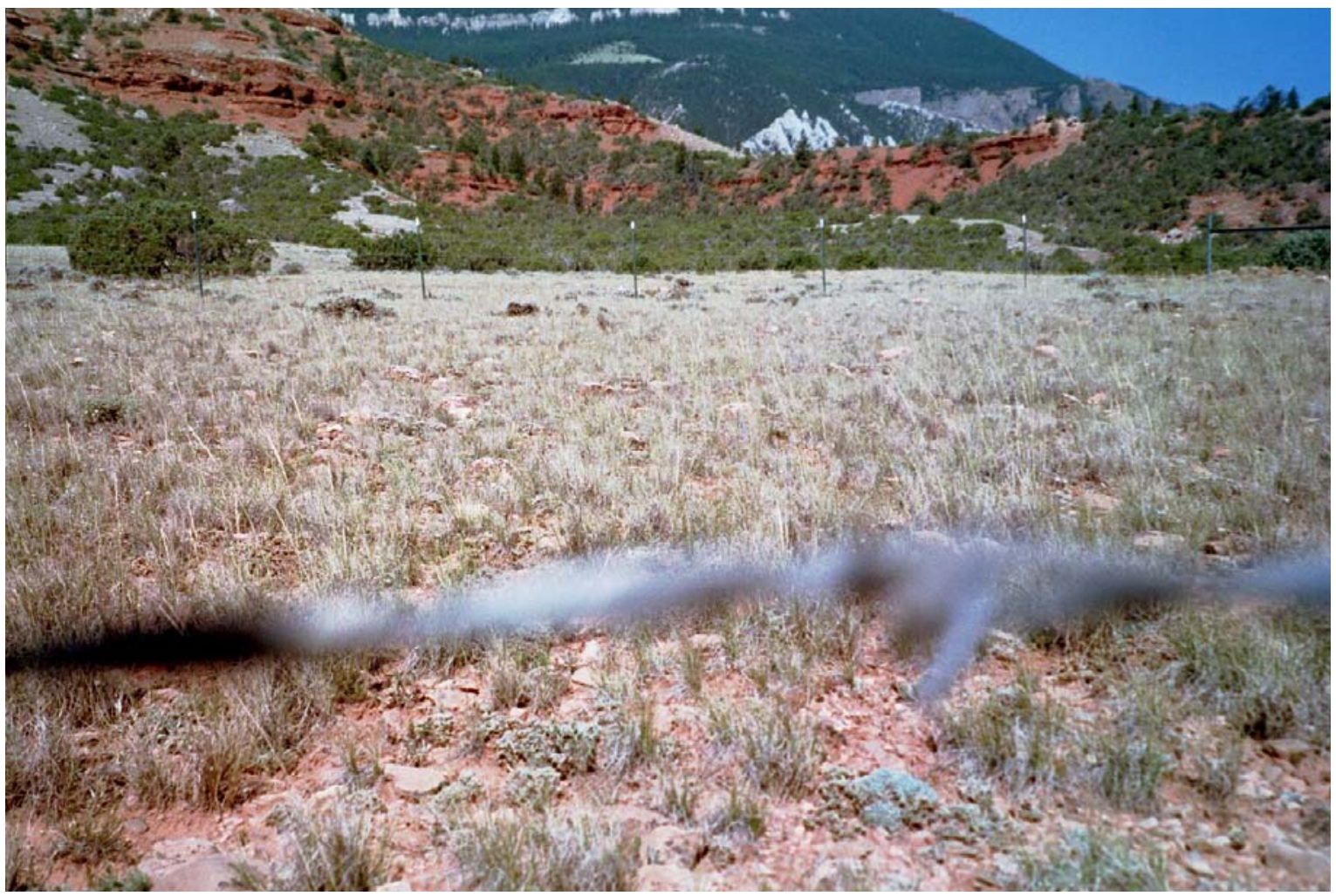

Photo 20. North Lockhart Ranch - Close view of vegetation inside the permanent exclosure. Barbed-wire strand is unintentionally visible in the foreground. 


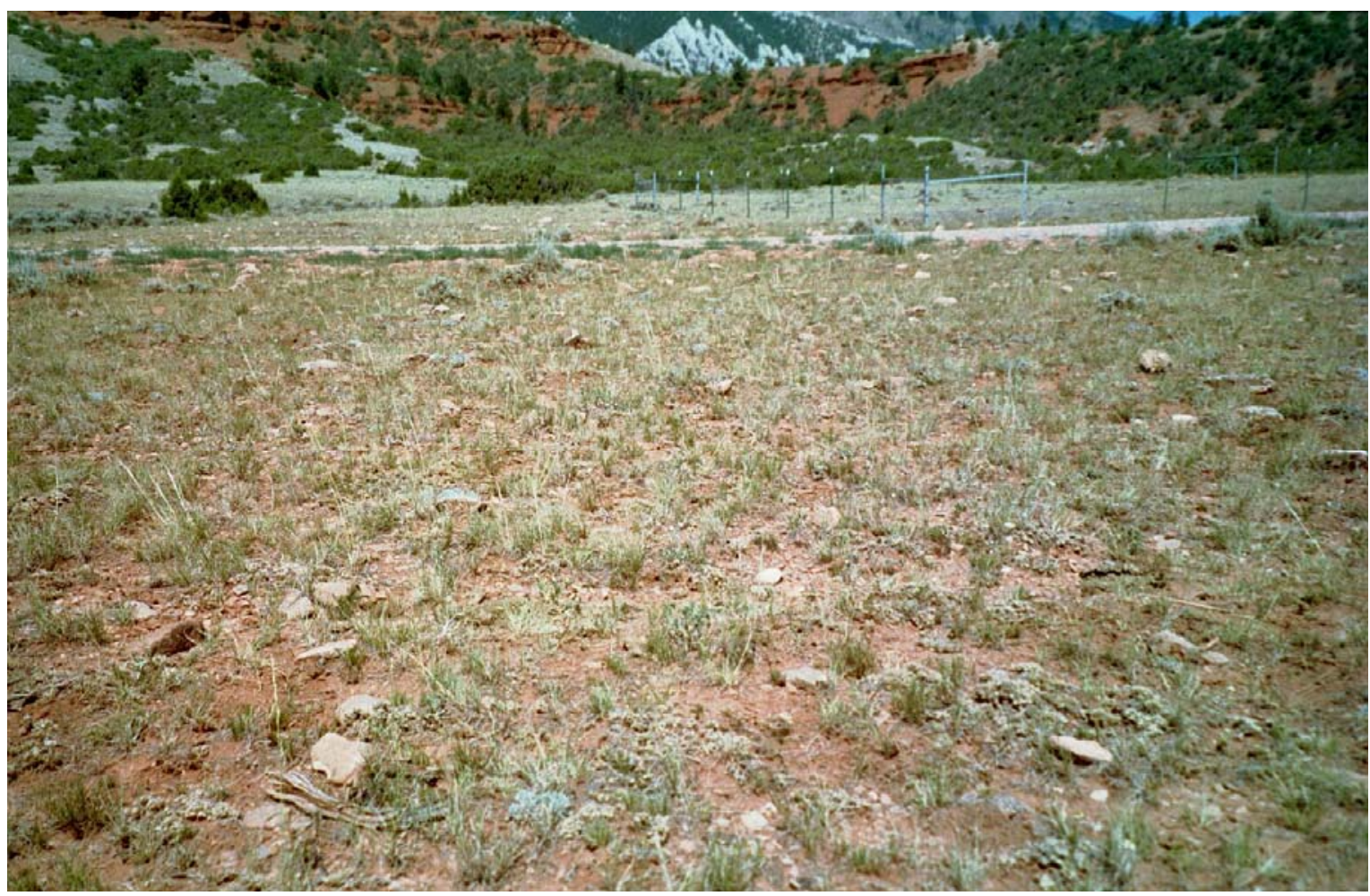

Photo 21. North Lockhart Ranch - Close view of vegetation outside permanent exclosure in control plot. Unpaved road is visible running left to right. Permanent exclosure is visible in the background.

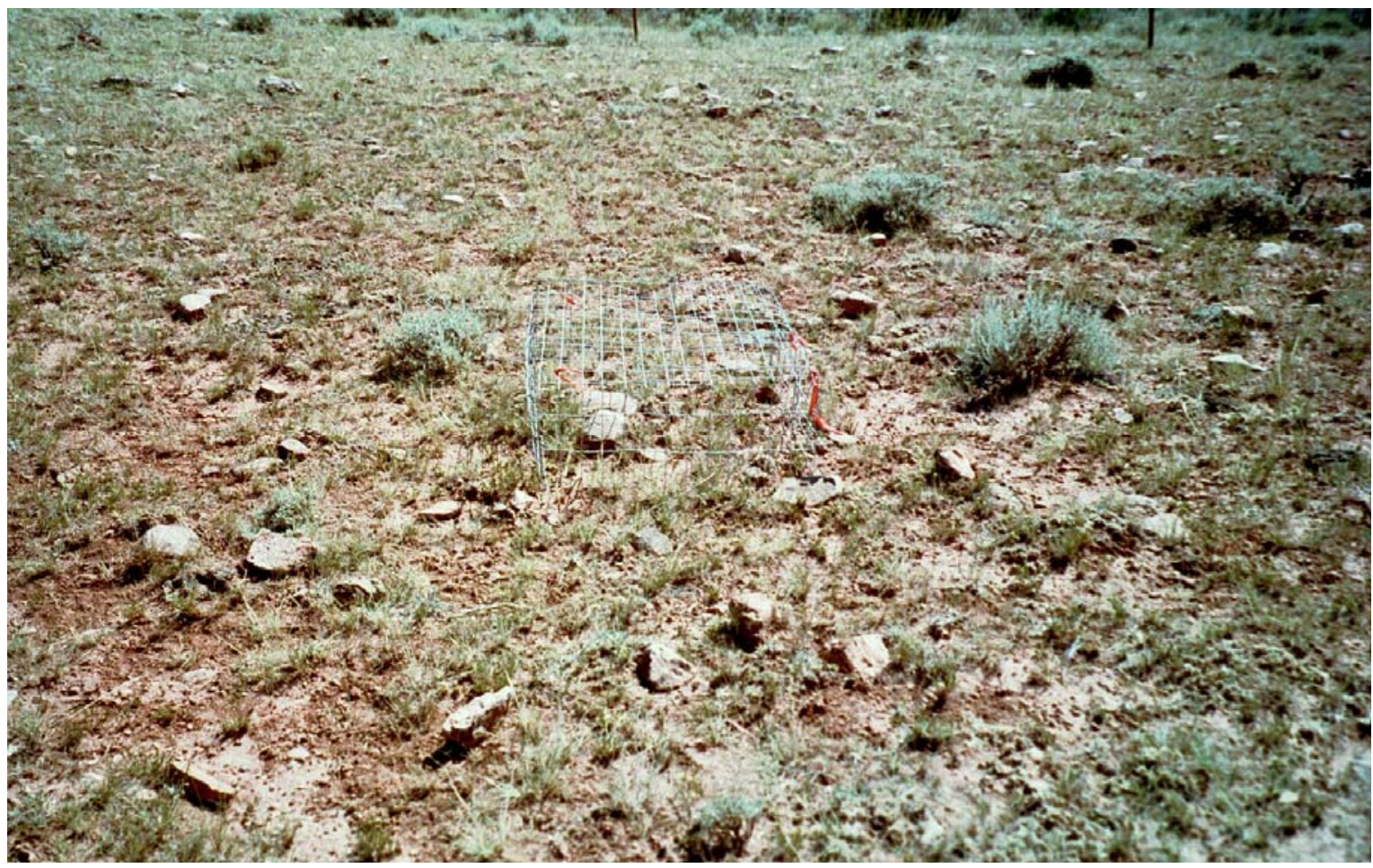

Photo 22. North Lockhart Ranch - View of temporary grazing cage outside permanent exclosure. The fence in the background is not the exclosure. 


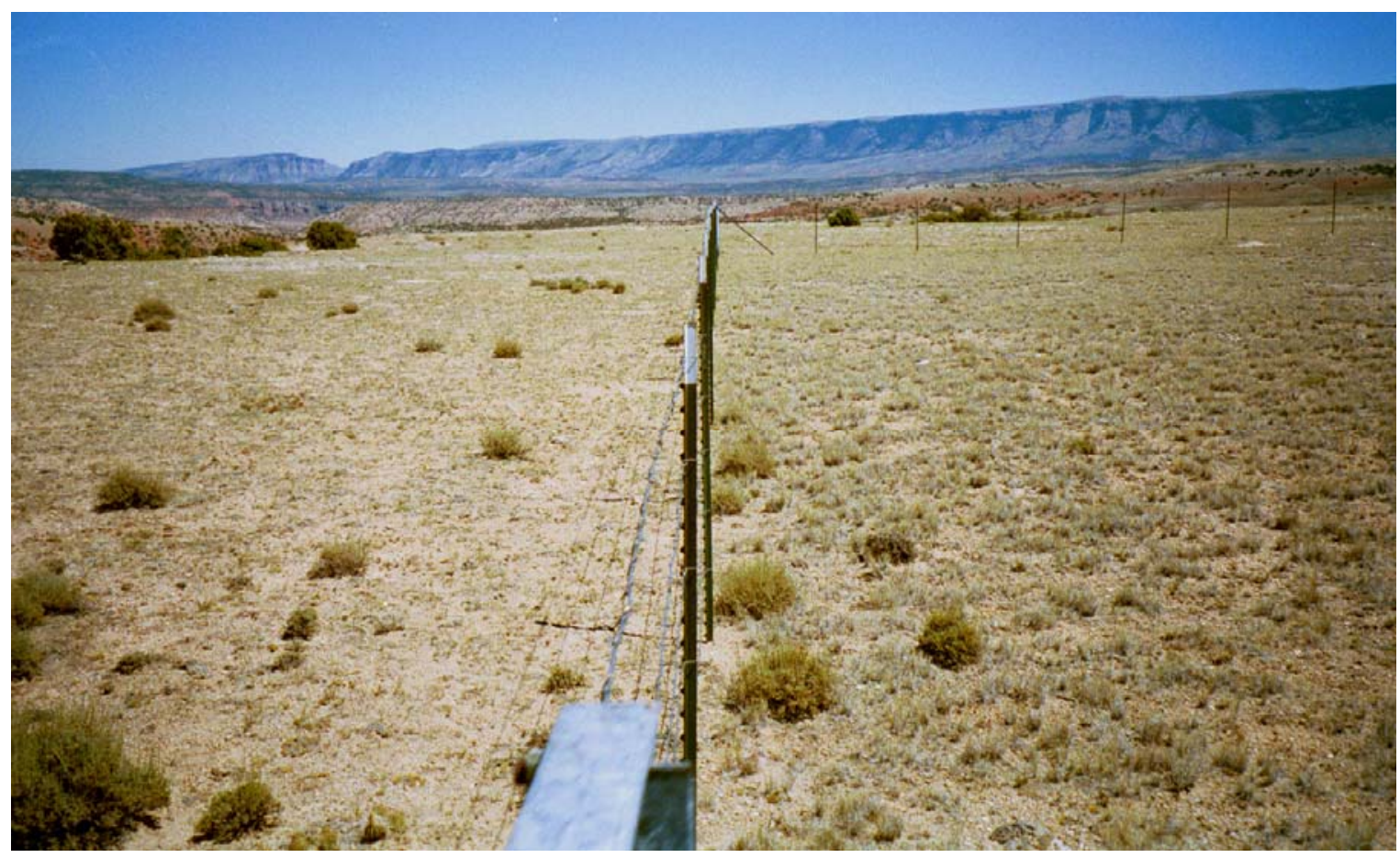

Photo 23. Peninsula - View along the fence line of the permanent exclosure. Exclosure was established in 1994. Cover and biomass of grass inside the exclosure (right) appears to be greater than outside the exclosure.

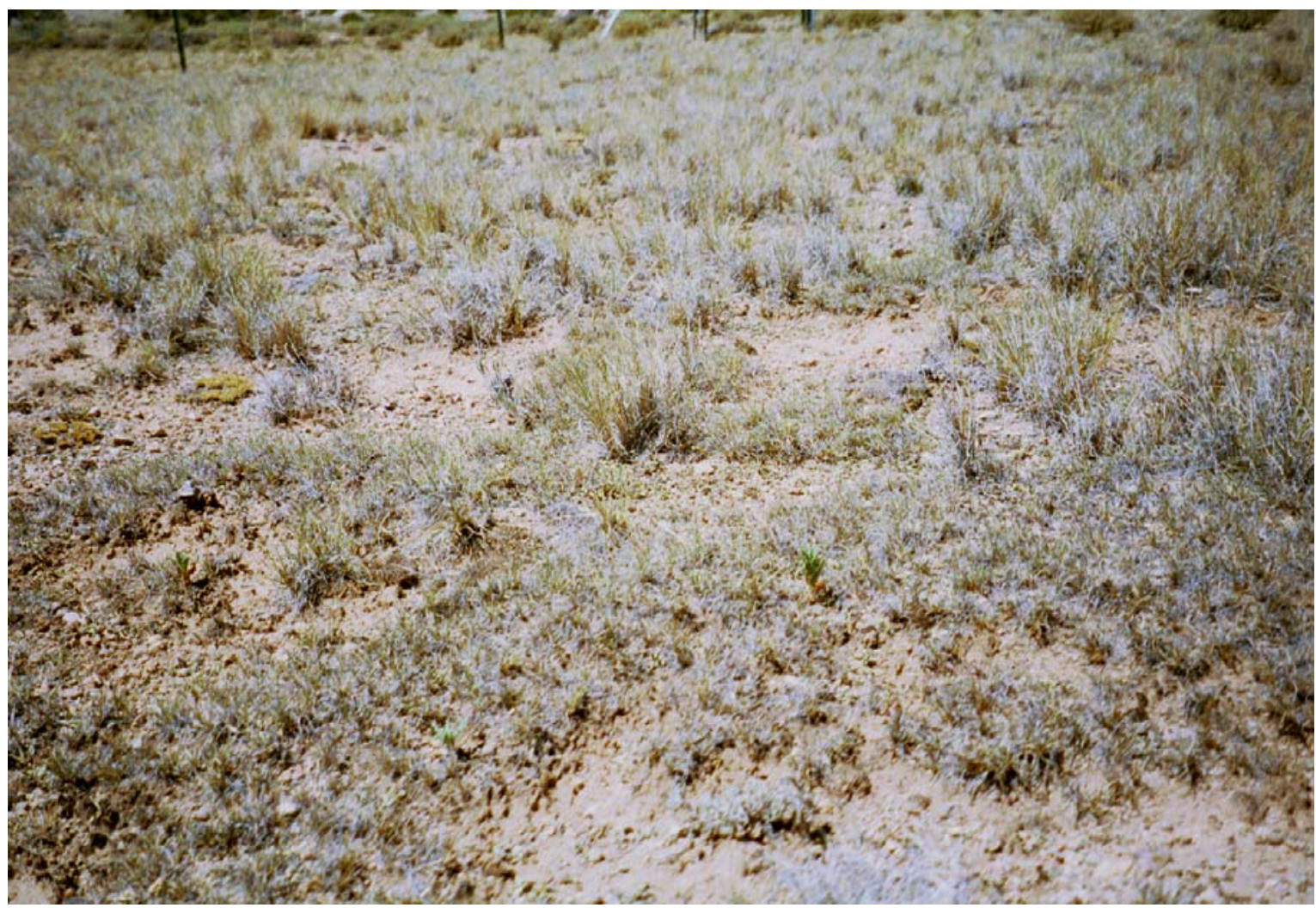

Photo 24. Peninsula - Close view of vegetation inside the permanent exclosure. Notice the standing dead grass. 


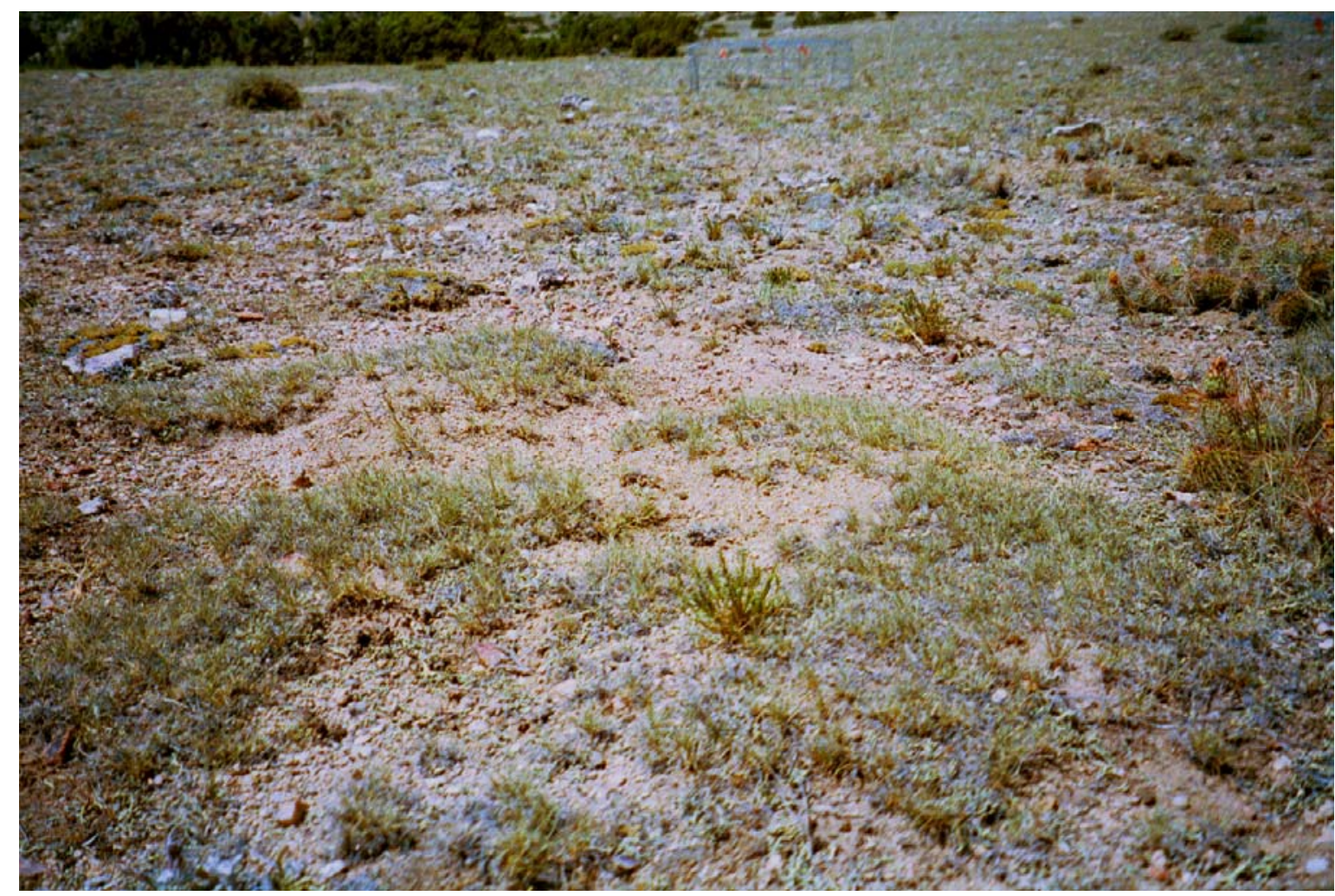

Photo 25. Peninsula - Close view of vegetation outside permanent exclosure in control plot. Grazing cage is visible in the backaround.

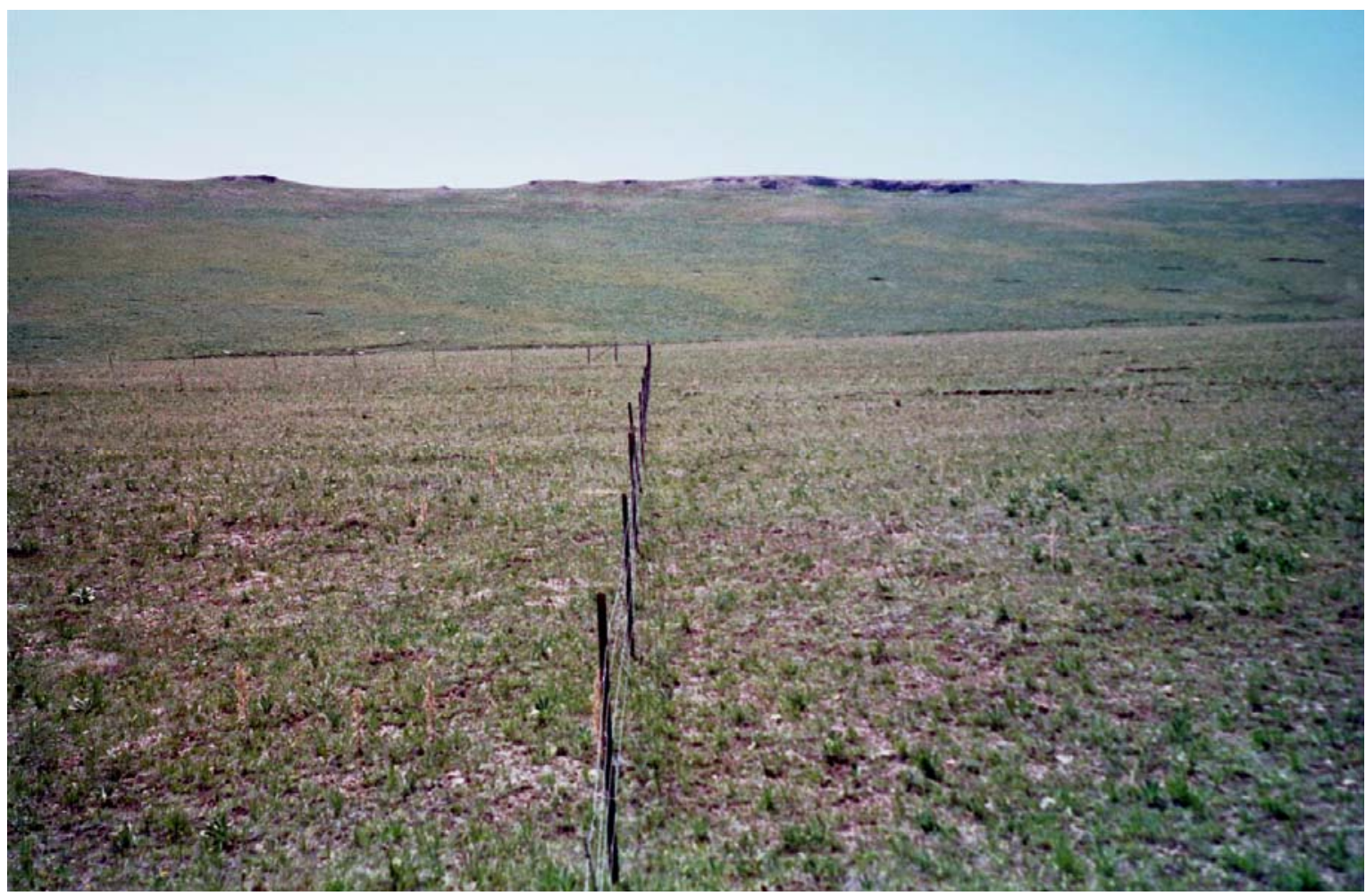

Photo 26. Penn's Cabin - View along fence line of permanent exclosure. Vegetation inside the exclosure (left) has been protected from grazing for approximately 40 years. 


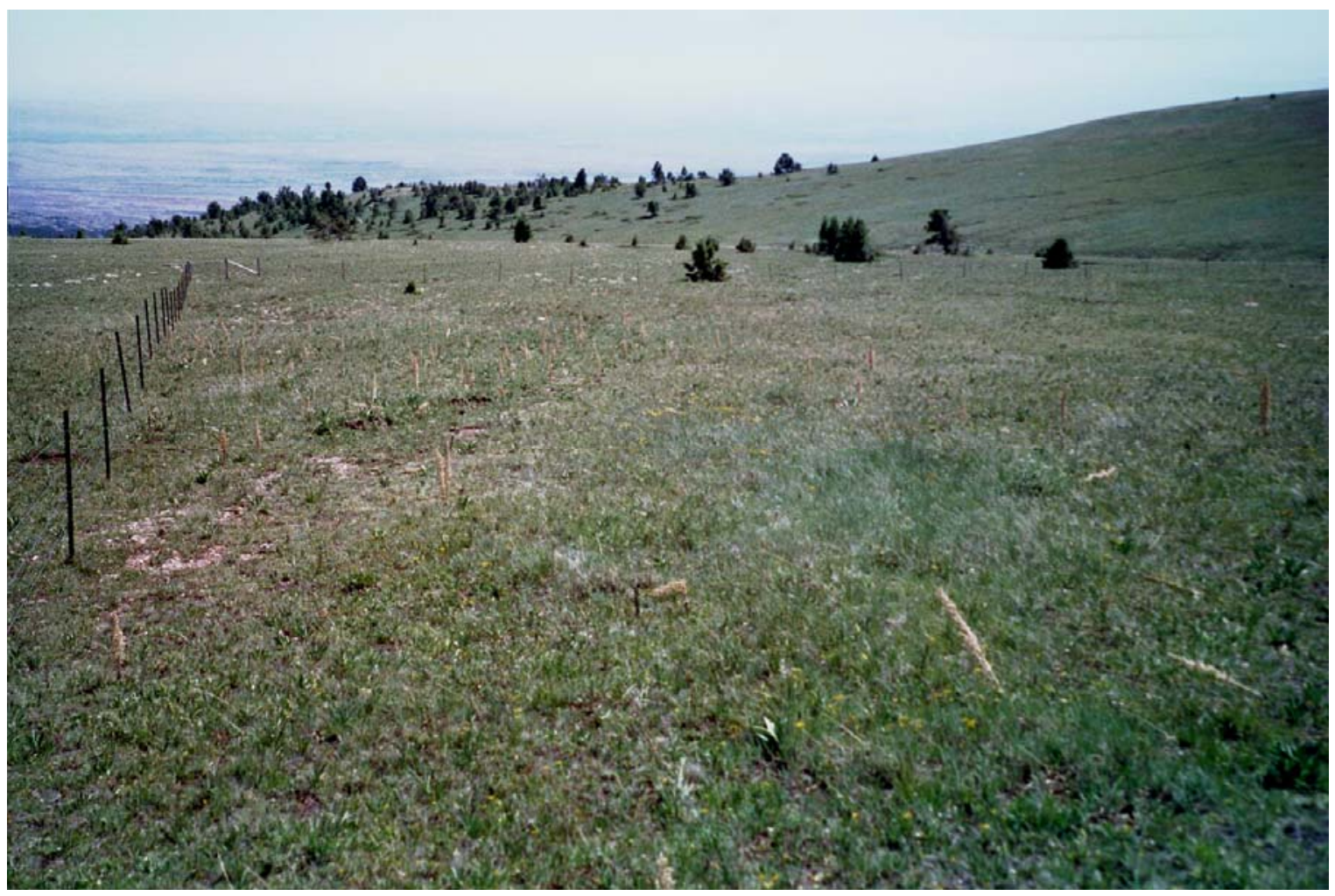

Photo 27. Penn's Cabin - View of vegetation inside permanent exclosure.

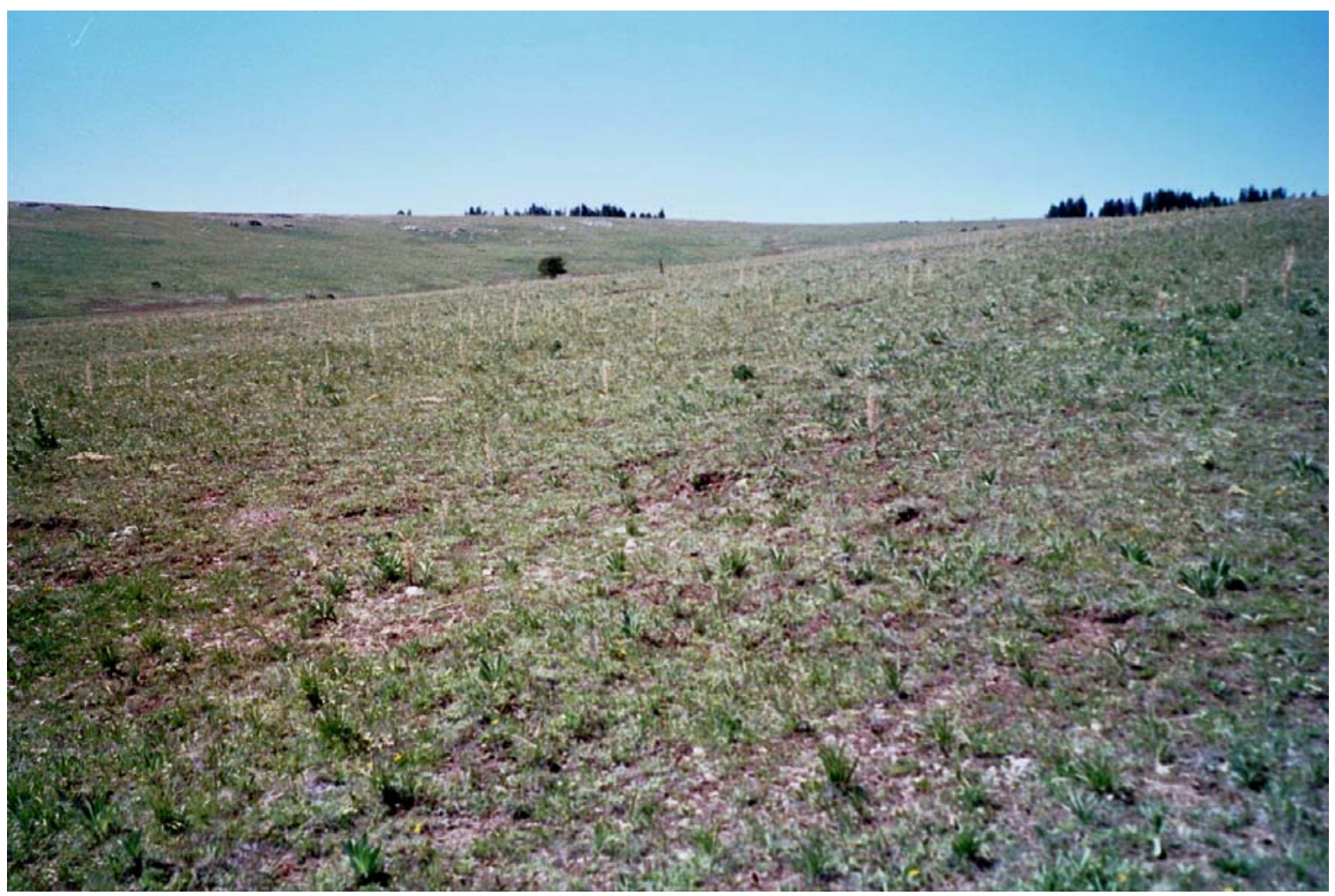

Photo 28. Penn's Cabin - View of vegetation outside permanent exclosure. 


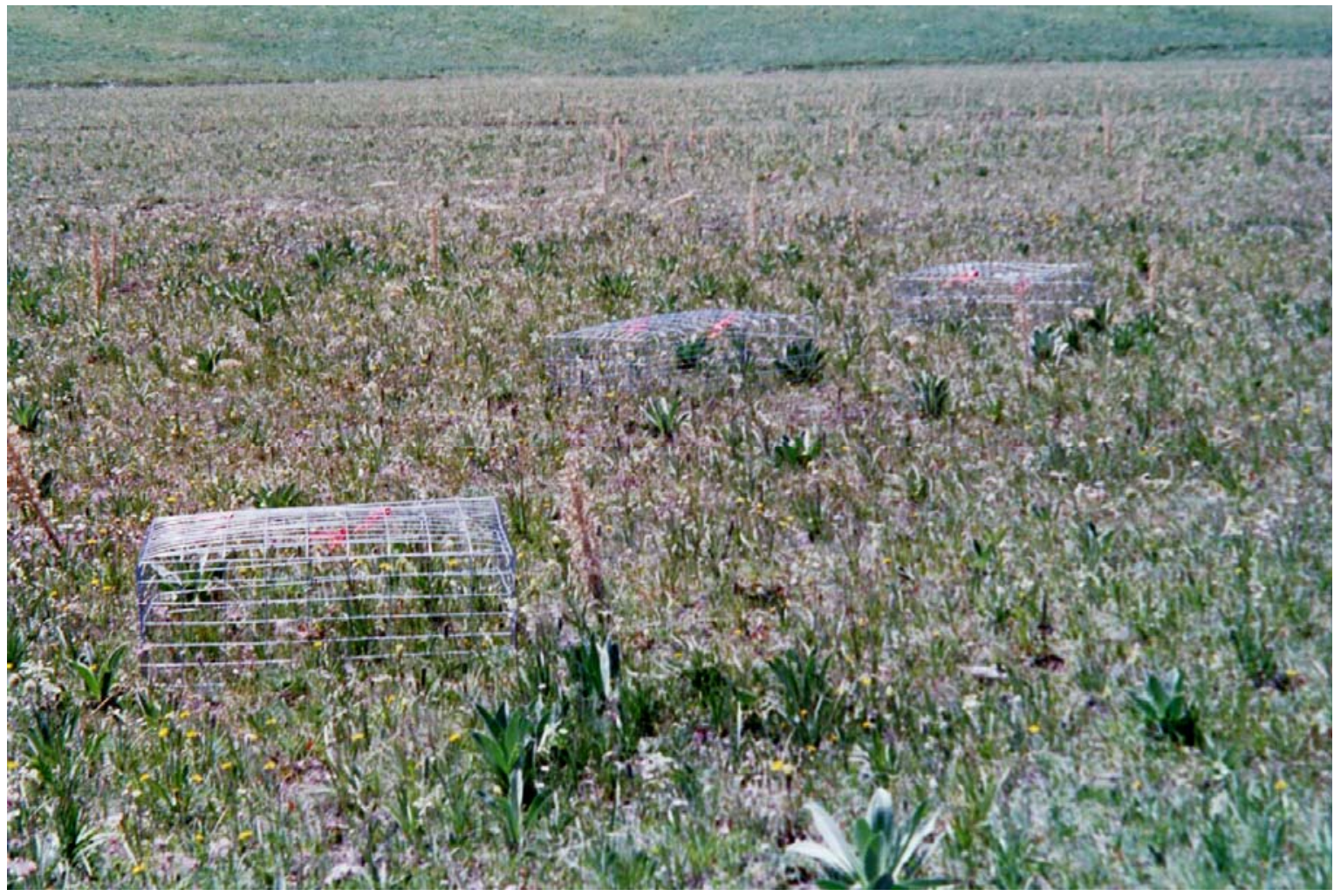

Photo 29. Penn's Cabin - View of temporary grazing cage outside permanent exclosure.

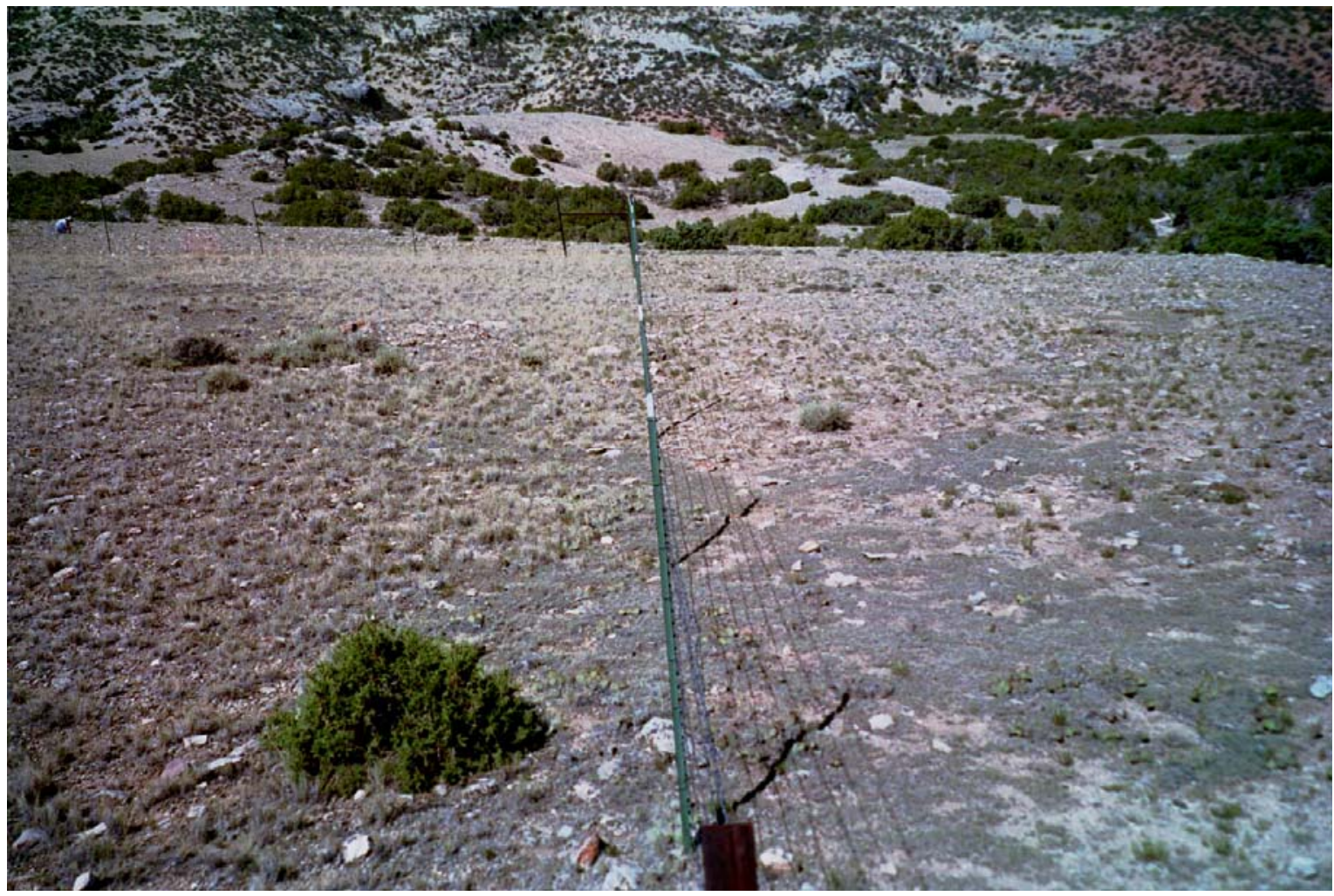

Photo 30. South Dryhead - View along fence line of permanent exclosure. Vegetation inside permanent exclosure (left) has been protected from grazing since 1992. 


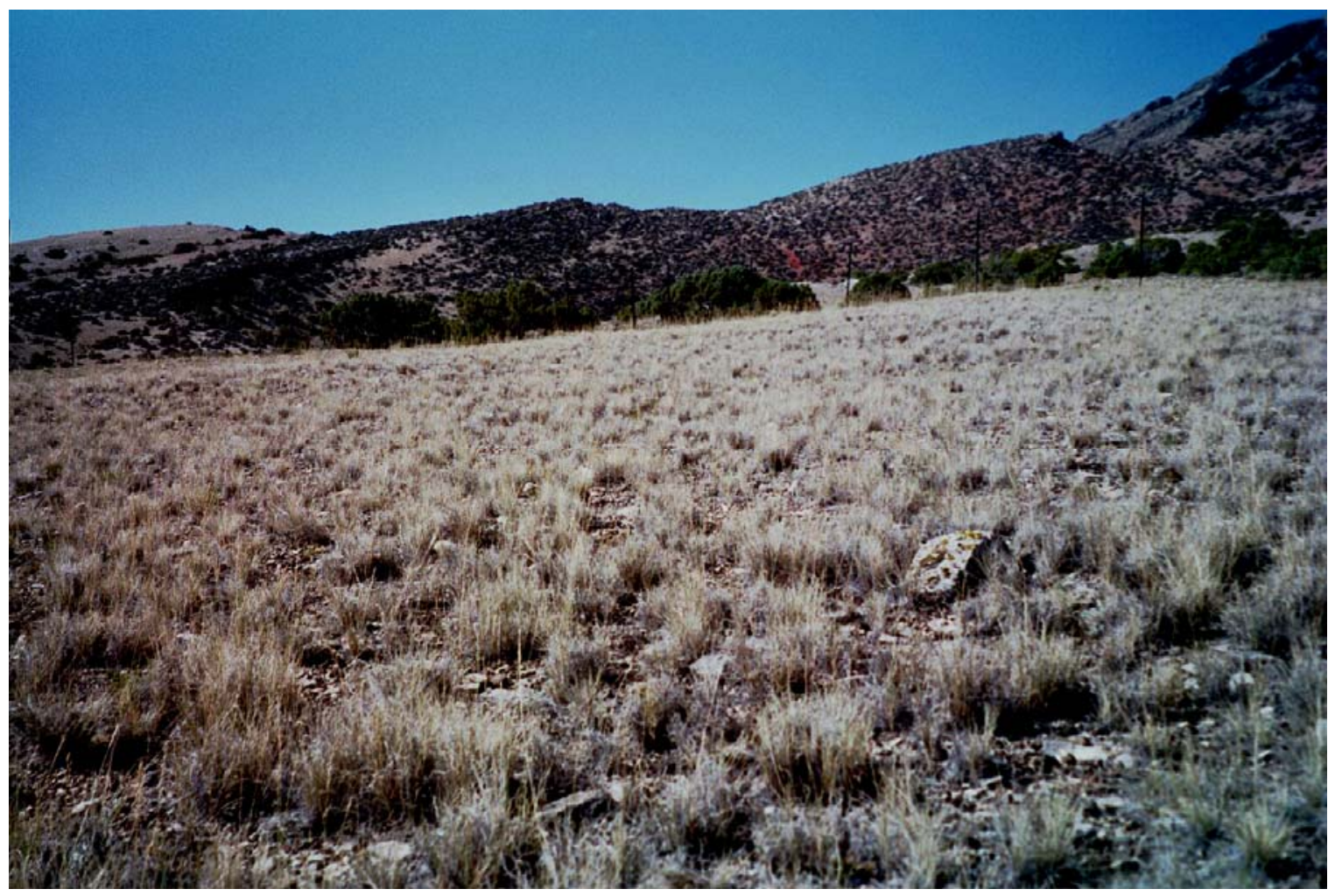

Photo 31. South Dryhead - Close view of vegetation inside permanent exclosure. Compare to photograph 32.

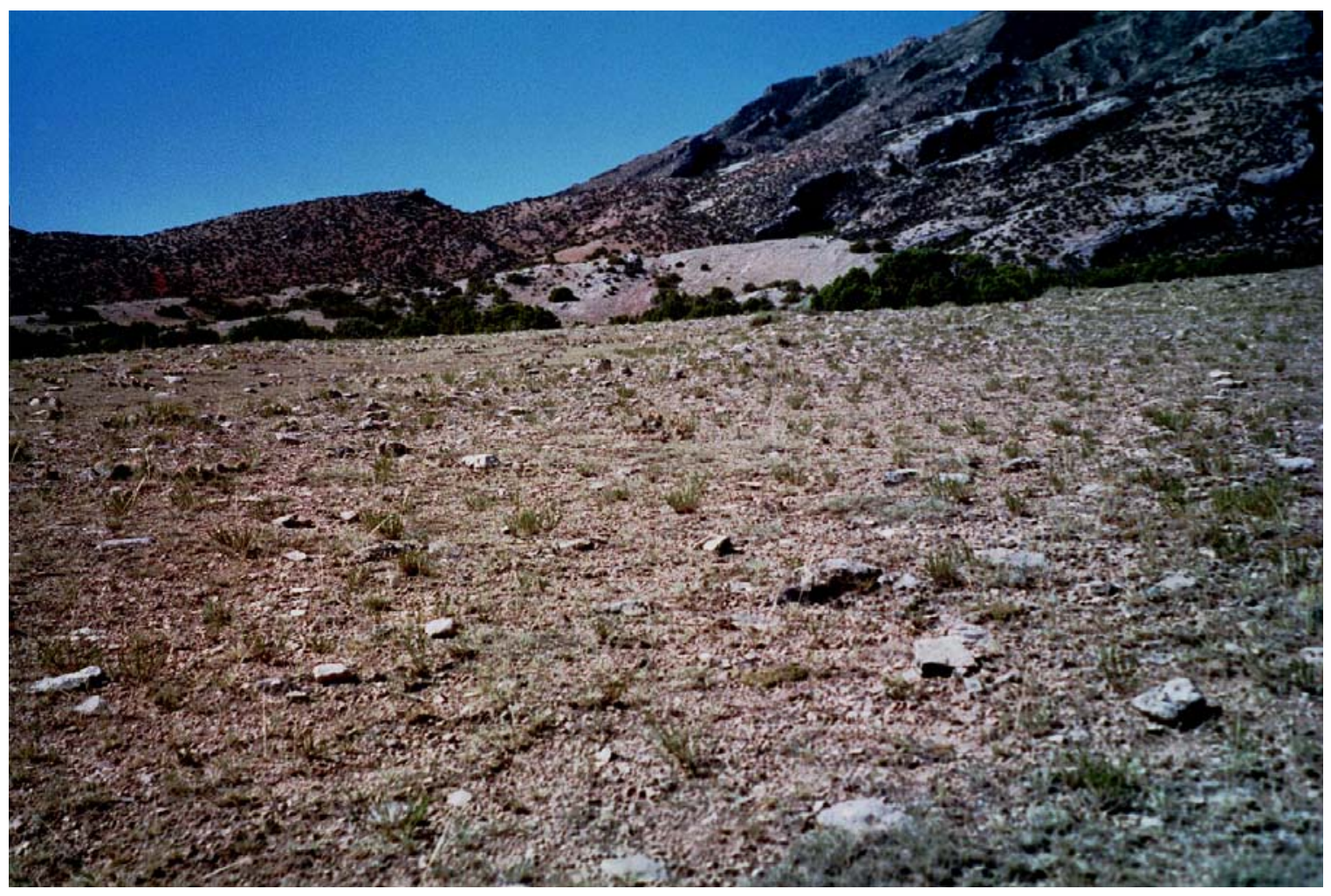

Photo 32. South Dryhead - Close view of vegetation outside permanent exclosure. 


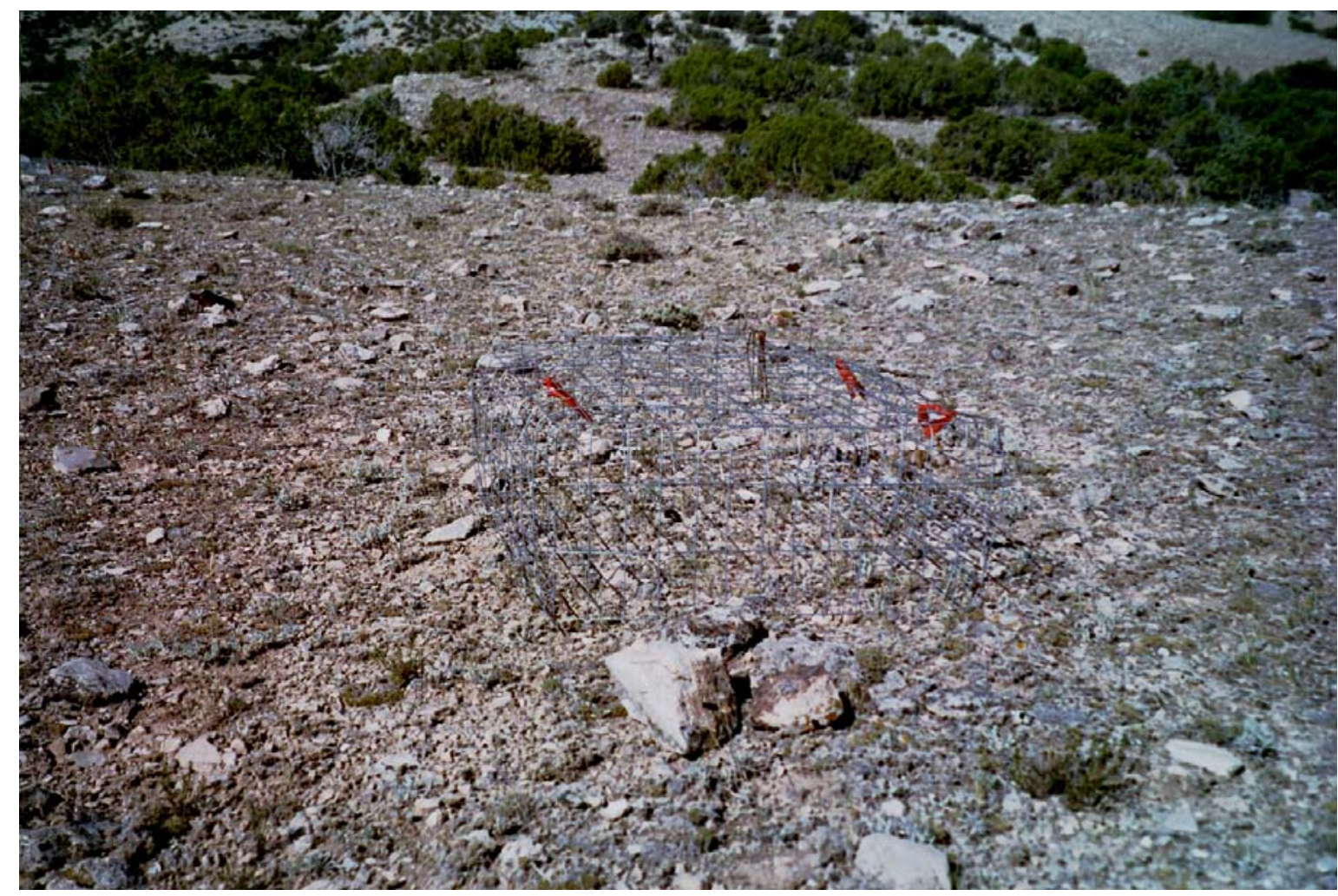

Photo 33. South Dryhead - Close view of temporary grazing cage outside permanent exclosure.

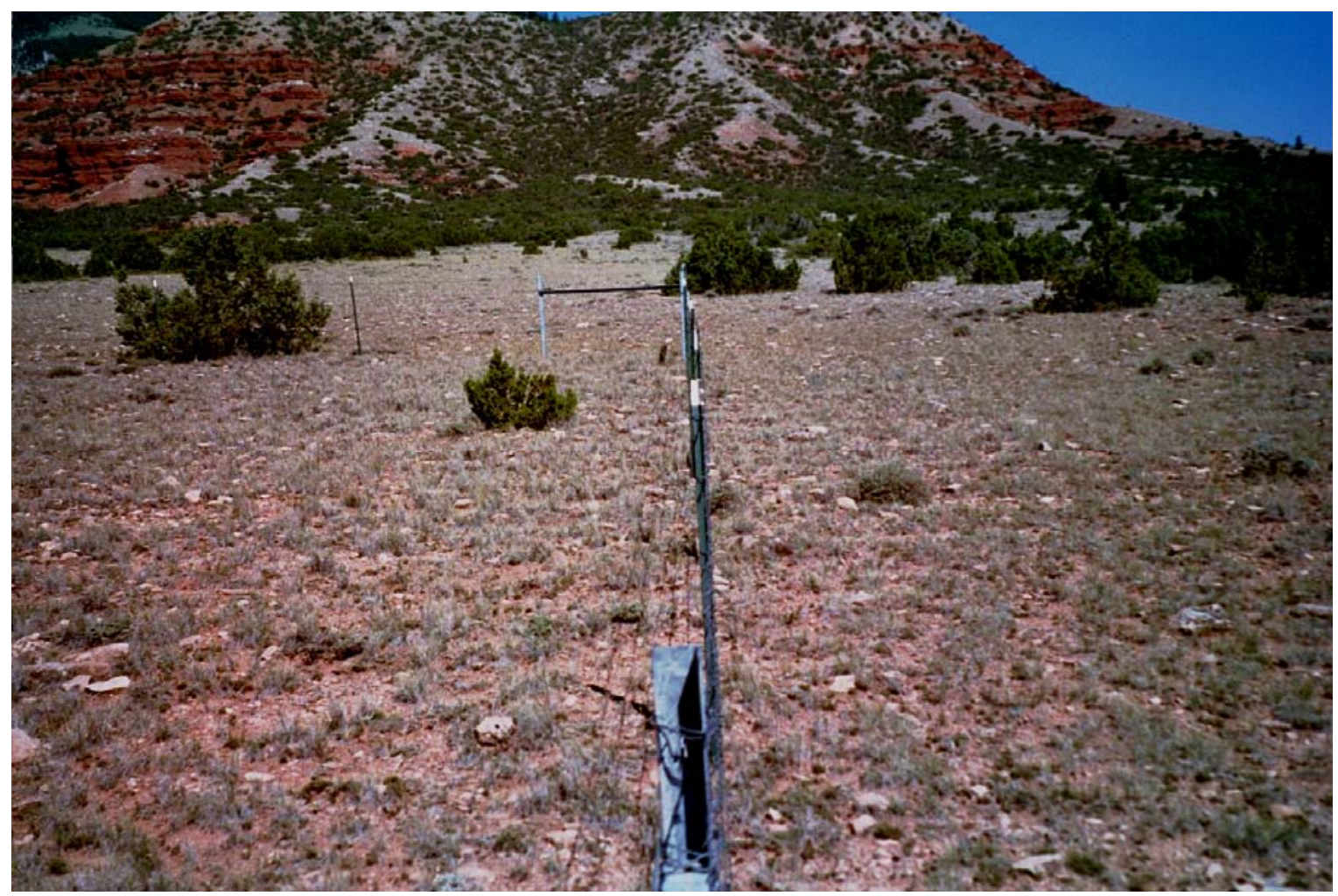

Photo 34. South Lockhart Ranch - Close view of vegetation inside permanent exclosure. 


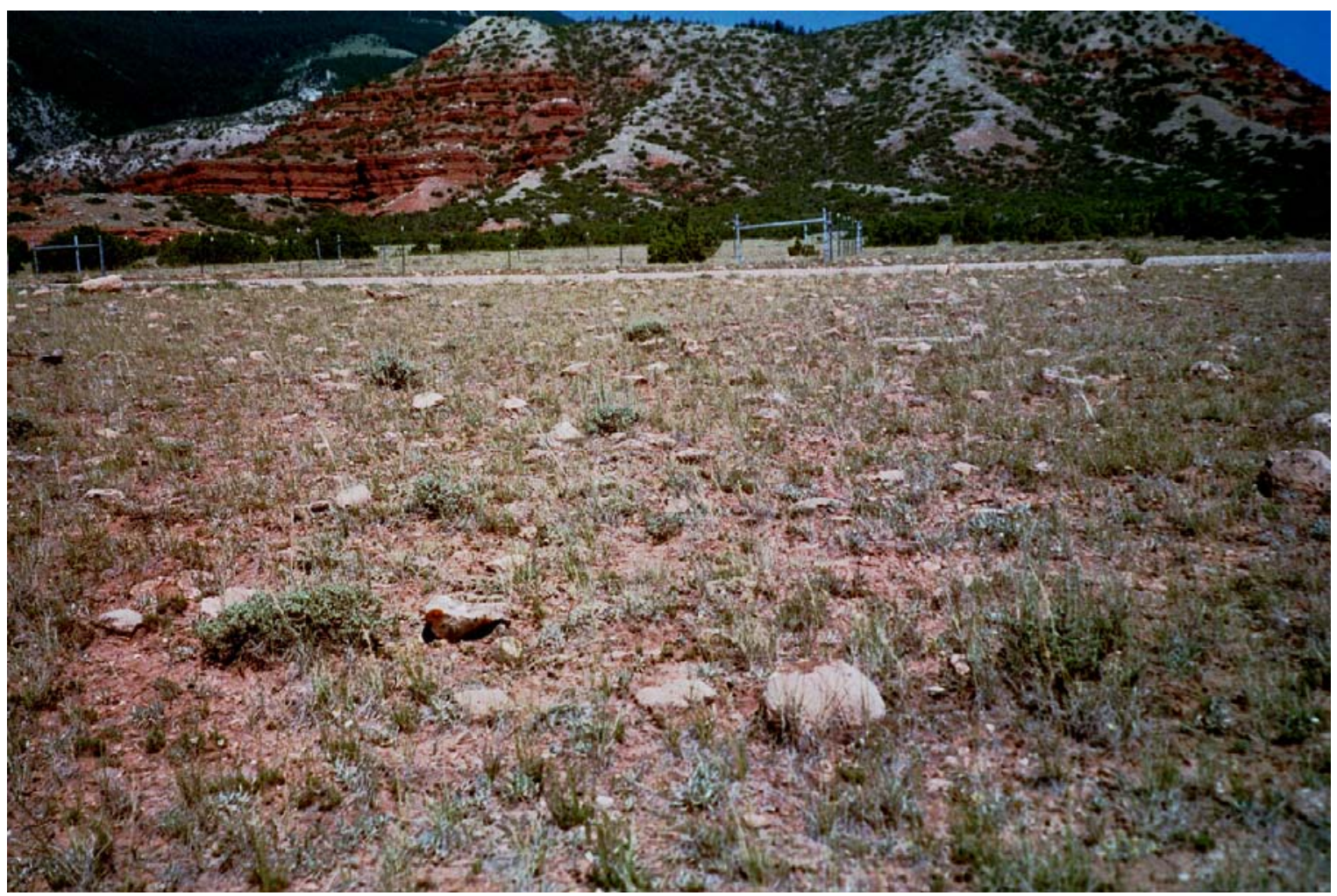

Photo 35. South Lockhart Ranch - Close view of vegetation outside permanent exclosure.

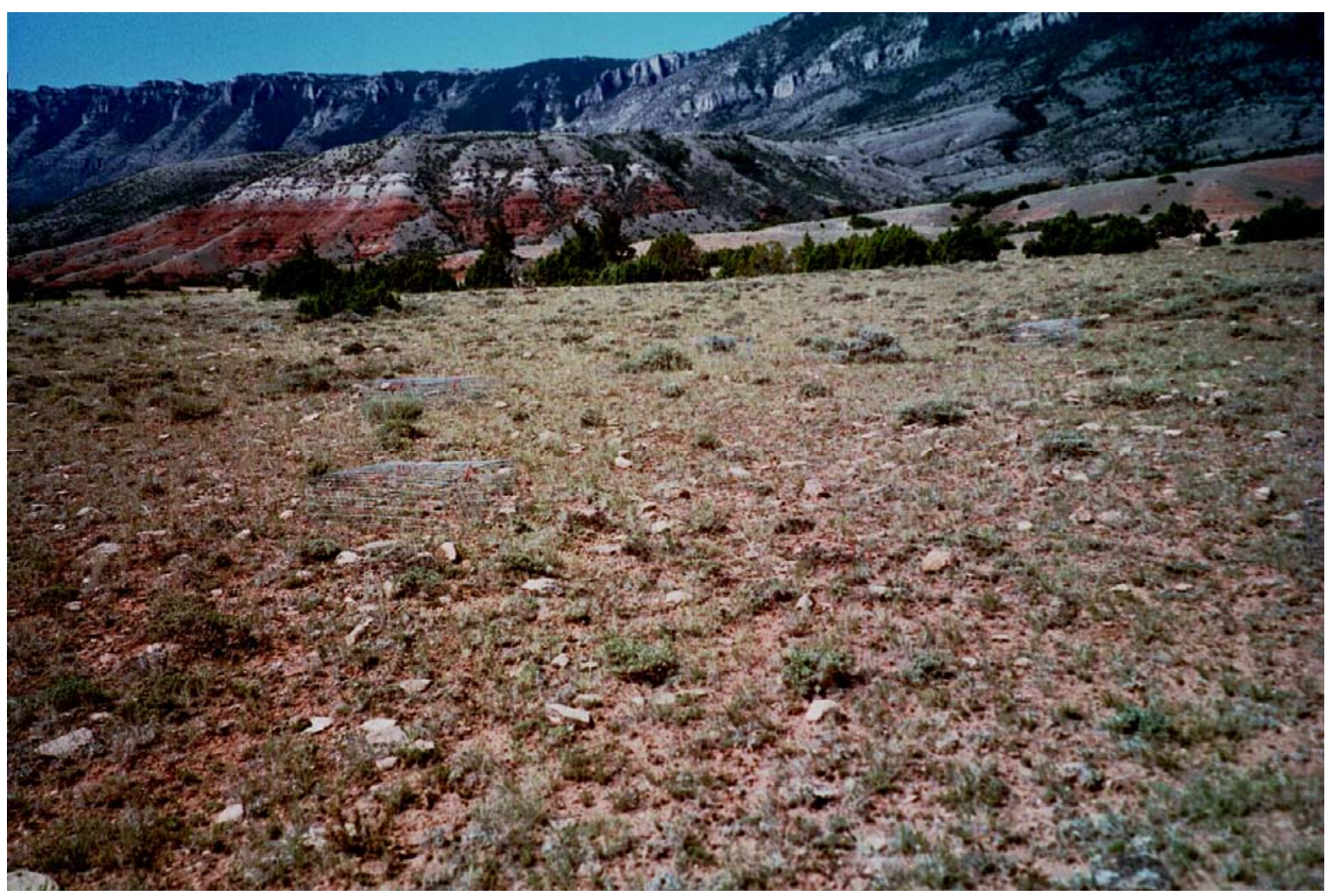

Photo 36. South Lockhart Ranch - Close view of temporary grazing cages outside permanent exclosure. Two cages are visible near the left center of the photograph. 


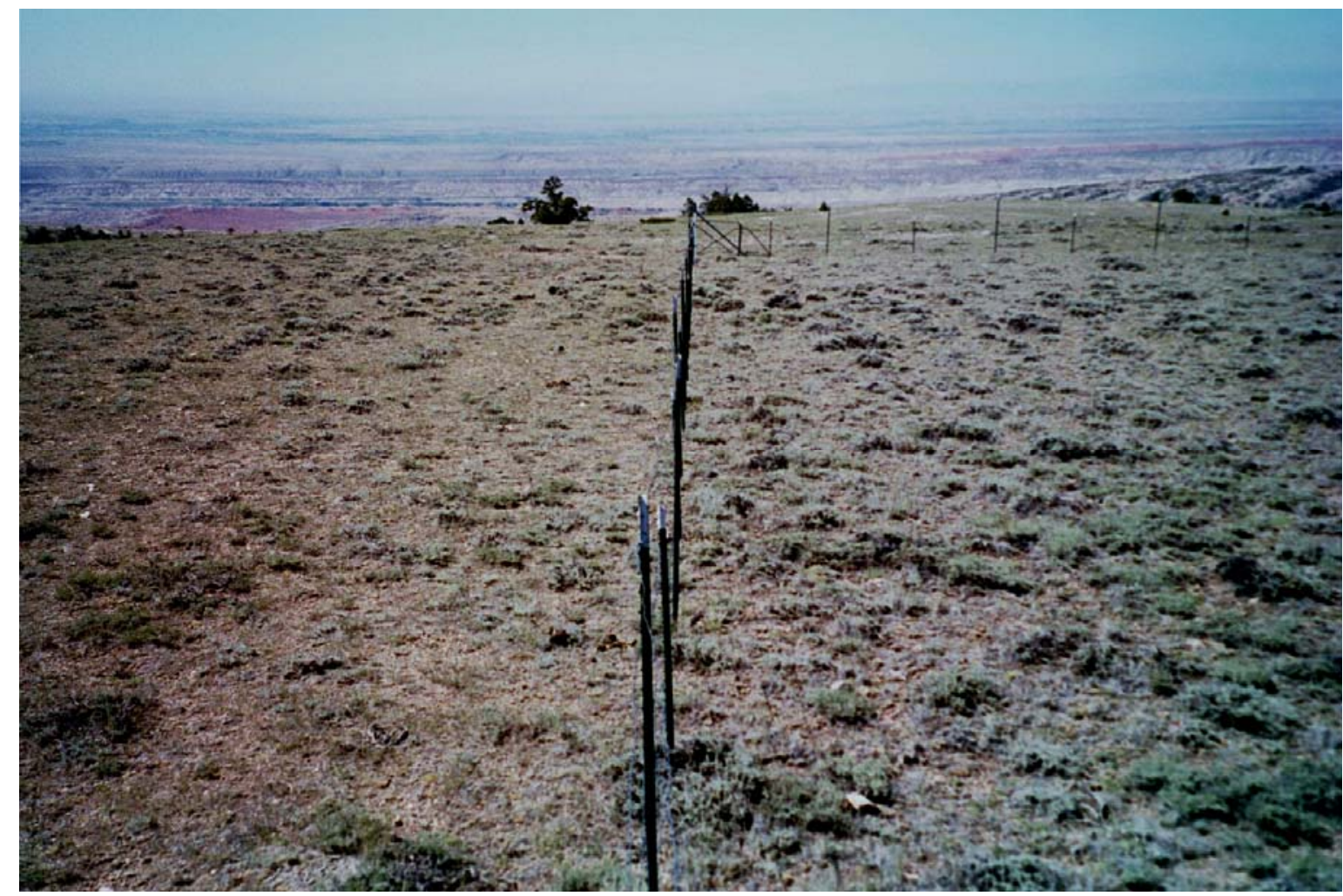

Photo 37. Sykes Ridge - View along fenceline of permanent exclosure established in 1992.

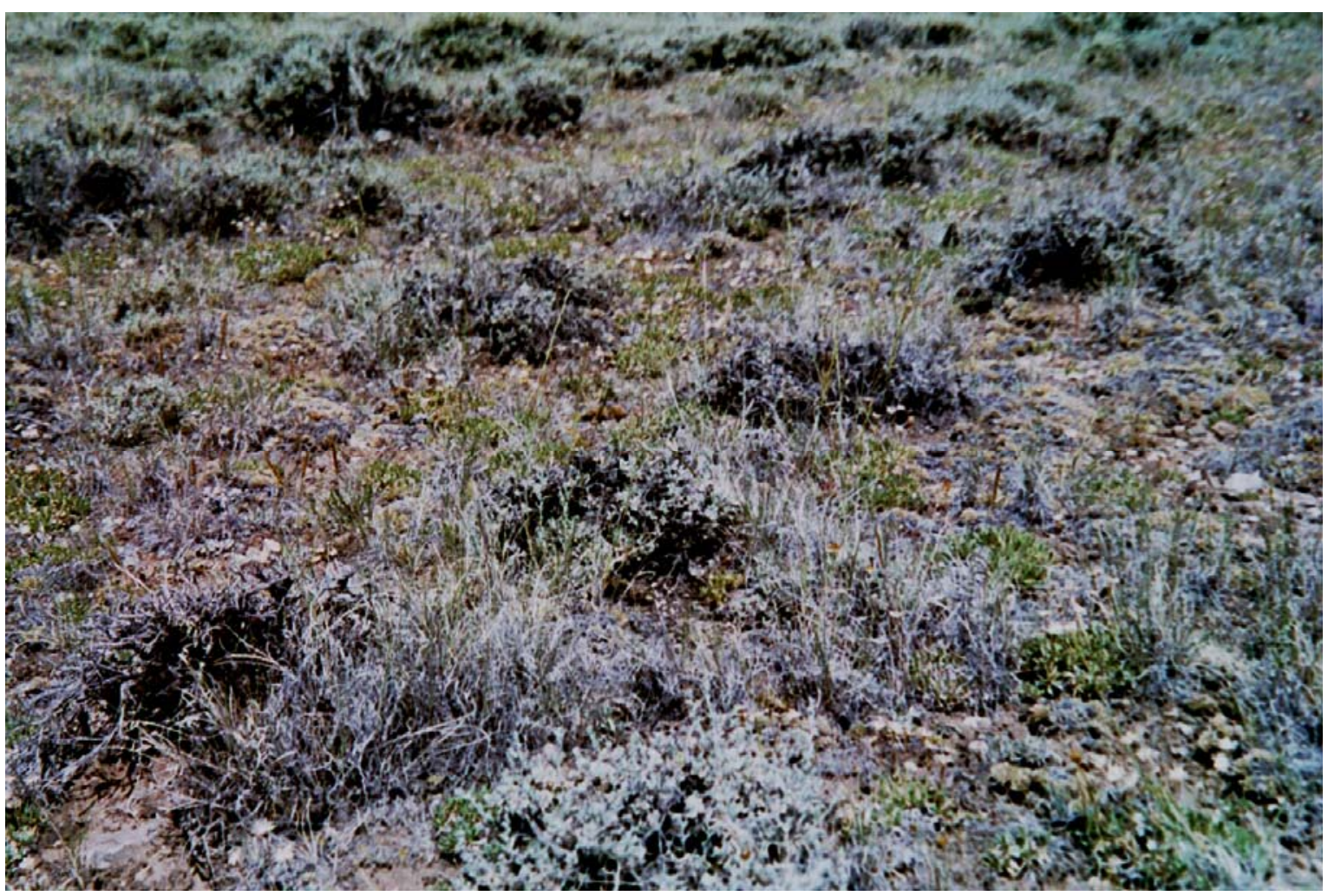

Photo 38. Sykes Ridge - Close view of vegetation inside permanent exclosure. 


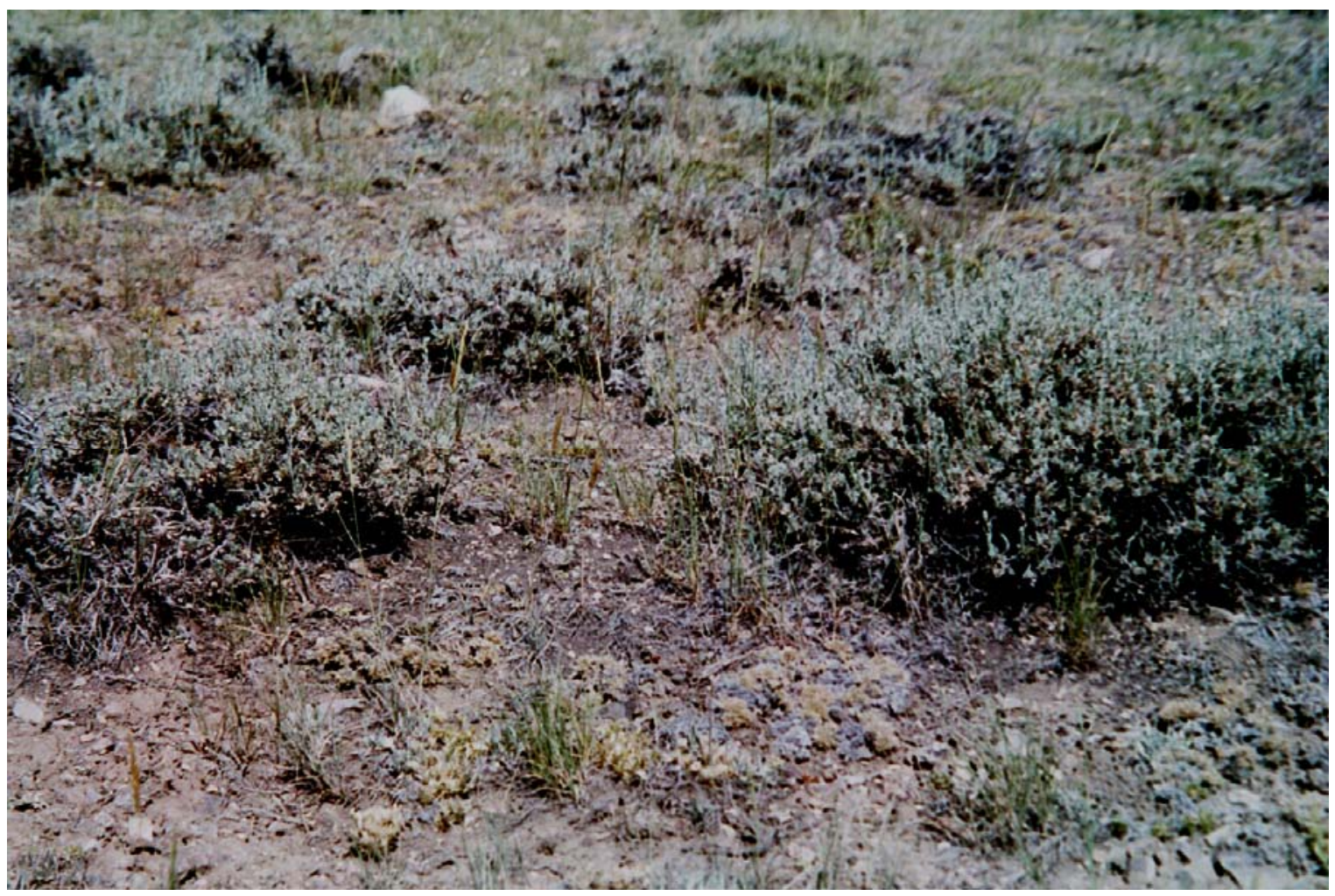

Photo 39. Sykes Ridge - Close view of vegetation outside permanent exclosure.

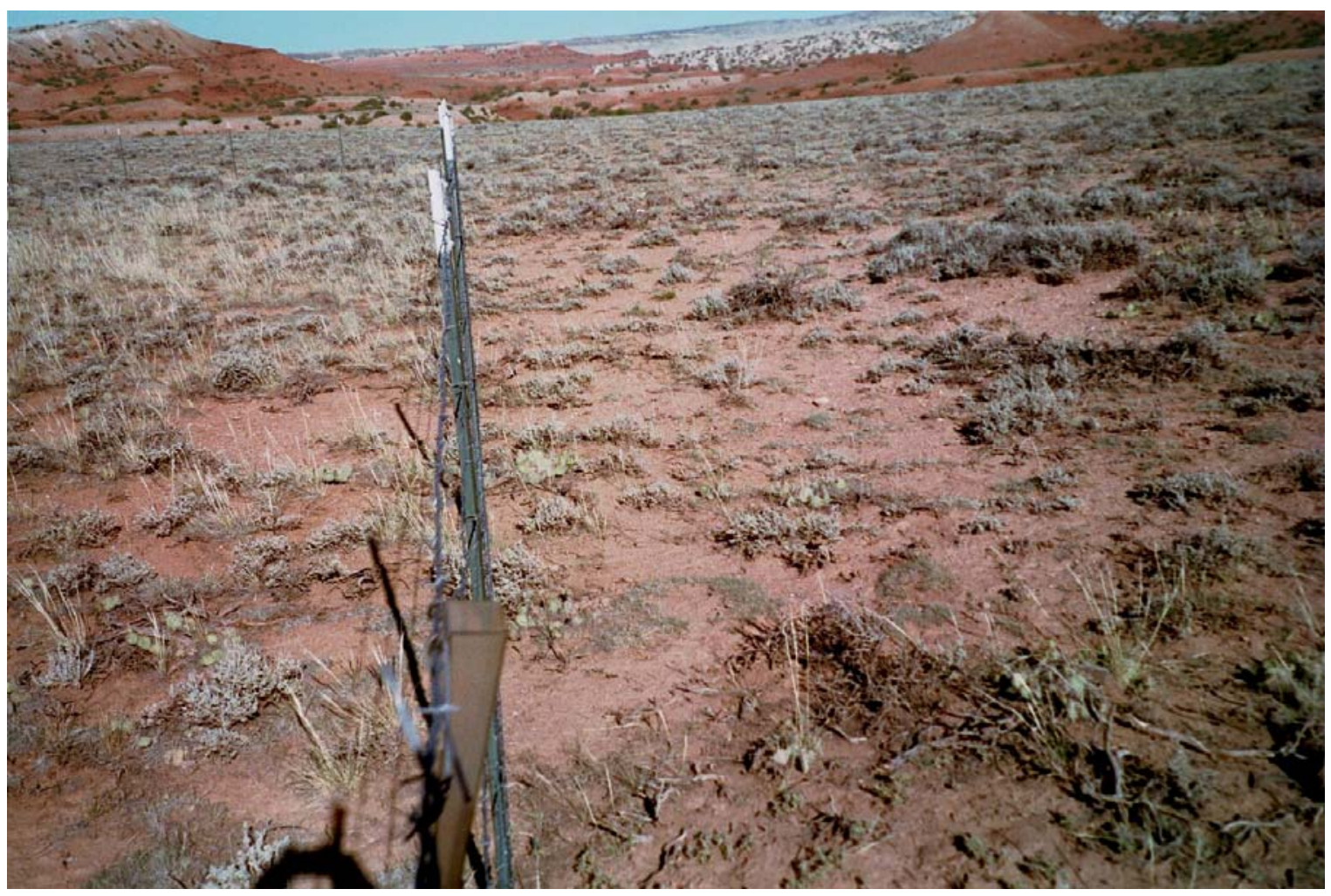

Photo 40. Turkey Flats - View along fence line of permanent exclosure. Exclosure was established in 1994. Inside of exclosure is to the left of the fence. 


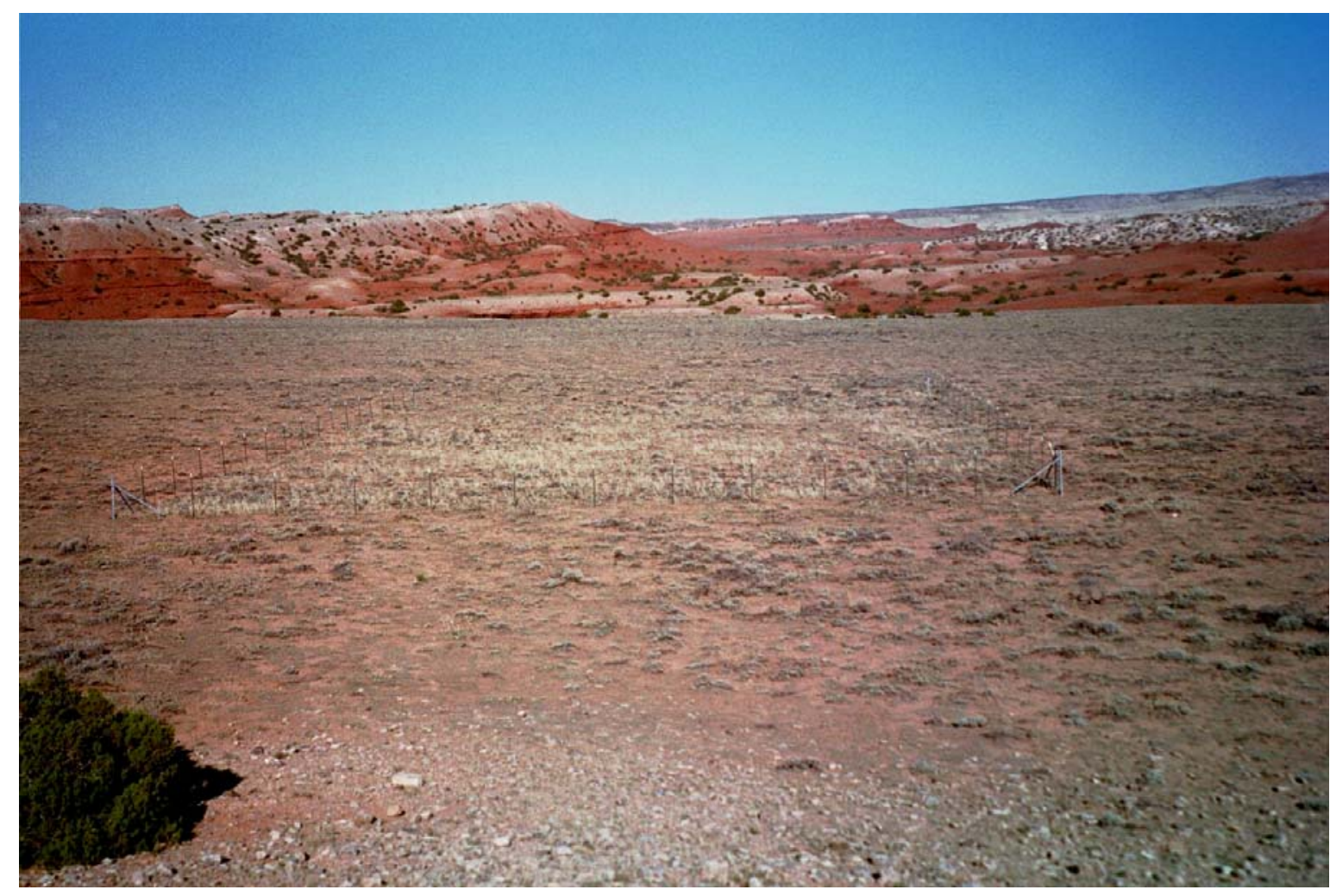

Photo 41. Turkey Flats - Landscape view of permanent exclosure. Notice standing dead grass inside

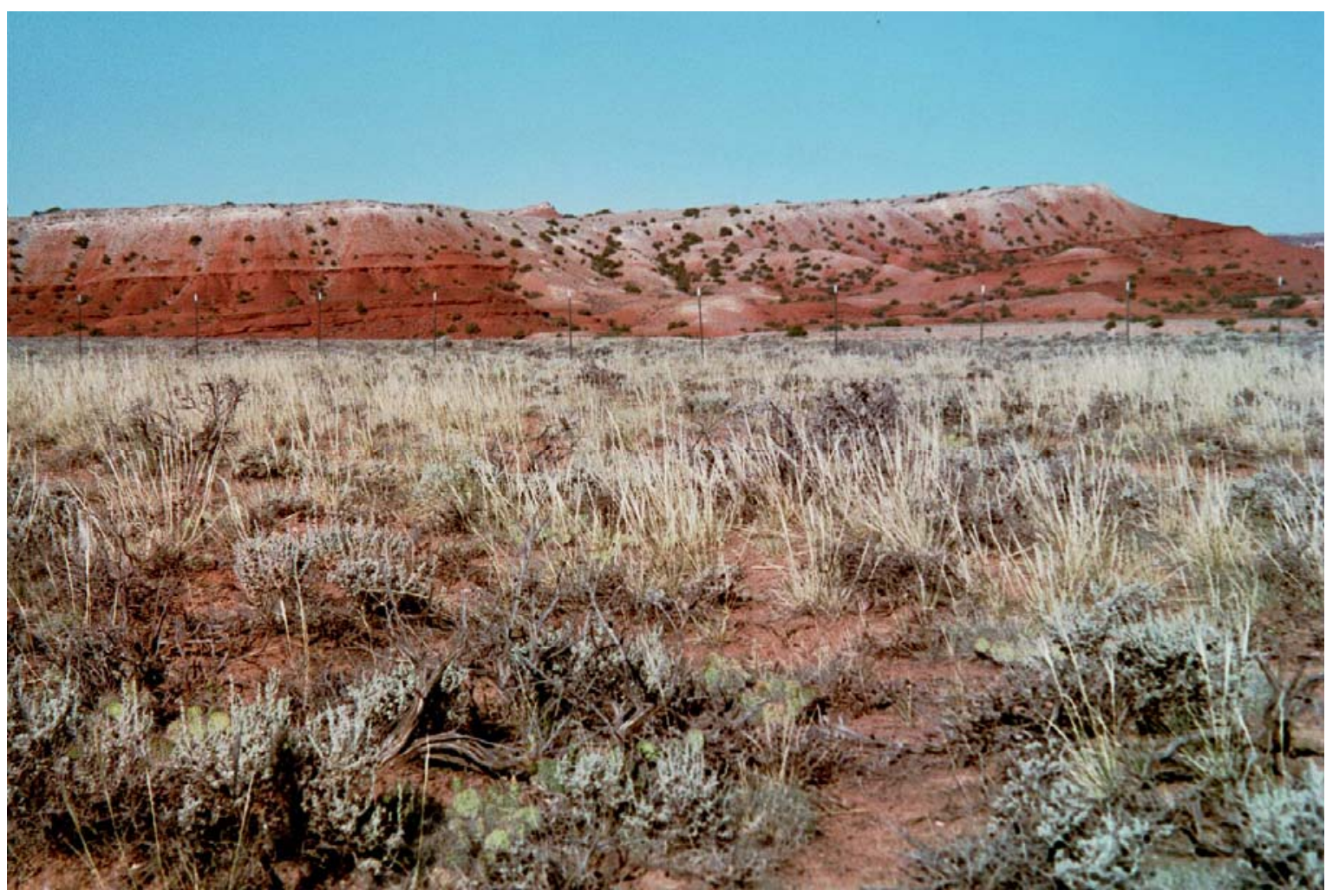

Photo 42. Turkey Flats - Close view of vegetation inside permanent exclosure. 


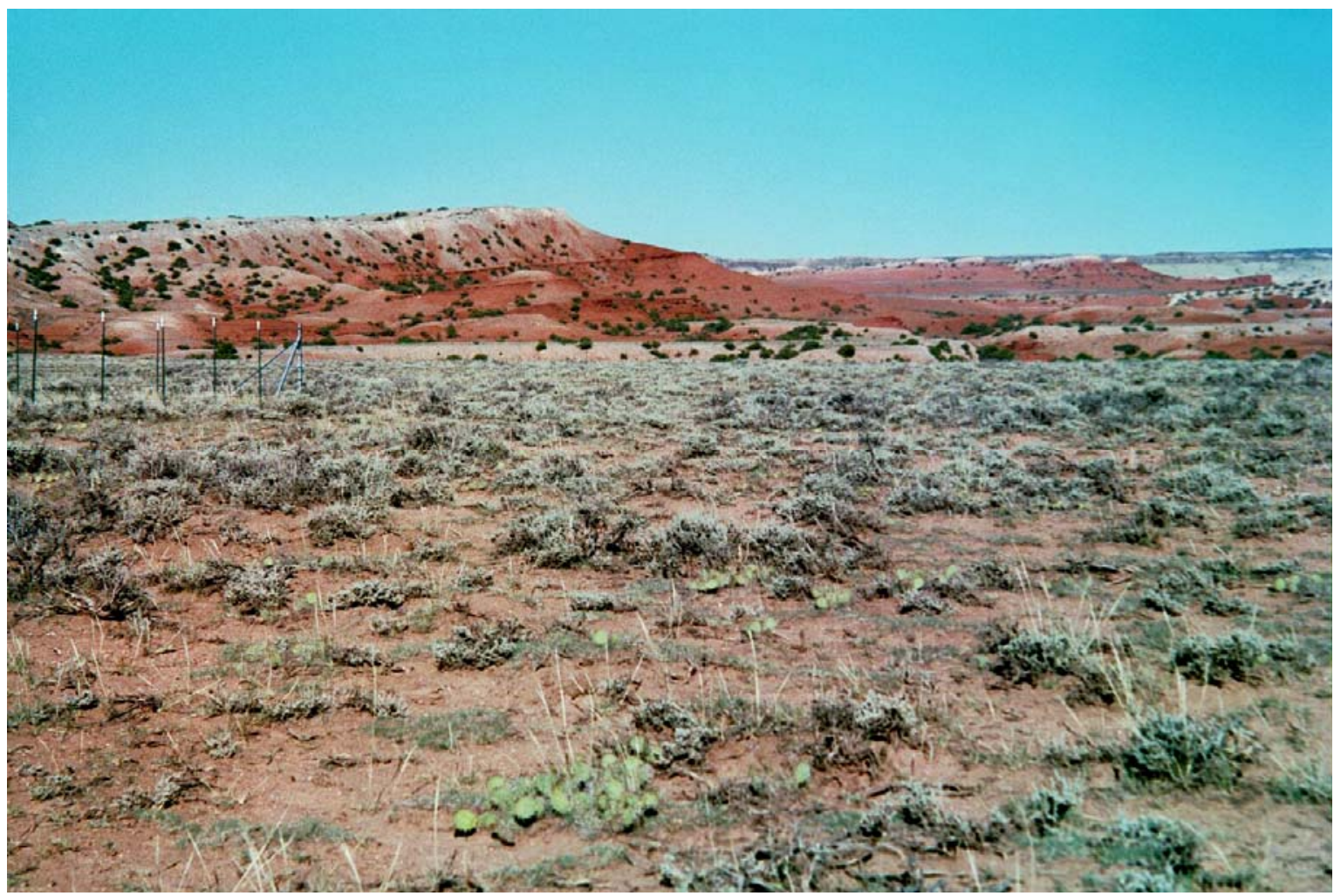

Photo 43. Turkey Flats - Close view of vegetation outside permanent exclosure. Exclosure corner is visible to the left.

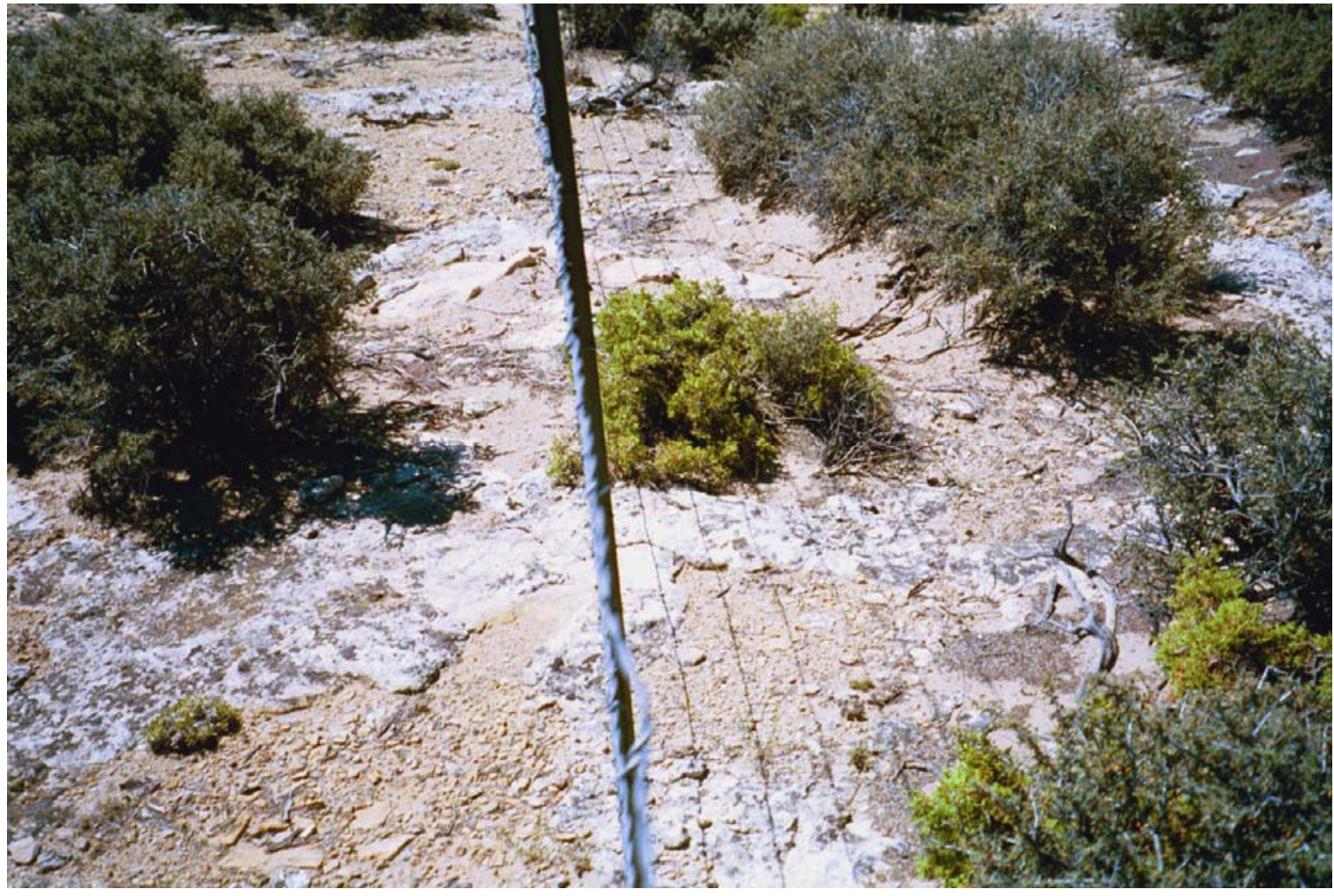

Photo 44. Yellow Hill - View along fence line of permanent exclosure. Exclosure was erected in 1994 


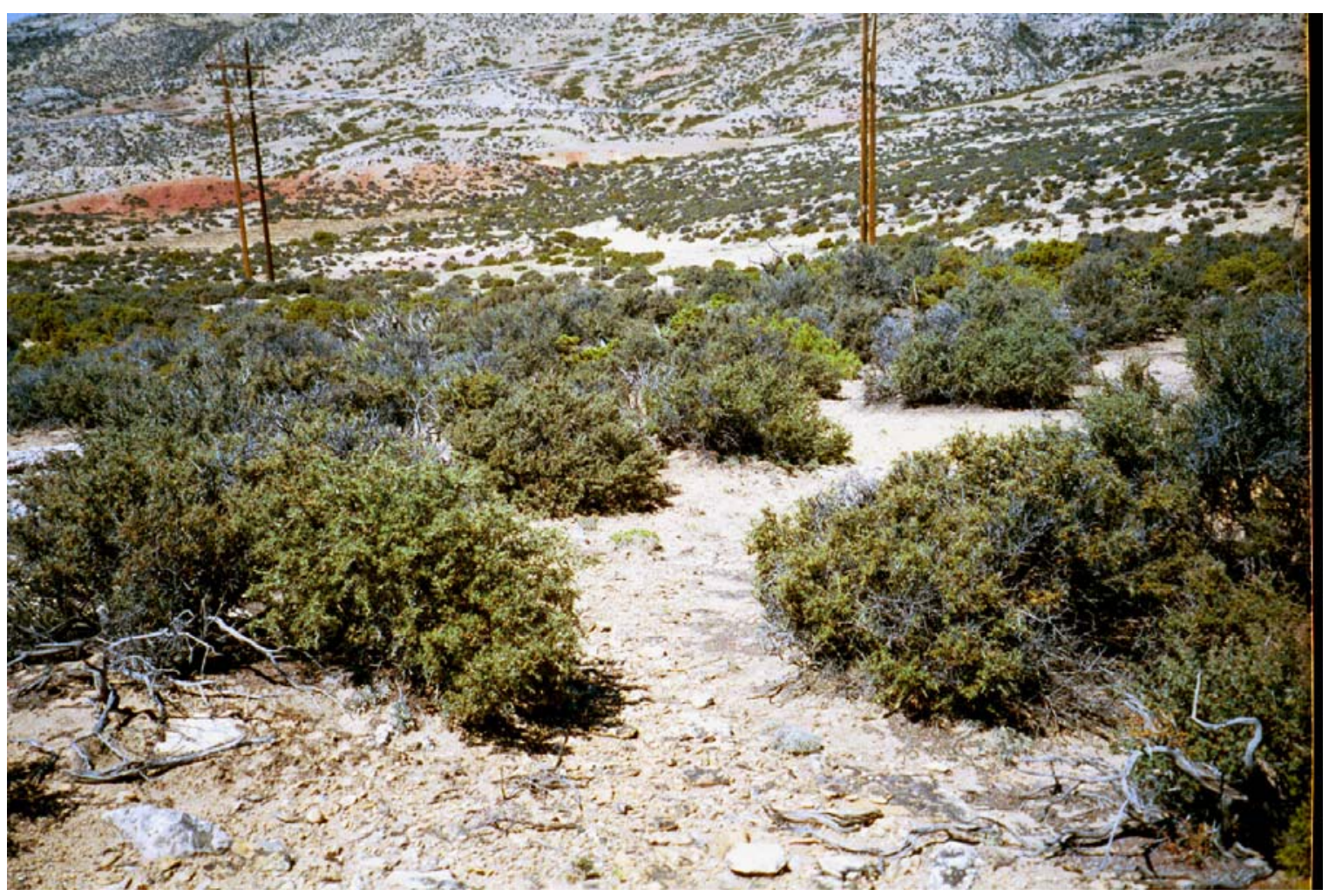

Photo 45. Yellow Hill - Close view of vegetation inside permanent exclosure.

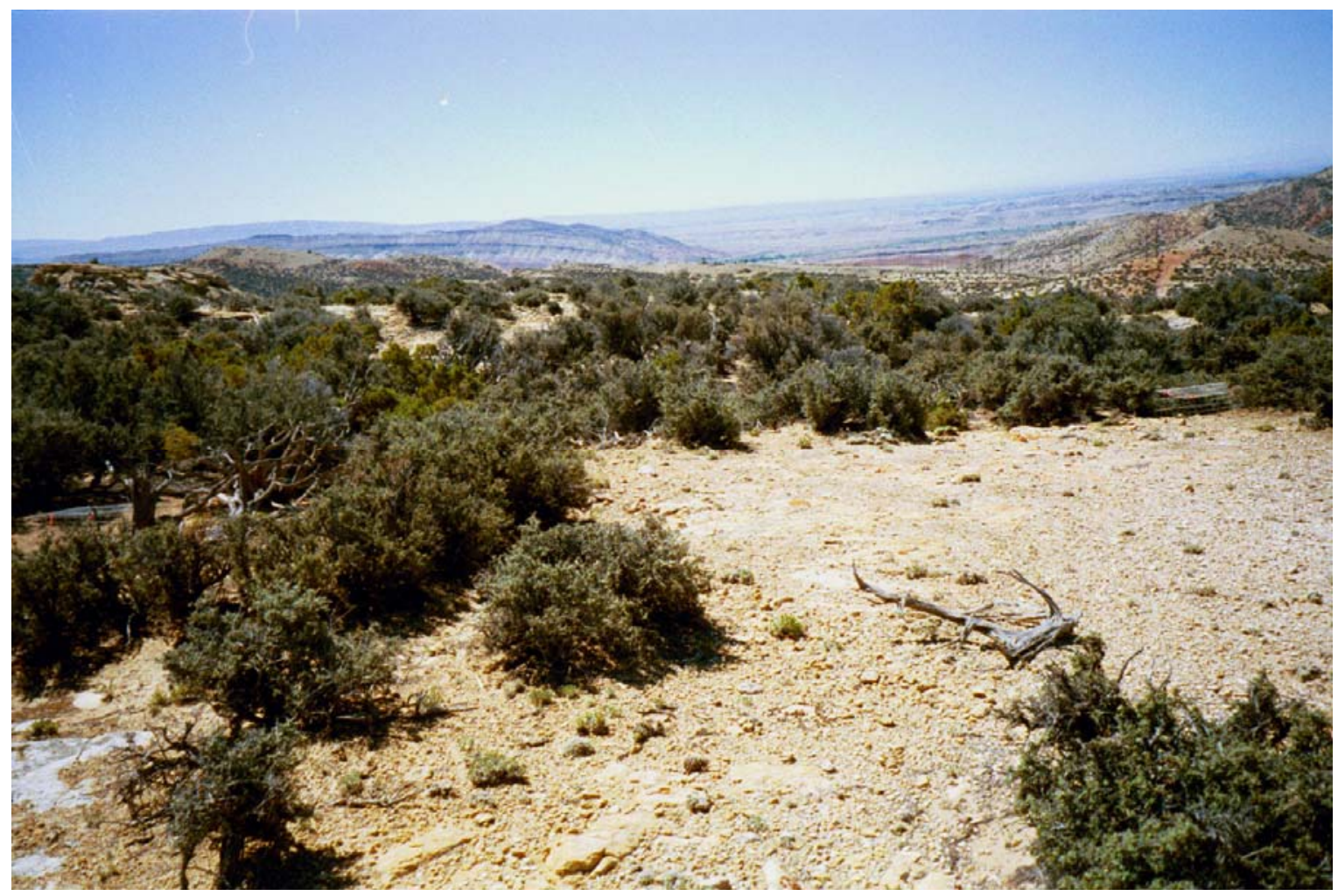

Photo 46. Yellow Hill - Close view of vegetation outside permanent exclosure. 


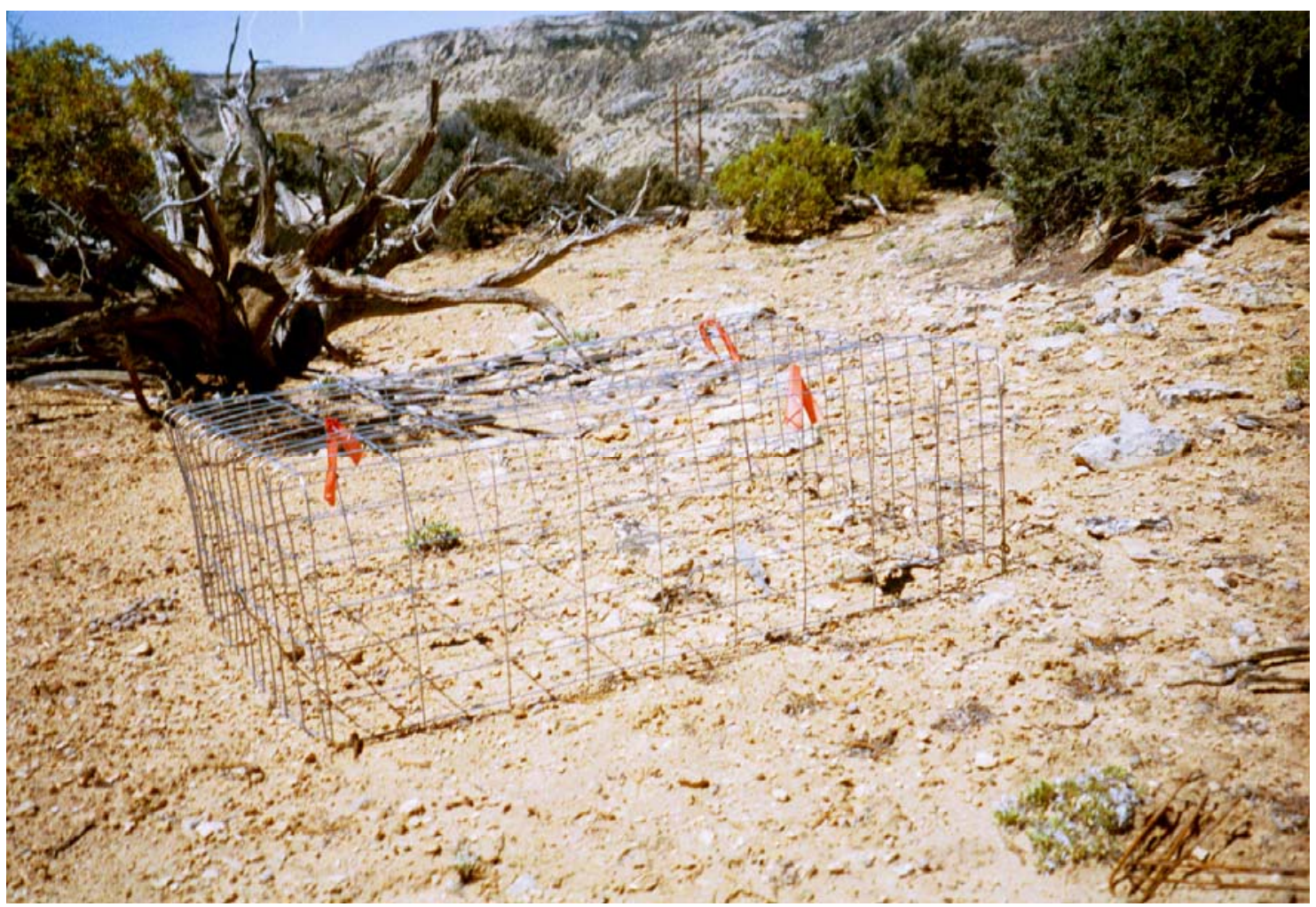

Photo 47. Yellow Hill - View of temporary grazing cage outside permanent exclosure. 


\section{Attachment B. Cushion Plant Site Photos}

Photographs were taken in early July 2002. Views are close-ups of the $1 \mathrm{~m} \mathrm{x} 1 \mathrm{~m}$ sampling grid placed in each plot type at each of the four sites: North and South Dryhead and North and South Lockhart Ranch. 


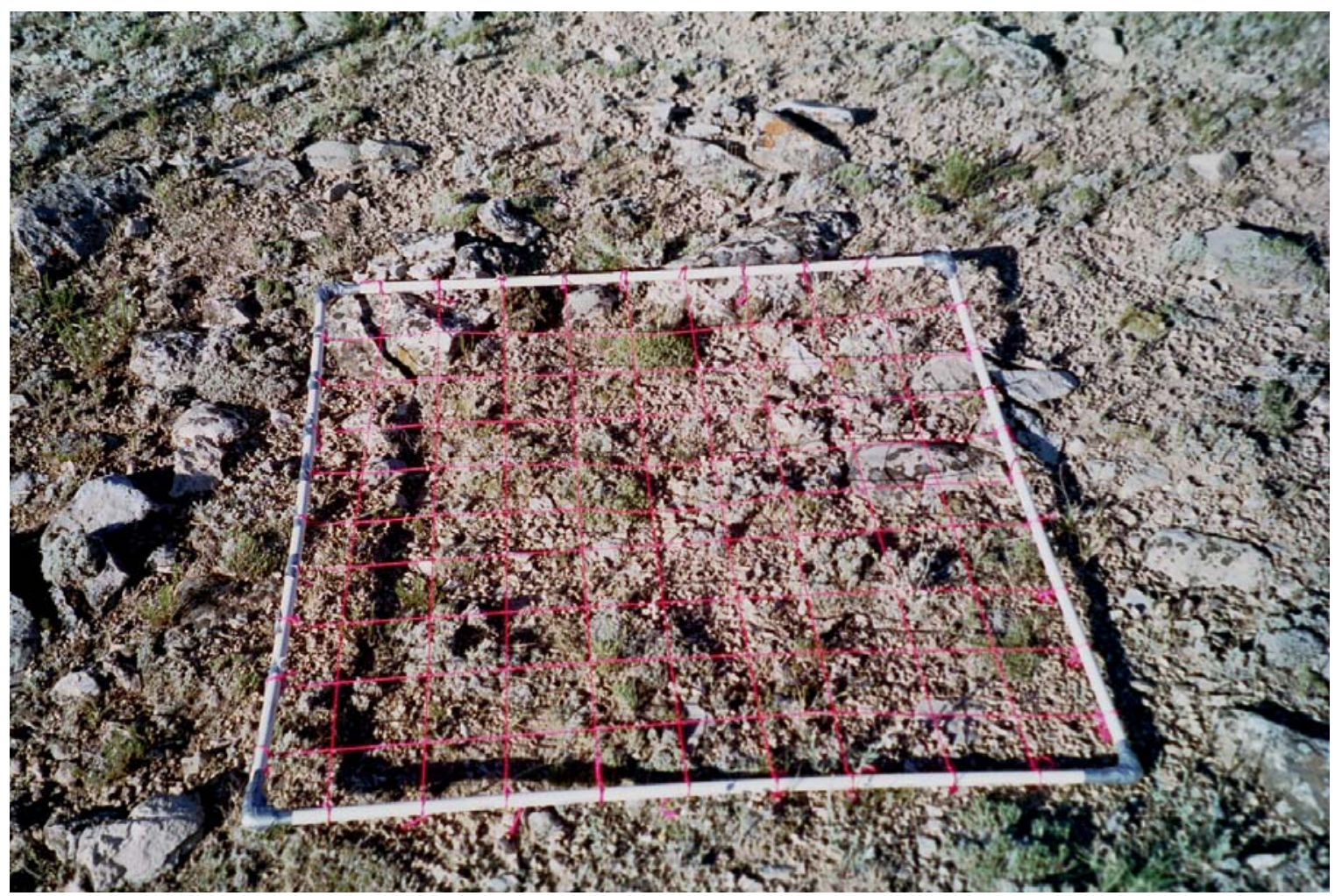

Photo 1. North Dryhead - Cushion plant grid in control plot outside permanent exclosure.

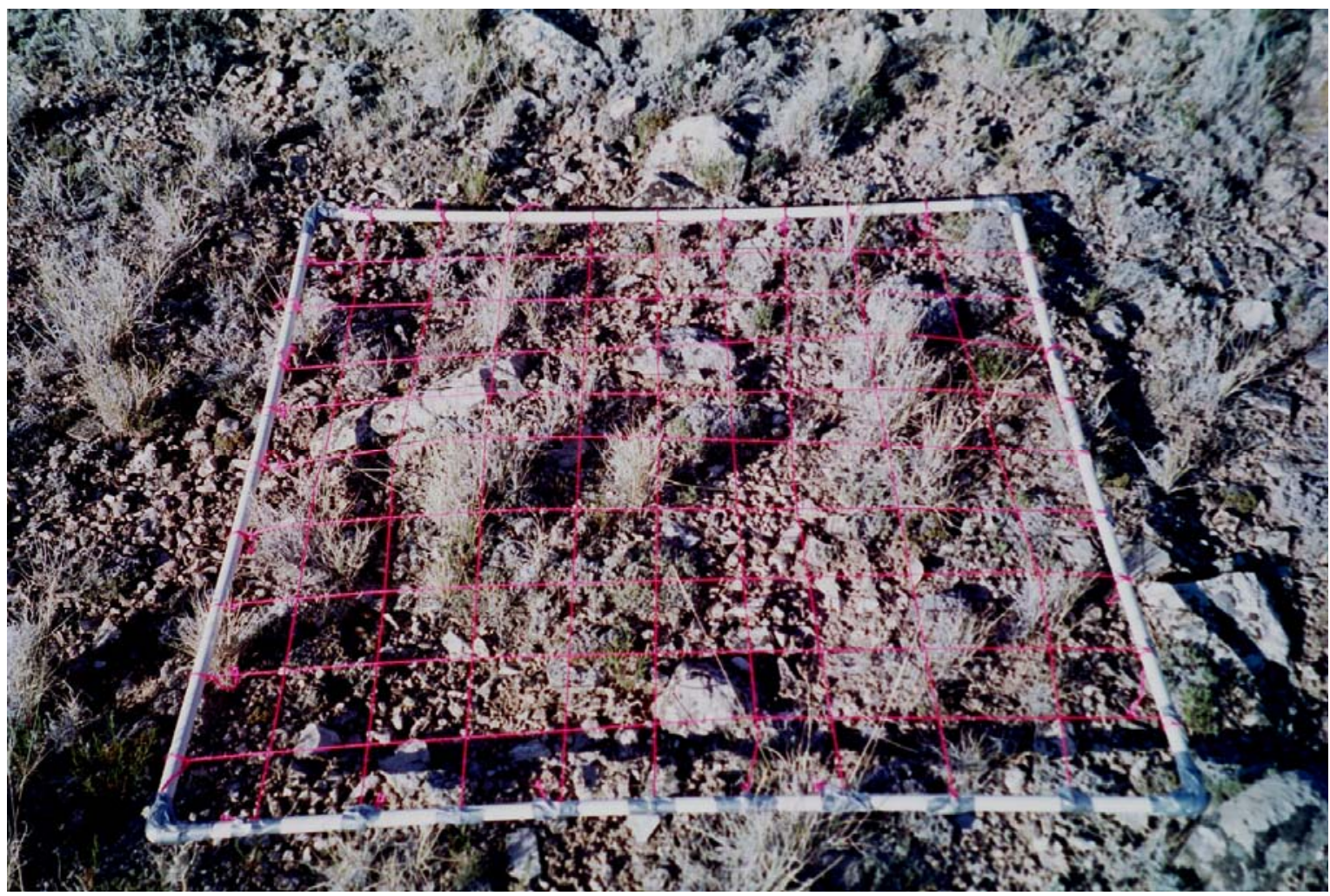

Photo 2. North Dryhead - Cushion plant grid inside permanent exclosure. Exclosure was erected in 1992. 


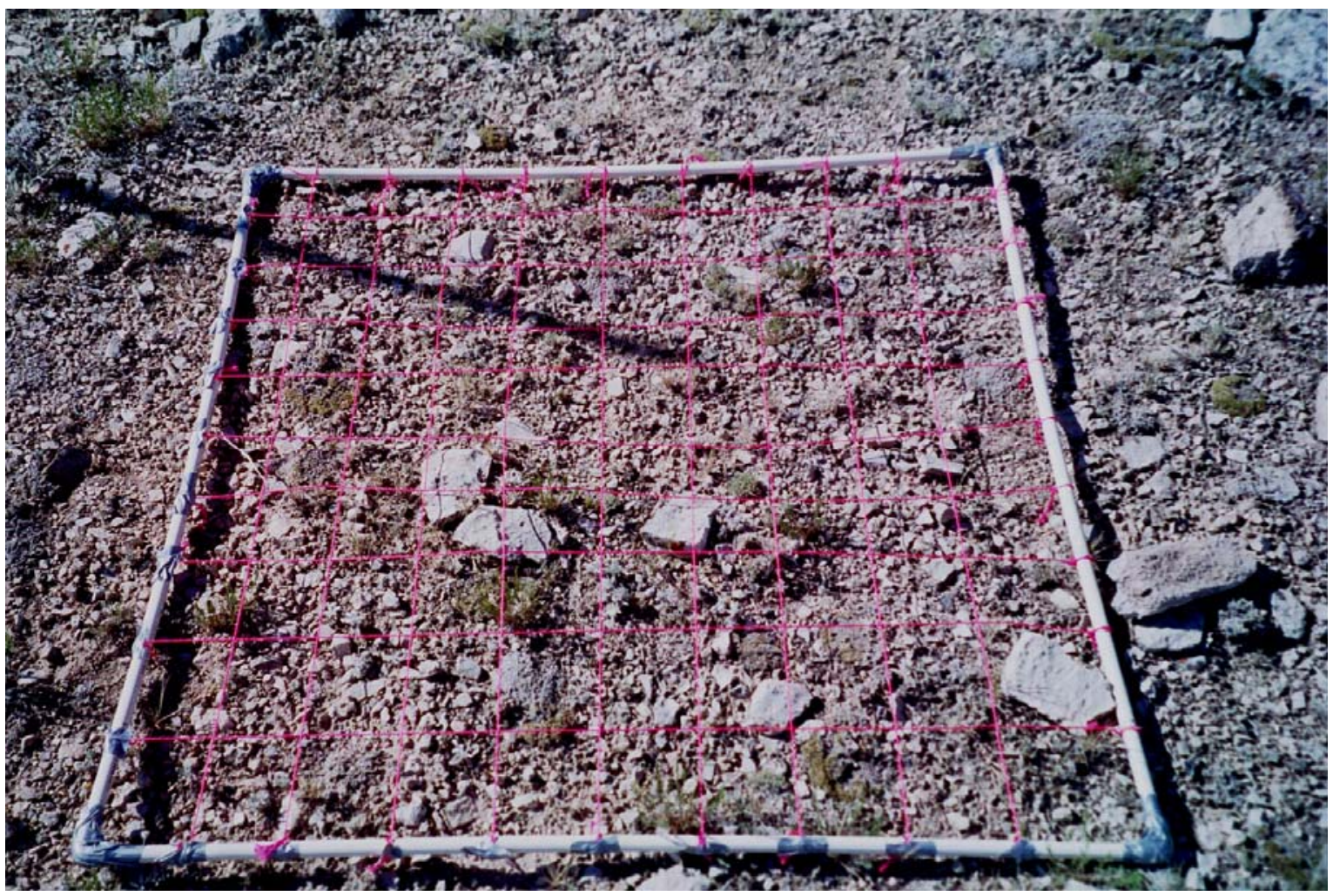

Photo 3. South Dryhead - Cushion plant grid in control plot outside permanent exclosure.

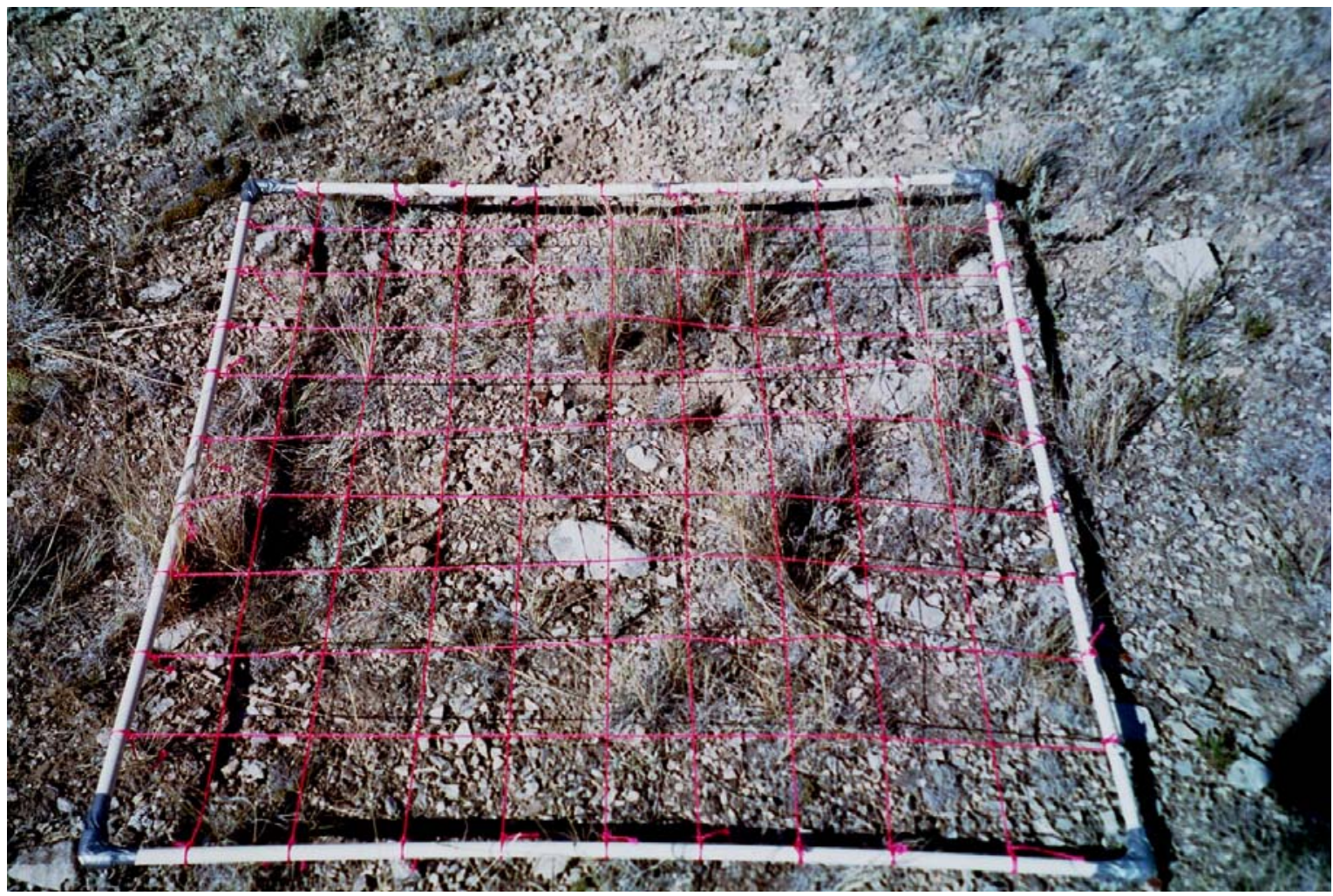

Photo 4. South Dryhead - Cushion plant grid inside permanent exclosure. Exclosure was erected in 1992. 


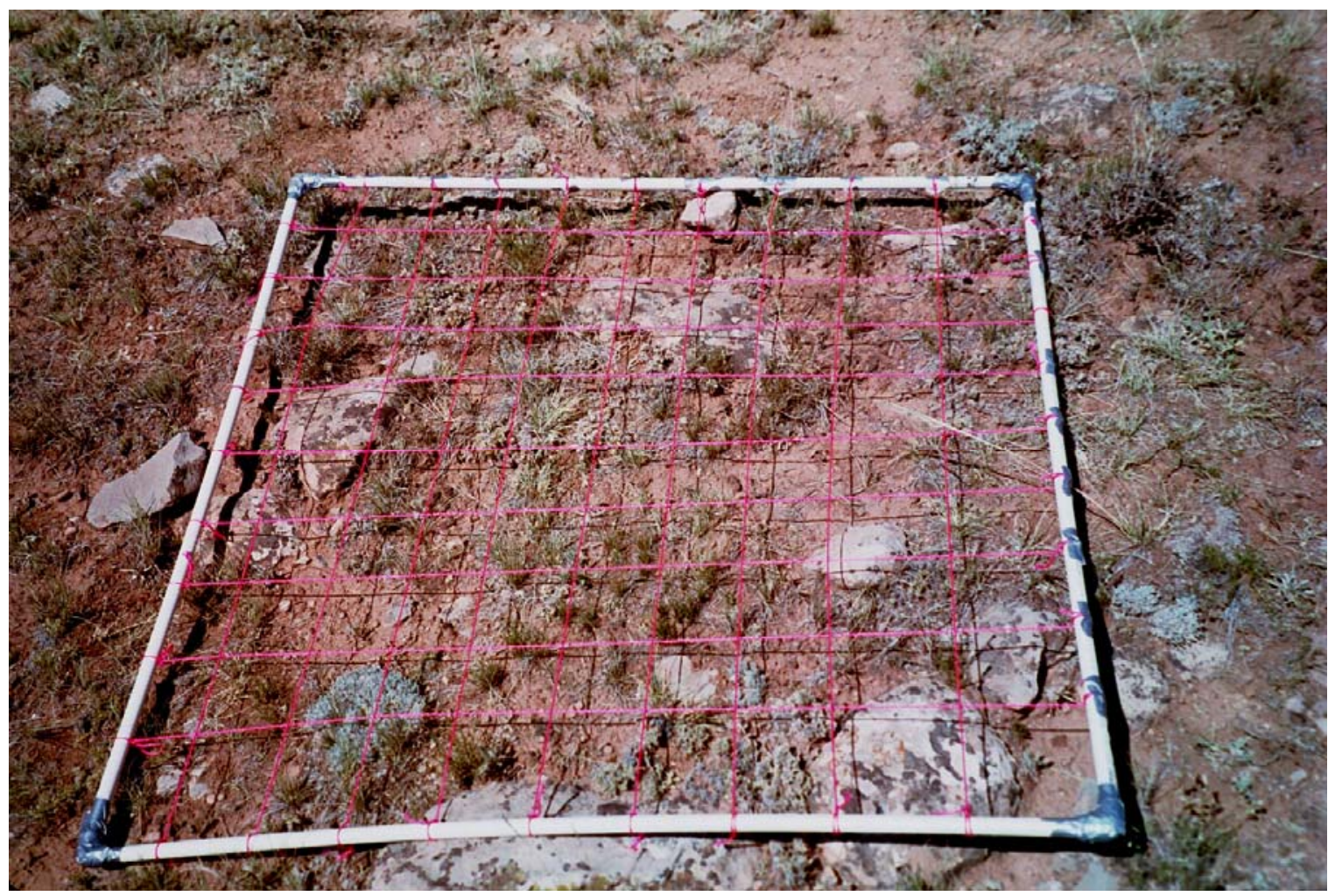

Photo 5. North Lockhart Ranch - Cushion plant grid in control plot outside permanent exclosure.

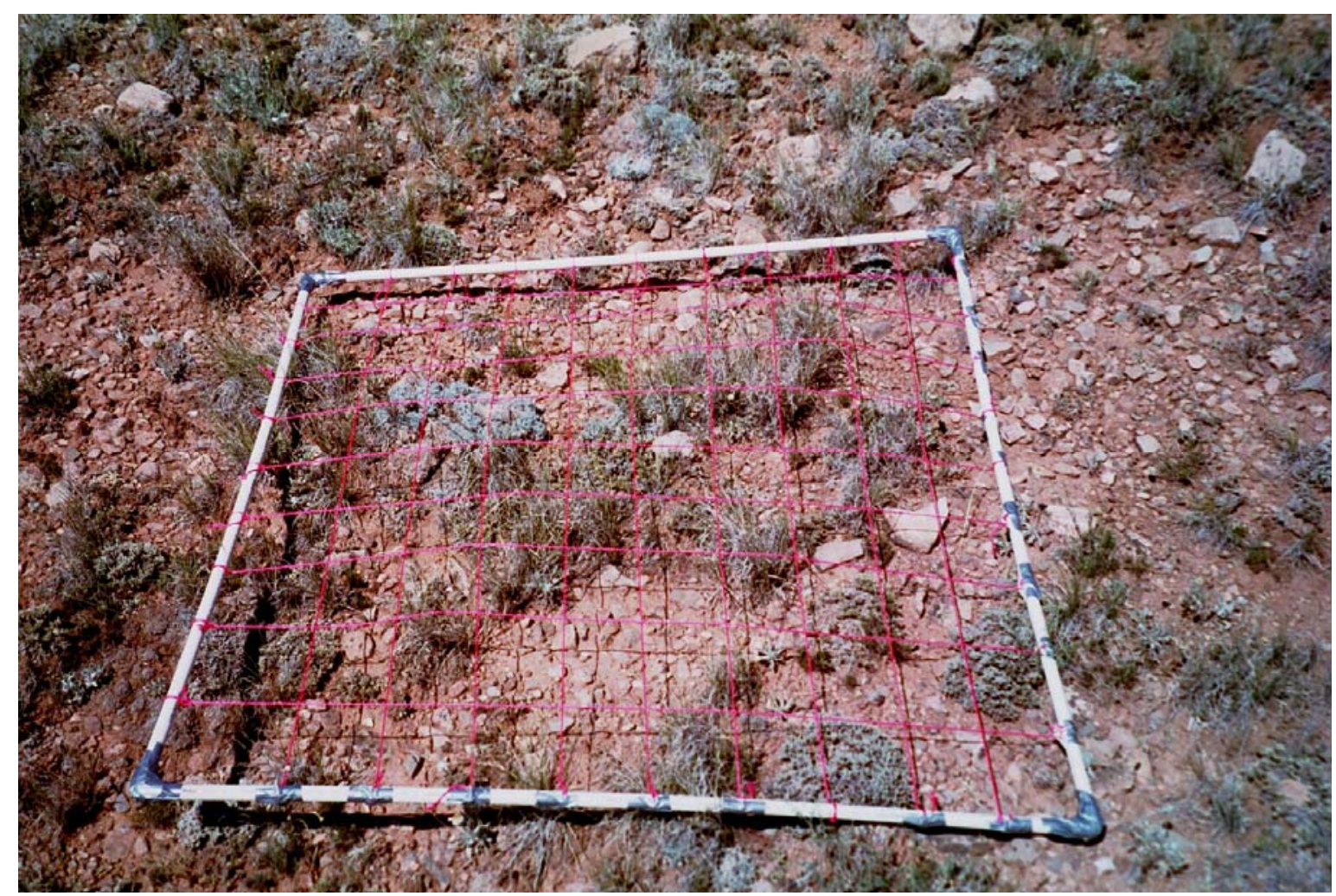

Photo 6. North Lockhart Ranch - Cushion plant grid inside permanent exclosure. The exclosed plot has been protected from grazing and cattle trailing since 1994. 


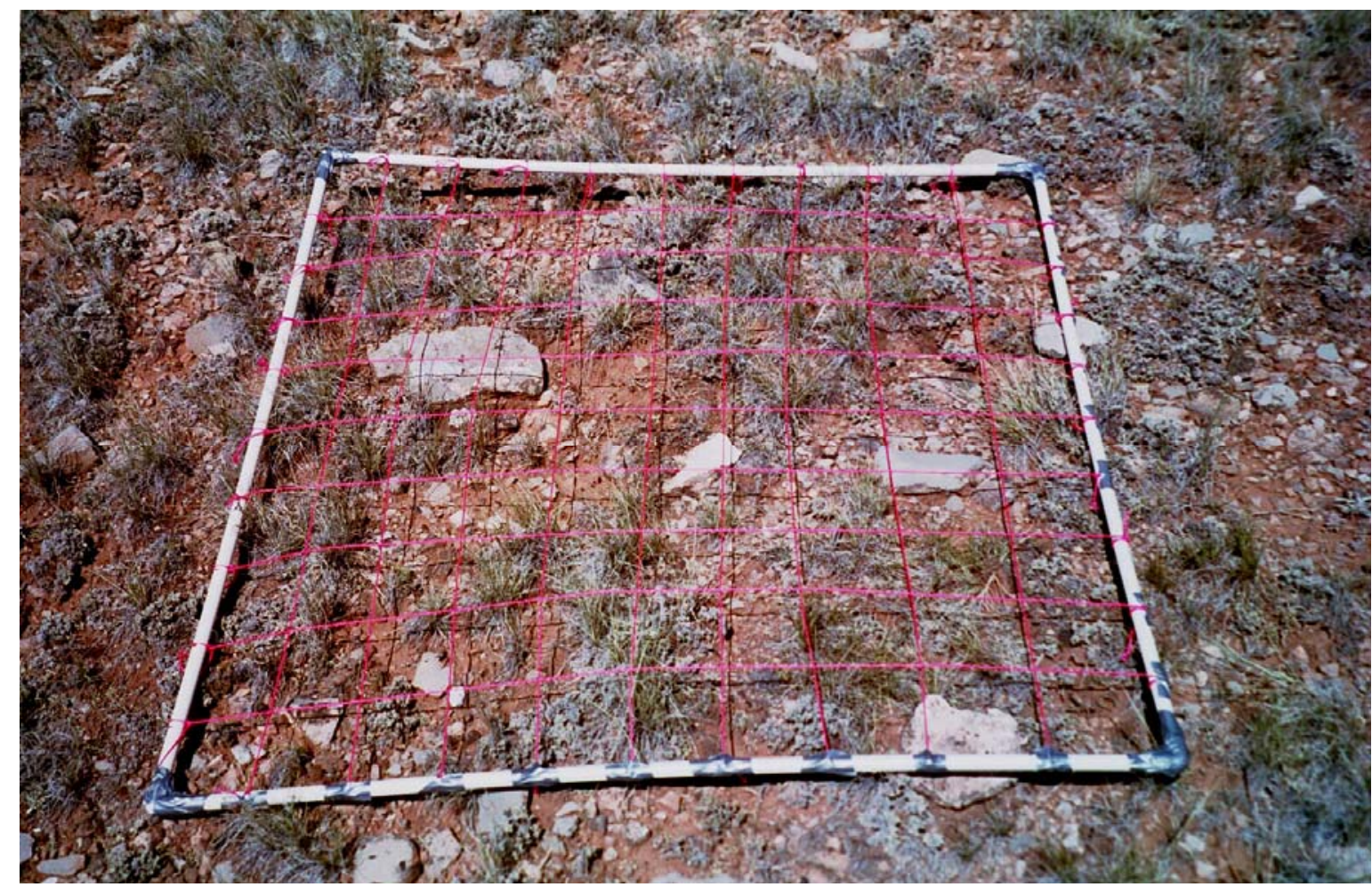

Photo 7. North Lockhart Ranch - Cushion plant grid in "native" plot. This plot is removed from the road and was selected in 1994 to be comparable to the control and exclosed plots, but less susceptible to heavy cattle trailing because of distance from the road.

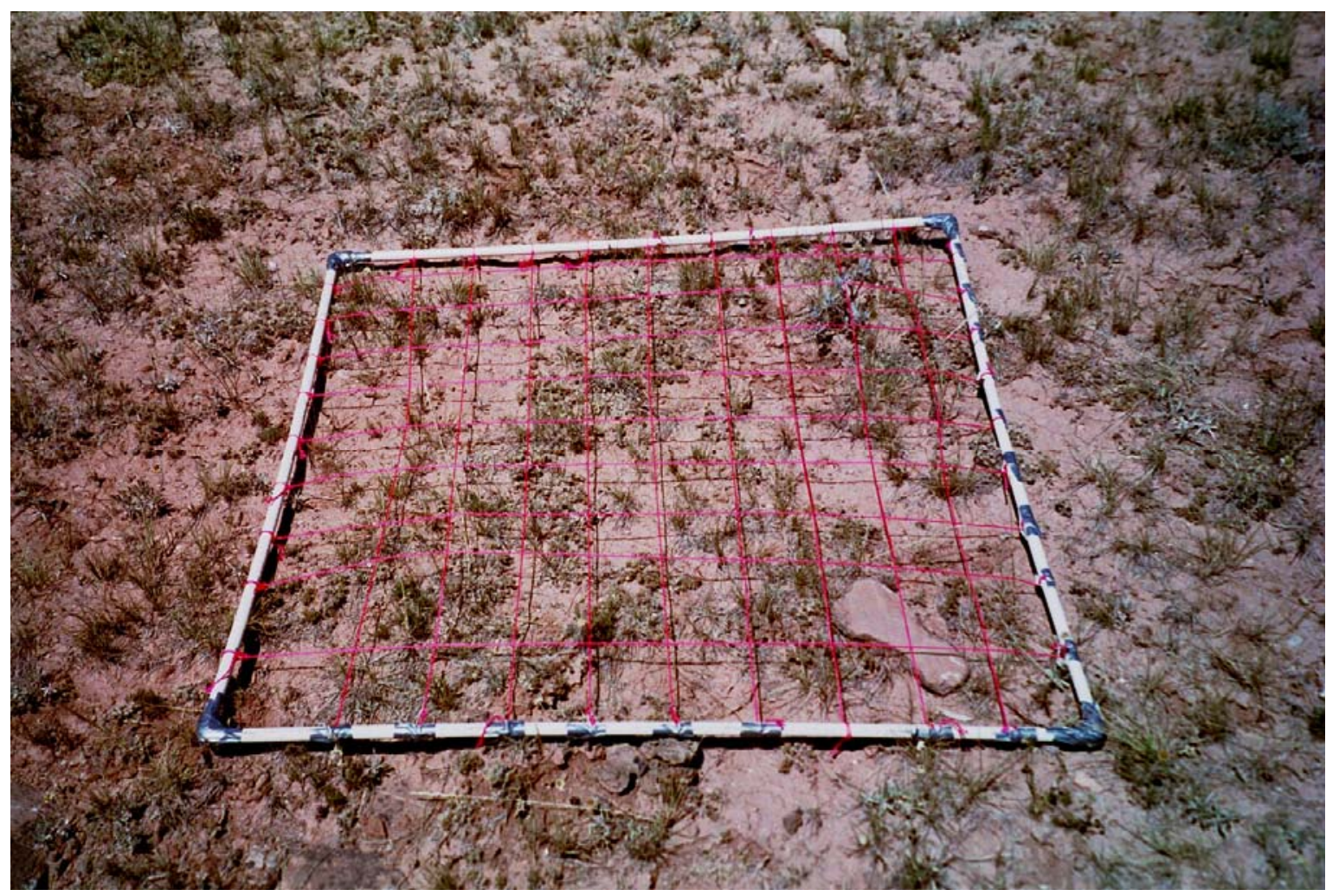

Photo 8. South Lockhart Ranch - Cushion plant grid in control plot outside permanent exclosure. 


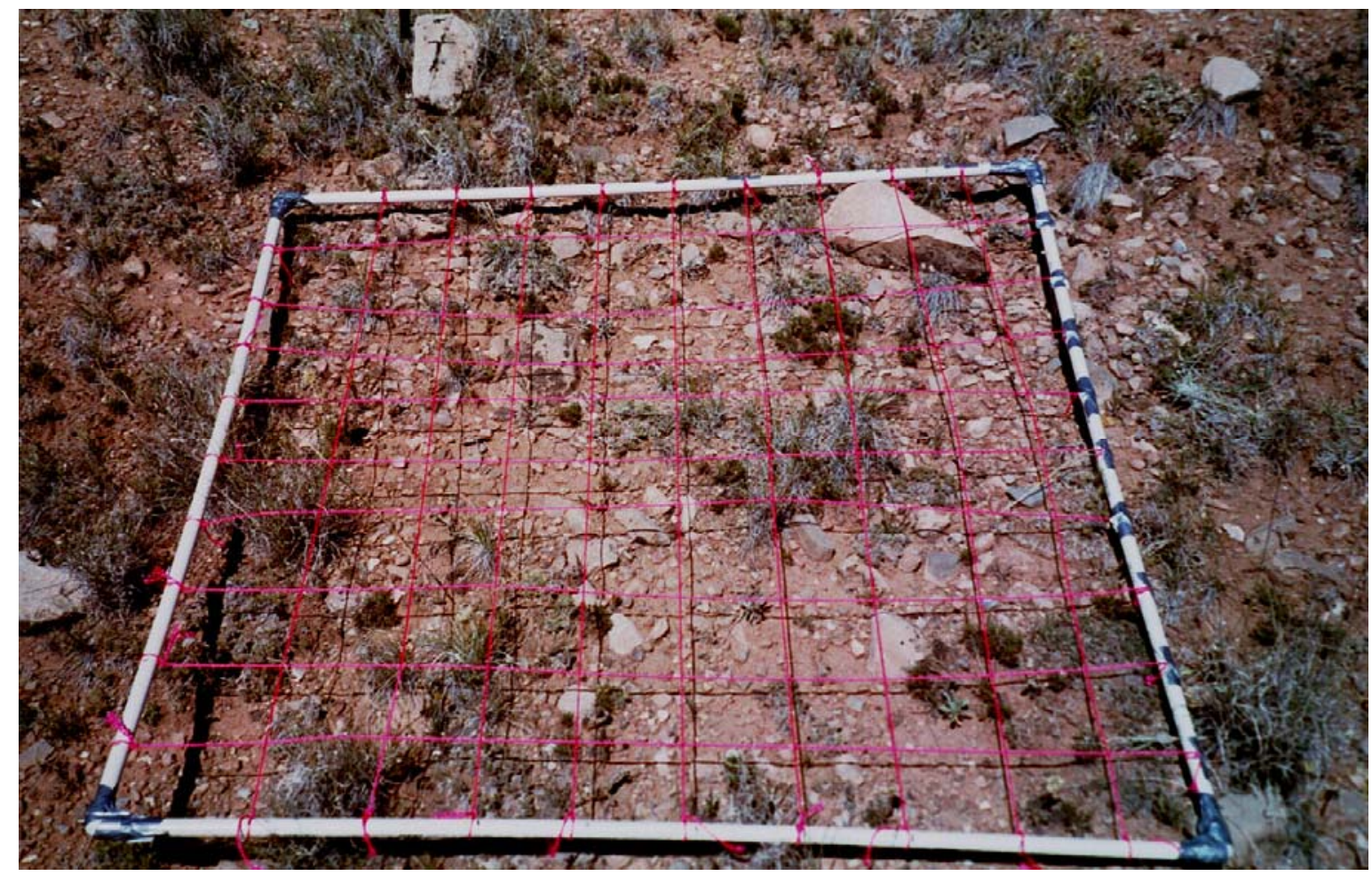

Photo 9. South Lockhart Ranch - Cushion plant grid inside permanent exclosure. Exclosure was established in 1994 to protect the plot from trailing cattle.

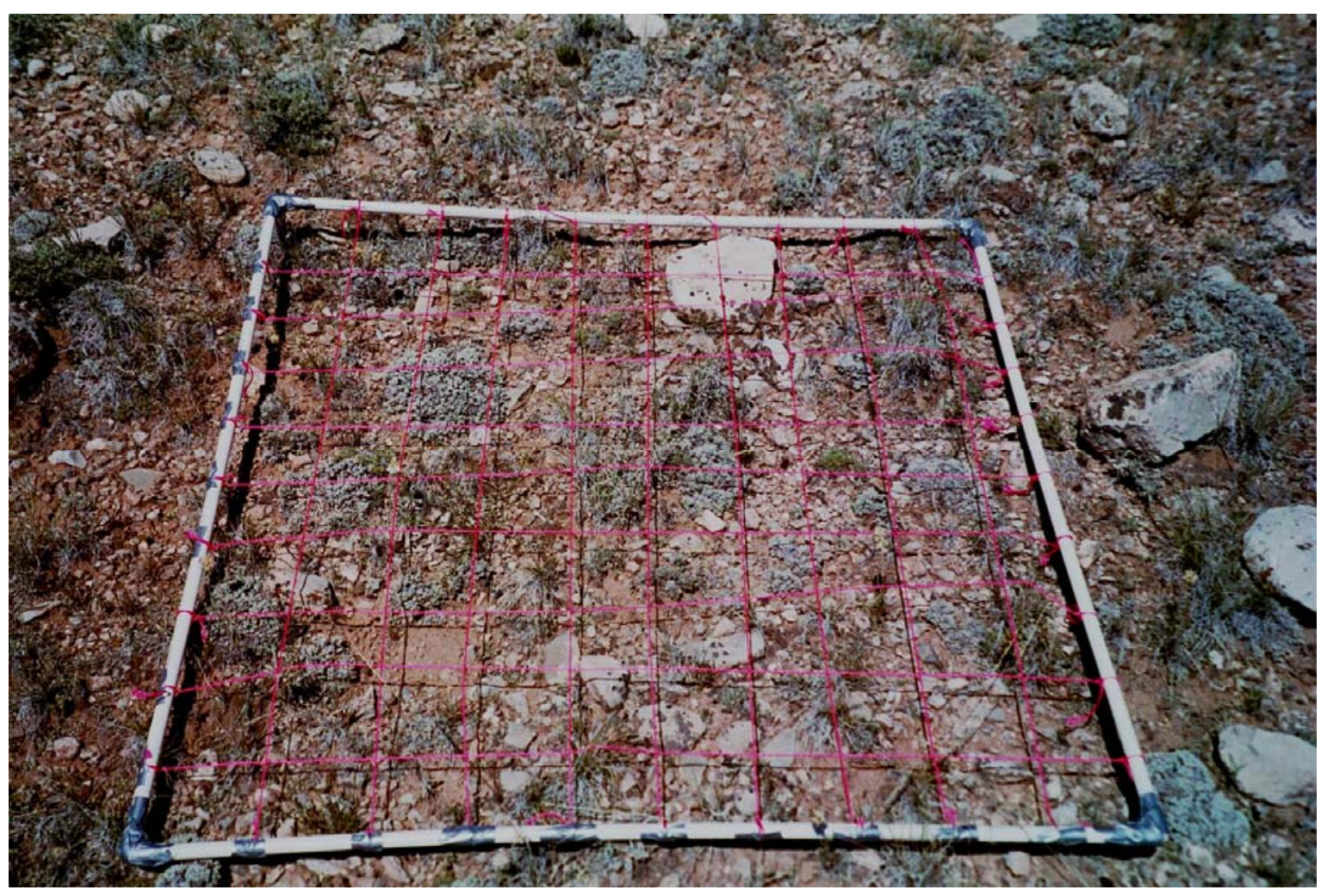

Photo 10. South Lockhart Ranch - Cushion plant grid in "native" plot. The $25 \times 25$ m native plot was selected in 1994 to be comparable to the control and exclosed plots, but less likely to be used by trailing cattle because it is not adjacent to the road. 


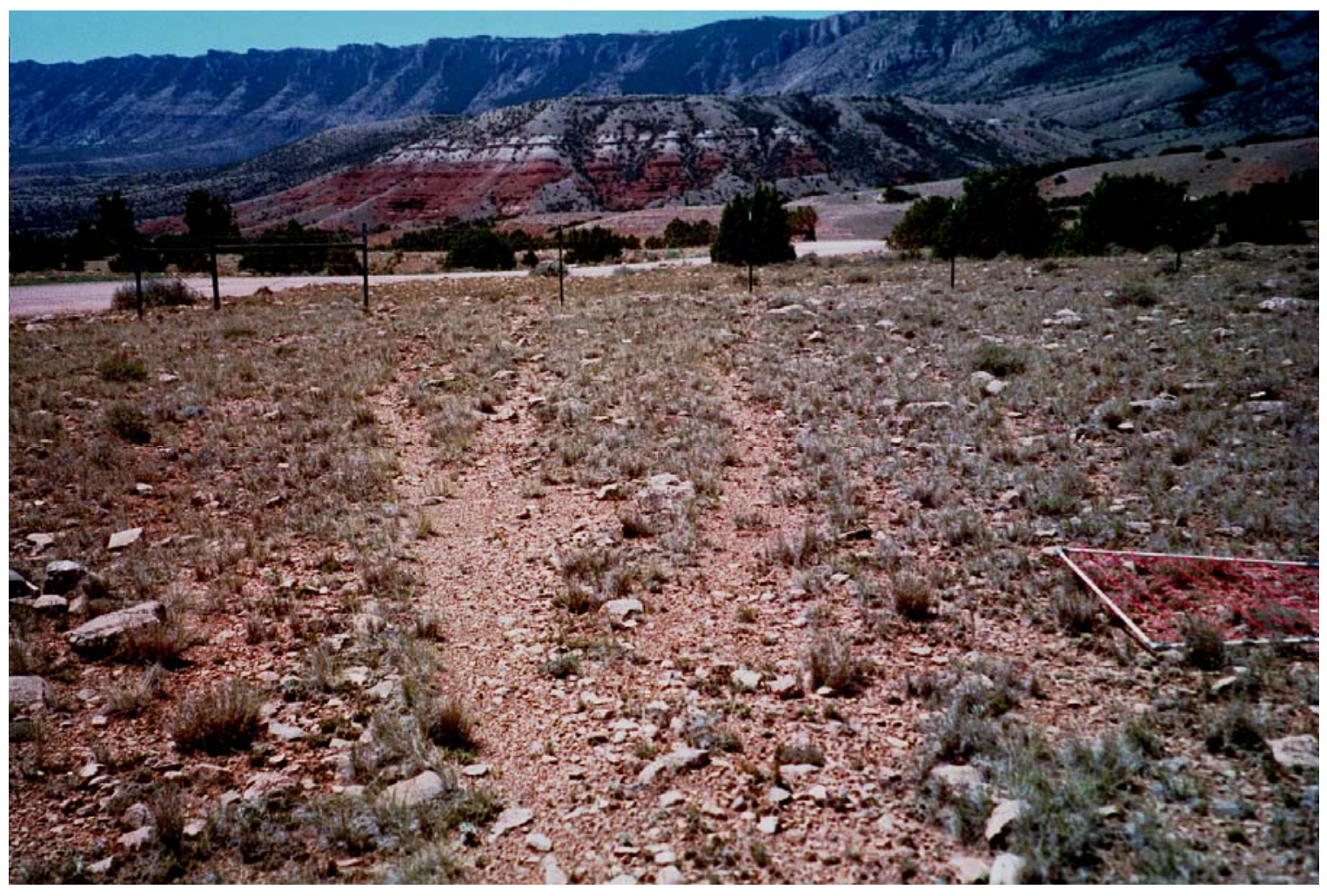

Photo 11. South Lockhart Ranch - View of cattle trails crossing through the interior of the exclosed plot. The exclosure was erected in 1994. The $1 \times 1 \mathrm{~m}$ grid in the right foreground provides scale. Cattle travel along the unpaved road running left to right behind the exclosure fence posts. 



\section{Habitat Modeling}

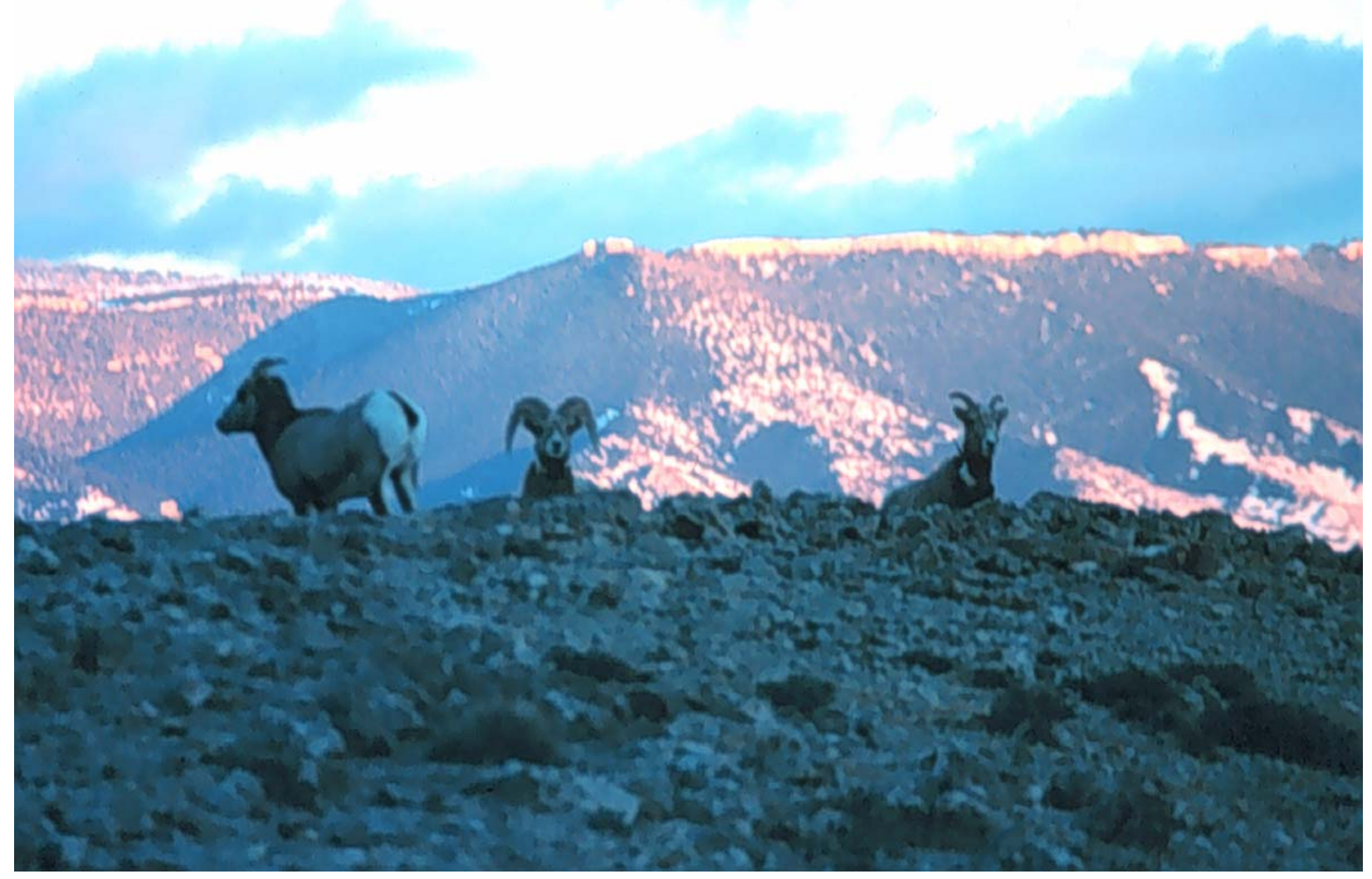





\section{Bighorn Sheep Habitat Suitability Assessment of the Greater Bighorn Canyon National Recreation Area: A Higher Resolution Analysis}

By Michelle A. Gudorf, Denver, Colorado

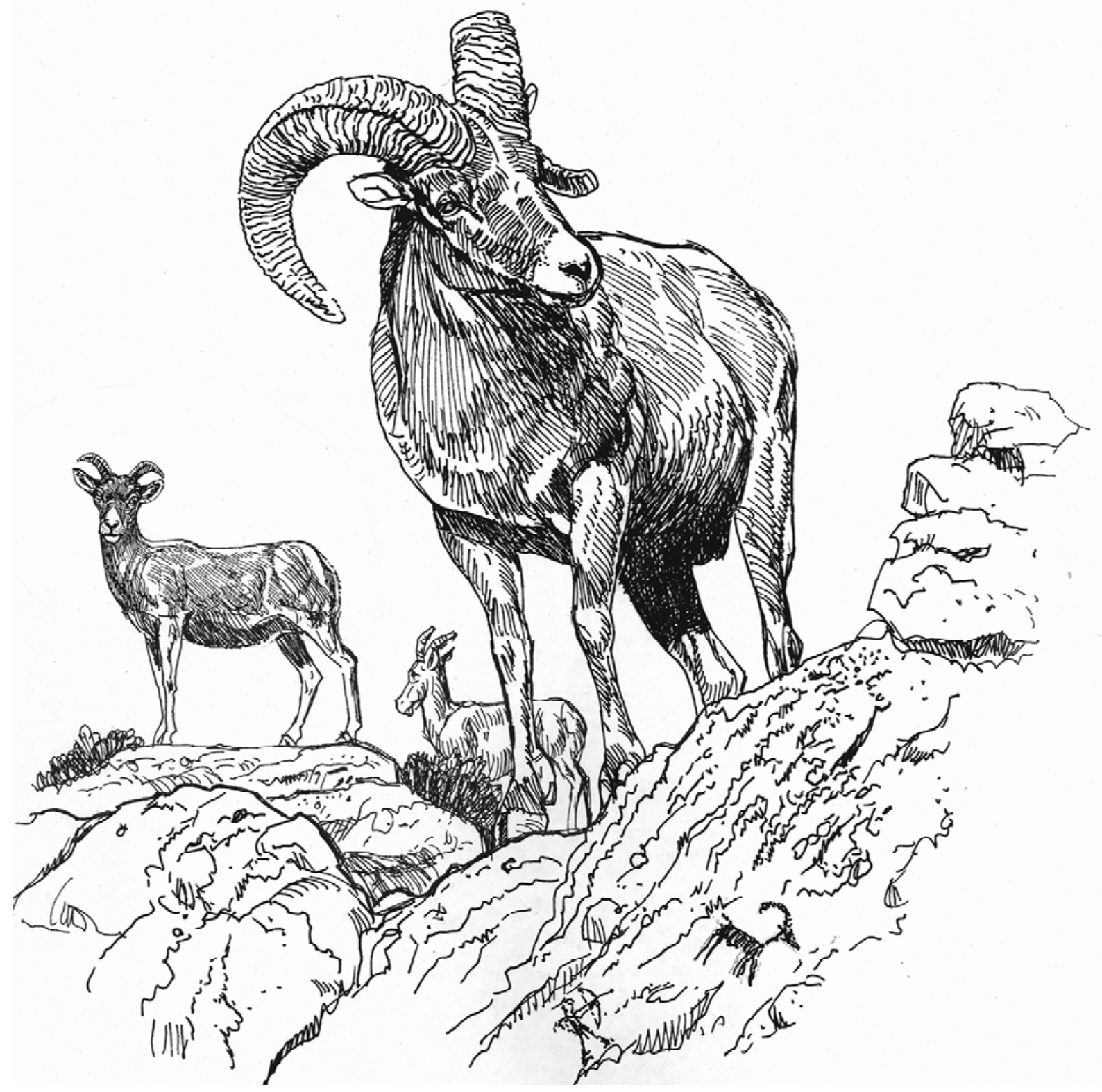





\section{Statement of the Problem and Study Objective}

In 1996, the National Park Service (NPS) and U.S. Geological Survey, Biological Resources Discipline (USGS-BRD) prepared a report that identified areas of suitable habitat for bighorn sheep restoration in the greater Bighorn Canyon National Recreation Area (BICA) (Gudorf and others, 1996).

In August 2001, the USGS-BRD obtained funding to reevaluate the area. Our objective was to evaluate potential suitable bighorn sheep habitat in the greater BICA using improved data. This reassessment identifies habitat factors that limit bighorn sheep in the region, and evaluates and identifies occupied and unoccupied habitat. The model was run in two ways, both with and without a criteria of "proximity to perennial water sources."

\section{Methods}

\section{The Habitat Evaluation Procedure}

Habitat parameters considered critical for Rocky Mountain bighorn sheep (Ovis canadensis canadensis) were defined by Smith and others (1991). These parameters were derived from the literature, applied to a population of bighorn sheep on Bear Mountain, Utah and used to develop a model for evaluating bighorn sheep habitat (Smith and others 1991). The model was tested and refined (Johnson and Swift, 2000) by evaluating habitat parameters in areas with successful versus unsuccessful bighorn sheep translocations in Colorado.

The model identifies regions of habitat adequate to support a minimum viable population of bighorn sheep. A population of 100-125 individuals has been proposed as the number of bighorn sheep necessary for short-term persistence through several decades (Sands, 1976; Van Dyke and others, 1983; Berger, 1990). For this analysis, a minimum viable population was defined as 125 bighorn (Smith and others, 1991). Metapopulations were defined as collective subpopulations with limited gene flow (Bleich and others, 1990).

The habitat model incorporates a process of elimination, where land area is systematically removed from consideration if it does not meet specific habitat criteria. Remaining land areas may be considered suitable bighorn sheep habitat. Patches of habitat deemed suitable must be of sufficient size to sustain a viable population or must occur in proximity, such that the combined area would support a viable metapopulation.

\section{Data}

Values for the bighorn sheep model parameters were obtained from field observations, historical records, digital data and paper maps, and census and aerial point locations from a Global Positioning System (GPS) (Table 1). These values were used to identify regions of the study area that met specific habitat criteria identified in the model. The model did not consider forage type and biomass, predation, interagency plans for adjacent regions, or wild ungulate concentrations. 
Table 1. Data sources for the bighorn sheep habitat criteria values used in the GIS analysis.

\begin{tabular}{|c|c|c|}
\hline Criteria value & Source & Scale/Resolution \\
\hline $\begin{array}{l}\text { Core habitat including escape terrain } \\
\text { (slope), buffer; aspect }\end{array}$ & $\begin{array}{l}\text { USGS Digital Elevation Models } \\
\text { (DEMs) }\end{array}$ & $30 \mathrm{~m}$ resolution \\
\hline Proximity to Perennial Water Sources & $\begin{array}{l}\text { 1. USGS/NPS Inventory and } \\
\text { Monitoring (I\&M) Digital line graph } \\
\text { (DLG) Hydrology data for all USGS } \\
\text { quadrangles except Red Pryor Mtn } \\
\text { and Bear Canyon (MT). } \\
\text { 2. Streams and lake points for Red } \\
\text { Pryor Mtn and Bear Canyon (MT) } \\
\text { quadrangles were provided by USFS } \\
\text { (Vicki Murfitt, Custer National } \\
\text { Forest) } \\
\text { Note: this analysis includes results } \\
\text { for inclusion and exclusion of this } \\
\text { habitat criteria. }\end{array}$ & $1: 24,000$ \\
\hline $\begin{array}{l}\text { Natural Barriers (impassable cliffs, } \\
\text { large or fast moving bodies of water, } \\
\text { great distances between escape } \\
\text { terrain, corridors of dense vegetation) }\end{array}$ & $\begin{array}{l}\text { USGS topographical maps; field } \\
\text { surveys }\end{array}$ & $1: 24,000$ \\
\hline \multirow[t]{3}{*}{$\begin{array}{l}\text { Manmade barriers (roads, aquaducts, } \\
\text { canals, fences, reservoirs, ) }\end{array}$} & USGS DLG data & $\begin{array}{l}\text { Roads-1:24,000 and } 1: 100,000 \text { for } 1 \\
\text { USGS quad area (Cowley, WY) }\end{array}$ \\
\hline & NPS (BICA) digital data for fences & $1: 24,000$ \\
\hline & USFS digital line data & $\begin{array}{l}\text { Roads-1:24,000 for Medicine Wheel } \\
\text { and Mexican Hill quads }\end{array}$ \\
\hline $\begin{array}{l}\text { Human Use Areas (residential, } \\
\text { commercial, or industrial } \\
\text { developments, highways, roads, and } \\
\text { structures) }\end{array}$ & $\begin{array}{l}\text { Urban areas from vegetation maps } \\
\text { (see Horizontal Visibility) }\end{array}$ & From $1: 24,000$ to $1: 100,000$ \\
\hline Snowpack & $\begin{array}{l}\text { Due to insufficient quantified data } \\
\text { documenting snowpack, this } \\
\text { parameter was not incorporated into } \\
\text { the GIS analysis of suitable habitat. }\end{array}$ & \\
\hline \multirow[t]{4}{*}{ Horizontal Visibility } & $\begin{array}{l}\text { Wyoming Gap Analysis, 1996, Land } \\
\text { Cover for WY }\end{array}$ & $1: 100,000$ \\
\hline & $\begin{array}{l}\text { NPS: Vegetation Ecology in the } \\
\text { Bighorn Canyon NRA (Knight and } \\
\text { others, 1987) }\end{array}$ & $1: 24,000$ \\
\hline & $\begin{array}{l}\text { Wildlife Spatial Analysis Lab, The } \\
\text { University of Montana, Montana Gap } \\
\text { Analysis : Montana Landcover, } 1998\end{array}$ & $1: 100,000$ or $90 \mathrm{~m}$ resolution \\
\hline & $\begin{array}{l}\text { Land Cover Classifications for the } \\
\text { Sheridan Region, Wyoming Game } \\
\text { and Fish Department, } 2001\end{array}$ & $28.5 \mathrm{~m}$ resolution \\
\hline \multirow[t]{2}{*}{ Domestic Sheep Grazing } & $\begin{array}{l}\text { BLM: digital allotment data } \\
\text { BIA contacted-no grazing of } \\
\text { domestic sheep }\end{array}$ & $\begin{array}{l}1: 24,000 \\
\text { not applicable }\end{array}$ \\
\hline & $\begin{array}{l}\text { USFS (Sheridan and Custer districts): } \\
\text { digital allotment data }\end{array}$ & $1: 24,000$ \\
\hline
\end{tabular}




\section{Study Area}

For this analysis, we maintained the study area boundary identified in the 1996 analysis. The study area was determined from approximately a one quad extension from the northern, eastern, and southern boundaries of BICA, and a two quad extension from the western boundary, in an effort to identify all suitable bighorn habitat within the vicinity of BICA (Figure 1).

The study area encompasses $3418.81 \mathrm{~km}^{2}$, and extends from:

1. 108:30:00W 44:44:50N

2. 108:29:59W 45:00:03N

3. $108: 29: 53 \mathrm{~W} 44: 59: 50 \mathrm{~N}$

4. $108: 37: 29 \mathrm{~W} 45: 07: 30 \mathrm{~N}$

5. 108:29:59W 45:07:24N

6. $108: 29: 59 \mathrm{~W} 45: 14: 59 \mathrm{~N}$

7. $108: 14: 59 \mathrm{~W} 45: 14: 59 \mathrm{~N}$

8. $108: 14: 59 \mathrm{~W} 45: 22: 29 \mathrm{~N}$

9. $107: 52: 29 \mathrm{~W} 45: 22: 29 \mathrm{~N}$
10. 107:52:30W 45:30:00N

11. $107: 44: 59 \mathrm{~W} 45: 29: 59 \mathrm{~N}$

12. 107:45:00W 45:15:00N

13. $107: 52: 29 \mathrm{~W} 45: 14: 59 \mathrm{~N}$

14. 107:52:29W 45:07:30N

15. 107:59:59W 45:07:29N

16. 107:59:59W 44:59:59N

17. 107:52:30W 45:00:00N

18. 107:52:29W 44:44:50N

\section{Definition of Bighorn Sheep Habitat Parameters}

\section{Habitat Requirements}

Six key habitat criteria identified in the bighorn sheep habitat assessments used for this analysis were integrated in a geographic information system (GIS) to determine areas of suitable habitat (Smith and others, 1991; Johnson and Swift, 2000). Geophysical and biological habitat parameters include buffered escape terrain, aspect, horizontal visibility, proximity to perennial water sources, natural barriers, and snowpack. Land management parameters are human activities, constructed barriers, and livestock grazing.

In the 1996 analysis, we defined escape terrain as slopes from $27^{\circ}-85^{\circ}$ based on the Smith and others (1991) conversions of percent slope to degree slope. However, we later noted that the conversion should actually be $30^{\circ}$. Therefore, escape terrain was defined for this analysis as slopes $30^{\circ}-90^{\circ}$. In Wyoming, bighorn sheep have been known to utilize vertical rock walls with shelves large enough for footholds, thus the range of known utilized slopes was increased from $85^{\circ}-90^{\circ}$ (Hughes, 1997). These slopes provide protection from predators and disturbances and are a critical feature for bighorn sheep (Honess and Frost, 1942; Buechner, 1960; Cooperrider 1969; Ferrier and Bradley, 1970; Geist, 1971; Holl and Bleich, 1983; Wilson and others, 1980; Van Dyke and others, 1983). Land areas surrounding the escape terrain that were within $300 \mathrm{~m}$, or within 1,000 $\mathrm{m}$ when the area was bordered by escape terrain on more than two sides (enabling sheep to view escape terrain $1,000 \mathrm{~m}$ in the distance) were considered to be close enough to escape terrain for bighorn sheep to seek refuge during disturbances. These areas (henceforth referred to as "core habitat") provide the core area of potential suitable habitat.

From this core habitat we removed land areas that included any of the following six features:

1) Horizontal Visibility: Areas that had less than $62 \%$ horizontal visibility. Horizontal visibility is a value used to express the openness of the habitat. Bighorn sheep are better able to detect predators and other disturbances, as well as maintain contact with members of their herd in areas with good visibility. In this study, horizontal visibility was defined as the percentage of a bighorn's lateral view that was not obscured by vegetation. Visibility was measured along predator approach paths, not into, or over, cliffs. Areas with horizontal visibility $62 \%$ or greater were considered suitable. Areas of $30-61 \%$ visibility were acceptable, if less than $4,500 \mathrm{~m}$ in width, because sheep could use these areas as movement corridors. Additionally, areas of less than $30 \%$ visibility if less than $100 \mathrm{~m}$ in width were also defined as acceptable following Johnson and Swift (2000). 


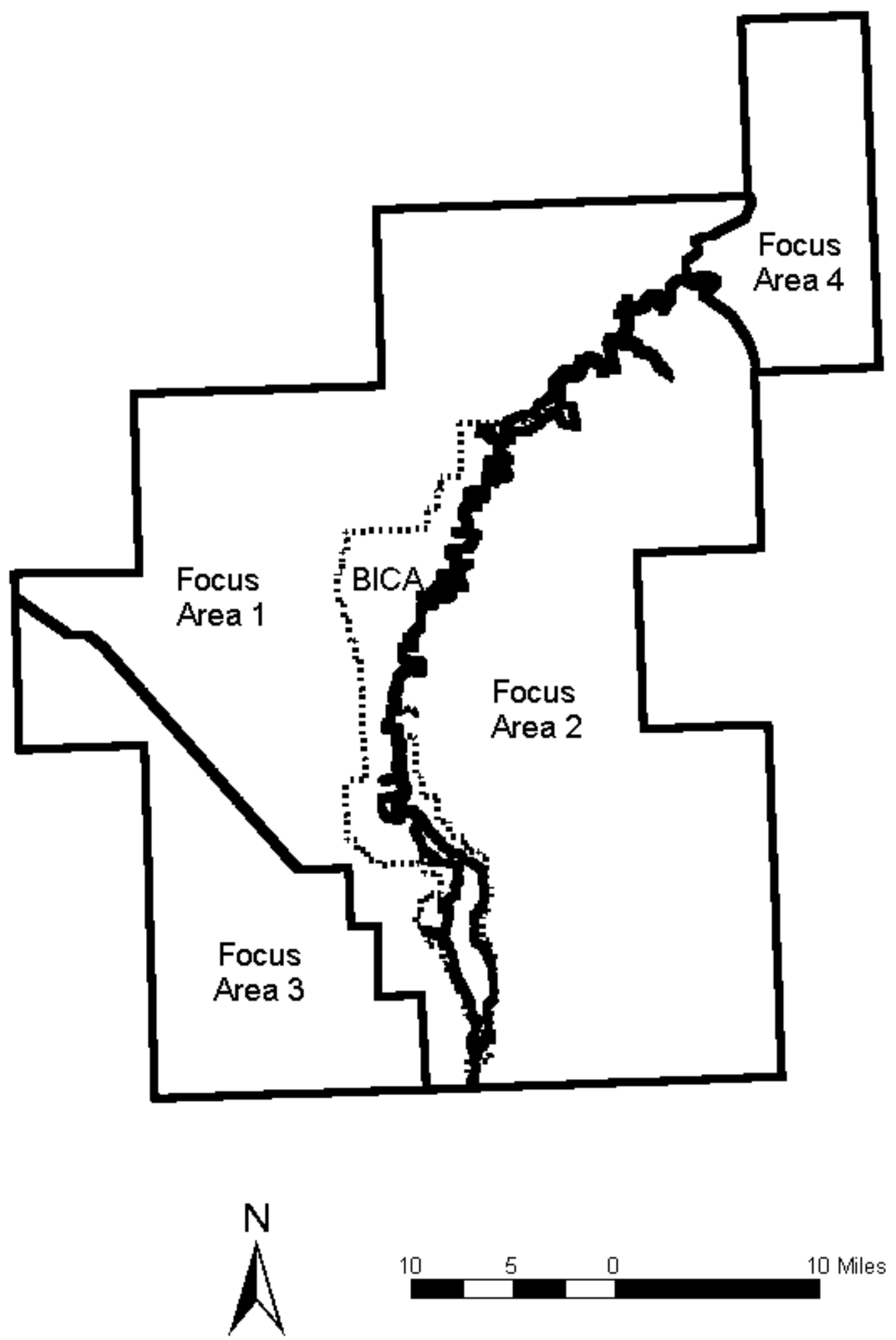

Figure 1. Study and focus areas for the bighorn sheep suitable habitat analysis within the greater Bighorn Canyon National Recreation Area (BICA), Montana and Wyoming. 
2) Proximity to Perennial Water Sources: Areas more than $3.2 \mathrm{~km}$ from perennial water sources. Proximity to perennial water sources should be within $3.2 \mathrm{~km}$ of the core area (McQuivey, 1978; Smith and others, 1991). However, in drought years bighorn sheep will range greater than $3.2 \mathrm{~km}$ for water. Water sources for bighorn sheep include seeps, springs, and perennial snow patches as well as riverine and lacustrine features (Smith and others, 1991). As these types of perennial and intermittent water sources have not been adequately mapped in this study area, the inclusion of this parameter is questionable. Therefore, the model was run both including and excluding this criterion, so resource managers can make the decision as to which results to use.

3) Human Use Areas: Areas that are developed and land within $150 \mathrm{~m}$ of these areas if the disturbance was severe enough to elicit avoidance by bighorns (e.g., residential, commercial, or industrial developments, major highways, and structures).

4) Natural and Manmade Barriers to Bighorn Sheep Movement: Areas that contained barriers to routine bighorn movement: manmade barriers (e.g. fences, roads, canals, aquaducts, housing developments, reservoirs) and natural barriers (impassable cliffs, large or fast moving bodies of water, great distances between escape terrain, corridors of dense vegetation). These features were identified and evaluated on a case-by-case basis for determination of their hindrance to bighorn sheep occupancy of an area or movement through an area. Any areas determined a hindrance and in union with core habitat were considered unsuitable and removed from core habitat. This criterion wasn't modeled to determine suitable habitat, however, any barriers will be provided as an overlay and should be considered by managers prior to translocation.

5) Proximity to Exotic Relatives: Areas occupied by domestic sheep. Domestic sheep (and introduced exotic populations of Ovis genus) harbor diseases that infect bighorn sheep. Disease transmissions from domestic sheep have caused catastrophic die-offs of bighorn sheep (Jessup, 1981; Goodson, 1982; Capurro, 1988; Coggins, 1988). Zeigenfuss and others (2000) found that populations of translocated bighorn sheep separated by less than $4.6 \pm 1.4 \mathrm{~km}$ were unsuccessful, populations with separations from $12.3 \pm 4.6 \mathrm{~km}$ were moderately successful, and populations with separations from $23.0 \pm 6.5 \mathrm{~km}$ were successful. Maintaining a larger distance between domestic sheep and bighorn sheep reduced the probability of disease transmission. This criterion was not modeled to exclude suitable habitat, however, the overlay provided of the domestic sheep grazing allotments and their proximity to suitable bighorn sheep habitat must be considered by managers prior to translocation. For purposes of this model, the buffer zones of domestic sheep grazing allotments range from 0-7 km (unsuccessful), 7-17 km (moderately successful), and 17-29 $\mathrm{km}$ (very successful).

6) Patch Size: Isolated patches of habitat that are too small to support a minimum viable population of bighorn sheep. Hughes (1997) suggests removing contiguous patches less than 100 ha for suitable habitat, 25 ha for winter habitat, and 52 ha for summer habitat in size from consideration. Hughes calculated these patch sizes based on the Smith and others (1991) suggestion that a 100-ha patch of suitable habitat will likely support no more than 4 sheep.

\section{Seasonal Range Requirements}

Bighorn sheep have varying habitat needs during different periods of the year. Specific ranges for summer, winter, and lambing period were determined by removing areas from the modeled suitable habitat that did not meet the criteria for that seasonal range. Summer range is defined as the buffered area of escape terrain found within the area of suitable habitat (excluding the actual area of the slopes $\left(30^{\circ}-90^{\circ}\right)$. Winter range is defined as only southern aspects of slopes $30^{\circ}-90^{\circ}\left(135^{\circ}-225^{\circ}\right.$ aspects) within suitable habitat and less than $25 \mathrm{~cm}$ snowpack. Average snowpack data was unavailable for $80 \%$ of the study area and was not included in this analysis. Lambing habitat was defined as all suitable habitat greater than 2 hectares (to reduce vulnerability of ewes and young to predation and sensitivity to disturbance), with southern, western, and eastern aspects $\left(90^{\circ}-270^{\circ}\right.$ aspects) with $31^{\circ}-90^{\circ}$ slopes, and within $1,000 \mathrm{~m}$ of perennial water sources. Birthing typically occurs on the steepest slopes, but "lambing period habitat" also encompasses areas used during the six-week postpartum period before ewes and lambs join nursery groups. 


\section{Model Modifications}

Zeigenfuss and others (2000) tested the Smith and others (1991) model accuracy in predicting translocation success and then modified it to include additional factors that improved its usefulness in predicting appropriate translocation sites. They found translocations were more successful when sheep were placed into discrete habitat patches containing a high proportion of lambing period habitat (greater than $4 \%$ of suitable habitat) where animals could exhibit a migratory tendency, and no contact with domestic sheep or a greater distance to domestic sheep allotments (greater than $23 \mathrm{~km}$ ). The rate of population growth for bighorn sheep populations was best predicted by area of lambing period habitat, potential area of winter range, and distance to domestic sheep (Zeigenfuss and others, 2000). Additionally, they proposed that the minimum area for release be at least $32 \mathrm{~km}^{2}$ for prairie-badlands topography, $85 \mathrm{~km}^{2}$ for Rocky Mountain topography, and $381 \mathrm{~km}^{2}$ for Colorado Plateau deserts topography [far larger than the minimum $17 \mathrm{~km}^{2}$ proposed by Smith and others (1991)]. Finally, they proposed that lambing habitat should constitute $4 \%$ or more of the suitable habitat, and summer habitat should be $19 \mathrm{~km}^{2}$ or larger (Zeigenfuss and others, 2000).

\section{Focus Areas}

In the 1996 analysis, the study area was divided in to 4 focus areas (Gudorf and others, 1996). The focus areas were delineated by natural separations in suitable habitat along the Bighorn River, and by adequate patch size determined by the results of the analysis. We have used the same focus areas for this 2002 analysis (Figure 1).

\section{Results}

The greater BICA study area is $3,418 \mathrm{~km}^{2}$. We identified $993 \mathrm{~km}^{2}$ of core habitat. This area total varies significantly from the 1996 analysis (Gudorf and others, 1996) where $2,170.75 \mathrm{~km}^{2}$ of buffered escape terrain or "core" habitat was identified. The difference in the total area occurs in the identification of slopes. Slope delineation occurs by running an algorithm defined by a simple command in spatial software on the digital elevation model data (DEMs). I used degrees of slope in the 2002 analysis that were different from the 1996 analysis $\left(30^{\circ}-90^{\circ}\right.$ in 2002 vs. $27^{\circ}-85^{\circ}$ in 1996). For the purpose of understanding where the discrepancy arose, I created a test slope file. In the 1996 analysis, the GRASS GIS software used to run the habitat suitability model identified a total of $711 \mathrm{~km}^{2}$ of slopes $27^{\circ}-85^{\circ}$. In this 2002 analysis, the ArcInfo/GRID GIS software used to run the habitat suitability model identified $284 \mathrm{~km}^{2}$ of $27^{\circ}-85^{\circ}$ slopes. This significantly reduces the amount of available core habitat (and thus suitable habitat) for this analysis compared with the 1996 analysis. A complete analysis of this discrepancy has not been done. The difference in slope identification could occur either in the different DEM data sources used in both analyses, or in the different GIS software (and algorithms) used.

Following are the results of the land area removed from the $993 \mathrm{~km}^{2}$ of core habitat based on the habitat suitability model discussed in previous sections of this report (Table 2). 
Table 2. Quantifiable criteria used in the GIS for determination of land area suitable for bighorn sheep in the $3,418 \mathrm{~km}^{2}$ study area for the greater BICA. Note that there is some overlap of exclusionary criteria in some areas (e.g., removal of land areas due to poor horizontal visibility and proximity to perennial water sources).

\begin{tabular}{|c|c|}
\hline Bighorn Sheep habitat requirements & $\begin{array}{l}\text { Land area removed from Core habitat } \\
\left(993.41 \mathrm{~km}^{2}\right) \text { due to habitat criteria } \\
\text { [corehab10] }\end{array}$ \\
\hline Horizontal visibility & $103.69 \mathrm{~km}^{2}$ \\
\hline $\begin{array}{l}\text { Proximity to perennial water sources } \\
(3.2 \mathrm{~km})\end{array}$ & $95.95 \mathrm{~km}^{2}$ \\
\hline Human use (includes roads) & $88.55 \mathrm{~km}^{2}$ \\
\hline $\begin{array}{l}\text { Proximity to domestic sheep: } \\
\text { From } 0-17 \mathrm{~km} \text { buffer zone }\end{array}$ & $171.83 \mathrm{~km}^{2}$ \\
\hline
\end{tabular}

\title{
Horizontal Visibility
}

Four vegetation maps were reviewed, and an extensive field assessment was completed by K. Schoenecker (USGS-BRD, Ft. Collins, CO) in November 2001 to determine horizontal visibility in each vegetation zone. Twelve vegetation classification zones were identified. Zones with less than $62 \%$ horizontal visibility were considered unsuitable habitat for bighorn sheep. A total of $103.69 \mathrm{~km}^{2}$ were removed from the core habitat due to low horizontal visibility. Below is a complete listing of the vegetation types for each map and their horizontal visibility rating:

\section{Wyoming Gap Analysis, 1996, Landcover for Wyoming}

Primary: grass dominated riparian/Secondary: Saltbrush fans $=40 \%$ visibility

Forest dominated $=43 \%$ visibility

Primary: Juniper woodland/Secondary: Xeric upland shrub $=55 \%$ visibility

Primary: Juniper woodland/Secondary: Limber pine, short grass prairie, and basin exposed rock, soil $=62 \%$ visibility

Primary: Basin exposed rock/Secondary: Desert shrub, juniper woodland, WY big sagebrush $=63 \%$

visibility

Primary: Mixed grass prairie/Secondary: WY big sagebrush $=82 \%$ visibility

Primary: Desert shrub/Secondary: Basin exposed rock, soil

Primary: Saltbrush fans/Secondary: Desert shrub, WY big sagebrush $=94 \%$ visibility

Primary: Irrigated crops/Secondary: Desert shrub, forest dominated riparian $=100 \%$ visibility

\section{NPS: Vegetation Ecology in the BICA (Knight and others, 1987)}

\author{
Marsh $=40 \%$ visibility \\ Floodplain shrubland, Floodplain woodland, Creek woodland $=43 \%$ visibility \\ Juniper/ Mountain Mahogany, Limber pine woodland $=55 \%$ visibility \\ Juniper woodland $=62 \%$ visibility \\ Douglas fir woodland, Ponderosa pine woodland, Spruce-fir woodland $=63 \%$ visibility \\ Mountain mahogany woodland $=65 \%$ visibility \\ Mixed grass prairie, Basin grassland $=82 \%$ visibility \\ Sagebrush desert shrubland, Sagebrush steppe $=86 \%$ visibility \\ Mixed desert shrubland, Saltbrush desert shrubland, Great Plains shrubland, Wind swept plateau $=94 \%$ \\ visibility \\ Floodplain meadow or mudflat $=100 \%$ visibility
}




\title{
USGS Gap Analysis Program: Montana Landcover, 1997
}

\author{
Shrub Riparian $=21 \%$ visibility \\ Conifer riparian, Broadleaf riparian, Mixed broadleaf and Conifer riparian $=43 \%$ visibility \\ Limber pine $=55 \%$ visibility \\ Rocky Mountain juniper, Utah juniper $=62 \%$ visibility \\ Rock, Mines, Quarries, Gravel pits, Mixed barren sites, Low density xeric forest, Mixed broadleaf forest, \\ Lodgepole pine, Douglas fir, Mixed Whitebark pine forest, Mixed subalpine forest, Mixed xeric forest, \\ Mixed broadleaf and Conifer forest, Standing burnt forest $=63 \%$ visibility \\ Mixed mesic shrubs, Mesic shrub-Grassland Associations $=65 \%$ visibility \\ Altered herbaceous grasslands, Very low cover grasslands, Low/Moderate cover grasslands, \\ Moderate/High cover grasslands, Montane parklands and Subalpine meadows, Graminoid and Forb \\ riparian, Alpine meadows $=82 \%$ visibility \\ Silver sage, Sagebrush $=86 \%$ visibility \\ Mixed xeric shrubs, Salt-desert shrub/Dry salt flats, Xeric shrub-Grassland Associations $=94 \%$ visibility \\ Agricultural lands (dry and irrigated), Snowfields or ice $=100 \%$ visibility
}

\section{Landcover Classifications for the Sheridan Region Wyoming Game and Fish Department, 2001}

Moist deciduous wooded draw trees/Shrubs I and II, Bur oak, Riparian Willow and Wet site shrubs, Cottonwood/Willow, Riparian aspen, Riparian spruce/fir, Riparian spruce/fir and Lodgepole combination, Riparian lodgepole pine, Riparian ponderosa pine, Riparian Douglas fir and Limber pine, Riparian limber pine $=43 \%$ visibility

Limber pine $=52 \%$ visibility

Juniper $=62 \%$ visibility

Rock/bare soil, Aspen, Spruce/fir, Spruce/fir and Lodgepole combination, Lodgepole pine, Ponderosa pine, Douglas fir and Limber pine, Early successional lodgepole pine, Early successional ponderosa pine $=63 \%$ visibility

Mountain mahogany $=65 \%$ visibility

Very sparse dry herbaceous rangelands, Sparse dry herbaceous rangelands, Thin dry herbaceous rangelands, Medium herbaceous rangelands, High medium herbaceous rangelands, Green herbaceous rangelands, Very green herbaceous rangelands, Riparian moist grass/sedge/rush $=82 \%$ visibility

Big sagebrush I (moderately dense crown closure) and II (dense crown closure), Shrub/grass mix (three-tip sagebrush, black sagebrush, desert shrub), Greasewood and rabbitbrush $=86 \%$ visibility

Agricultural lands $=100 \%$ visibility

\section{Proximity to Perennial Water Sources}

Areas of core habitat greater than $3.2 \mathrm{~km}$ from perennial water sources were removed in one analysis. A total of $95.95 \mathrm{~km}^{2}$ were removed from the core habitat due to this criterion. (Note: A second analysis was run excluding this criterion.)

\section{Human Use Areas}

Human use areas such as residential, commercial and industrial areas removed $37.72 \mathrm{~km}^{2}$ from core habitat. Primary roads were buffered $150 \mathrm{~m}$ and all other roads assigned $30 \mathrm{~m}$ widths. A total of $50.83 \mathrm{~km}^{2}$ were removed from the core habitat due to this criterion. 


\section{Natural and Manmade Barriers}

No natural landscape features in the study area were considered permanent barriers to bighorn sheep movements (Gudorf and others, 1996). Bighorn Canyon and Bighorn Lake may be viewed as obstacles, and yet bighorn sheep reportedly dispersed from Devil's Canyon to the western side of Bighorn Canyon (Coates and Schemnitz, 1989). Bighorn may be able to cross the lake during winter freeze-ups, although radio-tracking data over the past 3 years has revealed no animal locations on the east side of Bighorn Lake (K. Schoenecker, unpub. data, 2003). No roads or trails were considered barriers. No impassable stretches of fence line were noted (Gudorf and others, 1996). New fences constructed in the recreation area incorporate modifications recommended by Helvie (1971) to allow for the passage of bighorn sheep. However, all translocation sites should be inspected for fences that would hinder or impede bighorn sheep movements, and such fences should be modified by installing crawl under/over areas, or removed.

\section{Domestic Sheep Grazing}

Domestic sheep allotments occur in the southeastern and southwestern corners of the study area. Burt Jellison (Sheridan Region Wyoming Game and Fish Department, oral commun., 2001) indicated that the Wyoming Game and Fish has a Sheep Biologist Working Group involved in buying out domestic sheep grazing permittees and when possible, transferring allotments from the Absaroka Mountains to the Bighorn Mountains. The USFS is promoting sheep grazing over cattle grazing allotments in the northeastern WY area (Jack Manoni, oral commun., 2001). The Beaver Creek allotment is within the study area. Consider any area of suitable bighorn habitat 17-29 km or greater from the domestic sheep allotments as suitable. All areas of suitable habitat that are less than $17 \mathrm{~km}$ from domestic sheep grazing allotments are identified. A total of $154.62 \mathrm{~km}^{2}$ of otherwise $823.90 \mathrm{~km}^{2}$ suitable bighorn sheep habitat could be removed from suitable habitat due to sheep grazing allotments.

\section{Patch Size}

Habitat patches too small to have any value as habitat, should be eliminated. Hughes (1997) suggests removing contiguous patches less than 100 ha for suitable habitat, 25 ha for winter habitat, and 52 ha for summer habitat from consideration. Hughes calculated these patch sizes based on the Smith and others (1991) suggestion that a 100-ha patch of suitable habitat will likely support no more than 4 sheep (Tables 3 and 4).

\section{Focus Areas}

Habitat patches should be large enough to support a minimum viable population of bighorn sheep. We have determined the BICA region to be best represented by the prairie-badlands type topography. Therefore, using the calculations derived by the Zeigenfuss and others (2002) for a minimum viable population of bighorn sheep, areas smaller than $32 \mathrm{~km}^{2}$ for general suitable habitat, $6.5 \mathrm{~km}^{2}$ for winter range, $8.4 \mathrm{~km}^{2}$ for summer range, and $4 \%$ of the suitable habitat for lambing habitat should not be considered for translocations (Tables 3 and 4). 
Table 3. Estimates of bighorn sheep habitat in the greater BICA, based on habitat criteria defined in this report inc/uding the criterion for proximity to perennial water sources. Areas identified here represent habitat both prior to and after reductions due to patch size requirements. After patch size requirement reductions, the remaining areas must be large enough to support a minimum viable population of bighorn sheep (125) based on the Zeigenfuss and others (2000) calculations. Focus area totals are based on area available after patch size requirement reductions. These results do not take into account the effects of domestic sheep on the availability of bighorn sheep habitat. Note that southeastern and southwestern portions of the study area have a number of domestic sheep grazing allotments that will reduce the amount of available habitat if not managed. See Figures 2-9 and Table 5 for additional information.

\begin{tabular}{|c|c|c|c|c|c|c|c|}
\hline & $\begin{array}{l}\text { Area available } \\
\text { (prior to patch } \\
\text { size requirement } \\
\text { reductions) in } \mathbf{k m}^{2}\end{array}$ & $\begin{array}{l}\text { Area available } \\
\text { (after patch size } \\
\text { requirement } \\
\text { reductions) in } \text { km }^{2}\end{array}$ & $\begin{array}{l}\text { Focus } \\
\text { Area } 1 \\
\text { in } \mathbf{k m}^{2}\end{array}$ & $\begin{array}{l}\text { Focus } \\
\text { Area } 2 \\
\text { in } \mathbf{k m}^{2}\end{array}$ & $\begin{array}{l}\text { Focus } \\
\text { Area } 3 \\
\text { in } \mathbf{k m}^{2}\end{array}$ & $\begin{array}{l}\text { Focus } \\
\text { Area } 4 \\
\text { in } \mathbf{k m}^{2}\end{array}$ & $\begin{array}{l}\text { Area required for MVP } \\
\text { (Zeigenfuss and others, } \\
\text { 2000; Smith and others, } \\
\text { 1991) in } \mathrm{km}^{2}\end{array}$ \\
\hline Suitable Habitat & $\begin{array}{l}823.90 \\
\text { (Figure 2) }\end{array}$ & $\begin{array}{l}777.28 \\
\text { (Figure 2) }\end{array}$ & 245.64 & 511.33 & 7.59 & 5.24 & $\begin{array}{l}85 \text { (Zeigenfuss and } \\
\text { others) }\end{array}$ \\
\hline Summer Habitat & $\begin{array}{l}635.75 \\
\text { (Figure 3) }\end{array}$ & $\begin{array}{l}592.22 \\
\text { (Figure 3) }\end{array}$ & 203.67 & 365.24 & 8.55 & 11.19 & $\begin{array}{l}19 \text { (Ziegenfuss and } \\
\text { others) }\end{array}$ \\
\hline Winter Habitat & $\begin{array}{c}45.59 \\
\text { (Figure 4) }\end{array}$ & $\begin{array}{l}27.58 \\
\text { (Figure 4) }\end{array}$ & 6.35 & 21.10 & 0 & 0 & 6.5 (Smith and others) \\
\hline Lambing Habitat & $\begin{array}{l}\text { N/A } \\
\text { (Figure 8) }\end{array}$ & $\begin{array}{c}3.62 \\
\text { (Figure 8) }\end{array}$ & .36 & 3.19 & 0 & 0 & $\begin{array}{l}4 \% \text { of suitable habitat } \\
\text { (Zeigenfuss and others) } \\
\text { or } 24.81\end{array}$ \\
\hline
\end{tabular}

Table 4. Estimates of bighorn sheep habitat in the greater BICA area, based on habitat criteria defined in this report but excluding the criterion for proximity to perennial water sources. Areas identified here represent habitat both prior to and after reductions due to patch size requirements. After patch size requirement reductions, the remaining areas must be large enough to support a minimum viable population of bighorn sheep (125) based on the Zeigenfuss and others (2000) calculations. Focus area totals are based on area available after patch size requirement reductions. These results do not take into account the effects of domestic sheep on the availability of bighorn sheep habitat. Note that southeastern and southwestern portions of the study area have a number of domestic sheep grazing allotments that will reduce the amount of available habitat if not managed. See Figures 2-9 and Table 5 for additional information.

\begin{tabular}{|c|c|c|c|c|c|c|c|}
\hline & $\begin{array}{l}\text { Area available } \\
\text { (prior to patch } \\
\text { size requirement } \\
\text { reductions) in } \text { km }^{2}\end{array}$ & $\begin{array}{l}\text { Area available } \\
\text { (after patch size } \\
\text { requirement } \\
\text { reductions) in } \text { km }^{2}\end{array}$ & $\begin{array}{l}\text { Focus } \\
\text { Area } 1 \\
\text { in } \mathbf{k m}^{2}\end{array}$ & $\begin{array}{l}\text { Focus } \\
\text { Area } 2 \\
\text { in } \mathbf{k m}^{2}\end{array}$ & $\begin{array}{l}\text { Focus } \\
\text { Area } 3 \\
\text { in } \mathbf{k m}^{2}\end{array}$ & $\begin{array}{l}\text { Focus } \\
\text { Area } 4 \\
\text { in } \mathrm{km}^{2}\end{array}$ & $\begin{array}{l}\text { Area required for MVP } \\
\text { (Zeigenfuss and others, } \\
\text { 2000; Smith and others, } \\
\text { 1991) in } \mathrm{km}^{2}\end{array}$ \\
\hline Suitable Habitat & $\begin{array}{l}877.83 \\
\text { (Figure 5) }\end{array}$ & $\begin{array}{l}831.76 \\
\text { (Figure 5) }\end{array}$ & 293.85 & 515.12 & 10.08 & 5.24 & $\begin{array}{l}85 \text { (Zeigenfuss and } \\
\text { others) }\end{array}$ \\
\hline Summer Habitat & $\begin{array}{l}684.53 \\
\text { (Figure 6) }\end{array}$ & $\begin{array}{c}639.84 \\
\text { (Figure 6) }\end{array}$ & 245.83 & 368.30 & 10.94 & 11.19 & $\begin{array}{l}19 \text { (Zeigenfuss and } \\
\text { others) }\end{array}$ \\
\hline Winter Habitat & $\begin{array}{l}48.51 \\
\text { (Figure 7) }\end{array}$ & (Figure 7) & 9.05 & 21.60 & 0 & 0 & 6.5 (Smith and others) \\
\hline Lambing Habitat & N/A & $\begin{array}{c}3.62 \\
\text { (Figure 8) }\end{array}$ & .36 & 3.19 & 0 & 0 & $\begin{array}{l}4 \% \text { of suitable habitat } \\
\text { (Zeigenfuss and others) } \\
\text { or } 33.27\end{array}$ \\
\hline
\end{tabular}




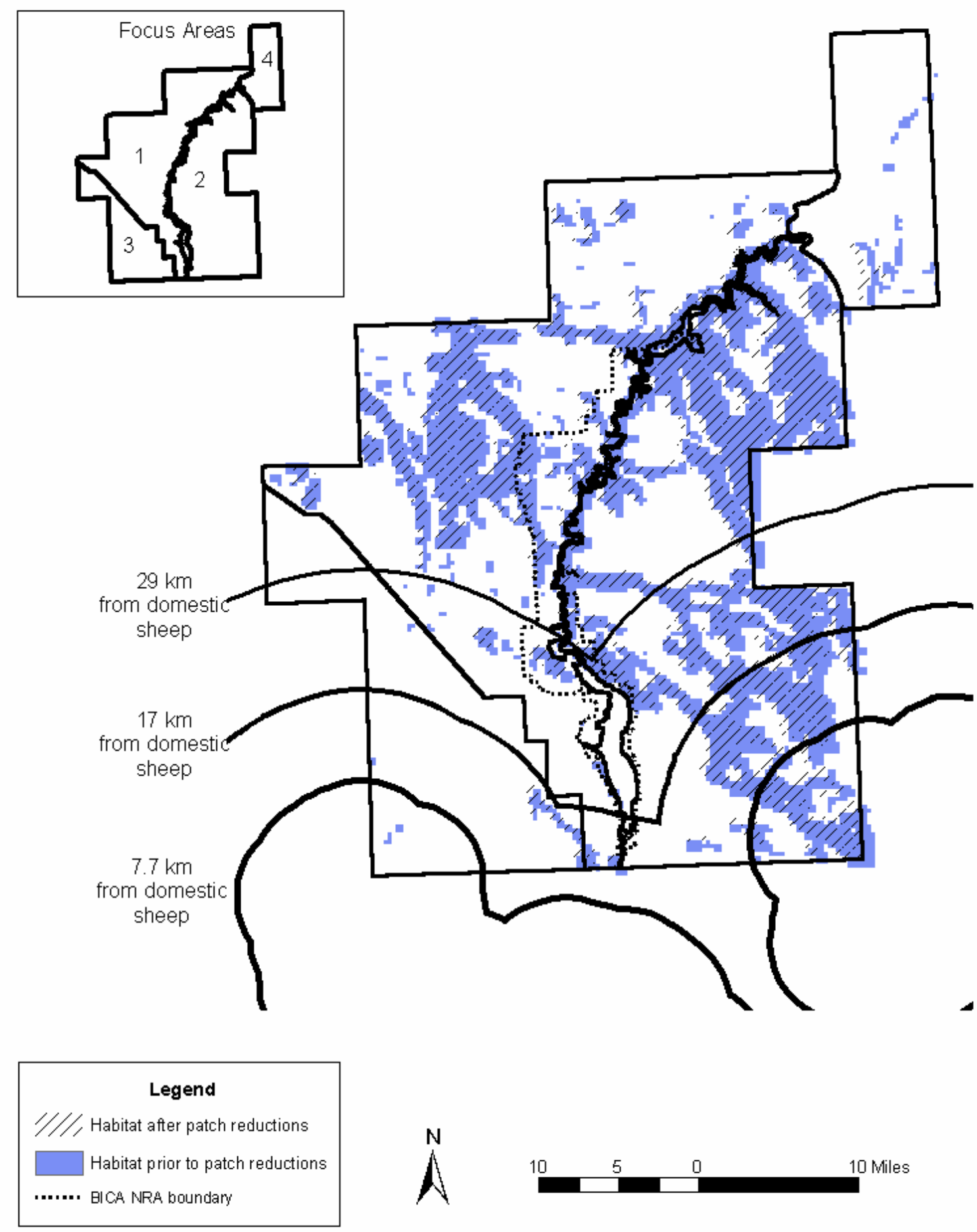

Figure 2. Total suitable bighorn sheep habitat including proximity to perennial water sources criteria. 


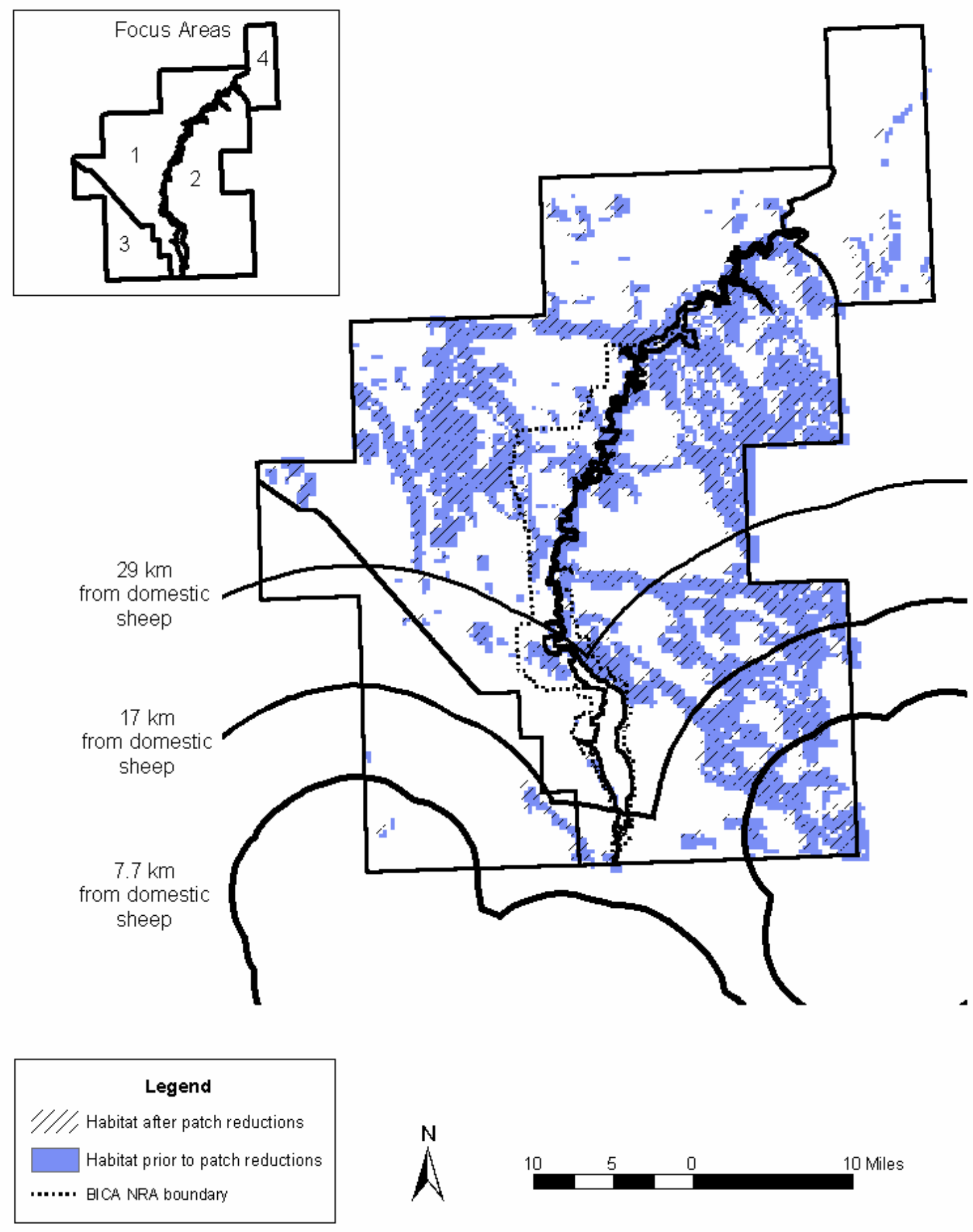

Figure 3. Suitable bighorn sheep summer habitat including proximity to water criteria. 


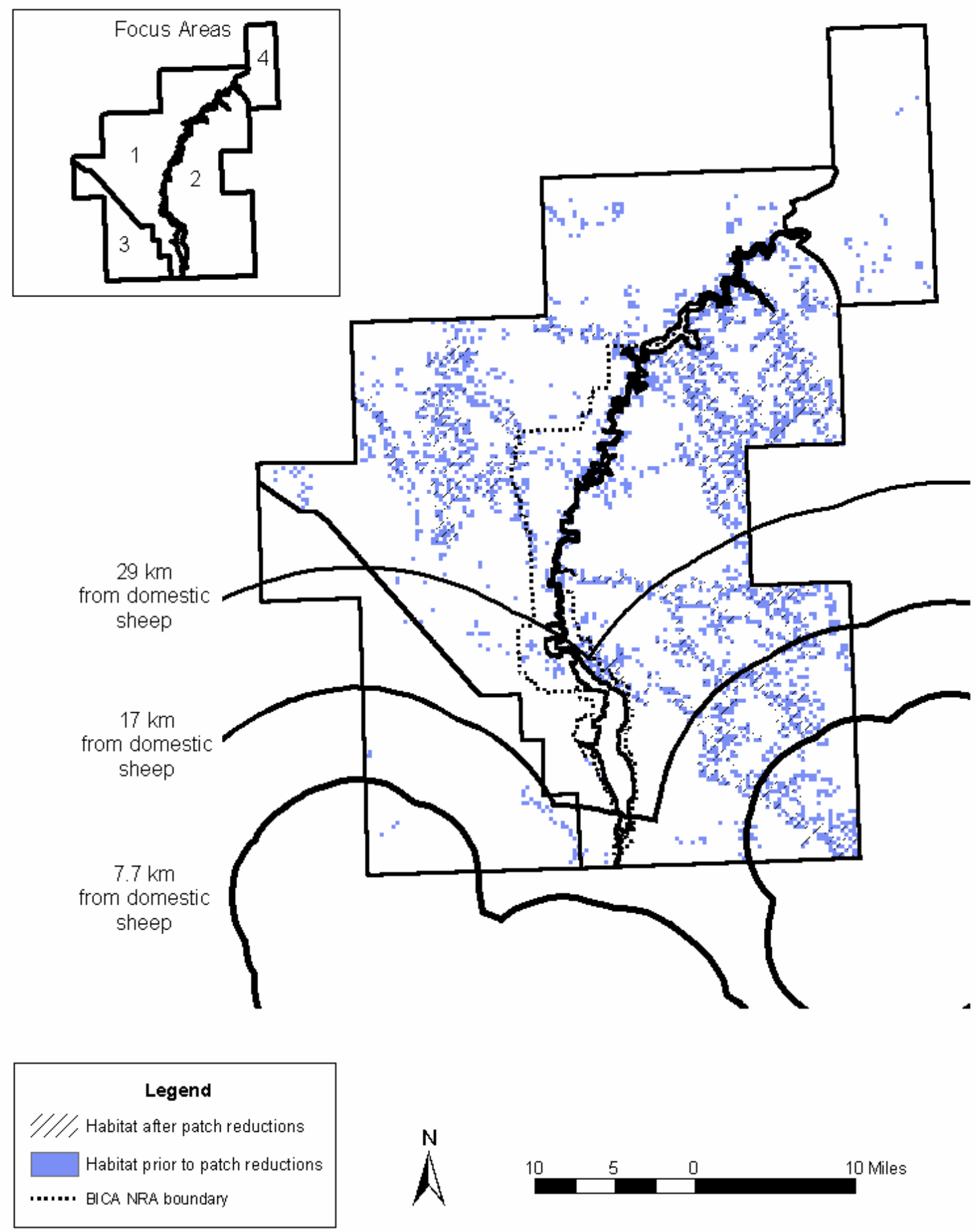

Figure 4. Suitable bighorn sheep winter habitat including proximity to perennial water sources criteria. 


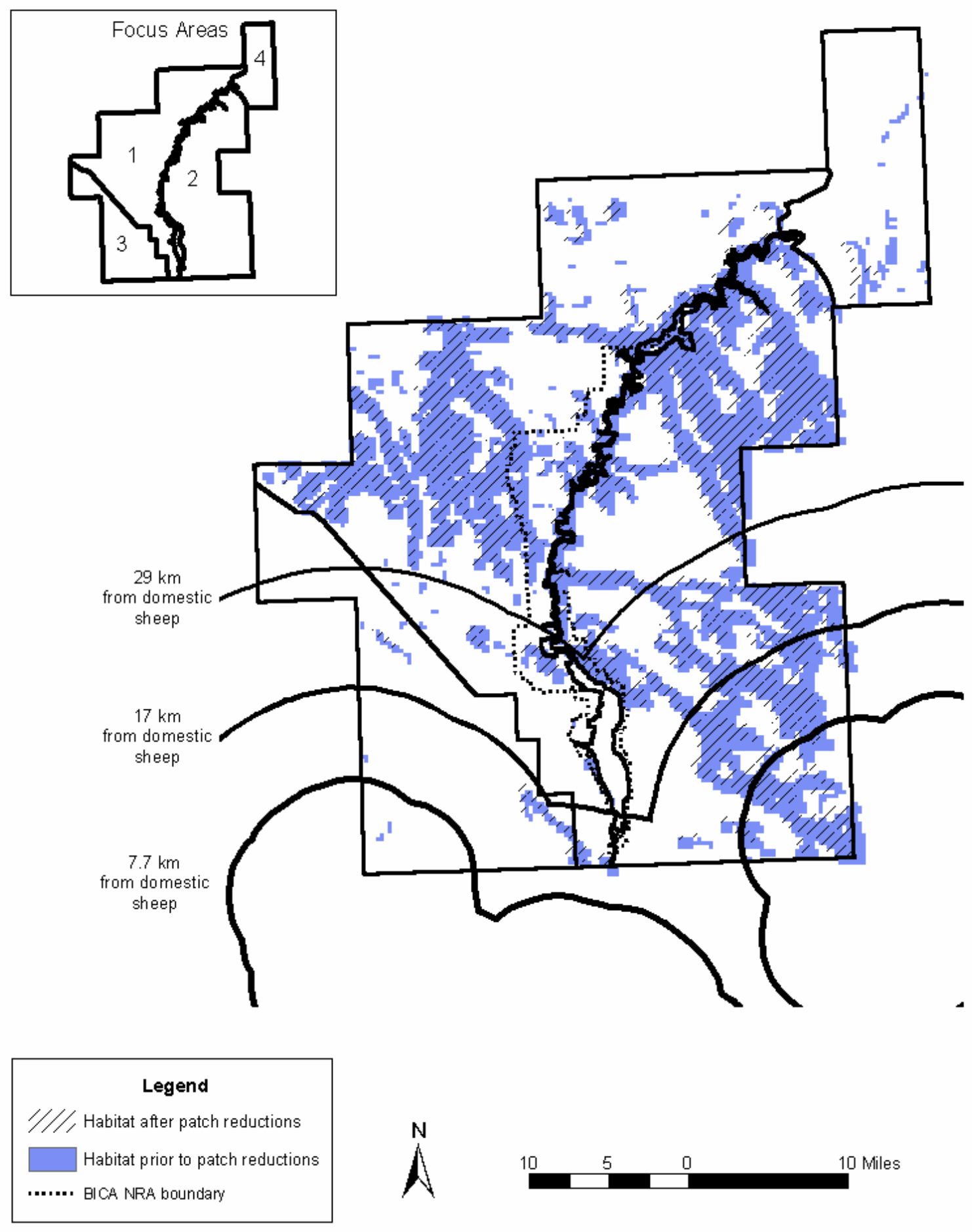

Figure 5. Suitable bighorn sheep habitat without proximity to perennial water sources criteria. 


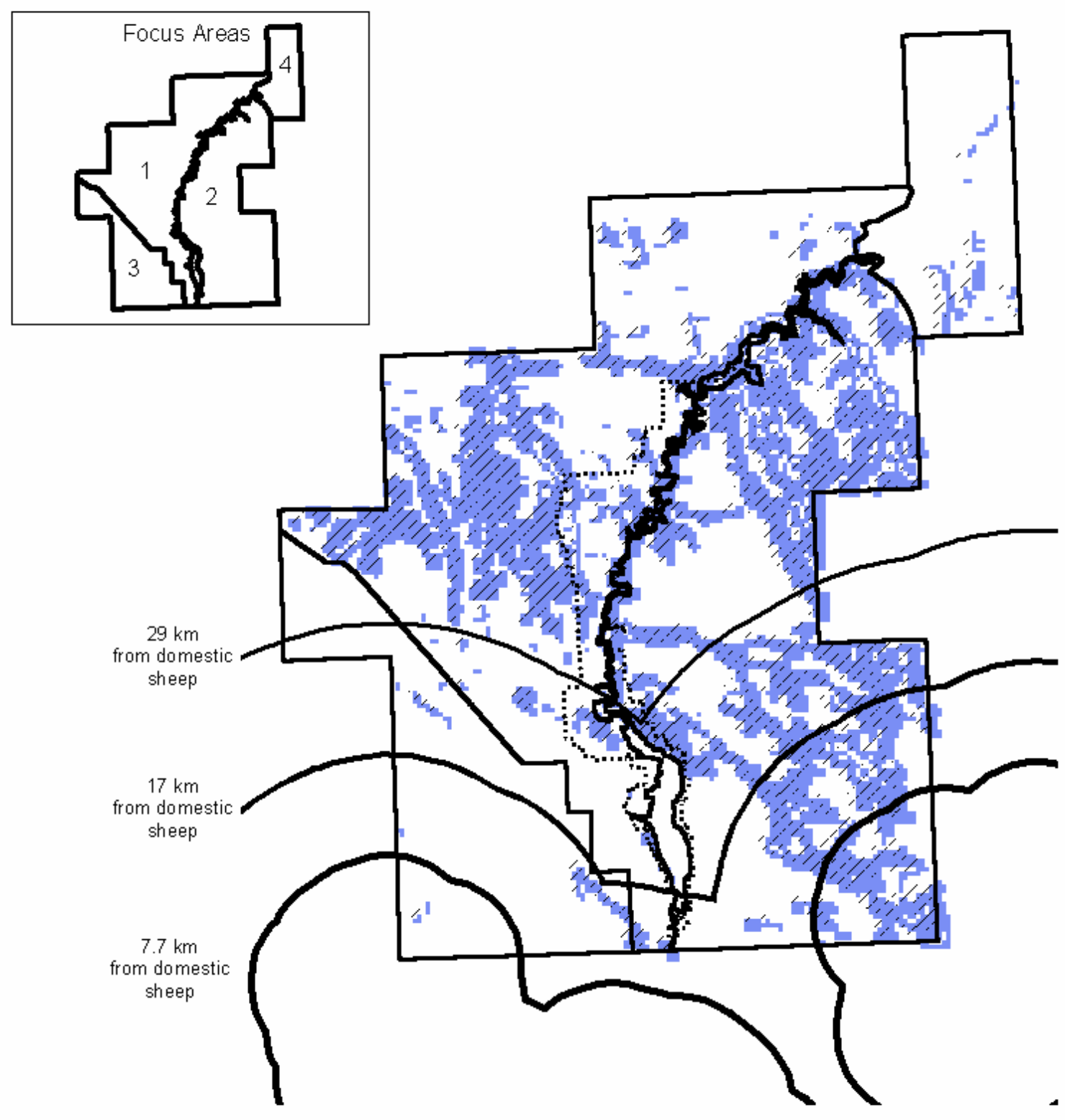

\begin{tabular}{|c|} 
Legend \\
I//, Habitat after patch reductions \\
Habitat prior to patch reductions \\
$\ldots . . .$. . EICA NRA boundary
\end{tabular}

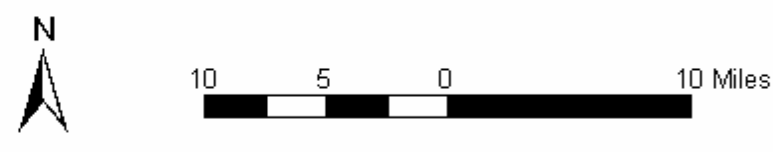

Figure 6. Suitable bighorn sheep summer habitat without proximity to perennial water sources criteria. 


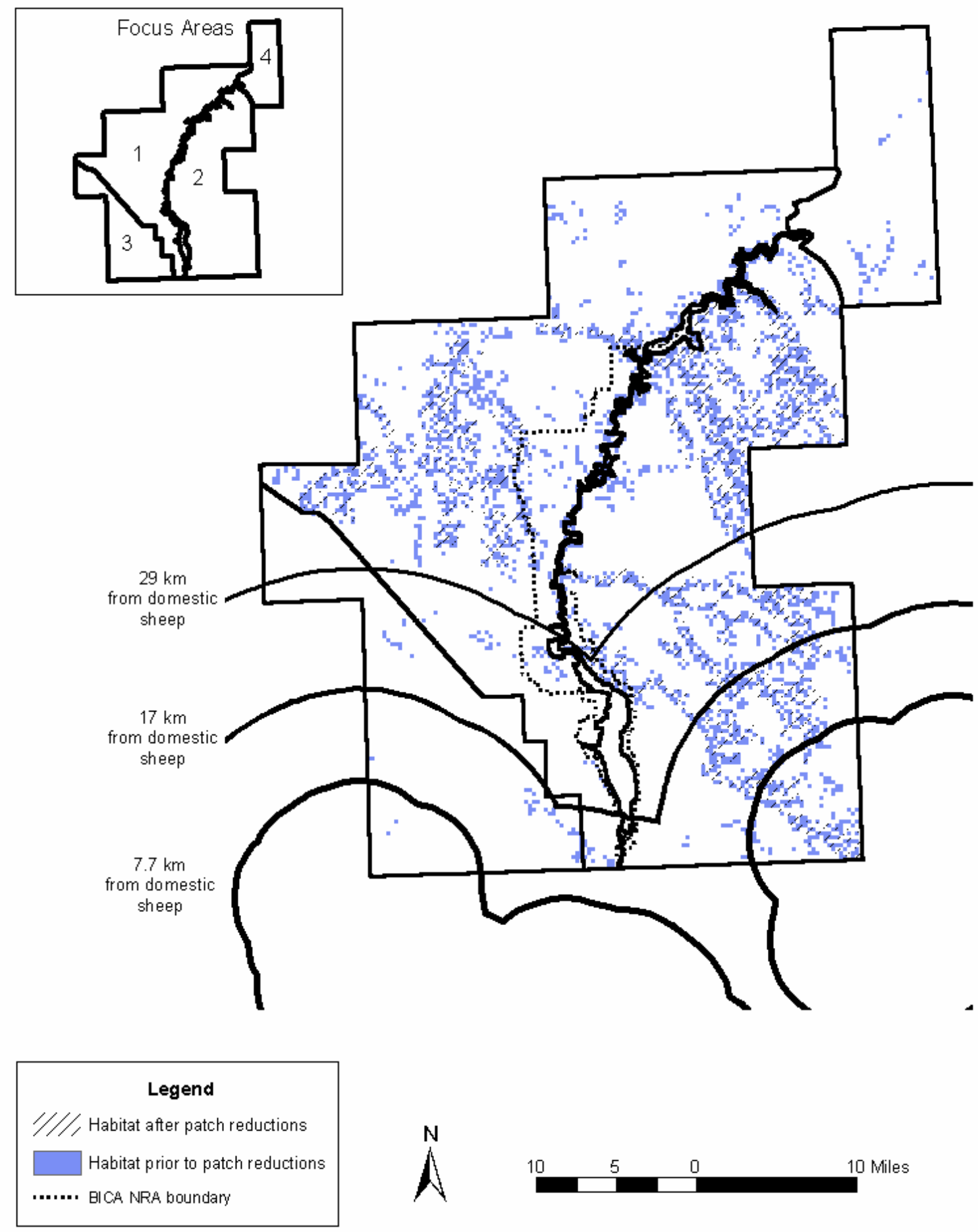

Figure 7. Suitable bighorn sheep winter habitat without proximity to perennial water sources criteria. 


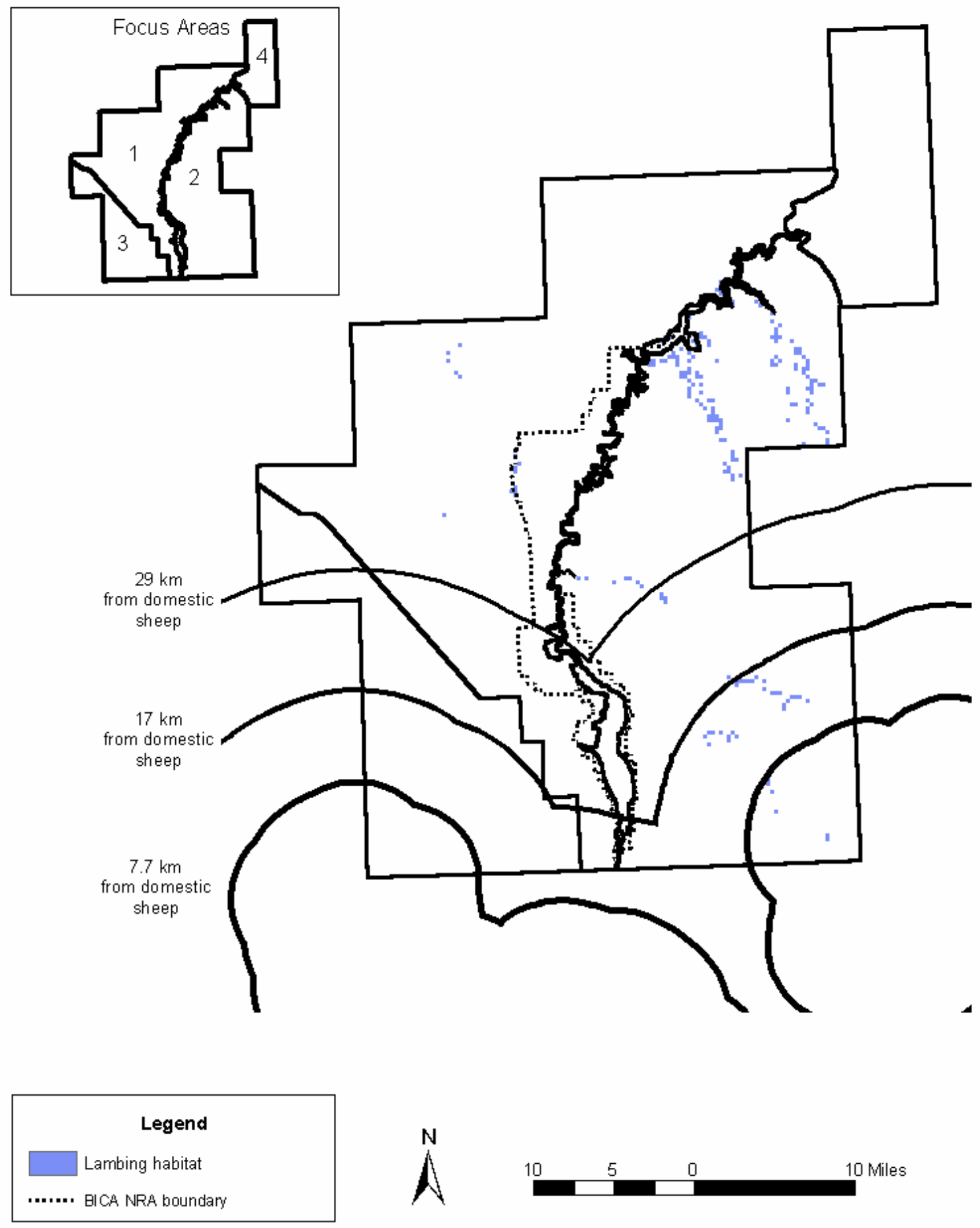

Figure 8. Suitable bighorn sheep lambing habitat. 


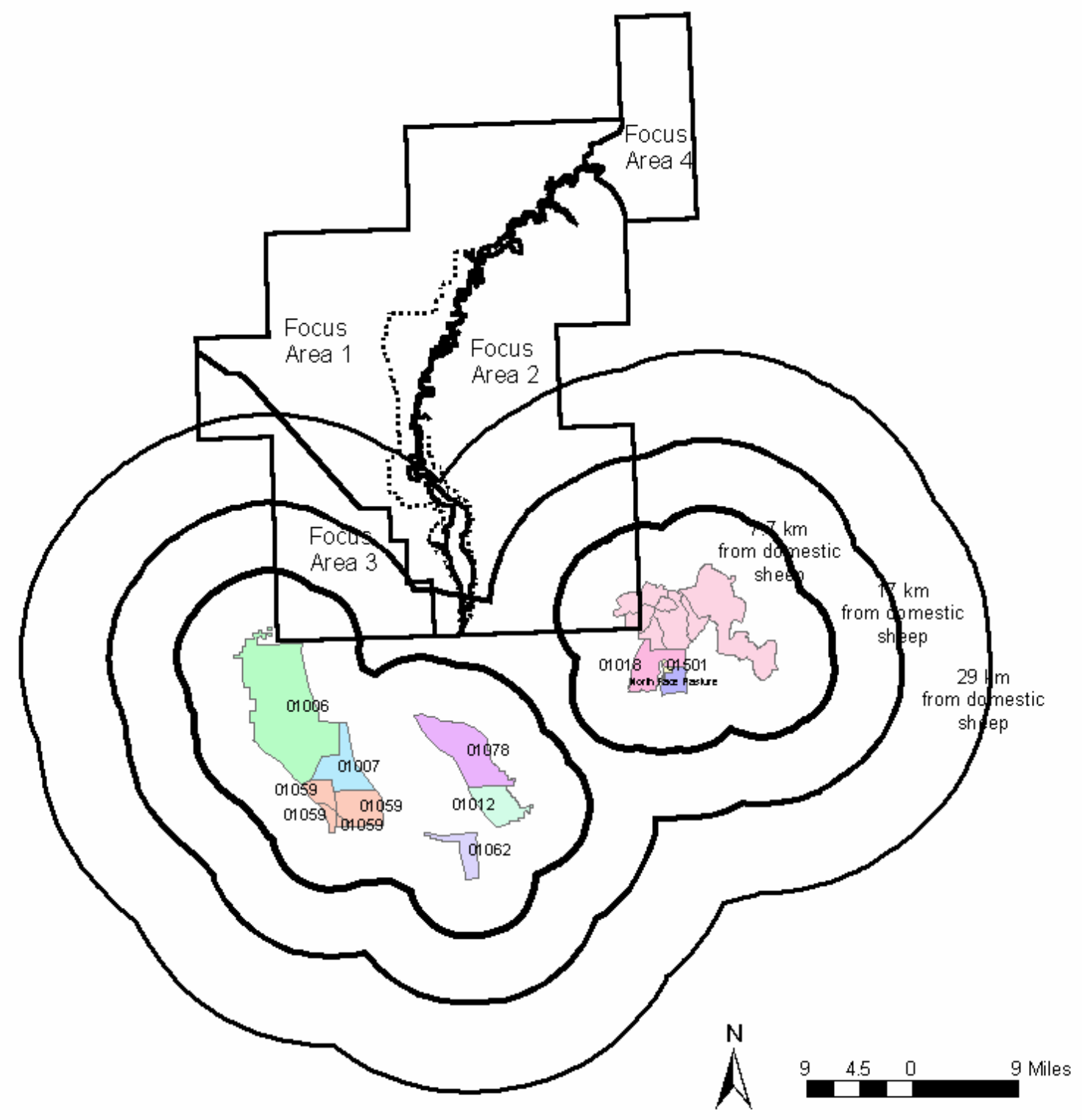

Figure 9. Domestic sheep grazing allotments (BLM and USFS) and buffer zones around and near the study area. 
Table 5. Proximity to domestic sheep grazing allotments. Includes proximity to perennial water sources criteria. Most habitat reductions due to domestic sheep grazing occur in focus areas 2 and 3 , and as most of the areas of suitable habitat occur in focus area 2, this report has only included the habitat reductions for focus area 2. Zeigenfuss and others (2000) found that populations of bighorn sheep separated by less than $4.6 \pm 1.4 \mathrm{~km}$ were unsuccessful, populations with separations from $12.3 \pm 4.6 \mathrm{~km}$ were moderately successful, and populations with separations from $23.0 \pm 6.5 \mathrm{~km}$ were successful. For this model, the buffer zones from domestic sheep grazing allotments range from 0-7 km (unsuccessful), 7-17 km (moderately successful), and 17-29 km (very successful). Areas falling within the $17-29 \mathrm{~km}$ buffer zone area are included in the analysis as they represent the range of $23 \mathrm{~km} \pm$ $6.5 \mathrm{~km}$.

\begin{tabular}{|c|c|c|c|c|}
\hline \multirow[b]{2}{*}{ Distance from domestic sheep } & \multicolumn{4}{|c|}{$\begin{array}{l}\text { Suitable habitat removed due to proximity to domestic sheep within focus } \\
\text { area } 2\left(\mathrm{~km}^{2}\right)\end{array}$} \\
\hline & $\begin{array}{l}\text { Suitable } \\
\text { habitat }\end{array}$ & Summer habitat & Winter habitat & Lambing habitat \\
\hline 0-7 km (unsuccessful populations) & 47.51 & 35.55 & 1.68 & .14 \\
\hline $\begin{array}{l}7-17 \mathrm{~km} \text { (moderately successful } \\
\text { populations) }\end{array}$ & 154.62 & 104.13 & 5.73 & .61 \\
\hline $\begin{array}{l}17-29 \mathrm{~km} \text { (very successful } \\
\text { populations) }\end{array}$ & 278.34 & 198.58 & 10.44 & .73 \\
\hline
\end{tabular}

\section{Non GIS Factors}

This analysis did not incorporate several factors that need to be considered prior to any translocation:

Cattle occur in the study area (Gudorf and others, 1996). Impacts that cattle have on bighorn sheep such as forage competition are not clearly understood. It has been suggested that cattle should be restricted from bighorn sheep watering sites to limit possible transmission of disease (Jessup, 1985). The presence of cattle has had less effect on bighorn sheep herd health than the presence of domestic sheep (Dodd and Brady, 1986).

Mountain lion predation is a mortality factor in the bighorn sheep herds in BICA (Gudorf and others, 1996; K. Schoenecker, oral commun., 2003). Predation was determined to be the cause of death of two radio-collared bighorn sheep in BICA in previous studies (Irby and others, 1995), and the cause of 13 radio-collared bighorn sheep mortalities over a 3 year period (K. Schoenecker, oral commun., 2003).

K. Schoenecker and F. Singer (USGS-BRD, Fort Collins, CO) conducted a study of plant forage quantity and quality in the study area, however, results weren't available at the time of this analysis. Results could be incorporated into the vegetation maps identifying areas of greater productivity. These results could be used to produce an overlay in GIS and incorporated into the results of this analysis. In his masters thesis, Lee Hughes (1997) developed a method for incorporating forage quantity (percent cover) and quality into the habitat suitability model.

\section{Discussion}

It is important to view the suitable habitat data alongside the seasonal range data to identify areas supporting all range requirements. According to this analysis, focus areas 1 and 2 have adequate suitable habitat and summer and winter seasonal habitat to support a minimum viable population of bighorn sheep. However, according to this analysis, lambing habitat is limited in all focus areas. Resource managers and wildlife biologists have observed ewes lambing within a microhabitat of benches along the cliffs of the Bighorn Canyon (F. Singer, K. Schoenecker, oral commun., 2002). They have GPS point data of lambing sites. We recommend further analysis of lambing sites by overlaying the GPS points with aspect, suitable habitat, forage quantity and quality data, in addition to any known predation information to determine if the limited lambing patch size predicted in this model will restrict growth of the population and identify if sheep are indeed using the areas of lambing habitat predicted by the model.

From January 2001 through October 2001, bighorn sheep locations were GPS'd by USGS-BRD field crews along the Bighorn Canyon. Bighorn sheep locations along Bighorn Canyon are overlayed onto suitable habitat (without proximity to water sources criterion) in Figure 10. A brief visual check was done to determine if bighorns 

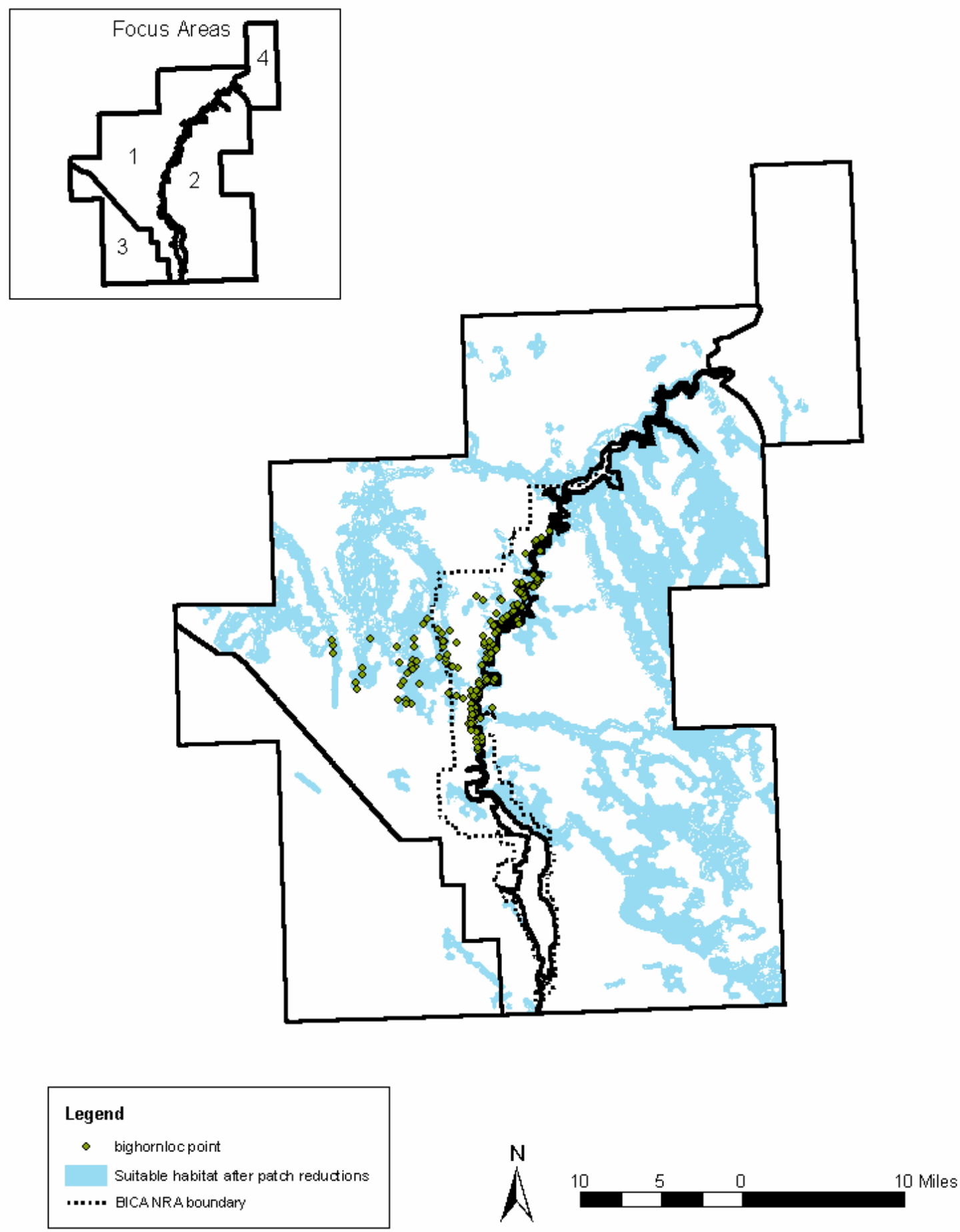

Figure 10. Current (2001) bighorn sheep locations within BICA. Each dot represents a group of bighorn sheep observed by ground crews. 
were using the suitable habitat predicted in this analysis. By visual estimation, over half (approximately $65 \%$ ) of the bighorn location points fall into areas of suitable habitat developed using patch size reduction and water criterion. If not falling within areas of suitable habitat, most fall within 500-1,000 m of buffered escape terrain. Bighorn sheep locations are coinciding more closely with predicted suitable habitat without using the proximity to water criterion. Further analysis should explore whether using the water criterion in this area benefits or limits the results of the model.

Winter and summer locations are displayed over seasonal habitat maps in Figures 11 and 12. These data can be used to identify if seasonal ranges predicted by the model are being used by the sheep, and for further studies to determine if adequate seasonal habitat is present in Bighorn Canyon.

\section{Management of Habitat}

For an analysis of management options, we determined if it is possible to add back some habitat removed due to unsuitability. The following are the criteria that removed the habitat, and suggestions for management of these variables, if possible.

1. Elevation (slope steepness) and distance to slopes cannot be managed. This is not a viable management option.

2. Roads cannot be eliminated with ease, and won't add significant area to the suitable habitat—sheep also cross roads in most cases. This is not a viable management option.

3. Distance to known perennial water sources reduced $96 \mathrm{~km}^{2}$ of suitable habitat. Solutions may include installing guzzlers or ponds. However, the cost may be too great to consider this a solution. Additionally, there does not appear to be a way to model for water placement and all of its possible permutations, as there are an infinite number of possible placements. Finally, data mapping all perennial water sources may not be accurate enough to use as a criterion for prediction of suitable bighorn sheep habitat. This may be a viable management practice, but cannot be determined in this analysis.

4. Human use areas cannot be eliminated with ease, and will not add significant area to the suitable habitat. Not likely a viable management option.

5. Improving horizontal visibility is cost effective. $64 \mathrm{~km}^{2}$ of suitable habitat were removed in this analysis due to poor horizontal visibility. Areas of dense vegetation known to be barriers to movement may be managed. This is a viable management option.

6. Isolated polygons or areas of suitable habitat smaller than $17 \mathrm{~km}$ are too small to support a viable population of bighorn sheep. It is possible that these small patches can be enlarged by improving the habitat surrounding them. These areas should be considered for possible expansion based on the results of management decisions to improve the habitat. These polygons will be included for visual display.

7. Distance to domestic sheep can be managed and at a reasonable cost. Eliminating or converting the domestic sheep grazing allotments could potentially add $154 \mathrm{~km}^{2}$ of suitable habitat. This is a viable management option.

In summary, there are two viable criteria: managing for horizontal visibility and proximity to domestic sheep. This analysis identified areas of marginal bighorn sheep habitat due to poor horizontal visibility and domestic sheep grazing allotments that may be improved with management techniques. Proper mechanical thinning and prescribed burning may open up larger patches of otherwise unsuitable habitat, or create corridors linking patches of suitable habitat. To determine these areas of potential suitable habitat, those areas that did not meet the horizontal visibility criteria are shown (Figure 13). All areas that cannot be managed (including inadequate escape terrain, distances too far from escape terrain, human use areas such as roads or developed areas, and distances too far from perennial water sources) remain excluded from the potentially manageable habitat identified in Figure 13 . Note that this analysis of management mapping makes the assumption that all costs for mechanical thinning or burning are equal based on vegetation. Additionally, all cells (areas) are considered equal in accessibility. Areas removed due to small patch size that may be managed if poor horizontal visibility is improved can be identified in Figure 13 and Table 6. Managers can overlay this grid of potentially manageable patches onto the reclassed vegetation maps and the original vegetation classifications. Additionally, areas of low horizontal visibility that may improve the overall areas of suitable habitat, but are too close to domestic sheep grazing allotments, are identified. 


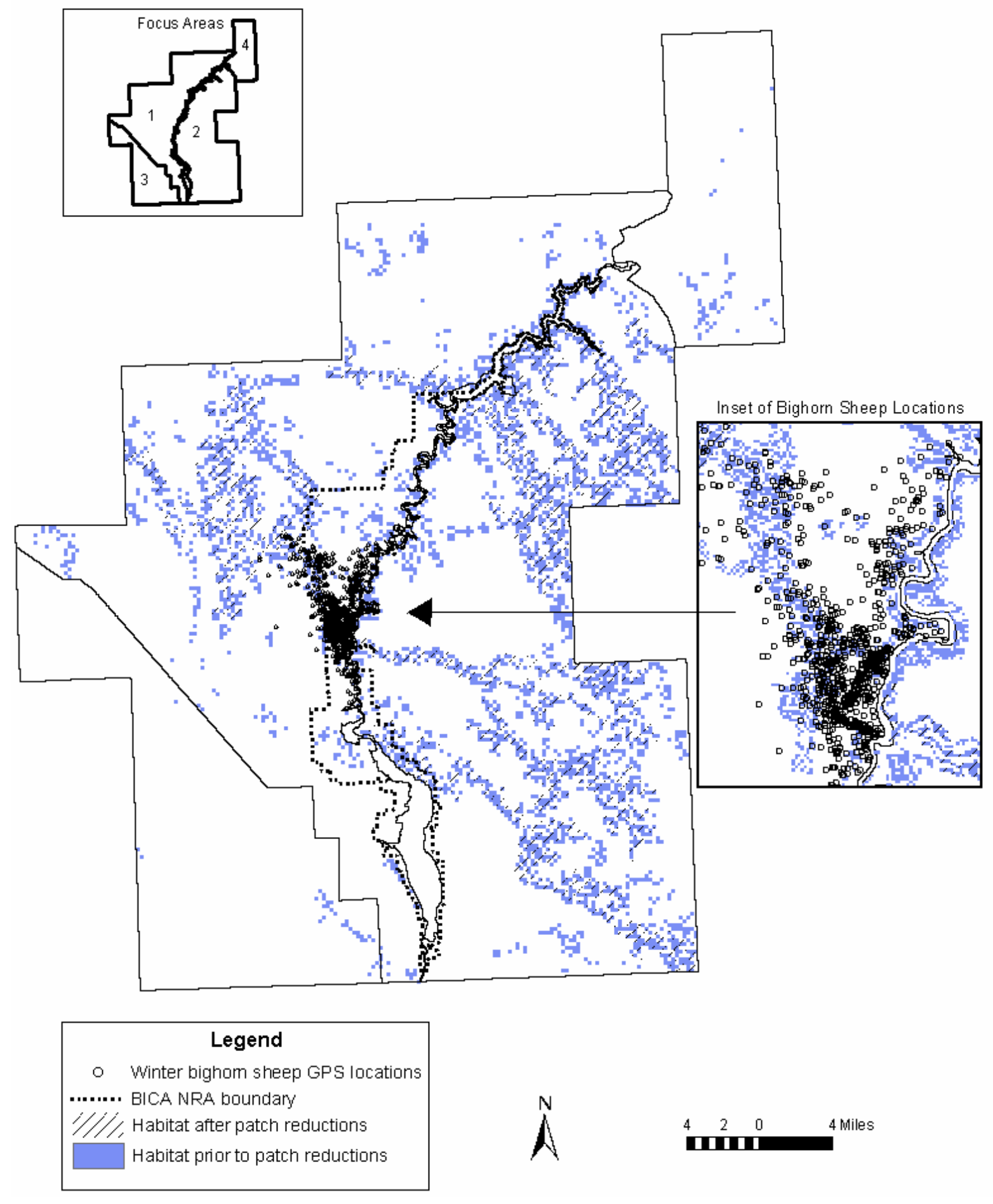

Figure 11. Bighorn sheep locations (1015 points) within suitable winter habitat in Bighorn Canyon. Locations were GPS'd from 1/01-3/01. 


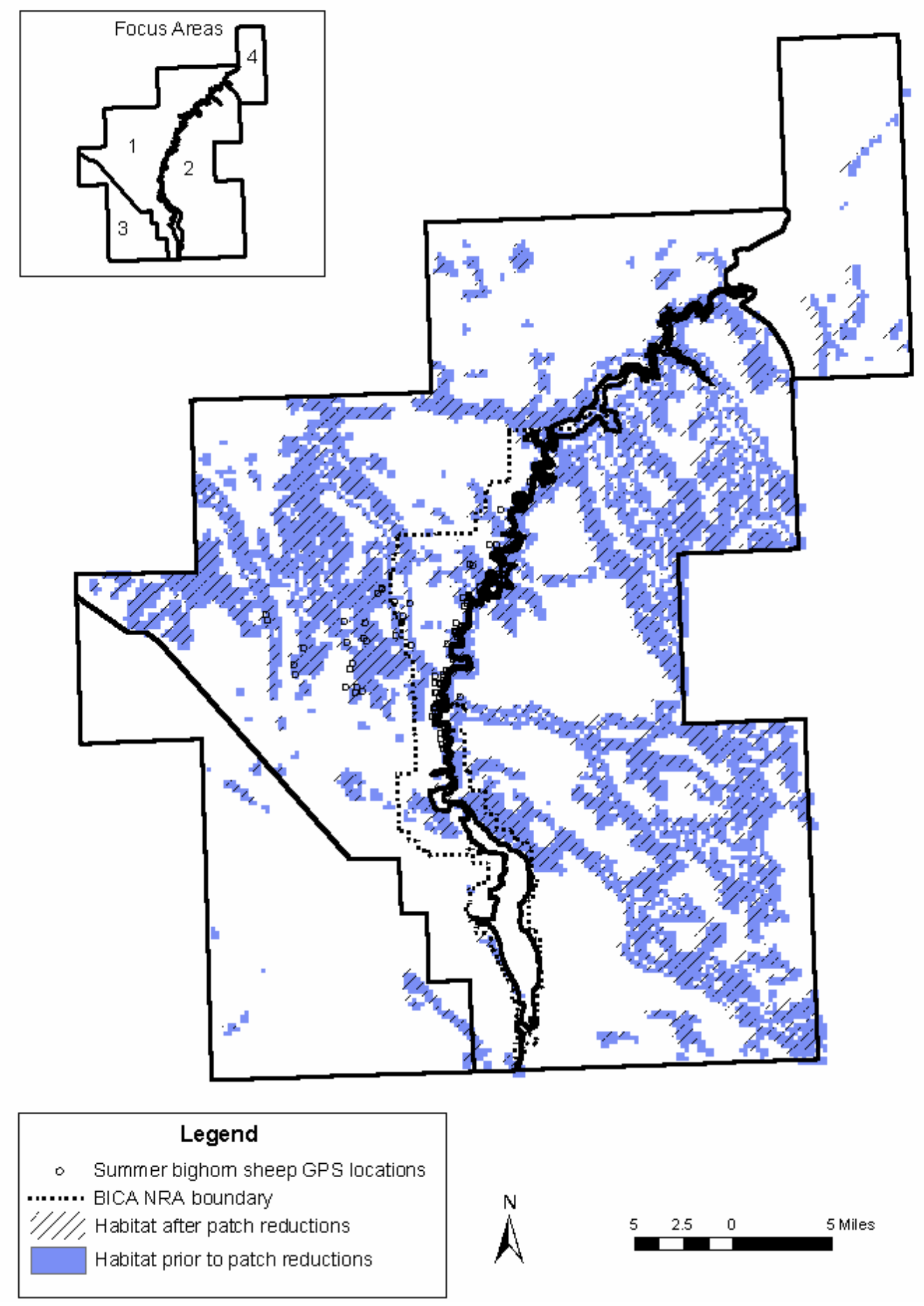

Figure 12. Bighorn sheep locations within suitable summer habitat in Bighorn Canyon. Locations GPS'd from 4/01-9/01. 

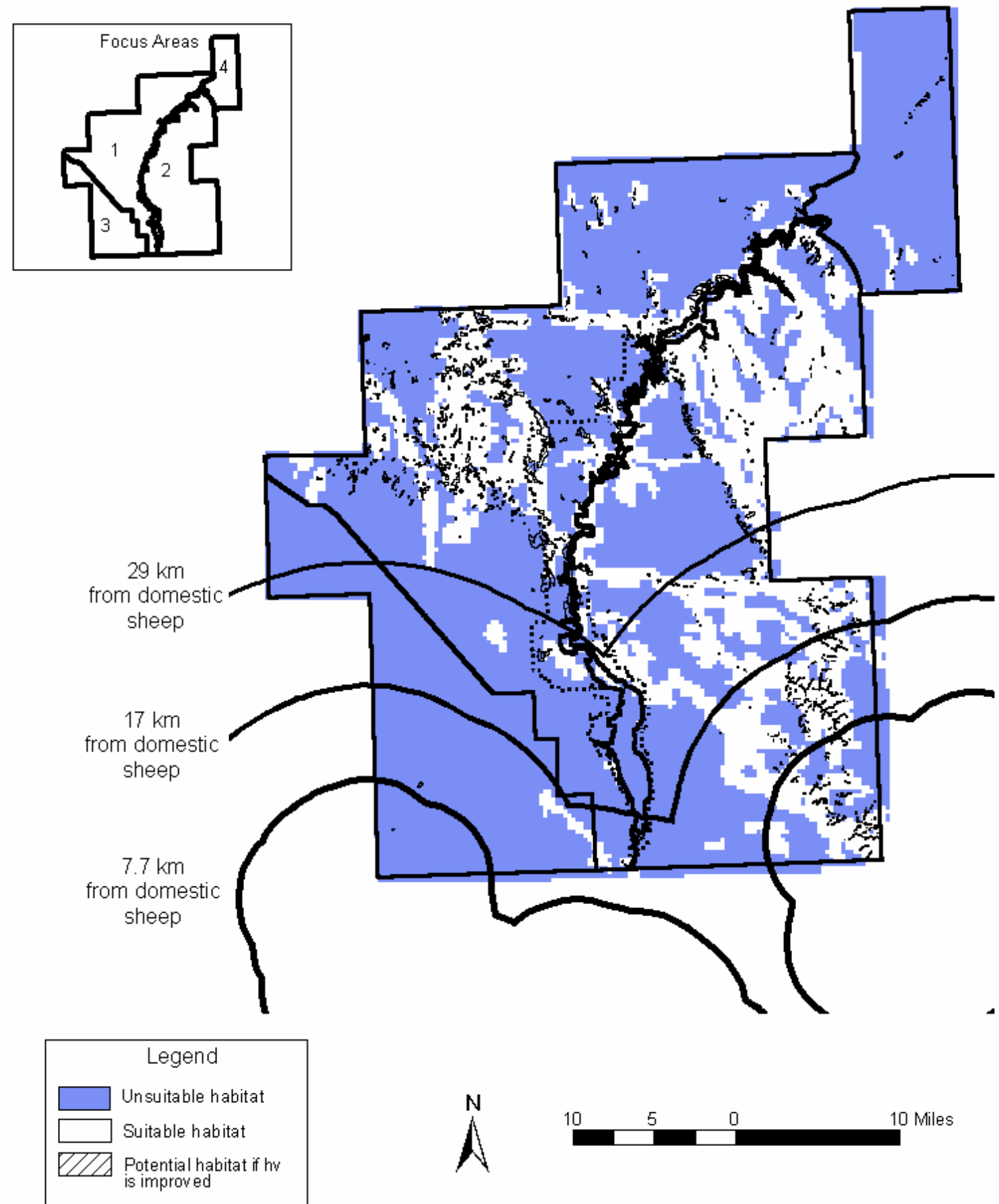

Figure 13. Potential suitable bighorn sheep habitat if areas initially classified as having poor horizontal visibility $(<62 \%)$ are cleared or burned. Note that shaded areas represent areas of non-suitable habitat so that areas reduced due to small patch size can be identified and reviewed for possible inclusion if management of horizontal visibility will improve these areas. Non-shaded areas within the study area represent suitable habitat using the proximity to water criterion. 
Persistence of bighorn sheep populations is strongly correlated to larger patch sizes of suitable habitat (Singer and others, 2001). The larger populations of bighorn sheep that may occupy larger patches of habitat conserve more genetic diversity, and are more likely to survive, persist, and increase following a disease outbreak (Berger, 1990, 1999; Singer and others, 2001). Populations of at least 300 animals were more likely to survive and recover from a disease epizootic (Singer and others, 2001). Once management improvement areas have been decided, then it can be determined if adequate seasonal habitat exists to support a minimum viable population of bighorns in the newly improved areas. Based on the results of this analysis, I recommend the managers of BICA take actions to increase both the patch size of suitable habitat and the overall size and quality of the habitat occupied by the current bighorn sheep populations.

Table 6. The total area of potential habitat that may be added back into each focus area if managed for poor horizontal visibility.

\begin{tabular}{l|c|c|c|c}
\hline & Focus Area 1 & Focus Area 2 & Focus Area 3 & Focus Area 4 \\
\hline $\begin{array}{l}\text { Potential area }\left(\mathrm{km}^{2}\right) \text { that can be } \\
\text { potentially manageable patches if } \\
\text { horizontal visibility is improved to 62\% }\end{array}$ & 42.72 & .19 .51 & .74 \\
\hline
\end{tabular}

\section{Literature Cited}

Bailey, J.A., 1990, Management of Rocky Mountain bighorn sheep herds in Colorado: Colorado Division of Wildlife Special Report $66,24 \mathrm{p}$.

Berger, J., 1990, Persistence of different sized populations: An empirical assessment of rapid extinctions in bighorn sheep: Conservation Biology, vol. 4, p. 91-98.

Bleich, V.C., Wehausen, J.D., and Holl, S.A., 1990, Desert-dwelling mountain sheep: Conservation implications of a naturally fragmented distribution: Conservation Biology, vol. 4, p. 383-390.

Buechner, H.K., 1960, The bighorn sheep in the United States, its past, present, and future: Wildlife Monographs, vol. 4, 174 p.

Capurro, W.N., 1988, Entire California bighorn herd dies in the Warner Mountains, p. 65 in Wild Sheep, Foundation for North American Wild Sheep: Summer issue, Ames, lowa, Sigler Printing and Publishing.

Coates, K.P., and Schemnitz, S.D., 1989, Habitat utilization, interspecific interactions and status of a recolonized population of bighorn sheep at a wild horse range: Project completion report to NPS and BLM, New Mexico State University, Las Cruces, $71 \mathrm{p}$.

Coggins, V.L., 1988, The Lostine Rocky Mountain bighorn sheep die-off and domestic sheep: Biennial Symposium of the Northern Wild Sheep and Goat Council, vol. 6, p. 57-64.

Cooperrider, A.Y., 1969, Competition for food between mule deer and bighorn sheep on Rock Creek winter range, Montana: M.S. thesis, Montana State University, Bozeman, $92 \mathrm{p}$.

Dodd, N.L. and Brady, W.W., 1986, Cattle grazing influences on vegetation of a sympatic desert bighorn range in Arizona: Desert Bighorn Council Transactions, vol. 32, p. 1-6.

Ferrier, G.J., and Bradley, W.G., 1970, Bighorn habitat evaluation in the Highland Range in southern Nevada: Desert Bighorn Sheep Council Transactions, vol. 14, p. 69-93.

Geist, V., 1971, Mountain sheep, a study in behavior and evolution: Chicago, University of Chicago Press, 383 p.

Goodson, N.J., 1982, Effects of domestic sheep grazing on bighorn sheep populations: Biennial Symposium of Northern Wild Sheep and Goat Council, vol. 3, p. 287-313.

Gudorf, M.A., Sweanor, P., and Singer, F.J., 1996, Bighorn sheep habitat assessment of the Greater Bighorn Canyon National Recreation Area, National Park Service and USGS Biological Resources Division cooperative report: Bighorn Canyon National Recreation Area, NPS, $44 \mathrm{p}$.

Helvie, J.B., 1971, Bighorns and fences: Desert Bighorns Sheep Council Transactions, no. 15, p. 53-62.

Holl, S.A., and Bleich, V.C., 1983, San Gabriel mountain sheep and biological and management considerations: San Bernadino National Forest, Calif., $135 \mathrm{p}$.

Honess, R.F., and Frost, N.M., 1942, A Wyoming bighorn sheep study: Wyoming Game and Fish Comm. Bull. No. 1127 pp.

Hughes, L.G., 1997, A GIS-based evaluation of the Bighorn Mountains for reintroduction of Rocky Mountain bighorn sheep: M.S. thesis, University of Wyoming, Laramie, Department of Zoology and Physiology, $98 \mathrm{p}$. 
Irby, L.R., Mackie, R.J., and Kissell, R.E., 1995, Competitive interactions between bighorn sheep, wild horses, and mule deer in Bighorn Canyon National Recreation Area and Pryor Mountain Wild Horse Range: Third annual report, Department of Biology, Montana State University, Bozeman.

Jessup, D.A., 1981, Pneumonia in bighorn sheep: effects on populations: Cal-Neva Wildlife Society Transactions, p. 72-78.

Jessup, D.A., 1985, Diseases of domestic livestock which threaten bighorn sheep populations: Desert Bighorn Council Transactions, vol. 29, p. 29-33.

Johnson, T.L. and Swift, D.M., 2000, A test of a habitat evaluation procedure for Rocky Mountain bighorn sheep: Restoration Ecology., vol. 8, no. 4S:47-56.

Knight, D.H., Jones, G.P., Akashi, Y., and Myers, R.W., 1987, Vegetation ecology in the Bighorn Canyon National Recreation Area: Final report, University of Wyoming National Park Service Research Center, $114 \mathrm{p}$.

McQuivey, R.P., 1978, The desert sheep of Nevada: Department of Fish and Game Bulletin, no. 6, Reno, NV, 81 p.

Sands, A.R., 1976, Evaluation of potential California bighorn sheep habitat, Jackson Mountains, Nevada: M.S. thesis, Humboldt State University, Arcata, Calif., $104 \mathrm{p}$.

Singer, F. ., Zeigenfuss, L.C.,.Spicer, L., 2001, The role of patch size, disease, and movement in the rapid extinction of bighorn sheep: Conservation Biology, vol. 15, p. 6-13.

Smith, T.S., Flinders, J.T., and Winn, D.S., 1991, A habitat evaluation procedure for Rocky Mountain bighorn sheep in the Intermountain West: Great Basin Naturalist, vol. 51, p. 205-225.

Van Dyke, W.A., Sands, A., Yoakum, J., Polentz, A., and Blaisdell, J., 1983, Wildlife habitat in managed rangelands-the Great Basin of southeastern Oregon bighorn sheep: USDA Forest Service General Technical Report, Pacific Northwest Forest and Range Experiment Station, Portland, Oregon, $37 \mathrm{p}$.

Wilson, L.O., Blaisdell, J., Welsh, G., Weaver, R., Brigham, R., Kelly, W., Yoakum, J., Hinks, M., Turner, J., and DeForge, J., 1980, Desert bighorn habitat requirements and management recommendations: Desert Bighorn Council Transactions, vol. 24. p. 1-7.

Zeigenfuss, L.C., Singer, F.J., and Gudorf, M.A., 2000, Test of a habitat suitability model for bighorn sheep: Restoration Ecology, vol. 8, no. 4S:38-46. 


\section{An Animal Location-Based Habitat Suitability Model for Bighorn Sheep and Wild Horses in Bighorn Canyon National Recreation Area and the Pryor Mountain Wild Horse Range, Montana, and Wyoming}

By Gary Wockner, NREL/Colorado State University; Francis J. Singer and Kathryn A. Schoenecker, U.S. Geological Survey

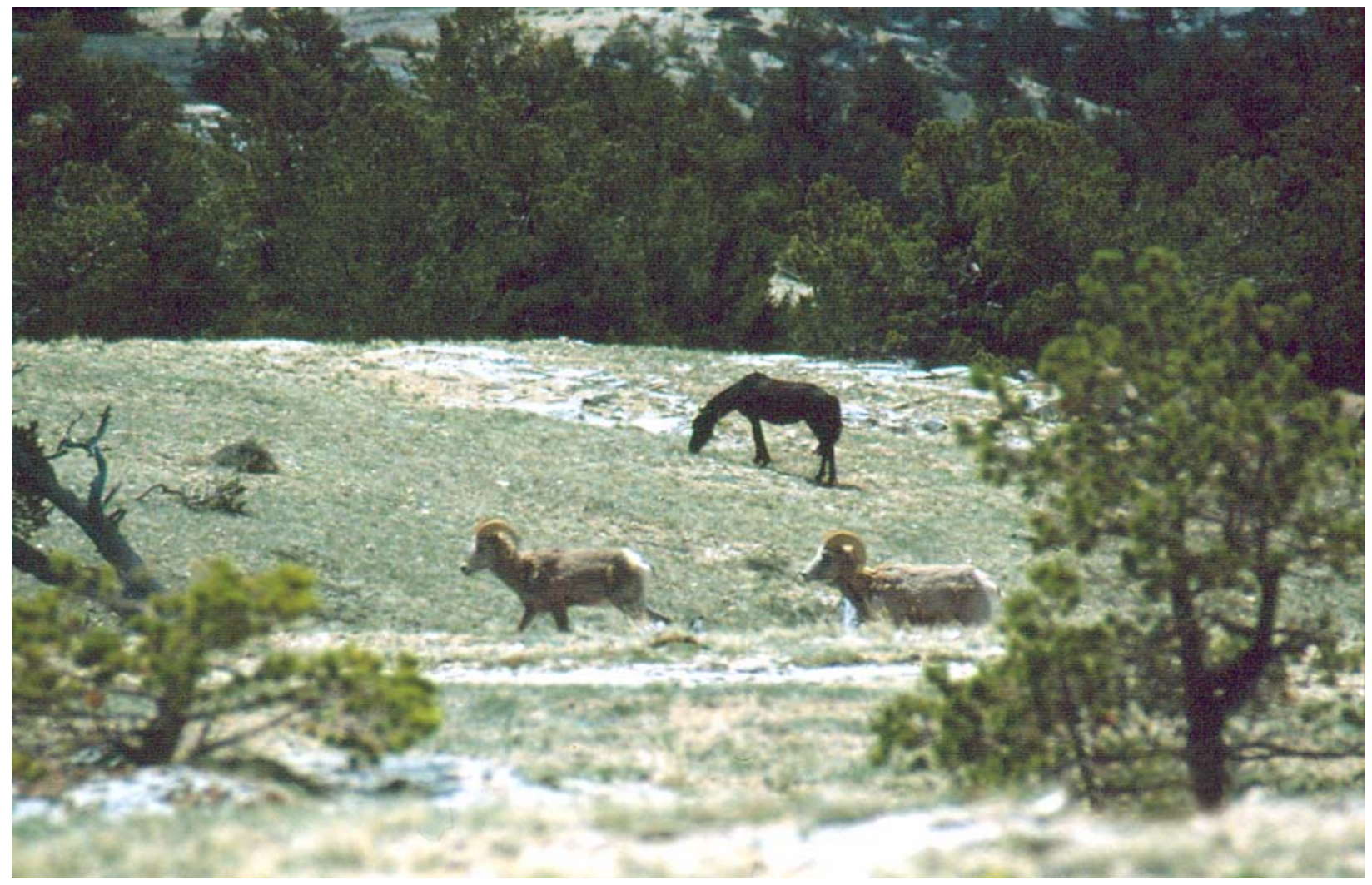




\section{Introduction}

The purpose of this habitat suitability model is to provide a tool that will help managers and researchers better manage bighorn sheep and wild horses in the Bighorn Canyon National Recreation Area (BICA) and Pryor Mountain Wild Horse Range (PMWHR). A concern in the management of the Pryor Mountain wild horse population is whether or not the wild horses compete with bighorn sheep for available forage or available space. Two studies have been conducted that have shown no obvious, convincing competition between the two species. A study of diets and habitat-use of both species revealed substantial diet overlap only during some seasons, but there were considerable spatial and habitat separations between wild horses and bighorns during all seasons (Kissell and others, 1996). This empirical data was then used in a modeling exercise that predicted that neither the current (about 160 horses at the time of the analysis) nor larger numbers of wild horses on the area (e.g., about 200 horses) would result in reduced numbers or condition of bighorn sheep (Coughenour 1999). But competition is a very complex biological process to document. Bighorns might have already been spatially avoiding wild horses when these studies were conducted.

A second concern for managers is that earlier studies suggest both species are not using many areas of the range that appear to be suitable (Gudorf and others, 1996; Kissell and others, 1996). A primary goal for the management of both species is to increase their numbers for purposes of genetic conservation and viability. The bighorn sheep population declined during the mid-1990's from a peak of about 211 animals to 100 animals at present. Absolute minimum goals for genetic viability in the bighorn sheep herd (genetic effective population size of $\mathrm{N}_{e} \geq 50$ ) suggest at least 150 animals should be present, while studies of persistence suggest populations of 250+ are more likely to recover rapidly and persist should the population experience an epizootic die-off (Singer and others, 2001). Since all bighorn sheep populations are potentially vulnerable to disease epizootics, managing for larger populations of 200-300 animals appears to increase the potential for long-term persistence (Berger, 1990; Singer and others, 2001).

Wild horses are not prone to rapid disease die-offs. However, minimum goals for genetic viability in the Pryor Mountain wild horses $\left(\mathrm{N}_{\mathrm{e}} \geq 50\right)$ require that at least 160 animals be present on the range (Singer and others, 2000). Since the $\mathrm{N}_{\mathrm{e}} \geq 50$ goal is set for the breeding of domestic animals, and since the vagaries of drought, severe winters, predation, and other stochastic events cause stress in wild animals, larger goals for $\mathrm{N}_{\mathrm{e}}\left(\right.$ e.g. $\left.\mathrm{N}_{\mathrm{e}} \geq 100\right)$ for wild horses are even more desirable (USDI, BLM, 1999; Gross, 2000). Expanding the area of the wild horse range is one option, but the prospects for expanding the range do not appear to be great (L. Coates-Markle, BLM, oral comm.). A second option would be to increase the amount of useable habitat for horses on the existing range. One goal of this modeling effort was to use GIS-based habitat analyses to determine the reason wild horses are not using some areas of the range, and to explore the potential for making some of these areas useable.

The National Park Service (NPS) has shown considerable interest in management actions within BICA that will increase the range, useable habitat, and population size of bighorn sheep. There has also been interest expressed by the Bureau of Land Management (BLM) and wild horse advocates to improve the useable habitat for wild horses and to possibly increase the size of the horse range.

\section{Objectives}

Our objectives were to:

1. Develop separate GIS-based habitat suitability models for bighorn sheep and wild horses for summer and winter ranges based on a unified vegetation coverage created by Gudorf (2002). Our models are based on animal location information gathered over the previous five years.

2. Compare the bighorn sheep habitat suitability model created here, using animal locations, to a more general model completed by Gudorf (2002).

3. Compare modeled habitat to actual animal locations for both species.

4. Create maps of unused bighorn sheep and wild horse habitat.

5. Use the model to identify potential habitat for both species that could be created by: 
a. Manipulating vegetation types (bighorn sheep)

b. Adding water sources and trails (wild horses)

c. Opening up the Sorensen extension on NPS lands, and adding U.S. Forest Service (USFS) lands (wild horses)

6. Compare overlap of the two species, and compare areas modeled as bighorn sheep habitat to areas modeled as wild horse habitat.

\section{Methods}

Habitat suitability models were developed for two overlapping areas. The bighorn sheep model covered BICA and surrounding areas while the wild horse model covered the PMWHR (Figure 1). Arcview GIS was used to compile a database of several themes of potential importance to these ungulates within those two areas including:

1. Elevation data was obtained from a 30-m resolution Digital Elevation Model (DEM) from the US Geological Survey.

2. Slope was calculated from the 30-m DEM.

3. Aspect was calculated from the 30-m DEM and then cosine transformed to have values from 1 to -1 .

4. Canopy cover (used only in the wild horse model) data was derived by Coughenour (1999) from various sources including USGS maps and Knight and others (1987).

5. Vegetation coverage was derived from four sources: BICA vegetation map from Knight and others (1987), Montana GAP, Wyoming Game and Fish vegetation map, and Wyoming GAP. These four maps were merged together using the methods of Gudorf (2002). The finalized vegetation map appears in Figure 2.

6. Distance from water was calculated by using water source data compiled from BICA maps, F. Singer (USGS) and L. Coates-Markle (BLM). Water sources include seasonal springs, water catchments, and tanks. For the purposes of this model, all sources were assumed to be functional except two midelevation tanks, which are currently inactive. We modeled a scenario that made these two tanks active and available, as an example of a potential management action.

7. Sheep and horse locations are from summer and winter data. Wild horse locations were acquired from 2 aerial helicopter population surveys/year from 1996-2002 and from ground crew observations (ground tracking) from 1998-2001. Bighorn sheep locations were acquired from aerial helicopter population surveys (1-2/yr) from 1997-2001, and boat surveys, fixed-wing surveys, and systematic ground tracking of 30 radio-collared bighorns from 2000-2002. Summer data was defined as being from April 1-September 30; winter data from October 1-March 31. For wild horses, each data point represents one group of wild horses, where groups ranged in size from one to twelve animals. For sheep, each data point also represents one group of animals. To give a portrayal of species overlap, sheep and horse summer locations are displayed in Figure 3, and winter locations are displayed in Figure 4.

8. Distance to escape terrain (used in the bighorn sheep model only) was derived using Arcview by buffering slopes greater than 30 degrees with a $300 \mathrm{~m}$ buffer, or buffering with a $1,000 \mathrm{~m}$ buffer where slopes were present on two sides (Smith and others, 1991).

9. Initially, the input variable of horizontal visibility for bighorn sheep was obtained from Schoenecker (unpublished data, 2003) as defined in Gudorf (2002). However, because visibility exactly correlated with vegetation (each vegetation type had one single visibility rating), the statistical procedure eliminated visibility in regression analyses. Thus, we did not use visibility per se in our analyses, but it was incorporated into each vegetation type. Therefore, our discussions regarding improving bighorn sheep habitat center on vegetation types and shifting vegetation types to those that are more used by bighorn sheep instead of "improving visibility" for sheep. 


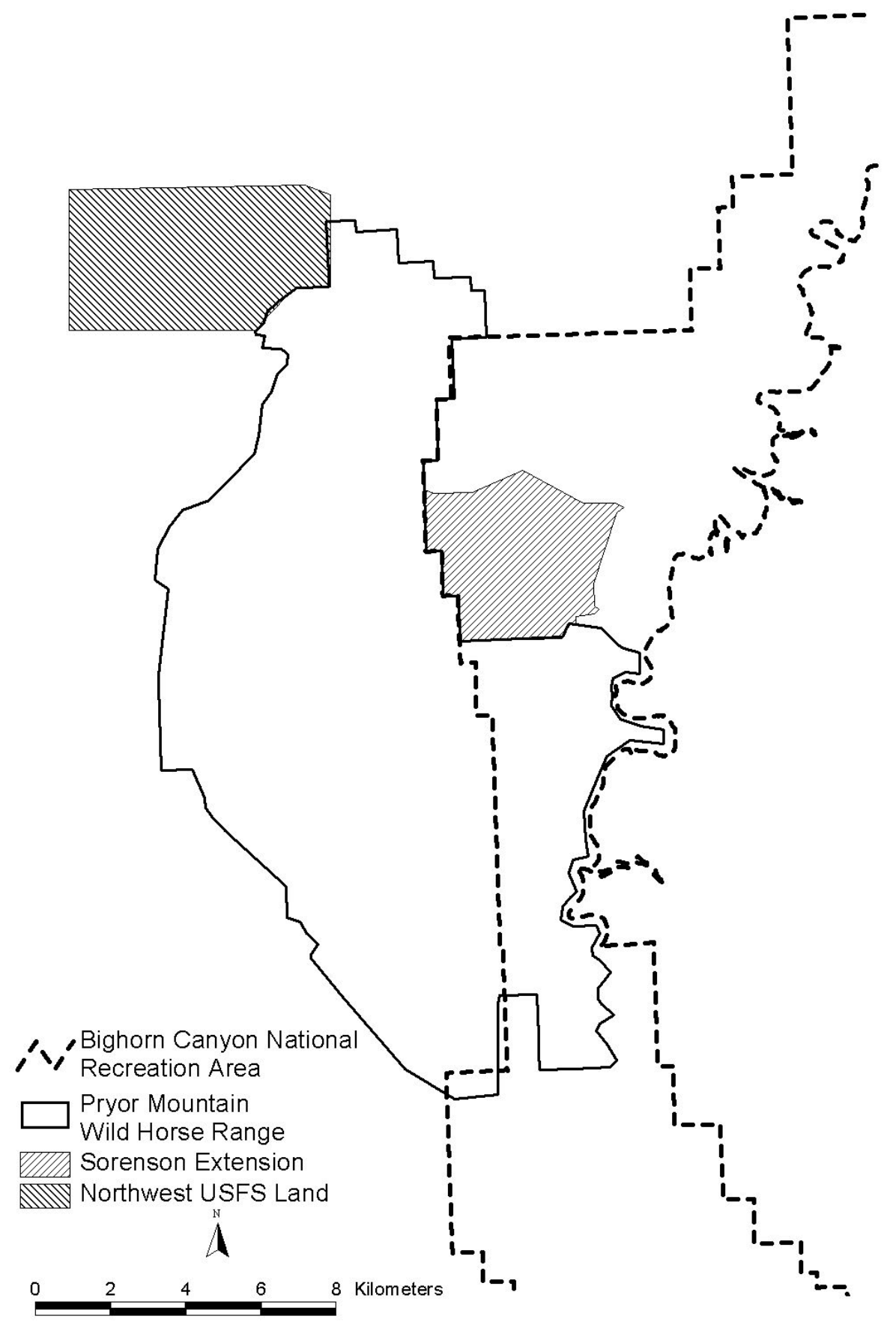

Figure 1. Management boundaries for bighorn sheep and wild horse habitat suitability models in BICA, the PMWHR, and surrounding USFS and state lands in Montana and Wyoming. 


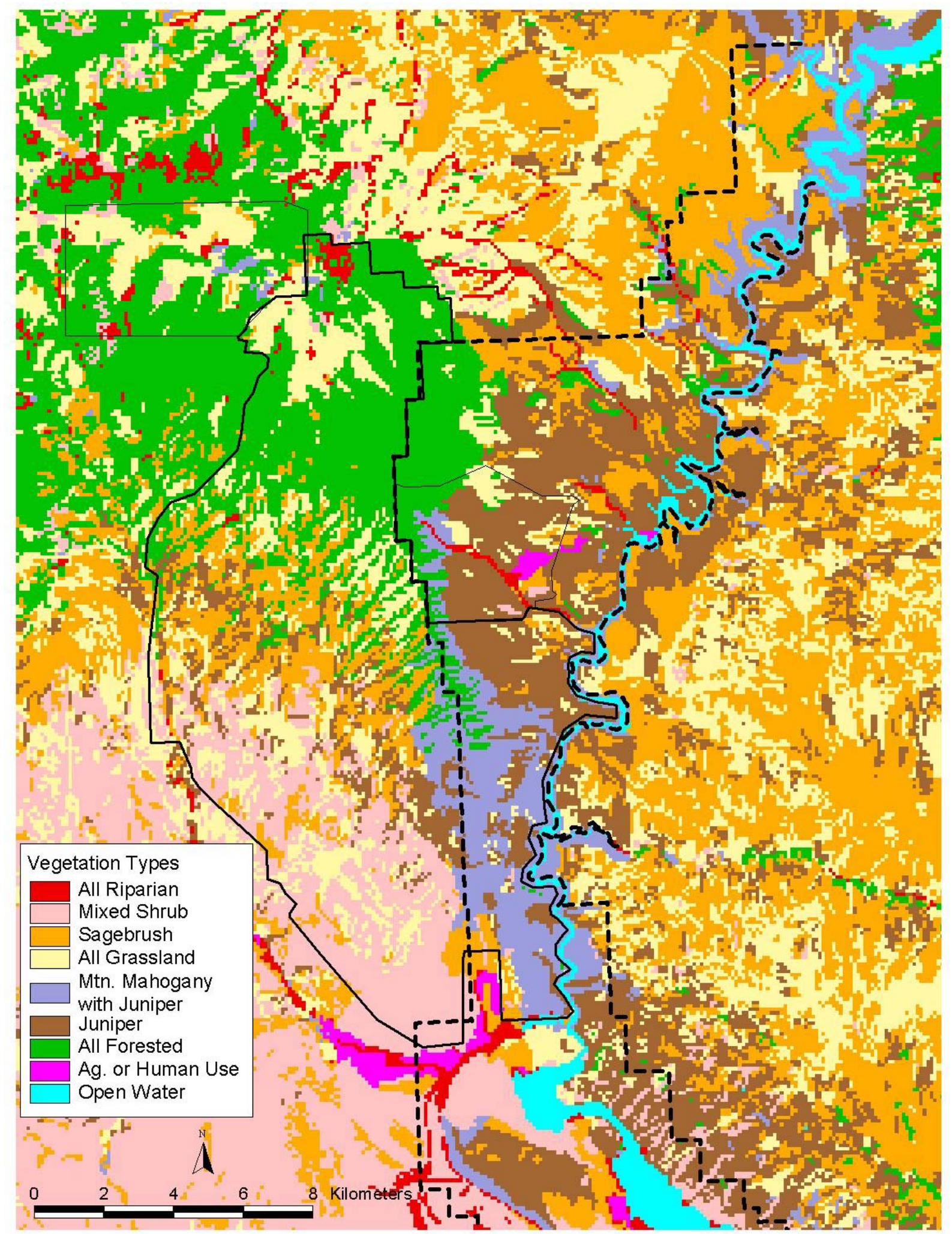

Figure 2. Final vegetation coverage for the modeling efforts in BICA, the PMWHR, and surrounding USFS and state lands in Montana and Wyoming. 


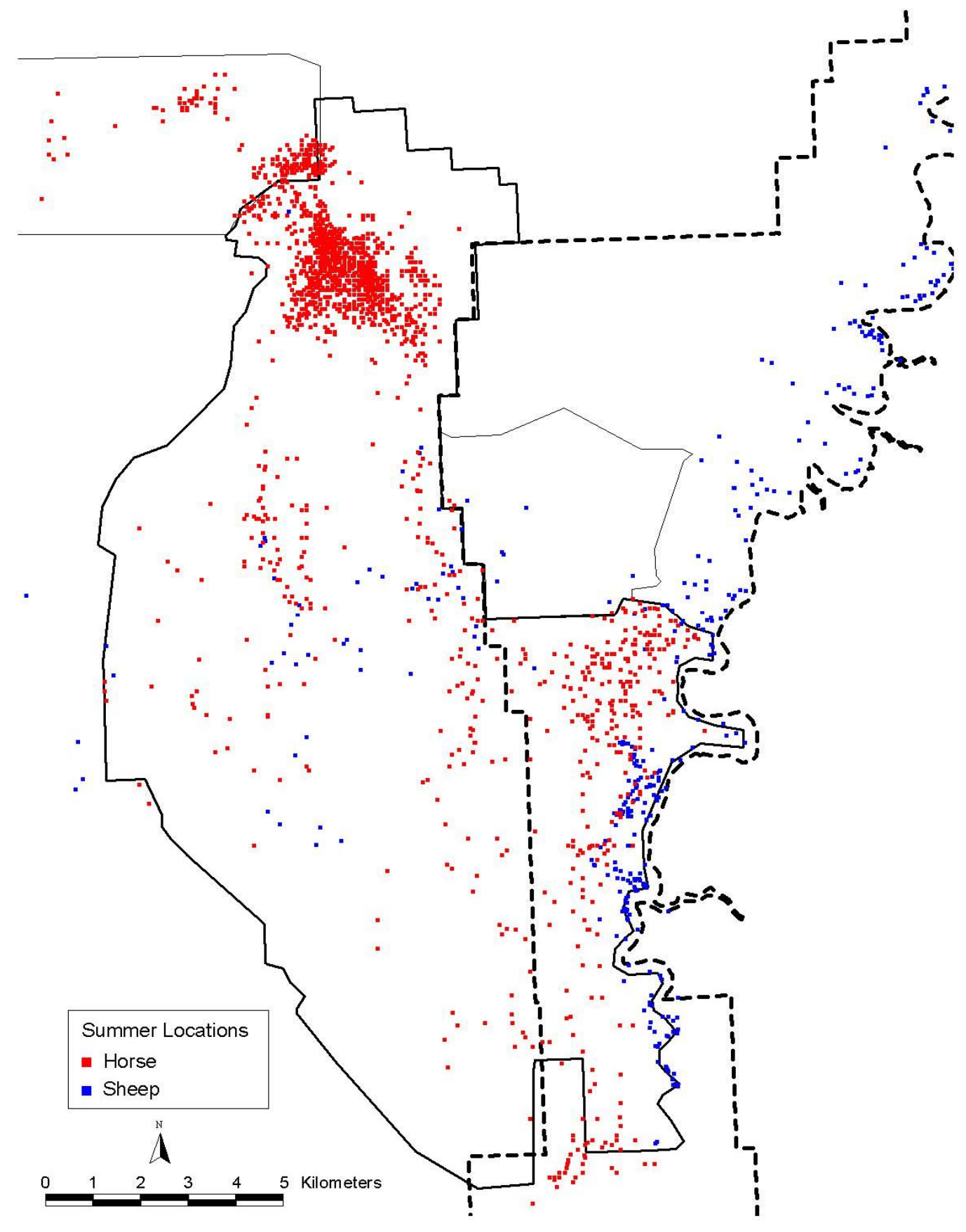

Figure 3. Summer locations of bighorn sheep and wild horses in BICA, the PMWHR, and surrounding USFS and state lands in Montana and Wyoming, 1996-2002. 


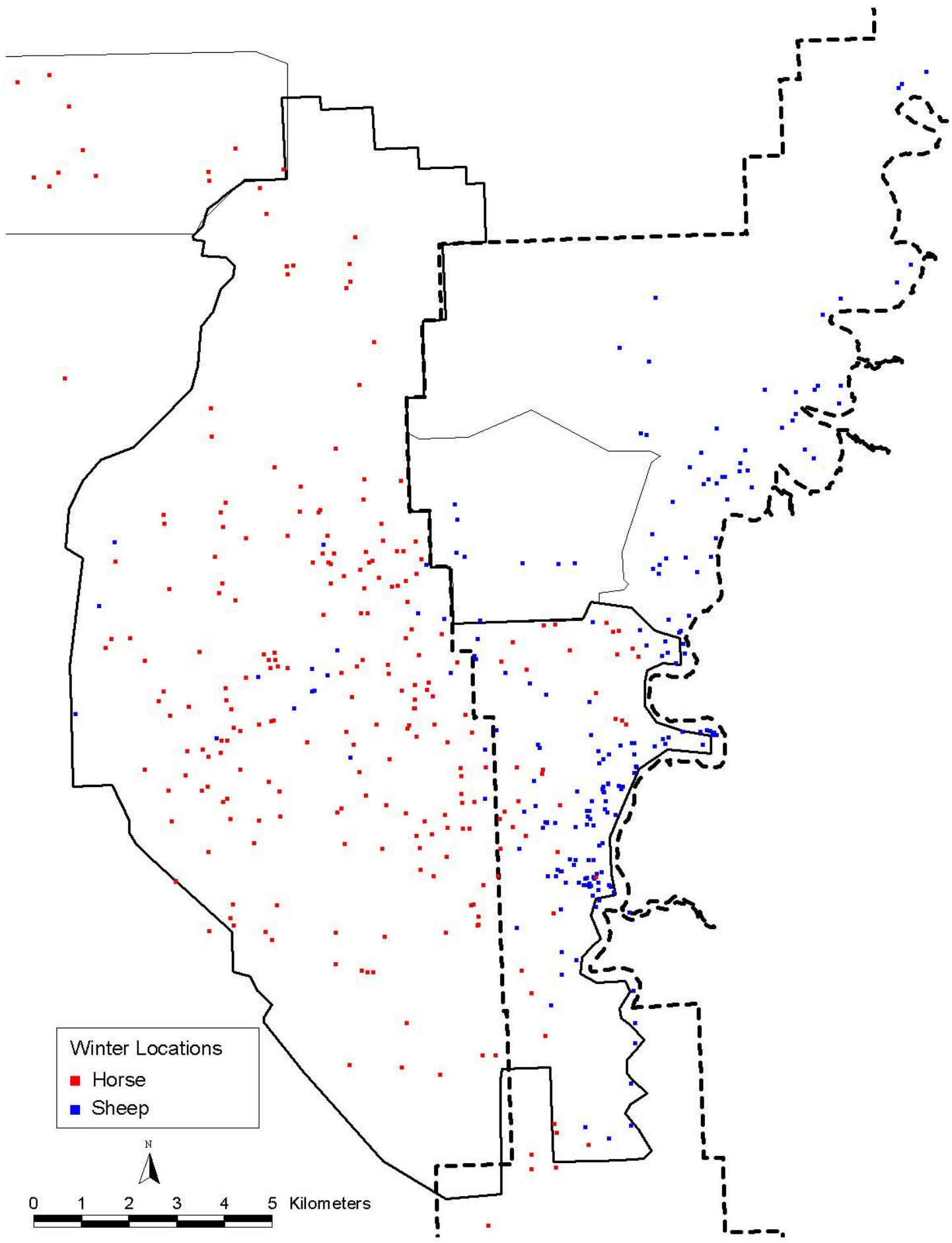

Figure 4. Management boundaries for bighorn sheep and wild horse habitat suitability models in BICA, the PMWHR, and surrounding USFS and state lands in Montana and Wyoming. 
Using a GIS-sampling process, sheep and horse locations were overlain on the above geographic grids and pertinent data was sampled for each location. Logistic regression analyses were performed to determine the best model for predicting habitat selection for each species for both summer and winter seasons. The dichotomous response variable was "observed habitat use" versus "randomly generated" locations. Akaike's information criteria (AIC) were used to determine the best model for predicting habitat selection for each species and season. The models compared habitat variables for animal-selected areas with those at random locations throughout the range. We used 2,147 summer locations and 250 winter locations of wild horses, and 395 summer locations and 223 winter locations of bighorn sheep. equation:

The probability of use of a habitat by wild horses and bighorn sheep can be predicted using the following

$$
P_{i}=\frac{e^{\beta_{0}+\beta_{1} X_{1 i}+\ldots \beta_{K} X_{K i}}}{1+e^{\beta_{0}+\beta_{1} X_{1 i}+\ldots \beta_{K} X_{K i}}}
$$

where $\beta_{0} \ldots \beta_{K}$ are the parameter estimates in the logistic regression equation, and $X_{1 i} \ldots X_{K i}$ are the values of the habitat variables (van Manen and Pelton, 1997). This model can then be used to create management scenarios by varying the above GIS input coverages. Scenarios can be tested by changing the habitat variables (adding a water source or changing access), re-running the equation and comparing the outcome to the base model. In the figures and results that follow, four categories were used to define habitat suitability — suitable, acceptable, marginal, and unsuitable. "Suitable" was defined as having a probability of use between 0.75 and 1.0, "acceptable" was between 0.50 and 0.75 , "marginal" between 0.25 and 0.50 , and less than 0.25 was "unsuitable." Areas that were modeled suitable or acceptable habitat were defined as "favorable" habitats.

In addition to the multiple logistic regression which creates the mapped probability values, we also performed single variable logistic regression. These regressions help tease out the details in multiple models. For example, while the multiple model will display the best combined model, it is not likely to be feasible for managers to manipulate multiple variables, especially those that are constant, like elevation, slope, aspect, and distance to escape terrain. Distance to water, vegetation, and canopy cover, on the other hand, are manipulatable, and the single variable logistic regression displays where managers might get the most effect for a given manipulation. A higher coefficient value suggests a higher importance, or benefit, to manipulation of that variable.

\section{Results and Discussion for Bighorn Sheep}

\section{Summer Habitat Suitability Model}

Bighorn sheep locations in summer (Figure 3) were clustered near the edge of Bighorn Canyon primarily near the lower end of the Park but also scattered along the canyon edge upwards towards the north. The summer bighorn sheep model coefficients derived by the multiple logistic regression appear in Table 1. Four variables slope, elevation, distance to escape terrain, and vegetation - were significant in the model. In the combined model with these four variables, sheep preferred steeper slopes, lower elevations, and closeness to escape terrain. In the vegetation categories, sagebrush was held as the constant variable while all other categories were compared to it. Assigning sagebrush as the constant variable was random and had no meaning. Any variable could have equally been the constant. Positive and negative effects on the model are only in comparison to sagebrush in this case, and may not be negative overall. In this comparison, the category mountain-mahogany/juniper had the highest positive effect, with riparian, juniper, and grassland also having positive effects on the model. Forest and mixed shrub had negative effects on the model compared to sagebrush (Table 1).

Figure 5 depicts the habitat suitability map for bighorn sheep in the summer. As per the quantitative model results in Table 1, the map shows darker areas where suitability is highest. These darker areas spatially coincide with the variables in the Table 1. Darker areas are primarily steeper slopes, at lower elevations, that are close to escape terrain, and primarily in the vegetation types of mountain-mahogany/juniper, riparian, juniper, and grassland. Any habitat manipulations that increased these four favorable vegetation types in areas located in proximity to the three favorable variables that are fixed (on steep slopes, at low elevations, close to escape terrain) would likely increase 
the amount and area of suitable summer bighorn sheep habitat. Additionally, Figure 5 allows us to find areas that are under-utilized by the current distribution of bighorn sheep. Sheep locations are depicted by red dots, so black areas that occur without nearby red dots can be interpreted as underutilized habitat.

Table 1. Multiple logistic output for bighorn sheep and wild horse, summer and winter models.

\begin{tabular}{lllll}
\hline & \multicolumn{2}{c}{ Bighorn Sheep } & \multicolumn{2}{c}{ Wild Horses } \\
\cline { 2 - 5 } & Summer & Winter & Summer & Winter \\
\hline Intercept & 2.0906 & 3.1937 & -3.8975 & -1.7938 \\
Variable & Coefficients & & & \\
Distance to water & $\mathrm{n} / \mathrm{a}$ & $\mathrm{n} / \mathrm{a}$ & -0.00061 & 0.000295 \\
Aspect & $\mathrm{n} / \mathrm{a}$ & $\mathrm{n} / \mathrm{a}$ & 0.2914 & $\mathrm{n} / \mathrm{a}$ \\
Slope & 0.0126 & $\mathrm{n} / \mathrm{a}$ & -0.0572 & -0.0626 \\
Elevation & -0.00132 & -0.00211 & 0.00253 & 0.000798 \\
Distance to escape terrain (sheep only) & -0.00068 & -0.00063 & $\mathrm{n} / \mathrm{a}$ & $\mathrm{n} / \mathrm{a}$ \\
Vegetation Cover Types & & & & \\
1. All riparian & 0.3720 & 0.4147 & 0.3351 & 2.4458 \\
2. Mixed shrub & -0.1754 & -1.6843 & -1.5492 & -0.9195 \\
3. Sagebrush & 0.0 & 0.0 & 0.0 & 0.0 \\
4. All grassland & 0.2862 & 0.3356 & -0.0389 & -0.4482 \\
5. Mt. mahogany with juniper & 0.9536 & 1.3638 & 0.3102 & -0.2646 \\
6. Juniper & 0.3435 & 0.7429 & 0.8430 & -0.3173 \\
7. All forested & -0.6476 & -0.3756 & -0.0178 & -0.3006 \\
8. Ag. and human use & $\mathrm{n} / \mathrm{a}$ & $\mathrm{n} / \mathrm{a}$ & $\mathrm{n} / \mathrm{a}$ & $\mathrm{n} / \mathrm{a}$ \\
9. Open Water & $\mathrm{n} / \mathrm{a}$ & $\mathrm{n} / \mathrm{a}$ & $\mathrm{n} / \mathrm{a}$ & $\mathrm{n} / \mathrm{a}$ \\
Canopy Coverage (horses only) & & & & \\
Very low (0-10\%) & $\mathrm{n} / \mathrm{a}$ & $\mathrm{n} / \mathrm{a}$ & 0.9055 & 0.7694 \\
Low (10-40\%) & $\mathrm{n} / \mathrm{a}$ & $\mathrm{n} / \mathrm{a}$ & -0.5745 & 0.7969 \\
Medium (40-70\%) & $\mathrm{n} / \mathrm{a}$ & $\mathrm{n} / \mathrm{a}$ & -0.1327 & -0.2628 \\
High (70-100\%) & $\mathrm{n} / \mathrm{a}$ & $\mathrm{n} / \mathrm{a}$ & 0.0 & 0.0 \\
\hline
\end{tabular}

Table 2 allows us to see how well the model fits the currently mapped sheep locations. There were a total of 395 summer sheep observations. Of those 395, 160 fell into areas modeled as "acceptable" and 161 fell into areas modeled as "suitable". In total, 322 of the 395 observations - $81.3 \%$ - were in areas with favorable modeled suitability. This is somewhat to be expected, since locations were used to build the model. Only 73 (18.7\%) locations were in habitat modeled as less favorable. A true test of our model would be to take an independent set of locations (not those used to build the model) and test them in the model. We also note that our model does not make statements or predictions about areas that are modeled suitable bighorn sheep habitat where there are no bighorn sheep locations. We do not know why sheep do not appear to be using these areas. We suggest additional fieldwork and investigations with more statistical evaluations to answer that question.

\section{Winter Habitat Suitability Model}

Much like the summer locations, bighorn sheep are clustered near the edge of Bighorn Canyon primarily near the lower end of the Park but also scattered along the canyon edge upwards towards the north in winter (Figure 4). Winter model results also appear in Table 1. Only three variables - elevation, distance to escape terrain, and vegetation - were significant in the model. In the combined model with these three variables, sheep preferred lower elevations, and closeness to escape terrain. In the vegetation categories, again, sagebrush was held as the 


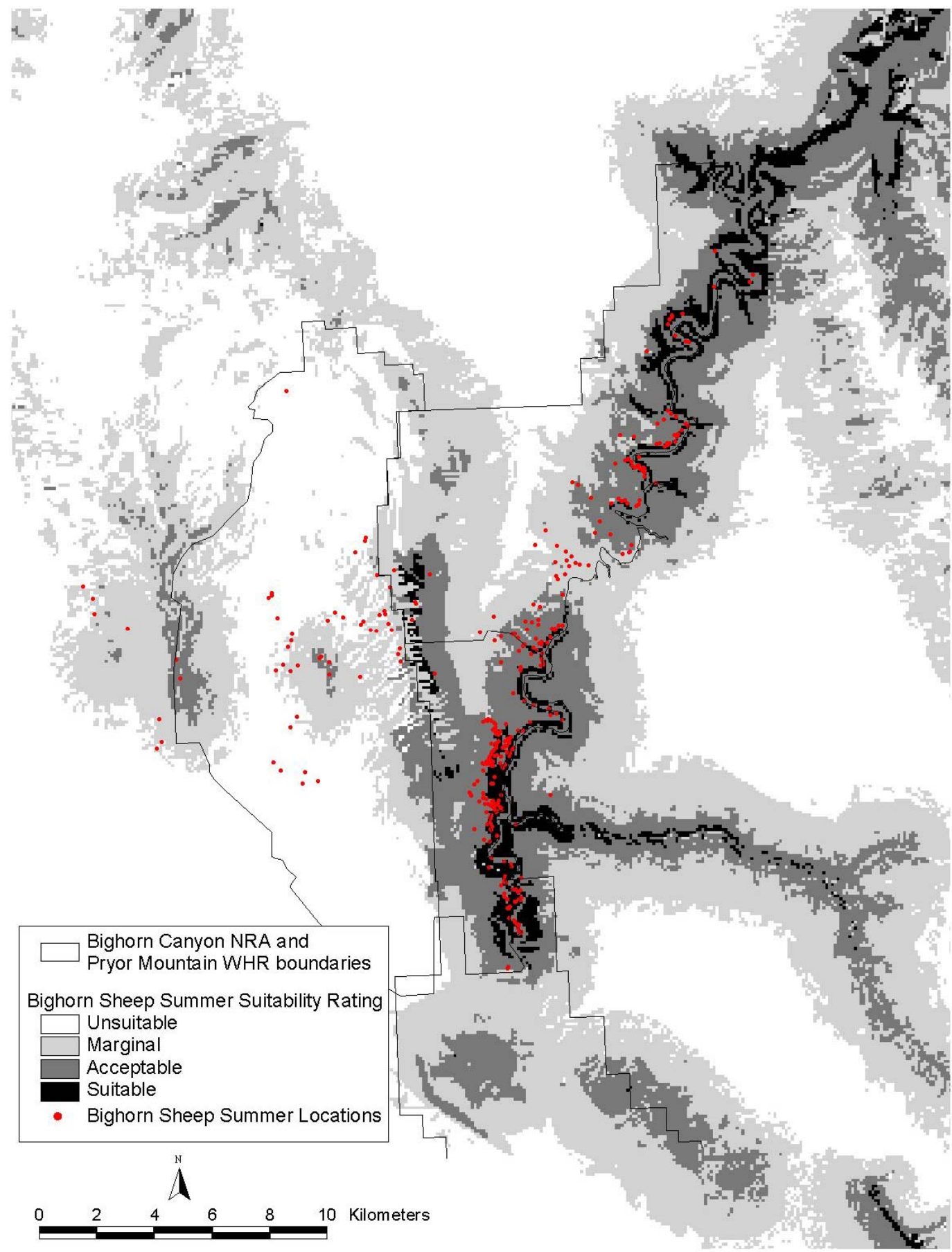

Figure 5. Bighorn sheep summer habitat suitability ratings with sheep locations. Dark colored areas that do not contain red dots represent unused, but favorable (suitable plus acceptable) habitat. 
Table 2. Percent of bighorn sheep observations found in suitable and acceptable bighorn sheep habitat in both models for BICA and surrounding lands.

\begin{tabular}{lcccc}
\hline & \multicolumn{3}{c}{ Bighorn Sheep Model Criteria } \\
\hline & $\begin{array}{c}\text { Number of } \\
\text { observations in } \\
\text { suitable }\end{array}$ & $\begin{array}{c}\text { Number of } \\
\text { observations in } \\
\text { acceptable }\end{array}$ & Total observations & $\begin{array}{c}\text { Percent of observations in } \\
\text { suitable or acceptable }\end{array}$ \\
\cline { 2 - 5 } $\begin{array}{l}\text { Summer (Animal } \\
\text { Location-Based } \\
\text { Model) }\end{array}$ & 161 & 160 & 395 & 81.3 \\
$\begin{array}{l}\text { Winter (Animal } \\
\text { Location-Based }\end{array}$ & 100 & 85 & 222 & 83.3 \\
$\begin{array}{l}\text { Model) } \\
\text { Summer } \\
\text { Intermountain- }\end{array}$ & & & 395 & 20.8 \\
$\begin{array}{l}\text { West Model) } \\
\text { Winter } \\
\text { (Intermountain- }\end{array}$ & 82 & & & \\
West Model) & 39 & & 222 & 17.6 \\
\hline
\end{tabular}

constant variable while all other categories were compared to it. In this comparison, the category named mountainmahogany/juniper had the highest positive effect, with juniper, riparian, and grassland also having positive effects. Forest and mixed shrub had negative effects compared to sagebrush, and thus they are considered less favorable habitat for bighorn sheep than sagebrush and the four types with positive effects.

Figure 6 depicts the habitat suitability map for bighorn sheep in the winter. As per the quantitative model results in Table 1, the map shows darker areas where suitability is highest which spatially coincide with variables listed in Table 1. Darker areas are primarily at lower elevations that are close to escape terrain, and primarily in the vegetation types of mountain-mahogany/juniper, riparian, juniper, and grassland. Any habitat manipulations which increased these four favorable vegetation types while being in proximity to the other two favorable variables (lower elevations and close to escape terrain) would likely increase the area of suitable winter bighorn sheep habitat. Additionally, Figure 6 allows us to find areas that are underutilized by the current distribution of bighorn sheep. Sheep locations are depicted by red dots. Black areas that occur without nearby red dots can be interpreted as underutilized habitat. These areas have the ability to support animals but our model does not address why animals do not appear to be found there.

Table 2 allows us to see how well the model fits the currently mapped sheep locations. There were a total of 222 winter sheep observations. Of those 222, 85 fell into areas modeled as "acceptable" and 100 fell into areas modeled as "suitable." In total then, 185 of the 222 observations - $83.3 \%$ - were in areas with favorable modeled suitability. Thirty-seven observations $(16.7 \%)$ were in areas rated as less favorable in the model.

\section{Comparison of the Animal Location-Based Model with the Intermountain West Generic Model}

We compared the animal location-based model described in this report to another bighorn sheep habitat suitability model, developed by Smith and others (1991) and Gudorf (2002). The Smith and others (1991) model is a broad-based intermountain-west model, covering several states. Gudorf (2002) modified Smith and others (1991) to create a model specific to BICA. The animal location-based bighorn sheep habitat suitability model (this report) is a modification of van Manen and Pelton (1997).

Figure 7 and Figure 8 compare bighorn sheep model suitability as predicted by the two different models for both summer and winter, respectively. In the figures, red hatched areas are predicted as suitable by the Intermountain-West Model, while black areas are predicted as suitable by the Animal Location-Based Model. 


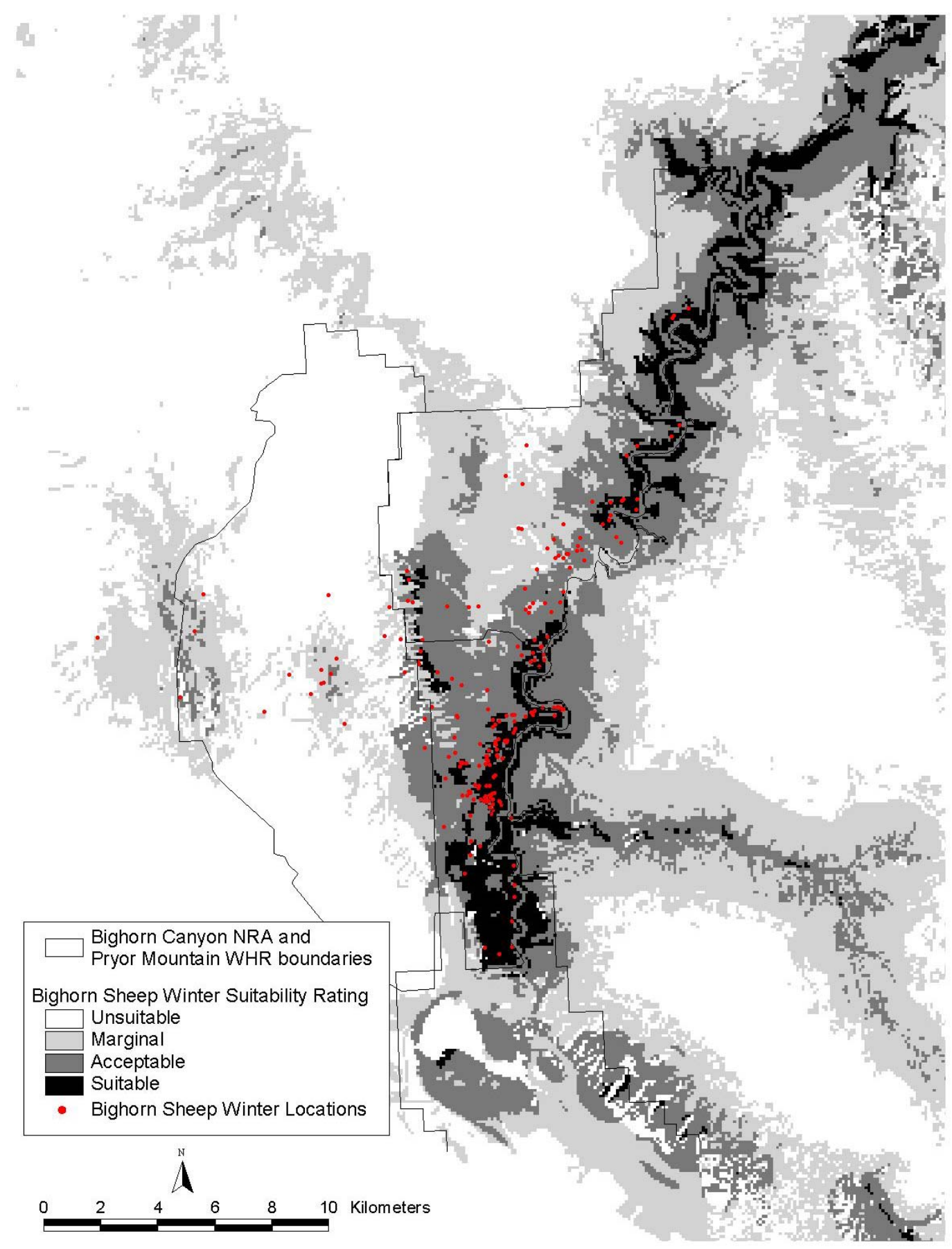

Figure 6. Bighorn sheep winter habitat suitability ratings with sheep locations. Dark colored areas that do not contain red dots represent unused, but favorable (suitable plus acceptable) habitat. 


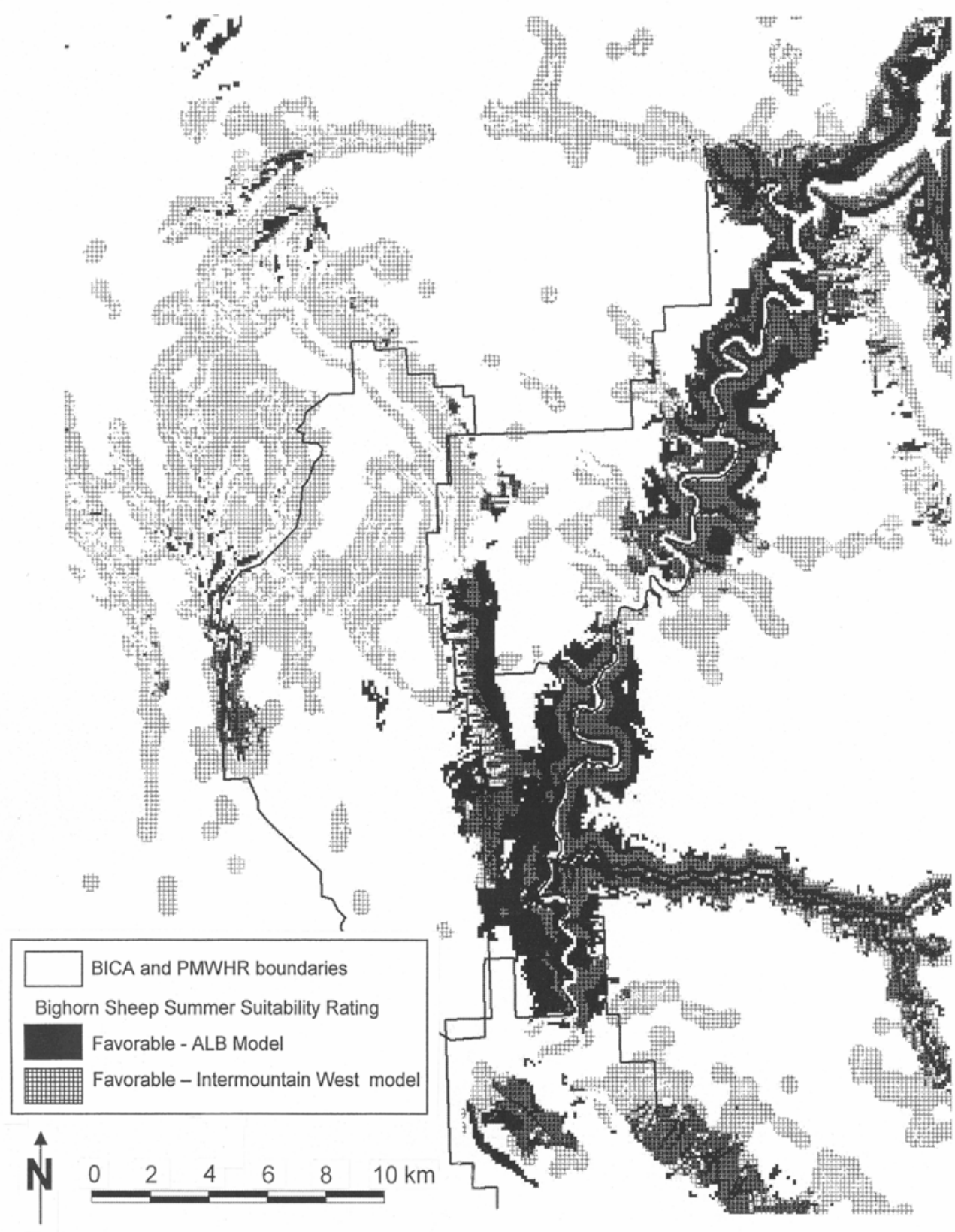

Figure 7. Bighorn sheep summer habitat suitability ratings compared for the Animal Location-Based (ALB) model and the Intermountain West model. 


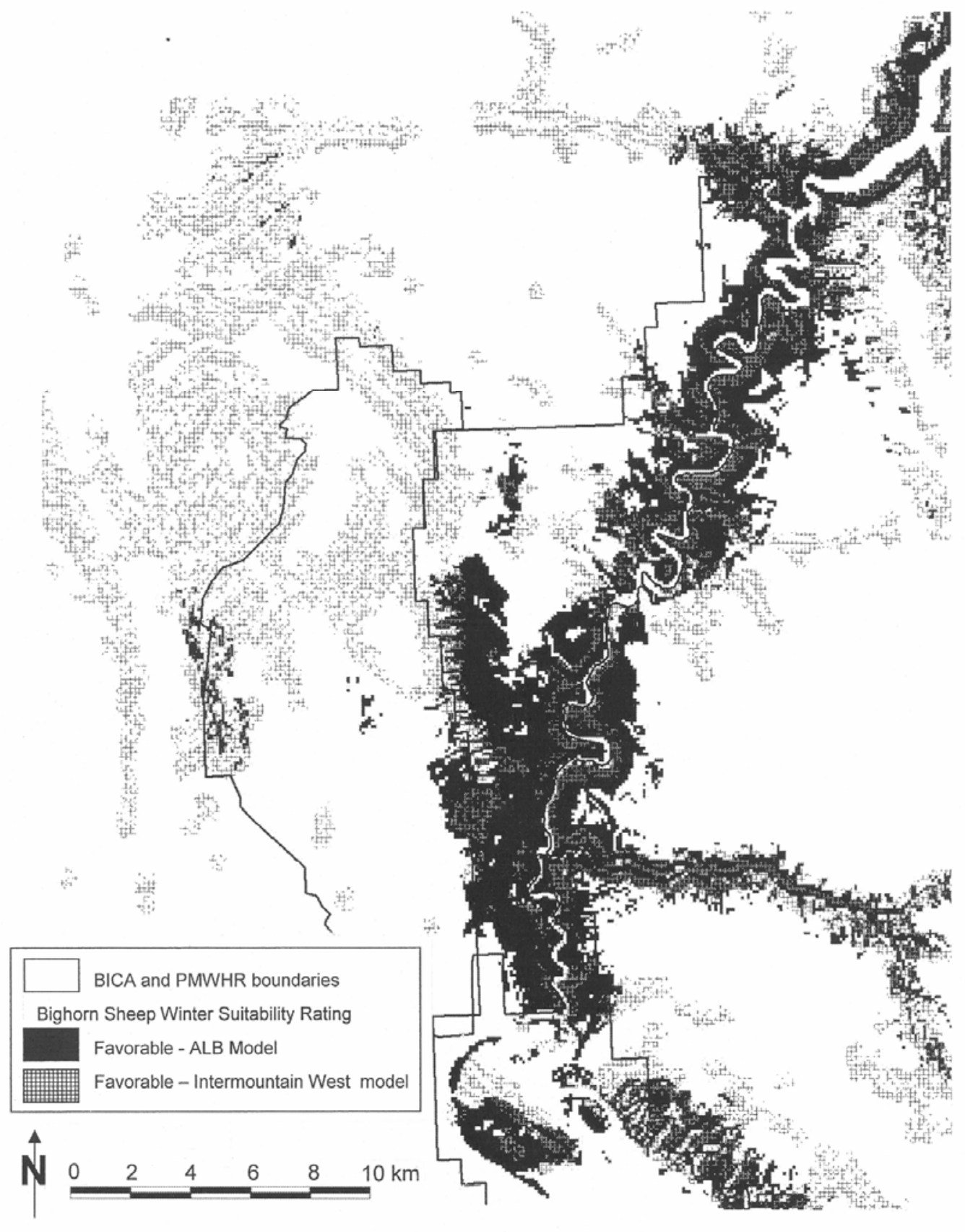

Figure 8. Bighorn sheep winter habitat suitability ratings compared for the Animal Location-Based (ALB) model and Intermountain West model. 
The Intermountain-West Model operates quite differently than the Animal Location-Based Model. Whereas the Animal Location-Based Model uses actual sheep locations to predict suitability, the Intermountain-West Model does not use sheep locations, and uses a progressive reduction process as outlined in Gudorf (2002). This "progressive reduction" involves a process of elimination, where land area is systematically removed from consideration if it does not meet specific criteria for bighorn sheep habitat; criteria obtained from the literature. Remaining land areas may be considered suitable bighorn sheep habitat. Patches of habitat deemed suitable must be of sufficient size to sustain a viable population or must occur in proximity, so that the combined area would support a viable metapopulation. This progressive reduction process was originally developed as a more generalized rangewide model, then refined by using sheep locations at other bighorn habitats in Utah, Wyoming, and Colorado, and finally, adapted to the BICA by Gudorf and others (1996) and Gudorf (2002).

There are two primary differences in the models that account for the discrepancies in Figures 7 and 8 . The first discrepancy exists along Bighorn Canyon where the Animal Location-Based Model predicts large areas of suitable habitat while the Intermountain-West Model predicts much smaller, patchier suitability. This is due to the use of horizontal visibility as a variable in the Intermountain-West Model, which removes vegetation types that have a horizontal visibility for bighorn sheep lower than $62 \%$. Horizontal visibility is the percent of area within a set distance that sheep can see without obstruction to detect predators and is a key requirement for bighorn sheep habitat, since bighorn sheep rely primarily on sight to detect predators. Several studies have tried to quantify and test the horizontal visibility requirements for bighorn sheep (Table 3 ). The visibility rating for each vegetation type in BICA was measured using methods of Johnson and Swift (1995) and used by Gudorf (2002) for her analysis. One of the vegetation types in the Knight and others (1987) vegetation map, "juniper-mountain mahogany woodland," had a visibility rating of 55\% and was thus removed from suitability in the Intermountain-West Model. In comparing the Animal Location-Based and Intermountain-West Models, large areas of this vegetation type exist along the canyon in BICA, especially nearer to the southern end. These areas are included in the Animal Location-Based Model but excluded in the Intermountain-West Model.

The second difference exists around the northern and eastern sides of the wild horse range where the Intermountain-West Model includes large areas that are not included in the Animal Location-Based Model. These areas are included in the Intermountain-West Model because its criteria find these areas close enough to escape terrain and water sources while also having adequate visibility. The Animal Location-Based Model, however, does not include these areas because the vegetation categories were not preferred, distance to escape terrain was too far, and elevations too high.

Table 3. Primary sources of information on horizontal visibility for suitable habitat for bighorn sheep.

\begin{tabular}{ll}
\hline \multicolumn{1}{c}{ Source } & \multicolumn{1}{c}{ Description } \\
\hline Smith and others (1991) & $\begin{array}{l}\text { Original study that developed methodology for } \\
\text { determining horizontal visibility for bighorn sheep in the } \\
\text { field. Recommends visibility }>80 \% \text { for bighorn sheep. }\end{array}$ \\
& $\begin{array}{l}\text { A test and modification of habitat evaluation procedures. } \\
\text { Johnson and Swift (2000) }\end{array}$ \\
& $\begin{array}{l}\text { Modified recommended visibility upwards to }>62 \% \text { for } \\
\text { bighorn sheep based on study area tests. }\end{array}$ \\
& $\begin{array}{l}\text { Tested a modified Smith and others (1991) model against } \\
\text { translocation success. }\end{array}$ \\
Zeigenfuss and others (2000) & $\begin{array}{l}\text { Management of bighorn sheep herds in Colorado. Tests } \\
\text { visibility and makes recommendations for opening up } \\
\text { habitats in all 3 studies. }\end{array}$ \\
Railey (1990) & \\
\hline
\end{tabular}

A comparison of the Animal Location-Based and Intermountain-West Models for the BICA summer and winter habitat appears in Table 2. Of the 395 summer observations, 82, or 20.8\%, fell into the areas predicted as "suitable" in the Intermountain-West Model, and of the 222 winter observations, 39, or 17.6\%, fell into areas predicted as "suitable" in the Intermountain-West Model. Both models have utility. A generic model for a 3-state 
area is very useful and applicable in that setting, while an animal location-based model may be more useful to a specific herd, as in this case.

\section{Bighorn Sheep Habitat Use}

In order to test whether bighorn sheep were using habitat types in proportion to their availability (Table 4a,b), we used a chi-square test following Neu and others (1974) and Byers and others (1984). We found that the expected number of bighorn sheep groups using various habitat types differed significantly $(P<0.0001)$ from the observed number of bighorn sheep groups using different vegetation types in both winter and summer. We examined several comparisons between observed and expected occurrence of bighorn sheep groups in order to detect preference or avoidance of specific habitat types (Neu and others, 1974; Table 4a,b). When we evaluated each habitat type, we found that in summer, mixed shrub, sagebrush, juniper, and forest habitat types are used less than expected based on available habitat, while mountain mahogany and riparian areas were used more than expected based on available habitat (Table 4a). Bighorn sheep appear to be using grassland habitats in summer proportional to its availability. This suggests that bighorn sheep in BICA are selecting mountain mahogany habitats and riparian areas over other habitats as a preferred habitat types in summer.

In winter (Table 4b), bighorn sheep used mixed shrub, sagebrush, grassland, and forest habitat types less than their availability. As in summer, sheep used mountain mahogany and riparian areas more than expected based on available habitat. In winter they used juniper habitat in proportion to its availability, unlike summer when they used it less than its availability, suggesting juniper is a habitat type they rely upon to get through winter months.

Our findings suggest that bighorn sheep in BICA prefer mountain mahogany in both winter and summer over other types. This is also somewhat inconsistent with other studies that have found that bighorn sheep prefer sagebrush habitats over other vegetation types. It may be that much of the sage habitat in the park and surrounding lands is too far from escape terrain or has other negative factors that preclude bighorns from selecting it.

\section{Bighorn Sheep Habitat Improvement Scenarios}

Bighorn sheep summer habitat factors include, slope, and distance to escape terrain, elevation, and vegetation. The first three of these factors are fixed geophysical features that cannot be manipulated by managers. The fourth, vegetation, can be changed using various means including burning, clearing, planting, reseeding, etc. From Table 1, we see that mountain mahogany/juniper has the highest quantitative effect in the regression equation.

The quantitative results in Table 1 can be ranked according to the degree of effect the change in vegetation type would have on habitat suitability. Table 5 ranks the vegetation types in three levels. Mountain mahogany/juniper, all riparian, juniper, and all grassland have the highest values and receive the highest rank. Sagebrush and mixed shrub have similar but lower values and are ranked second. All forested has the lowest value and rank.

As an example of treatable areas, Figure 9a depicts map-cells that are not already "Suitable" or "Acceptable" in summer but could become so if treatments occurred. Areas in Figure 9a that are color-coded are close enough to escape terrain, have adequate slopes, and low enough elevations to become suitable given vegetation treatments. The four color-coded vegetation types in Figure 9a are juniper, sagebrush, mixed shrub, and all forested. The same methods were used to create Figure 9b, which depicts areas in winter which could become suitable given vegetation treatments.

Although the ranking in Table 5 provides general information derived from the logistic regression model, specific recommendations for treatments come from additional sources beyond the model (Table 6). Recommended treatments and the management priority of those treatments are described in Table 6 and the text that follows. 
Table 4. Occurrence of bighorn sheep observations in 7 habitat types in: (a) summers 2000 to 2002, and (b) winters 1999-2000 to 2001-2002, in Bighorn Canyon National Recreation Area and surrounding lands, Wyoming and Montana. * indicates a significant difference at the 0.05 level between expected and observed use of habitat type.

4a

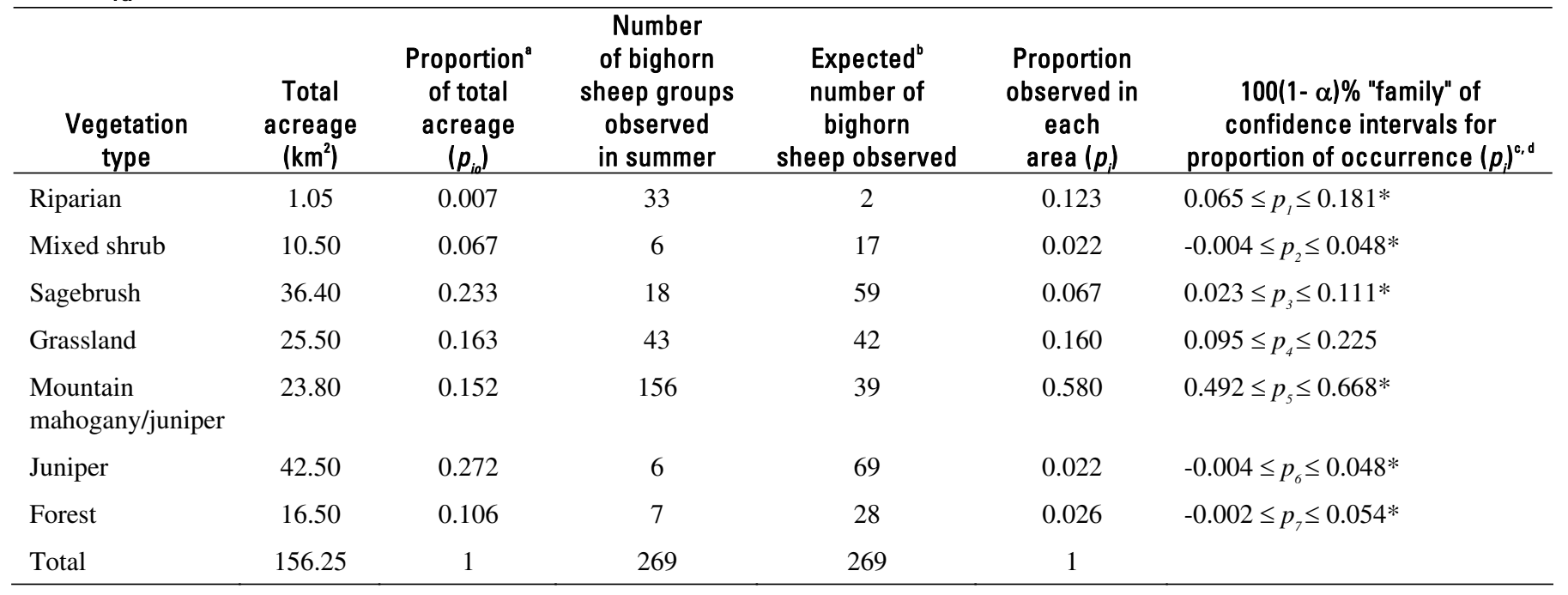

$4 \mathrm{~b}$

\begin{tabular}{|c|c|c|c|c|c|c|}
\hline $\begin{array}{c}\text { Vegetation } \\
\text { type }\end{array}$ & $\begin{array}{l}\text { Total } \\
\text { acreage } \\
\left(\mathrm{km}^{2}\right)\end{array}$ & $\begin{array}{c}\text { Proportion }{ }^{\mathrm{a}} \\
\text { of total } \\
\text { acreage } \\
\left(p_{i_{0}}\right)\end{array}$ & $\begin{array}{c}\text { Number } \\
\text { of bighorn } \\
\text { sheep groups } \\
\text { observed in } \\
\text { winter }\end{array}$ & $\begin{array}{c}\text { Expected }^{b} \\
\text { number of } \\
\text { bighorn sheep } \\
\text { groups }\end{array}$ & $\begin{array}{c}\text { Proportion } \\
\text { observed in each } \\
\text { area }\left(p_{i}\right)\end{array}$ & $\begin{array}{c}100(1-\alpha) \% \text { "family" of } \\
\text { confidence intervals for } \\
\text { proportion of occurrence }\left(p_{i}\right)\end{array}$ \\
\hline Riparian & 1.05 & 0.007 & 13 & 2 & 0.059 & $0.012 \leq p_{1} \leq 0.105^{*}$ \\
\hline Mixed shrub & 10.50 & 0.067 & 1 & 18 & 0.005 & $-0.009 \leq p_{2} \leq 0.019^{*}$ \\
\hline Sagebrush & 36.40 & 0.233 & 14 & 63 & 0.063 & $0.016 \leq p_{3} \leq 0.110^{*}$ \\
\hline Grassland & 25.50 & 0.163 & 18 & 44 & 0.081 & $-0.028 \leq p_{4} \leq 0.134^{*}$ \\
\hline $\begin{array}{l}\text { Mountain } \\
\text { mahogany/juniper }\end{array}$ & 23.80 & 0.152 & 89 & 41 & 0.400 & $0.304 \leq p_{5} \leq 0.496^{*}$ \\
\hline Juniper & 42.50 & 0.272 & 80 & 73 & 0.360 & $0.266 \leq p_{6} \leq 0.454$ \\
\hline Forest & 16.50 & 0.106 & 7 & 28 & 0.032 & $-0.002 \leq p_{7} \leq 0.066^{*}$ \\
\hline Total & 156.25 & 1 & 222 & 222 & 1 & \\
\hline
\end{tabular}

${ }^{\mathrm{a}}$ Proportion of total acreage represents expected bighorn sheep observation values if bighorn sheep occurred in each habitat in exact proportion to availability.

${ }^{\mathrm{b}}$ Calculated by multiplying proportion of acreage by sample size $\left(p_{i o} \times n\right)$; i.e., $0.106 \times 269=28$.

${ }^{\mathrm{c}} p_{i}$ represents theoretical proportion of occurrence and is compared to corresponding $p_{i o}$ (acreage) to determine if hypothesis of proportional use is accepted or rejected, i.e., $p_{i}=p_{i o}$

${ }^{\mathrm{d}}$ Byers and others (1984); Bonferroni correction applied. 


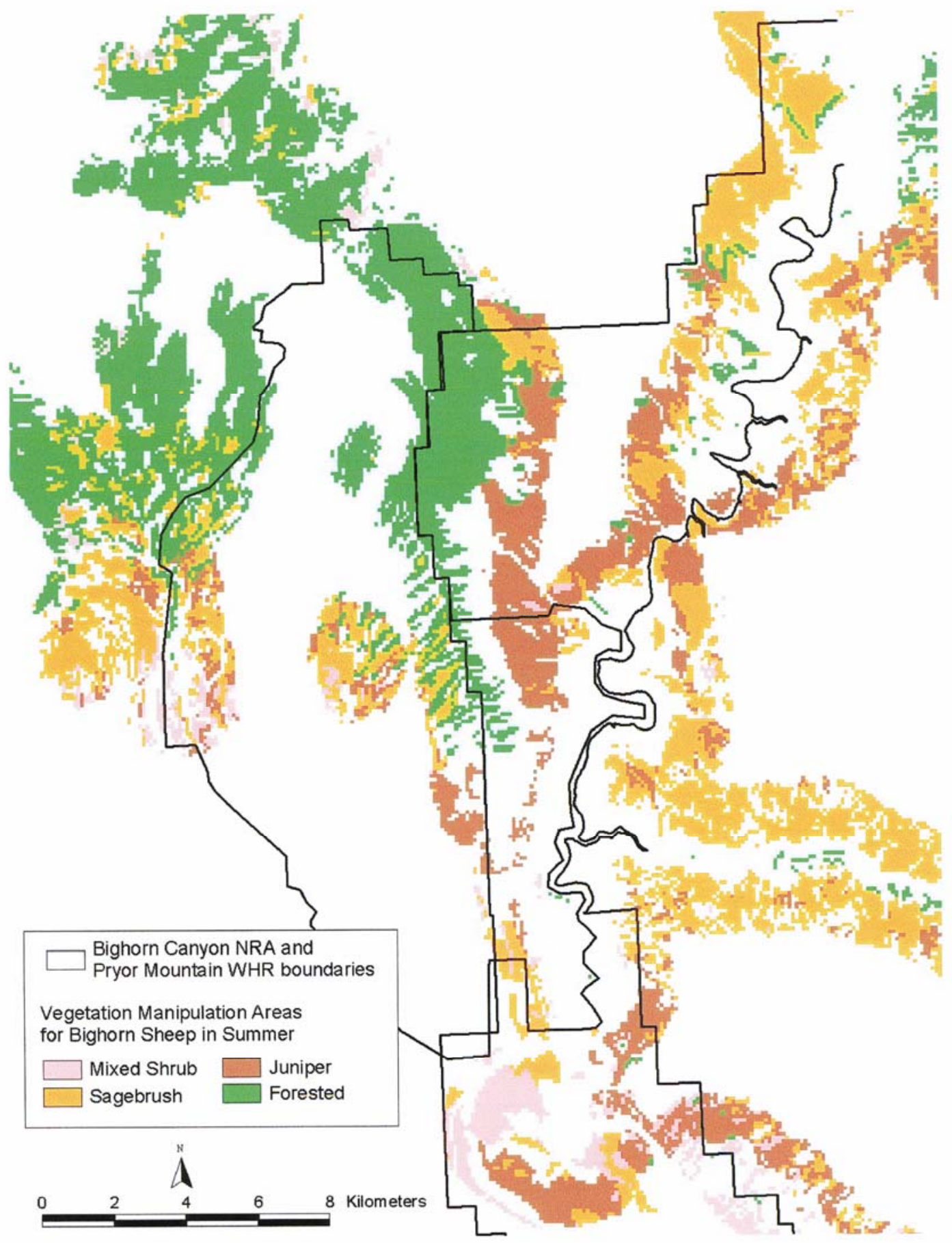

Figure 9a. Vegetation types and locations that could become suitable or acceptable summer bighorn sheep habitat if treatments occurred. Treatments might include clearing, burning, reseeding, etc. 


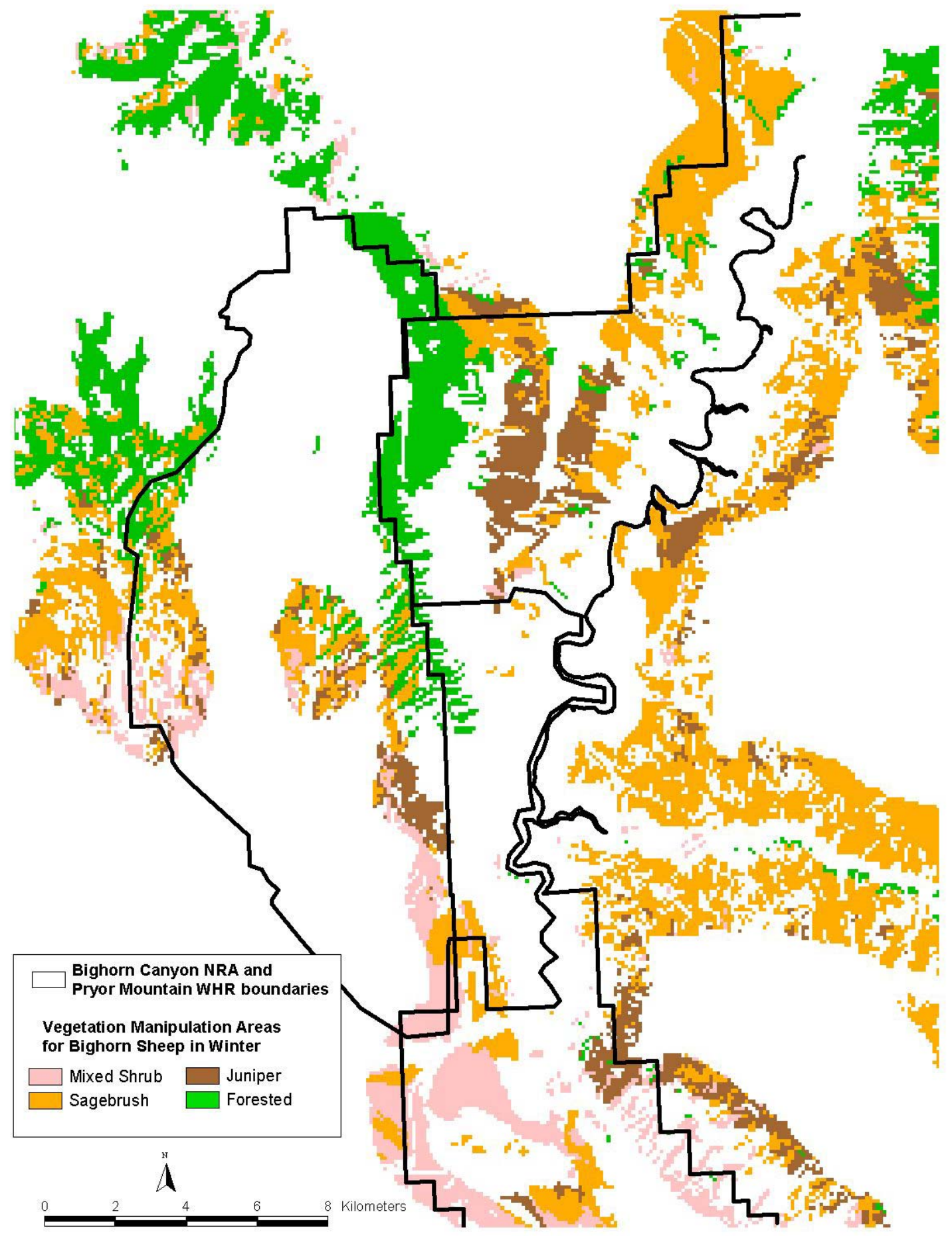

Figure 9b. Vegetation types and locations that could become suitable or acceptable winter bighorn sheep habitat if treatments occurred. Treatments might include clearing, burning, reseeding, etc. 
Table 5. Suitability rank for vegetation manipulations for bighorn sheep.

\begin{tabular}{ll}
\hline Rank & Vegetation type \\
\hline 1. (high) & $\begin{array}{l}\text { Mountain Mahogany/Juniper } \\
\text { All Riparian } \\
\text { Juniper } \\
\end{array}$ \\
& All Grassland \\
& $\begin{array}{l}\text { Sagebrush } \\
\text { Mixed Shrub }\end{array}$ \\
& All Forested \\
\hline
\end{tabular}

Of the vegetation types in Table 6 that could be treated and yield a benefit to bighorns, several deserve greater discussion:

Mountain Mahogany — Burning of mature mountain mahogany stands may provide some benefits to bighorn sheep even though mature patches are already a preferred type. Mountain mahogany is not dependent on fire, and seedlings will germinate around a mature canopy, although mountain mahogany typically resprouts strongly following burning. In one study, only $25 \%$ of the plants died following burning and the shrubs showed an increase in production following the fire (Cook and others, 1994). The stands would be opened up for a few years and the herbaceous understory might increase in forage quality (Cook and others, 1994). In a few cases, more mountain mahogany plants died following burning (Arno and others, 1986).

We recommend the burning of pure mountain mahogany stands as a low priority, since the stands will not increase in area, and seedlings can already germinate under mature shrubs. However, burning of mixed mountain mahogany-juniper is a moderate priority for bighorn sheep - substantial areas of a preferred type could be opened up. Because burning effects are variable from area to area, we suggest an experimental approach.

Juniper Woodland - The highest priority for park management is the burning or clearing of select dense juniper patches. Some open juniper patches are already highly suitable habitat. However, the more dense patches will not be used. These could be burned or cleared and very substantial amounts of newly suitable habitat could be created. Managers could identify those stands that would benefit by treatment, characterized by areas of horizontal visibility $<62 \%$ (Johnson and Swift, 2000). Treatment effects will be quite long-lived and thus should be a high priority. These same statements will apply to xeric open forest stands.

Sagebrush Steppe - Bighorn sheep habitat could be increased considerably by the burning or clearing of tall, dense big sagebrush. Big sagebrush does not resprout and is readily killed by fire (Blaisdell, 1953). The patch is opened up and grass and forb forages may increase (Perryman and others, 2002). Burning may reduce the sagebrush canopy for more than 16 years, and take 25-30 years to re-establish pre-burn conditions (Wambolt and others, 2001). Thus, treatment effects are only of moderate duration.

Grassland - Low priority for treatment. The habitat is already open and suitable for bighorn sheep. A flush of nutrients and increased biomass from the burning may be desirable, but short-lived — typically only $2-3$ years duration.

Mixed Shrub - The benefits from burning will be similar to that for sagebrush steppe. These stands are typically denser. The big sagebrush and bitterbrush will be reduced by burning, opened up, and forages benefited. Some of the bitterbrush will resprout (Blaisdell and Mueggler, 1956; Clark and others, 1982), and will then reseed onto the site, over a period of a few years (Daubenmire and Daubenmire, 1968). Again, there is very little of this type on the BICA study area in areas that have other habitat attributes for bighorn sheep, so there is little potential for management. 
Table 6. Burning treatments to conduct in BICA and surrounding lands, Wyoming and Montana, to improve habitat for bighorn sheep. Treatments should only occur in vegetation types where criteria of slope, aspect and elevation are suitable, since these criteria are fixed and can not be modified (Figure 9).

\begin{tabular}{|c|c|c|c|c|c|c|c|}
\hline $\begin{array}{l}\text { Current } \\
\text { suitability } \\
\text { rank of } \\
\text { untreated } \\
\text { vegtype } \\
\end{array}$ & $\begin{array}{l}\text { Pre-burn } \\
\text { vegtype }\end{array}$ & $\begin{array}{l}\text { Immediate } \\
\text { post burn }\end{array}$ & $\begin{array}{c}\text { Management } \\
\text { decision to } \\
\text { treat }\end{array}$ & $\begin{array}{c}\text { Benefit to } \\
\text { bighorns } \\
\text { of } \\
\text { treatment }\end{array}$ & $\begin{array}{l}\text { Long-term } \\
\text { post burn }\end{array}$ & Comments & Source \\
\hline High & $\begin{array}{l}\text { Mature } \\
\text { mountain } \\
\text { mahogany } \\
\text { stands }\end{array}$ & $\begin{array}{l}\text { Mountain } \\
\text { mahogany } \\
\text { root } \\
\text { resprouts }\end{array}$ & Low & $\begin{array}{l}\text { Low to } \\
\text { moderate }\end{array}$ & $\begin{array}{l}\text { Mature } \\
\text { mountain } \\
\text { mahogany } \\
\text { stands }\end{array}$ & $\begin{array}{l}\text { Mature mountain } \\
\text { mahogany already a } \\
\text { preferred type for } \\
\text { bighorn sheep; some } \\
\text { benefits from } \\
\text { burning, especially } \\
\text { when mixed with } \\
\text { junipers. }\end{array}$ & $\begin{array}{l}\text { Arno and } \\
\text { others } \\
\text { (1986); } \\
\text { Cook and } \\
\text { others } \\
\text { (1994); } \\
\text { Schultz and } \\
\text { others } \\
\text { (1996); } \\
\text { Ibanex and } \\
\text { Schupp } \\
\text { (2001) }\end{array}$ \\
\hline High & $\begin{array}{l}\text { Juniper } \\
\text { woodland }\end{array}$ & $\begin{array}{l}\text { Open } \\
\text { grassland }\end{array}$ & $\begin{array}{l}\text { High for those } \\
\text { stands with } \\
\text { limited } \\
\text { horizontal } \\
\text { visibility }\end{array}$ & High & $\begin{array}{l}\text { After } \geq 50 \\
\text { years, } \\
\text { juniper } \\
\text { stand will } \\
\text { recover }\end{array}$ & $\begin{array}{l}\text { Some juniper stands } \\
\text { are already open } \\
\text { enough to provide } \\
\text { suitable habitat to } \\
\text { bighorns. Dense } \\
\text { patches would } \\
\text { become suitable } \\
\text { habitat if burned or } \\
\text { cleared. }\end{array}$ & \\
\hline Medium & $\begin{array}{l}\text { Sagebrush } \\
\text { steppe }\end{array}$ & Grassland & High & High & $\begin{array}{l}\text { After } 20 \\
\text { years, } \\
\text { sagebrush } \\
\text { steppe }\end{array}$ & $\begin{array}{l}\text { Tall sagebrush } \\
\text { communities will be } \\
\text { opened up and will } \\
\text { be more suitable to } \\
\text { bighorns. Short } \\
\text { stature and open } \\
\text { sagebrush stands } \\
\text { would not benefit } \\
\text { greatly by treatment. }\end{array}$ & $\begin{array}{l}\text { Blaisdell } \\
(1953) ; \\
\text { Wambolt } \\
\text { and others } \\
(2001) ; \\
\text { Perryman } \\
\text { and others } \\
(2002)\end{array}$ \\
\hline Low & $\begin{array}{l}\text { Mesic } \\
\text { dense } \\
\text { forest }\end{array}$ & $\begin{array}{l}\text { New } \\
\text { conifers } \\
\text { would } \\
\text { rapidly } \\
\text { reseed onto } \\
\text { site }\end{array}$ & Low & $\begin{array}{l}\text { Low/No } \\
\text { benefit }\end{array}$ & Conifers & $\begin{array}{l}\text { Any benefit to } \\
\text { bighorns would be } \\
\text { very brief as tree } \\
\text { seedlings quickly } \\
\text { recover on the site. }\end{array}$ & \\
\hline Low & $\begin{array}{l}\text { Xeric open } \\
\text { forest }\end{array}$ & $\begin{array}{l}\text { Grassland } \\
\text { for } \sim 20 \\
\text { years }\end{array}$ & High & High & $\begin{array}{l}\text { In } 20 \text { years, } \\
\text { open forest } \\
\text { recovers }\end{array}$ & $\begin{array}{l}\text { An excellent type for } \\
\text { treatment. Challenges } \\
\text { to managing the fire } \\
\text { due to heavier fuel } \\
\text { loadings. }\end{array}$ & $\begin{array}{l}\text { Coughenour } \\
\text { (1999) }\end{array}$ \\
\hline
\end{tabular}


Table 6. Continued.

\begin{tabular}{|c|c|c|c|c|c|c|c|}
\hline $\begin{array}{l}\text { Current } \\
\text { suitability } \\
\text { rank of } \\
\text { untreated } \\
\text { vegtype }^{1} \\
\end{array}$ & $\begin{array}{l}\text { Pre-burn } \\
\text { vegtype }\end{array}$ & $\begin{array}{l}\text { Immediate } \\
\text { post burn }\end{array}$ & $\begin{array}{l}\text { Management } \\
\text { decision to } \\
\text { treat }\end{array}$ & $\begin{array}{l}\text { Benefit to } \\
\text { bighorns } \\
\text { of } \\
\text { treatment }\end{array}$ & $\begin{array}{l}\text { Long-term } \\
\text { post burn }\end{array}$ & Comments & Source \\
\hline Medium & $\begin{array}{l}\text { Mixed } \\
\text { shrub }\end{array}$ & Grassland & High & High & $\begin{array}{l}\text { Shrub stand } \\
\text { opened up } \\
\text { for } 15-20 \\
\text { years }\end{array}$ & $\begin{array}{l}\text { Very little mixed shrub } \\
\text { vegetation type exists on } \\
\text { the BICA study area in } \\
\text { areas that also have } \\
\text { other habitat attributes } \\
\text { for bighorn sheep, so } \\
\text { less potential for } \\
\text { management. }\end{array}$ & $\begin{array}{l}\text { Clark and } \\
\text { others } \\
\text { (1982); } \\
\text { Blaisdell } \\
\text { and } \\
\text { Mueggler } \\
(1956)\end{array}$ \\
\hline High & Riparian & $\begin{array}{l}\text { Resprouting of } \\
\text { willows, } \\
\text { cottonwoods, } \\
\text { and other } \\
\text { riparian shrubs }\end{array}$ & Low & Low & $\begin{array}{l}\text { Riparian } \\
\text { community }\end{array}$ & $\begin{array}{l}\text { Open riparian patches } \\
\text { are already suitable to } \\
\text { bighorns. New riparian } \\
\text { areas cannot be created } \\
\text { by treatments, but } \\
\text { visibility can be } \\
\text { improved where there } \\
\text { are tall shrubs or trees. A } \\
\text { small amount of new } \\
\text { feeding areas or } \\
\text { movement corridors } \\
\text { could be created by } \\
\text { treatment, but overall } \\
\text { amount of treatable } \\
\text { patches are limited by } \\
\text { low abundance of } \\
\text { riparian areas in BICA. }\end{array}$ & \\
\hline Medium & Grassland & Grassland & Low & Low & Grassland & $\begin{array}{l}\text { Some very short term } \\
\text { benefits to forage } \\
\text { biomass and quality } \\
\text { could occur. }\end{array}$ & $\begin{array}{l}\text { Hobbs } \\
\text { and } \\
\text { Spowart } \\
(1984)\end{array}$ \\
\hline
\end{tabular}

${ }^{1}$ Based on habitat suitability ratings of the Animal Location-Based model (this report).

Caveats to Burning Treatments - We suggest keeping the following things in mind regarding the feasibility of burning treatments.

- Some drier types may not be burnable due to lack of fuel.

- Burning off dominant woody plants, such as mountain mahogany may be inadvisable. It takes a long time to grow mountain mahogany in those habitats, and in fact those habitats are better adapted for mountain mahogany than grass, which would be unlikely to replace it. Moreover, mountain mahogany is a primary diet item for bighorn sheep in this herd.

- In mesic dense forest, new conifers may not rapidly reseed onto the site after burning, and grass may not grow in some of those habitats due to poor soils.

- Soil sampling and/or analysis by a range ecologist is recommended before any burning treatments occur.

In many of the vegetation types, thinning to improve visibility will yield benefits to bighorns. Several studies (summarized in Table 3) have documented the effect that visibility has on bighorn behavior and habitat. Given this research and the goals of BICA to increase bighorn habitat, locating and thinning dense vegetation in stands of mountain mahogany, juniper, sagebrush, and riparian areas will likely increase habitat. Work by Schoenecker and others (2004) showed that visibility is different even within the same vegetation types in different 
parts of the bighorn sheep range in Bighorn Canyon. Therefore, we recommend more field work to determine which specific areas should be treated by thinning. The fact that one visibility rating was used in our model for each vegetation type across the entire study area, even though multiple visibility ratings are occurring within the same vegetation type, is a problem that can be addressed only by considerable field measurements. Once this data is available, our model can be modified to incorporate a more precise representation of horizontal visibility.

\section{Results and Discussion for Wild Horses}

\section{Current Summer Habitat Selections and Distributions of Wild Horses}

In summer, wild horses are clustered at the north end of the range in areas predominated by grassland and riparian vegetation, and also clustered along the eastern edge of the range nearer to Bighorn Canyon (Figure 3). Summer model results are given in Tables 1 and 7. In the summer model, all variables - vegetation, canopy cover, elevation, slope, aspect, and distance to water - were significant in the multiple logistic equation. Horses preferred higher elevations, areas closer to water sources, flatter slopes, southerly facing aspects, more open forest canopies, and open non-forest vegetation types (non-forested, grassland and shrubs). Habitat manipulations which increase water availability in non-forested areas would likely increase the amount of suitable habitat for wild horses. As suggested by the single variable regression output in Table 7, habitat manipulations which increased the amount of useable grassland and riparian vegetation would have the largest effect.

Figure 10 depicts the habitat suitability map for wild horses in summer. As per the quantitative model results in Table 1, the map shows darker areas where suitability is highest which spatially coincide with variables listed in Table 1. Additionally, Figure 10 allows us to find areas that are underutilized by the current distribution of wild horses. Horse locations are depicted by red dots. Black areas that occur without nearby red dots can be interpreted as underutilized habitat.

Table 7. Single variable regression output for bighorn sheep and wild horse, summer and winter models.*

\begin{tabular}{lllll}
\hline & \multicolumn{2}{c}{ Bighorn Sheep } & \multicolumn{2}{c}{ Wild Horses } \\
\cline { 2 - 5 } & Summer & Winter & Summer & Winter \\
\hline Variable & Coefficients & & & \\
Distance to water & -0.00066 & -0.00045 & -0.00098 & 0.000315 \\
Aspect & 0.2825 & 0.4118 & -0.2926 & -0.3808 \\
Slope & 0.0494 & 0.0201 & -0.0546 & -0.0492 \\
Elevation & -0.00230 & -0.00273 & 0.00247 & 0.000097 \\
Distance to escape terrain (sheep only) & -0.00095 & -0.00072 & $\mathrm{n} / \mathrm{a}$ & $\mathrm{n} / \mathrm{a}$ \\
Vegetation Cover Types & & & & \\
1. All riparian & 1.1088 & 1.2082 & 1.8912 & 1.4302 \\
2. Mixed shrub & -0.9789 & -2.2432 & -2.1718 & -0.6163 \\
3. Sagebrush & 0.0 & 0.0 & 0.0 & 0.0 \\
4. All grassland & -0.1150 & -0.0468 & 1.2529 & -0.0950 \\
5. Mt. mahogany with Juniper & 1.6813 & 1.8998 & -0.5755 & -0.2968 \\
6. Juniper & 0.6305 & 1.1211 & -0.1698 & -0.1790 \\
7. All forested & -1.0378 & -1.1785 & 0.4110 & -0.5749 \\
8. Ag. and human use & $\mathrm{n} / \mathrm{a}$ & $\mathrm{n} / \mathrm{a}$ & $\mathrm{n} / \mathrm{a}$ & $\mathrm{n} / \mathrm{a}$ \\
9. Open water & $\mathrm{n} / \mathrm{a}$ & $\mathrm{n} / \mathrm{a}$ & $\mathrm{n} / \mathrm{a}$ & $\mathrm{n} / \mathrm{a}$ \\
Canopy Coverage (horses only) & & & & \\
Very Low (0-10\%) & $\mathrm{n} / \mathrm{a}$ & $\mathrm{n} / \mathrm{a}$ & 0.6559 & 0.7136 \\
Low (10-40\%) & $\mathrm{n} / \mathrm{a}$ & $\mathrm{n} / \mathrm{a}$ & -1.6183 & 0.8045 \\
Medium (40-70\%) & $\mathrm{n} / \mathrm{a}$ & $\mathrm{n} / \mathrm{a}$ & 0.3153 & -0.1136 \\
High (70-100\%) & $\mathrm{n} / \mathrm{a}$ & $\mathrm{n} / \mathrm{a}$ & 0.0 & 0.0 \\
\hline
\end{tabular}

*Each coefficient in the single regression output also has an associated intercept, which is not displayed in the table. 


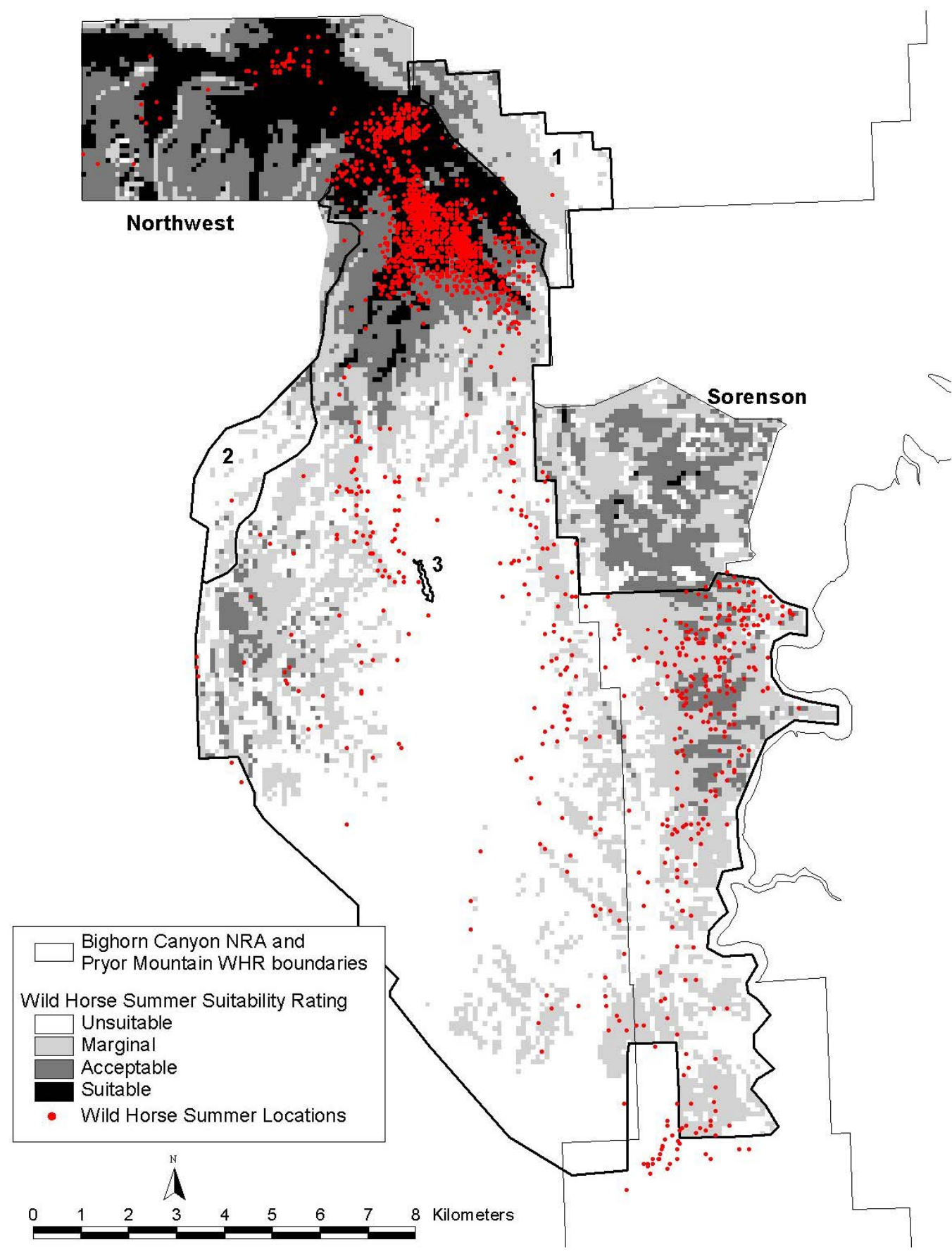

Figure 10. Wild horse summer habitat suitability ratings with horse locations. Dark colored areas that do not contain dots represent unused, but favorable (suitable plus acceptable) habitat. Area 1 is the north unit, area 2 is the west unit, and area 3 is the central unit. 
Table 8 allows us to see how well the model fits the currently mapped wild horse locations. There were a total of 2150 summer wild horse observations. Of those 2150, 277 fell into areas modeled as "acceptable" and 1374 fell into areas modeled as "suitable." In total then, 1651 of the 2150 observations $(76.8 \%)$ were in areas with favorable modeled suitability (suitable plus acceptable).

\section{Current Winter Habitat Selections and Distributions of Wild Horses}

Winter wild horse locations appear in Figure 4, and depict a very even distribution of animals throughout the lower portion of the range. Winter model results are given in Tables 1 and 7 . In the winter model, while all variables except aspect are significant, only three variables offer large numeric effects in the model — slope, vegetation, and canopy. Wintering wild horses prefer flatter slopes, more open forest canopies, and riparian vegetation. Habitat manipulations which decrease canopy cover and increase riparian vegetation would likely increase suitability for wild horses.

Figure 11 depicts the habitat suitability map for wild horses in the winter. As per the quantitative model results in Table 1, the map shows darker areas where suitability is highest which spatially coincide with variables listed in Table 1. Additionally, Figure 11 depicts areas that are underutilized by the current distribution of wild horses, since dark areas that occur without nearby red dots can be interpreted as underutilized but otherwise potentially favorable habitat.

Table 8 shows how well the model fits the currently mapped wild horse locations. There were a total of 250 winter wild horse observations. Of those 250, 125 fell into areas modeled as "acceptable" and 33 fell into areas modeled as "suitable." In total then, 151 of the 250 observations $(63.2 \%)$ were in areas with favorable modeled suitability.

Wild horses use low elevation, drier habitats during winter. Water is much less limiting in winter since they eat snow, and there are five known low-elevation water sources. Thus, wild horses are able to use much of the badlands, shrub, and dry grassland habitats that could not be used during summer due to the lack of water. Water alone, however, probably does not explain the movement of most of the population to the high elevation, mountain top, sub-alpine grasslands during summer. Nitrogen concentrations of these mountain top grasslands were as high as $3.4 \%$, while low elevation grasses tend to average 0.5 to $1.0 \%$ during summer (Peterson, 1999). There are clearly nutritional advantages for the horses to forage in the high-elevation grasslands for as long into the winter as feasible, until snow drives them to lower and mid-elevations.

\section{Potential Habitats that are Unused or Little-Used by Wild Horses-Habitat Improvement Scenarios}

We identified three areas that were either totally unused or only lightly-used by wild horses: (1) a north unit, (2) a west unit, and (3) a central unit (labeled 1, 2, and 3 on Figure 10). The north unit is the largest $\left(7.4 \mathrm{~km}^{2}\right) \mathrm{of} \mathrm{these}^{\circ}$ areas and it does support occasional use by wild horses. It might be possible to create an access trail around this cliff, but much of the north unit is already accessible. About three-fourths of the unit was rated as unsuitable or marginal habitat (it has north and east exposures and further distances to water) and we suspect this explains why the area receives only minimal use. The north unit contains $0.1 \mathrm{~km}^{2}$ of "suitable" and $1.1 \mathrm{~km}^{2}$ of "acceptable" summer habitat (Table 9).

Table 8. How well the models fit the actual observations.

\begin{tabular}{|c|c|c|c|c|}
\hline \multicolumn{5}{|c|}{ Wild Horse Model Fitness } \\
\hline & $\begin{array}{c}\text { Number of observations } \\
\text { in "suitable" }\end{array}$ & $\begin{array}{l}\text { Number of observations } \\
\text { in "acceptable" }\end{array}$ & Total observations & $\begin{array}{l}\text { Percent of observations in } \\
\text { suitable or acceptable }\end{array}$ \\
\hline Summer & 1,374 & 277 & 2,150 & 76.8 \\
\hline Winter & 33 & 125 & 250 & 63.2 \\
\hline
\end{tabular}




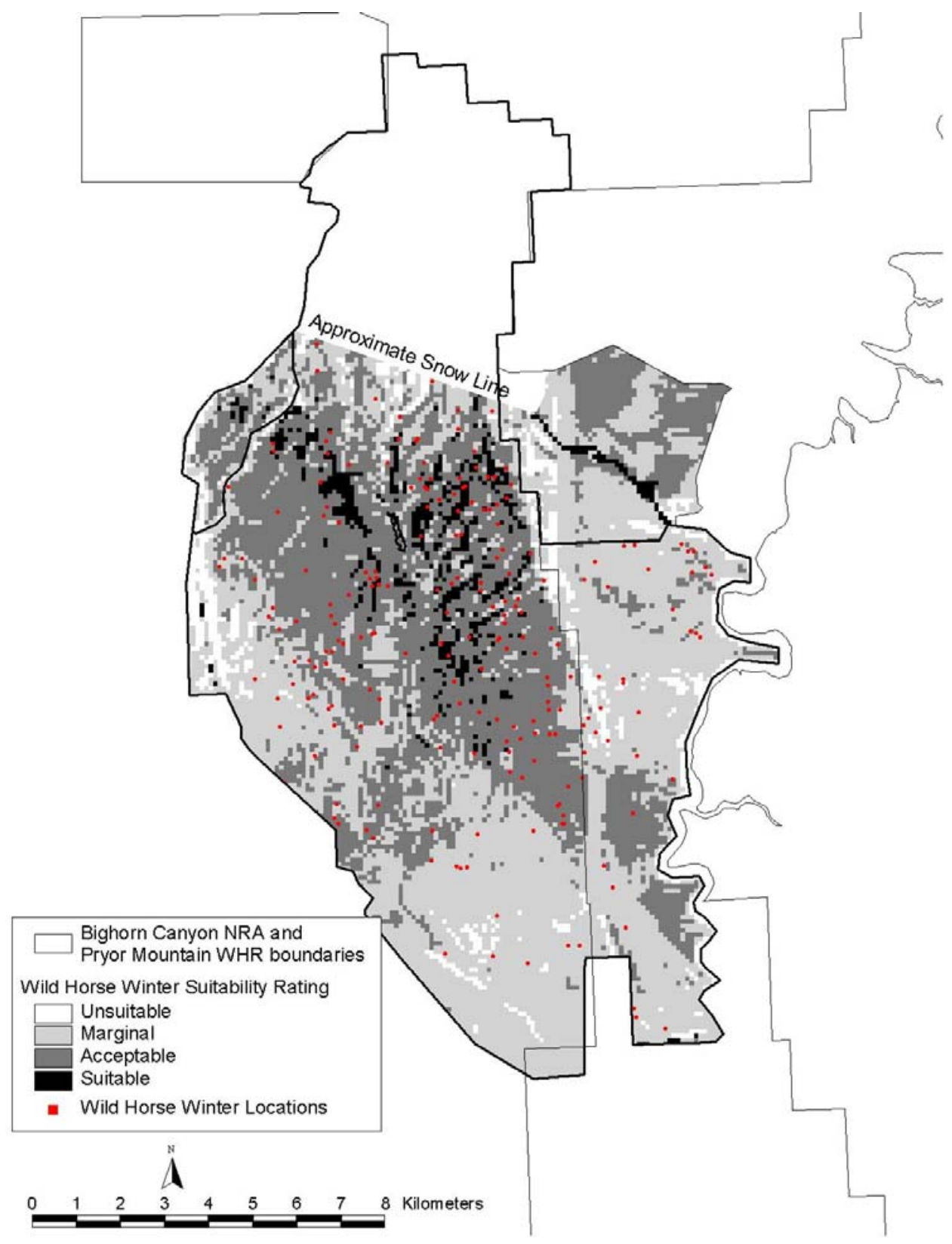

Figure 11. Wild horse winter habitat suitability ratings with horse locations. Dark colored areas that do not contain red dots represent unused, but favorable (suitable plus acceptable) habitat. 
Table 9. Amount of suitable habitat under different wild horse model scenarios.

\begin{tabular}{llcc}
\hline \multicolumn{1}{c}{ Season } & \multicolumn{1}{c}{ Model scenario } & $\begin{array}{c}\text { Acceptable } \\
\left(\mathbf{k m}^{2)}\right.\end{array}$ & $\begin{array}{c}\text { Suitable } \\
\left(\mathbf{k m}^{2)}\right.\end{array}$ \\
\hline Summer & Total current range & 14.7 & 8.9 \\
& New water sources functioning & 22.4 & 9.6 \\
& Total In No/Low access units & 1.2 & 0.1 \\
& - North unit (1) & 1.1 & .1 \\
& - West unit (2) & 0.1 & 0 \\
& - Central unit (3) & 0 & 0.1 \\
& Sorenson Extension (NPS) & 6.9 & 11.8 \\
& Northwest National Forest Area & 9.3 & 8.9 \\
\hline Winter & Total current range & 58.6 & 0.6 \\
\hline & Sorenson Extension (NPS) & 5.8 & \\
\hline
\end{tabular}

The western unit is very inaccessible and was not used by wild horses for the duration of this study. There is only one known potential crossing of a steep canyon to this area, and old horse trails suggest some wild horses knew of this crossing and used the area in the early 1990's. This abandoned trail could possibly be improved, or wild horses may rediscover the trail and once again use the area (there was evidence on the Nov. 2001 flight of renewed activity on the east end of the crossing trail). However, the unit contains very little high quality summer habitat $-0.0 \mathrm{~km}^{2}$ of "suitable" and $0.1 \mathrm{~km}^{2}$ of "acceptable" summer habitat (Table 9). But if the habitat was treated and the trail improved, it may open up new habitat for wild horses.

The central unit is very small (about $0.1 \mathrm{~km}^{2}$ ) and is the middle portion of the Big Coulee Canyon. Wild horses use most of this canyon and there are many ingress and egress trails between the canyon and the adjacent ridges and rolling grass/juniper habitats to the east. The vast majority of the Big Coulee Canyon is already highly available to wild horses. The central unit contains no "suitable" or "acceptable" summer habitat (Table 9).

\section{Potential Additions of New Areas to the Wild Horse Range}

As a demonstration model, two areas that are not currently part of the existing wild horse range were assessed using the wild horse habitat suitability model (Figure 10). The northwest area covers $25 \mathrm{~km}^{2}$ and receives trespass use by wild horses that cross through the buck-and-pole fence that forms the western boundary of the wild horse range. Cattle fences and steep canyons prohibit horses from using the rest of the area. The areas that receive some use are Tony's Island, Big Ice Cave, Dry Head Vista, and west of Dry Head Vista. Commissary Ridge and west of Big Ice Cave are not generally accessible to wild horses due to good four-strand cattle fences, although even here an occasional harem finds its way around the fence and can be found on Commissary Ridge. The area that receives use contains $9.3 \mathrm{~km}^{2}$ of "acceptable" and $11.8 \mathrm{~km}^{2}$ of "suitable" summer habitat (Table 9). Wild horses can also make some use of this northwest area in the winter by confining their grazing to the windswept ridges just west of the Dryhead Vista, on Commissary Ridge, or on Tony's Island.

A second potential addition, the Sorenson Area, is part of the BICA. Although the area is not officially part of the PMWHR, the area was used by wild horses for ten years under a temporary agreement between the BLM and the NPS. Wild horses have not used the area since 1992 (Peterson, 1999). The Sorenson Area contains $7.0 \mathrm{~km}^{2}$ of favorable wild horse summer range $\left(6.9 \mathrm{~km}^{2}\right.$ - acceptable, $0.1 \mathrm{~km}^{2}$ - suitable), and $6.4 \mathrm{~km}^{2}$ of favorable horse winter range (Table 7). Current underutilized habitat on the wild horse range is shown in Figure 11. 


\section{New Water Sources}

Again for purposes of demonstration only, we modeled a scenario which added new water sources at midelevations on the horse range (Figure 12). Two nonfunctional water sources, if made functional again, would add $7.7 \mathrm{~km}^{2}$ of acceptable and $0.7 \mathrm{~km}^{2}$ of suitable summer habitat to the amount already available in summer (Table 9). However, many of these same mid-elevation areas are already high quality winter range, and encouraging summer forage utilization near the hypothetical new water sources might remove or decrease some badly needed winter forage.

\section{Prescribed Burning and Clearing}

The conversion of conifer forest or shrubland into a high elevation or mid-elevation grassland would clearly create new summer habitat for wild horses. Grassland fires can also temporarily increase production and forage quality of the grasses for horses (Rowland and others, 1983; Canon and others, 1987). Burning existing open grassland could be used as a technique to better distribute horses across the entire landscape as they are attracted to the new burns. However, burning or clearing may also result in no positive or even a negative effect on forages. For example, prescribed burning does not always increase production or forage quality (Hobbs and Spowart, 1984; Singer and others, 2004). Additionally, converting existing forest to a stand of young tree seedlings, or to a forb community, would have little benefit to the wild horses. As one example, the clearcuts located near Big Ice Cave that have a high forb component and many conifer saplings have received almost no use by wild horses over the years of this study (the single exception is one harem that has used the clearcuts).

Projecting a burning/clearing scenario was beyond the scope of this project. We had insufficient information to predict what plant communities would result following treatment of conifer stands at various slopes, elevations, and aspects. The habitat model, however, might be used for these future projections if more information on fire effects was available.

\section{Overlap of Bighorn Sheep and Wild Horse Habitats}

Managers desire to increase the amount of bighorn sheep habitat in order to increase the viability of the species in and around BICA. Questions have arisen about whether wild horses and bighorn sheep compete for the same habitat, and to what extent, if at all, wild horses may out-compete bighorn sheep and thus restrict bighorn sheep viability across the BICA. Thus, the overlap of the two species is of interest to managers.

Figures 13 and 14 are generalized overlap maps for actual sheep and horse locations for both summer and winter. Animal locations were buffered with a $300 \mathrm{~m}$ polygon and intersected to create areas of overlap. During the summer there is significant overlap near the eastern, lower edge of the horse range and a few hot spots across the middle of the horse range. During winter, the overlap is sprinkled throughout the middle of the horse range. A visual inspection of the areas of overlap does not yield any conclusive variables in common to both species' selected habitats. Due to the arbitrary assignment of polygon size and other subjective factors, we do not recommend a statistical analysis of the overlap versus non-overlap areas. Local managers can likely use these maps to tease out the differences, if any, that exist between overlap and non-overlap areas.

Figures 15 and 16 attempt to graphical display modeled overlap by depicting the areas that summer and winter models predict as "suitable" or "acceptable" by both species. The dark cells on the map are areas where the models predict that necessary habitat exists for both species. Significant overlap occurs in the modeled habitats in roughly the same places as the actual observations in Figures 13 and 14.

A possible future use of the model could be to manipulate vegetation types so that bighorn habitat could be increased while horse habitat remained the same. This procedure might involve identifying areas near adequate sheep escape terrain where vegetation could be either cleared/burned or planted with certain sheep-preferred species. This project would be quite complex, and would involve significant manipulations as well as continual monitoring to make sure changes vegetation species composition were occurring as predicted. 


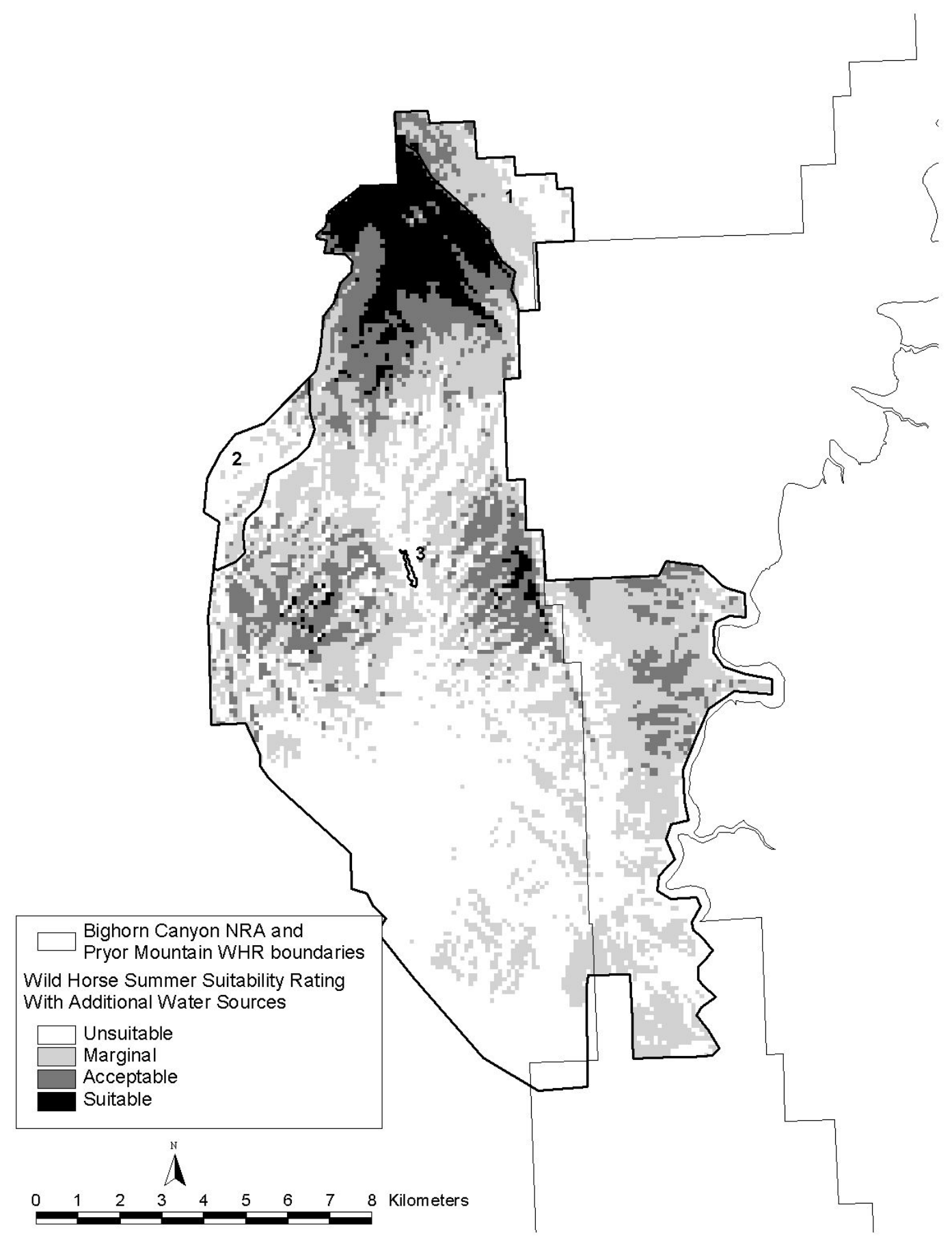

Figure 12. Wild horse summer habitat suitability ratings with additional water sources. Area 1 is the north unit, area 2 is the west unit, and area 3 is the central unit. 


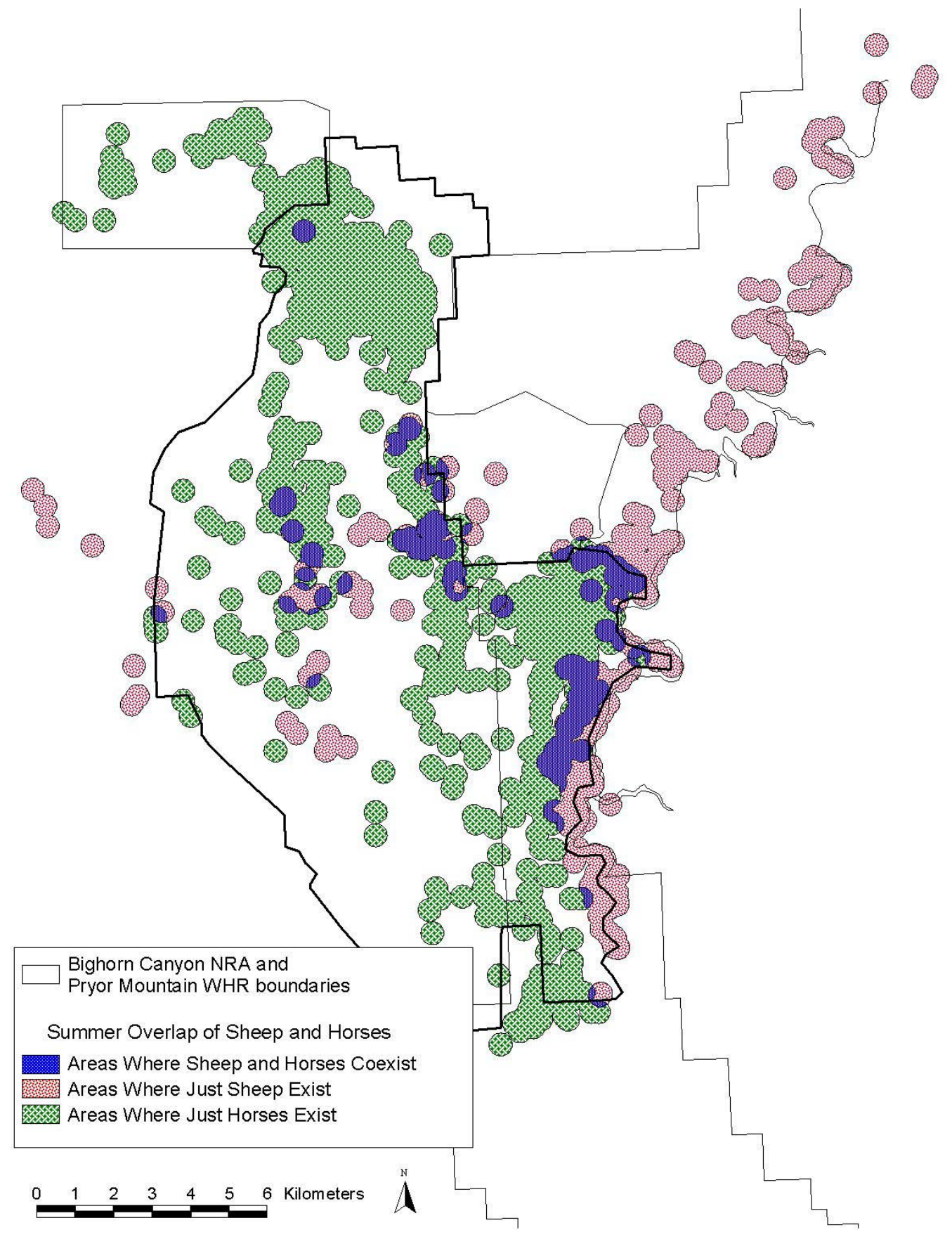

Figure 13. Areas of summer overlap between wild horses and bighorn sheep. Blue areas represent overlap. 


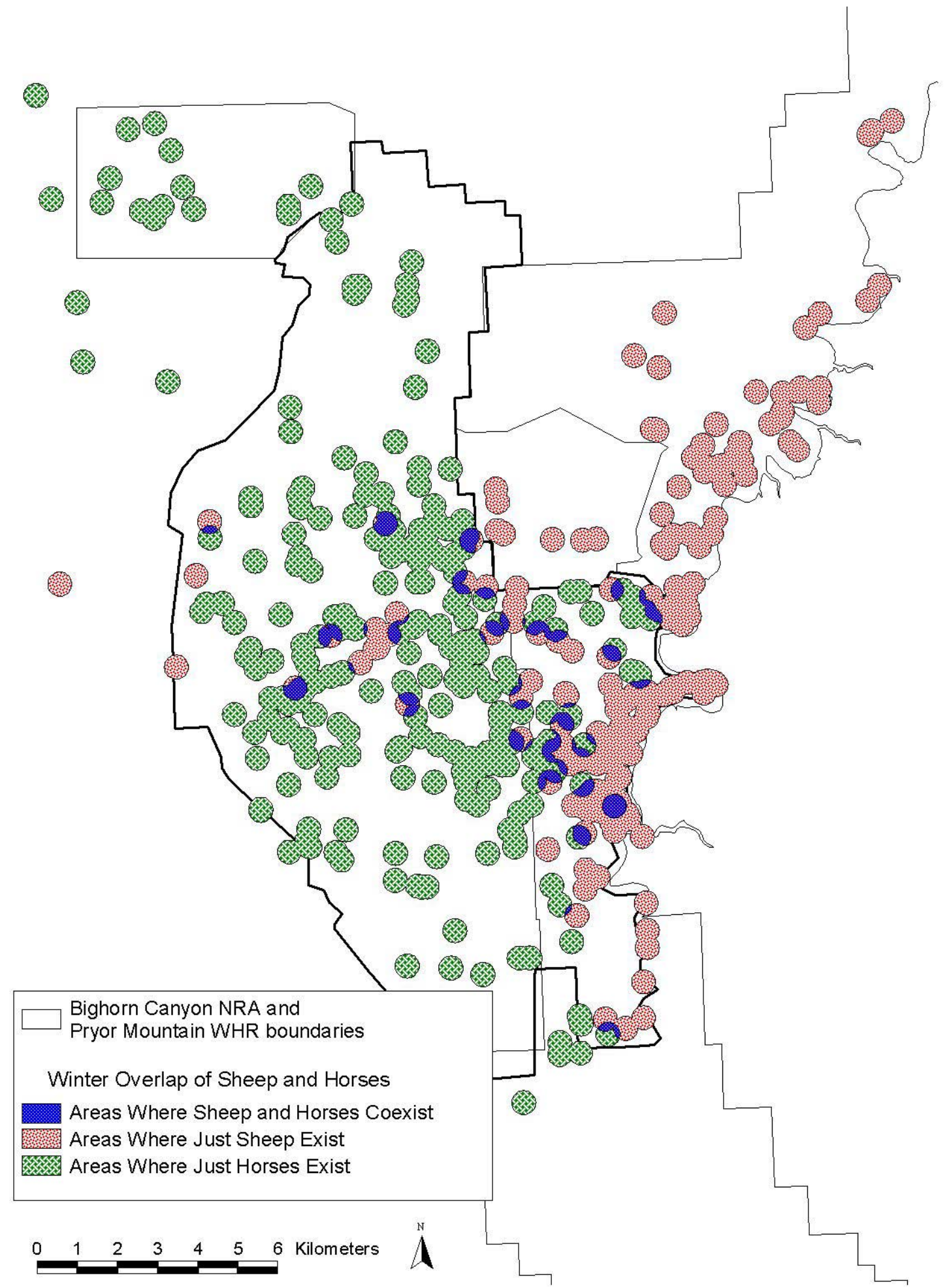

Figure 14. Areas of winter overlap between wild horses and bighorn sheep. Blue areas represent overlap. 


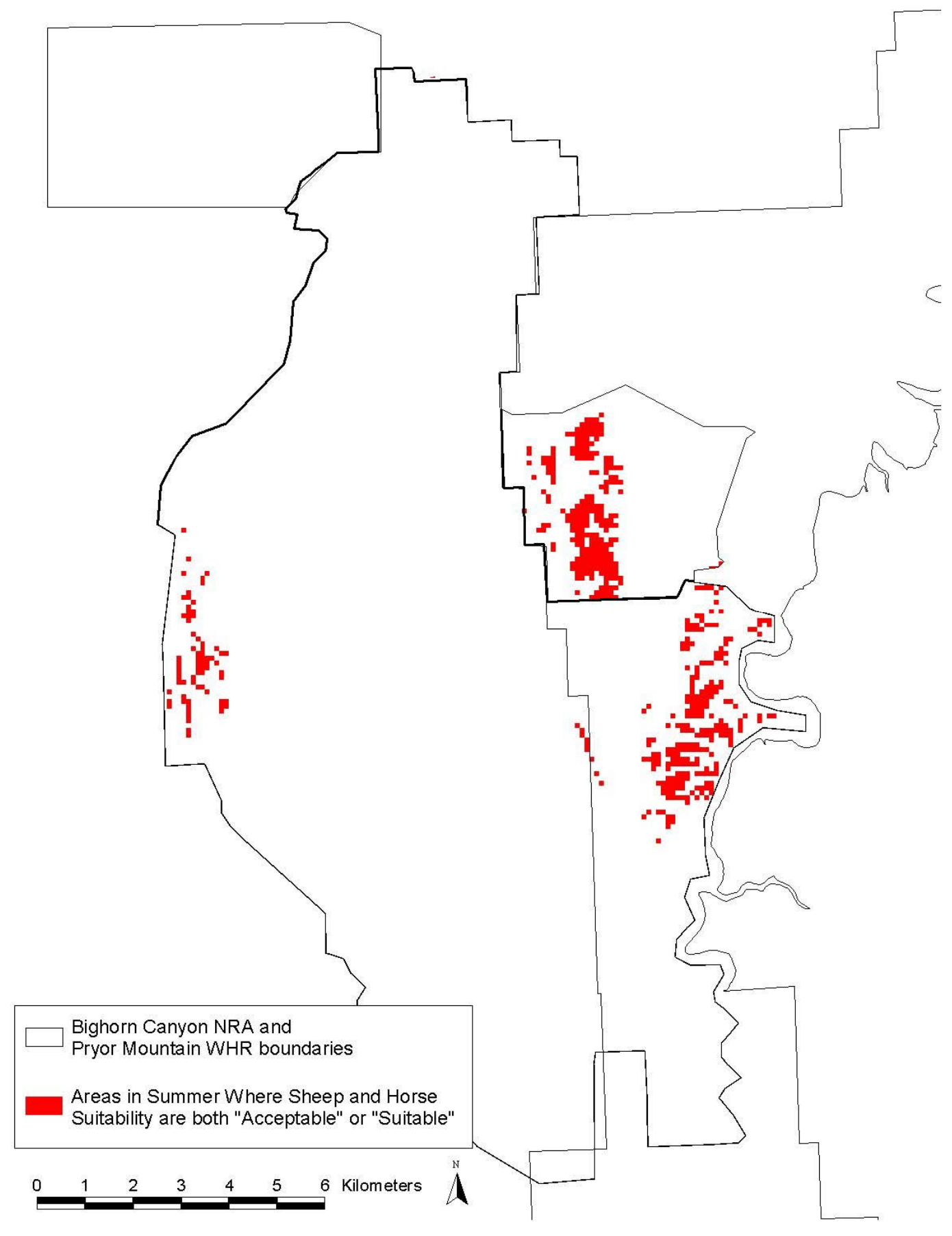

Figure 15. Areas in summer where bighorn suitability and wild horse suitability are "acceptable" or "suitable" for both species. 


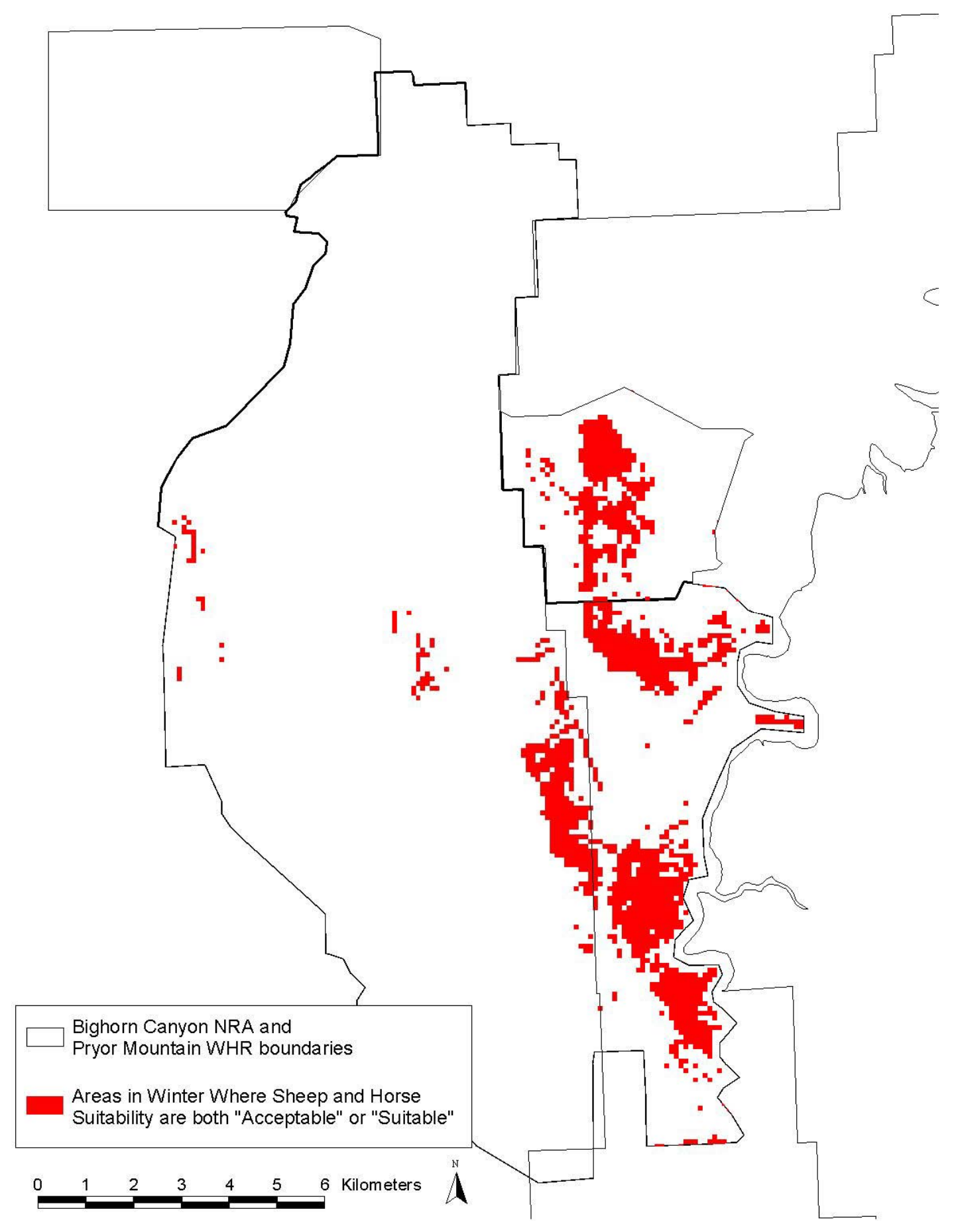

Figure 16. Areas in winter where bighorn suitability and wild horse suitability are "acceptable" or "suitable" for both species. 
Additionally, the current available data for bighorn sheep and wild horse locations was obtained over several years and under several varying sampling regimens. For example, horse and sheep locations were obtained on different dates and by varying methods, and so species overlap can only be broadly estimated as having occurred in the same season of the year. In order to properly account for species overlap, an intense field investigation which covered the entire range of both species on the same dates would yield a truly accurate sample to answer these important questions.

\section{Conclusions}

1. There is considerable unused winter and summer habitat for bighorn sheep north of the currently occupied area, along the Bighorn River canyon and in Devil's Canyon. Areas south of the currently occupied area were not highly suitable. Suitable sheep habitat in Crooked Creek was limited, and suitable habitat in West Pryor was very limited.

2. There was considerable favorable unused summer habitat for wild horses, especially in areas northwest of the Range on national forest and in the Sorenson extension.

3. There is little favorable unused winter habitat for wild horses across the range. Most unused favorable winter habitat was in area 2 and in the Sorenson extension.

4. All four of the suitability models based on animal locations presented here were successful and predicted most of the areas used by either bighorn sheep or wild horses. Considering some observations were of animals moving between suitable habitats, we rate both models as highly successful. The Intermountain-West model was considerably less successful than the Animal LocationBased model in predicting areas used by bighorn sheep.

5. Areas of overlap between bighorn sheep and wild horses exist in specific areas across the middle portion of the horse range. Further studies into the locations and consequences of this overlap are warranted but beyond the scope of this initial project.

6. This habitat suitability analysis suggests the following management actions would reap the most benefits to both species:

\section{Bighorn Sheep}

- Translocate or encourage bighorn sheep dispersal into the northern end of Bighorn Lake, Devil's Canyon, and south Bighorn Lake areas.

- Use clearing or burning to create additional habitat focusing on the following areas:

- Areas closer to the Bighorn Lake and Canyon, or the deep Crooked Creek Canyon as depicted in Figure 9.

- Areas that add useable clusters of suitable habitat that can support new nursery bands of ewes/lambs/sub-adults (i.e., as opposed to small isolated patches).

- Consider connecting habitats and creating new patches in a leap-frog fashion.

- The Big Coulee, West Pryor, and the northwest periphery of the study area are low priorities for improvements.

- By focusing on the vegetation types of juniper, sagebrush, and mixed shrub, the greatest amount of suitable habitat might be created. Juniper could be cleared to create better visibility, while thinning, burning, or clearing of shrubs might also create more favorable habitat.

\section{Wild Horses}

- Summer range: adding the northwest USFS section, adding water holes expeditiously, clearing key forested habitats, and adding the Sorenson extension would yield the most benefits.

- Winter range: clear key forested habitats, encourage use of the western PMWHR (area 2), and add the Sorenson extension to increase wild horse habitat. 


\section{Literature Cited}

Arno, S.F., and Wilson, A.E., 1986, Dating past fires in curlleaf mountain-mahogany communities.: Journal of Range Management, v. 39 , no. 3, p. 241-243.

Bailey, J.A., 1990, Management of Rocky Mountain bighorn sheep herds in Colorado: Colorado Division of Wildlife Special Report $66,24 \mathrm{p}$.

Berger, J., 1990, Persistence of different sized populations: an empirical assessment of rapid extinctions in bighorn sheep: Conservation Biology, v. 4, p. 91-98.

Blaisdell, J.P., 1953, Ecological effects of planned burning of sagebrush grass range on the Upper Snake River Plains: U.S. Department of Agriculture Technical Bulletin 1075.

Blaisdell, J.P., and Mueggler, W.F., 1956, Sprouting bitterbrush following burning or top removal: Ecology, vol. 37, p. 365-370.

Byers, C.R., and Steinhorst, R.K., 1984, Clarification of a technique for analysis of utilization-availability data: Journal of Wildlife Management, vol. 48, p. 1050-1053.

Canon, S.K., Urness, P.J., and Debyle, N.V., 1987, Habitat selection, foraging behavior, and dietary nutrition of elk in burned aspen forest: Journal of Range Management, v. 40, no. 5, p. 433-438.

Clark, R.G., Britton, C.M., and Sneva, F.A., 1982, Mortality of bitterbrush after clipping in eastern Oregon: Journal of Range Management, v. 35, no. 6. p. 711-714.

Cook, J.G., Hershey, T.J., and Irwin, L.L., 1994, Vegetative response to burning on Wyoming mountain-shrub big game ranges: Journal of Range Management, vol. 47, no. 4, p. 296-302.

Coughenour, M.B., 1999, Ecosystem modeling of the Pryor Mountain Wild Horse Range, Final report to the USGS-Biological Resources Division, U.S. National Park Service, and U.S. Bureau of Land Management: Natural Resources Ecology Lab, Colorado State University, Fort Collins, $65 \mathrm{p}$.

Daubenmire, R., and Daubenmire, J.B., 1968, Forest vegetation of eastern Washington and northern Idaho: Washington Agricultural Experiment Station Technical Bulletin No., Pullman, Wash.

Gross, J.E., 2000, A dynamic simulation model for evaluating effects of removal and contraception on genetic variation and demography: Biological Conservation, v. 96, p. 319-330.

Gudorf, M., 2002, Bighorn sheep habitat suitability assessment of the Greater Bighorn Canyon National Recreation Area: A higher resolution analysis., report to National Park Service, $27 \mathrm{p}$.

Gudorf, M., Sweanor, P.Y., Singer, F.J., Blankenship, A., Bleich, V., Easterly, T., Emmerich, J., Eustace, C., Irby, L., Jaynes, D., Jellison, B., Kissell, R., Lindsay, J., Parks, J., Peters, T., Reid, K., Stewart, S., and Voss, T., 1996, Bighorn sheep habitat assessment of the Greater Bighorn Canyon National Recreation Area, National Park Service and National Biological Service cooperative report: Bighorn Canyon National Recreation Area, Lovell, Wyoming, 43 p.

Hobbs, N.T., and Spowart, R.A., 1984, Effects of prescribed fire on nutrition of mountain sheep and mule deer during winter and spring: Journal of Wildlife Management, v. 48, p. 551-560.

Ibanex, I., and Schupp, E.W., 2001, Positive and negative interactions between environmental conditions affecting Cercocarpus ledifolius seedling survival: Oecologia, v. 129, no. 4, p. 543-550.

Johnson, T.J., and Swift, D.M., 1995, A test of a habitat evaluation procedure for Rocky Mountain bighorn sheep: Final report to Rocky Mountain Regional Office, National Park Service, Denver, Colo., $25 \mathrm{p}$.

Johnson, T.L.., and Swift, D.M., 2000, A test of a habitat evaluation procedure for Rocky Mountain bighorn sheep: Restoration Ecology, v. 8, no. 4S, p. 47-56.

Kissell, R.E., Irby, L.R., and Mackie, R.J., 1996, Competitive interactions among bighorn sheep, feral horses, and mule deer in Bighorn Canyon NRA and the Pryor Mountain Wild Horse Range: Completion report on cooperative agreement no. CA1268-1-9017.

Knight, D.H., Jone, G.P., Akashi, Y., and Myers, R.W., 1987, Vegetation ecology in the Bighorn Canyon National Recreation Area: Final report to the University of Wyoming, National Park Service Research Center, Laramie.

Neu, C.W., Byers, C.R., and Peek, J.M., 1974, A technique for analysis of utilization-availability data: Journal of Wildlife Management, v. 38, p. 541-545.

Perryman, B.L., Olson, R.A., Petersburg, S., and Naumann, 2002, Vegetation response to prescribed fire in Dinosaur National Monument: Western North American Naturalist, v. 62, no. 4, p. 414-422.

Peterson, J., 1999, Ungulate/vegetation dynamics in the Pryor Mountain Wild Horse Range: PhD dissertation, Colorado State University, Fort Collins, $155 \mathrm{p}$.

Risenhoover, K.L., and Bailey, J.A., 1985, Foraging ecology of mountain sheep: Implications for habitat management: Journal of Wildlife Management, v. 49, p. 797-804. 
Risenhoover, K.L., Bailey, J.A., and Wakelyn, L.A., 1988, Assessing the Rocky Mountain bighorn sheep management problem.: Wildlife Society Bulletin, v. 16, p. 346-352.

Rowland, M.M., Allredge, A.W., Ellis, J.E., Weber, B.J., and White, G.C., 1983, Comparative winter diets of elk in New Mexico: Journal of Wildlife Management, v. 47, p. 924-932.

Schoenecker, K.A., Singer, F.J., Grams, K.A., and Roelle, J., 2004, Bighorn sheep (Ovis canadensis) survivorship and habitat studies in Bighorn Canyon National Recreation Area and surrounding lands, Wyoming and Montana, 2000-2003, U.S. Geological Survey Open File Report. In press.

Singer, F.J., Zeigenfuss, L.C., Coates-Markle, L., and Schwieger, F., 2000, A demographic analysis, group dynamics, and genetic effective number in the Pryor Mountain Wild Horse Population, 1992-1997, in Singer, F.J. and Schoenecker, K.A., compilers: Manager's summary - ecological studies of the Pryor Mountain Wild Horse Range, 1992-1997. U.S. Geological Survey, Midcontinent Ecological Science Center, Fort Collins, Colorado, p. 73-89.

Singer, F.J., Zeigenfuss, L.C., and Spicer, L., 2001, The role of patch size, disease, and movement in the rapid extinction of bighorn sheep: Conservation Biology, vol. 15, p. 1347-1354.

Singer, F.J., Coughenour, M.B., and Norland, J.E., 2004, Elk biology and ecology before and after the Yellowstone fires of 1988, in Wallace, L., ed., After the fires: the ecology of change in Yellowstone National Park. Yale University Press, New Haven and London, p. 117-139.

Smith, T.S., Flinders, J.T., and Winn, D.S., 1991, A habitat evaluation procedure for Rocky Mountain bighorn sheep in the Intermountain West: Great Basin Naturalist, v. 51, p. 205-225.

Schultz, B.W., Tausch, R.J., and Tueller, P.T., 1996, Spatial relationships among young Cercocarpus ledifolius: Great Basin Naturalist, v. 56, no. 3, p. 261-266.

U.S. Department of Interior and Bureau of Land Management, 1997, Summary recommendations - BLM Wild Horse and Burro population viability forum, BLM National Resource Note No. 35, National Science and Technology Center, BLM, Washington, D.C., $4 \mathrm{p}$.

van Manen, F.T., and Pelton, M.R., 1997, A GIS model to predict black bear habitat use: Journal of Forestry, August 1997, p. 6-12.

Wambolt, C.L., Walhof, K.S., and Frisina, M.R., 2001, Recovery of big sagebrush communities after burning in south-western Montana: Journal of Environmental Management, v. 61, p. 243-252. 


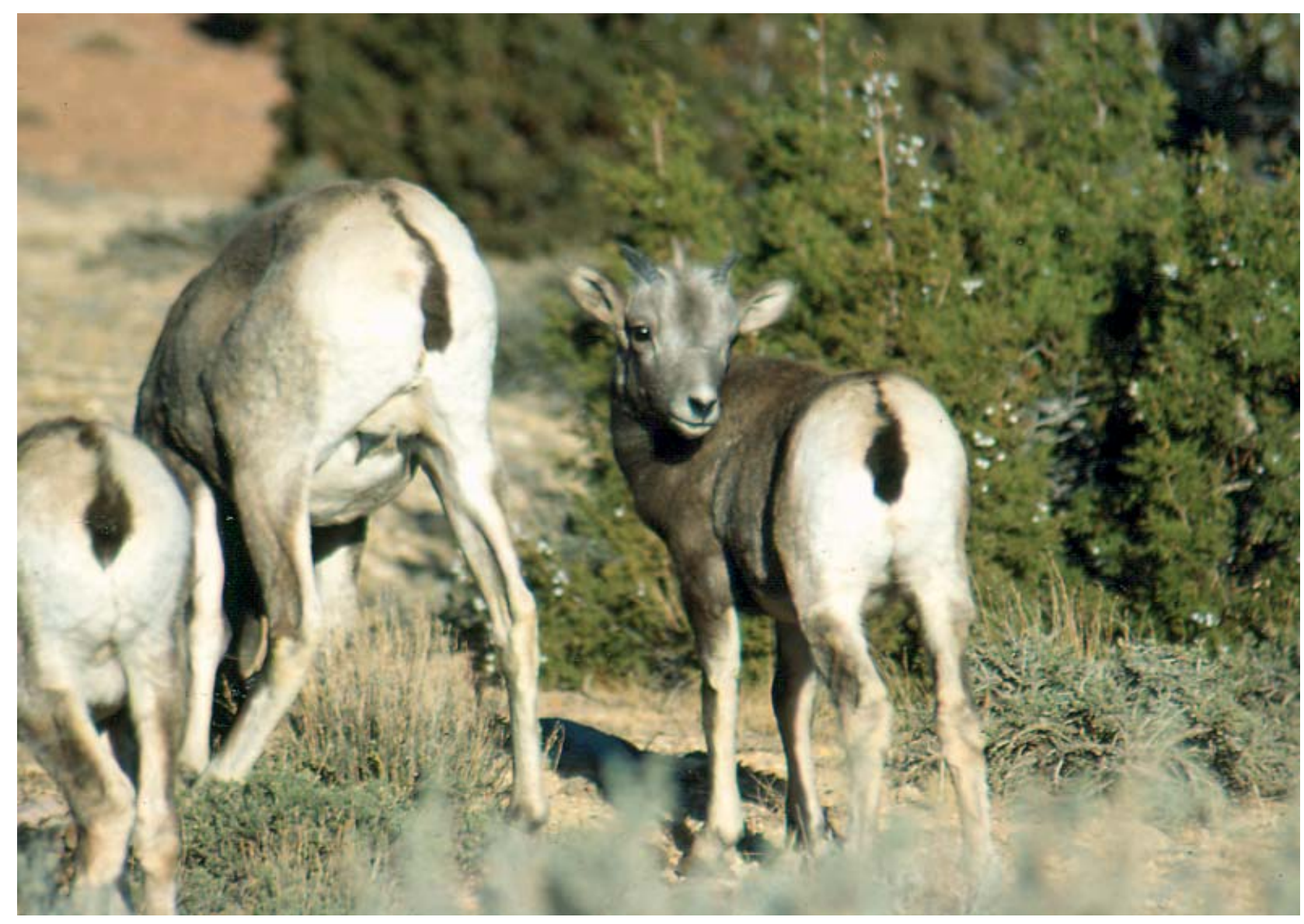

